CLEAN COAL TECHNOLOGY (CCT)

\title{
500 MW DEMONSTRATION OF ADVANCED \\ WALL-FIRED COMBUSTION TECHNIQUES \\ FOR THE REDUCTION OF NITROGEN OXIDE (NOx) \\ EMISSIONS FROM COAL-FIRED BOILERS
}

Phase 4 - Digital Control System and Optimization

\author{
DOE Contract Number \\ DE-FC22-90PC89651 \\ SCS Contract Number \\ C-91-000027
}

\author{
Prepared by: \\ Southern Company Services, Inc. \\ 600 North 18 Street \\ Birmingham, Alabama 35202
}

September 1998

Cleared by DOE patent Counsel on June 23, 1998 


\section{LEGAL NOTICE}

This report was prepared by Southern Company Services, Inc. pursuant to a cooperative agreement partially funded by the U.S. Department of Energy and neither Southern Company Services, Inc. nor any of its subcontractors nor the U.S. Department of Energy, nor any person acting on behalf of either:

Makes any warranty or representation, express or implied with respect to the accuracy, completeness, or usefulness of the information contained in this report, or process disclosed in this report may not infringe privatelyowned rights; or

Assumes any liabilities with respect to the use of, or for damages resulting from the use of, any information, apparatus, method or process disclosed in this report.

Reference herein to any specific commercial product, process, or service by trade name, trademark, manufacturer, or otherwise, does not necessarily constitute or imply its endorsement, recommendation, or favoring by the U.S. Department of Energy. The views and opinion of authors expressed herein do not necessarily state or reflect those of the U.S. Department of Energy. 


\section{ABSTRACT}

This report presents the results of a U.S. Department of Energy (DOE) Clean Coal Technology (CCT) project demonstrating advanced wall-fired combustion techniques for the reduction of nitrogen oxide (NOx) emissions from coal-fired boilers. The project was conducted at Georgia Power Company's Plant Hammond Unit 4 located near Rome, Georgia. The DOE Cooperative Agreement Number for this project is DE-FC22-90PC89651.

The Clean Coal Technology Program is a jointly funded effort between government and industry to move the most promising advanced coal-based technologies from the research and development stage to the commercial marketplace. The Clean Coal effort sponsors projects that are different from traditional research and development programs sponsored by the DOE. Traditional projects focus on long-range, high-risk, high-payoff technologies with the DOE providing the majority of the funding. In contrast, the goal of the Clean Coal Program is to demonstrate commercially feasible, advanced coal-based technologies that have already reached the "proof-of-concept" stage.

As originally planned, the primary objective of the demonstration at Hammond Unit 4 was to determine the long-term effects of commercially available wall-fired low NOx combustion technologies on NOx emissions and boiler performance. In supporting this objective, baseline testing was conducted on the unit followed by installation and testing of an advanced overfire air system and low NOx burners, separately and in combination. These tests constituted Phases 1 through 3 of the project. These results were reported previously in the final report for these phases [SCS 1998].

An important result from Phase 1-3 testing was that combustion optimization had the potential to enhance boiler performance. Based on these results, a scope addition was proposed to the project funders (DOE, EPRI, and Southern Company) to add another task to the project. This task, added as Phase 4 of the project, evaluated advanced digital control and optimization techniques as applied to (1) reduction of NOx emissions, (2) mitigation of adverse impacts of low NOx burners and advanced overfire air system, and (3) improvement of boiler efficiency. The purpose of this report is to provide a technical account of Phase 4 of the project. 


\section{ACKNOWLEDGMENTS}

As with any project of this complexity and duration (1988 through 1998), a number of individuals contributed to its success. The project managers at DOE and EPRI provided invaluable commitment, support, and guidance during the course of the project:

Art Baldwin, U.S. Department of Energy

David Eskinazi, Electric Power Research Institute

Jim Longanbach, U.S. Department of Energy

Scott Smouse, U.S. Department of Energy

Rick Squires, Electric Power Research Institute (now with PowerGen)

Jeff Stallings, Electric Power Research Institute

The following individuals and their respective organizations provided outstanding testing, data analysis, and reporting services:

Innovative Combustion Technologies, Richard Storm

Radian International, Jim Noblett and George Warriner

Special thanks to Bob Kelly, Kerry Kline, Jose Perez, Mike Slatsky, and Toby Whatley (all of SCS) for providing timely and high quality design and support for the project. Lastly, thanks go out to the Plant Hammond staff and in particular Perry Boren, W.C. Dunaway, and Ernie Padgett for their gracious toleration of our frequent requests and for allowing their unit to be used in the testing of numerous technologies. 


\section{POINT OF CONTACT}

$\underline{\text { Southern Company Services }}$

John N. Sorge

Southern Company Services, Inc.

600 North 18th Street

Birmingham, AL 35202

Tel: 205.257.7426

E-mail: jnsorge@southernco.com

U.S. Department of Energy

Jim Longanbach

U.S. Department of Energy

Federal Energy Technology Center

3610 Collins Ferry Road

Morgantown, WV 26505

Tel: 304.285.4659

E-mail: jlonga@fetc.doe.gov
Georgia Power Company

W. E. (Ernie) Padgett

Georgia Power Company / Plant Hammond 5963 Alabama Highway SW

Coosa, GA 30129

Tel: 706.290.6223

Electric Power Research Institute

Jeffery W. Stallings

Electric Power Research Institute

3412 Hillview Ave.

Palo Alto, CA 94304-1395

Tel: 650.855.2427

E-mail: jstallin@epri.com 


\section{TABLE OF CONTENTS}

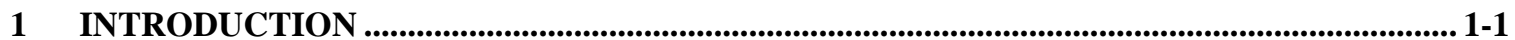

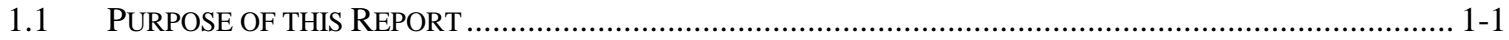

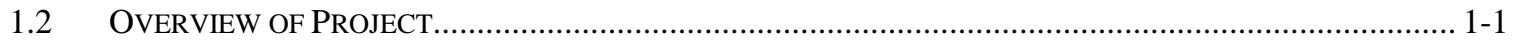

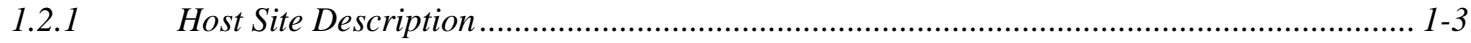

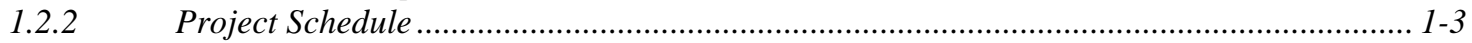

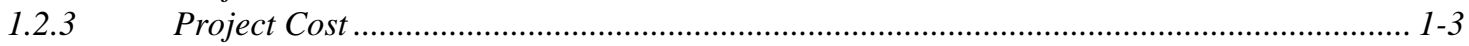

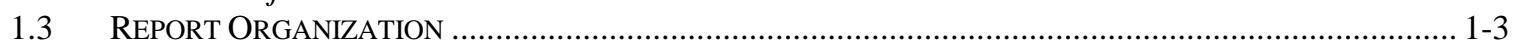

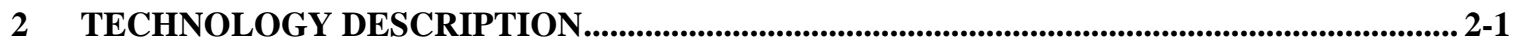

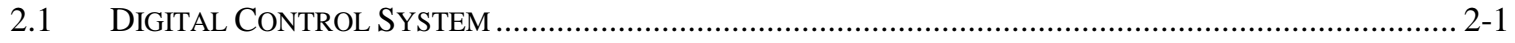

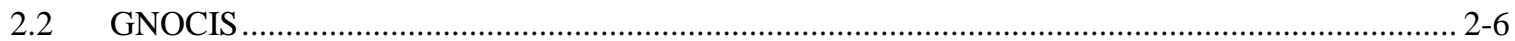

3 BASIS FOR INSTALLING GNOCIS AND THE DCS................................................................. 3-1

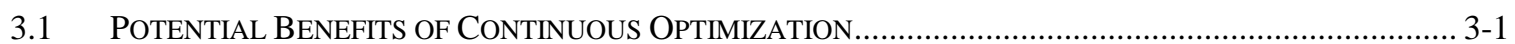

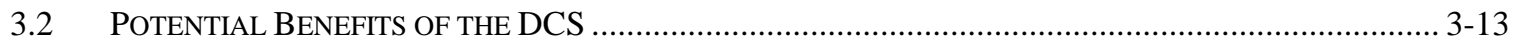

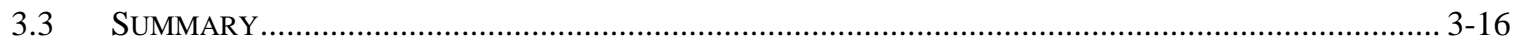

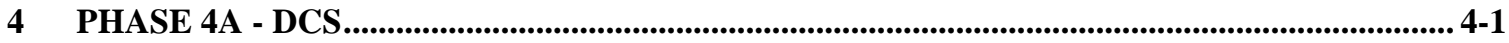

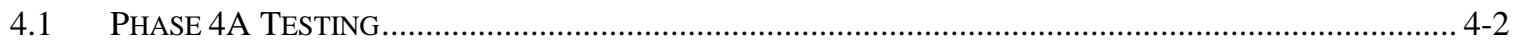

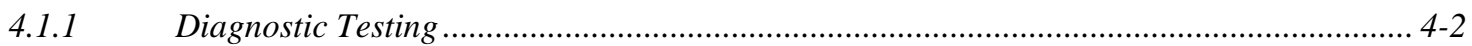

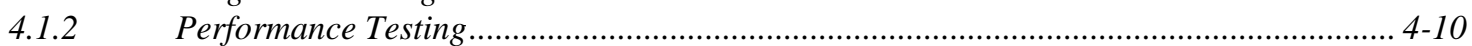

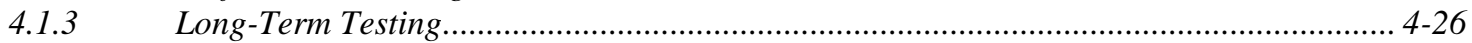

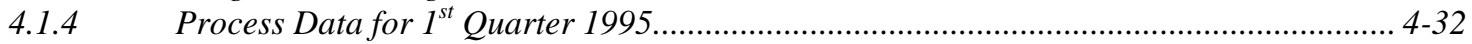

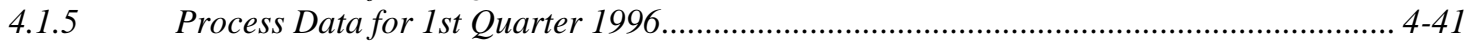

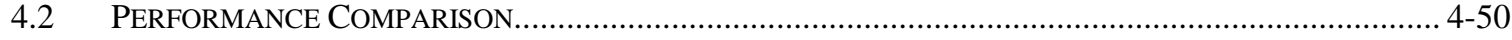

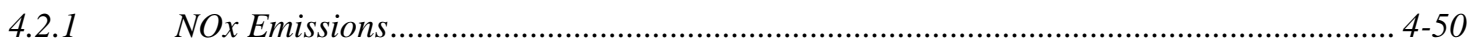

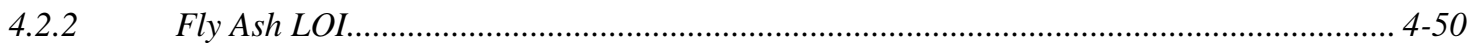

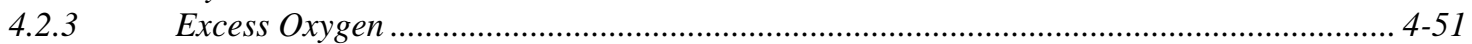

4.2.4 Economizer Exit and Air Heater Exit Temperatures ..................................................... 4-51

4.2.5 Main Steam and Hot Reheat Temperatures .............................................................. 4-51

5 OPTIMIZATION …..................................................................................................................................... 5-1

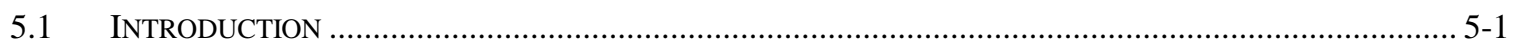

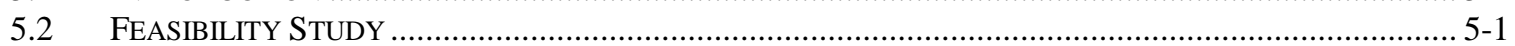

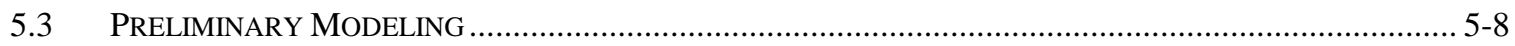

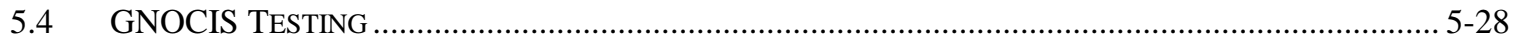

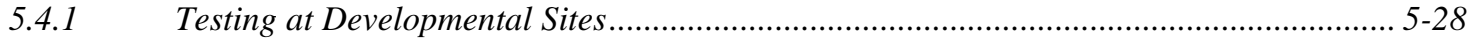

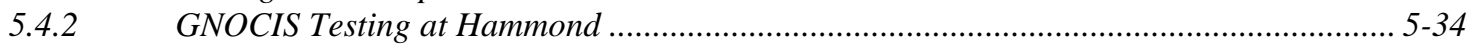

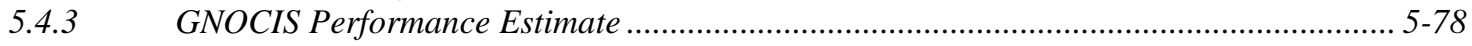

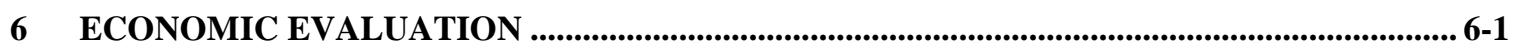

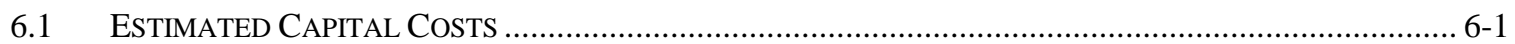

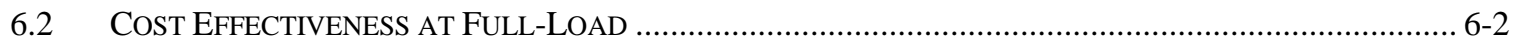

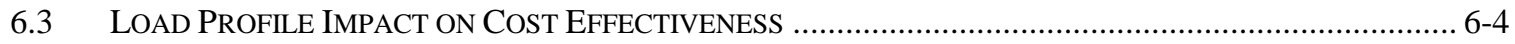

7 SUMMARY AND CONCLUSIONS ................................................................................................. 7-1

BIBLIOGRAPHY

APPENDIX A - BASELINE TEST DATA 
TABLE OF CONTENTS 


\section{LIST OF FIGURES}

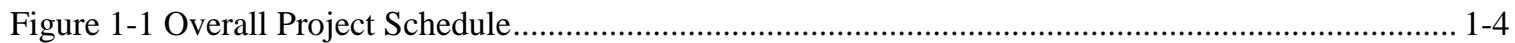

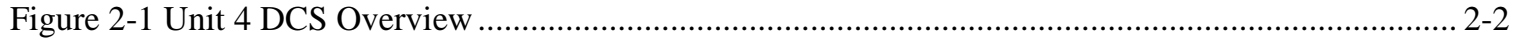

Figure 2-2 Unit 1-4 Control Room Layout as Currently Implemented...................................................... 2-3

Figure 2-3 Unit 1-4 Control Room Layout (Planned)............................................................................. 2-4

Figure 2-4 Unit 4 Benchboard ..................................................................................................... 2-4

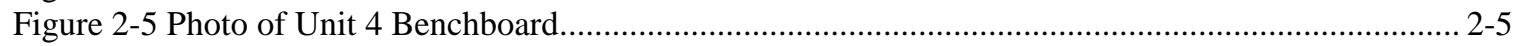

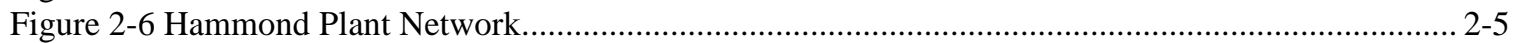

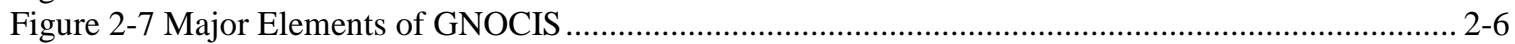

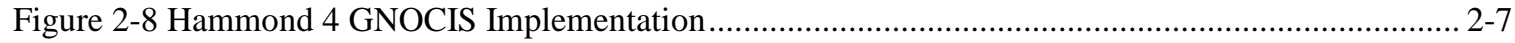

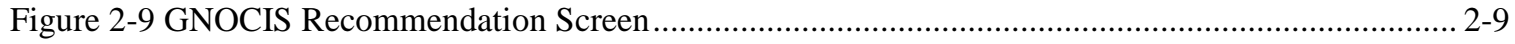

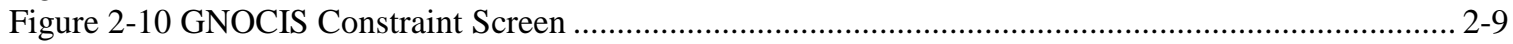

Figure 3-1 Typical NOx and LOI vs. Excess Oxygen Characteristics.................................................... 3-2

Figure 3-2 Typical Boiler Efficiency Losses vs. Excess Air Characteristic ……..................................... 3-2

Figure 3-3 NOx vs. LOI Testing / All Sensitivities (Phase 3A) …….................................................. 3-3

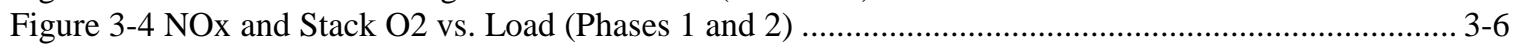

Figure 3-5 NOx and Stack O2 vs. Load (Phases 3A and 3B) ............................................................ 3-7

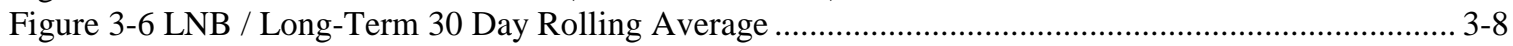

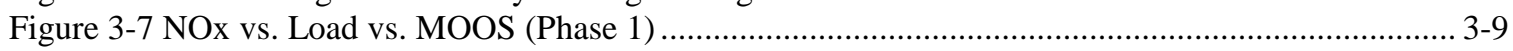

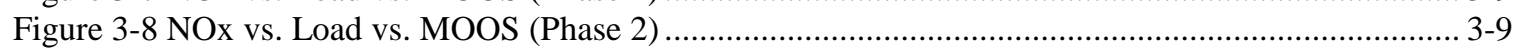

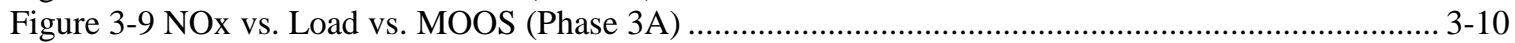

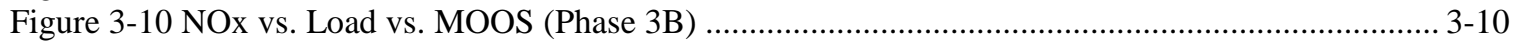

Figure 3-11 Dry Flue Gas Loss Variations with Load (Baseline) ........................................................ 3-11

Figure 3-12 Excess Oxygen Variations with Load (Baseline)............................................................... 3-12

Figure 3-13 Economizer Outlet Temperature Variations with Load (Baseline) ........................................ 3-12

Figure 3-14 Steam Temperature vs. Heat Rate ……….......................................................................... 3-13

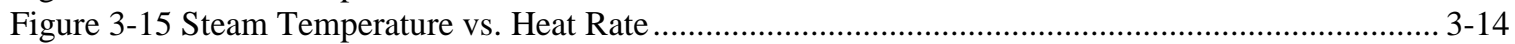

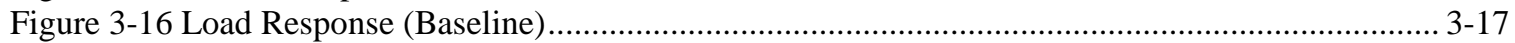

Figure 3-17 Excess Oxygen Response (Baseline) ......................................................................... 3-17

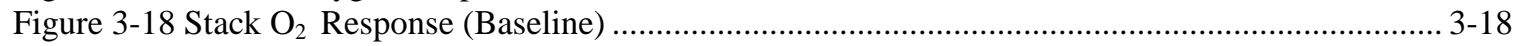

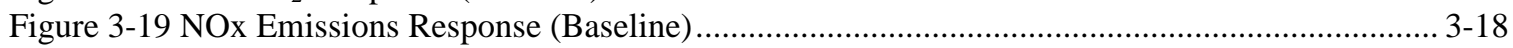

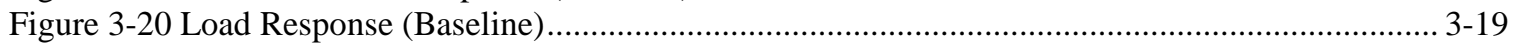

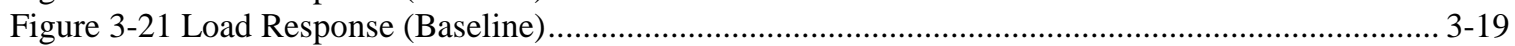

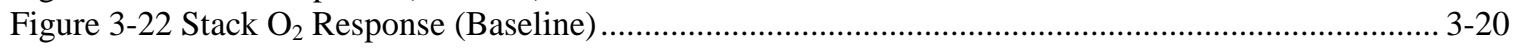

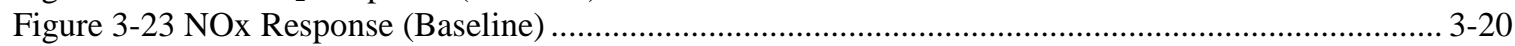

Figure 3-24 Fuel Flow (Baseline) .............................................................................................. 3-21

Figure 3-25 Throttle Temperature Response (Baseline) ............................................................... 3-21

Figure 3-26 Reheat Temperature Response (Baseline) _..................................................................... 3-22

Figure 3-27 Throttle Pressure Response (Baseline) _........................................................................ 3-22

Figure 3-28 Air Heater Outlet Temperature Response (Baseline)................................................... 3-23

Figure 3-29 Economizer Outlet Temperature Response (Baseline)......................................................... 3-23

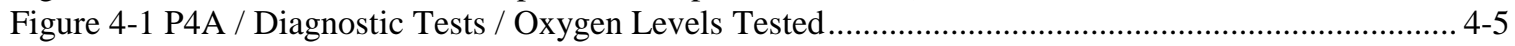

Figure 4-2 P4A / Diagnostic Tests / OFA Air Levels Tested ................................................................. 4-5

Figure 4-3 P4A /Diagnostic Tests / NOx Emissions............................................................................... 4-6

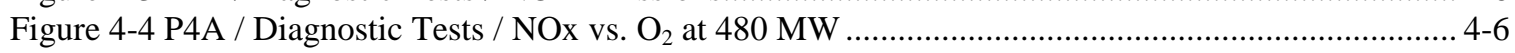

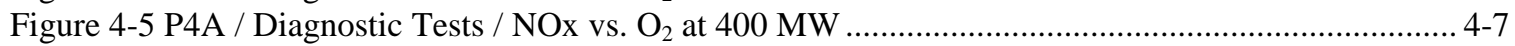

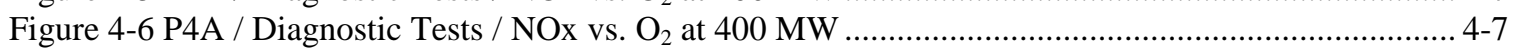

Figure 4-7 P4A / Diagnostic Tests / NOx vs. $\mathrm{O}_{2}$ / All Loads ............................................................... 4-8

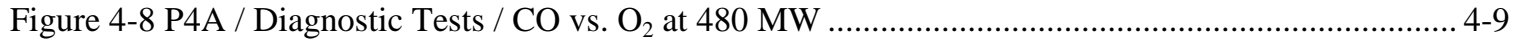

Figure 4-9 P4A / Diagnostic Tests / Response Plots at 480 MW .............................................................. 4-9

Figure 4-10 P4A / Measured Dirty Air Velocity by Mill and Coal Pipe .................................................. 4-15

Figure 4-11 P4A / Deviation of Coal Pipe Dirty Air Velocity from Mill Average ..................................... 4-15

Figure 4-12 P4A / Measured Coal Flows by Mill and Coal Flow ........................................................... 4-16 
Figure 4-13 P4A / Deviation of Coal Pipe Flow from Mill Average Flow................................................ 4-16 Figure 4-14 P4A / Primary Air Distribution .............................................................................................. 4-17

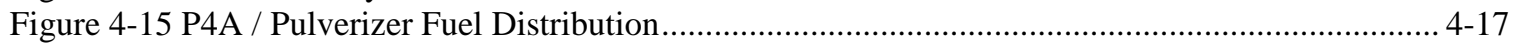

Figure 4-16 P4A / Pulverizer Air to Fuel Ratio ............................................................................. 4-18

Figure 4-17 P4A / Indicated vs. Measured OFA Flow - Northeast Quadrant ........................................... 4-18

Figure 4-18 P4A / Indicated vs. Measured OFA Flow - Northwest Quadrant............................................. 4-19

Figure 4-19 P4A / Indicated vs. Measured OFA Flow - Southeast Quadrant ............................................ 4-19

Figure 4-20 P4A / Indicated vs. Measured OFA Flow - Southwest Quadrant............................................ 4-20

Figure 4-21 P4A / Actual vs. Indicated Overfire Air Flow.................................................................. 4-20

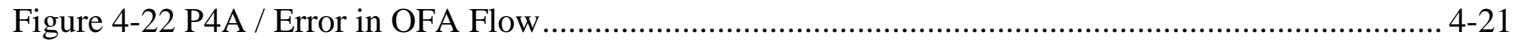

Figure 4-23 P4A / Distribution of Unit Air Flow by Load ................................................................. 4-22

Figure 4-24 P4A / Distribution of Unit Air Flow by Component ......................................................... 4-22

Figure 4-25 P4A / Performance Tests / NOx Emissions ......................................................................... 4-24

Figure 4-26 P4A / Performance Tests / Fly Ash LOI ........................................................................... 4-24

Figure 4-27 P4A / Long-Term Daily Average Characteristics ……............................................................... 4-27

Figure 4-28 P4A / Long-Term Diurnal Characteristics .................................................................... 4-28

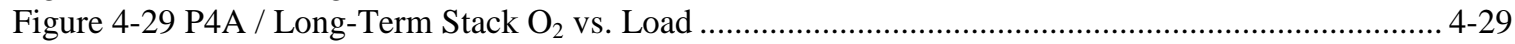

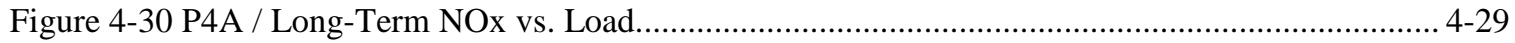

Figure 4-31 P4A / Long-Term CO vs. Load.................................................................................... 4-30

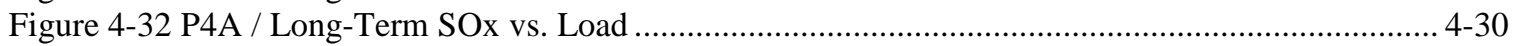

Figure 4-33 P4A - Main Steam Temperature vs. Load (1Q95) ............................................................ 4-34

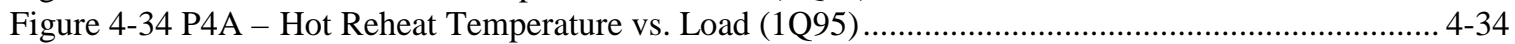

Figure 4-35 P4A - Main Steam Pressure vs. Load (1Q95) .............................................................. 4-35

Figure 4-36 P4A - Secondary Air Heater A Gas Inlet Temperature vs. Load (1Q95) .............................. 4-35

Figure 4-37 P4A - Secondary Air Heater B Gas Inlet Temperature vs. Load (1Q95) .............................. 4-36

Figure 4-38 P4A - Secondary Air Heater A Gas Outlet Temperature vs. Load (1Q95) ........................... 4-36

Figure 4-39 P4A - Secondary Air Heater B Gas Outlet Temperature vs. Load (1Q95)........................... 4-37

Figure 4-40 P4A - Excess Oxygen East Duct vs. Load (1Q95) ............................................................. 4-37

Figure 4-41 P4A - Excess Oxygen West Duct vs. Load (1Q95) ........................................................ 4-38

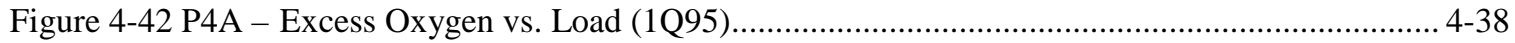

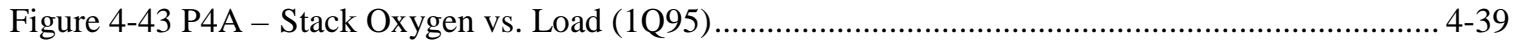

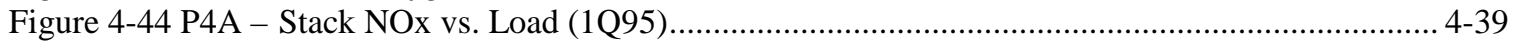

Figure 4-45 P4A - Mill Coal Flows vs. Load (1Q95) ............................................................................ 4-40

Figure 4-46 P4A - Main Steam Temperature vs. Load (1Q96)................................................................. 4-43

Figure 4-47 P4A - Hot Reheat Temperature vs. Load (1Q96) ............................................................ 4-43

Figure 4-48 P4A - Main Steam Pressure vs. Load (1Q96) ................................................................... 4-44

Figure 4-49 P4A - Secondary Air Heater A Gas Inlet Temperature vs. Load (1Q96) ............................... 4-44

Figure 4-50 P4A - Secondary Air Heater B Gas Inlet Temperature vs. Load (1Q96) ............................... 4-45

Figure 4-51 P4A - Secondary Air Heater A Gas Outlet Temperature vs. Load (1Q96) ............................ 4-45

Figure 4-52 P4A - Secondary Air Heater B Gas Outlet Temperature vs. Load (1Q96)............................ 4-46

Figure 4-53 P4A - Excess Oxygen Left (West) vs. Load (1Q96) ........................................................ 4-46

Figure 4-54 P4A - Excess Oxygen Right (East) vs. Load (1Q96) ...................................................... 4-47

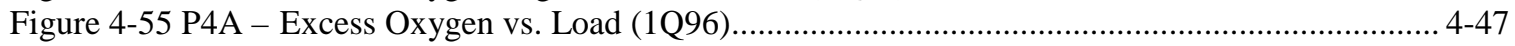

Figure 4-56 P4A - Stack Oxygen (Dry) vs. Load (1Q96) .................................................................... 4-48

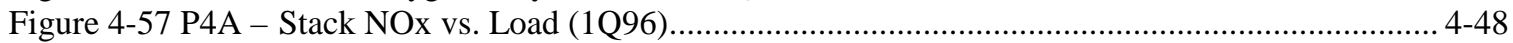

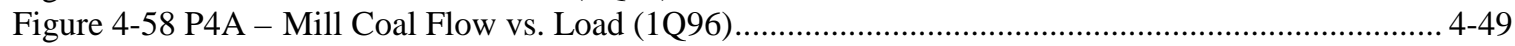

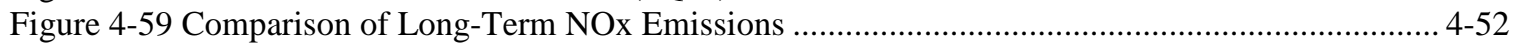

Figure 4-60 Comparison of Long-Term NOx Emissions (Reduced Range) ......................................... 4-52

Figure 4-61 P4A - Comparison of Performance Tests NOx Levels ...................................................... 4-53

Figure 4-62 P4A - Comparison of Performance Tests LOI Levels ...................................................... 4-54

Figure 4-63 P4A - Comparison of Performance Tests to Predicted Long-Term LOI Levels .................... 4-55

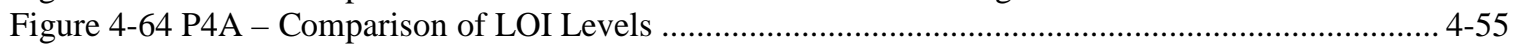

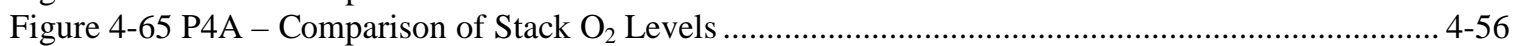

Figure 4-66 P4A - Comparison of Economizer Outlet $\mathrm{O}_{2}$ Levels ........................................................ 4-56

Figure 4-67 P4A - Comparison of Economizer Gas Inlet Temperatures ................................................. 4-57

Figure 4-68 P4A - Comparison of Economizer Gas Outlet Temperatures............................................... 4-57 
Figure 4-69 P4A - Comparison of Main Steam Temperatures............................................................ 4-58 Figure 4-70 P4A - Comparison of Hot Reheat Temperatures............................................................. 4-58 Figure 5-1 Feasibility Study - NOx Reduction for the Two Experiments ............................................. 5-6 Figure 5-2 Feasibility Study - Plot of the NOx and Load Behavior for Experiment 2 ............................. 5-7 Figure 5-3 Load, NOx, CO, and SOx Profiles During Preliminary Modeling........................................ 5-10 Figure 5-4 NOx vs. Load and Excess Oxygen................................................................................. 5-13

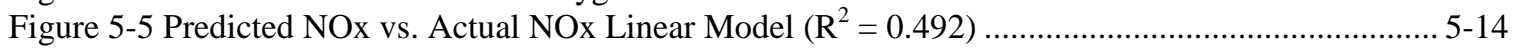

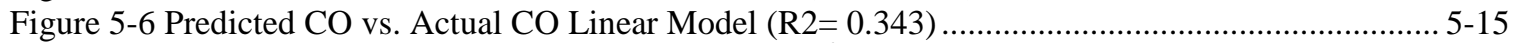

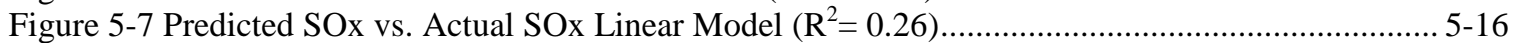

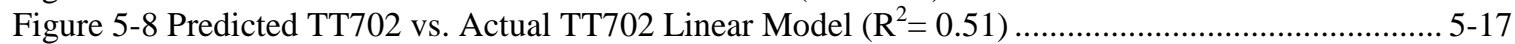

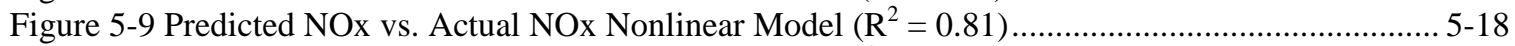

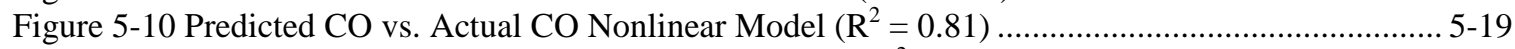

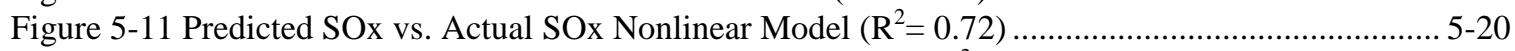

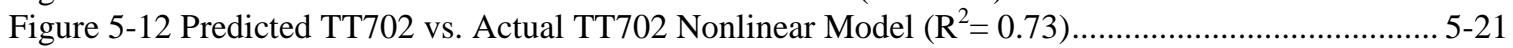
Figure 5-13 Predicted NOx vs. Actual NOx Nonlinear Model.............................................................. 5-22 Figure 5-14 Predicted CO vs. Actual CO Nonlinear Model ................................................................. 5-22 Figure 5-15 Back Propagation Network vs. Radial Basis Network Approximation (NOx) ..................... 5-23 Figure 5-16 Backpropagation Network vs. Radial Basis Network Approximation (CO)......................... 5-23

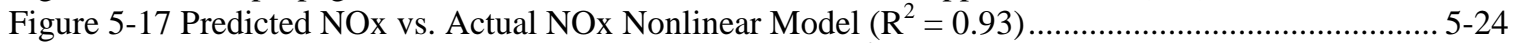

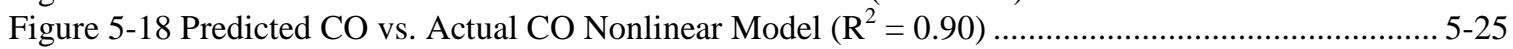

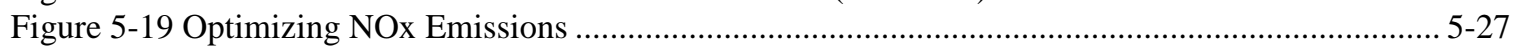

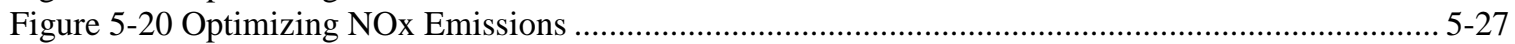

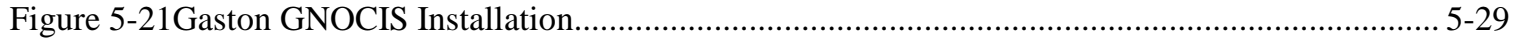

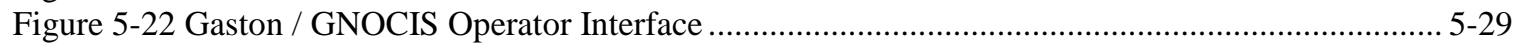

Figure 5-23 Gaston / Maximize Efficiency Objective ....................................................................... 5-30

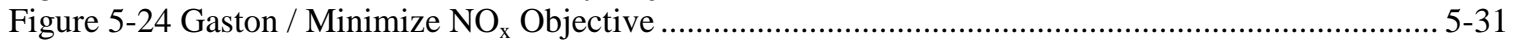

Figure 5-25 Gaston / Maximize Efficiency / Closed-Loop.................................................................. 5-31

Figure 5-26 Kingsnorth / GNOCIS Minimize Carbon-in-Ash ........................................................... 5-32

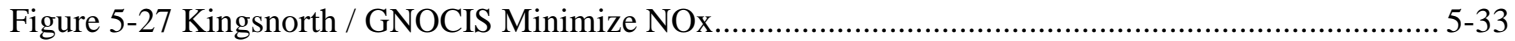

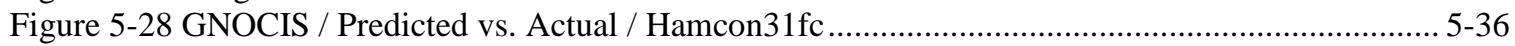

Figure 5-29 GNOCIS / Test 154 / Optimized Variables.................................................................... 5-39

Figure 5-30 GNOCIS / Test 154 / Manipulated Variables ………......................................................... 5-40

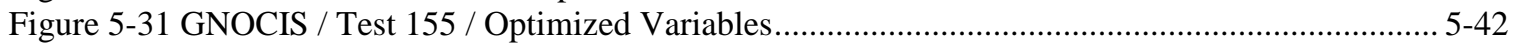

Figure 5-32 GNOCIS / Test 155 / Manipulated Variables ...................................................................... 5-43

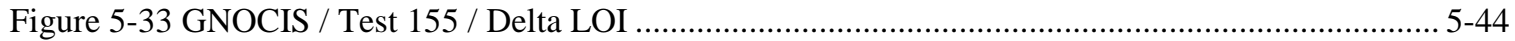

Figure 5-34 GNOCIS / Test 156 / Optimized Variables................................................................... 5-45

Figure 5-35 GNOCIS / Test 156 / Manipulated Variables ................................................................... 5-46

Figure 5-36 GNOCIS / Test 156 / Delta LOI …………..................................................................... 5-47

Figure 5-37 GNOCIS / Test 156 / Delta Efficiency................................................................................. 5-47

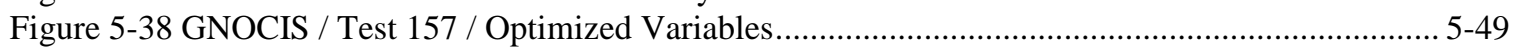

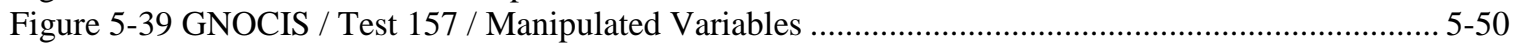

Figure 5-40 GNOCIS / Test 157 / Excess Oxygen Comparison............................................................. 5-51

Figure 5-41 GNOCIS / Test 157 / Delta LOI ………..................................................................... 5-51

Figure 5-42 GNOCIS / Predicted vs. Actual / Hamcon31h ................................................................... 5-54

Figure 5-43 GNOCIS / Predicted vs. Actual / Hamcon31h / LOI ........................................................ 5-55

Figure 5-44 GNOCIS / Predicted vs. Actual / Hamcon31h / Efficiency ...................................................... 5-55

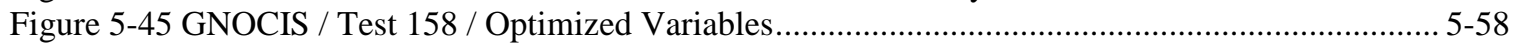

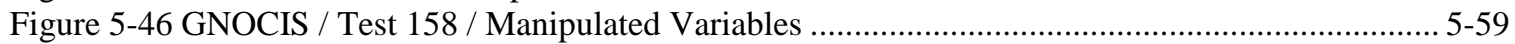

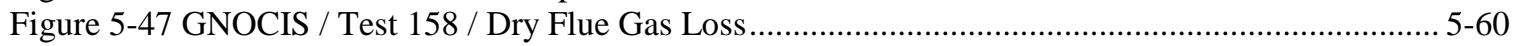

Figure 5-48 GNOCIS / Test 158 / Boiler Efficiency ……............................................................... 5-60

Figure 5-49 GNOCIS / Test 159 / Optimized Variables...................................................................... 5-62

Figure 5-50 GNOCIS / Test 159 / Manipulated Variables ...................................................................... 5-63

Figure 5-51 GNOCIS / Test 159 / Dry Flue Gas Loss.............................................................................. 5-64

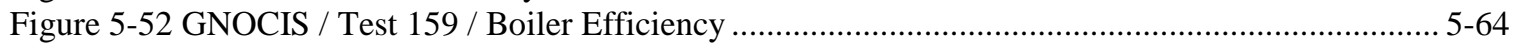

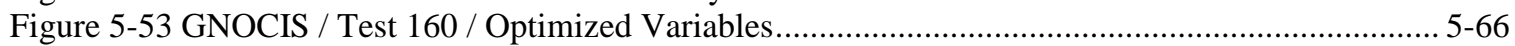

Figure 5-54 GNOCIS / Test 160 / Manipulated Variables ..................................................................... 5-67 
Figure 5-55 GNOCIS / Test 160 / Comparison of LOI Signals ................................................................ 5-68

Figure 5-56 GNOCIS / Test 160 / Air Heater Temperatures ................................................................. 5-69

Figure 5-57 GNOCIS / Test 161 / Optimized Variables................................................................... 5-71

Figure 5-58 GNOCIS / Test 161 / Manipulated Variables ..................................................................... 5-72

Figure 5-59 GNOCIS / Test 161 / Comparison of LOI Signals................................................................. 5-73

Figure 5-60 GNOCIS / Test 161 / Delta Efficiency.............................................................................. 5-73

Figure 5-61 GNOCIS / Test 162 / Optimized Variables........................................................................ 5-75

Figure 5-62 GNOCIS / Test 162 / Manipulated Variables ………….................................................. 5-76

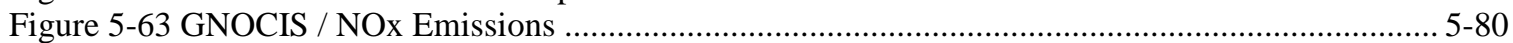

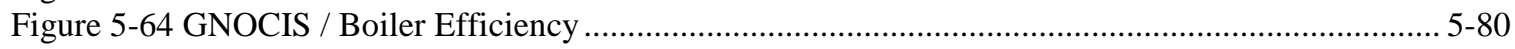

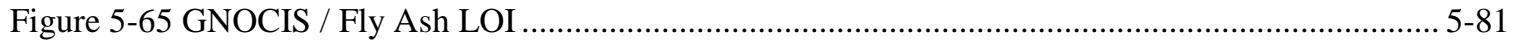

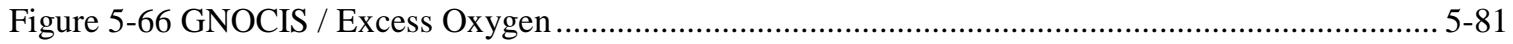

Figure 5-67 GNOCIS / Minimize NOx Emissions / Mill Bias ........................................................... 5-82

Figure 5-68 GNOCIS / Minimize NOx Emissions / Overfire Air Bias .................................................... 5-82

Figure 5-69 GNOCIS / Maximize Efficiency / Mill Bias ....................................................................... 5-83

Figure 5-70 GNOCIS / Maximize Efficiency / Overfire Air Bias ........................................................ 5-83

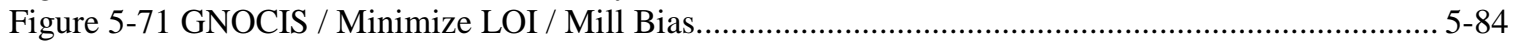

Figure 5-72 GNOCIS / Minimize LOI / Overfire Air Bias.................................................................. 5-84

Figure 6-1 Load Profiles ................................................................................................................... 6-5 


\section{LIST OF TABLES}

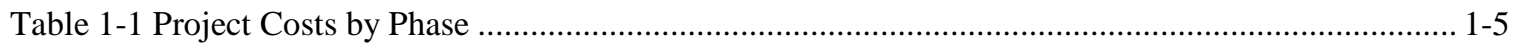

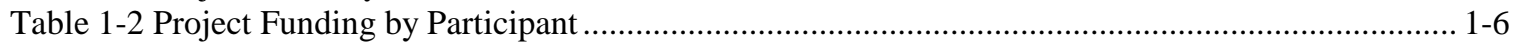

Table 2-1 Combustion Tuning Control Points at Hammond 4 .............................................................. 2-8

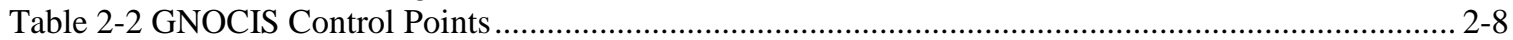

Table 3-1 Factors Controlling the Formation of NOx ........................................................................ 3-1

Table 3-2 Hammond 4 / NOx vs. LOI Tests / Parameters Tested .................................................................. 3-3

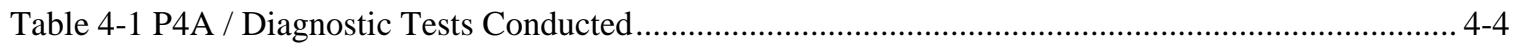

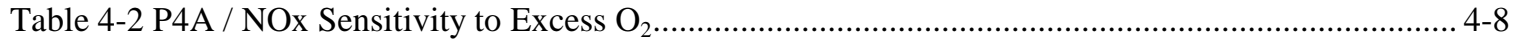

Table 4-3 P4A / Performance Tests Conducted.................................................................................... 4-14

Table 4-4 P4A / Performance Tests / Mill Grinding Performance …….................................................... 4-14

Table 4-5 P4A / Performance Tests / Combustion Air Flow ………...................................................... 4-21

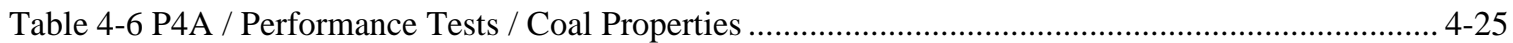

Table 4-7 P4A / Descriptive Statistics for Daily Average NOx Emissions ................................................... 4-31

Table 4-8 P4A - NOx Emissions vs. Mill Pattern (1Q95) ...................................................................... 4-40

Table 4-9 P4A - NOx Emissions vs. Mill Pattern (1Q96) ...................................................................... 4-49

Table 4-10 NOx Emissions Obtained During Long-Term and Performance Tests ................................... 4-53

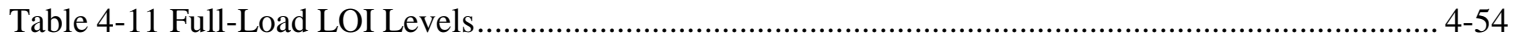

Table 5-1 Feasibility Study - Problem Formulation Experiment 1 …….................................................. 5-4

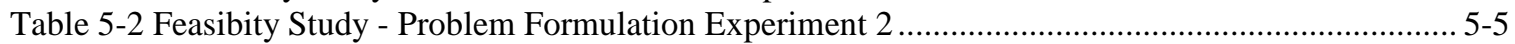

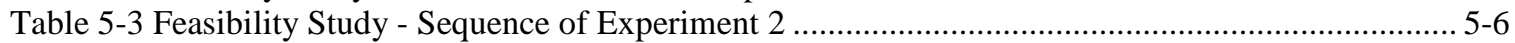

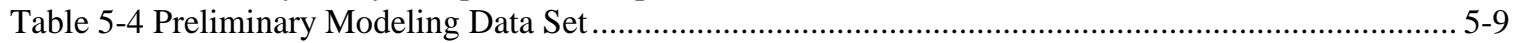

Table 5-5 Model Inputs and Outputs ............................................................................................... 5-11

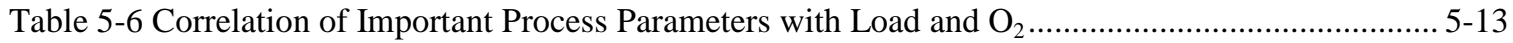

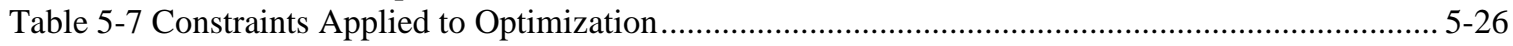

Table 5-8 Control Model Structure for February 1996 Testing .............................................................. 5-35

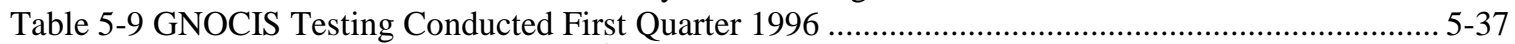

Table 5-10 Control Model Structure for $2^{\text {nd }}$ Quarter 1996 Testing........................................................ 5-53

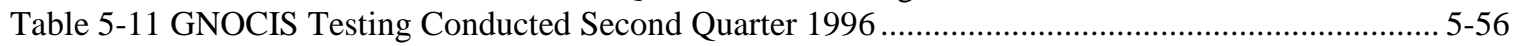

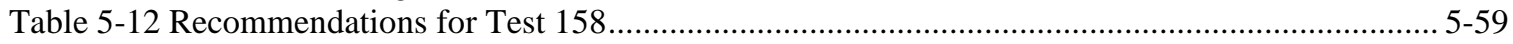

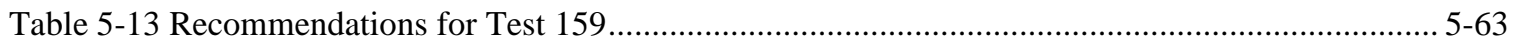

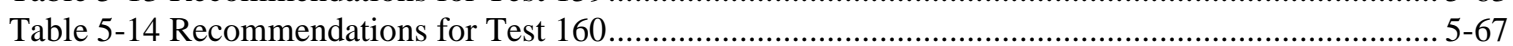

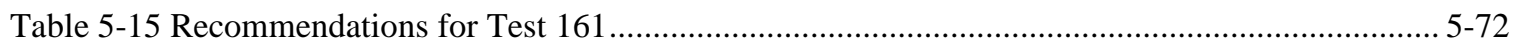

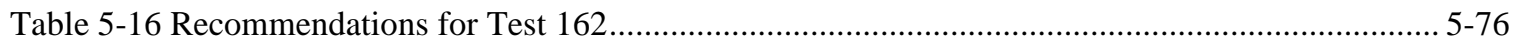

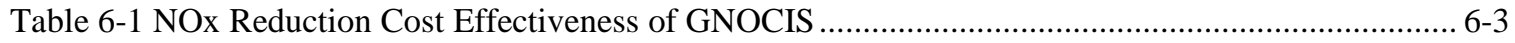

Table 6-2 NOx Reduction Cost Effectiveness of GNOCIS ...................................................................... 6-3

Table 6-3 NOx Reduction Cost Effectiveness of Low NOx Technologies ............................................. 6-4

Table 6-4 NOx and NOx Reduction vs. Load Profile and Operating Mode ............................................... 6-5

Table 6-5 Average Heat Rate Deviation vs. Load Profile and Operating Mode............................................ 6-6

Table 6-6 Fuel Cost Deviation vs. Load Profile and Operating Mode .................................................... 6-6

Table 6-7 NOx Reduction Cost Effectiveness vs. Load Profile and Operating Mode................................. 6-6 
LIST OF TABLES

Xviii 


\section{LIST OF ABBREVIATIONS}

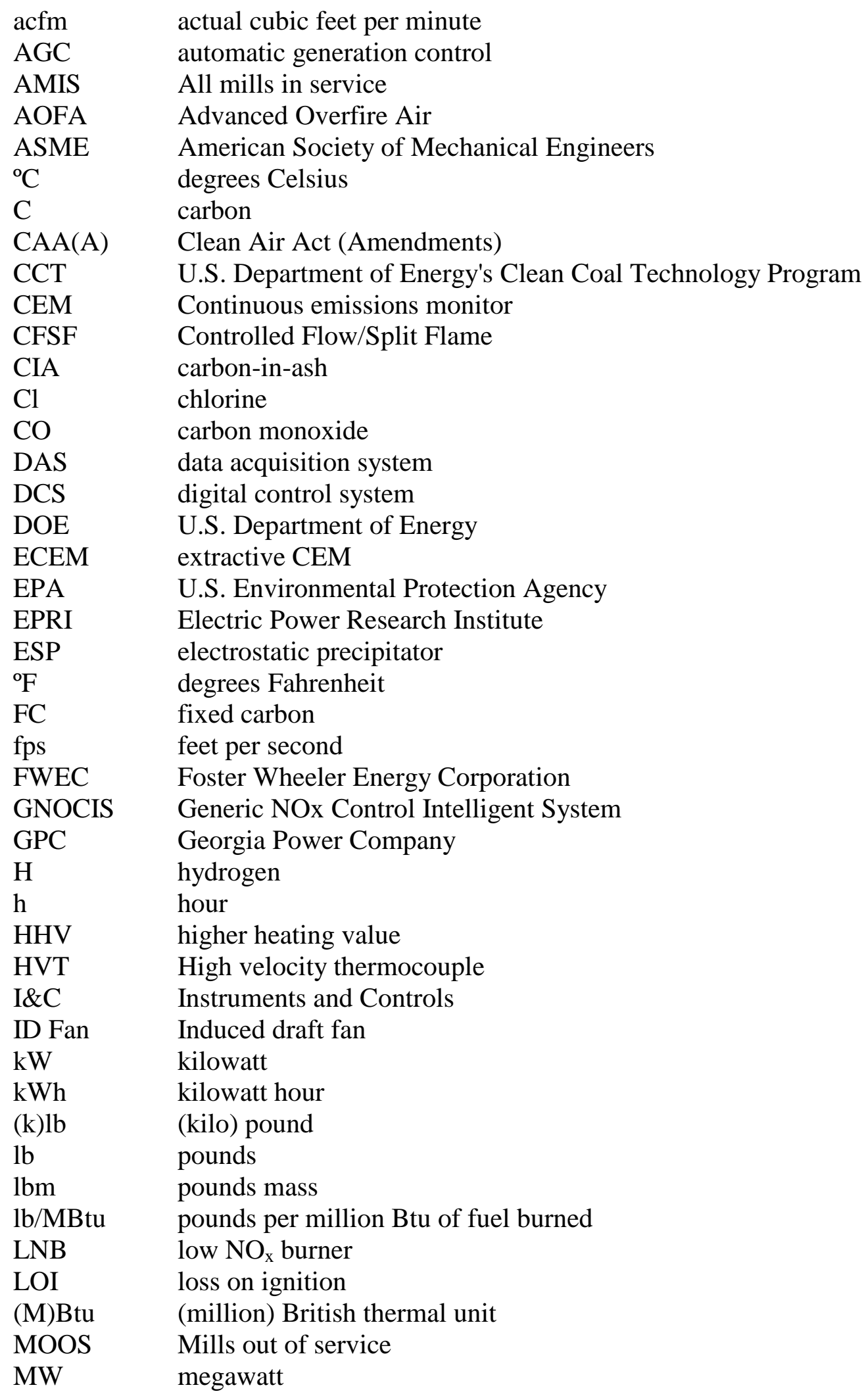




$\begin{array}{ll}\text { N } & \text { nitrogen } \\ \text { NO } & \text { nitrogen oxide } \\ \text { NOx } & \text { nitrogen oxides } \\ \text { NSPS } & \text { New Source Performance Standards } \\ \text { O, } \mathrm{O}_{2} & \text { oxygen } \\ \text { OFA } & \text { overfire air } \\ \text { O\&M } & \text { operation and maintenance } \\ \text { PA fan } & \text { primary air fan } \\ \text { ppm } & \text { parts per million } \\ \text { psia } & \text { pounds per square inch absolute } \\ \text { psig } & \text { pounds per square inch gauge } \\ \text { PTC } & \text { Performance Test Codes } \\ \text { RSD } & \text { relative standard deviation } \\ \text { S } & \text { second } \\ \text { S } & \text { sulfur } \\ \text { SCS } & \text { Southern Company Services } \\ \text { SO } 2 & \text { sulfur dioxide } \\ \text { THC } & \text { total hydrocarbons } \\ \text { UARG } & \text { Utility Air Regulatory Group } \\ \text { UBC } & \text { unburned carbon } \\ \text { VM } & \text { volatile matter } \\ \text { W.c. } & \text { water column }\end{array}$




\section{EXECUTIVE SUMMARY}

This report discusses the results of a U.S. Department of Energy Clean Coal Technology (CCT) demonstration of advanced wall-fired combustion techniques for the reduction of nitrogen oxide (NOx) emissions from coal-fired boilers. The project was conducted at Georgia Power Company's Plant Hammond Unit 4 located near Rome, Georgia. Hammond Unit 4 is a Foster Wheeler Energy Corporation (FWEC) opposed wall-fired boiler, rated at $500 \mathrm{MW}$. The primary goal of this project was the characterization of the low NOx combustion equipment through the collection and analysis of long-term emissions data. The project was funded by the Electric Power Research Institute, Southern Company, and U.S. Department of Energy.

As originally planned, the primary objective of the demonstration at Hammond Unit 4 was to determine the long-term effects of commercially available wall-fired low NOx combustion technologies on NOx emissions and boiler performance. In supporting this objective, baseline testing was conducted on the unit followed by installation and testing of an Foster Wheelers advanced overfire air system and Controlled Flow / Split Flame low NOx burners, separately and in combination. These tests constituted Phases 1 through 3 of the project. These results were reported previously in the final report for these phases [SCS 1998].

An important result from Phase 1-3 testing was that combustion optimization had the potential to enhance boiler performance. Based on these results, a scope addition was proposed to the project funders to add another task to the project. This task, added as Phase 4 of the project, evaluated advanced digital control and optimization techniques as applied to (1) reduction of NOx emissions, (2) mitigation of adverse impacts of low NOx burners and advanced overfire air system, and (3) improvement of boiler efficiency. For the optimization effort, the principal effort was placed on the application of GNOCIS (Generic NOx Control Intelligent System).

Based on competitive bidding, a Foxboro I/A DCS was selected for installation at Hammond replacing the pneumatic control system. The DCS was installed at Hammond during a ninemonth outage starting in September 1993 and continuing to June 1994. Since there had been major modifications to the unit during the outage (precipitator replacement, mill replacements, turbine upgrades), testing was conducted on the unit following this outage to reevaluate the performance of the unit in particular with regards to NOx emissions. This testing was conducted over an extended period lasting from third quarter 1994 and continuing to first quarter 1996. The major findings were that although the DCS greatly improved the dynamic performance of the unit and the ease of which process data could be accessed and analyzed, the DCS did not appear to actually improve unit performance.

The second part of Phase 4 of the project was the installation and demonstration of GNOCIS. GNOCIS is an enhancement to digital control systems (DCS) targeted at improving utility boiler efficiency and reducing emissions. GNOCIS utilizes a neural-network model of the combustion characteristics of the boiler that reflects both short-term and longer-term trends in boiler characteristics. A constrained-nonlinear optimizing procedure is applied to identify the best set points for the plant. These recommended set points can be implemented automatically without operator intervention (closed-loop), or, at the plant's discretion, conveyed to the plant operators for implementation (open-loop). The software is designed for continuous on-line use. GNOCIS 
development was funded by the Electric Power Research Institute, PowerGen, Southern Company, Radian International, U.K. Department of Trade and Industry, and U.S. Department of Energy. GNOCIS was under development at Alabama Power's Gaston Unit 4 and PowerGen's Kingsnorth Unit 1 from 1994 through 1996 (PowerGen, 1997).

Following the work at these two sites, GNOCIS was installed and became fully operational at Hammond during first quarter 1996. At Hammond, GNOCIS was designed to operate in either open-loop (advisory) or closed-loop (supervisory) modes, although more emphasis was placed on the latter. During first quarter and second quarter 1996, short-term testing on the unit was conducted. The results from this testing were similar to that observed at the other GNOCIS sites with NOx reductions of around 10 to $15 \%$ and efficiency improvements of about $0.5 \%$. Additional GNOCIS testing at Hammond was hoped for; however, due in part to the relative unavailability of the unit for testing, this testing never materialized. Although testing was not as extensive as first hoped, numerous GNOCIS tests have been conducted at Hammond and other sites and it is felt that the results obtained at Hammond are representative of the true performance of the technology.

Using the available short-term test results, model studies further predict that GNOCIS could, at least for this unit, simultaneously reduce NOx emissions and improve unit heat rate. The results of these studies are shown in Table ES-1 through Table ES-4 for several operating mode/load profile combinations. In most scenarios, GNOCIS improved both unit heat rate and reduced NOx emissions.

Table ES-1 NOx and NOx Reduction vs. Load Profile and Operating Mode

\begin{tabular}{|c|c|c|c|c|}
\hline & \multicolumn{4}{|c|}{ GNOCIS Operating Mode } \\
\hline Load Profile (Ib/Mbtu / \% Reduction) & Baseline & $\begin{array}{l}\text { Minimize } \\
\text { NOx }\end{array}$ & $\begin{array}{l}\text { Maximize } \\
\text { Efficiency }\end{array}$ & $\begin{array}{c}\text { Minimize } \\
\text { LOI }\end{array}$ \\
\hline Phase 1 & 0.42 & $0.37 / 11 \%$ & $0.39 / 6 \%$ & $0.45 /-9 \%$ \\
\hline Base Load & 0.43 & $0.38 / 12 \%$ & $0.39 / 7 \%$ & $0.46 /-9 \%$ \\
\hline Peaking Load & 0.41 & $0.35 / 13 \%$ & $0.43 /-6 \%$ & $0.42 /-3 \%$ \\
\hline Cycling Load & 0.40 & $0.36 / 10 \%$ & $0.39 / 4 \%$ & $0.43 /-8 \%$ \\
\hline Flat Load & 0.40 & $0.36 / 11 \%$ & $0.40 / 0 \%$ & $0.43 /-6 \%$ \\
\hline
\end{tabular}

Table ES-2 Average Heat Rate Deviation vs. Load Profile and Operating Mode

\begin{tabular}{lcccc}
\hline \multicolumn{1}{c}{ Load Profile (Btu/kWh) } & Baseline & $\begin{array}{c}\text { GNOCIS Operating Mode } \\
\text { Minimize } \\
\text { NOx }\end{array}$ & $\begin{array}{c}\text { Maximize } \\
\text { Efficiency }\end{array}$ & $\begin{array}{c}\text { Minimize } \\
\text { LOI }\end{array}$ \\
\hline Phase 1 & -- & -47 & -78 & 38 \\
Base Load & -- & -56 & -88 & 47 \\
Peaking Load & -- & 1 & -37 & -6 \\
Cycling Load & -- & -43 & -71 & 18 \\
Flat Load & -- & -25 & -56 & 5 \\
\hline
\end{tabular}

Positive number indicates poorer heat rate, negative numbers improved heat rate. 
Table ES-3 Fuel Cost Deviation vs. Load Profile and Operating Mode

\begin{tabular}{lrrrr}
\hline \multirow{2}{*}{ Load Profile } & Baseline & \multicolumn{4}{c}{ GNOCIS Operating Mode } \\
& & \multicolumn{1}{c}{ NOximize } & Maximize & Minimize \\
& -- & $-\$ 237,610$ & $-\$ 391,804$ & \multicolumn{1}{c}{ LOI } \\
\hline Phase 1 & -- & $-\$ 280,727$ & $-\$ 446,273$ & $\$ 237,479$ \\
Base Load & -- & $\$ 4,483$ & $-\$ 187,014$ & $-\$ 28,909$ \\
Peaking Load & -- & $-\$ 216,281$ & $-\$ 356,717$ & $\$ 90,939$ \\
Cycling Load & -- & $-\$ 127,076$ & $-\$ 283,833$ & $\$ 26,589$ \\
Flat Load & & & &
\end{tabular}

Positive number is an expenditure.

Negative number is a savings.

Table ES-4 NOx Reduction Cost Effectiveness vs. Load Profile and Operating Mode

\begin{tabular}{|c|c|c|c|c|}
\hline \multirow[b]{2}{*}{ Load Profile (\$/lb NOx removed) } & \multicolumn{4}{|c|}{ GNOCIS Operating Mode } \\
\hline & Baseline & $\begin{array}{l}\text { Minimize } \\
\text { NOx }\end{array}$ & $\begin{array}{l}\text { Maximize } \\
\text { Efficiency }\end{array}$ & $\begin{array}{c}\text { Minimize } \\
\text { LOI }\end{array}$ \\
\hline Phase 1 & -- & $-\$ 261$ & $-\$ 684$ & $\mathrm{n} / \mathrm{a}$ \\
\hline Base Load & -- & $-\$ 277$ & $-\$ 627$ & $\mathrm{n} / \mathrm{a}$ \\
\hline Peaking Load & -- & $\$ 43$ & $\mathrm{n} / \mathrm{a}$ & $\mathrm{n} / \mathrm{a}$ \\
\hline Cycling Load & -- & $-\$ 293$ & $-\$ 975$ & $\mathrm{n} / \mathrm{a}$ \\
\hline Flat Load & -- & $-\$ 177$ & $-\$ 2,403$ & $\mathrm{n} / \mathrm{a}$ \\
\hline
\end{tabular}

Again, the above tables are based on the extrapolation of available test data to various long-term operating profiles.

Based on GNOCIS testing at this site and others, at plant management's request, GNOCIS is being incorporated into the unit's standard operating procedures. Also, consideration is being given to applying GNOCIS to other plant processes. 
EXECUTIVE SUMMARY

xxiv 


\section{INTRODUCTION}

\subsection{Purpose of this Report}

This report presents the results of Phase 4 of a U.S. Department of Energy (DOE) Clean Coal Technology (CCT) project demonstrating advanced wall-fired combustion techniques for the reduction of nitrogen oxide (NOx) emissions from coal-fired boilers. Phase 4 consisted of the installation and testing of a digital control system and on-line combustion optimization system. The project was conducted on Unit 4 at Georgia Power Company's Plant Hammond, located near Rome, Georgia. The technologies demonstrated on this unit include Foster Wheeler Energy Corporation's advanced overfire air system and Controlled Flow/Split Flame low NOx burner. The DOE Cooperative Agreement Number for this project is DE-FC22-90PC89651.

The project was managed by Southern Company Services, Inc. (SCS) on behalf of the project cofunders: Southern Company, U.S. Department of Energy (DOE), and Electric Power Research Institute (EPRI). Southern Company, the largest producer of electricity in the United States is the parent firm of Alabama Power, Georgia Power, Gulf Power, Mississippi Power and Savannah Electric. Based in Atlanta, Southern Company supplies electricity in nine countries on four continents and provides energy-related marketing, trading and technical services and wireless telecommunications. SCS provides engineering, research, and financial services to Southern Company.

The Clean Coal Technology Program is a jointly funded effort between government and industry to move the most promising advanced coal-based technologies from the research and development stage to the commercial marketplace. The Clean Coal effort sponsors projects that are different from traditional research and development programs sponsored by the DOE. Traditional projects focus on long range, high risk, high payoff technologies with the DOE providing the majority of the funding. In contrast, the goal of the Clean Coal Program is to demonstrate commercially feasible, advanced coal-based technologies that have already reached the "proof of concept" stage. As a result, the Clean Coal Projects are jointly funded endeavors between the government and the private sector, conducted as cooperative agreements in which the industrial participant contributes at least fifty percent of the total project cost.

\subsection{Overview of Project}

The primary objective of the demonstration at Hammond Unit 4 was to determine the long-term effects of commercially available wall-fired low NOx combustion technologies on NOx emissions and boiler performance. Short-term tests of each technology were also performed to provide engineering information about emissions and performance trends. A target of achieving fifty percent NOx reduction using combustion modifications was established for the project.

Specifically, the original objectives of the project were:

- Demonstrate in a logical stepwise fashion the short-term NOx reduction capabilities of the following advanced low NOx combustion technologies: 
- Advanced Overfire Air (AOFA)

- Low NOx burners (LNB)

․ LNB with AOFA

- Determine the dynamic, long-term emissions characteristics of each of these combustion NOx reduction methods using statistical techniques.

- Evaluate the progressive cost effectiveness (i.e., dollars per ton NOx removed) of the low NOx combustion techniques tested.

- Determine the effects on other combustion parameters (e.g., CO production, carbon carryover, particulate characteristics) of applying the NOx reduction methods listed above.

To accomplish these evaluations, the project was partitioned into the following test phases:

- Phase 1 - Baseline

- Phase 2 - Advanced Overfire Air

- Phase 3A - Low NOx Burners

- Phase 3B - Low NOx Burners plus Advanced Overfire Air

Each of the phases of the project involved three distinct testing periods - short-term characterization, long-term characterization, and short-term verification. The short-term characterization testing established the trends of NOx versus various parameters and establishes the influence of the operating mode on other combustion parameters. The long-term characterization testing (50 to 80 continuous days of testing) established the dynamic response of the NOx emissions to all of the influencing parameters encountered. The short-term verification testing documented any fundamental changes in NOx emissions characteristics that may have occurred during the long-term test period. The results from Phases 1-3 can be found in the final report for these phases [SCS 1998].

Over the course of the project, several tasks not part of the original project scope were included:

- Chemical Emissions Testing - Chemical emissions testing was conducted during Phases 2 and $3 \mathrm{~A}$.

- Demonstration of On-Line Carbon-in-Ash Monitors.

- Digital Controls / Optimization - This task, added as Phase 4 of the project, evaluated advanced digital control and optimization techniques as applied to (1) reduction of NOx emissions, (2) mitigation of adverse impacts of low NOx burners and advanced overfire air system, and (3) improvement of boiler efficiency. 
The results of the chemical emissions testing and on-line carbon-in-ash monitors are presented in other reports [Radian 1993][SCS 1997]. This report is the subject of Phase 4 - the digital control / optimization phase.

\subsubsection{Host Site Description}

Georgia Power Company's Plant Hammond Unit 4 is a Foster Wheeler Energy Corporation (FWEC) opposed wall-fired boiler, rated at $500 \mathrm{MW}$ gross, with design steam conditions of 2500 psig and $1000 / 1000^{\circ} \mathrm{F}$ superheat/reheat temperatures, respectively. Hammond 4 was placed into commercial operation on December 14, 1970. Prior to the LNB retrofit, six FWEC Planetary Roller and Table type mills provided pulverized eastern bituminous coal (12,900 Btu/lb, 33\% $\mathrm{VM}, 53 \% \mathrm{FC}, 1.7 \% \mathrm{~S}, 1.4 \% \mathrm{~N}$ ) to 24 pre-NSPS, FWEC Intervane burners. During the LNB outage, the existing burners were replaced with FWEC Control Flow/Split Flame burners. The unit was also retrofit with six Babcock and Wilcox MPS 75 mills during the course of the demonstration (two each during the spring 1991, spring 1992, and fall 1993 outages). The burners are arranged in a matrix of twelve burners ( 4 wide $\mathrm{x} 3 \mathrm{high}$ ) on opposing walls with each mill supplying coal to 4 burners per elevation. As part of this demonstration project, Hammond 4 was retrofit with a FWEC designed Advanced Overfire Air System. The unit is equipped with a coldside ESP and utilizes two regenerative secondary air heaters and two regenerative primary air heaters. Designed for pressurized furnace operation, Hammond 4 was converted to balanced draft operation in 1977. The unit was equipped with a Bailey pneumatic boiler control system during the baseline, AOFA, LNB, and LNB+AOFA phases of the project. Further details on the unit configuration and operating performance can be found elsewhere [SCS 1998].

\subsubsection{Project Schedule}

Figure 1-1 shows the overall schedule for the project. Baseline, AOFA, LNB, and LNB+AOFA installation and testing were conducted from 1989 through 1993. On December 6, 1994, DOE approved a project scope addition to demonstrate the use of advanced on-line control and optimization techniques to combustion optimization.

\subsubsection{Project Cost}

The total estimated cost of the project is $\$ 15,853,890$. The Participants' cash contribution and the Government share in the costs of this project are shown in Table 1-1. The costs quoted are those submitted in the most recent Cooperative Agreement modification. A summary of funding by contributor is shown in Table 1-2.

\subsection{Report Organization}

The purpose of this report is to provide a technical account of Phase 4 of the project. The following is a brief description of the information provided in each section:

- Section 1 - Introduction - Background and funding information.

- Section 2 - Technology Descriptions of the DCS and GNOCIS 
- Section 3 - Basis for Installing the DCS and GNOCIS

- $\quad$ Section 4 - DCS Testing

- Section 5 - Optimization

- Section 6 - Conclusions

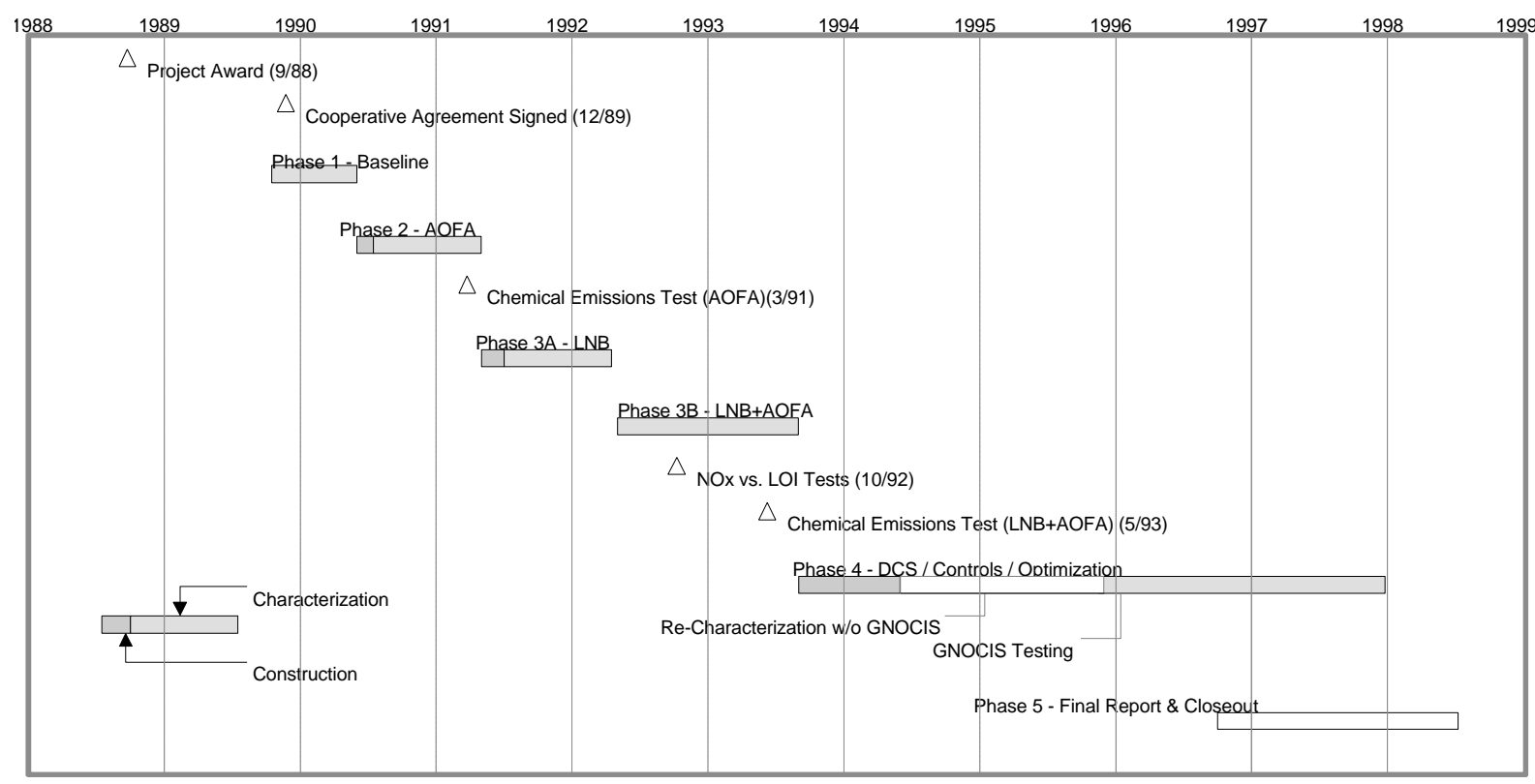

Figure 1-1 Overall Project Schedule 
Table 1-1 Project Costs by Phase

\begin{tabular}{|c|c|c|}
\hline Phase & Dollar Share (\$) & Percent Share (\%) \\
\hline \multicolumn{3}{|l|}{ Phase 0 - Pre-Award } \\
\hline Government & $\$ 122,311$ & $41 \%$ \\
\hline \multirow[t]{2}{*}{ Participant } & $\$ 179,637$ & $59 \%$ \\
\hline & $\$ 301,948$ & \\
\hline \multicolumn{3}{|c|}{ Phase 1 - Baseline Testing } \\
\hline Government & $\$ 660,426$ & $45 \%$ \\
\hline \multirow[t]{2}{*}{ Participant } & $\$ 813,739$ & $55 \%$ \\
\hline & $\$ 1,474,165$ & \\
\hline \multicolumn{3}{|c|}{ Phase 2 - AOFA Installation and Characterization } \\
\hline Government & $\$ 1,712,745$ & $45 \%$ \\
\hline \multirow{2}{*}{ Participant } & $\$ 2,110,346$ & $55 \%$ \\
\hline & $\$ 3,823,091$ & \\
\hline \multicolumn{3}{|c|}{ Phase 3 - LNB Installation and Characterization } \\
\hline Government & $\$ 2,571,446$ & $45 \%$ \\
\hline \multirow{2}{*}{ Participant } & $\$ 3,168,389$ & $55 \%$ \\
\hline & $\$ 5,739,835$ & \\
\hline \multicolumn{3}{|c|}{ Phase 4 - Digital Control System } \\
\hline Government & $\$ 1,076,000$ & $30 \%$ \\
\hline \multirow[t]{2}{*}{ Participant } & $\$ 2,522,338$ & $70 \%$ \\
\hline & $\$ 3,598,338$ & \\
\hline \multicolumn{3}{|c|}{ Phase 5 - Project Close-out and Final Reporting } \\
\hline Government & $\$ 410,598$ & $45 \%$ \\
\hline \multirow[t]{2}{*}{ Participant } & $\$ 505,915$ & $55 \%$ \\
\hline & $\$ 916,513$ & \\
\hline Total Project Funding & $\$ 15,853,890$ & \\
\hline
\end{tabular}


Table 1-2 Project Funding by Participant

\begin{tabular}{lrc}
\hline Participant & Dollar Contribution & Percent \\
\hline DOE & $\$ 6,553,526$ & 41.3 \\
EPRI + Southern Company & $\$ 9,300,364$ & 58.7 \\
Total & $\$ 15,853,890$ & 100 \\
\hline
\end{tabular}




\section{TECHNOLOGY DESCRIPTION}

Three FWEC low NOx technologies were tested at Hammond: the Advanced Overfire Air (AOFA), the CF/SF Low NOx Burners (LNB), and the LNB+AOFA. These NOx control technologies were tested during Phases 1-3 of the project and the results are described elsewhere [SCS 1998]. The objective of Phase 4 of the project at Plant Hammond was to evaluate and demonstrate the effectiveness of advanced digital control/optimization methodologies as applied to the NOx abatement technologies installed at this site (LNB and AOFA). The combustion optimization system chosen for demonstration was GNOCIS (Generic NOx Control Intelligent System). This section provides an overview of the digital control system and GNOCIS.

\subsection{Digital Control System}

An integral part of Phase 4 of the project was the design and installation of a digital control system to be the host of the advanced control/optimization strategies being developed. SCS Engineering had overall responsibility for the following major activities:

- Preliminary engineering

- Procurement

- Detail engineering

- Digital control system configuration

- Installation and checkout

In general, the system consisted of Unit Master, Fuel Control, Air Flow Control, Furnace Pressure Control, Feedwater Control, Steam Temperature Control, Condensate Control, Auxiliary Control, DCA Heater Level Control, Ash Handling System, Precipitator Energy Management System, Precipitator Fire Protection, and Burner Management System. In total, the digital control system was configured for 2352 input/output points consisting of 572 analog inputs, 116 analog outputs, 1032 digital inputs, and 632 digital outputs with the balance being allocated spares.

Based on a competitive evaluation, a Foxboro I/A Series System DCS was selected for installation. The Foxboro I/A Series System is a fully distributable, digital control system designed to address a broad range of application requirements. The DCS provides nodes of interchangeable hardware and software modules that can be matched to the process application. Although not necessarily unique to the Foxboro I/A System, the following are some of the important characteristics of this digital control system:

- Fully distributable, both functionally and physically, allowing installation of the control system hardware in the field (i.e. near the burner front and mills) -- no special environment for the control system hardware is needed. 
- Extensive use of standard communication networks. I/A Series nodes communicate with each other using a MAP compatible network. Gateways are provided for communication to other devices via RS-232-C, RS-485, X.25, Modbus, Allen-Bradley Data Highway, IEEE 802.3 (CSMA/CD), IEEE 802.4 (token passing) and others.

- Open system architecture. The digital control system is built using the following constructs: (1) operating system - "VENIX", a version of "UNIX", (2) development language - "C", (3) relational data base - "INFORMIX", and (4) network - IEEE 802.3 and 802.4. Adherence to these standards facilitates software portability from and to other platforms and allows current software to be utilized as new hardware technology is introduced.

- Increased reliability from the use of sealed modules interconnected by serial communications and the application of redundant hardware modules on critical control loops.

An overview of the system installed at Hammond Unit 4 is shown in Figure 2-1.

\section{Engineering Workstations}

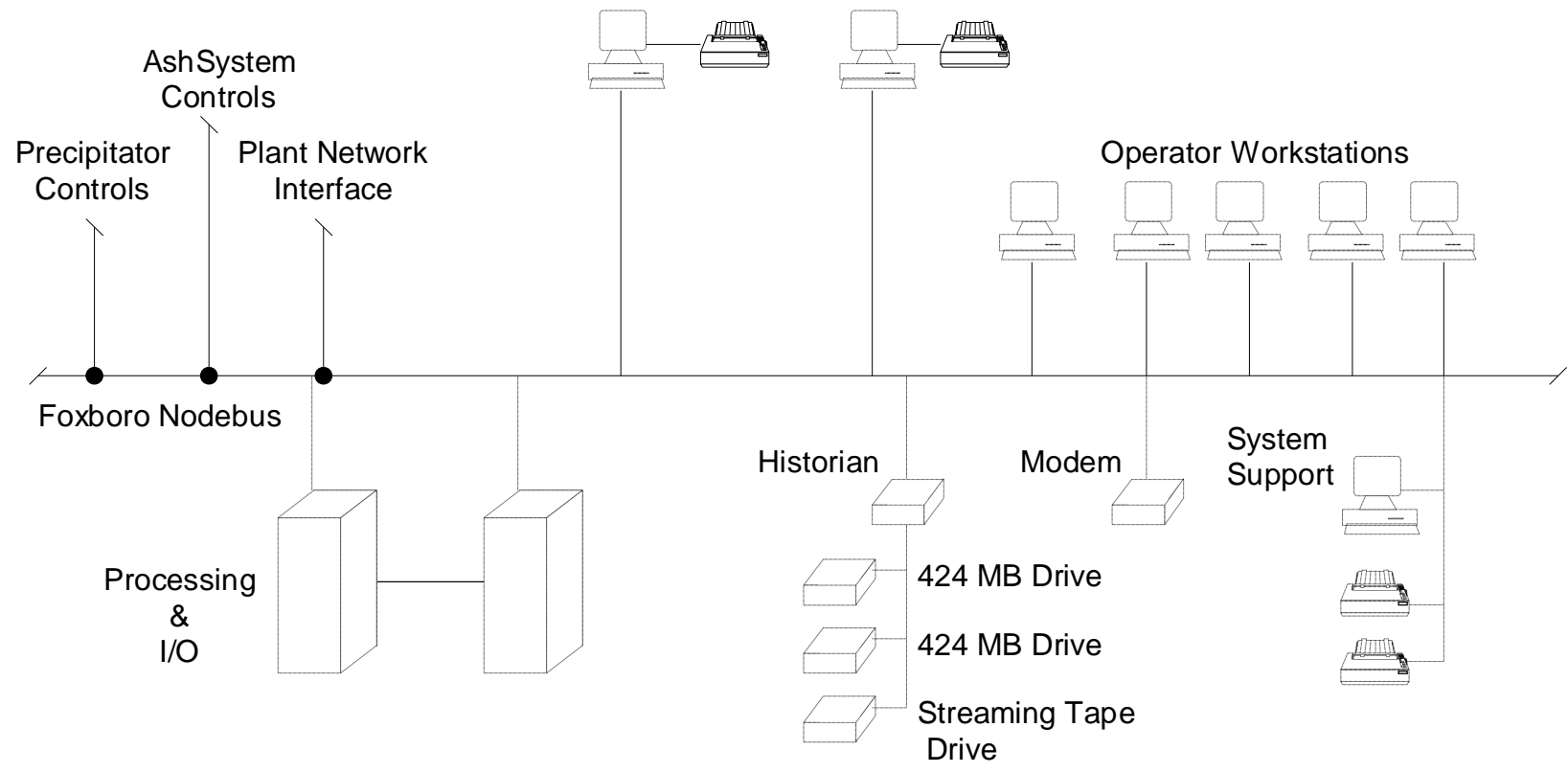

Figure 2-1 Unit 4 DCS Overview

As part of this project, the control room was modified to accept the new Unit 4 digital control system. A plan drawing of the retrofitted Unit 1-4 control room is shown in Figure 2-2. As shown, the pre-existing Unit 4 benchboards were removed and replaced with a CRT based control panel. Also shown in this figure is the retrofitted Unit 3 benchboard that was upgraded during fall 1993. In addition to the upgrades to Units 3 and 4, Georgia Power is also considering upgrading the digital control systems on Units 1 and 2. Figure 2-3 shows the control room as envisioned following upgrades on all four units. Digital control system and control room modifications for Units 1,2, and 3 are not a part of the Wall-Fired Project. A schematic of the 
new Unit 4 benchboard is shown in Figure 2-4 and a photo in Figure 2-5. As can be inferred from this figure, operator interaction with the digital control system is almost exclusively through the operator displays.

In addition to the inter-DCS network, the Unit 4 DCS (and the others also), are connected through a router to the plant's token-ring PC engineering and administrative LAN and the corporate wide area network (WAN) (Figure 2-6). The latter enables remote access of process data and facilitates software maintenance. A Sun Sparcstation 5, hosting the advanced control/optimization software, is connected to this network.

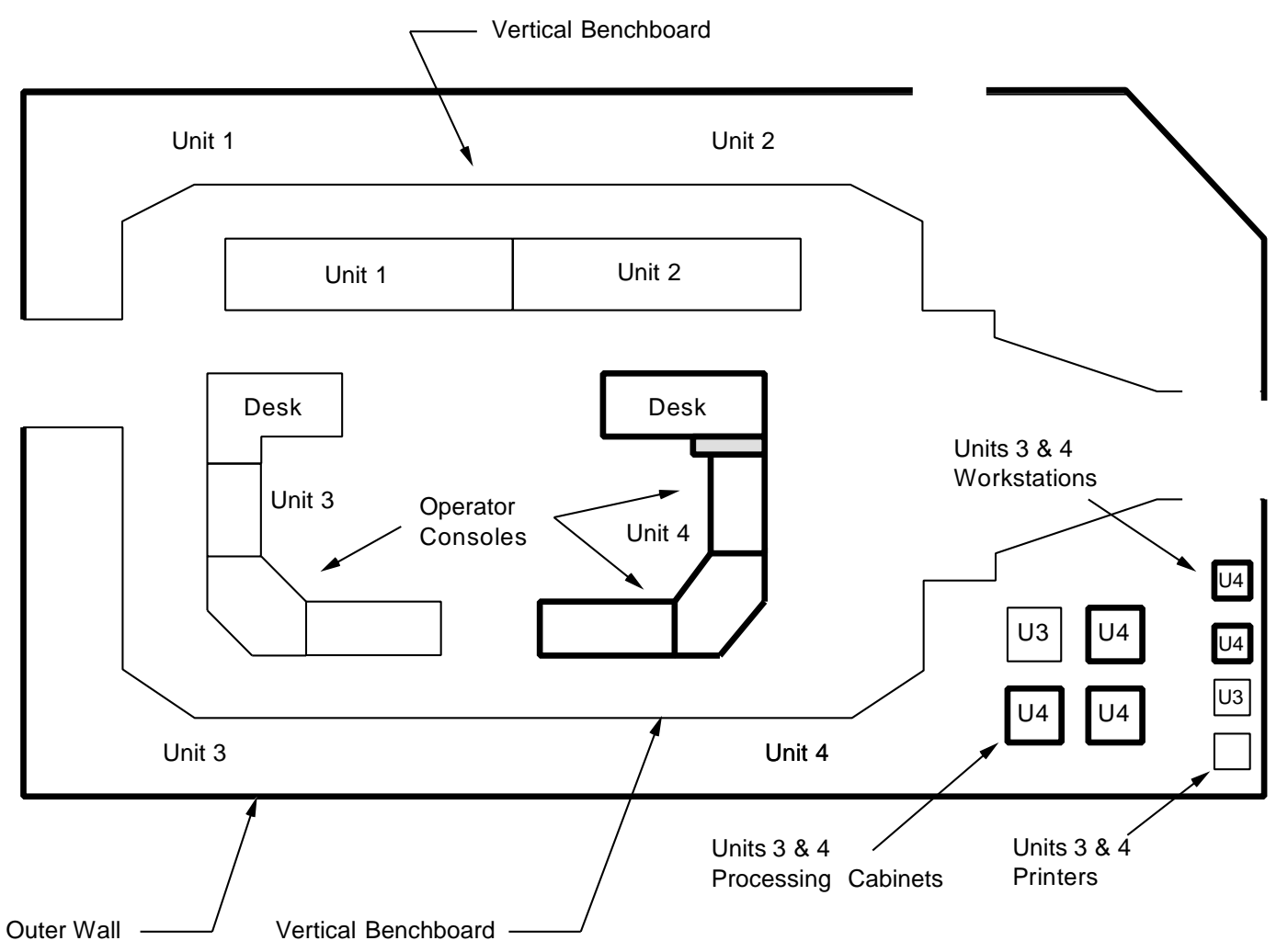

Figure 2-2 Unit 1-4 Control Room Layout as Currently Implemented 


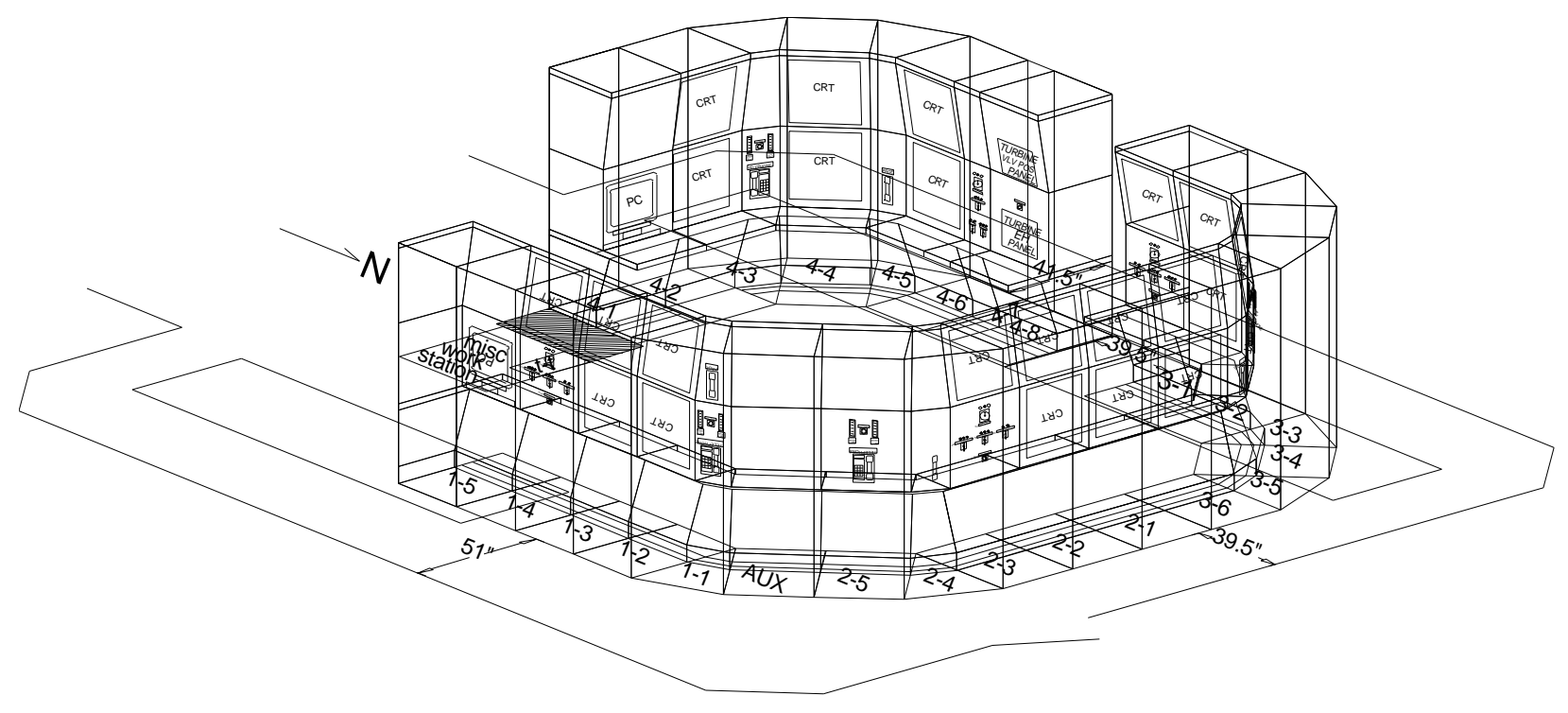

Figure 2-3 Unit 1-4 Control Room Layout (Planned)

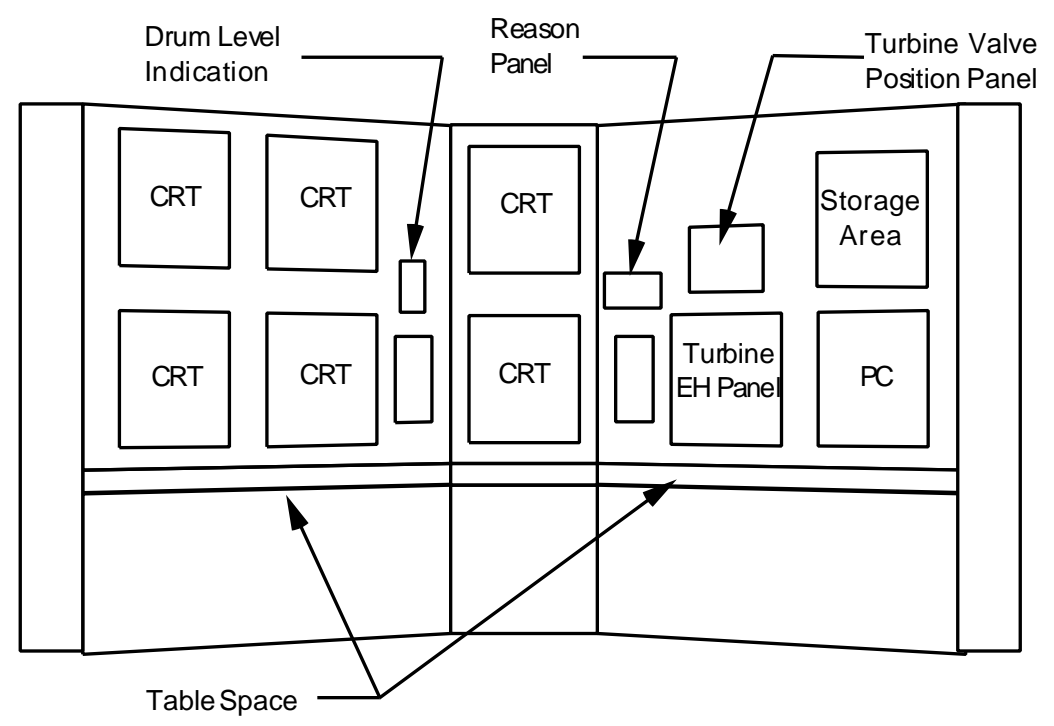

Figure 2-4 Unit 4 Benchboard 


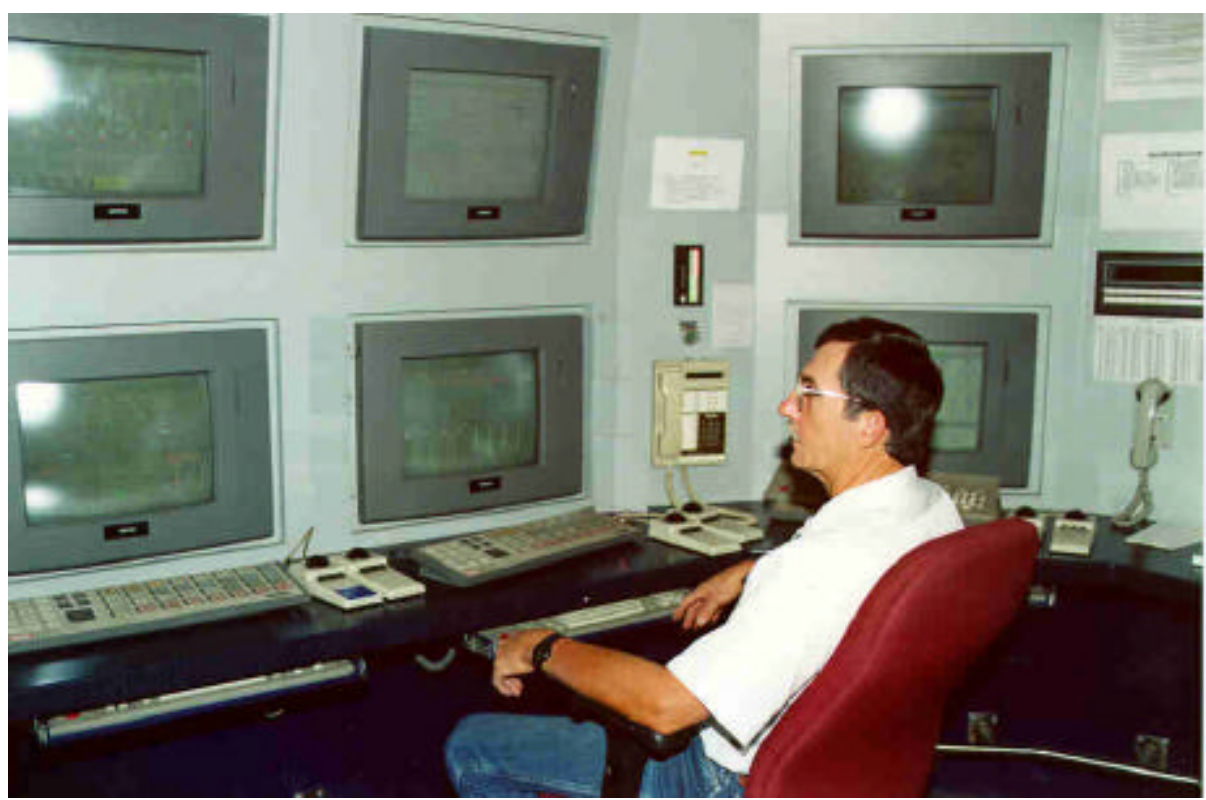

Figure 2-5 Photo of Unit 4 Benchboard

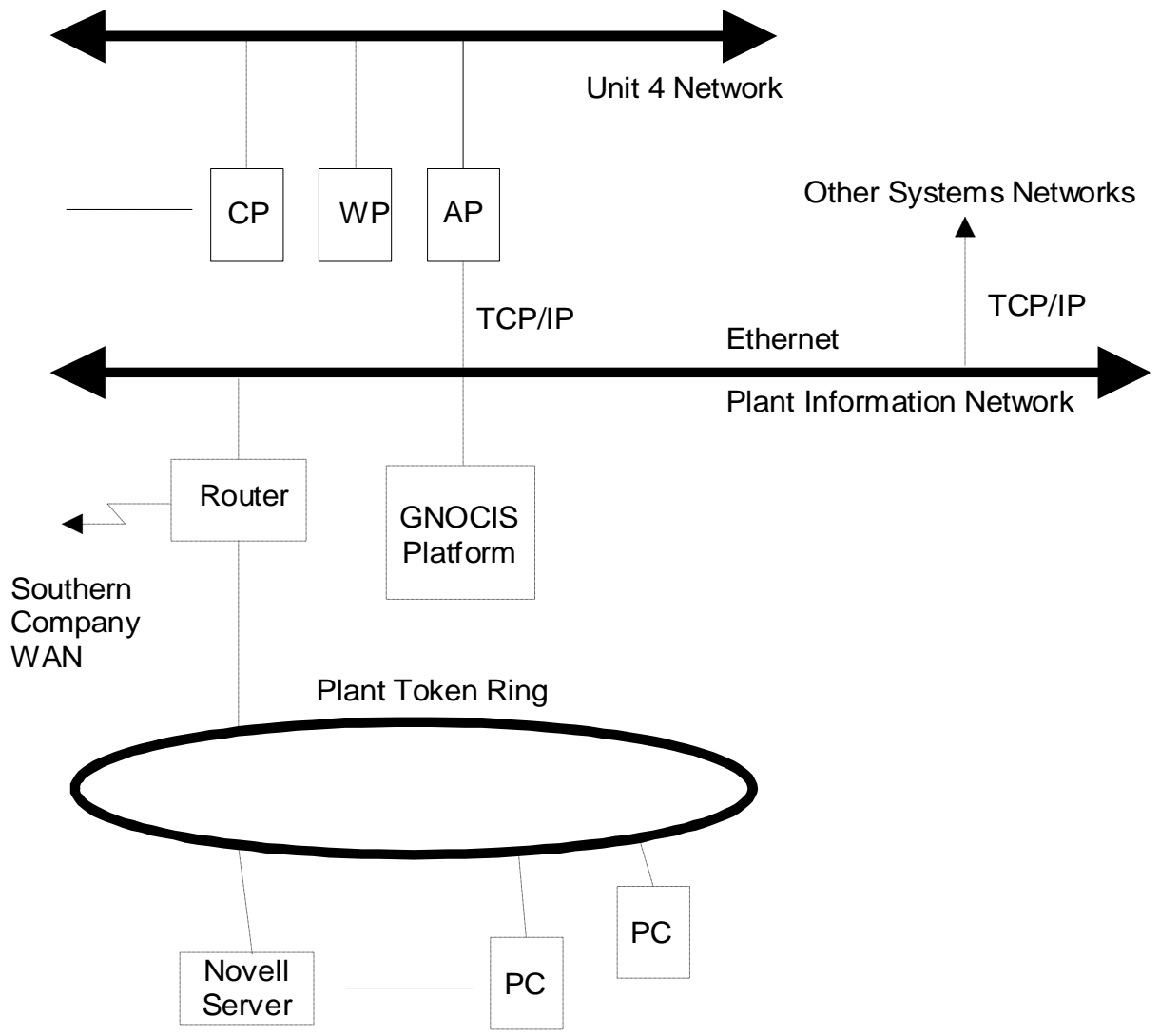

Figure 2-6 Hammond Plant Network 


\subsection{GNOCIS}

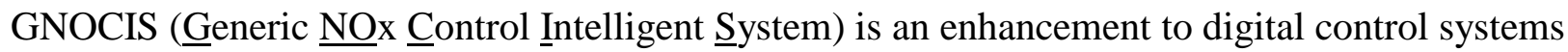
(DCS) targeted at improving utility boiler efficiency and reducing emissions. GNOCIS is designed to operate on units burning gas, oil, or coal and is available for all combustion firing geometries. GNOCIS development was funded by a consortium consisting of the Electric Power Research Institute, PowerGen, Southern Company, Radian International, U.K. Department of Trade and Industry, and U.S. Department of Energy.

GNOCIS utilizes a neural-network model of the combustion characteristics of the boiler that reflects both short-term and longer-term trends in boiler characteristics. A constrained-nonlinear optimizing procedure is applied to identify the best set points for the plant. These recommended set points can be implemented automatically without operator intervention (closed-loop), or, at the plant's discretion, conveyed to the plant operators for implementation (open-loop). The software is designed for continuous on-line use. The major elements of GNOCIS are shown in Figure 2-7.

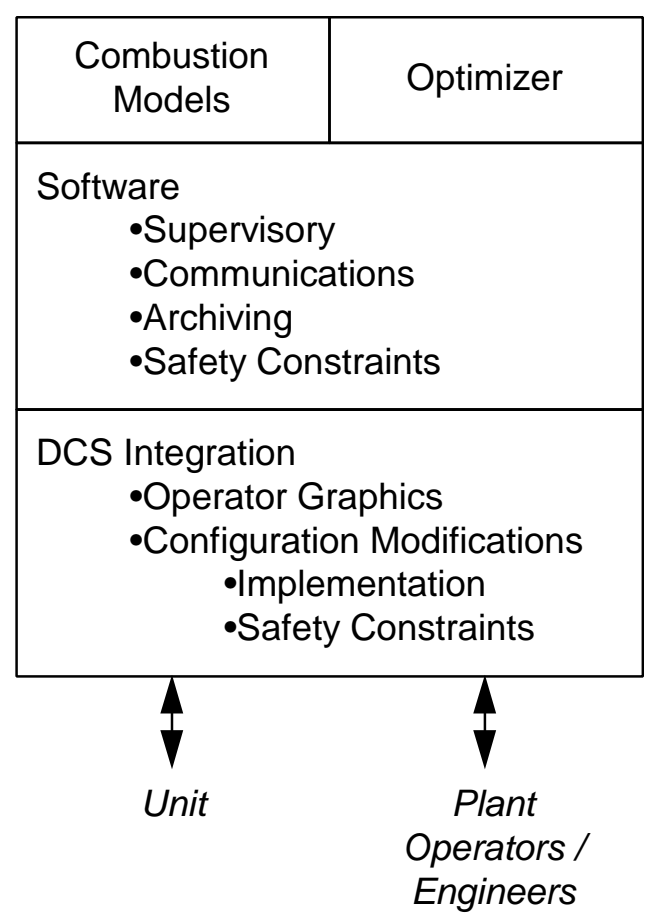

Figure 2-7 Major Elements of GNOCIS 
The recommendations provided by GNOCIS, whether open- or closed-loop, are supervisory in nature and are ideally implemented via the DCS. As shown in Figure 2-8, GNOCIS utilizes process data collected from the DCS. Once determined, the recommendations are provided to the operator through the DCS or other displays. The operator can then make the final determination on whether these recommendations should be implemented. Alternatively, the recommendations are automatically implemented via the DCS.

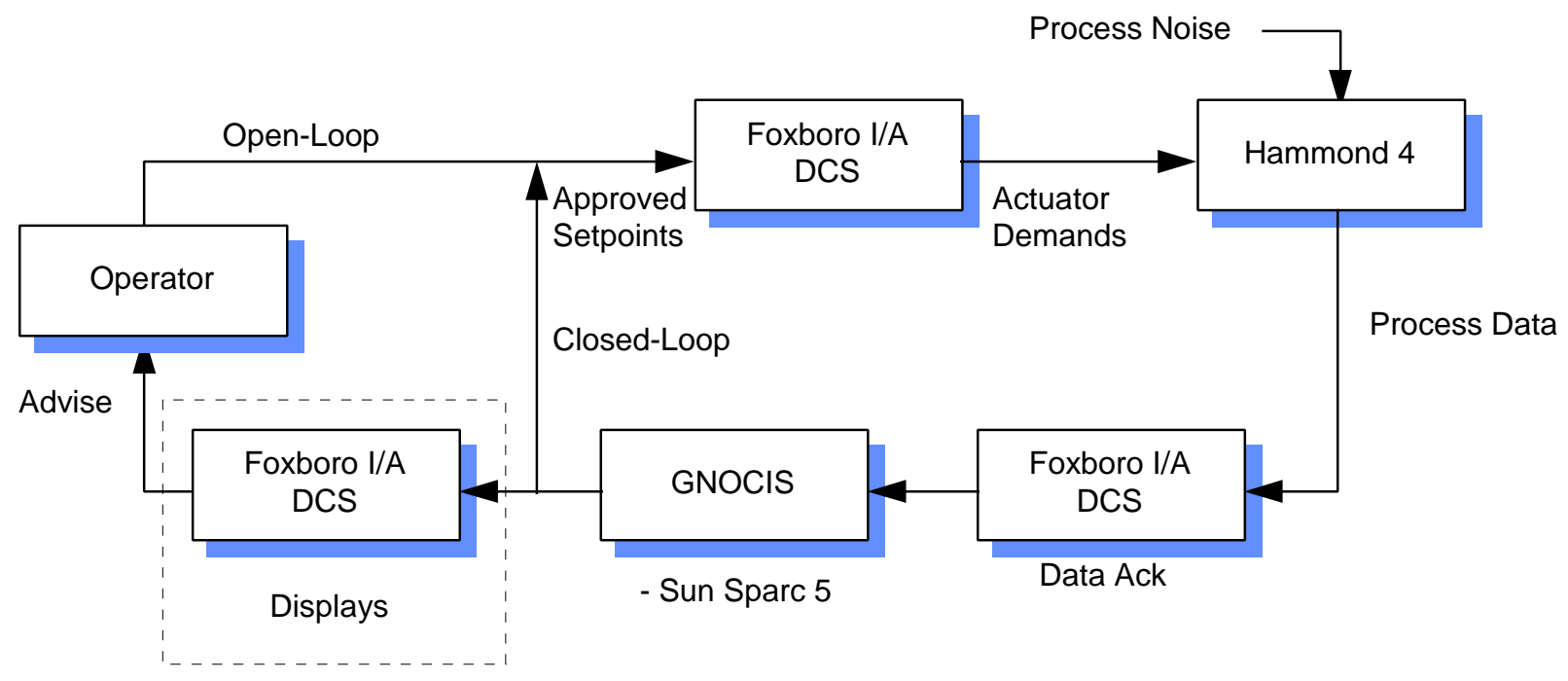

Figure 2-8 Hammond 4 GNOCIS Implementation

Combustion optimization difficulty at Hammond has increased dramatically since the installation of the low NOx burners and advanced overfire air system. This added difficulty is a result of the increase in the number of adjustments and sensitivity of these burners to operating conditions (Table 2-1). Using this list as a starting point, GNOCIS was designed to make use of the variables shown in Table 2-2. The control variables in the first tier have been implemented, and, if successful, additional variables from the subsequent tiers will be considered if their inclusion improves the performance of the system significantly. Software hooks were designed into the DCS to facilitate the incorporation of these signals into the control logic.

Sample operator graphics for GNOCIS are shown in Figures 2-9 and 2-10. Typically, the DCS operator displays are the principal interface to GNOCIS. These displays must (1) clearly convey to the operator the recommendations and predicted benefits and (2) allow the operator flexibility in setting constraints. As shown, the operator is presented with the current operating conditions and two sets of recommendations and predictions. One set corresponds to the current mills-inservice operating condition. If accepted, the operator can either implement the recommendations by individually setting the manipulated parameters to the targets or have the DCS automatically implement the recommendations (Implement Recommendations). When clamped, the operating parameter is assumed clamped to the current operating condition, and the optimization is performed with the remaining parameters. The operator can also remove or add parameters from the optimization by using this screen (Clamped / Free).

Since in many instances the mill selection can affect performance and emissions, it is important to provide recommendations concerning the mills in service. However, due to many externalities 
not measurable by the DCS or best judged by the operator, the mill configuration cannot be achieved or is not desirable. As a compromise, another set of recommendations are provided as to the optimum mills-in-service and the performance/emissions benefits. Given the predicted improvement and the current state of the plant, the operator can decide whether it is of overall advantage to change the mills in service. Close-loop mode, if implemented, is obtained by selecting the Close Loop button from this screen.

Table 2-1 Combustion Tuning Control Points at Hammond 4

\begin{tabular}{lc}
\hline Pre-LNB+AOFA Retrofit & Post-LNB+AOFA Retrofit \\
\hline Burners & Burners \\
Sleeve registers (24) & Sleeve registers (24) \\
Secondary air & Tip Positions (24) \\
Windbox balancing dampers & Inner registers (24) \\
Mill Biasing & Outer registers (24) \\
& Advanced overfire air \\
& Can-in-can dampers (8) \\
& Flow control dampers (4) \\
& Secondary air \\
& Windbox balancing dampers \\
& Boundary air \\
& Mill Biasing \\
\hline
\end{tabular}

Table 2-2 GNOCIS Control Points

\begin{tabular}{|c|c|c|c|}
\hline Parameter of Interest & Controlled Parameter & $\begin{array}{l}\text { Advisory } \\
\text { Mode } \\
\text { Open-Loop }\end{array}$ & $\begin{array}{l}\text { Supervisory } \\
\text { Mode } \\
\text { Close-Loop }\end{array}$ \\
\hline \multicolumn{4}{|l|}{ First Tier } \\
\hline Overall Furnace Air / Fuel Ratio & Excess $\mathrm{O}_{2}$ Bias & Y & $\mathrm{Y}$ \\
\hline Overall Furnace Staging & AOFA Flow (4) & $\mathrm{Y}$ & $\mathrm{Y}$ \\
\hline AOFA Distribution & AOFA Flow (4) & $\mathrm{Y}$ & $\mathrm{Y}$ \\
\hline Mill Biasing & Mill Coal Flow (6) & Y & $\mathrm{Y}$ \\
\hline Mills-in-Service & Mill Coal Flow (6) & $\mathrm{Y}$ & Advise \\
\hline \multicolumn{4}{|l|}{ Second Tier } \\
\hline AOFA Distribution & AOFA Can Dampers (8) & $\mathrm{Y}$ & $\mathrm{Y}$ \\
\hline $\begin{array}{l}\text { Furnace Secondary Air } \\
\text { Distribution }\end{array}$ & $\begin{array}{l}\text { Burner Sleeve Dampers by Banks } \\
\text { (8) }\end{array}$ & Y & Y \\
\hline \multicolumn{4}{|l|}{ Third Tier } \\
\hline $\begin{array}{l}\text { Furnace Secondary Air } \\
\text { Distribution }\end{array}$ & Burner Sleeve Dampers (24) & Y & Y \\
\hline
\end{tabular}




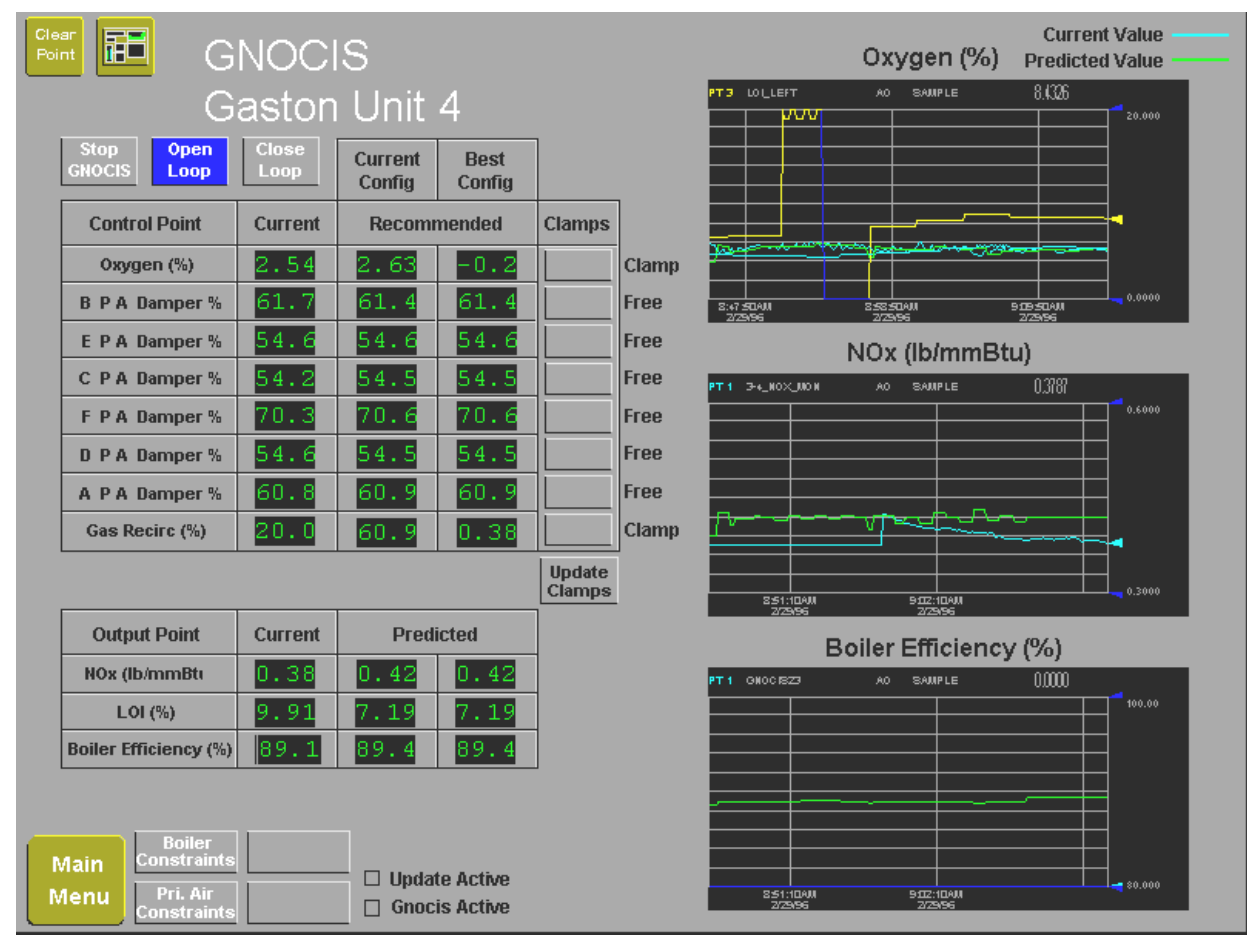

Figure 2-9 GNOCIS Recommendation Screen

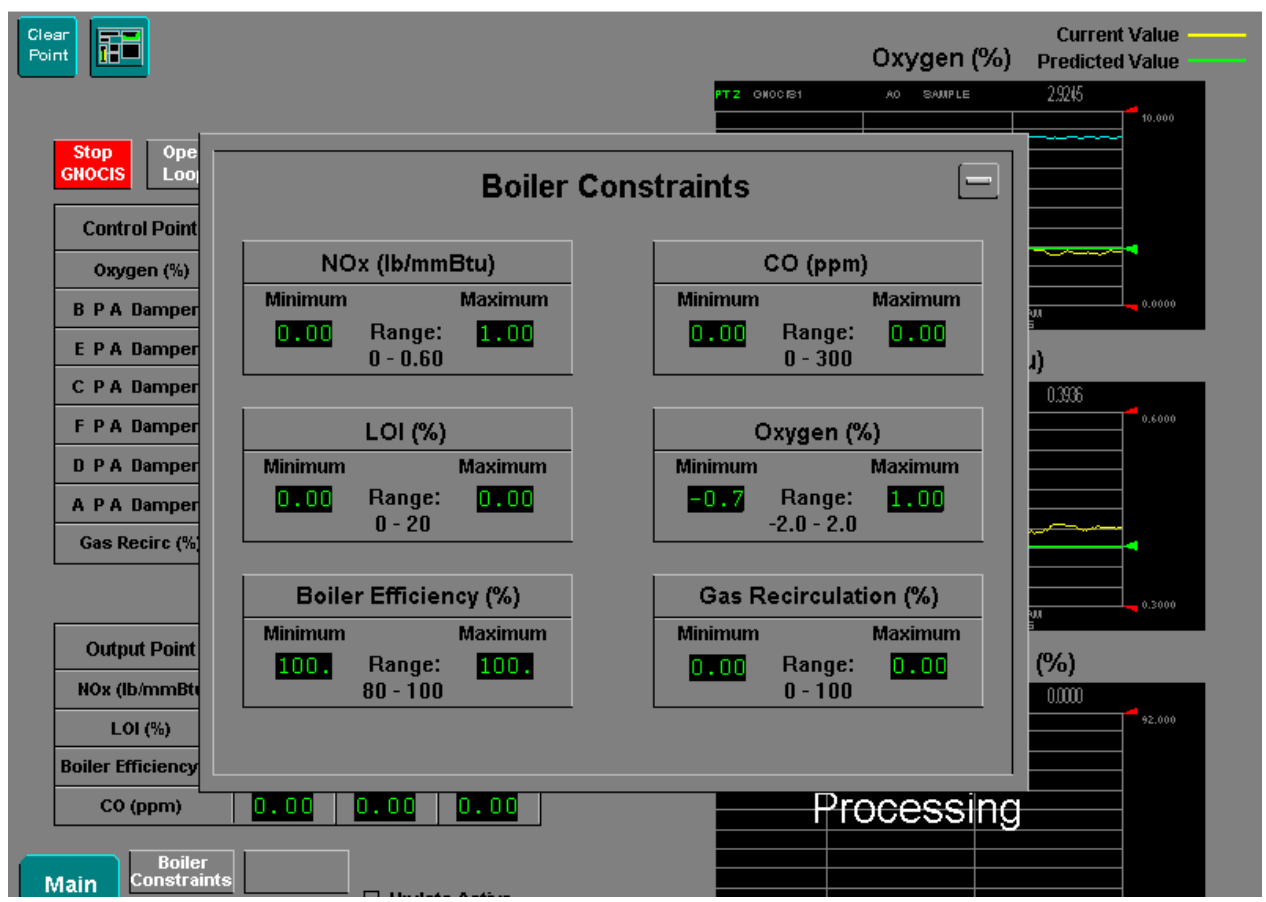

Figure 2-10 GNOCIS Constraint Screen 
TECHNOLOGY DESCRIPTION 


\section{BASIS FOR INSTALLING GNOCIS AND THE DCS}

\subsection{Potential Benefits of Continuous Optimization}

Unlike $\mathrm{SO}_{2}$ emissions that are primarily a function of the sulfur content of the fuel, NOx emissions are highly dependent on a number of parameters (Table 3-1). Nitrogen oxides (NOx) are formed in combustion processes through the thermal fixation of atmospheric nitrogen in the combustion air producing "thermal NOx" and the conversion of chemically bound nitrogen in the fuel producing "fuel NOx". NOx emissions can theoretically be reduced by lowering: (1) the primary flame zone $\mathrm{O}_{2}$ level, (2) the time of exposure at high temperatures, (3) the combustion intensity, and (4) primary flame zone residence time. NOx emission rates are strongly influenced by the apportionment of the air to the burners and AOFA system.

Table 3-1 Factors Controlling the Formation of NOx

\begin{tabular}{|c|c|c|}
\hline $\begin{array}{l}\text { Primary Equipment and Fuel } \\
\text { Parameters }\end{array}$ & $\begin{array}{c}\text { Secondary Combustion } \\
\text { Parameters }\end{array}$ & Fundamental Parameters \\
\hline \multicolumn{3}{|l|}{ Inlet temperature \& velocity } \\
\hline Furnace design & Combustion intensity & \\
\hline Fuel composition & Heat removal rate & Oxygen level \\
\hline Injection pattern of fuel \& air & Mixing of combustion products & Peak temperature \\
\hline Size of particles & Local fuel/air ratio & Exposure time at peak temperature \\
\hline Burner swirl & Turbulent distortion of flame zone & \\
\hline
\end{tabular}

As with NOx emissions, boiler performance is heavily influenced by boiler operating parameters, both controllable and non-controllable. The performance includes efficiency, steam temperatures, unburned combustibles, and air heater exit air temperatures. The operating parameters that can affect the performance include among others excess oxygen, fuel quality, mills-in-service, and fuel and combustion air distribution.

An example of the interdependencies and conflicting goals that must be considered can be seen in Figure 3-1. As shown, as excess air (or equivalently, excess oxygen) decreases, NOx decreases while LOI increases. High LOI is indicative of poor combustion and therefore poor boiler performance. Also, on units which sell their fly ash, an increase in fly ash LOI can change the fly ash from a marketable commodity to an undesirable byproduct. A decision must be made as to what is the optimum operating condition based on economic and environmental considerations. Similar comprises must also be made when optimizing boiler efficiency (Figure 3-2). In this case, the optimum operating condition is clear as long as the performance index is defined as boiler efficiency and other parameters (such as NOx emissions) are not considered. Conflicting objectives such as these have been observed on Hammond Unit 4 and other units. For example, it has been thoroughly documented that NOx production rate is an increasing function of the excess oxygen level while fly ash LOI is a decreasing function. Therefore using this control alone, to reduce LOI, excess oxygen levels would need to be raised, however, this 
would also result in an increase in NOx emissions. These dependencies have been and continue to be well documented in the industry [EPRI, 1993][Sorge, 1993][SCS, 1998][Tavoulareas, 1993][SCS 1993][Petrill, 1993].

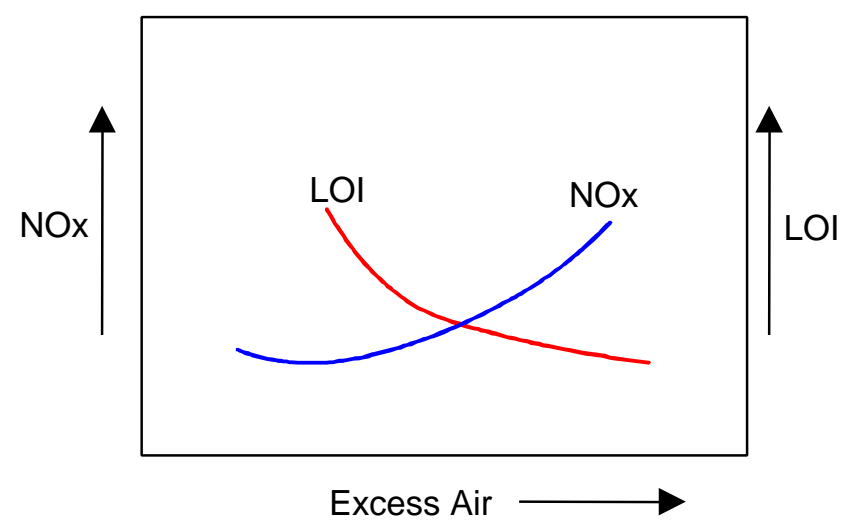

Figure 3-1 Typical NOx and LOI vs. Excess Oxygen Characteristics

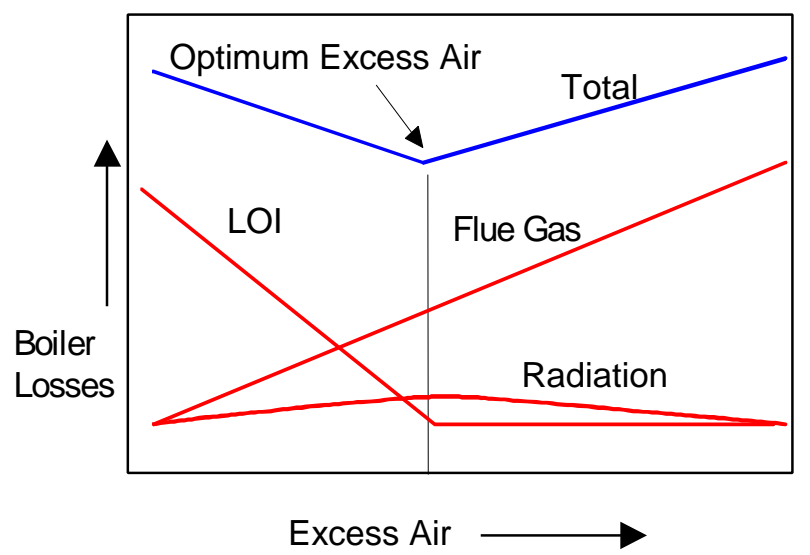

Figure 3-2 Typical Boiler Efficiency Losses vs. Excess Air Characteristic

These tradeoffs in performance have been evident at Hammond 4 since the start of project testing. A strong example of possible improvement in performance by operational adjustments can be seen in Figure 3-3. This data is from the NOx vs. LOI testing conducted on Hammond Unit 4 during October 12 - 28, 1992 [SCS, 1998]. The primary purpose of these tests was to determine the effects of various burner settings and mill operation on NOx emissions and unburned carbon levels in the fly ash. To assess the effects of each parameter, the test matrix was designed so that a single parameter was varied each test day and all other parameters were held constant to the extent possible. The parameters tested were (1) excess air, (2) mill coal flow bias, (3) burner sliding tip position, (4) burner outer register position, and (5) burner inner register position. The range of values tested is shown in Table 3-2. 


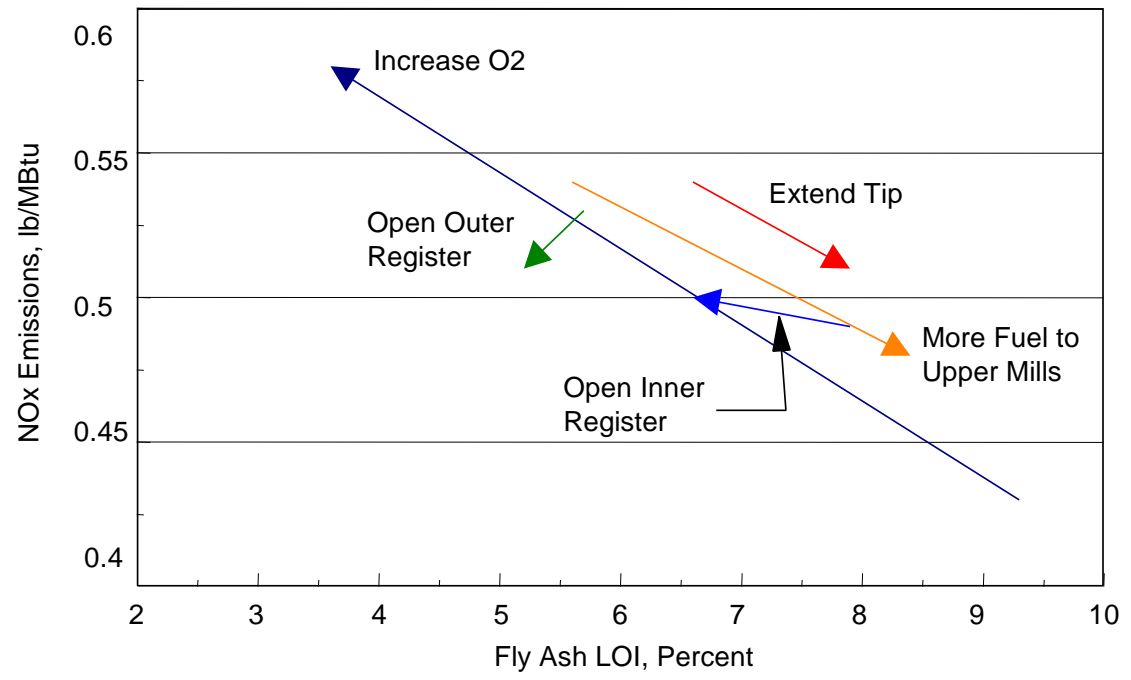

Figure 3-3 NOx vs. LOI Testing / All Sensitivities (Phase 3A)

Table 3-2 Hammond 4 / NOx vs. LOI Tests / Parameters Tested

\begin{tabular}{|c|c|c|c|}
\hline \multirow{2}{*}{ Parameter } & Nominal Value & \multicolumn{2}{|c|}{ Range Tested } \\
\cline { 2 - 4 } Excess Air & $4 \%$ & Low & High \\
Sleeve Damper & 7 " Outer burner columns & Not & $5.0 \%$ \\
& 4 " Inner burner columns & Adjusted & Not \\
Inner Register & $\sim 15 \%$ & Nominal & Nominal $+40 \%$ \\
Outer Register & $\sim 60 \%$ & $-20 \%$ of nominal & $+20 \%$ of nominal \\
Sliding Tip & +4 inches & +2 inches & +4 inches \\
Mill Bias & No bias & Upper Mills $+10 \%$ & Upper Mills $-10 \%$ \\
& & Lower Mills $-10 \%$ & Lower Mills $+10 \%$ \\
\hline
\end{tabular}


The NOx emissions and LOI levels varied from approximately $0.44 \mathrm{lb} / \mathrm{MB}$ tu to $0.57 \mathrm{lb} / \mathrm{MBtu}$ and $10 \%$ to $3 \%$, respectively. As expected, excess $\mathrm{O}_{2}$ level had a considerable effect on both NOx and LOI. For the other parameters considered, within the range of adjustments tested, mill bias and sliding tip position had the greatest influence on NOx and LOI. As can be seen from these graphs, there is some flexibility in selecting the optimum operating point and making tradeoffs between NOx emissions and fly ash LOI; however, much of the variation was the result of changes in excess $\mathrm{O} 2$. This figure shows for excess $\mathrm{O} 2$, mill bias, inner register, and sliding tip, any adjustments to reduce NOx emissions are at the expense of increased LOI. In contrast, the slope of the outer register characteristic suggests that an improvement in both NOx emissions and LOI can be achieved by adjustment of this damper. However, due to the relatively small impact of the outer register adjustment on both NOx emissions and LOI, it is likely that the positive NOx / LOI slope is an artifact of process noise.

In addition to the short-term effects, operating conditions also vary significantly during long-term operation and it is evident that a number of uncontrolled and unidentified variables greatly influence NOx production. These influencing variables are believed to be mill operating conditions (primary air temperatures, air/fuel ratios, flows, grind, and moisture), secondary air non-uniformity (air register settings, forced draft fan bias, and windbox pressure differential), coal variability, etc. The long-term NOx emission vs. load characteristics for the Phases 1 through 3B at Hammond are shown in Figure 3-4 and Figure 3-5. As can be seen in these figures, there are significant variations in the NOx emissions although it is believed there were (1) no changes in burner adjustments and (2) operating procedures did not vary during the data collection periods. Further evidence of this long-term variation is shown in Figure 3-6. As shown, NOx emissions increased over the approximate five-month test period by nearly $10 \%$. This increase is likely the result of a general rise in excess oxygen levels that occurred over the period. The cause of the increase in oxygen is not known.

As evidenced above, NOx emissions can be affected by a number of operation factors, especially excess oxygen levels and mills biasing /mills-in-service. The impact of mills-in-service on NOx emissions for the four phases are shown in Figure 3-7 to Figure 3-10. For Phase 1 (Baseline), on average, during the long-term period, NOx emissions were less when " $\mathrm{C}$ " mill (top elevation /front wall) was out of service and greater when "B" mill (bottom elevation / rear wall) was out of service, implying that the " $\mathrm{C}$ " mill was more of a contributor of NOx than " $\mathrm{B}$ " mill. At lower loads, the difference between the best and worse configuration for NOx was approximately 0.3 $\mathrm{lb} / \mathrm{MBtu}$ or $30 \%$ of the nominal level $(\sim 1.0 \mathrm{lb} / \mathrm{MBtu})$. The spread was similar during the AOFA phase (Figure 3-8). However for this phase, the best configuration for NOx excluded " $D$ " mill while the worse configuration for NOx excluded " $F$ " mill. During both of these phases (Baseline and AOFA), the unit was equipped with FWEC Intervane burners. For the LNB and LNB+AOFA phases, the NOx dependency on mills-in-service was much reduced in absolute terms from that which had been previously observed (Figure 3-9 and Figure 3-10, respectively). However, on a percentile basis, the variation remained in the neighborhood of $25 \%$ at low loads. During the LNB and LNB+AOFA test phases, FWEC's CF/SF low NOx burners were on the unit.

As with NOx emissions, parameters which affect boiler efficiency, and thereby unit heat rate, varied considerably during the long-term test periods. Boiler efficiency can be estimated by 
either the input/output method or loss method, with the latter method generally considered the most robust for coal-fired boilers. The major losses are dry flue gas, moisture in fuel, moisture from combustion, unburned combustibles, and radiation. The magnitudes of these losses vary with numerous parameters including boiler design, fuel type, load, and ambient conditions. Typical levels are as follows:

\begin{tabular}{lc}
\hline Loss & $\begin{array}{c}\text { Typical } \\
\text { Level }\end{array}$ \\
\hline Dry flue gas & 4.5 \\
Moisture in fuel & 1.5 \\
Moisture from combustion & 3.7 \\
Unburned combustibles & 0.2 \\
Radiation and convection loss & 0.2 \\
Manufacturer margin and unaccounted & 1.5 \\
\hline [CE, 1991] &
\end{tabular}

Of these losses, the dry flue gas loss and unburned combustibles are the ones impacted by operating conditions which may be subject to optimization. For example, a basic calculation for dry flue gas loss can be expressed as follows [Hill, 1987]:

$$
L_{d f g}=\left(T_{g o}-T_{a i}\right) \cdot\left\lfloor k_{1}+k_{2} \cdot\left(1+O_{2}\right)^{2}\right\rfloor
$$

where:

$$
\begin{aligned}
& L_{d f g}=\text { Dry flue gas loss } \\
& T_{g o}=\text { Gas outlet temperature } \\
& T_{a i}=\text { Air inlet temperature } \\
& O_{2}=\text { Excess oxygen } \\
& k_{1}, k_{2}=\text { Constants }
\end{aligned}
$$

In addition to the direct impact on this loss, excess oxygen can also affect the economizer outlet and air heater outlet gas temperatures. More detailed procedures can be found in the ASME Performance Test Codes and other references [ASME, 1985] [CE, 1991] [B\&W, 1992]. An example of the variations of some of these process variables from Phase 1 testing are shown in Figure 3-11. The dry flue gas loss variation (upper $95^{\text {th }}$ to lower $95^{\text {th }}$ percentile) averaged about $0.5 \%$ and in general was greater at the lower load ranges. This increased variation is likely the result of more operating flexibility (such as mill selection) at the lower loads.

More detail on the excess oxygen and economizer outlet temperatures for Phase 1 are shown in Figure 3-12 and Figure 3-13. As shown, the bias between the "A" and "B" sides was nearly $1 \%$ for most of the load range with the " $\mathrm{B}$ " side being the higher for all circumstances. The " $\mathrm{B}$ " side economizer outlet temperatures were also higher than the " $A$ " side temperatures for most of the load range. Although it varies from furnace to furnace, balancing the furnace tends to improve overall boiler performance. 
In summary, it was evident from results from Hammond 4 and elsewhere that operational adjustment has the potential for reducing NOx emissions, improving boiler performance, and mitigating the adverse impacts of low NOx burner retrofits.

Baseline
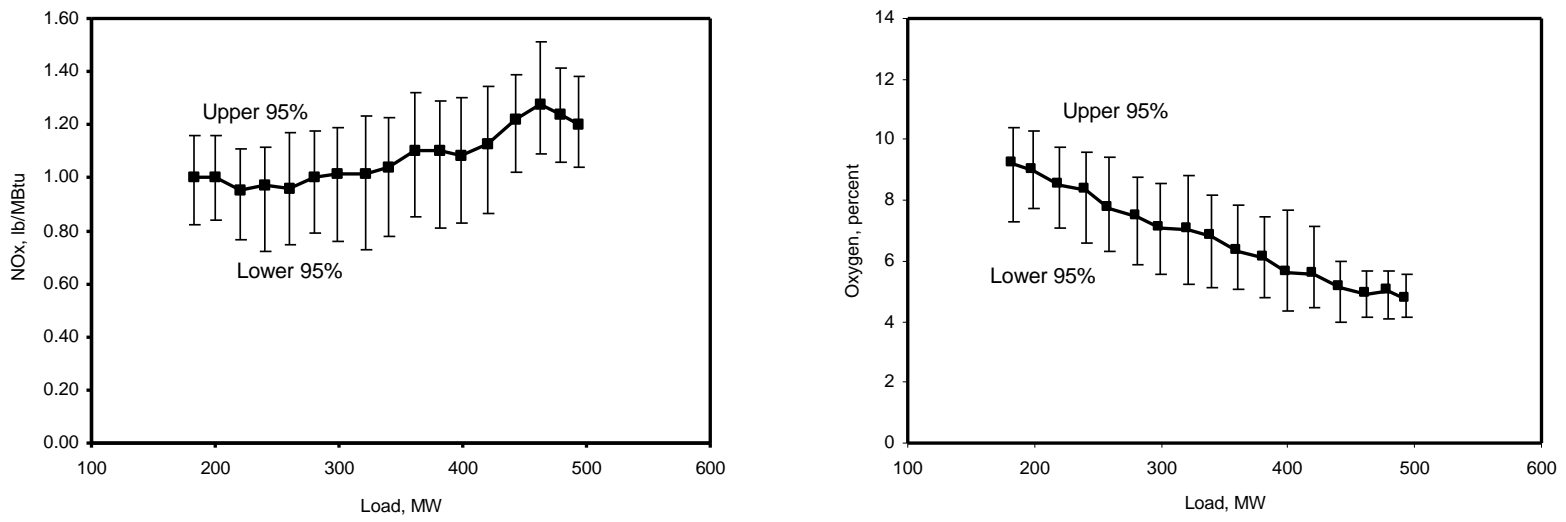

AOFA
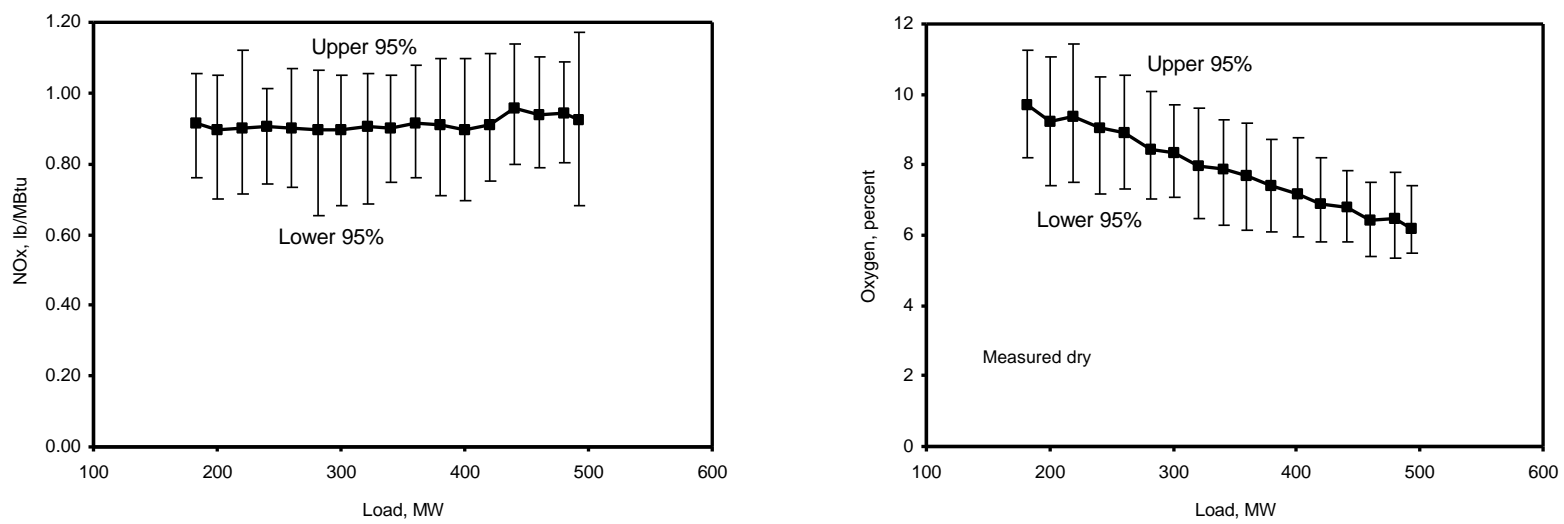

Figure 3-4 NOx and Stack O2 vs. Load (Phases 1 and 2) 
LNB
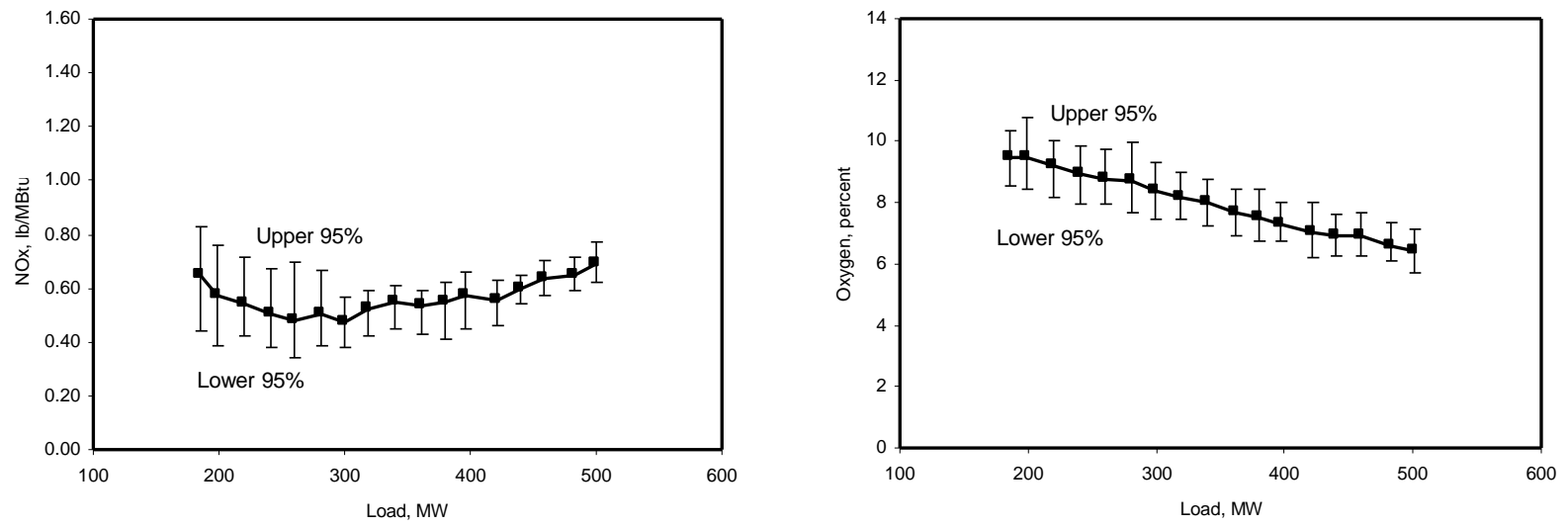

LNB+AOFA
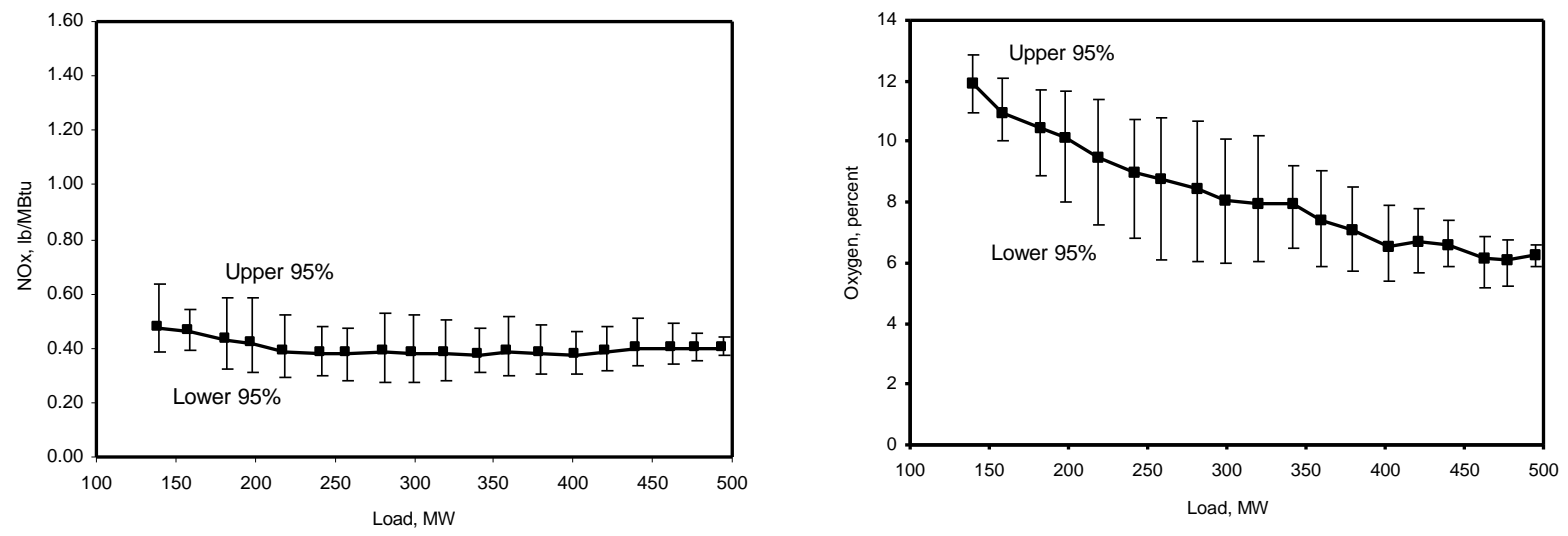

Figure 3-5 NOx and Stack O2 vs. Load (Phases 3A and 3B) 

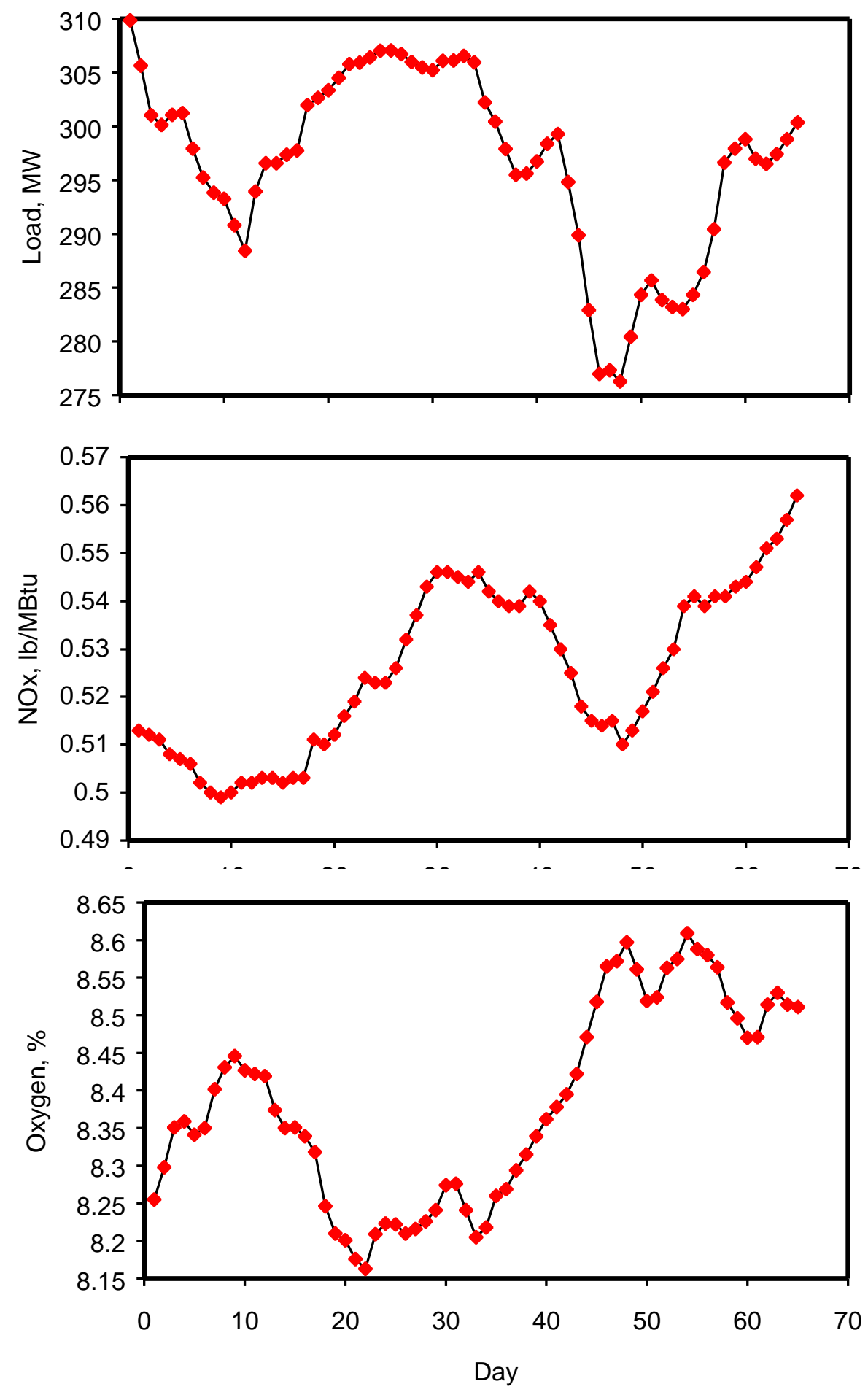

Figure 3-6 LNB / Long-Term 30 Day Rolling Average 


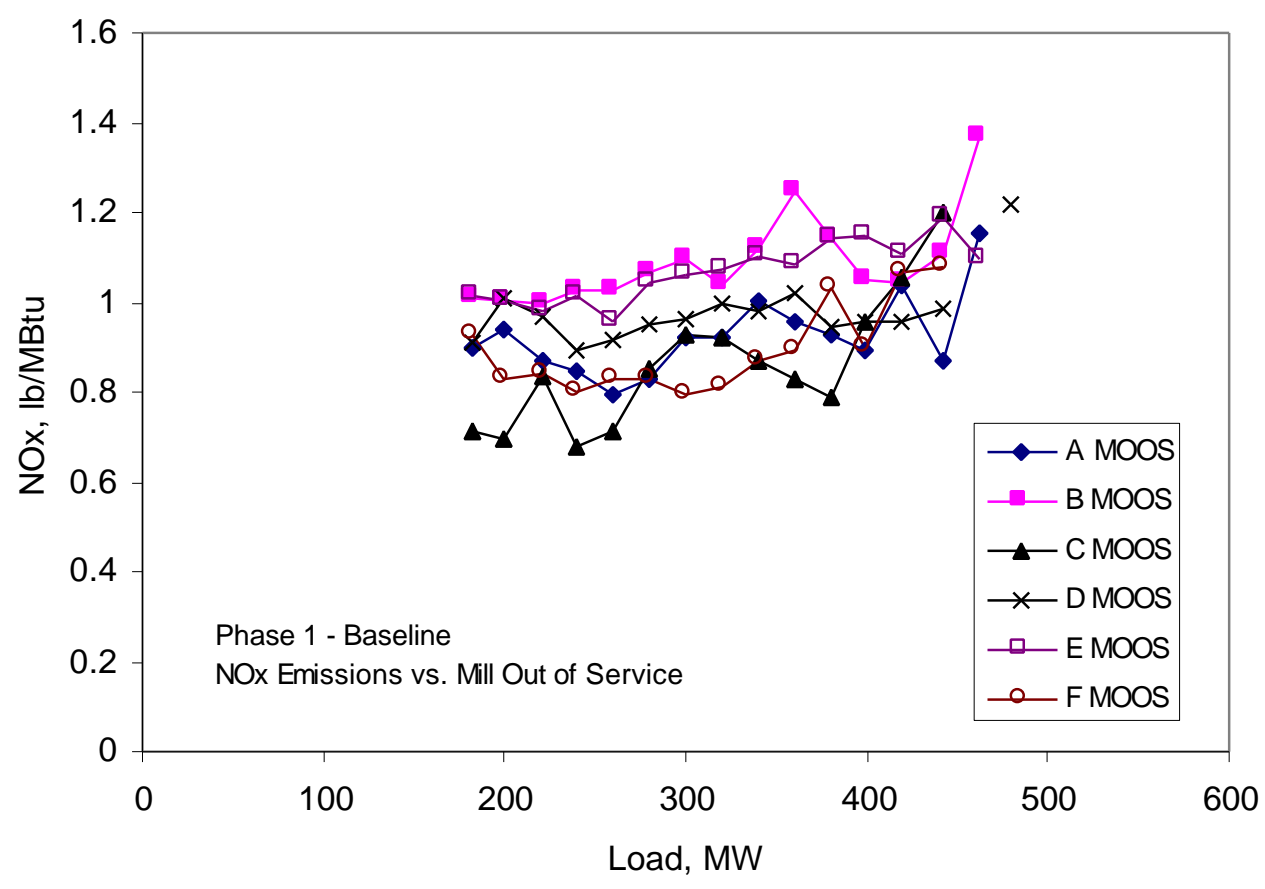

Figure 3-7 NOx vs. Load vs. MOOS (Phase 1)

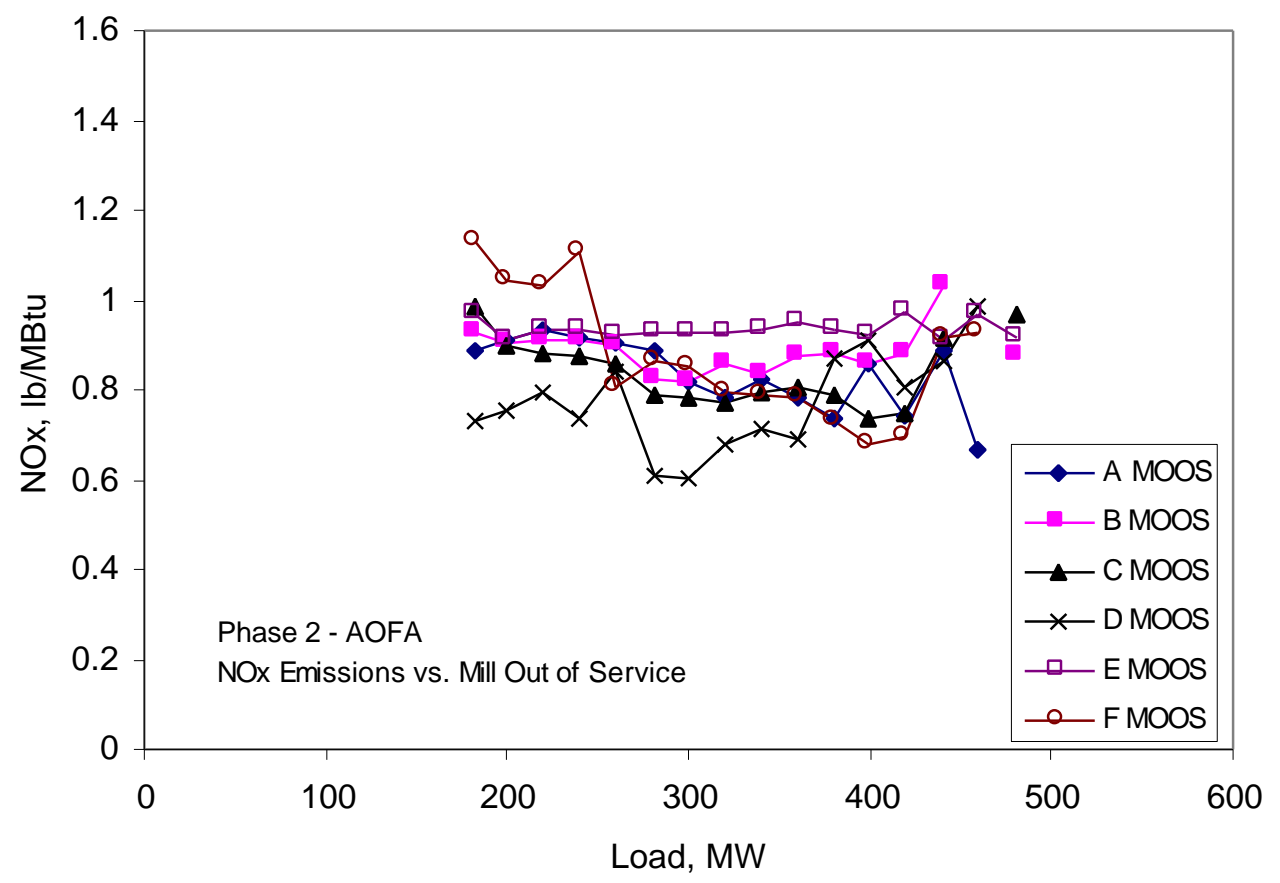

Figure 3-8 NOx vs. Load vs. MOOS (Phase 2) 


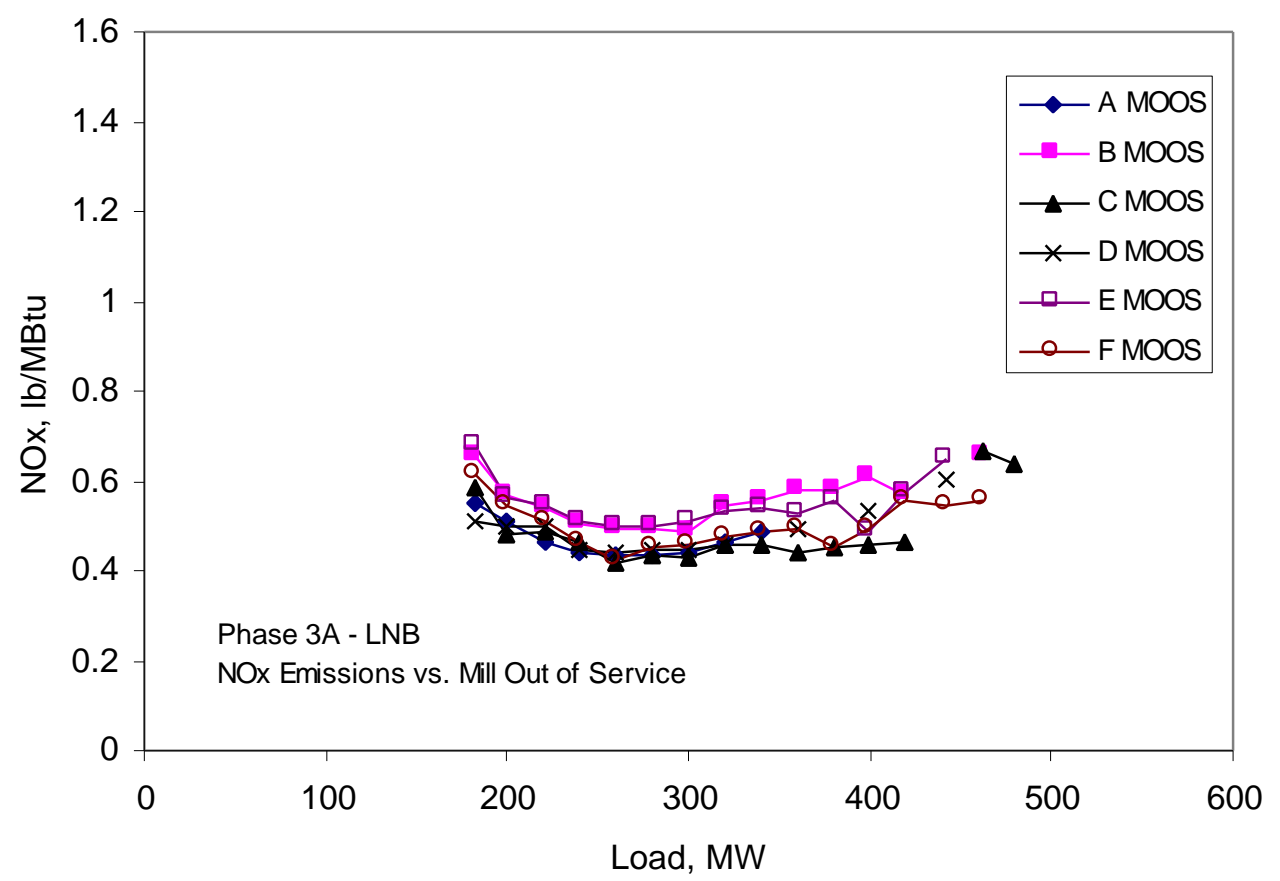

Figure 3-9 NOx vs. Load vs. MOOS (Phase 3A)

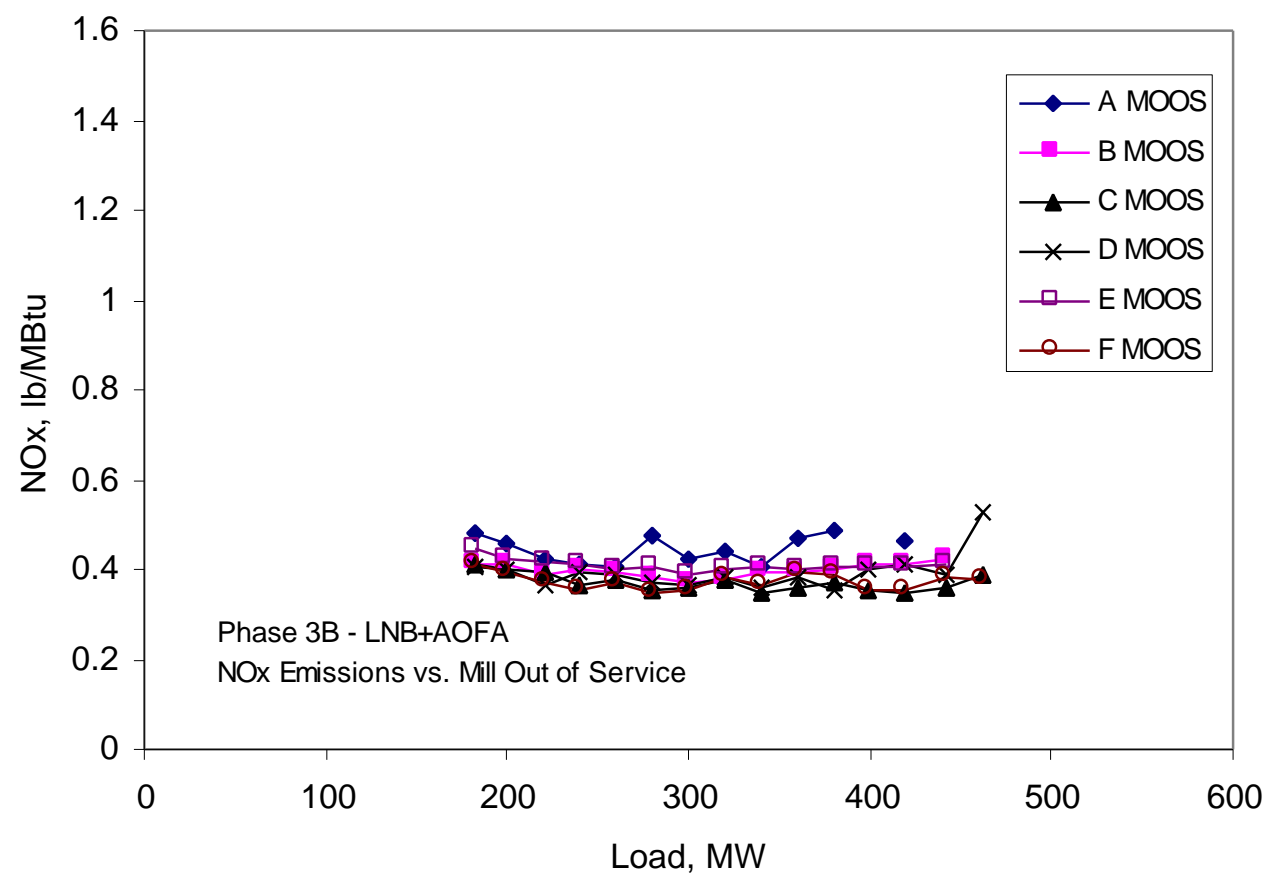

Figure 3-10 NOx vs. Load vs. MOOS (Phase 3B) 

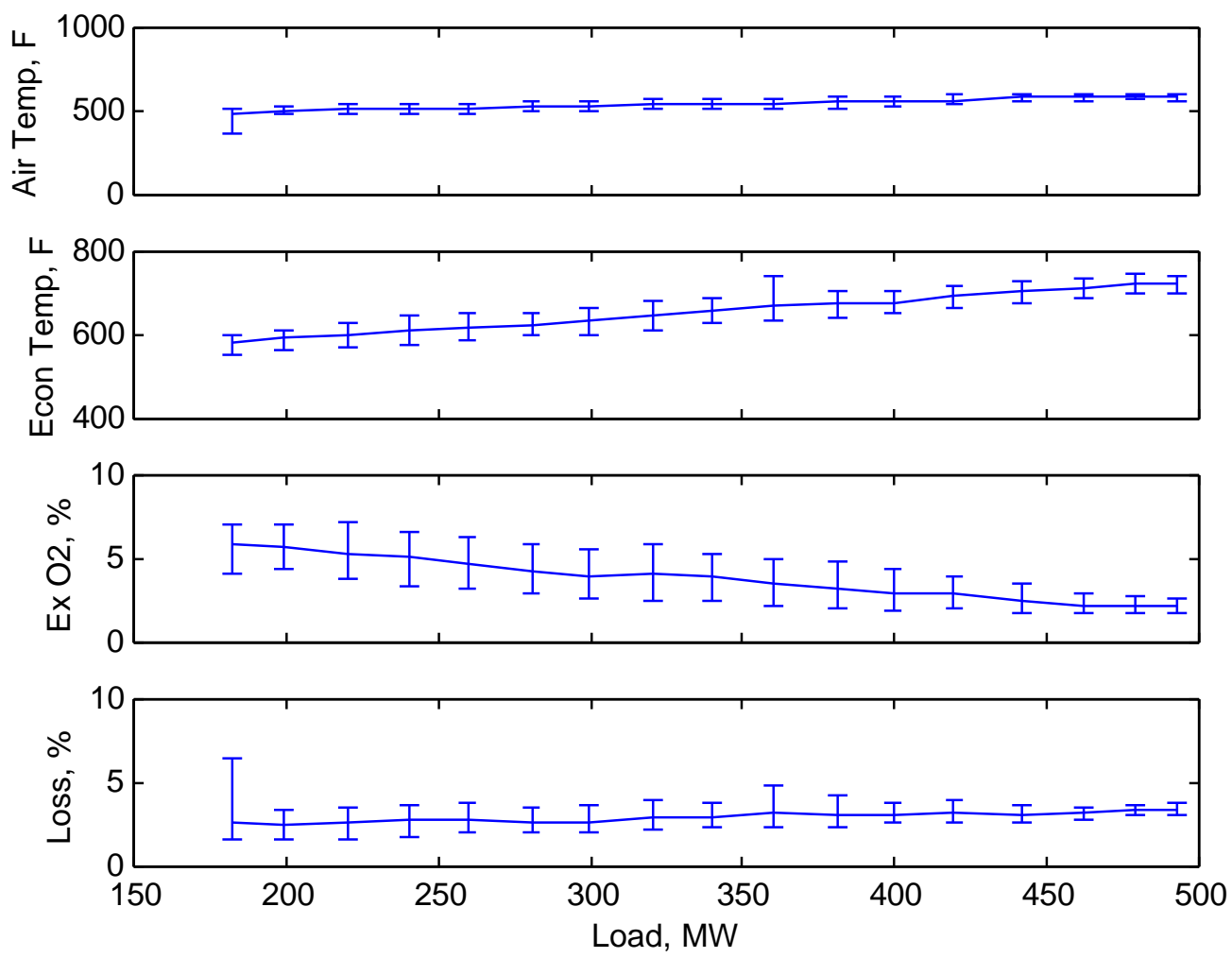

Mean, upper $95^{\text {th }}$, and lower $95^{\text {th }}$ percentiles shown

Figure 3-11 Dry Flue Gas Loss Variations with Load (Baseline) 


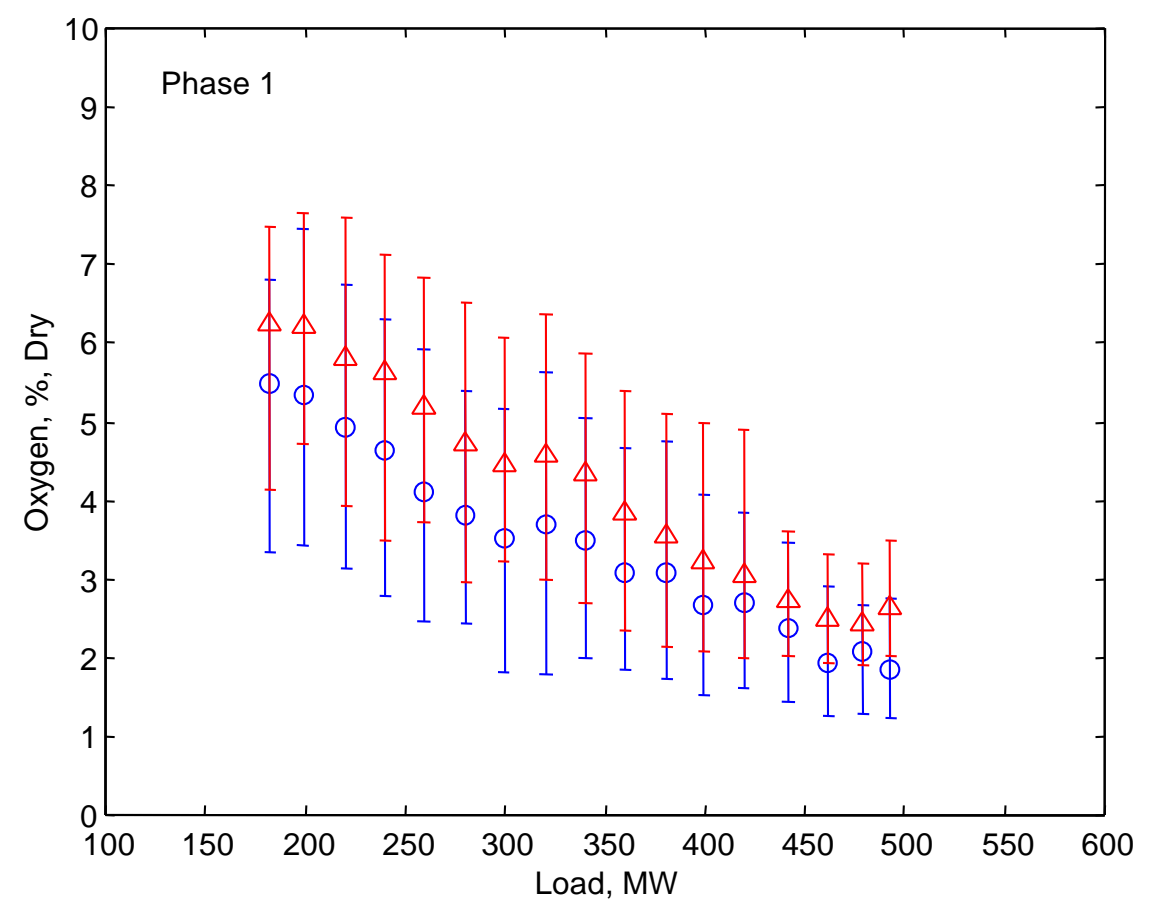

Figure 3-12 Excess Oxygen Variations with Load (Baseline)

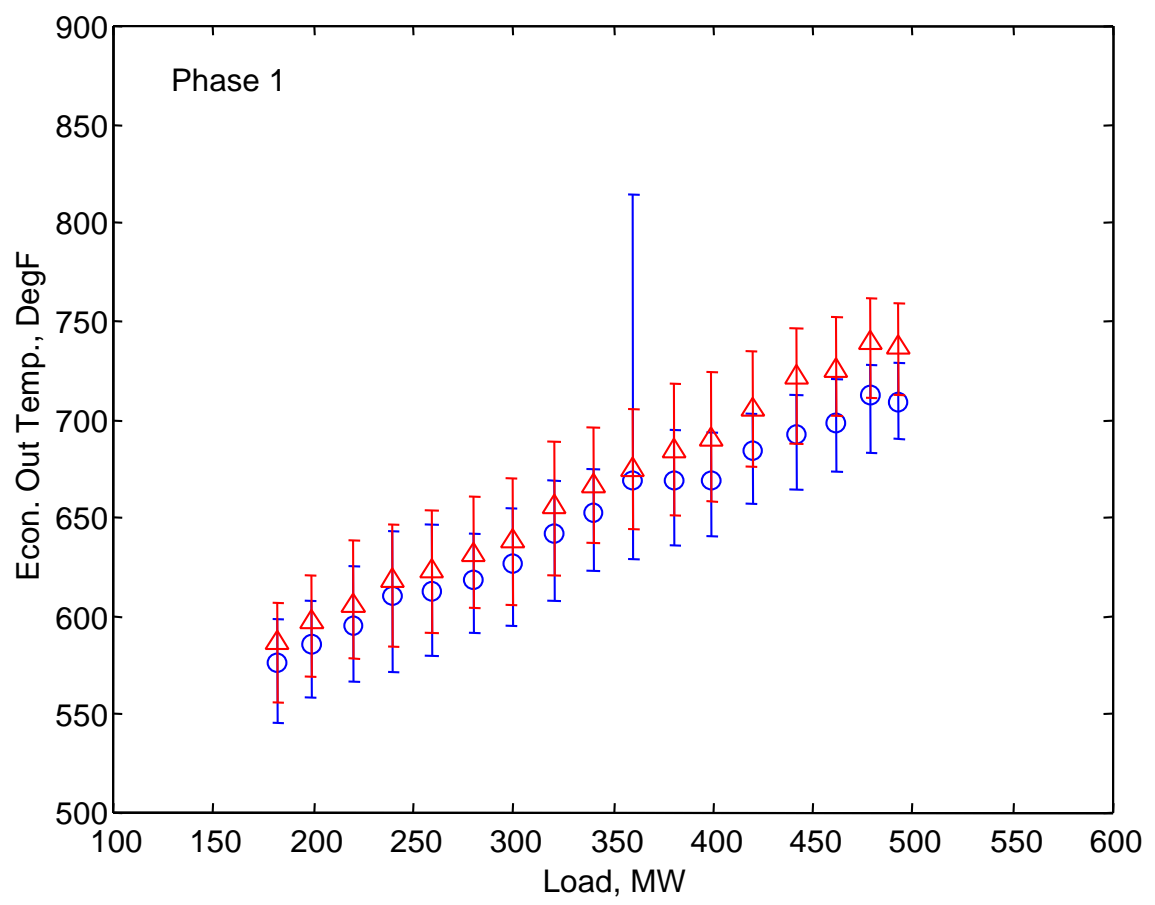

Figure 3-13 Economizer Outlet Temperature Variations with Load (Baseline) 


\subsection{Potential Benefits of the DCS}

In addition to the potential benefits that on-line continuous optimization might provide during steady-state unit operation, there was also reasonable probability that the installation of the DCS might itself provide benefits. Potential benefits include improved unit heat rate, extended equipment life, improved capability, improved availability, and faster loading rate [EPRI, 1992].

Improved plant heat rate. A DCS should provide better control of plant parameters than the control system (typically pneumatic or electronic) that it replaces. If the DCS does better control the unit to setpoint then there is some likelihood that there may be efficiency improvements, however, this is not always the case. These possible improvements can relate to either (1) eliminating the bias between desired operating point and actual operating point, (2) better dynamic control and reduced oscillation of the process, and (3) improved process information.

An example of the possible improvement that may result from the elimination of process bias is shown in Figure 3-14 in which three scenarios for steam temperatures are shown. For the lower trend, the control system controls steam temperature to an average of $990^{\circ} \mathrm{F}$ with $\pm 5^{\circ} \mathrm{F}$. The offset could be the result of a combination of (1) instrument inaccuracies, (2) control system inaccuracies (especially for pneumatic systems), or (3) setting of the setpoint to $990^{\circ} \mathrm{F}$ by plant staff to minimize transients above $1000^{\circ} \mathrm{F}$. If the DCS produces the temperature trend shown in the middle, there would be a heat rate improvement due to higher steam temperatures all else being equal. In general, a $10^{\circ} \mathrm{F}$ increase in steam temperature produces a $0.15 \%$ increase in turbine cycle heat rate [ASME, 1985]. On the other hand, the pre DCS retrofit trend could be as shown in the top. If this were the case, the DCS' better control of steam temperature would tend to decrease heat rate (the heat rate correction is linear about the design point, and therefore, a $10^{\circ} \mathrm{F}$ decrease in steam temperature produces a $0.15 \%$ decrease in turbine cycle heat rate). This same argument also applies to reheat temperature, steam pressure, excess oxygen, and perhaps others. Michael has

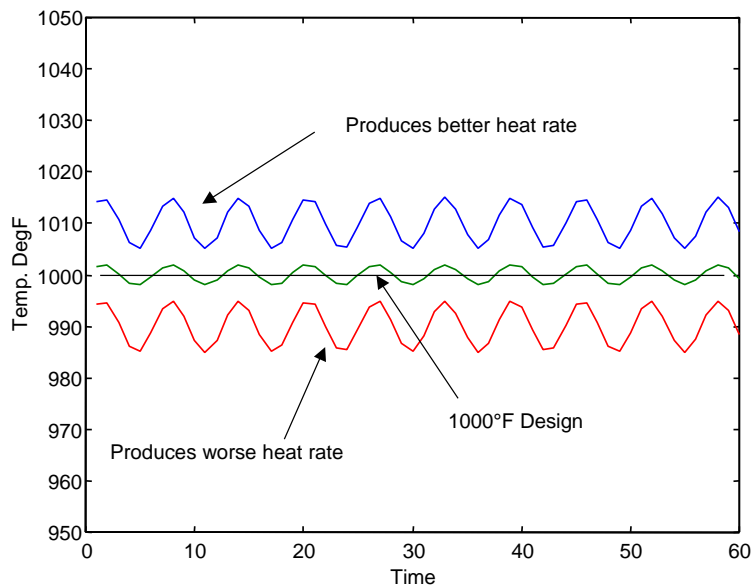

Figure 3-14 Steam Temperature vs. Heat Rate reported that heat rate improvements of up to $1.5 \%$ may be achieved if the unit is controlled better to setpoint [EPRI, 1992], however the assumption in this report is that reducing the biases are all to the advantage of heat rate.

As to the benefits to heat rate from reduced oscillation, based on dynamic computer modeling studies performed by Anderson, heat rate improvements of $0.5 \%$ would be obtainable on gas fired units [Anderson, 1989]. Another study by Chang found that unit dynamics had little impact on heat rate during unit regulatory dispatch with the majority of the impact occurring in the boiler [EPRI, 1982]. Chang speculated that the cause of the heat rate insensitivity to unit dynamics were due to (1) the changes in the stored energy of the boiler are very small as compared to the 
absolute level of stored energy and (2) the relative linearity of the stored energy changes as a function of input energy change. Note that the Chang study was different from the Anderson work in that the latter addressed degradations from process oscillations while the former looked at transients resulting from load dispatching. Chang also found that the effect of short duration transient mismatches between air and fuel resulted in only small cycling losses. Although Chang found that the transient inefficiencies were small, the difference between the heat rate when the unit is ramping down as opposed to ramping up is on the order of 7 to $10 \%(700-1000$ $\mathrm{Btu} / \mathrm{kWh})$.

As pointed out by Michael, a consideration in evaluating this benefit is if the better control allowed the setpoint to be brought closer to the design point [EPRI, 1992]. The example given in this report is that when main steam temperature is not adequately controlled, the plant operator may lower the setpoint below the design value to prevent the steam temperature at the high excursions from exceeding the design value (Figure 3-15).

Perhaps the most important factor in the DCS ability to improve heat rate is that process data is more readily available and tends to be of higher quality than that available from

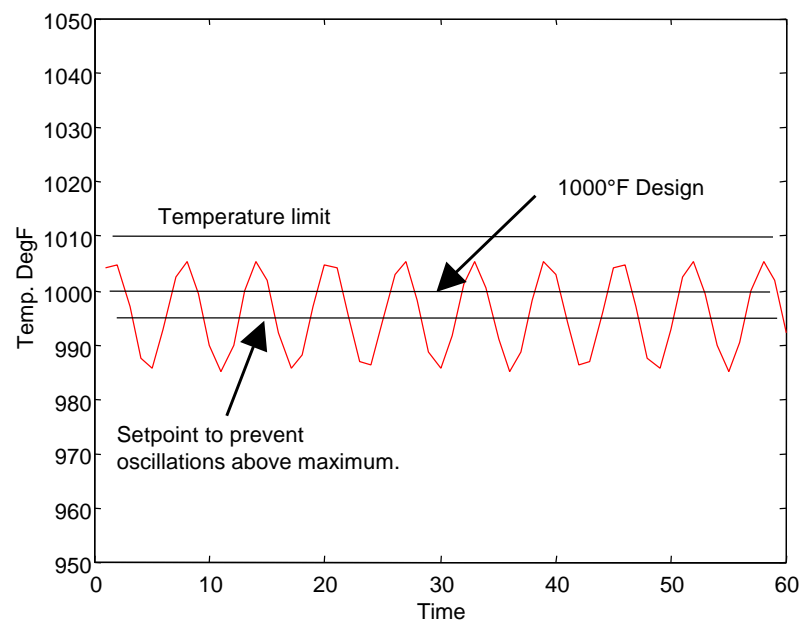

Figure 3-15 Steam Temperature vs. Heat Rate older control systems and therefore plant staff can better manage the unit's performance.

It is difficult to generalize whether a DCS will improve unit heat rate, due to varying fuels, capacity factors, equipment type, and equipment conditions. However, previous data collected on Southern Company units have found that on similar units, DCS equipped units tend to have better heat rates than those units without a DCS.

Extended plant equipment life spans. There is potential for lengthening the life spans of plant equipment by reducing the cycling (thermal and other) of the unit. There have been numerous studies which have dealt with these issues [EPRI, 1987][Riccardella, 1987][Weinstein, 1988].

Improved unit availability. Trips associated with the control system should be reduced with a DCS. Also, the time required to correct problems with a DCS should be less than that of either pneumatic or other control systems. A secondary effect is that equipment is less stressed thus improving availability since these components are less likely to fail [EPRI, 1992].

Improved unit flexibility and loading rate. Improved AGC response and wider operating ranges should be achievable with a DCS. For the latter, a lower unit minimum may be achievable due to better unit control than may be achieved with a non-DCS control system. As for AGC response, there is general recognition that an improved AGC response is of monetary benefit to a utility; however, there is no consensus on a methodology for calculating these benefits. In their report Control System Retrofit Guidelines, EPRI provides one approach [EPRI, 1992]. 
A description of these benefits and methodology for calculating the benefits can be found elsewhere [EPRI, 1992].

Pre-DCS retrofit data specific to Hammond 4 is shown in Figure 3-16 through Figure 3-28 for the period March 2, 12:00 noon to March 3, 12:00 noon. The load, excess $\mathrm{O}_{2}$, stack $\mathrm{O}_{2}$, and NOx emissions for a twenty-four hour period during baseline are shown in Figure 3-16 through Figure 3-19. As shown, the unit operated from minimum ( 170 MW) to maximum ( 480 MW) during this period. Excess $\mathrm{O}_{2}$ varied from nearly $2 \%$ to $8 \%$ with considerable bias between the "A" and "B" ducts. Stack $\mathrm{O}_{2}$ varied from a low of about $5.5 \%$ at the higher loads to near $10 \%$ at minimum load. There was a "high" frequency (peak-to-peak cycle of about 15 minutes) component to the stack $\mathrm{O}_{2}$ of about 0.5 percentage points. The cause of this component is not known, but it appears not to have affected the NOx readings (Figure 3-19). Finer time resolution is provided in Figure 3-20 through Figure 3-28. Although the 5-minute storage rate on the data acquisition somewhat limits dynamic analysis, several possible control related features are evident in these plots:

- There was a considerable split in excess oxygen between the " $\mathrm{A}$ " and "B" sides, especially at lower loads (2 percentage points) (Figure 3-20).

- Excess oxygen (both at the economizer outlet and stack) exhibited some overshoot at both the start and end of the low load period (Figure 3-21 and Figure 3-22).

- NOx emissions at the start and end of the low load period were greater than the nominal NOx level during this period (Figure 3-23). However, NOx emissions showed a sharp decrease during the high-to-low and low-to-high transitions. The control system is generally set up to cross-limit the combustion airflow during these load transitions, thereby supplying more combustion air than is normal for steady-state operation. Although it is normally expected that increased combustion air results in increased NOx emissions, this was not the case for these transitions.

- Superheat and reheat temperatures showed considerable variation from design values $\left(1000^{\circ} \mathrm{F}\right)$ especially at the load transitions (Figure 3-25 and Figure 3-26). On average, the temperatures were below design thereby adversely affecting heat rate (for superheat and reheat, there is approximately $15 \mathrm{Btu} / \mathrm{kWh}$ penalty for $10^{\circ} \mathrm{F}$ temperature deviation from design).

- Throttle pressure varied considerably, especially at the load transitions (Figure 3-27). The low-to-high transition produced higher throttle pressures, which tend to decrease heat rate (100 psi deviation yields $40 \mathrm{Btu} / \mathrm{kWh}$ change in heat rate).

- The "B" air heater gas outlet temperature was positively biased over the "A" side, as was the excess oxygen (Figure 3-28). Not necessarily control related, this temperature and excess differential could be the result of (1) differing air heater performance, including air inleakage, (2) furnace backpass air inleakage, (3) burner imbalances, and (4) secondary combustion air maldistribution. Air heater gas inlet temperatures also showed a bias from side-to-side (Figure 3-29). 


\subsection{Summary}

In summary, there was considerable evidence that the installation of a DCS and an on-line combustion optimization system such as GNOCIS had a high likelihood of improving unit performance both in terms of emissions and heat rate. 


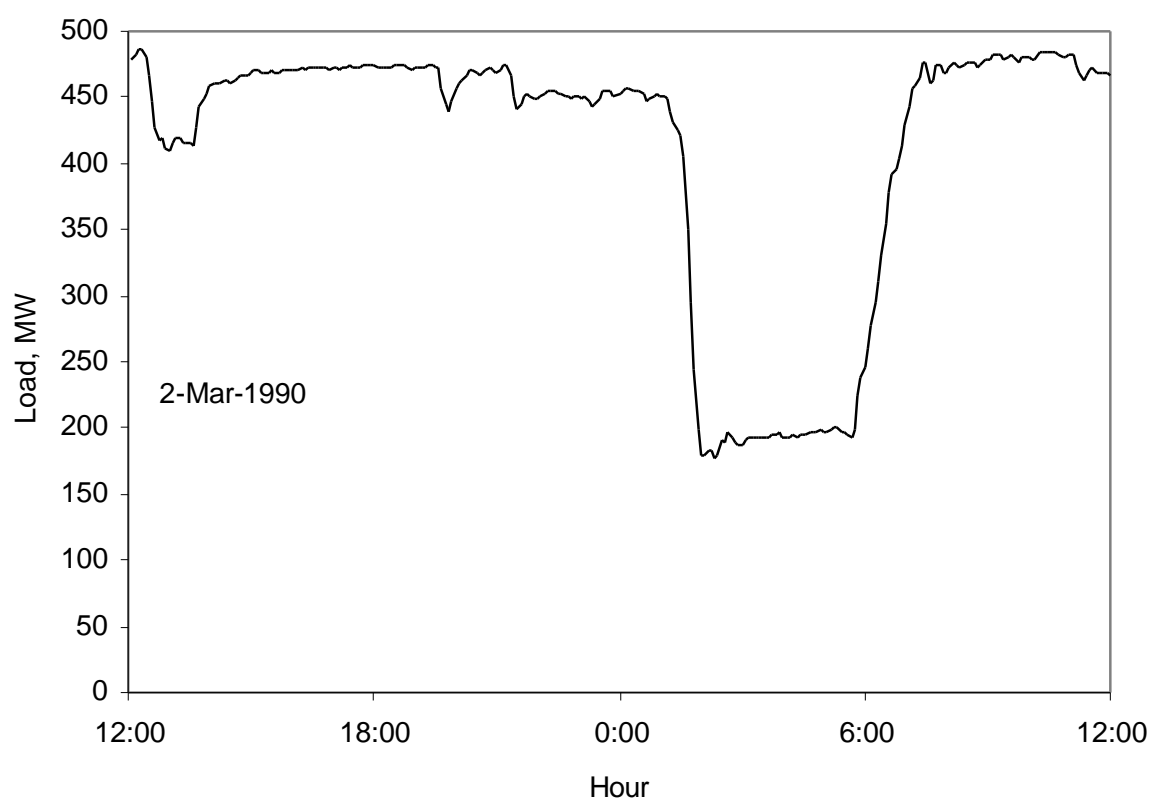

Figure 3-16 Load Response (Baseline)

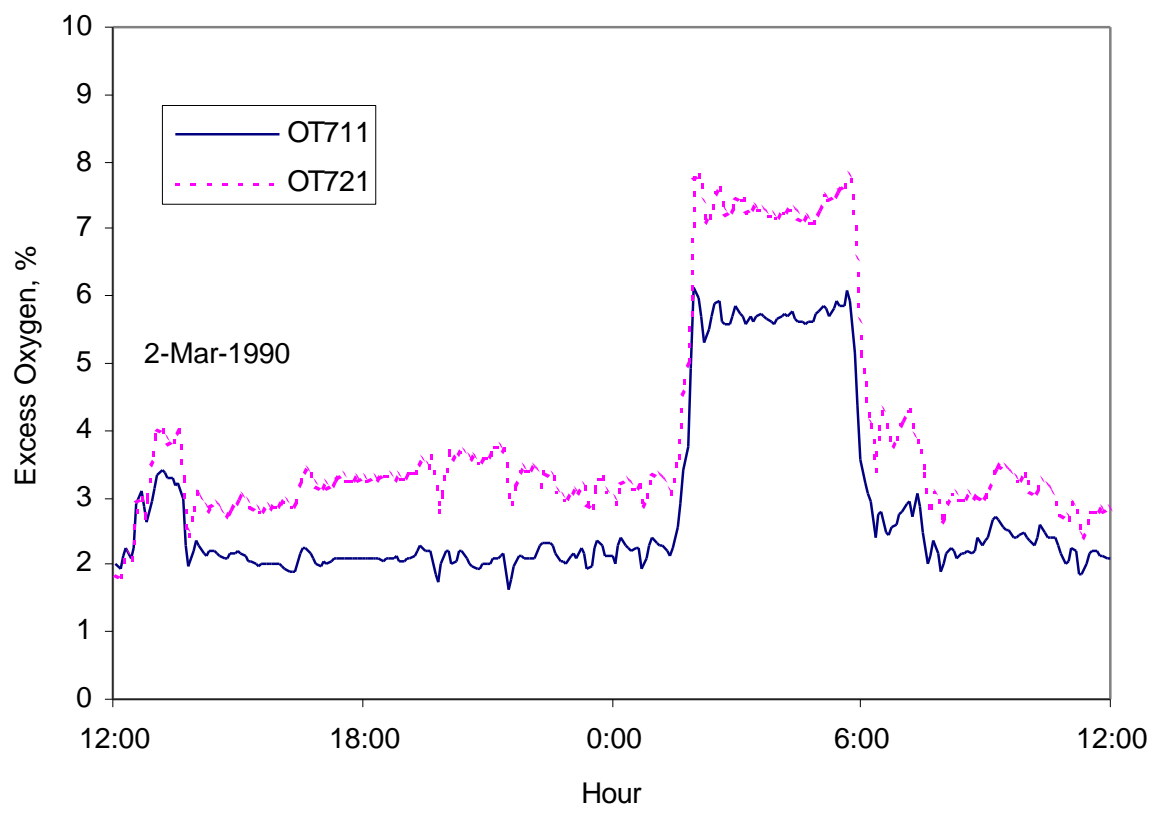

Figure 3-17 Excess Oxygen Response (Baseline) 


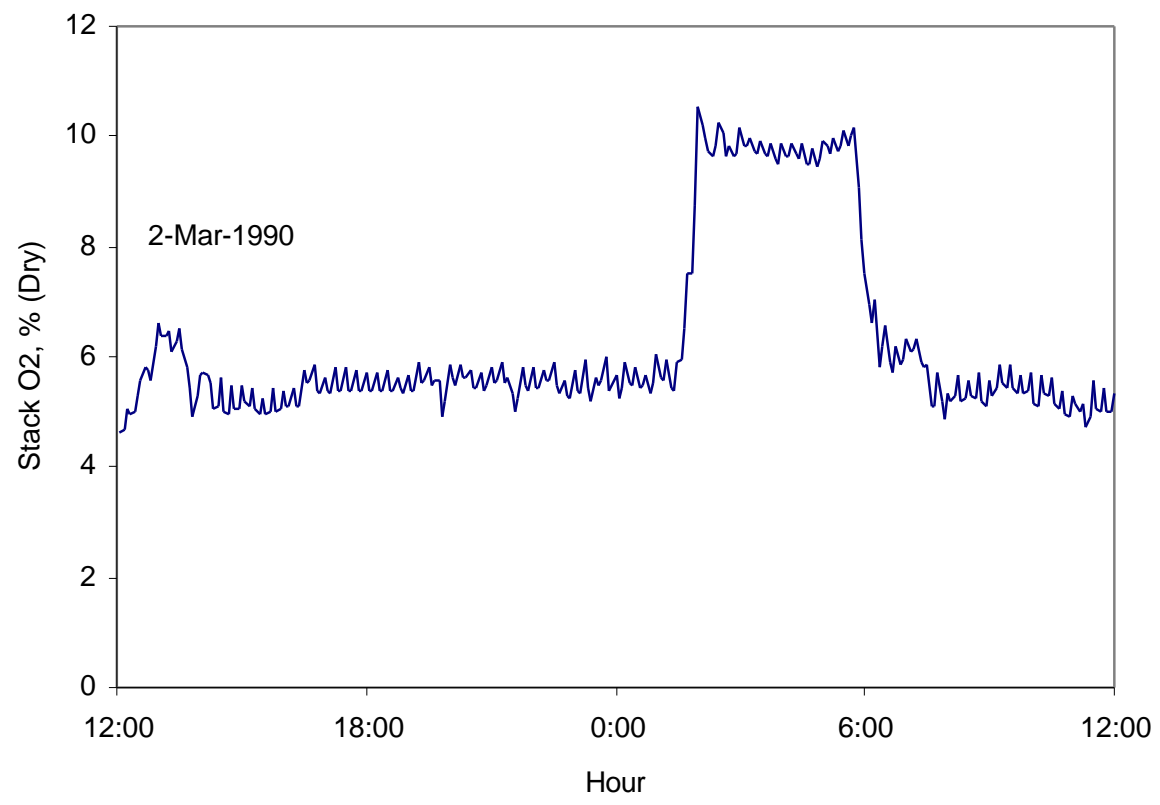

Figure 3-18 Stack $\mathrm{O}_{2}$ Response (Baseline)

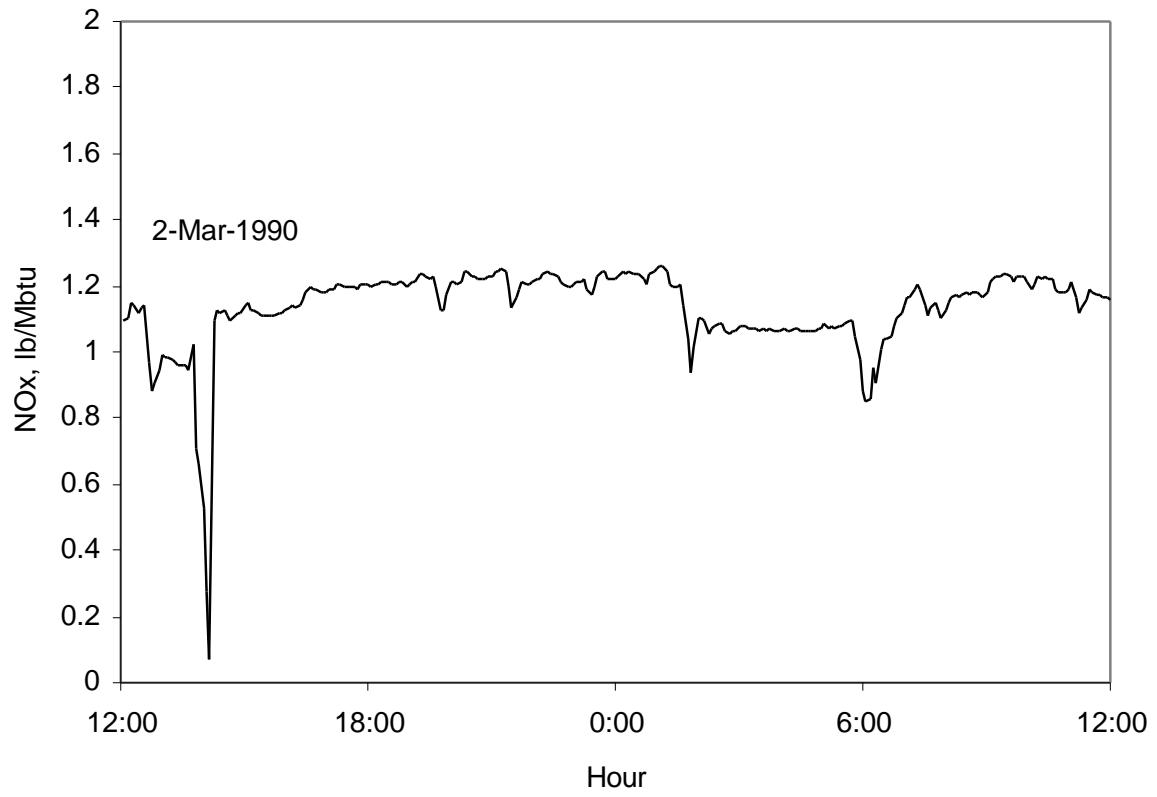

Figure 3-19 NOx Emissions Response (Baseline) 


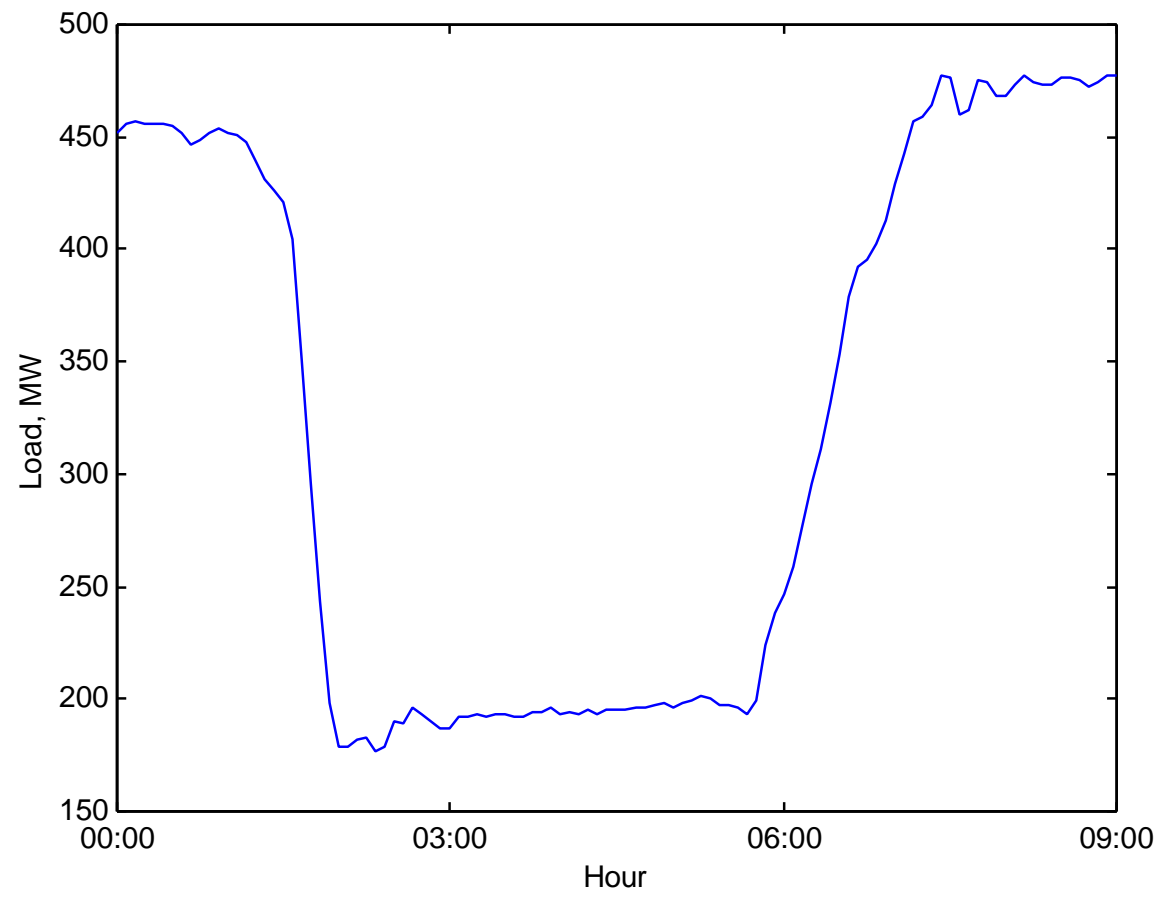

Figure 3-20 Load Response (Baseline)

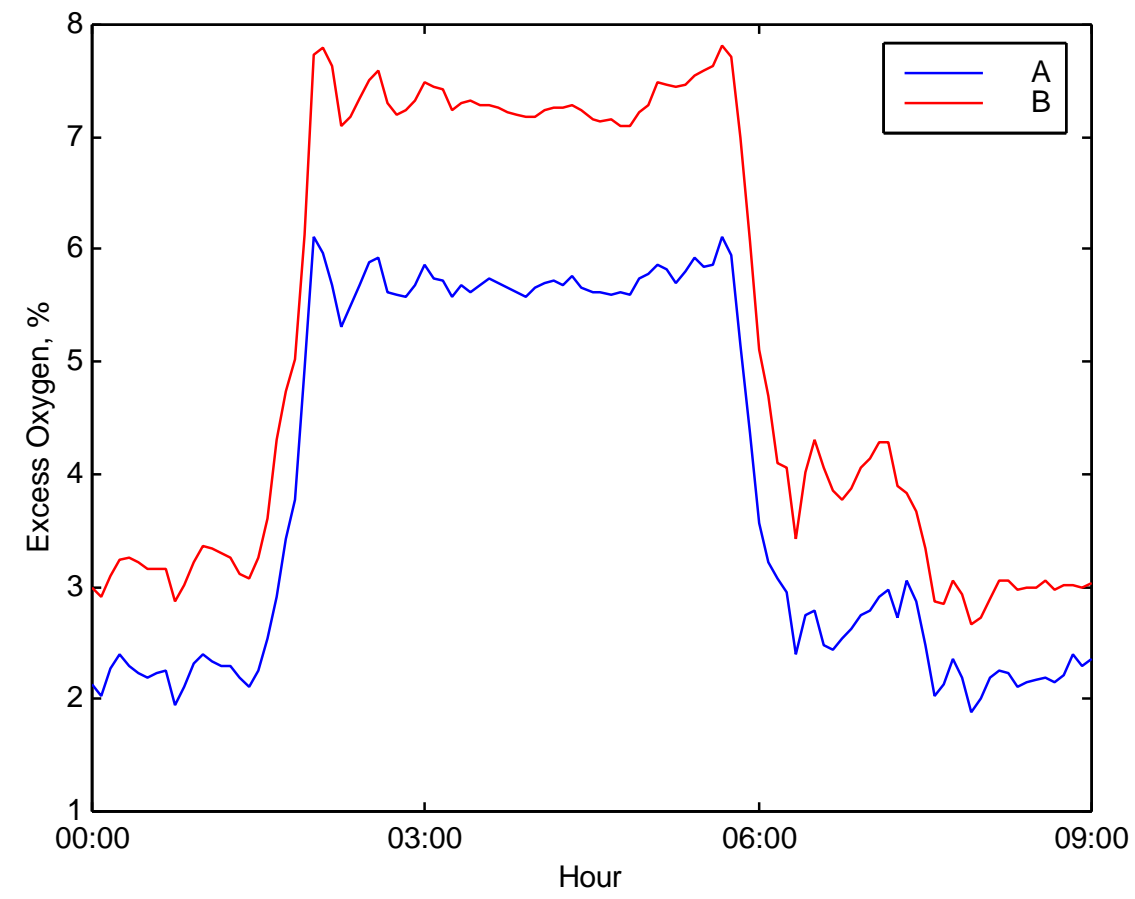

Figure 3-21 Load Response (Baseline) 


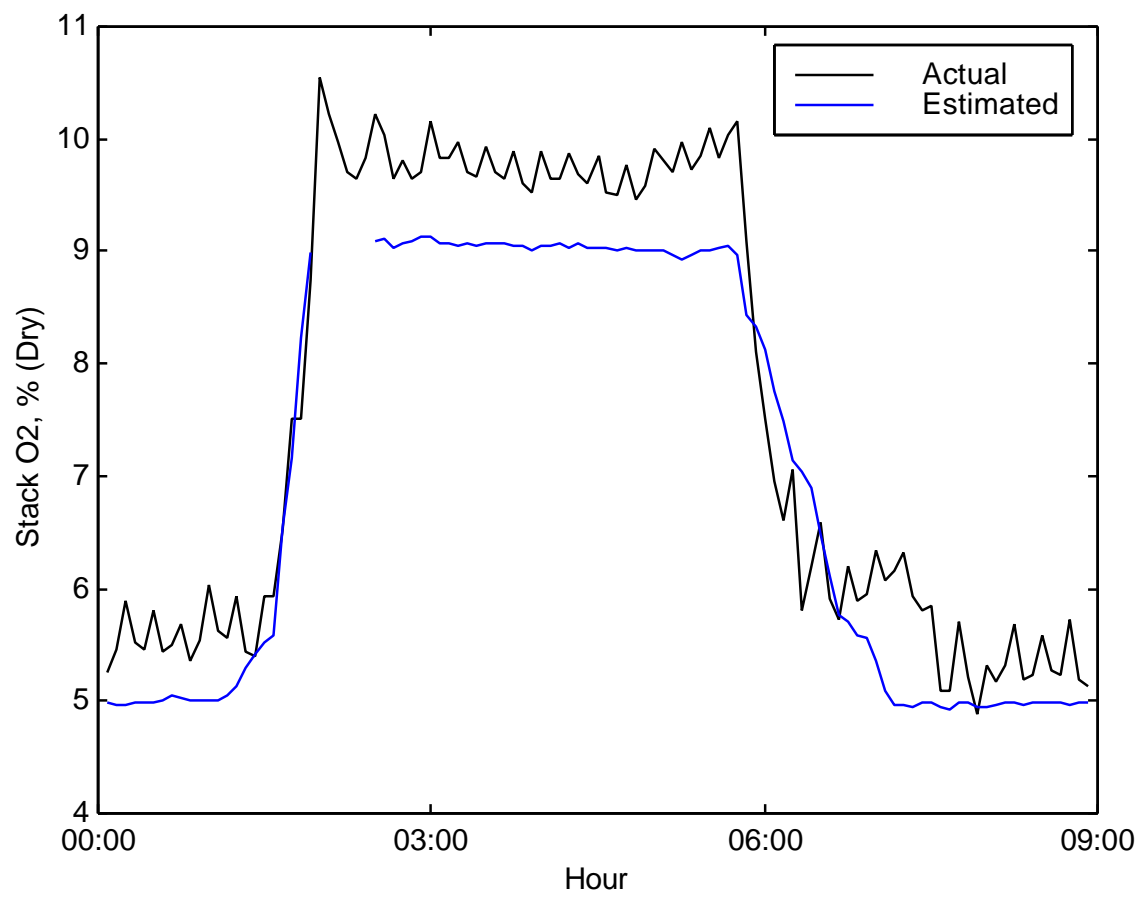

Figure 3-22 Stack $\mathrm{O}_{2}$ Response (Baseline)

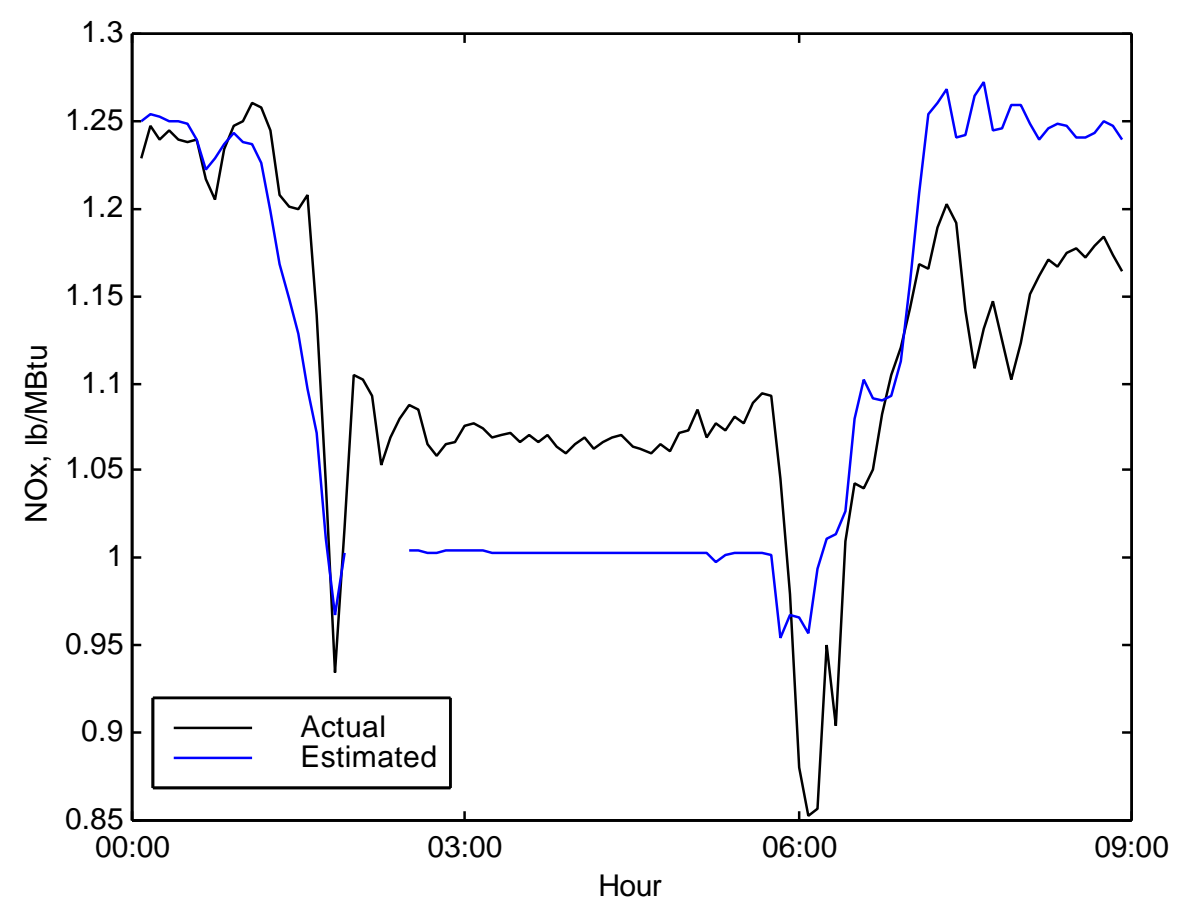

Figure 3-23 NOx Response (Baseline) 


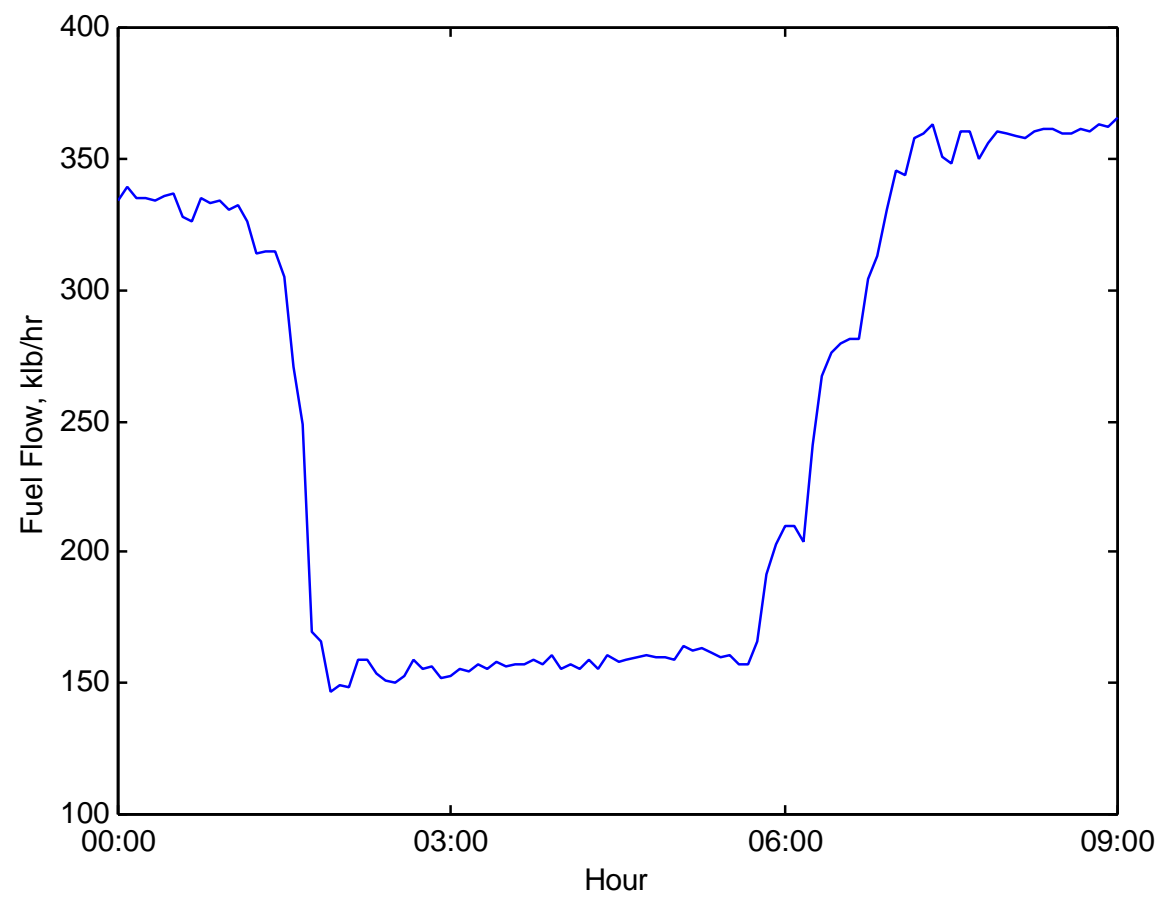

Figure 3-24 Fuel Flow (Baseline)

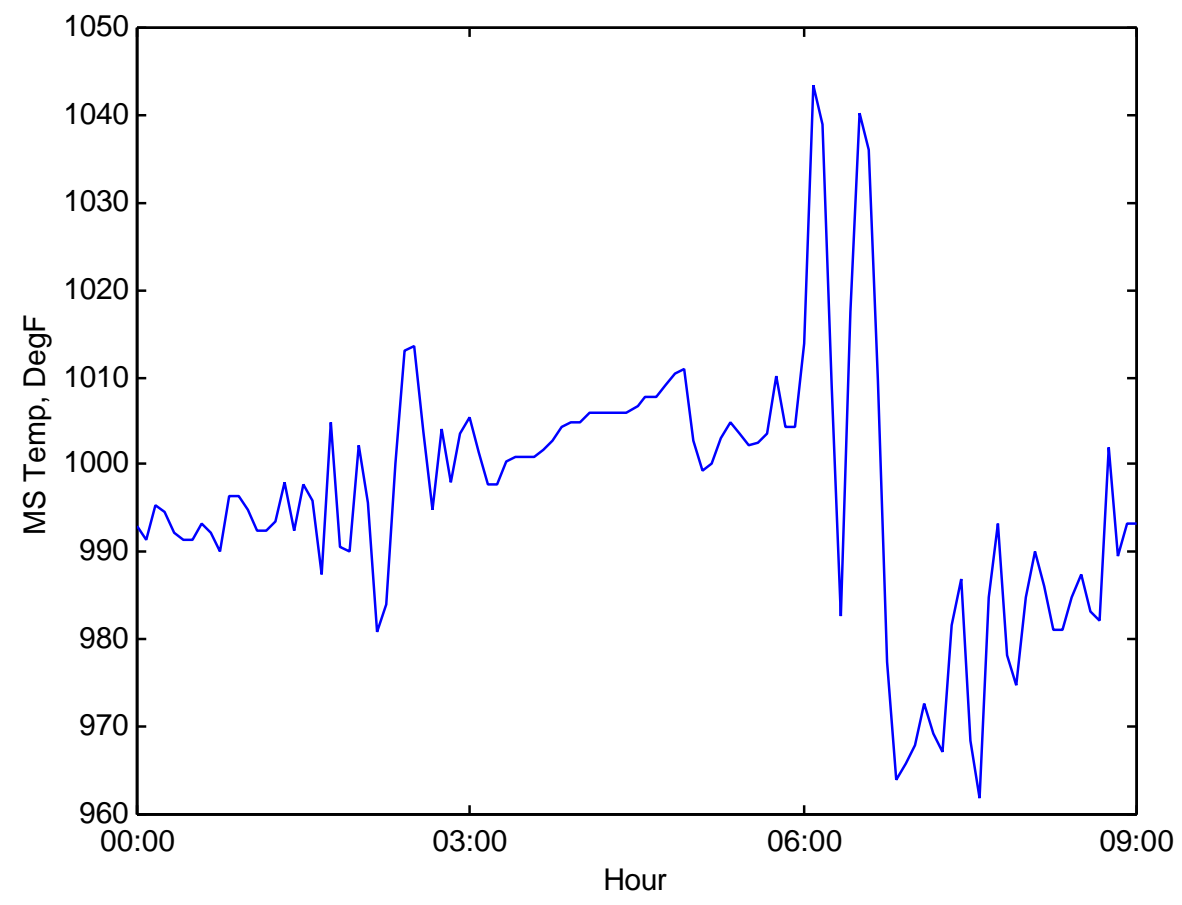

Figure 3-25 Throttle Temperature Response (Baseline) 


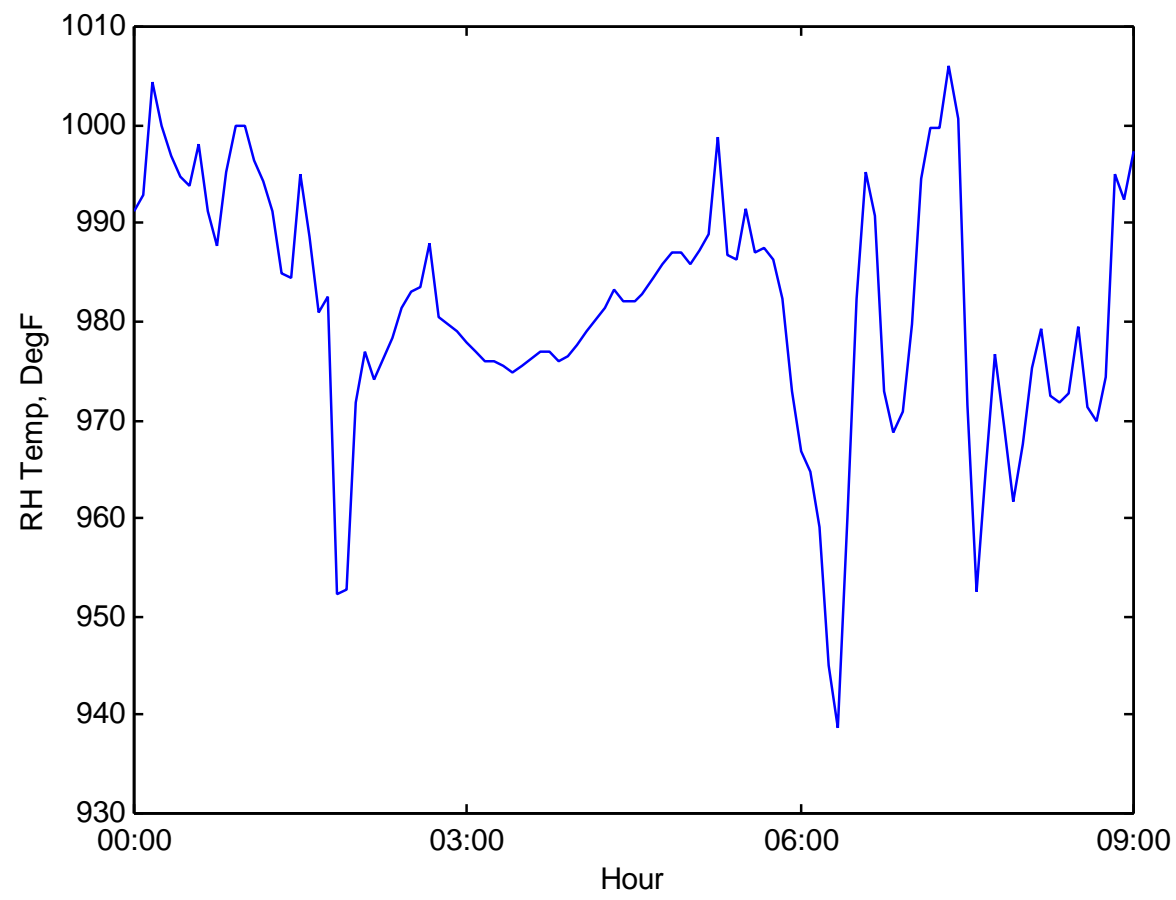

Figure 3-26 Reheat Temperature Response (Baseline)

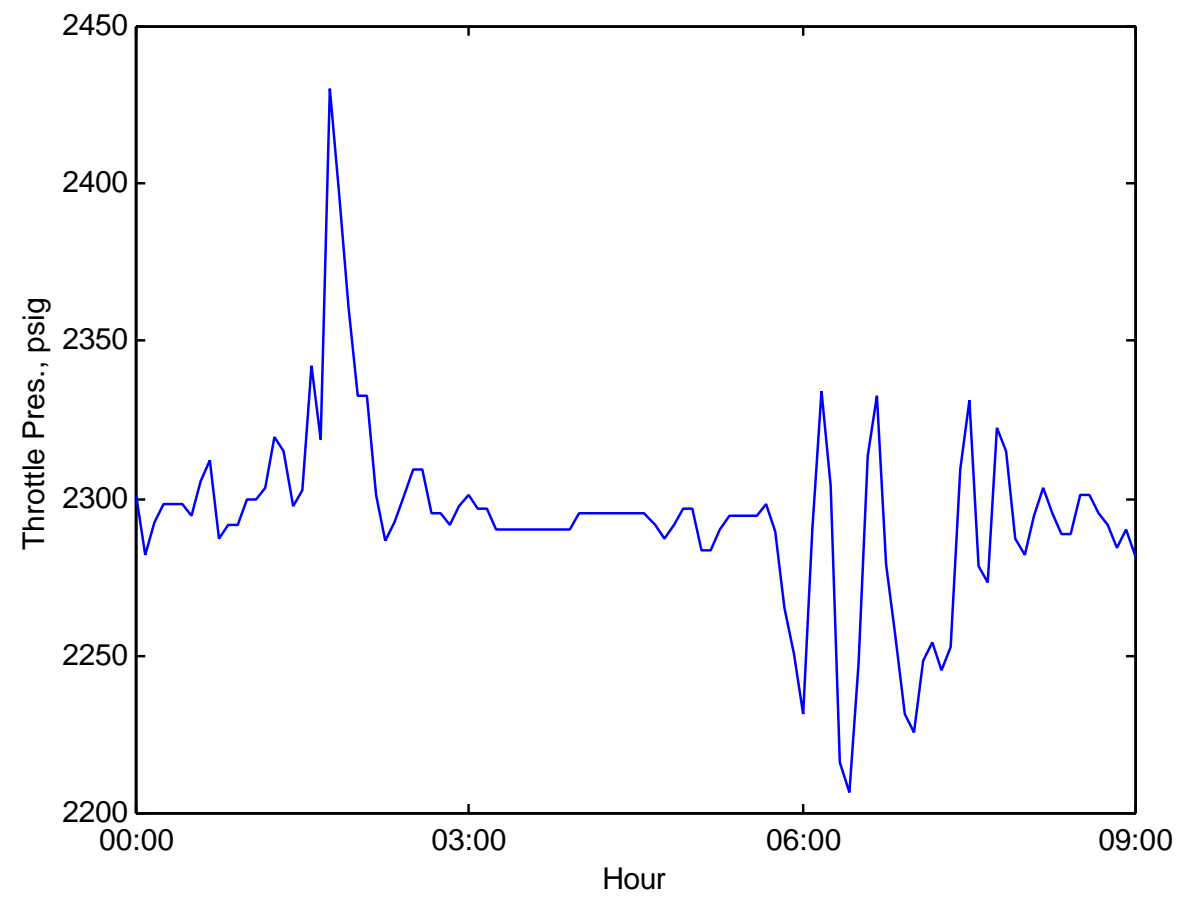

Figure 3-27 Throttle Pressure Response (Baseline) 


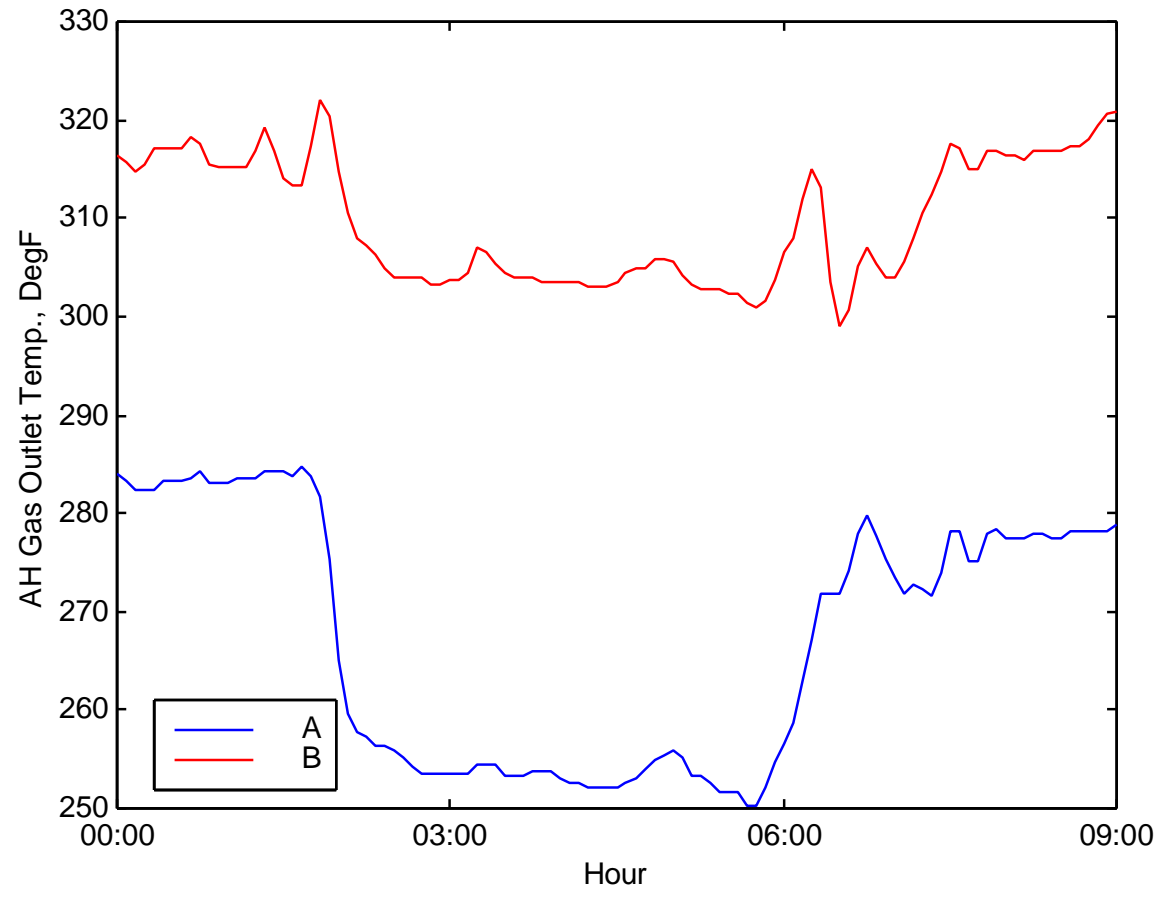

Figure 3-28 Air Heater Outlet Temperature Response (Baseline)

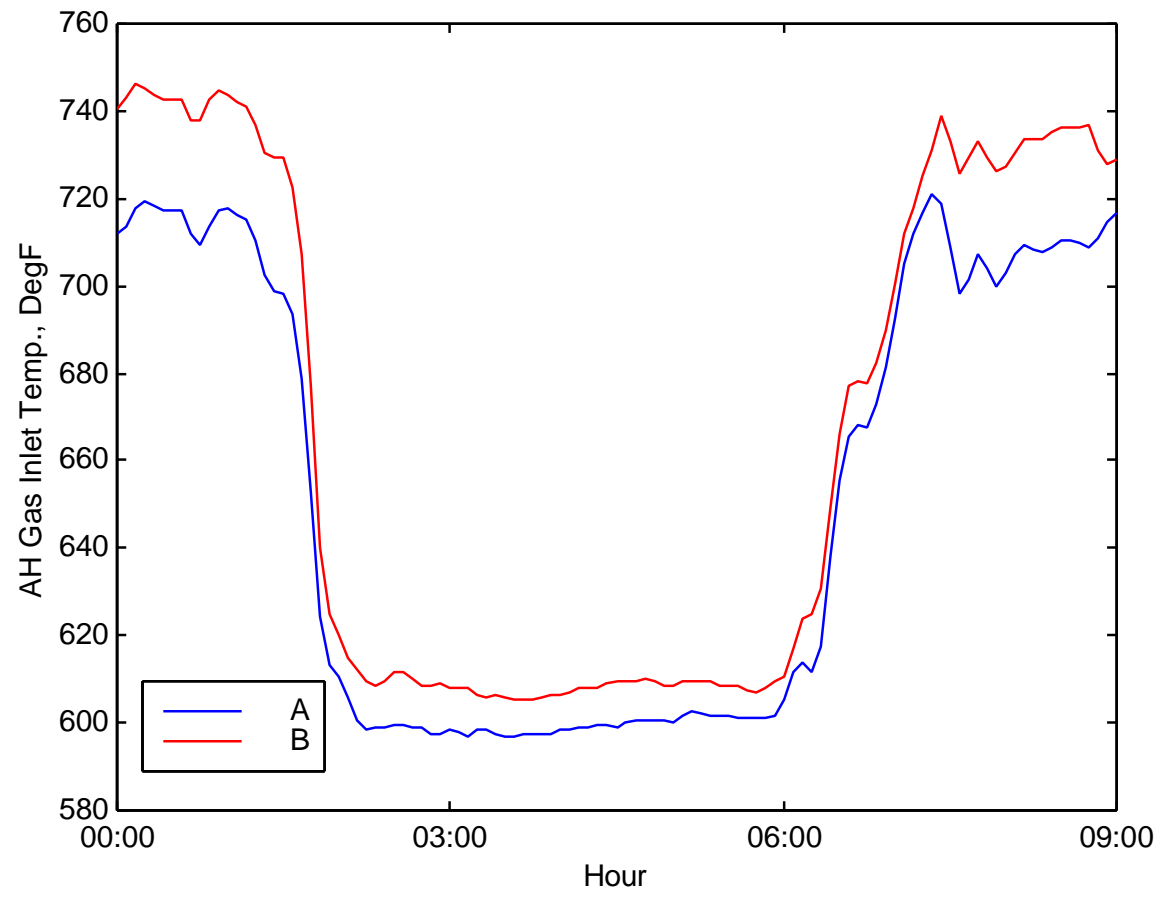

Figure 3-29 Economizer Outlet Temperature Response (Baseline) 
BASIS FOR INSTALLING GNOCIS AND THE DCS 


\section{PHASE 4A - DCS}

The overall goal of Phase 4 of the project was to evaluate the impact of digital control systems and on-line optimization techniques to NOx emissions, boiler efficiency, and other unit operational aspects. As part of this overall effort, several distinct test efforts were conducted:

- Characterization of the combustion characteristics of the unit following an extended outage including diagnostic and performance testing.

- LOI testing for the purpose of (1) further characterizing the unit and (2) evaluation of several on-line carbon-in-ash analyzers.

- GNOCIS testing to evaluate the performance of the on-line, continuous optimization tool selected for demonstration for this phase of the project.

The findings from the testing of the DCS as it applies to emissions and performance characteristics of the unit are discussed in this section. Findings related to the evaluation of the on-line carbon-in-ash analyzers are reported elsewhere [SCS 1997].

Several aspects of the test program differed from the prior phases, the most important of which are that the determinations of flue gas $\mathrm{SO}_{3}$ concentration, fly ash chemical composition, and fly ash particle size distribution were deleted from the test matrix. Other than the known impact of excess oxygen on the $\mathrm{SO}_{2}$-to- $\mathrm{SO}_{3}$ conversion rate, it was highly unlikely the unit modifications and operational changes would have any affect and therefore they were deleted for economic reasons.

On September 3, 1993, Hammond 4 began a major outage. Activities during this outage included (1) installation of a distributed digital control system, (2) installation of a new precipitator, (3) upgrades to the steam turbine, and (4) replacement of the two remaining FWEC Planetary and Table type mills (mills B and D) with Babcock and Wilcox MPS 75 mills. Following the nine-month outage, coal-fired operation resumed at Hammond Unit 4 on June 5, 1994.

Diagnostic testing took place during August 1994. Additional diagnostic testing and modified performance type testing was conducted during November 1994. The purpose of these tests was to determine the emissions and performance characteristics of the unit subsequent to the major modifications to the unit. Following the installation of two of the three on-line carbon-in-ash analyzers to be evaluated, a series of LOI tests was performed during August 1995. After the installation of the third analyzer, another LOI test series was conducted during February 1996. 


\subsection{Phase 4A Testing}

\subsubsection{Diagnostic Testing}

Preliminary diagnostic testing was conducted from August 5, 1994 to August 8, 1994. Diagnostic testing continued on November 2, 1994 through November 18, 1994. In total, 51 tests were conducted at four nominal load conditions (300, 400, 480, and $520 \mathrm{MW})$. A summary of these tests can be found in Table 4-1 with further information provided in Appendix A.

\section{$\underline{\text { NOx Emissions }}$}

The primary purpose of these tests was to determine the short-term NOx emissions characteristics particularly as a function of excess oxygen but also overfire air and mill biasing. As shown in Figure 4-1 and Figure 4-2, excess oxygen and overfire air levels were exercised well above and below "normal" levels yielding variations in NOx emissions (Figure 4-3) from approximately 0.35 to $0.55 \mathrm{lb} / \mathrm{MBtu}$ at full load $(480 \mathrm{MW}$ ) and 0.35 to $0.45 \mathrm{lb} / \mathrm{MBtu}$ at the low intermediate load ( $300 \mathrm{MW}$ ). Based on these $\mathrm{O}_{2}$ variations, the $\mathrm{NOx}$ vs. $\mathrm{O}_{2}$ gradient was determined for each of the three loads tested. As can be seen in Figure 4-4, at $480 \mathrm{MW}$, NOx emissions were highly dependent on excess $\mathrm{O}_{2}$ and, apparently, to a great extent, a linear function of excess $\mathrm{O}_{2}$ over the range tested $\left(\mathrm{R}^{2}>0.97\right)$. Also, it is apparent from this figure that the emission characteristics of the unit during the August 1994 testing were considerably different than that observed during the November testing with the latter being approximately $0.1 \mathrm{lb} / \mathrm{MBtu}$ less at the same oxygen levels. Also, the November data is more representative of that seen earlier from this unit. The cause of this discrepancy is unknown; however, potential reasons include:

- Change in Burner Tuning - During October 1994, the unit was off-line for approximately one month. During this period, it is conceivable that the burner registers (particularly the inner and outer registers) were adjusted. This is difficult to confirm or rebut since the actual positions of the registers is not accurately portrayed by the indicator at the boiler front and inspection from the windbox is required.

- Increase in Backpass Leakage - If furnace backpass leakage increased as a percentage of total combustion air between the August and November tests, for a given economizer exit oxygen level, the amount of combustion air in the combustion zone would be reduced. The reduced combustion air would lead to decreased NOx emission levels.

- Change in Sampling Line Leakage - Air infiltration into the ECEM sampling lines or bubbler would affect the excess oxygen level measured. Since the leakage would have no impact on $\mathrm{O}_{2}$ corrected NOx measurements, it would shift the NOx vs. Excess Oxygen curve to the right. This hypothesis is somewhat supported by other process data

Similar results were found at $400 \mathrm{MW}$ and $300 \mathrm{MW}$ load levels (Figure 4-5 and Figure 4-6). Comparisons of the sensitivities at the three loads tested are shown in Figure 4-5. As shown, NOx emissions sensitivity to excess $\mathrm{O}_{2}$ decreased with decreasing load (Figure 4-7). For comparison, the sensitivities determined from prior phases of the project are shown in Table 4-2. 
As can be seen, sensitivities varied greatly from phase-to-phase for a given load. The explanation for the variation is unknown at this time, however, a contributing factor is likely the relative (as compared to the latest testing) non-repeatability of the short-term tests during prior phases (Phases 1, 2, 3A, and 3B) and the resultant influence of this non-repeatability on sensitivity determination. For the testing conducted during August 1994, NOx emission characteristics were more repeatable than what had been observed in prior phases.

As can be seen in Figure 4-7, short-term, full load NOx emission levels were near 0.49 lb/MBtu at design excess $\mathrm{O}_{2}$ levels. This $\mathrm{NOx}$ emission level is above that experienced during the prior LNB plus AOFA test phase (Phase 3B) for which full load, normal excess $\mathrm{O}_{2}$ emission levels were approximately $0.40 \mathrm{lb} / \mathrm{MBtu}$. This increase in NOx emissions was also evident at the lower test loads (400 MW and $300 \mathrm{MW}$ ). The reduction could be the result of several factors including:

- AOFA Flow Rates - Indicated AOFA flow rates were below those used in the previous phase. Design AOFA flow rate is $800 \mathrm{klb} / \mathrm{h}$ at full load whereas during the August 1994 tests, AOFA rates were approximately $640 \mathrm{klb} / \mathrm{h}$.

- Mill Biasing - The inadvertent mill bias existing during Phase 3B which led to reduced NOx emissions may have no longer existed.

- Coal Properties - The coal used during the August 1994 testing could have been more favorable to NOx production.

- Selection of short-term test conditions which were not representative of long-term operation.

\section{$\underline{\text { CO Emissions }}$}

As experienced during prior phases, $\mathrm{CO}$ emissions were relatively low -- generally below $50 \mathrm{ppm}$ -- at recommended excess $\mathrm{O}_{2}$ levels. At full load, as excess $\mathrm{O}_{2}$ levels were reduced, $\mathrm{CO}$ emission levels rose producing the familiar "knee" in emissions (Figure 4-8). A similar CO vs. excess $\mathrm{O}_{2}$ characteristic was evident in the $400 \mathrm{MW}$ tests. At the $300 \mathrm{MW}$ load, excess $\mathrm{O}_{2}$ was not reduced sufficiently to generate increased $\mathrm{CO}$ emissions.

\section{$\underline{\text { Response Plots }}$}

The response plots (Figure 4-9) show the tradeoffs in combustion optimization. As previously shown, NOx emissions generally decrease with increased excess $\mathrm{O}_{2}$ whereas $\mathrm{CO}$ emissions and LOI generally increase, thereby producing a conflict of goals; i.e. to reduce both $\mathrm{NOx}, \mathrm{CO}$, and LOI to a minimum. As can be seen, using excess $\mathrm{O}_{2}$ alone, $\mathrm{NOx}$ emissions could be reduced to below $0.40 \mathrm{lb} / \mathrm{MBtu}$ while maintaining $\mathrm{CO}$ emissions below $50 \mathrm{ppm}$ and LOI below 8 percent. Similarly, overfire flow affects NOx, CO, and LOI whereas mill bias appears to only affect LOI (at least at full load). Using these variables (excess $\mathrm{O}_{2}$, OFA flow, and mill biasing) in combination could be used to optimize a combination of output variables (i.e. NOx, $\mathrm{CO}$, and LOI). 
Table 4-1 P4A / Diagnostic Tests Conducted

\begin{tabular}{|c|c|c|c|c|c|c|}
\hline $\begin{array}{c}\text { TEST } \\
\text { NO. }\end{array}$ & DATE & TEST CONDITIONS & LOAD & $\begin{array}{l}\text { MOOS } \\
\text { PATRN }\end{array}$ & $\begin{array}{l}\text { OFA } \\
\text { FLOW } \\
\text { KPPH }\end{array}$ & $\begin{array}{c}\text { Econ. O2 } \\
\text { DRY } \\
(\%)\end{array}$ \\
\hline $129-1$ & $08 / 05 / 94$ & HI-LOAD NORMAL O2 & 486 & AMIS & NA & 3.0 \\
\hline $129-2$ & $08 / 05 / 94$ & HI-LOAD LOW O2 & 483 & AMIS & NA & 2.7 \\
\hline $129-3$ & $08 / 05 / 94$ & HI-LOAD HIGH O2 & 483 & AMIS & NA & 3.9 \\
\hline $130-1$ & 08/06/94 & MID-LOAD LOW O2 & 398 & B & & 2.8 \\
\hline $130-2$ & $08 / 06 / 94$ & MID-LOAD NORM O2 & 400 & B & 297 & 3.6 \\
\hline $130-3$ & $08 / 06 / 94$ & MID-LOAD HIGH O2 & 398 & B & 318 & 4.7 \\
\hline $130-4$ & $08 / 06 / 94$ & MID-LOAD NORM O2, DECR OFA & 399 & B & 211 & 4.0 \\
\hline $130-5$ & $08 / 06 / 94$ & MID-LOAD NORM O2 & 399 & E & 294 & 3.7 \\
\hline $131-1$ & $08 / 07 / 94$ & MD/LO LOAD LOW O2 & 300 & $B, E$ & 119 & 4.4 \\
\hline $131-2$ & $08 / 07 / 94$ & MD/LO LOAD NORM O2 & 300 & $\mathrm{~B}, \mathrm{E}$ & 134 & 4.8 \\
\hline $131-3$ & $08 / 07 / 94$ & MD/LO LOAD HIGH O2 & 302 & $B, E$ & 143 & 5.5 \\
\hline $131-4$ & $08 / 07 / 94$ & MD/LO LOAD HIGHER O2 & 301 & $\mathrm{~B}, \mathrm{E}$ & 133 & 6.4 \\
\hline $132-1$ & $08 / 08 / 94$ & HI-LOAD LOW O2 & 482 & AMIS & 650 & 2.9 \\
\hline $132-2$ & 08/08/94 & HI-LOAD NORM O2 & 484 & AMIS & 658 & 3.5 \\
\hline $132-3$ & $08 / 08 / 94$ & HI-LOAD HIGH O2 & 479 & AMIS & 666 & 4.1 \\
\hline $132-4$ & $08 / 08 / 94$ & HI-LOAD FUEL BIASED TO UPPER MILLS & 476 & AMIS & 613 & 4.1 \\
\hline $132-5$ & $08 / 08 / 94$ & HI-LOAD FUEL BIASED TO UPPER MILLS & 479 & AMIS & 596 & 3.4 \\
\hline $133-1$ & $11 / 02 / 94$ & MID-LOAD NORMAL O2 & 401 & B & 278 & 4.0 \\
\hline $133-2$ & $11 / 02 / 94$ & MID-LOAD HIGH O2 & 401 & B & 276 & 4.8 \\
\hline $133-3$ & $11 / 02 / 94$ & MID-LOAD NORMAL O2 & 400 & B & 284 & 3.6 \\
\hline $133-4$ & $11 / 02 / 94$ & MID-LOAD LOW O2 & 401 & B & 278 & 2.8 \\
\hline $133-5$ & $11 / 02 / 94$ & MID-LOAD LOW O2 & 400 & $\mathrm{E}$ & 289 & 3.2 \\
\hline $133-6$ & $11 / 02 / 94$ & MID-LOAD NORMAL O2 & 401 & $\mathrm{E}$ & 306 & 4.2 \\
\hline 134-1 & $11 / 03 / 94$ & MID-LOAD NORMAL O2 BAL MILLS & 400 & B & 285 & 3.6 \\
\hline $134-2$ & $11 / 03 / 94$ & MID-LOAD FUEL BIASED TO LOWER MILLS & 400 & B & 287 & 3.5 \\
\hline $134-3$ & $11 / 03 / 94$ & MID-LOAD FUEL BIASED TO UPPER MILLS & 400 & B & 276 & 3.7 \\
\hline $134-4$ & $11 / 03 / 94$ & MID-LOAD NORMAL O2 BAL MILLS & 400 & B & 276 & 3.5 \\
\hline $135-1$ & $11 / 09 / 94$ & HIGH LOAD, AMIS, NOMINAL O2 & 481 & AMIS & 606 & 3.4 \\
\hline $135-2$ & $11 / 09 / 94$ & HIGH LOAD, AMIS, LOW O2 & 482 & AMIS & 653 & 2.9 \\
\hline $135-3$ & $11 / 09 / 94$ & HIGH LOAD, AMIS, HIGH O2 & 479 & AMIS & 675 & 3.9 \\
\hline $136-1$ & $11 / 10 / 94$ & HIGH LOAD, NOM O2, BALANCED MILLS & 478 & AMIS & 582 & 4.0 \\
\hline $136-2$ & $11 / 10 / 94$ & HIGH LOAD, NOM O2, COAL BIASED HIGH & 478 & AMIS & 595 & 4.1 \\
\hline $136-3$ & $11 / 10 / 94$ & HIGH LOAD, NOM O2, COAL BIASED LOW & 479 & AMIS & 597 & 4.0 \\
\hline $136-4$ & $11 / 10 / 94$ & HIGH LOAD, NOM O2, BALANCED MILLS & 480 & AMIS & 606 & 4.1 \\
\hline $137-1$ & $11 / 11 / 94$ & HIGH LOAD, NOM O2, BAL MILLS, NOM OFA & 478 & AMIS & 636 & 3.9 \\
\hline $137-2$ & $11 / 11 / 94$ & HIGH LOAD, NOM O2, BAL MILLS, HIGH OFA & 481 & AMIS & 872 & 4.1 \\
\hline $137-3$ & $11 / 11 / 94$ & HIGH LOAD, NOM O2, BAL MILLS, MID OFA & 480 & AMIS & 515 & 3.8 \\
\hline $137-4$ & $11 / 11 / 94$ & HIGH LOAD, NOM O2, BAL MILLS, LOW OFA & 480 & AMIS & 268 & 4.1 \\
\hline $143-1$ & $11 / 17 / 94$ & MAX LOAD, HIGH O2, BAL MILLS, NOM OFA & 519 & AMIS & 780 & 4.0 \\
\hline $143-2$ & $11 / 17 / 94$ & MAX LOAD, NOM O2, BAL MILLS, NOM OFA & 520 & AMIS & 774 & 3.3 \\
\hline $143-3$ & $11 / 17 / 94$ & MAX LOAD, LOW O2, BAL MILLS, NOM OFA & 521 & AMIS & 747 & 3.0 \\
\hline $143-4$ & $11 / 17 / 94$ & HIGH LOAD, NOM O2, BAL MILLS, HIGH OFA & 480 & AMIS & 823 & 3.8 \\
\hline $143-5$ & $11 / 17 / 94$ & HIGH LOAD, NOM O2, BAL MILLS, MID OFA & 479 & AMIS & 490 & 3.7 \\
\hline $143-6$ & $11 / 17 / 94$ & HIGH LOAD, NOM O2, BAL MILLS, MIN OFA & 479 & AMIS & 280 & 3.7 \\
\hline 144-1 & $11 / 18 / 94$ & LOW LOAD, HIGH O2, BAL MILLS, NOM OFA & 300 & $\mathrm{~B}, \mathrm{E}$ & 117 & 6.7 \\
\hline $144-2$ & $11 / 18 / 94$ & LOW LOAD, NOM O2, BAL MILLS, NOM OFA & 301 & $B, E$ & 126 & 6.0 \\
\hline $144-3$ & $11 / 18 / 94$ & LOW LOAD, LOW 2, BAL MILLS, NOM OFA & 301 & $B, E$ & 100 & 5.0 \\
\hline $144-4$ & $11 / 18 / 94$ & MID LOAD, HIGH O2, BAL MILLS, NOM OFA & 399 & $\mathrm{E}$ & 306 & 4.7 \\
\hline $144-5$ & $11 / 18 / 94$ & MID LOAD, LOW O2, BAL MILLS, NOM OFA & 400 & $E$ & 266 & 3.5 \\
\hline $144-6$ & $11 / 18 / 94$ & MID LOAD, NOM O2, BAL MILLS, NOM OFA & 399 & $\mathrm{E}$ & 307 & 3.9 \\
\hline $144-7$ & $11 / 18 / 94$ & MID LOAD, NOM O2, BAL MILLS, HIGH OFA & 399 & $\mathrm{E}$ & 492 & 4.0 \\
\hline
\end{tabular}




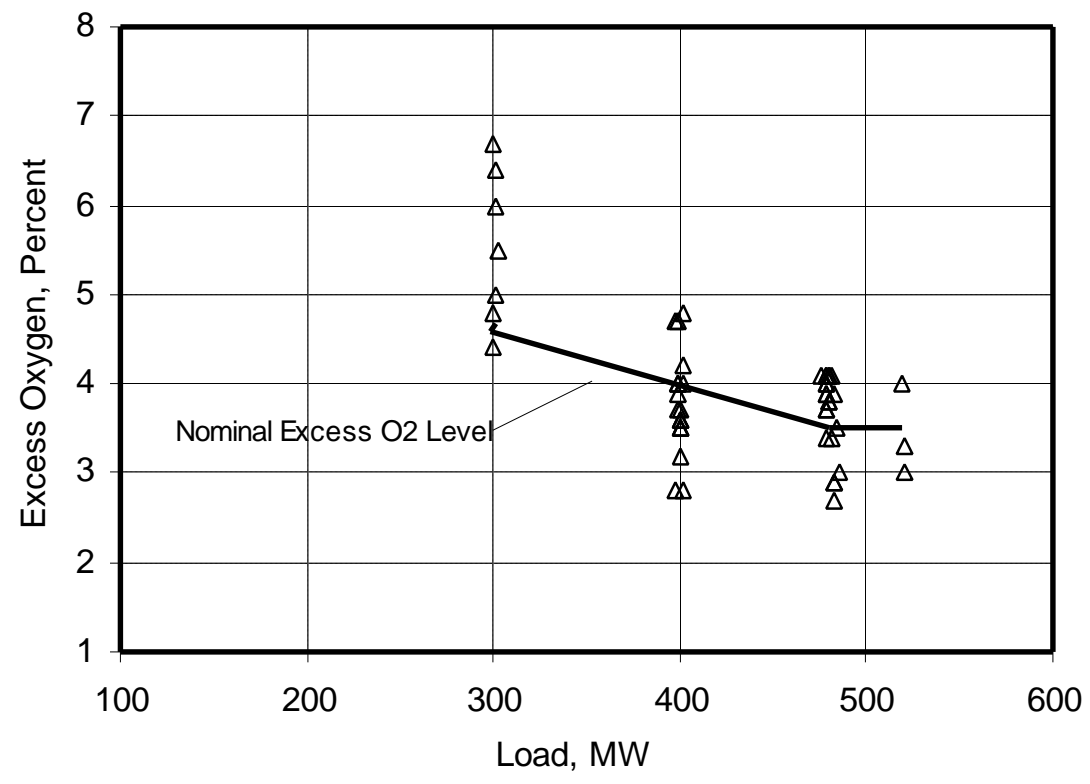

Figure 4-1 P4A / Diagnostic Tests / Oxygen Levels Tested

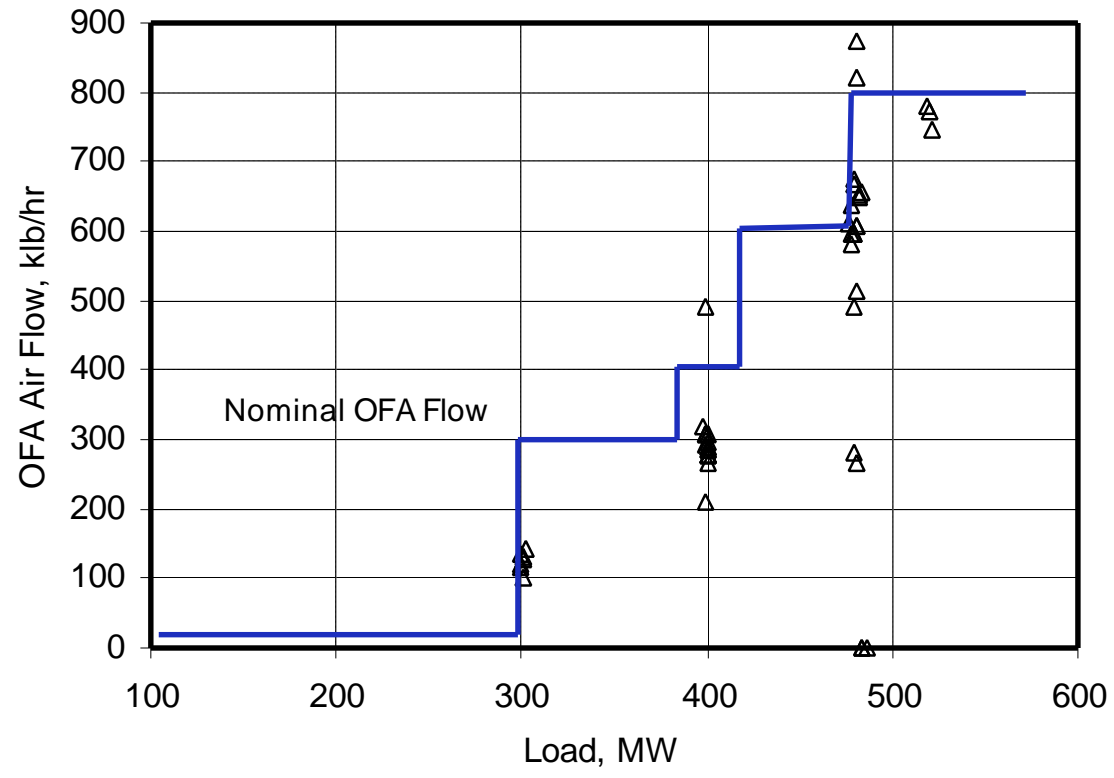

Figure 4-2 P4A / Diagnostic Tests / OFA Air Levels Tested 


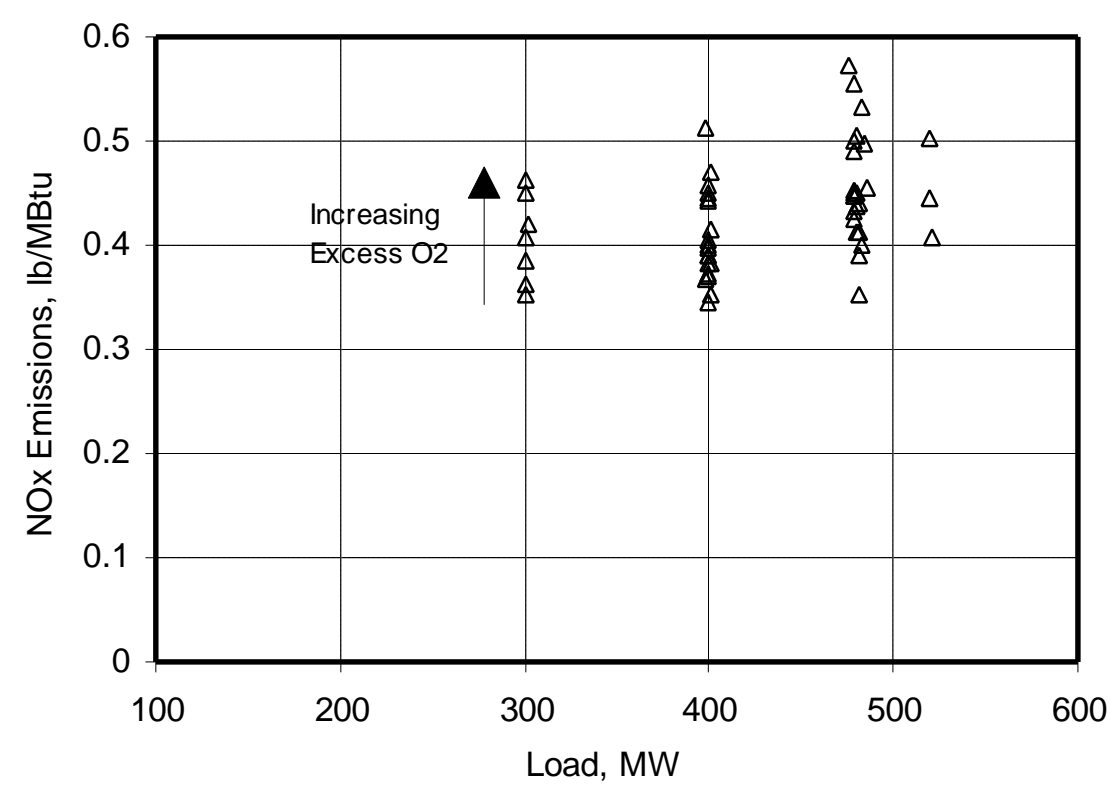

Figure 4-3 P4A /Diagnostic Tests / NOx Emissions

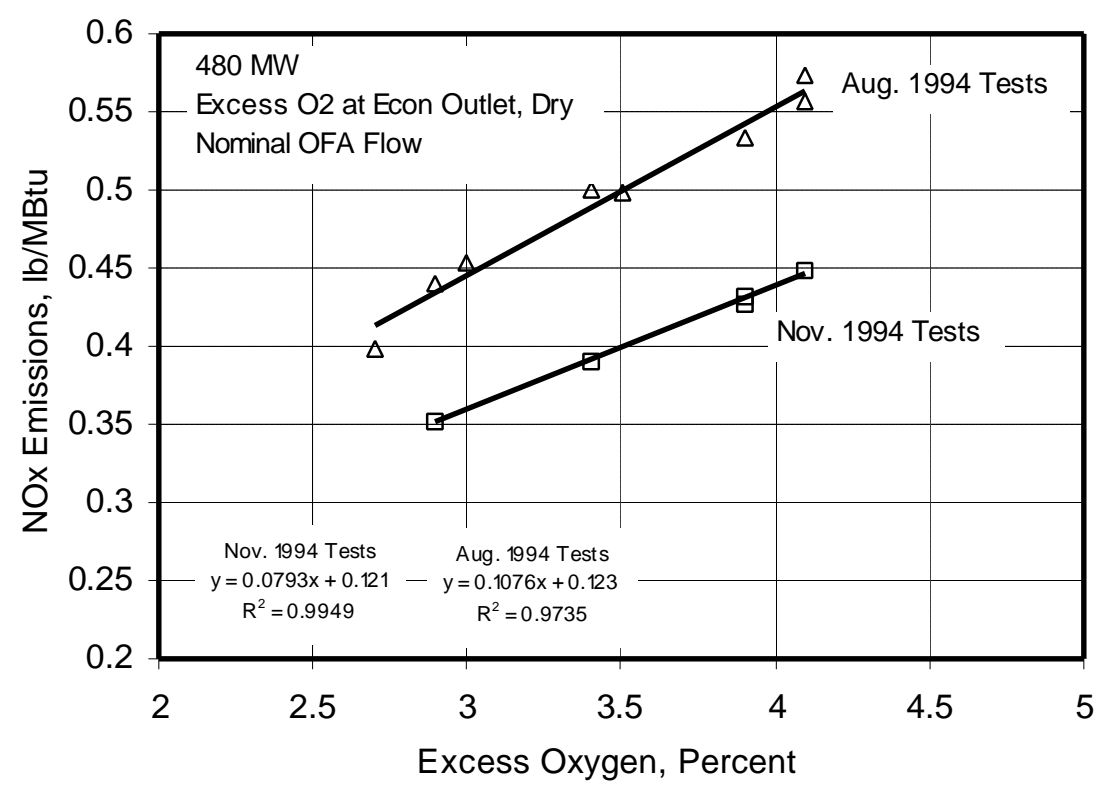

Figure 4-4 P4A / Diagnostic Tests / NOx vs. $\mathrm{O}_{2}$ at $480 \mathrm{MW}$ 


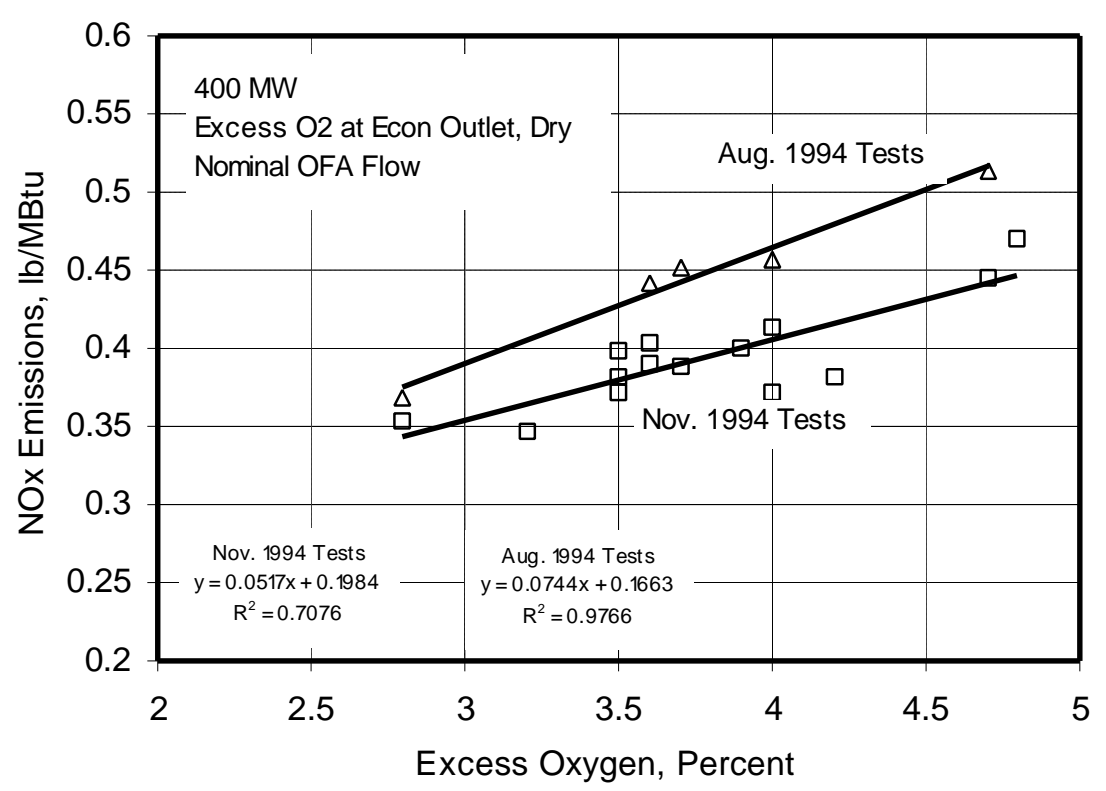

Figure 4-5 P4A / Diagnostic Tests / NOx vs. $\mathrm{O}_{2}$ at $400 \mathrm{MW}$

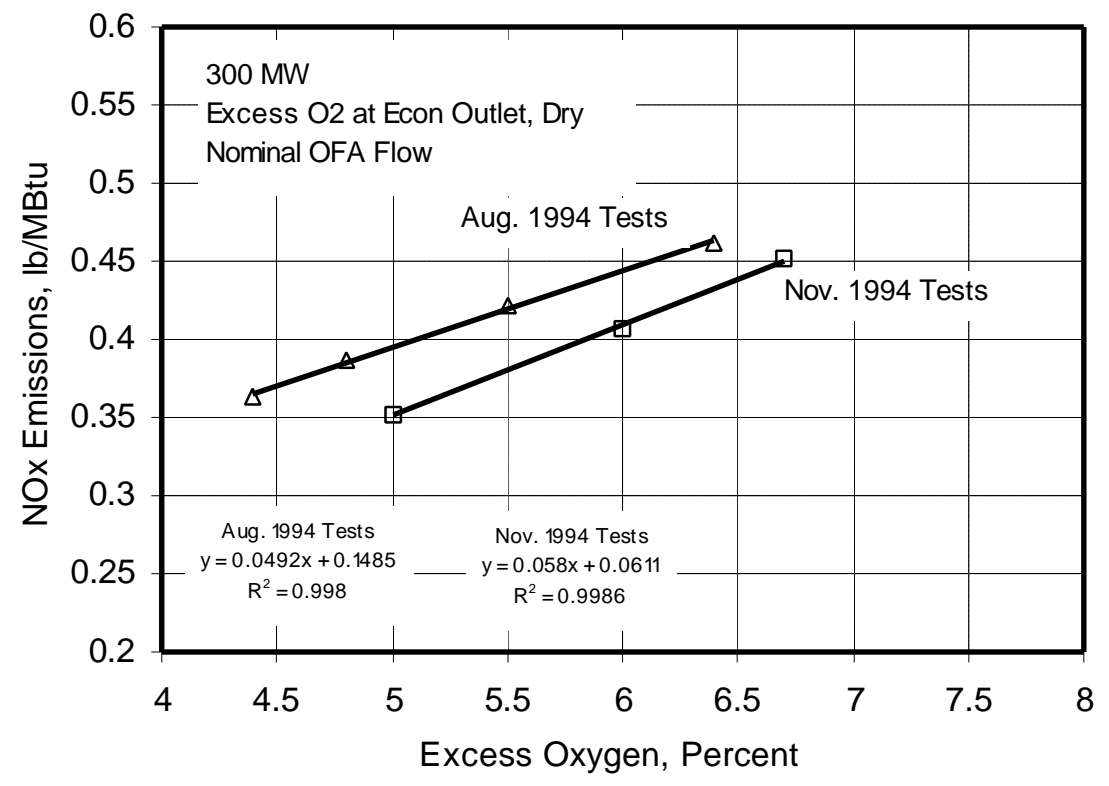

Figure 4-6 P4A / Diagnostic Tests / NOx vs. $\mathrm{O}_{2}$ at $400 \mathrm{MW}$ 


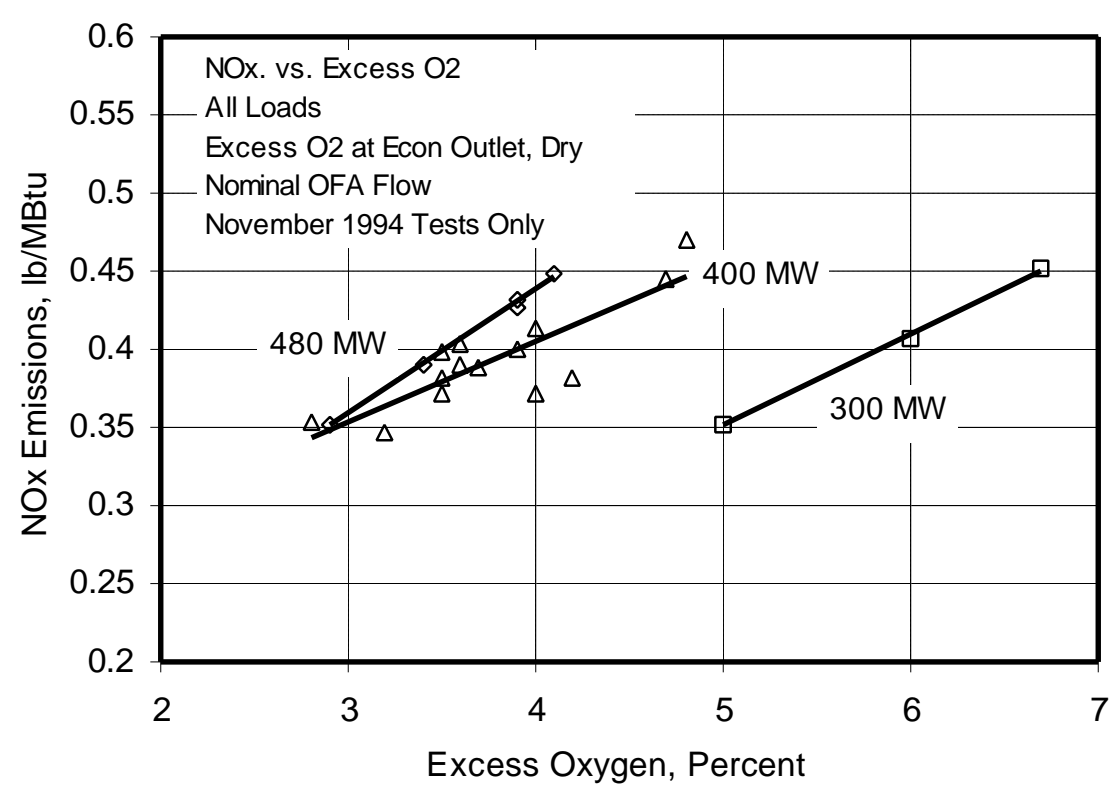

Figure 4-7 P4A / Diagnostic Tests / NOx vs. $\mathrm{O}_{2}$ / All Loads

Table 4-2 P4A / NOx Sensitivity to Excess $\mathrm{O}_{2}$

\begin{tabular}{|c|c|c|c|c|c|c|}
\hline \multirow{2}{*}{$\frac{\text { Nominal Load }}{\mathrm{MW}}$} & $\begin{array}{c}\text { 4A Diagnostic Tests } \\
\text { lovember } 1994 \\
\text { NOx } \\
\text { Sensitivity }\end{array}$ & \multirow[t]{2}{*}{$\mathrm{R}^{2}$} & \multicolumn{4}{|c|}{$\begin{array}{l}\text { Prior Phases } \\
\text { NOx Sensitivity }^{\#, *} \\
(\mathrm{lb} / \mathrm{MBtu}) /\left(\% \mathrm{O}_{2}\right)\end{array}$} \\
\hline & $(\mathrm{lb} / \mathrm{MBtu}) /\left(\% \mathrm{O}_{2}\right)$ & & 1 & 2 & $3 A$ & $3 \mathrm{~B}$ \\
\hline 480 & 0.0834 & 0.98 & $\sim 0.10$ & $\sim 0.09$ & $\sim 0.06$ & $\sim 0.05$ \\
\hline 400 & $0.0613^{\wedge}$ & 0.78 & $\sim 0.10$ & $\sim 0.11$ & $\sim 0.05$ & $\sim 0.08$ \\
\hline 300 & 0.058 & 0.99 & $\sim 0.08$ & $\sim 0.14$ & $\sim 0.04$ & $\sim 0.06$ \\
\hline
\end{tabular}

Based on short-term diagnostic tests.

\#See previous text for a discussion on the uncertainty of these results.

${ }^{\wedge} \mathrm{E}$ Mill out of service. 


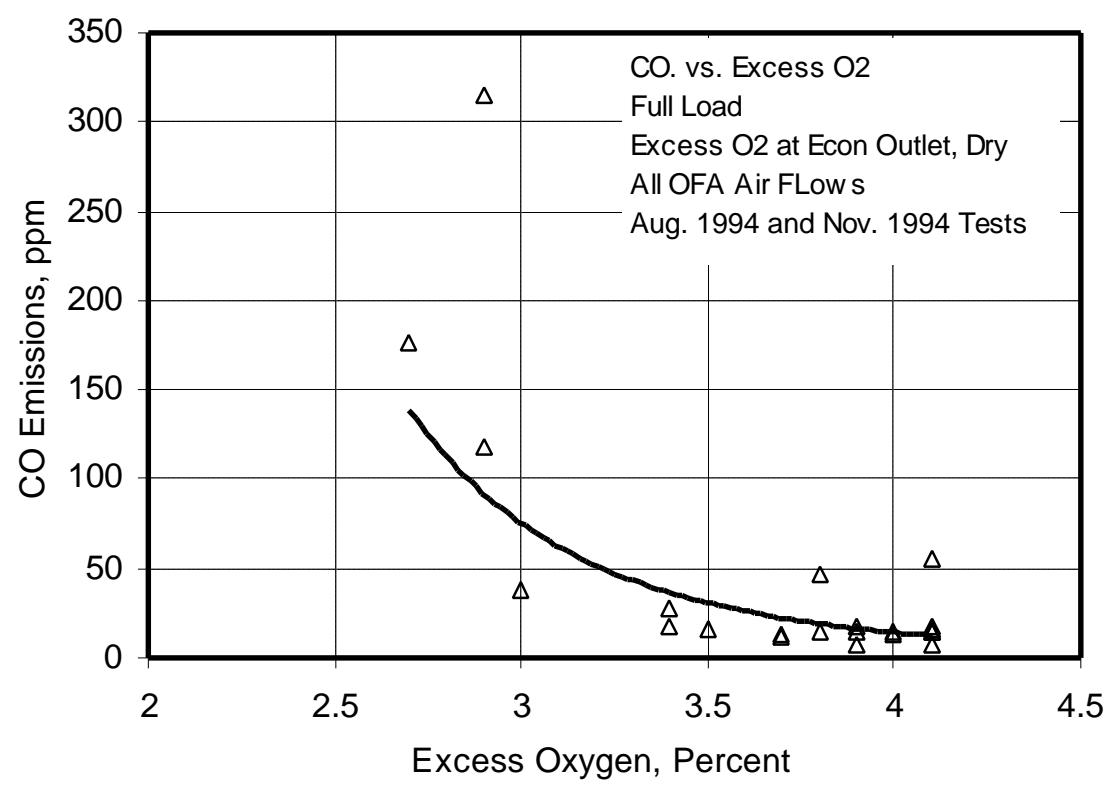

Figure 4-8 P4A / Diagnostic Tests / CO vs. $\mathrm{O}_{2}$ at $480 \mathrm{MW}$
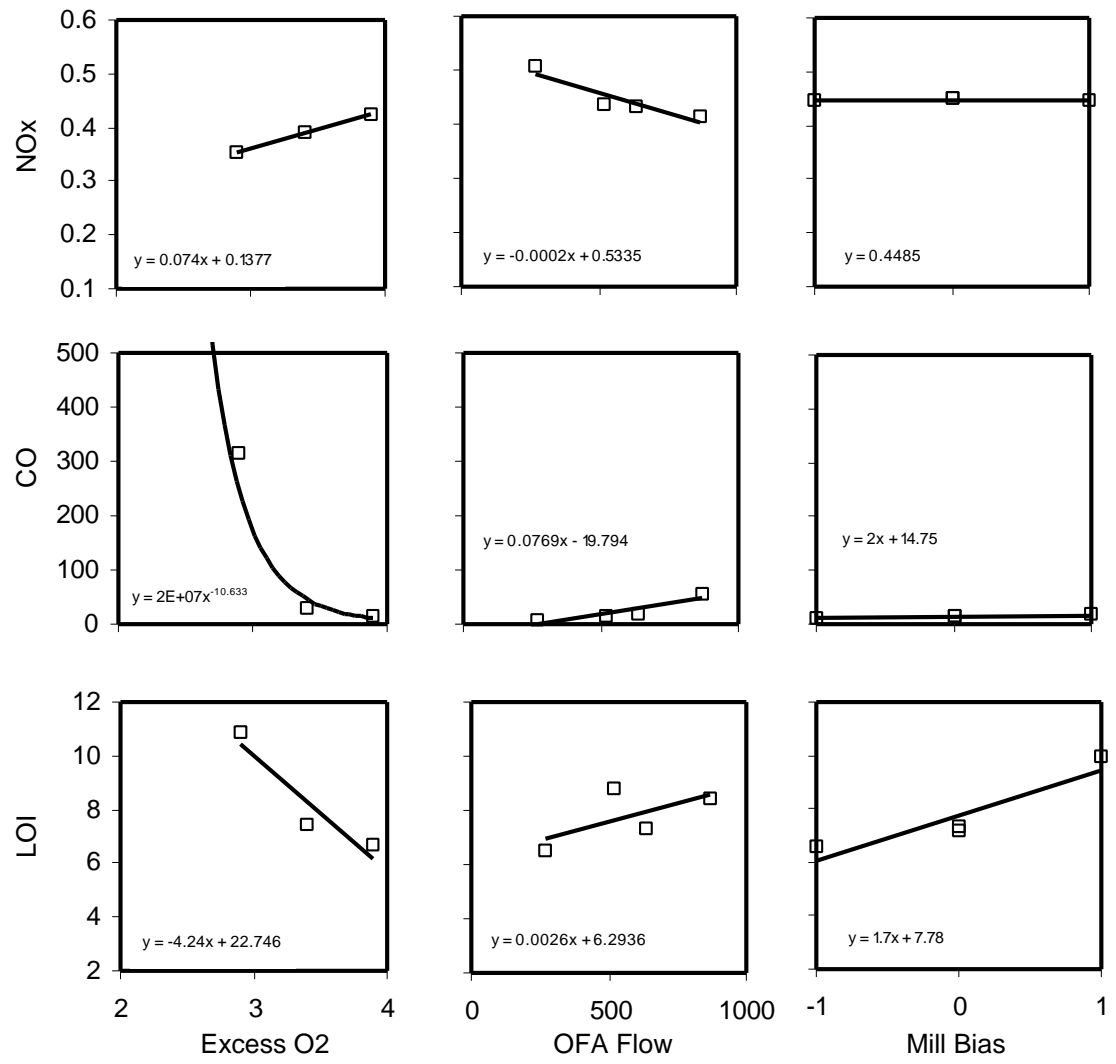

Figure 4-9 P4A / Diagnostic Tests / Response Plots at 480 MW 


\subsubsection{Performance Testing}

Performance testing was conducted from November 12 through November 16, 1994. As in prior phases of the project, performance tests were used (1) to establish baseline evaluation criteria for retrofits, (2) to quantify boiler characteristics for comparison with other phases of the program, and (3) for comparison with the results of the diagnostic trends. For each performance configuration (10- to 12- hour test day), the following types of data were obtained:

- Gaseous emission measurements of $\mathrm{NO}_{\mathrm{x}}, \mathrm{O}_{2}$, and $\mathrm{CO}$, each composed of at least 10 oneminute sample distribution manifold composite flue gas measurements.

- Two ASME PTC 4.1 boiler efficiency determinations.

- Isokinetic fly ash collection at the ESP inlet.

- Inlet fuel and air measurements (primary air distribution, secondary air distribution, coal particle size, and coal flow in each coal pipe).

The performance tests conducted during this period differed from those previously conducted for this project in that (1) fly ash resistivity, (2) flue gas $\mathrm{SO}_{3}$, and (3) furnace temperature profiles were not evaluated and coal pipe measurements were only conducted at full-load.

Five performance tests were conducted at nominal loads of 520, 400, 300, and $180 \mathrm{MW}$. At each nominal load, the coal firing rate was kept as constant as possible and generation allowed to swing slightly as affected by coal, boiler ash deposits, turbine cycle, and ambient variations. The coal feed rate to all in-service mills was kept as nearly equal as possible based upon digital control system readings. For each performance test, the desired test conditions were established and allowed to stabilize at least one hour prior to commencement of testing. Normal primary air/fuel ratios and mill outlet temperatures were maintained to the extent possible. A summary of the performance tests can be found in Table 4-3.

\subsubsection{Pulverizer Performance}

The airflow to each mill and the particle size and mass flow distributions of coal to each burner were measured. Specific determinations were:

- Coal fineness as percentage passing 50, 100, and 200 U.S. Standard Sieve designations,

- Dirty air flow and distribution between burner lines as observed by dirty air traverse,

- Fuel flow and distribution between burner lines as observed by isokinetic sample,

- Pulverizer air to fuel ratios,

- Primary air flow, as measured at the pulverizer inlet, and

- Temperature and static pressure of the fuel and air mixture in each burner line. 
Coal samples for coal fineness, fuel flow, and fuel distribution were collected utilizing an isokinetic coal sampler. Plant Hammond laboratory personnel performed coal sieving for fineness analysis. Coal fineness was ascertained during Tests 141 and 142 conducted at $520 \mathrm{MW}$. Isokinetic coal samples were not collected for fineness analysis during tests at 180, 300 , or $400 \mathrm{MW}$ since mill performance is generally poorest at higher mill loadings. Coal fineness was observed to be at or above typical levels (Table 4-4) ranging from 73 percent to 80 percent passing 200 mesh with 0.1 percent or less remaining on 50 mesh.

Generally, air and fuel balance between each pulverizer's burner lines was very good by industry standards. As shown in Figure 4-10 for Test 141, dirty air velocities were near 6000 fps with the minimum being approximately $5700 \mathrm{fps}$. Resultant airflow imbalance is shown in Figure 4-11. Fuel imbalance between the burners exceeded 10 percent of the mean during both tests on pulverizer A and during one of the two tests on pulverizers $C$ and F. Dirty air velocities were within 5 percent of the mean on all pulverizers except for pulverizer $\mathrm{F}$, which was only slightly beyond 5 percent. Coal flows and coal flow deviations are shown in Figure 4-12 and Figure 4-13, respectively.

Air and fuel flows on a per mill basis are shown in Figure 4-14 and Figure 4-15, respectively. For the tests (141 and 142), the mills were nominally balanced per control room instrumentation with a flow rate near $65 \mathrm{klb} / \mathrm{hr}$. Measured coal flow showed some imbalance with a difference of approximately $8 \mathrm{klb} / \mathrm{hr}$ between maximum and minimum flows (approximately 10 percent of nominal levels). Pulverizer air to fuel ratios were calculated by two methods. The first method calculates air to fuel ratio utilizing the fuel flow observed by the isokinetic sampler and measured dirty airflow. The second method utilizes readings obtained from the digital control system and primary airflow observed at the pulverizer inlet. Pulverizer air to fuel ratio observed by isokinetic sample ranged from 1.86 to 2.31 pounds of air per pound of coal (Figure 4-16). Pulverizer air to fuel ratio using primary air measured at the pulverizer inlet and feeder fuel flow ranged from 2.14 to 2.6 pounds of air per pound of coal. The design air/fuel ratio for these mills (all B\&W MPS 75) is 1.75 at full load, however, air flow was increased to help prevent coal layout and potential plugging in the burners.

\subsubsection{Air Flow Measurement}

Unit airflow was measured at the following locations:

Secondary air at east(A) and west (B) side main air venturi.

Total airflow leaving each of the air heaters was measured at this location. Airflow measured at this location includes airflow to the burners and to the advanced overfire air ports. Each venturi was traversed on an equal area measurement grid consisting of (48) traverse points (4 ports-12 points per port) by a three-hole Fecheimer probe. Secondary airflow was measured on all performance tests (Tests 138, 139, 140, 141 and 142). 


\section{Primary air at the pulverizer inlets.}

Primary airflow entering the pulverizer inlet (under the pulverizer's grinding table) was measured at this location. Airflow measured at this location includes combined tempering air from the forced draft fans and hot primary air from the primary air preheater. The point of measurement for primary air is prior to introduction of seal airflow. Due to this fact, primary airflow measured at this location will be lower than total airflow observed in the fuel lines. Inlet ducting of each pulverizer was traversed on an equal grid of (40) traverse points (10 ports -4 points per port) by a standard $90^{\circ}$ Pitot Tube. Primary airflow to each operating pulverizer was measured during all performance tests.

\section{Dirty airflow at the fuel lines}

Dirty airflow was measured in each of the pulverizer's four fuel lines. The total dirty airflow measured includes primary airflow (tempering and hot) and seal airflow to the pulverizer and coal feeders. Dirty airflow was measured on an equal area grid of (24) points (2 ports - 12 points per port) by a dirty air probe. Dirty air traverses were conducted to quantify pulverizer airflow and to establish isokinetic sampling rate for collection of coal samples. Dirty airflow was measured during performance tests at $520 \mathrm{MW}$ (Tests 141 and 142) and Test 138 at $400 \mathrm{MW}$. The dirty air probe was also utilized to quantify airflow through each pulverizer that was off-line during performance tests at $300 \mathrm{MW}$ and $180 \mathrm{MW}$.

\section{Overfire airflow}

Overfire airflow was measured in each of the four corners of the advanced overfire air windbox downstream of each louver damper assembly. Overfire airflow in each corner was traversed on an equal grid of (24) points (4 ports-6 points per port) by a three-hole Fecheimer probe. Overfire airflow was measured on all performance tests except for the test at $180 \mathrm{MW}$ (Test 140). During test 140 at $180 \mathrm{MW}$, duct velocities were between 0 and $80 \mathrm{fpm}$ and airflow at these velocities cannot be accurately measured using typical instrumentation. Very low duct velocities were also observed on other performance tests making repeatable and accurate test data difficult to obtain. Due to low duct velocities, a Microtector with 1/1000"w.c. resolution was required to measure the lower than typical velocities.

Overfire air flow measured by traverse was lower than that indicated by control room instrumentation. For all four windbox quadrants, actual overfire air flow was less than that indicated by plant instrumentation (Figures 4-17 through 4-20). In most instances, overfire air flow was 15 to 30 percent below that indicated by plant instrumentation. Higher absolute deviations between traverse measurements and plant instrumentation were observed at higher overfire airflows. The differences between the two measurements were not as pronounced in prior phases of the project in which this comparison was made. Although significant errors exist between the two measurements, these errors appear to be partly correctable using a linear calibration (Figure 4-21). Figure 4-22 shows the design and actual overfire flow rate as a function of load if these errors were not taken into consideration. Whether this simple correction factor would be sufficient for long-term operation is unknown. 
Total unit airflow was calculated by addition of air flow measured at the main air venturi(s), total primary air flow, seal air to the pulverizers and air flow to off-line pulverizers when applicable. Seal air to the pulverizer was ascertained by inference between dirty air flow measured in the fuel lines (which is inclusive of seal air flow) and primary air flow measured at the pulverizer inlet. Dirty airflow from the pulverizers was not measured during tests conducted at $300 \mathrm{MW}$ and 180 MW. Seal air to the pulverizers is not accounted for in total unit airflow during these tests. Table 4-5 summarizes the total unit airflow and the distribution of unit airflow during each performance test. Two or more traverses of overfire air and secondary air were conducted during each test.

Total unit airflow at full load was 6 to 10 percent higher than that observed during pervious phases. At low loads there was also increased airflow requirements. A summary of the partitioning of the combustion air between primary, secondary, and OFA airflows is shown in Figure 4-23 and Figure 4-24. This data indicates that the overfire airflow represented approximately 15 percent of the total combustion air flow at full load, decreasing to approximately 5 percent at $300 \mathrm{MW}$. Below $300 \mathrm{MW}$, the AOFA control dampers were in the closed position per FWEC recommendations.

As a result of the errors discussed above, overfire air flow, with respect to total unit air flow, was lower than observed during the Phase 3B testing phase conducted in June 1993. During Phase 3B, overfire air flow was observed to be 10 percent of total unit air flow at $300 \mathrm{MW}$ and 21 percent of total unit air flow at $480 \mathrm{MW}$. During this test, overfire air was 5 percent of total unit airflow at $300 \mathrm{MW}$ and 12 percent of total unit air flow at $520 \mathrm{MW}$. No performance tests were conducted at $480 \mathrm{MW}$ (520 MW tests were run) during this testing phase. The lower overfire air flows resulted in an increase of 13 percent to 21 percent of the total unit air flow delivered to the burners, as compared to the Phase 3B tests. Based on the perceived relatively large potential for measurement errors in the OFA measurement system but more so on equipment reliability problems, it was decided to forego the use of the OFA measurement in favor of the OFA control damper position for use in the on-line optimization strategies. 
Table 4-3 P4A / Performance Tests Conducted

\begin{tabular}{|c|c|c|c|c|c|c|c|c|c|c|}
\hline Test & Date & $\begin{array}{l}\text { Load } \\
\text { MW }\end{array}$ & $\begin{array}{l}\text { MOOS } \\
\text { Pattern }\end{array}$ & $\begin{array}{c}\text { OFA } \\
\text { Flow } \\
\text { (KPPH) }\end{array}$ & $\begin{array}{c}\text { Econ } \mathrm{O}_{2} \\
\text { Dry } \\
\%\end{array}$ & $\begin{array}{c}\text { Stack } \mathrm{O}_{2} \\
\text { Dry } \\
\%\end{array}$ & $\begin{array}{c}\mathrm{NOx} \\
\mathrm{lb} / \mathrm{MBtu}\end{array}$ & $\begin{array}{c}\mathrm{CO} \\
\mathrm{ppm}\end{array}$ & $\begin{array}{c}\text { Fly Ash } \\
\text { LOI } \\
\%\end{array}$ & $\begin{array}{c}\text { Fly Ash } \\
\text { Carbon } \\
\%\end{array}$ \\
\hline 138 & $11 / 12 / 94$ & 400 & $B$ & 293 & 3.9 & 5.5 & 0.38 & 49 & 8.4 & 7.7 \\
\hline 139 & $11 / 13 / 94$ & 300 & $\mathrm{~B}, \mathrm{E}$ & 90 & 4.8 & 6.9 & 0.34 & 51 & 8.1 & 7.1 \\
\hline 140 & $11 / 13 / 94$ & 180 & $B, D, E$ & 0 & 5.3 & 7.2 & 0.33 & 9 & 3.6 & 3.3 \\
\hline 141 & $11 / 15 / 94$ & 520 & None & 791 & 3.6 & 5.4 & 0.43 & 61 & 8.2 & 7.2 \\
\hline 142 & $11 / 16 / 94$ & 520 & None & 786 & 3.5 & 5.4 & 0.45 & 46 & 8.1 & 6.9 \\
\hline
\end{tabular}

Table 4-4 P4A / Performance Tests / Mill Grinding Performance

\begin{tabular}{c|c|c|c|c}
\hline \multicolumn{2}{c}{ Test 141 } & \multicolumn{2}{c}{ Test 142 } \\
\hline & \%Passing 200 Mesh & $\begin{array}{c}\text { \% Rem. on 50 } \\
\text { Mesh }\end{array}$ & \% Passing 200 Mesh & \% Rem. on 50 Mesh \\
\hline A & $74.48 \%$ & $0.10 \%$ & $73.69 \%$ & $0.10 \%$ \\
B & $77.38 \%$ & $0.04 \%$ & $80.03 \%$ & $0.09 \%$ \\
C & $73.30 \%$ & $0.11 \%$ & $76.49 \%$ & $0.07 \%$ \\
D & $76.76 \%$ & $0.03 \%$ & $76.73 \%$ & $0.02 \%$ \\
E & $73.48 \%$ & $0.05 \%$ & $75.41 \%$ & $0.05 \%$ \\
F & $74.87 \%$ & $0.12 \%$ & $76.58 \%$ & $0.11 \%$ \\
Average & $75.05 \%$ & $0.08 \%$ & $76.49 \%$ & $0.07 \%$ \\
\hline
\end{tabular}




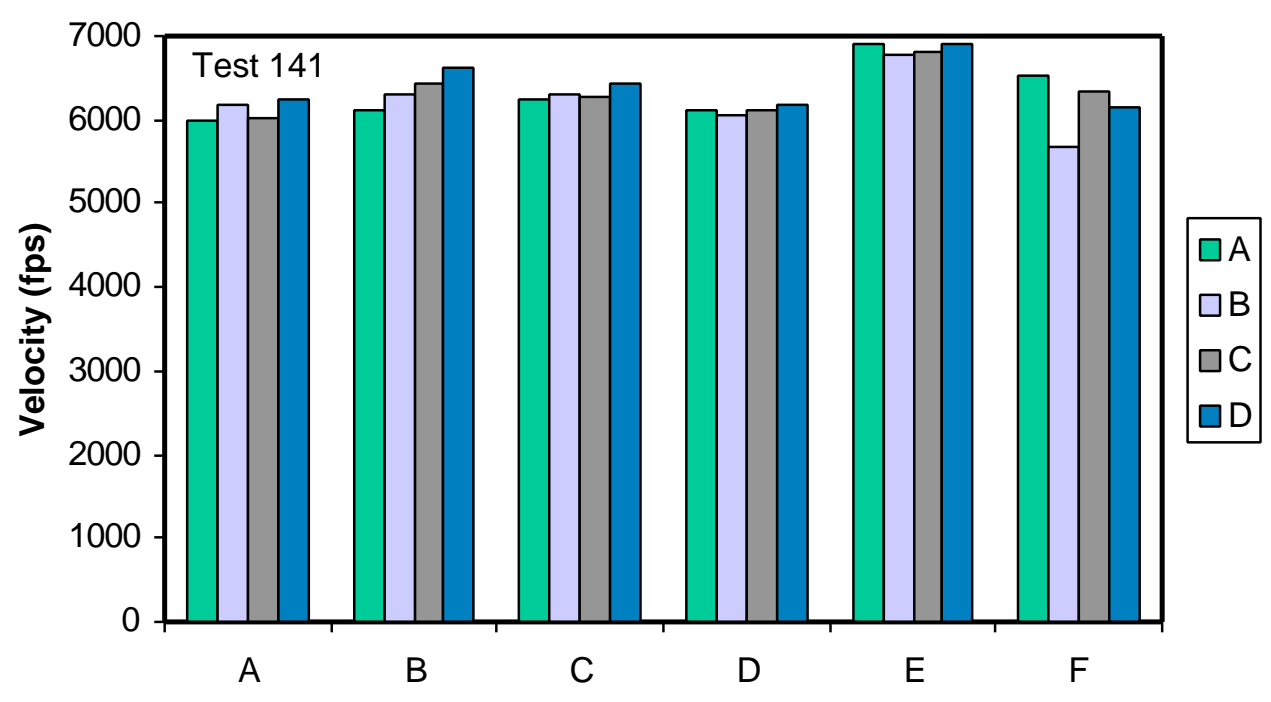

Figure 4-10 P4A / Measured Dirty Air Velocity by Mill and Coal Pipe

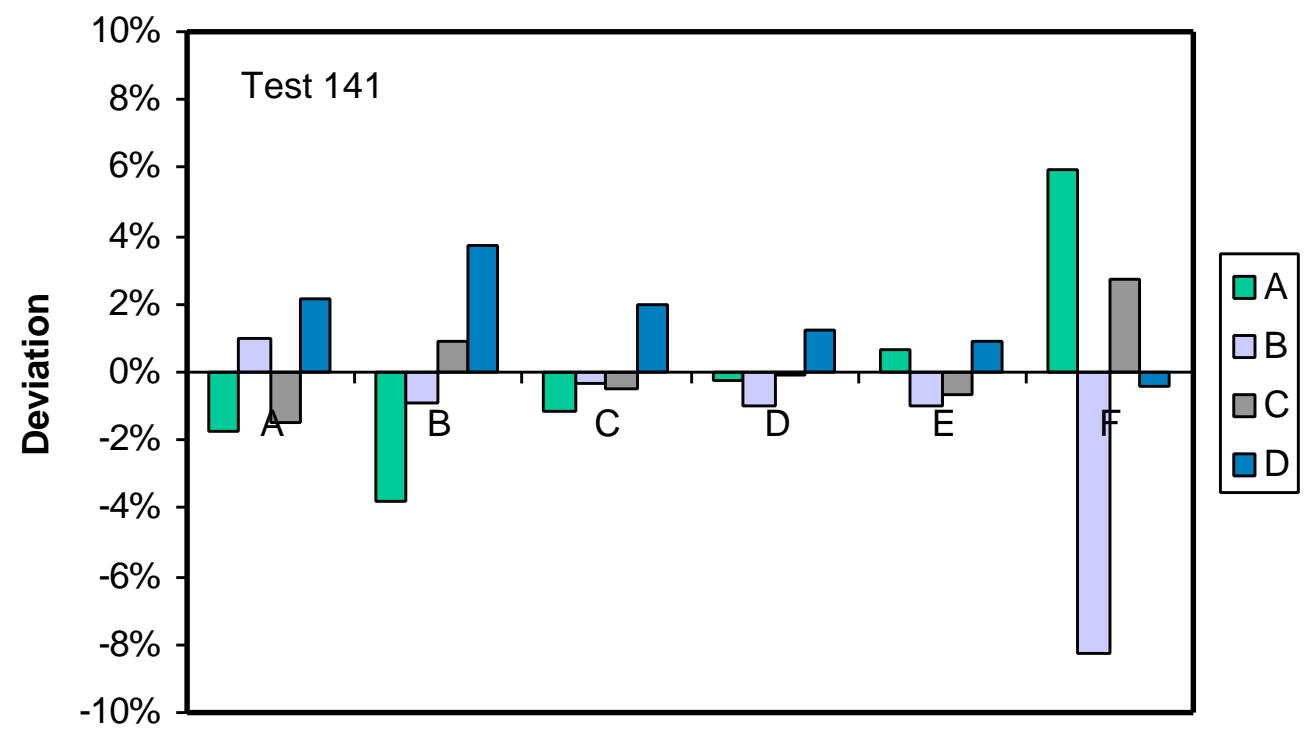

Figure 4-11 P4A / Deviation of Coal Pipe Dirty Air Velocity from Mill Average 


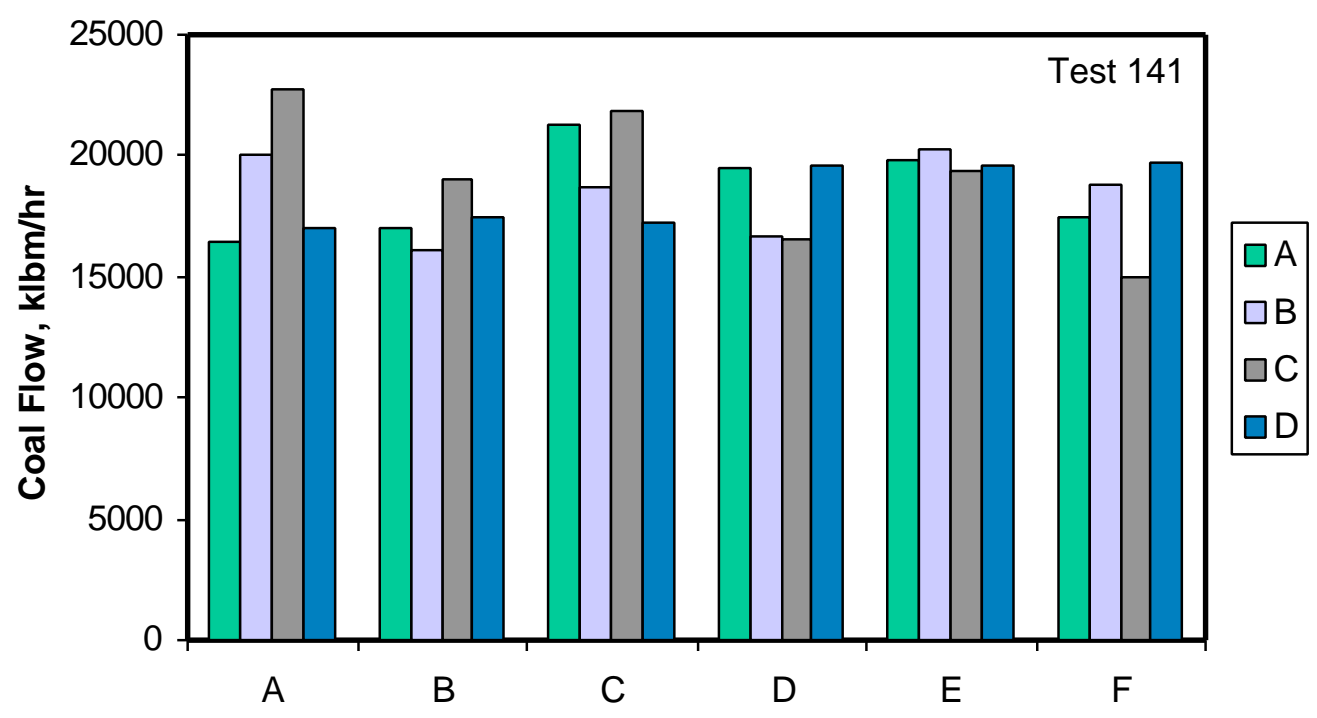

Figure 4-12 P4A / Measured Coal Flows by Mill and Coal Flow

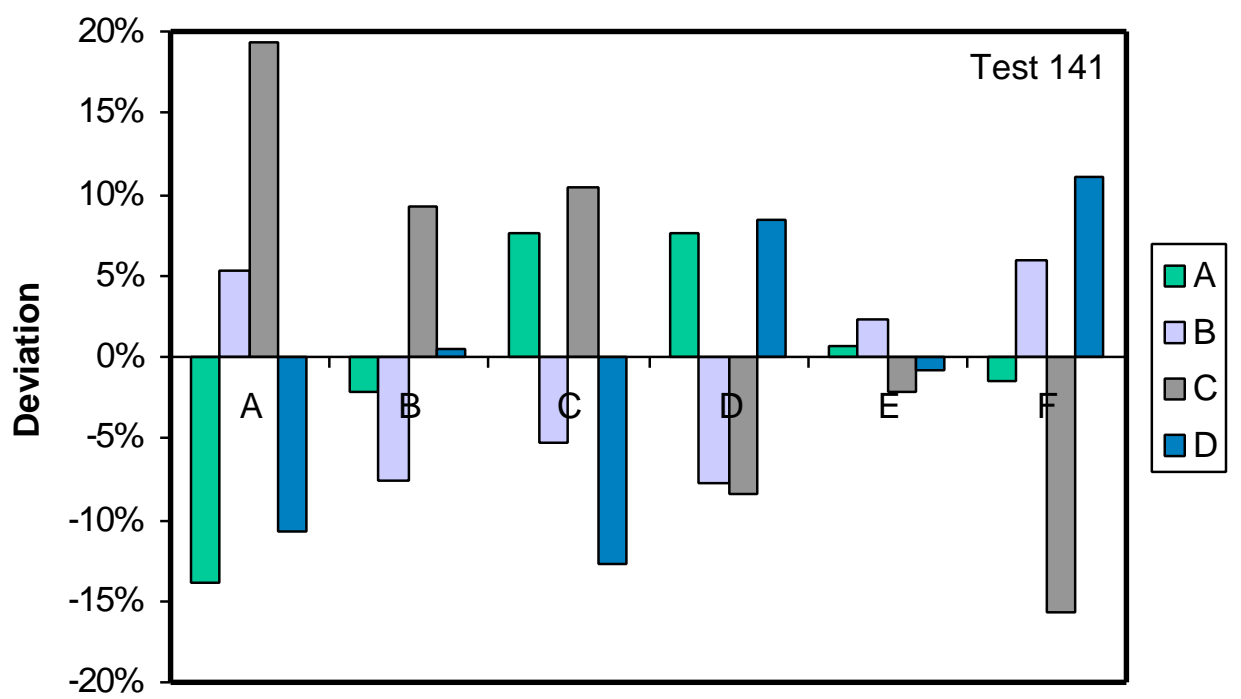

Figure 4-13 P4A / Deviation of Coal Pipe Flow from Mill Average Flow 


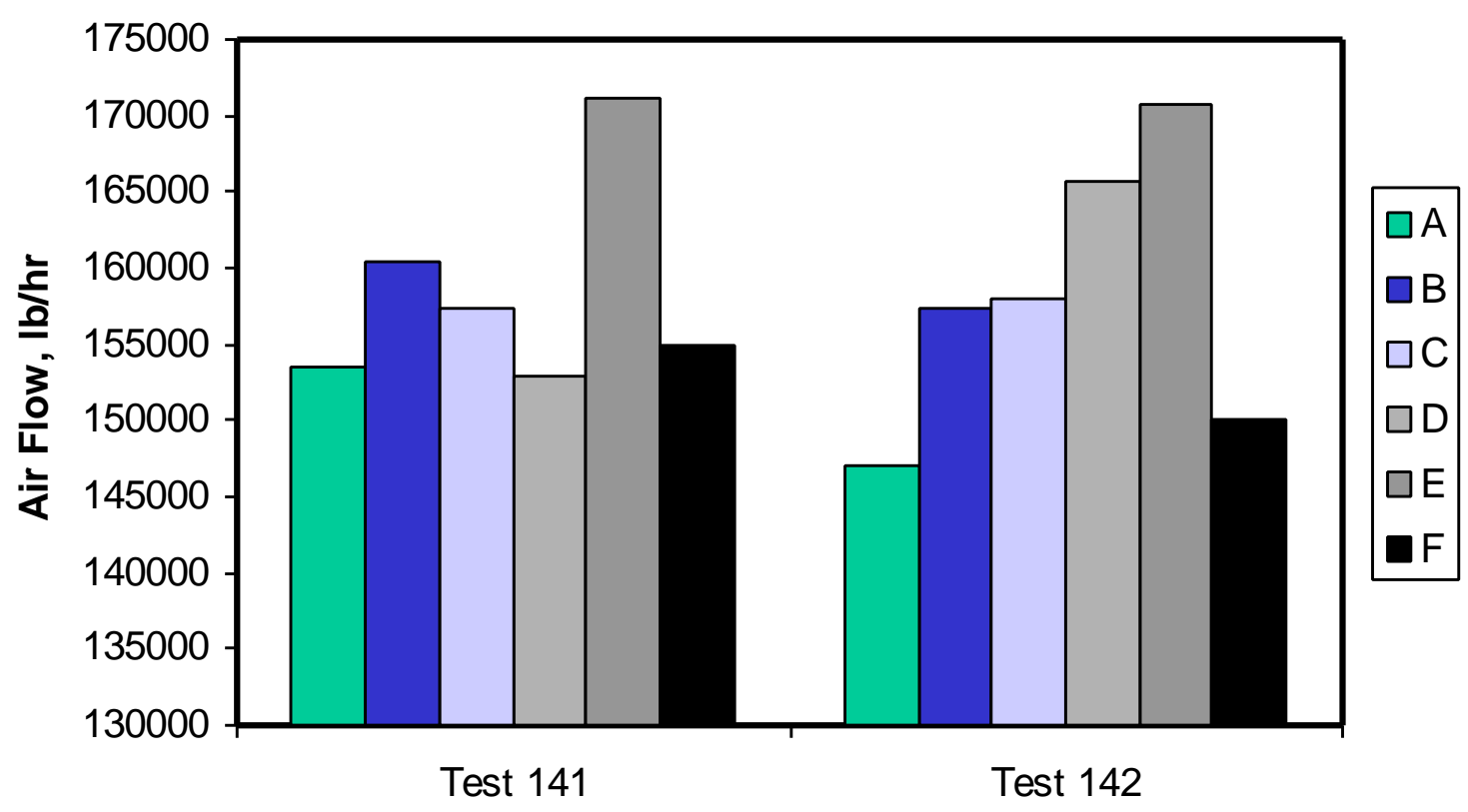

Figure 4-14 P4A / Primary Air Distribution

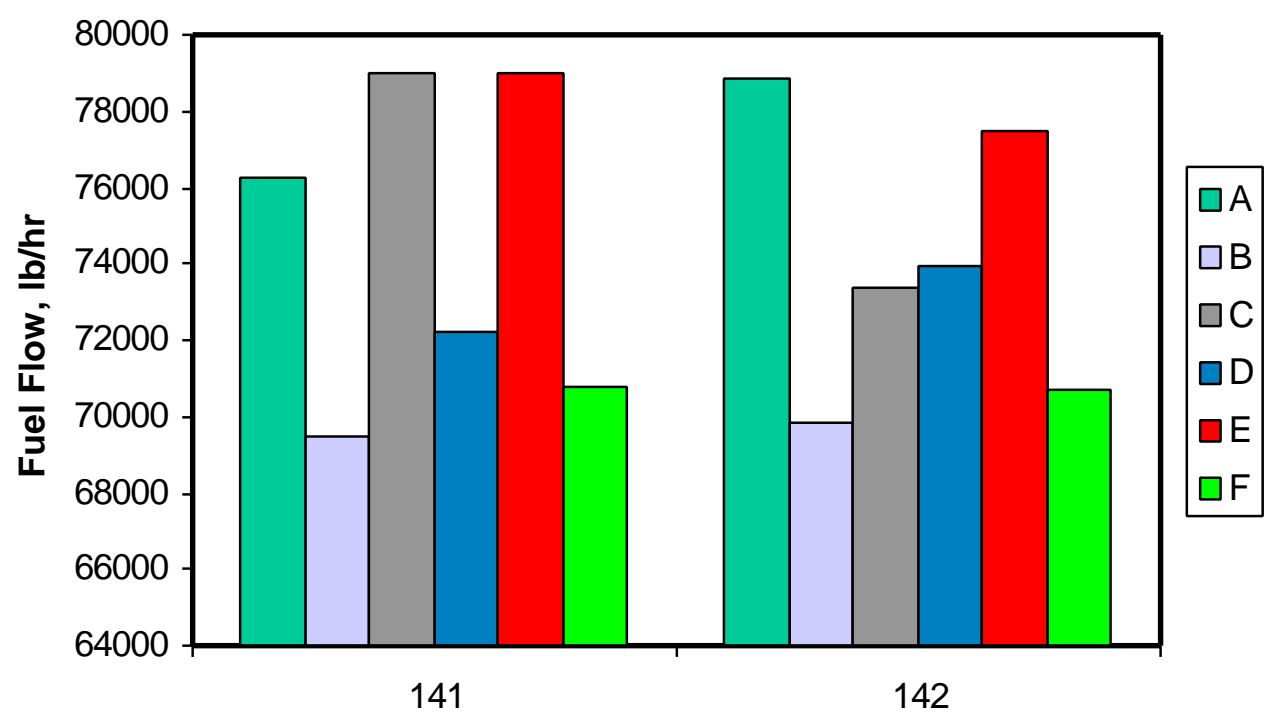

Figure 4-15 P4A / Pulverizer Fuel Distribution 


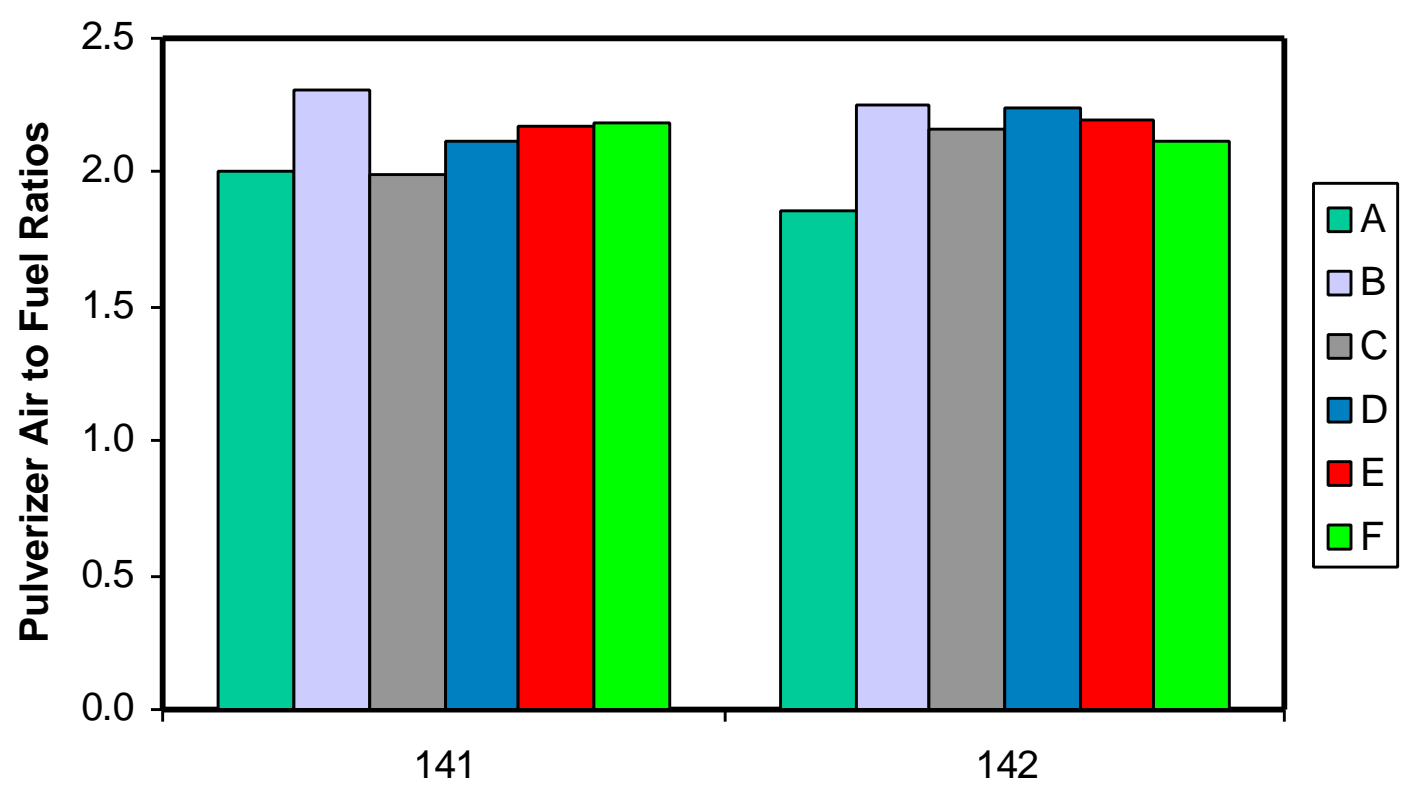

Figure 4-16 P4A / Pulverizer Air to Fuel Ratio

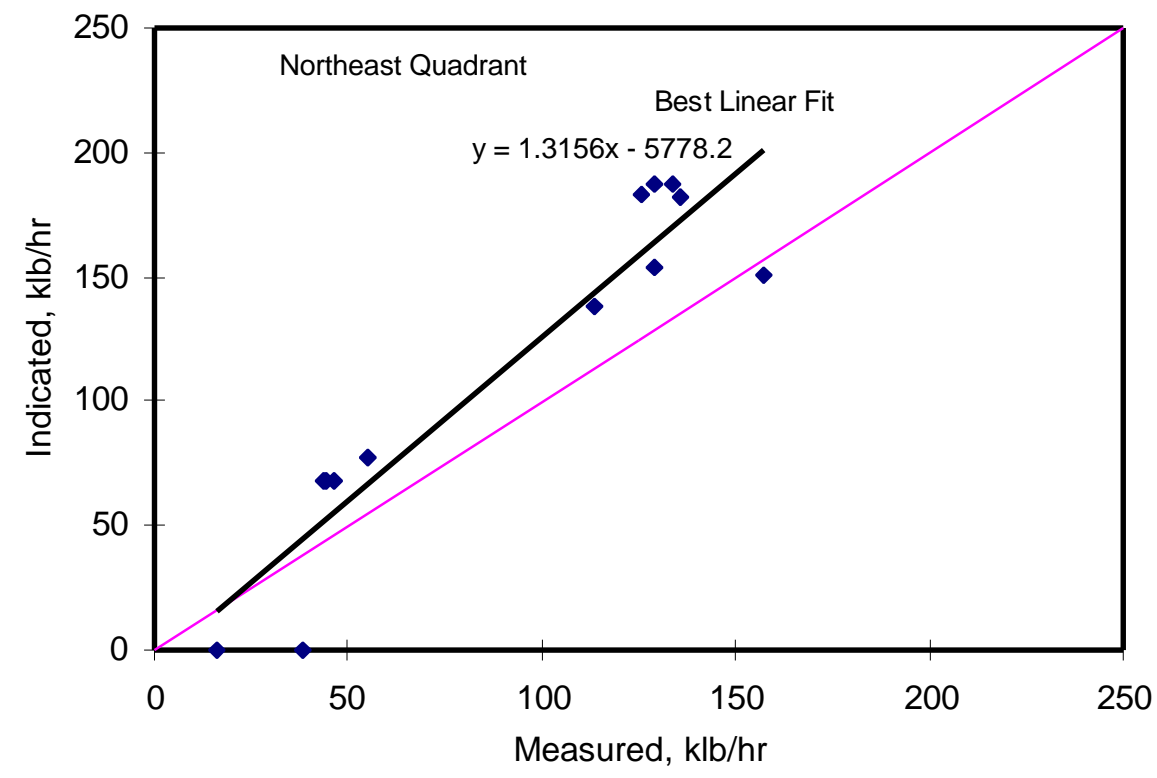

Figure 4-17 P4A / Indicated vs. Measured OFA Flow - Northeast Quadrant 


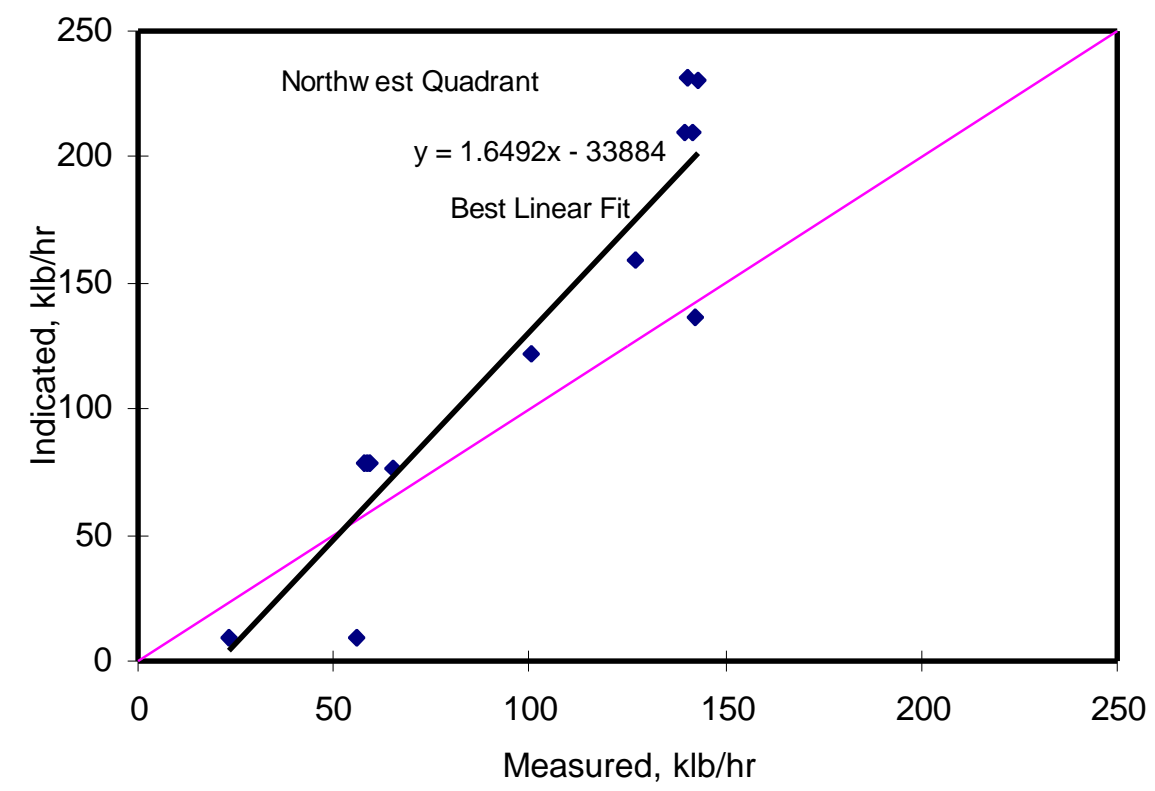

Figure 4-18 P4A / Indicated vs. Measured OFA Flow - Northwest Quadrant

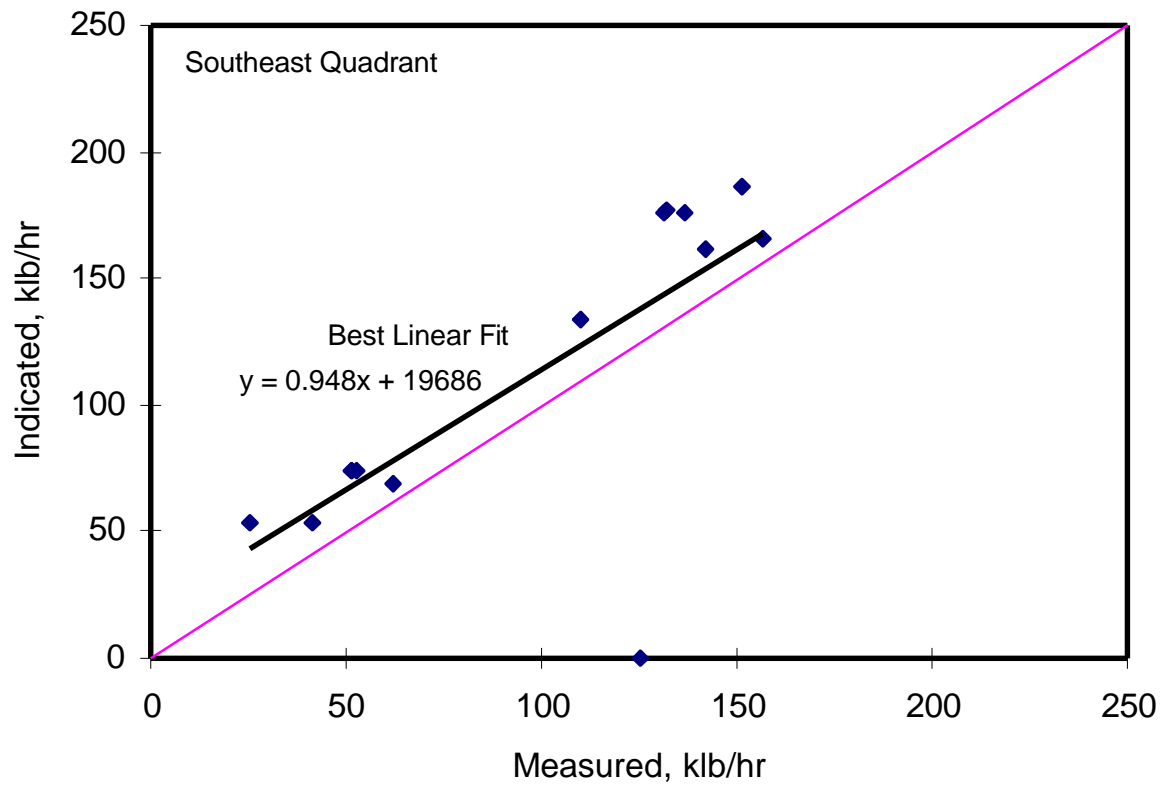

Figure 4-19 P4A / Indicated vs. Measured OFA Flow - Southeast Quadrant 


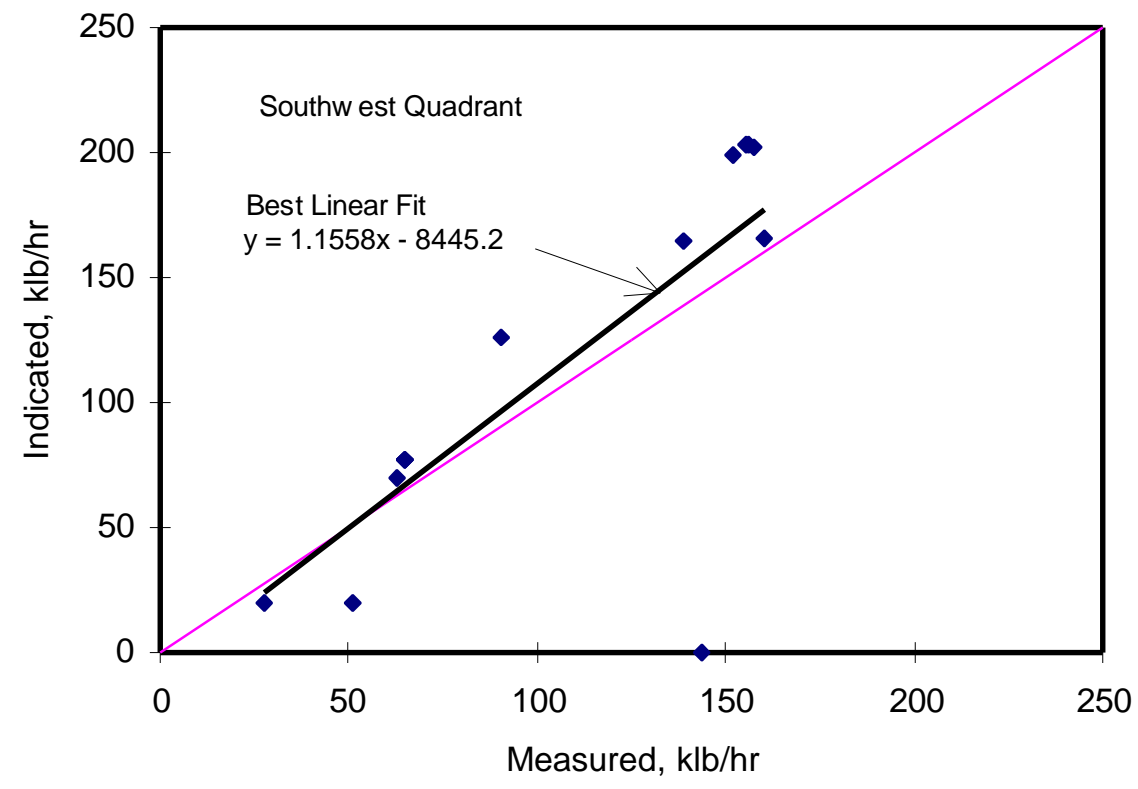

Figure 4-20 P4A / Indicated vs. Measured OFA Flow - Southwest Quadrant

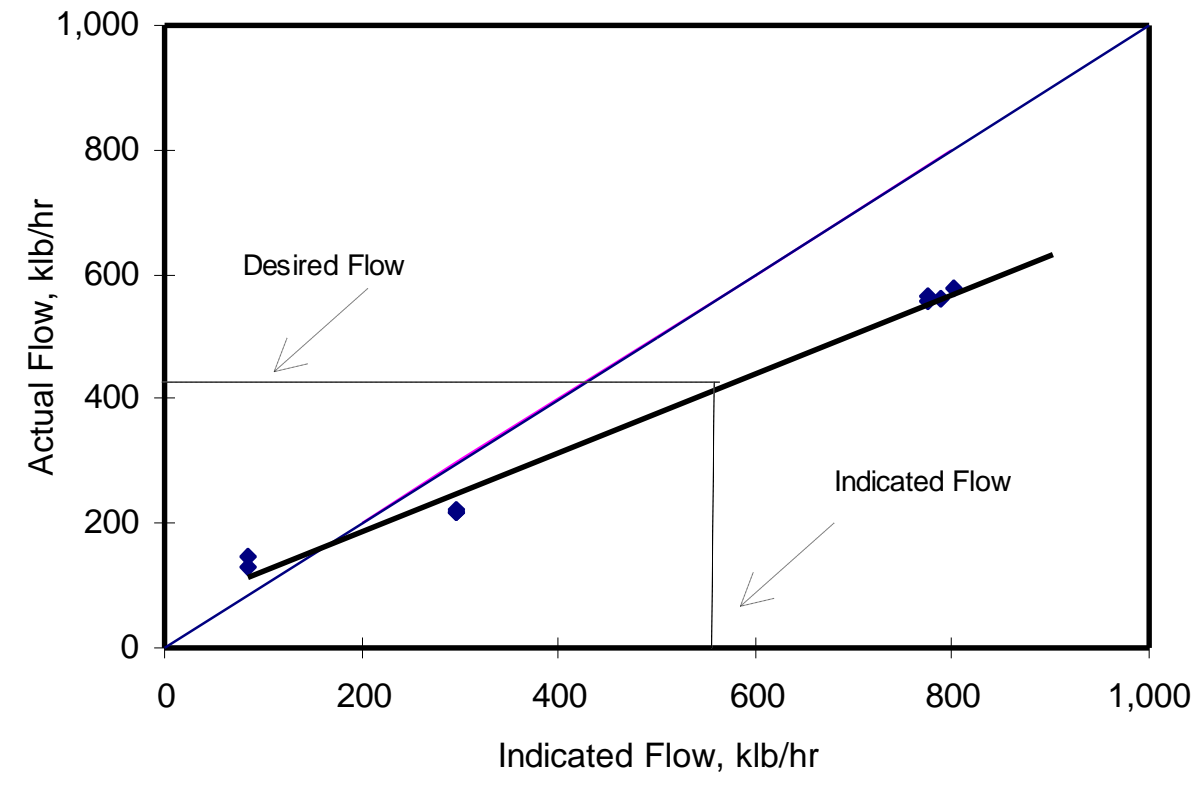

Figure 4-21 P4A / Actual vs. Indicated Overfire Air Flow 


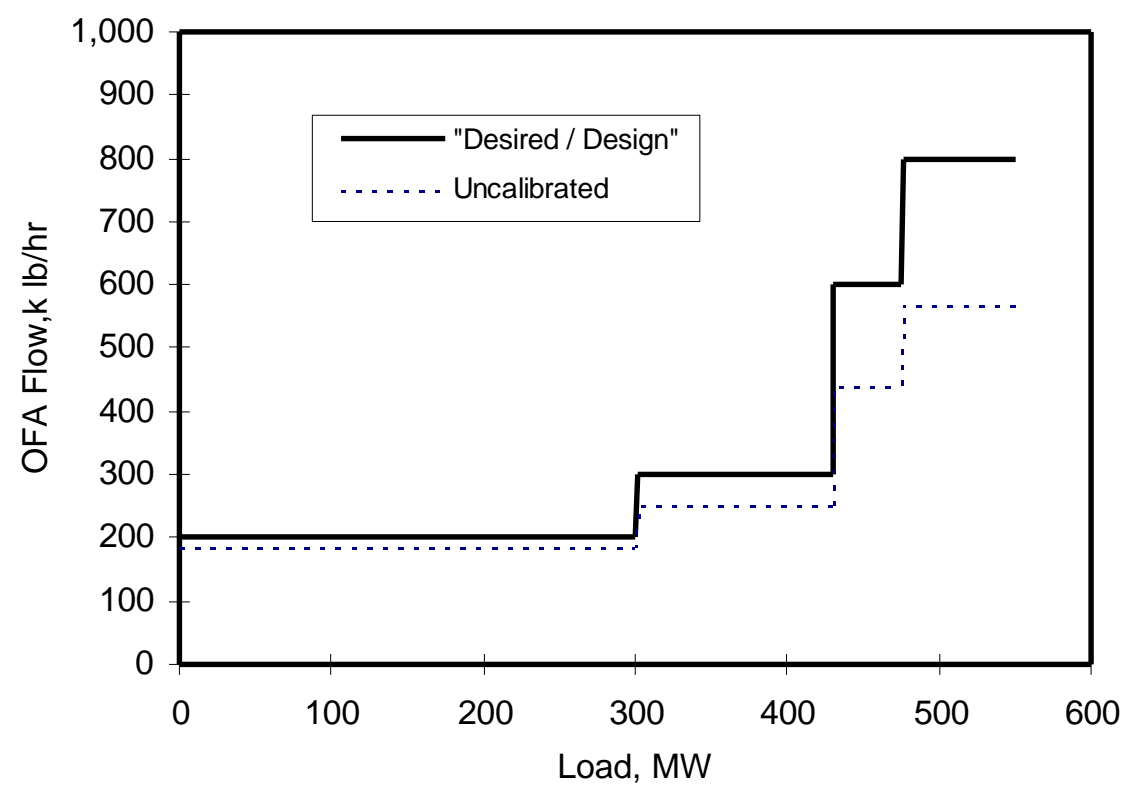

Figure 4-22 P4A / Error in OFA Flow

Table 4-5 P4A / Performance Tests / Combustion Air Flow

\begin{tabular}{lcccccc}
\hline Test Number & $\rightarrow$ & 138 & 139 & 140 & 141 & 142 \\
Unit Load (MW) & $\rightarrow$ & $400 \mathrm{MW}$ & $300 \mathrm{MW}$ & $180 \mathrm{MW}$ & $520 \mathrm{MW}$ & $520 \mathrm{MW}$ \\
\hline Pulverizer Primary Air (lb/hr) & & 734,888 & 556,118 & 383,764 & 902,090 & 899,812 \\
Pulverizer Seal Air (lb/hr) & & 72,734 & $\mathrm{Na}$ & $\mathrm{Na}$ & 47,990 & 49,208 \\
Secondary Air @ Venturi(s) ${ }^{*}(\mathrm{lb} / \mathrm{hr})$ & & $2,595,371$ & $2,073,794$ & $1,169,547$ & $3,648,928$ & $3,553,601$ \\
Overfire Air * (lb/hr) & 220,179 & 139,312 & $\mathrm{Na}$ & 569,025 & 561,753 \\
Secondary Air to Burners (lb/hr) & $2,375,192$ & $1,934,482$ & $\mathrm{Na}$ & $3,079,903$ & $2,991,848$ \\
Air to Off-line Mills (lb/hr) & $\mathrm{Na}$ & 204,432 & 377,199 & 0 & 0 \\
Total Unit Air (TUA) (lb/hr) & & $3,402,993$ & $2,834,344$ & $1,930,510$ & $4,599,008$ & $4,502,621$ \\
\hline
\end{tabular}




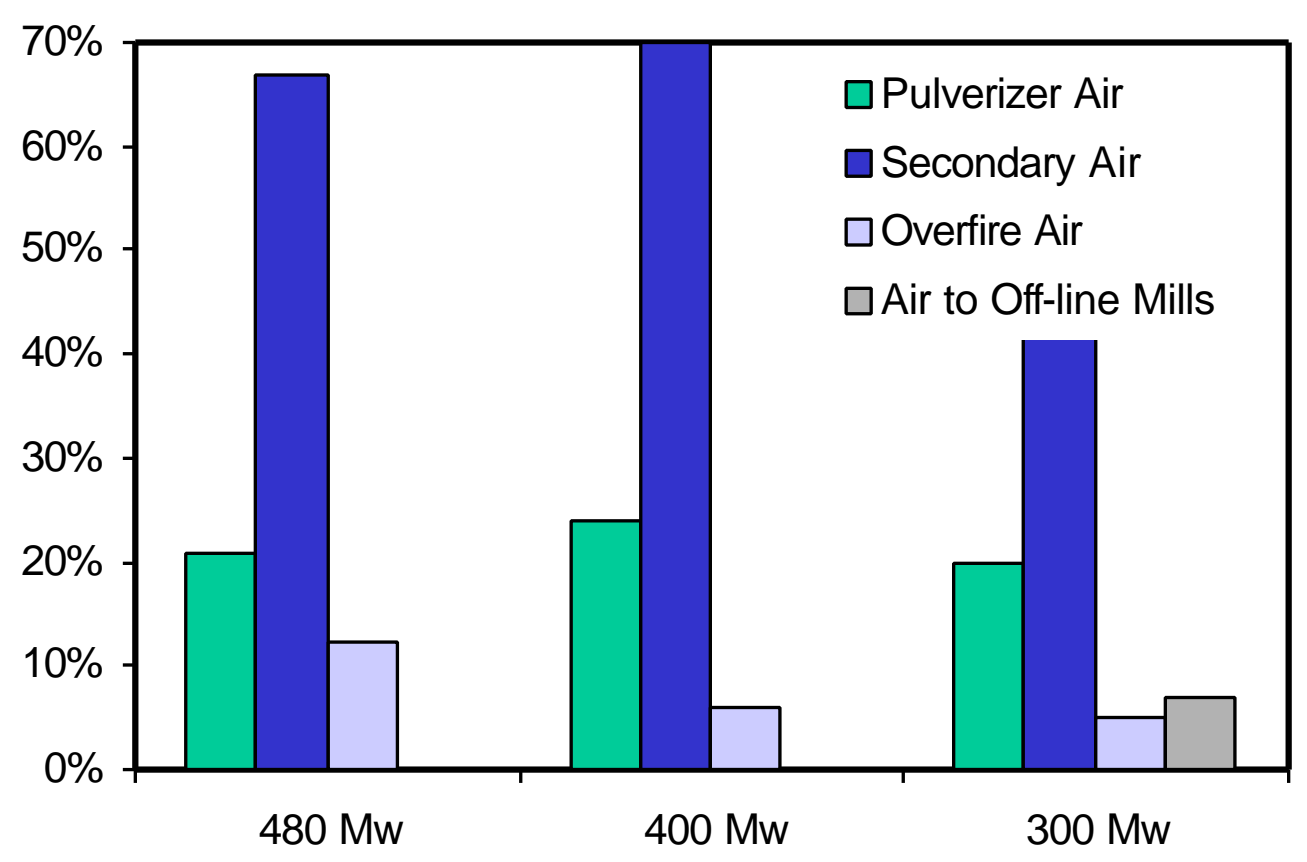

Figure 4-23 P4A / Distribution of Unit Air Flow by Load

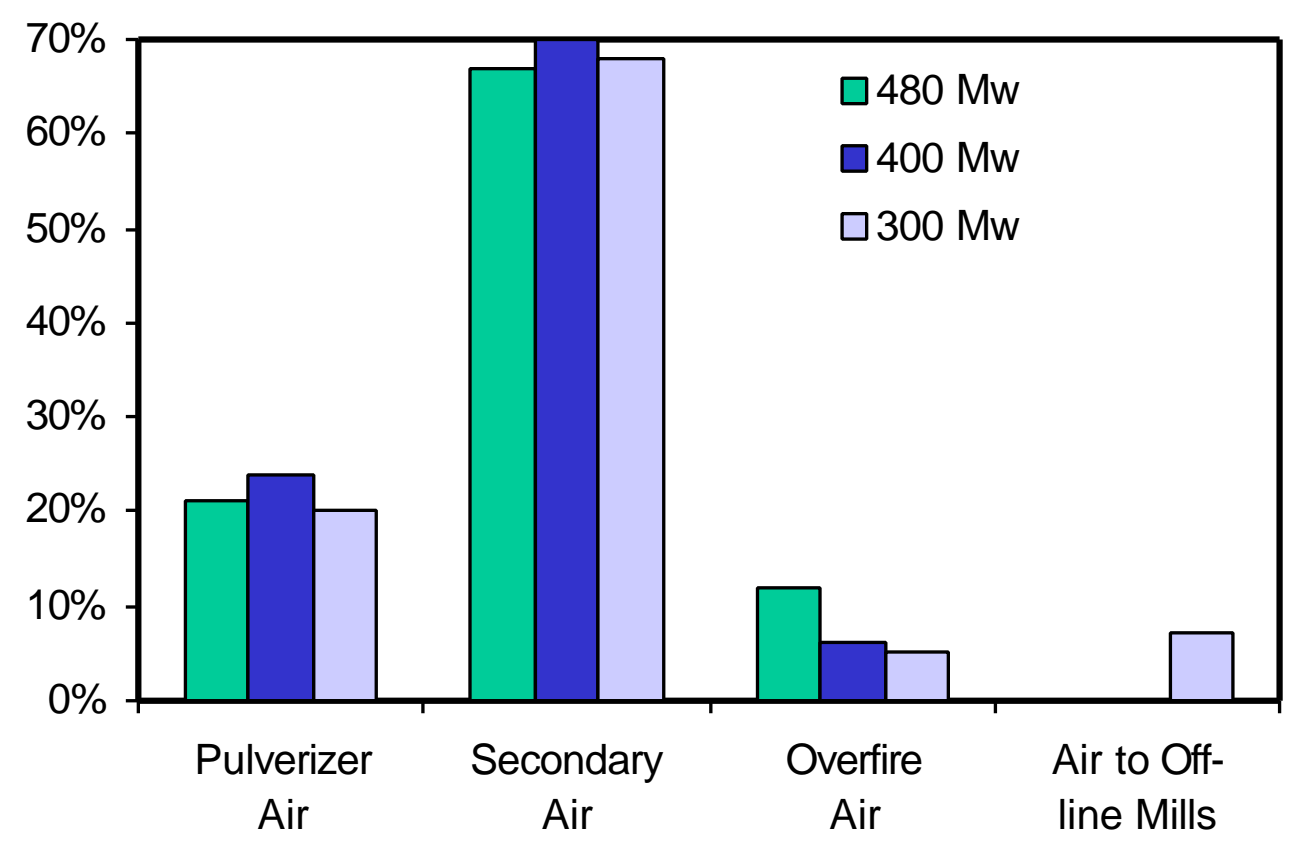

Figure 4-24 P4A / Distribution of Unit Air Flow by Component 


\subsubsection{NOx Emissions}

$\mathrm{NO}_{\mathrm{x}}$ emissions observed during the performance tests were comparable to those obtained during Phase 3B for all load levels (Figure 4-25). At $520 \mathrm{MW}, \mathrm{NO}_{\mathrm{x}}$ emissions were near $0.44 \mathrm{lb} / \mathrm{Btu}$, reducing to $0.33 \mathrm{lb} / \mathrm{MBtu}$ at the $180 \mathrm{MW}$ level. At full-load, $\mathrm{NO}_{\mathrm{x}}$ emission levels are between 30 to 35 percent of baseline levels.

\subsubsection{Fly Ash Loss-on-Ignition}

Fly ash loss-on-ignition levels were also similar to those observed during Phase 3B with full-load values of near 8 percent (Figure 4-26). Some decrease in LOI might have been expected since Phase 3B overall mill performance has improved as a result of the installation of two mills during the outage between Phases 3B and 4A. The cause for this lack of improvement in LOI is at this time unknown. Potential factors include:

- The mills that were replaced were not major contributors to LOI during Phase 3B,

- Changes in combustion air distribution, or

- Measurement error. 


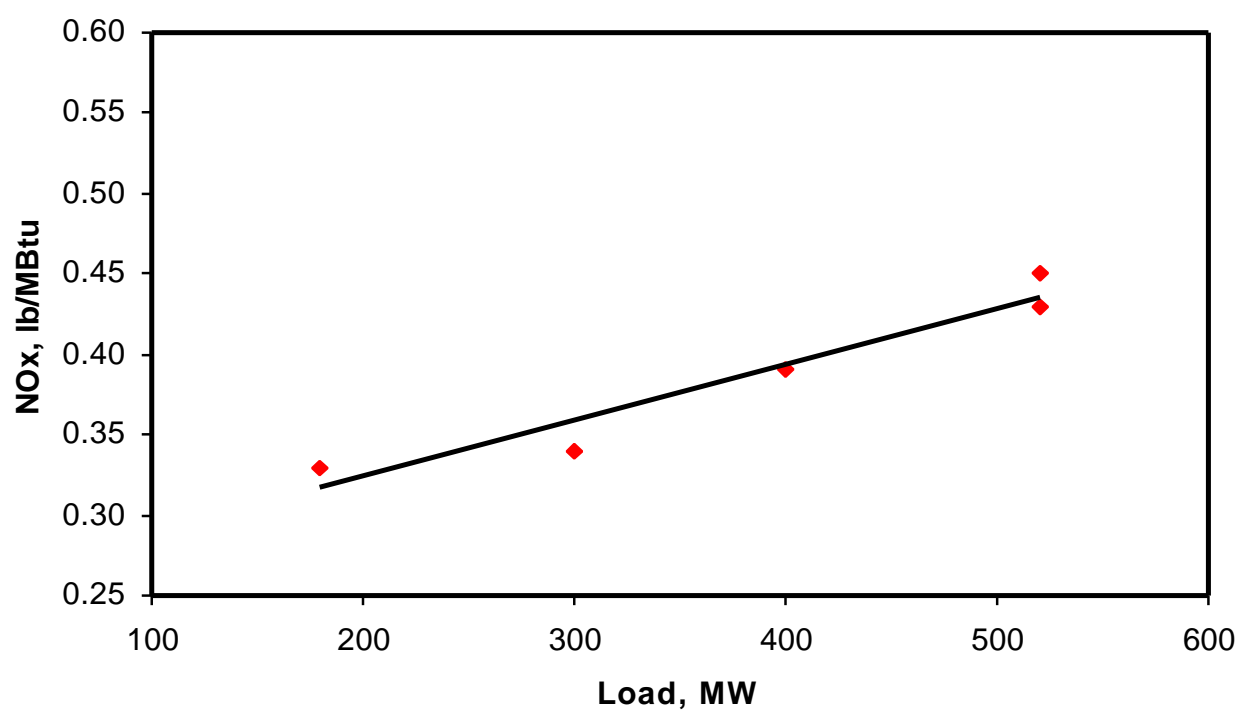

Figure 4-25 P4A / Performance Tests / NOx Emissions

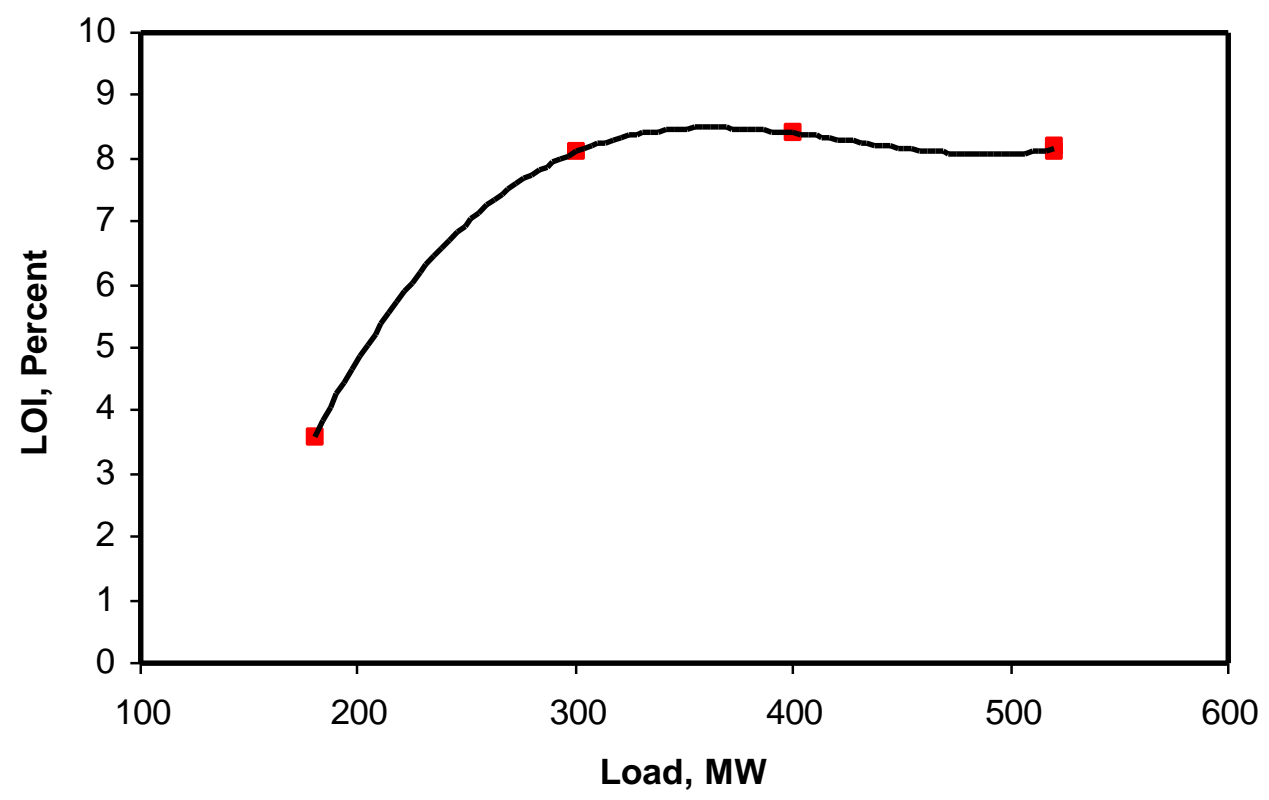

Figure 4-26 P4A / Performance Tests / Fly Ash LOI 


\subsubsection{Coal Properties}

As can be seen from Table 4-6, the coal utilized during the Phase 4A performance tests had similar characteristics to that used during Phase $3 \mathrm{~B}$ and prior phases. The individual analysis can be found in Appendix A.

Table 4-6 P4A / Performance Tests / Coal Properties

\begin{tabular}{|c|c|c|c|c|c|c|c|c|c|}
\hline \multirow[b]{3}{*}{ Characteristic } & \multirow[b]{3}{*}{ Units } & \multicolumn{8}{|c|}{ Phase } \\
\hline & & \multirow[b]{2}{*}{1} & \multirow[b]{2}{*}{2} & \multirow[b]{2}{*}{$3 A$} & \multirow[b]{2}{*}{$3 B$} & \multicolumn{4}{|c|}{$4 \mathrm{~A}$} \\
\hline & & & & & & Mean & Max & Min & Std.Dev. \\
\hline Moisture & $\%$ by Wt. & 4.3 & 5.6 & 5.7 & 6.4 & 6.0 & 6.8 & 4.7 & 0.70 \\
\hline Carbon & $\%$ by Wt. & 72.4 & 73.2 & 72.5 & 70.8 & 71.8 & 73.3 & 70.4 & 0.85 \\
\hline Hydrogen & \% by Wt. & 4.7 & 4.7 & 4.7 & 4.7 & 4.7 & 4.7 & 4.6 & 0.05 \\
\hline Nitrogen & $\%$ by Wt. & 1.4 & 1.4 & 1.4 & 1.4 & 1.3 & 1.4 & 1.3 & 0.02 \\
\hline Chlorine & \% by Wt. & 0.0 & 0.1 & 0.0 & 0.0 & 0.0 & 0.1 & 0.0 & 0.01 \\
\hline Sulfur & $\%$ by Wt. & 1.7 & 1.6 & 1.5 & 1.7 & 1.3 & 1.4 & 1.3 & 0.04 \\
\hline Ash & $\%$ by Wt. & 9.8 & 8.9 & 9.4 & 9.5 & 10.1 & 10.7 & 9.5 & 0.31 \\
\hline \multirow[t]{2}{*}{ Oxygen } & \% by Wt. & 5.7 & 4.6 & 4.7 & 5.6 & 4.8 & 5.4 & 4.4 & 0.30 \\
\hline & TOTAL & 100.0 & 100.0 & 100.0 & 100.1 & 100.0 & 100.1 & 100.0 & 0.01 \\
\hline $\mathrm{HHV}$ & BTU/lb & 12921 & 13000 & 12869 & 12494 & 12599 & 12855 & 12416 & 137 \\
\hline Volatile & $\%$ by Wt. & 33.5 & 33.27 & 32.56 & 33.6 & 32.0 & 32.5 & 31.4 & 0.4 \\
\hline Fixed C & $\%$ by Wt. & 52.7 & 52.22 & 52.29 & 50.4 & 51.9 & 52.9 & 51.1 & 0.4 \\
\hline Fixed C/Volatile & & 1.57 & 1.57 & 1.61 & 1.50 & 1.62 & 1.65 & 1.60 & 0.0 \\
\hline Oxygen/Nitrogen & & 3.95 & 3.20 & 3.41 & 4.01 & 3.65 & 4.11 & 3.27 & 0.3 \\
\hline
\end{tabular}




\subsubsection{Long-Term Testing}

As in prior phases, the long-term-testing consisted of continuous measurement of operating parameters while the unit operated under normal load dispatch. Long-term data was collected from July 12, 1994 through November 17, 1994. During this period, fifty-one (51) days of valid long-term data were collected composed of 1360 hourly averages and 16,572 five-minute averages. As before, the focus of the analysis was:

- Characterization of the daily load and NOx emissions.

- Characterization of the NOx emissions as a function of the $\mathrm{O}_{2}$ and mill patterns.

- Determination of the thirty-day rolling average NOx emissions.

- Determination of the achievable NOx emission level based upon valid days of CEMS data.

- Comparison of long-term results to short-term results.

The following paragraphs describe the major results of these analyses.

From this long-term data, the daily average load and NOx were determined (Figure 4-27). As shown, daily average load varied considerably during this test period, ranging from approximately $150 \mathrm{MW}$ to $450 \mathrm{MW}$. Daily average NOx emissions ranged from approximately $0.35 \mathrm{lb} / \mathrm{MBtu}$ to $0.53 \mathrm{lb} / \mathrm{MBtu}$, showing a general downward trend over this period. Diurnal characteristics for load and NOx are shown in Figure 4-28. For this period, the unit operated above $300 \mathrm{MW}$ approximately 13 hours. NOx emissions generally followed the load characteristic with maximum emissions corresponding to maximum load.

For the parametric analysis, all of the valid five-minute data were used. The five-minute data were analyzed to determine the overall relationship between NOx and load. Since the data was obtained while the unit was under normal dispatch, the data represents the long-term characteristics. The NOx versus load relationship was determined by first segregating the five minute average load data into $20 \mathrm{MW}$ wide load ranges. The population for each load range, as well as the lower five percentile and upper ninety-five percentile are shown for both load and NOx emission values. Figure 4-29 through Figure 4-32 illustrates the excess oxygen, NOx, CO, and SOx versus load trend for these data. The excess oxygen downstream of the air heater shows the same trend as that for the other phases of the program -- increasing excess oxygen with decreasing load. Contrary to what has been seen in prior phases, NOx, in general, increased with increasing load. $\mathrm{CO}$ emissions remained on average low during this period with maximum mean emissions of near $15 \mathrm{ppm}$. As would be expected, SOx emissions were independent of load. 

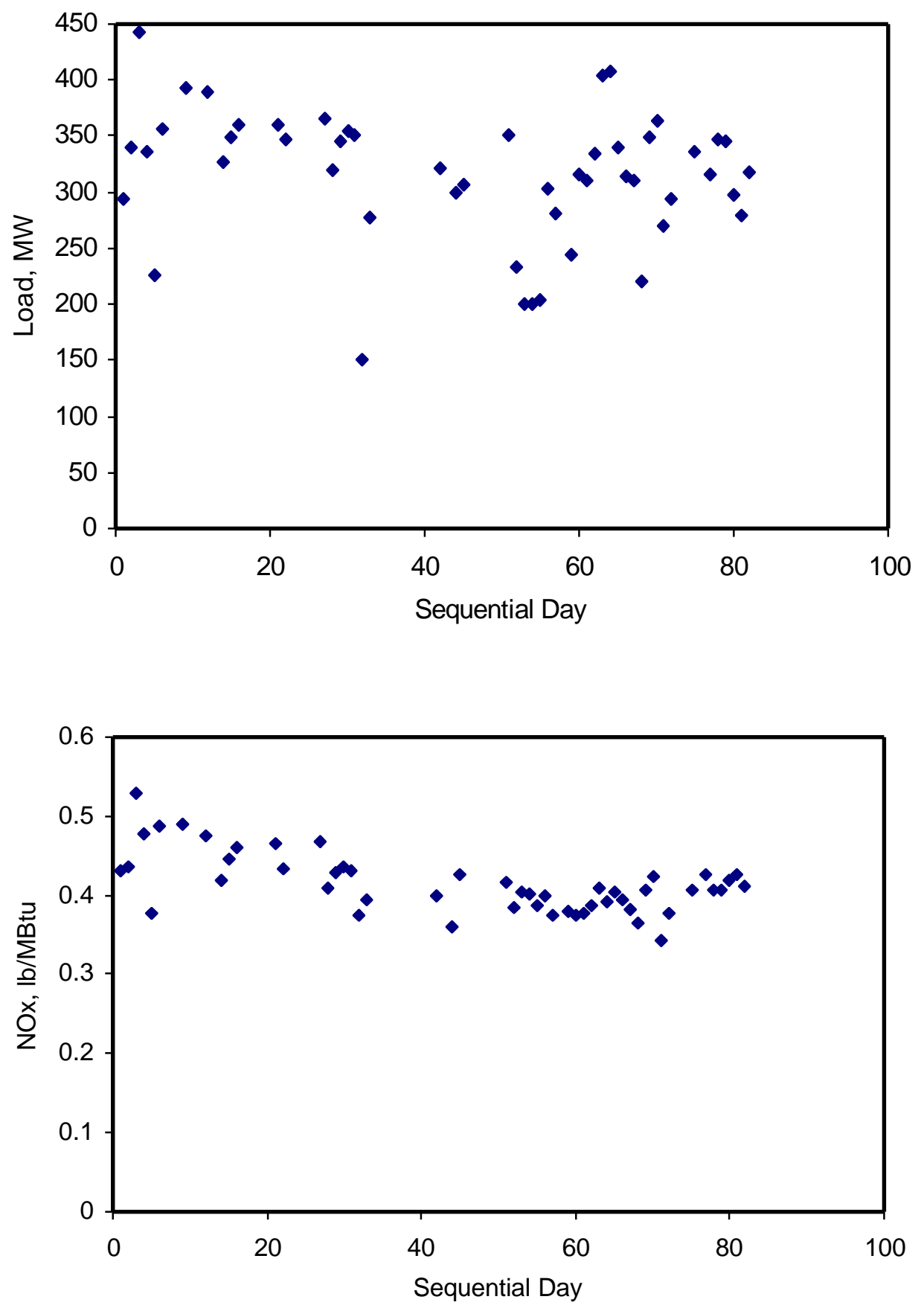

Figure 4-27 P4A / Long-Term Daily Average Characteristics 

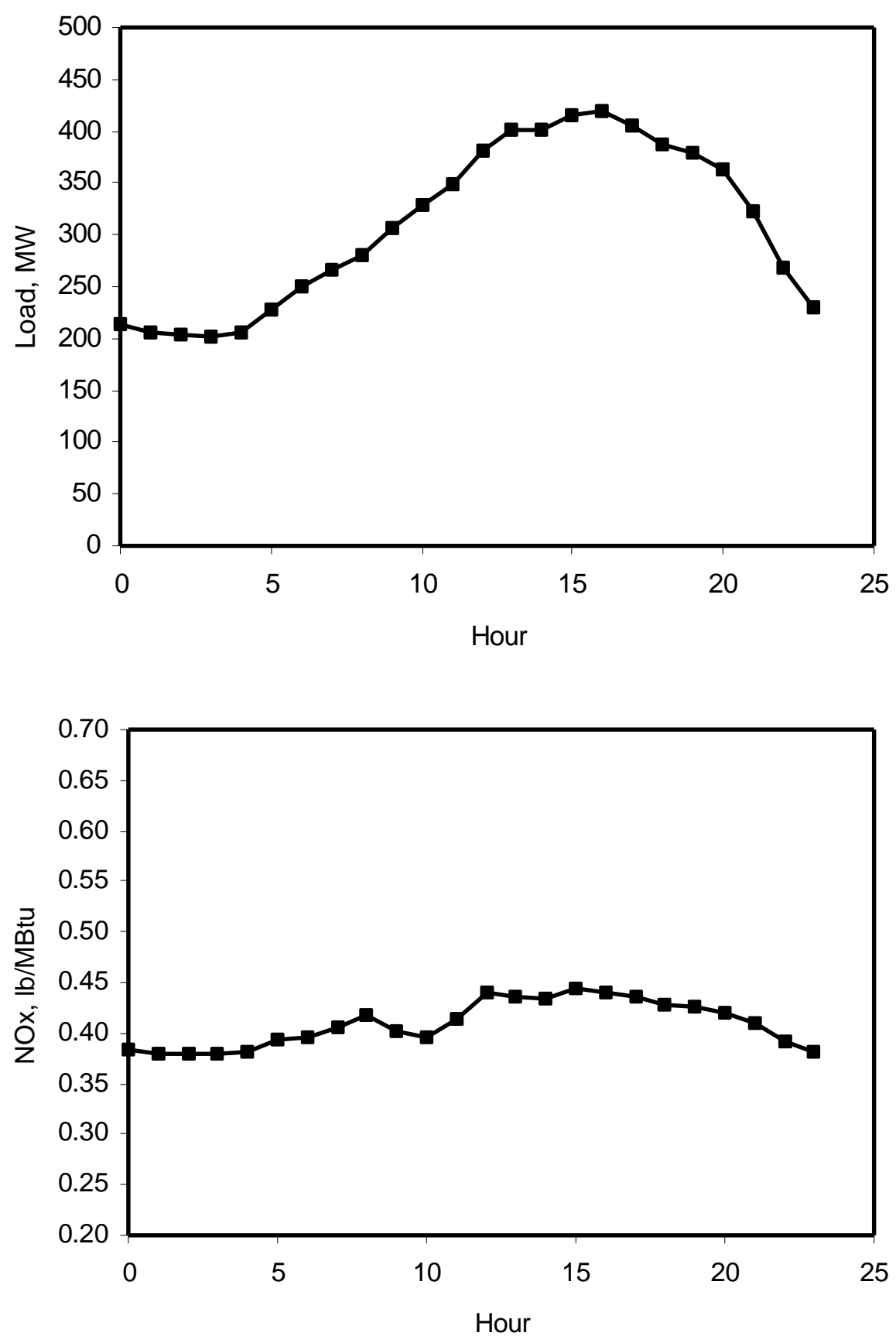

Figure 4-28 P4A / Long-Term Diurnal Characteristics 


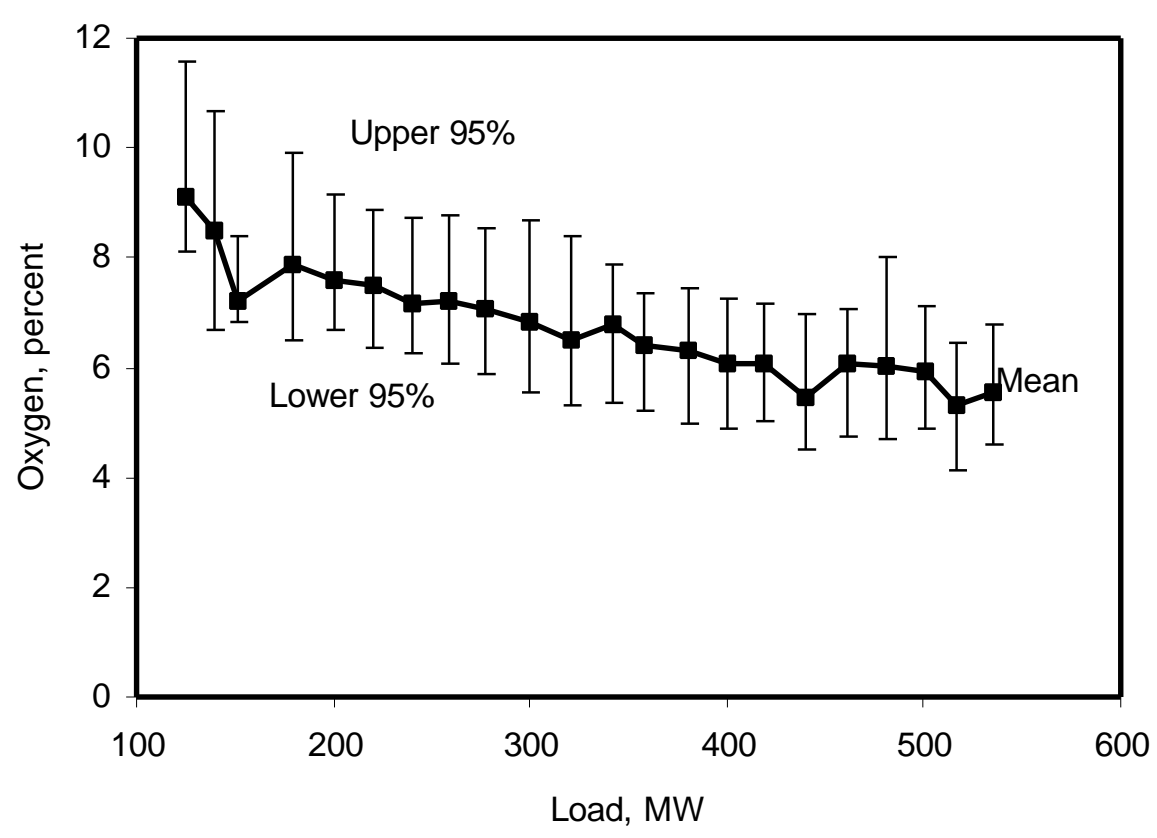

Figure 4-29 P4A / Long-Term Stack $\mathrm{O}_{2}$ vs. Load

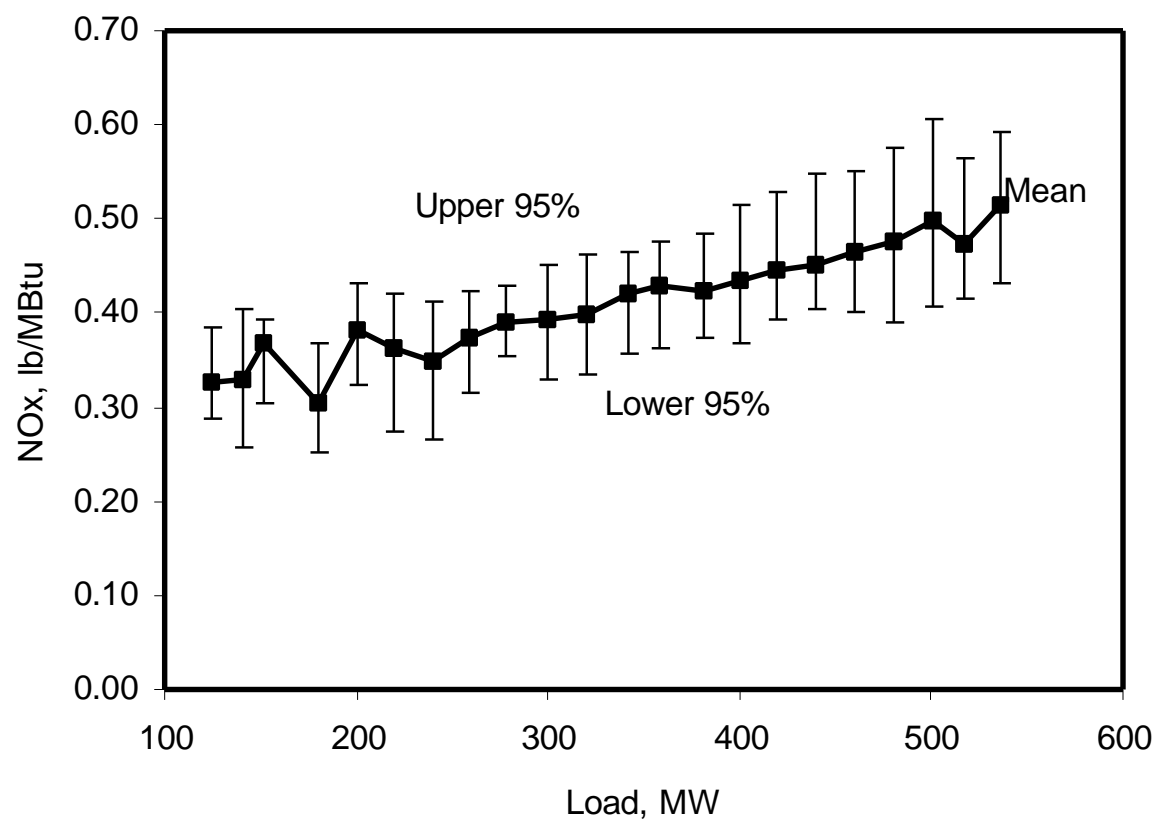

Figure 4-30 P4A / Long-Term NOx vs. Load 


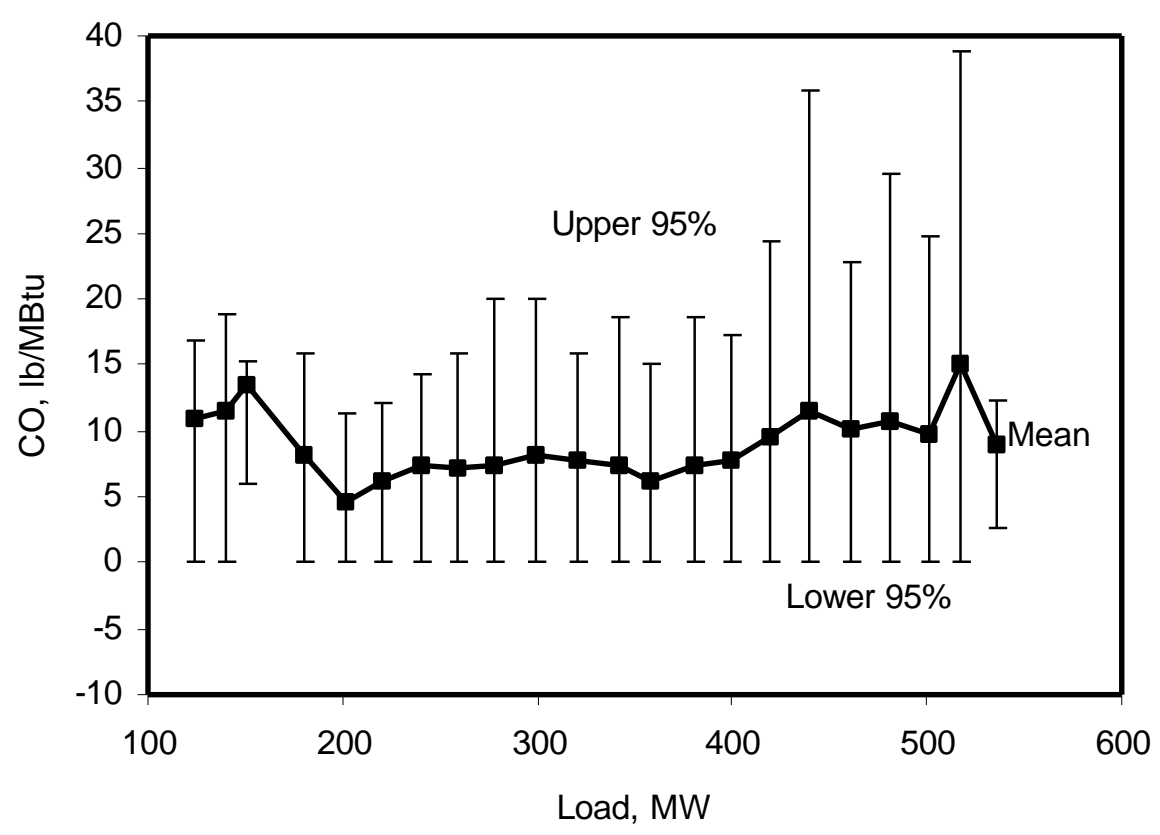

Figure 4-31 P4A / Long-Term CO vs. Load

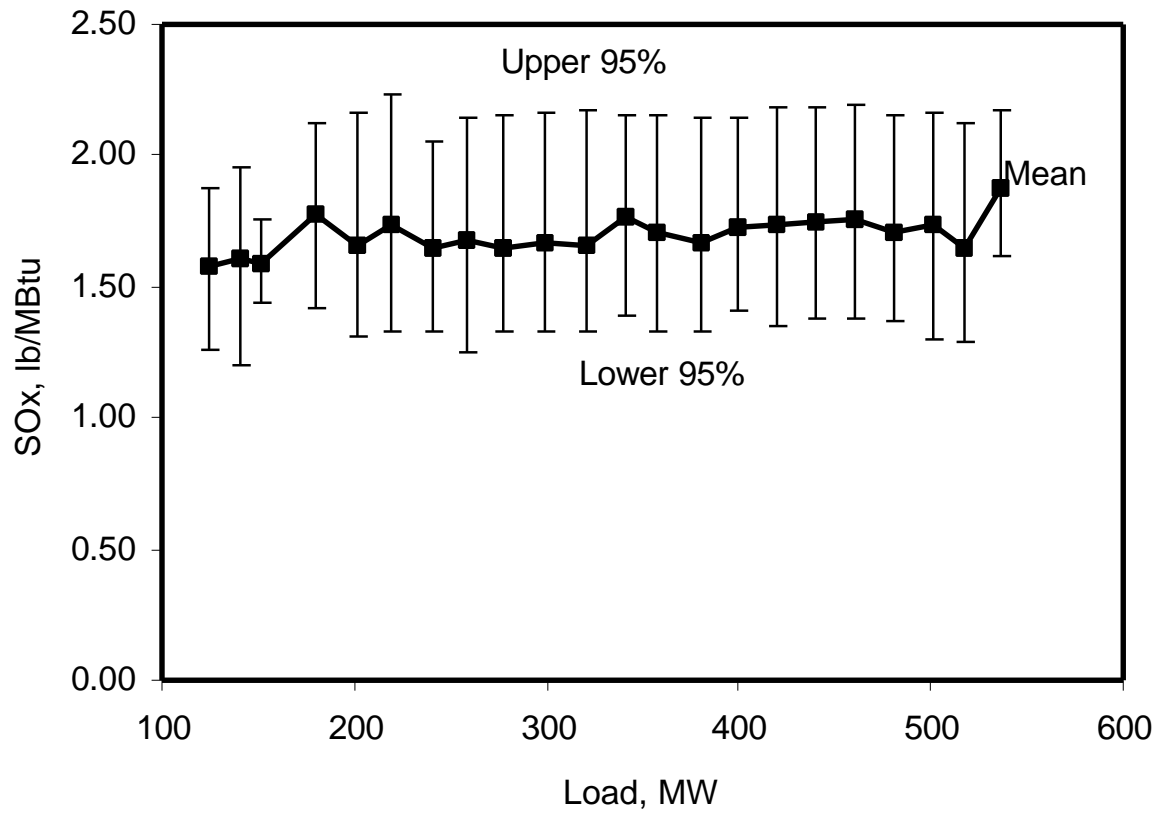

Figure 4-32 P4A / Long-Term SOx vs. Load 
The achievable NOx emission limit on a 30-day rolling average basis is determined using the descriptive statistics for 24-hour average NOx emissions. The descriptive statistics for the 24hour average NOx emissions data are shown in Table 4-7. As shown, fifty-one days of valid NOx emission data were collected during this time frame (June 1994 through November 1994). Average NOx emissions were $0.41 \mathrm{lb} / \mathrm{MBtu}$-- for comparison, the long-term NOx emissions during Phase $3 \mathrm{~B}$ were also $0.41 \mathrm{lb} / \mathrm{MBtu}$. The achievable emission depends on the long-term mean, variability, and autocorrelation level. Based on the daily values given, the 30-day achievable NOx emissions limit was found to be $0.45 \mathrm{lb} / \mathrm{MBtu}$. This limit should be exceeded, on average, once per ten years. The assumption related to these achievable emission levels is that the Hammond unit will be operated in the future under similar load dispatching and operating conditions (such as AOFA utilization). Other load scenarios, the thirty-day rolling averages would be different and therefore the achievable emission level would also be different.

\section{Table 4-7 P4A / Descriptive Statistics for Daily Average NOx Emissions}

\begin{tabular}{lc}
\hline Statistic & Value \\
\hline Number of Daily Values & 51 \\
Average Emissions $(\mathrm{lb} / \mathrm{MBtu})$ & 0.41 \\
Standard Deviation $(\mathrm{lb} / \mathrm{MBtu})$ & 0.037 \\
First Order Autocorrelation $(\rho)$ & 0.38 \\
AEL 30 Day $(\rho=0)$ & 0.44 \\
AEL 30 Day $(\rho=0.38)$ & 0.45 \\
\hline
\end{tabular}




\subsubsection{Process Data for $1^{\text {st }}$ Quarter 1995}

In addition to the long-term emissions data described earlier, process data was collected during all test phases to provide insight to changes in the boiler performance and turbine cycle heat rate. During Phases 1 through 3, this data was collected with the project's data acquisition system (DAS) [SCS, 1998]. For Phase 4, a large majority of the existing field inputs to the DAS were terminated at the just installed DCS. The plan was to have the archiving procedures set up prior to the return of the unit to operation in May 1994, however, due to problems with the DCS, data was not archived reliably until first quarter 1995.

\section{$\underline{\text { Steam Temperatures }}$}

Main steam and reheat temperatures are shown in Figure 4-33 and Figure 4-34, respectively. Main steam temperature averaged approximately $990^{\circ} \mathrm{F}$ at full load. The design steam temperature for the unit is $1000^{\circ} \mathrm{F}$. In general, a $10^{\circ} \mathrm{F}$ decrease in main steam temperature results in a 0.15 percent increase in turbine cycle heat rate for subcritical, drum units. There was some improvement in temperature at intermediate loads before decreasing at loads below $200 \mathrm{MW}$. Hot reheat temperature averaged near $997^{\circ} \mathrm{F}$ at the upper loads, again with the design being $1000^{\circ} \mathrm{F}$. As with main steam temperatures, there is a 0.15 percent increase in turbine cycle heat rate for a $10^{\circ} \mathrm{F}$ decrease in reheat temperature. Mean reheat temperature remained above $980^{\circ} \mathrm{F}$ until about $200 \mathrm{MW}$.

\section{$\underline{\text { Main Steam Pressure }}$}

Main steam pressure as a function of load is shown in Figure 4-35. As shown, the pressure remained near the design level of $2400 \mathrm{psig}$ for most of the load range, only dropping significantly below $200 \mathrm{MW}$. There is $0.4 \%$ decrease in turbine cycle heat rate for every $100 \mathrm{psi}$ deviation from design.

\section{$\underline{\text { Secondary Air Heater Inlet and Outlet Gas Temperatures }}$}

The secondary air heater inlet and outlet gas temperatures are shown in Figure 4-36 through Figure 4-39. Full load air heater inlet temperatures (economizer outlet temperatures) averaged near $780^{\circ} \mathrm{F}$. The design temperature for the unit is $710^{\circ} \mathrm{F}$ at full load. As expected, the temperature dropped with decreasing load, averaging near $650^{\circ} \mathrm{F}$ at $260 \mathrm{MW}$. The design temperature at this load is near $590^{\circ} \mathrm{F}$. The secondary air heater outlet temperature averaged approximately $310^{\circ} \mathrm{F}$ at full load dropping to near $280^{\circ} \mathrm{F}$ at $260 \mathrm{MW}$. The full load design temperature is near $282^{\circ} \mathrm{F}$.

\section{Excess Oxygen}

In addition to the ECEM excess oxygen measurement, excess oxygen was also measured at the economizer outlet using the plant's in situ instrumentation. Excess oxygen for the east and west economizer outlet is shown in Figure 4-40 and Figure 4-41, respectively. As shown in Figure 4-42, based on plant instrumentation, the east and west sides were relatively well balanced over the load range. The stack oxygen level is shown in Figure 4-43. 


\section{$\underline{\text { NOx Emissions }}$}

NOx emissions for first quarter 1995 are shown in Figure 4-44. As shown, NOx emissions averaged approximately $0.40 \mathrm{lb} / \mathrm{Mbtu}$ over the load range. The bars on this figure represent the $5^{\text {th }}$ and $95^{\text {th }}$ percentiles of NOx emissions data collected. Comparing these emissions characteristic with that seen from July to November 1994 (Figure 4-30) and during Phase 3B, it is evident that the NOx emissions had returned to levels seen during Phase 3B. The upward shift in NOx emissions in the July to November data set is likely related to the controllable operating parameters such as excess oxygen and mills in service.

\section{$\underline{\text { Mill Coal Flows }}$}

Mill coal flows as functions of load are shown in Figure 4-45. As shown, the "C" and "D" mills tended to be utilized earlier than the other mills during this period. The " $\mathrm{C}$ " and " $\mathrm{D}$ " supply the front-top and front-middle burners, respectively. The choice of mills will generally affect all boiler performance measures including NOx emissions, LOI, and efficiency. The mill patterns by load are provided in Appendix A. The most common mill patterns along with NOx emissions for several load ranges are shown in Table 4-8. As shown, mill pattern selection appeared to affect NOx emissions by approximately 10 percent. 


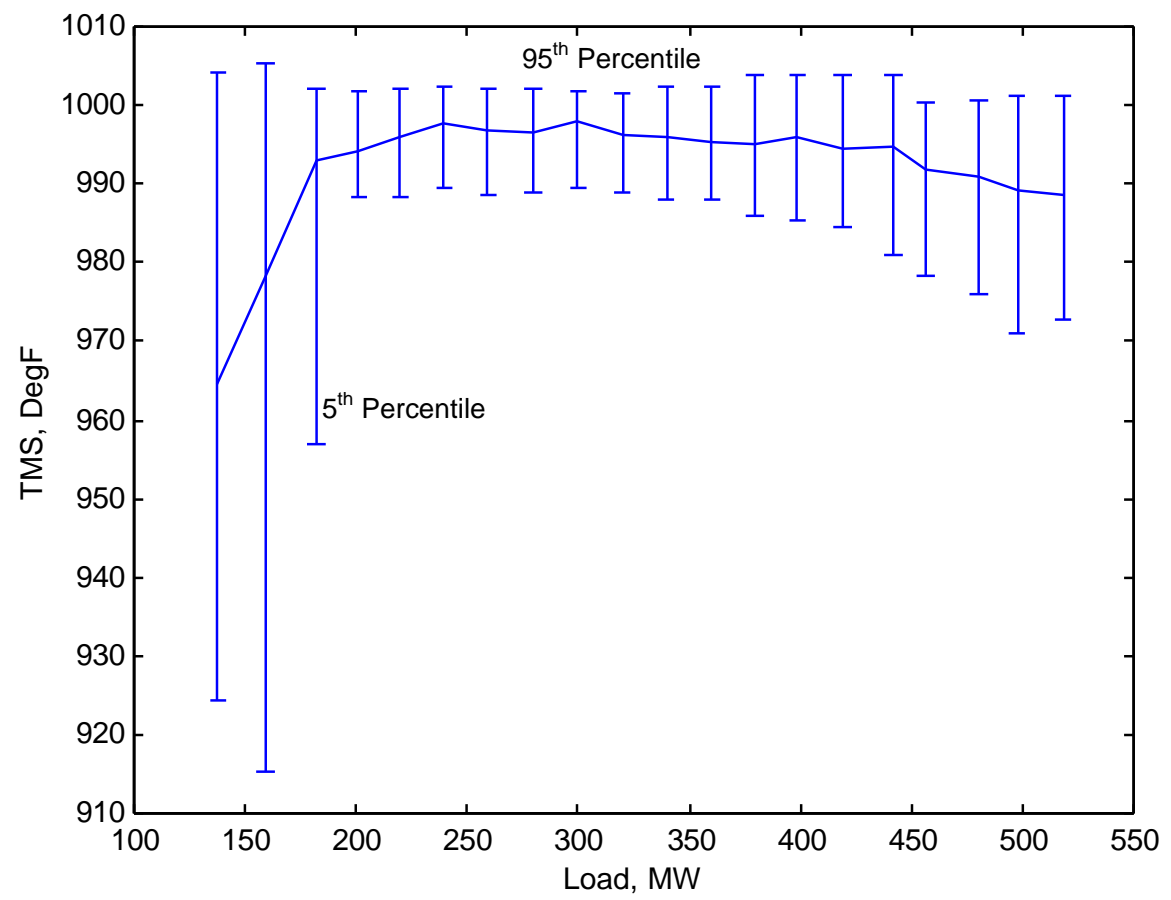

Figure 4-33 P4A - Main Steam Temperature vs. Load (1Q95)

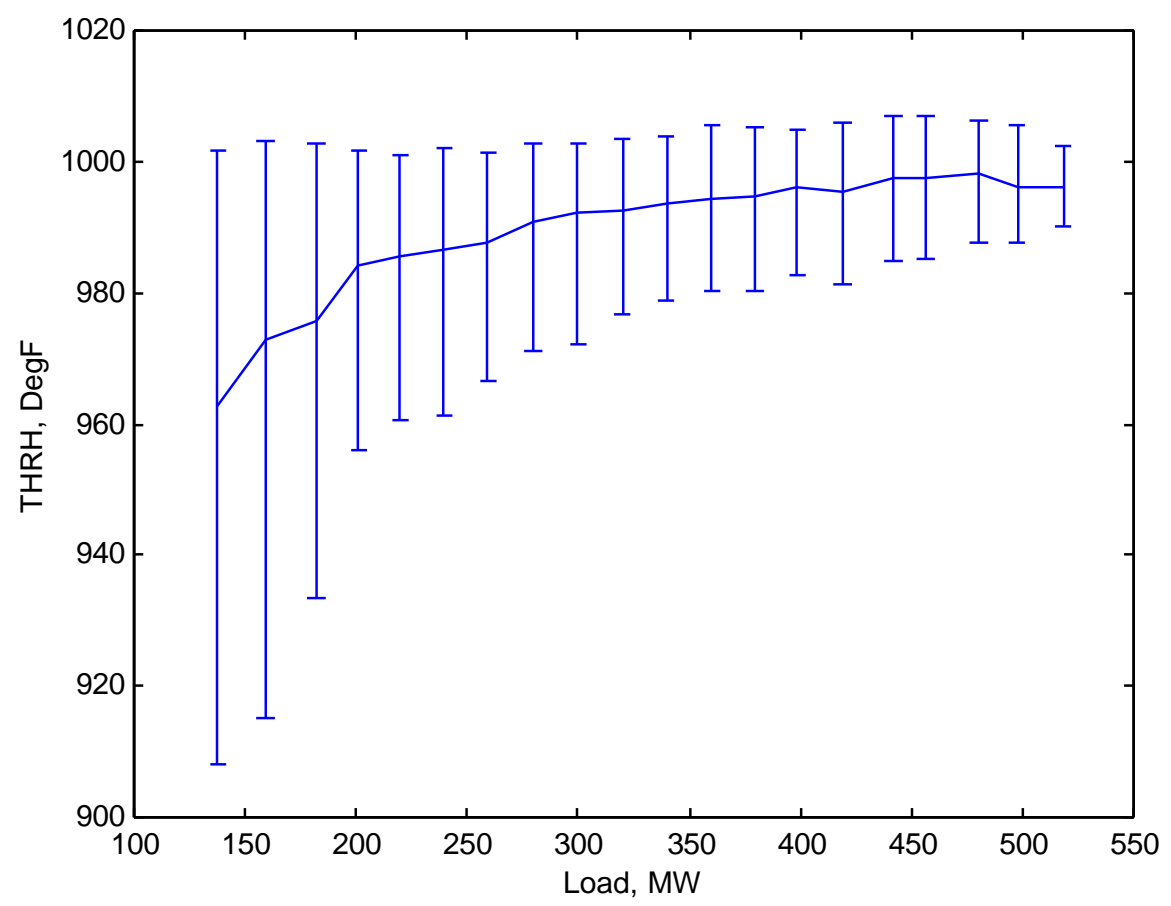

Figure 4-34 P4A - Hot Reheat Temperature vs. Load (1Q95) 


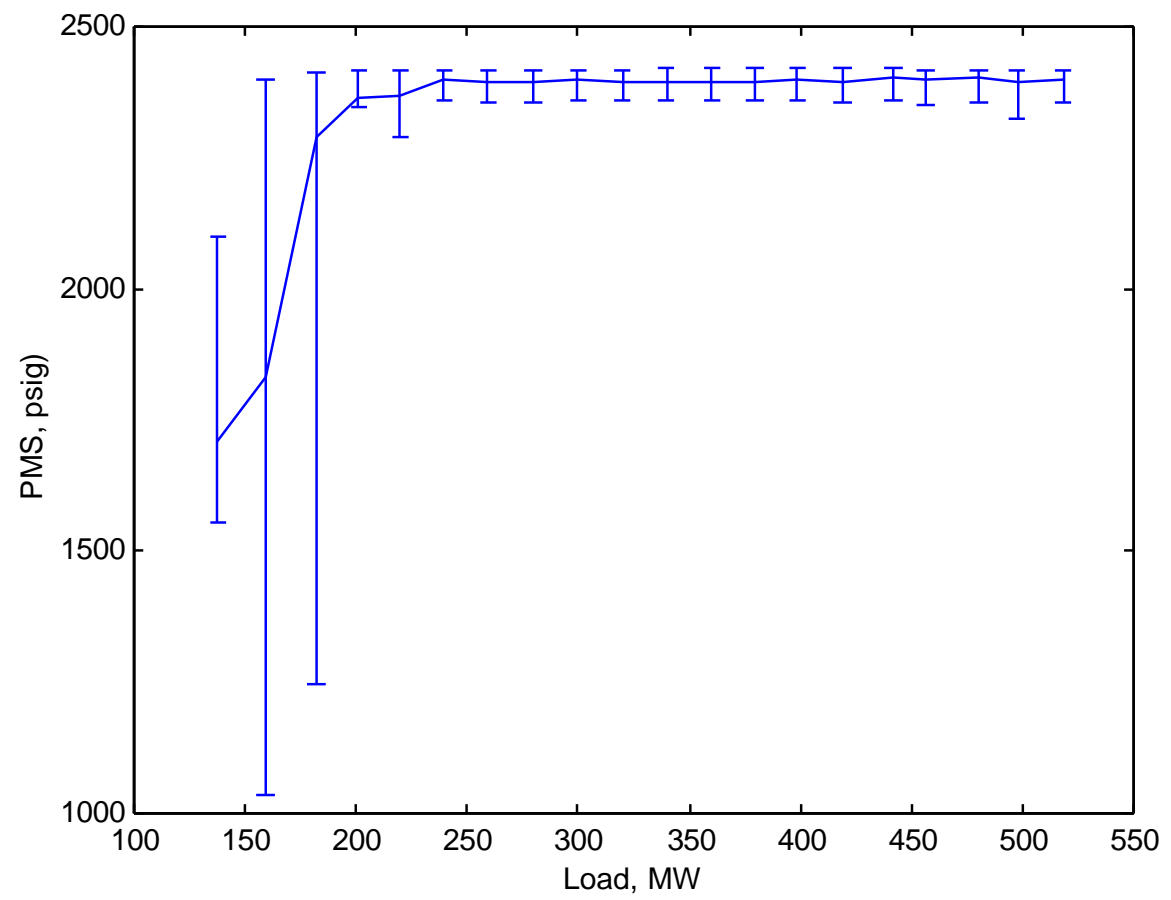

Figure 4-35 P4A - Main Steam Pressure vs. Load (1Q95)

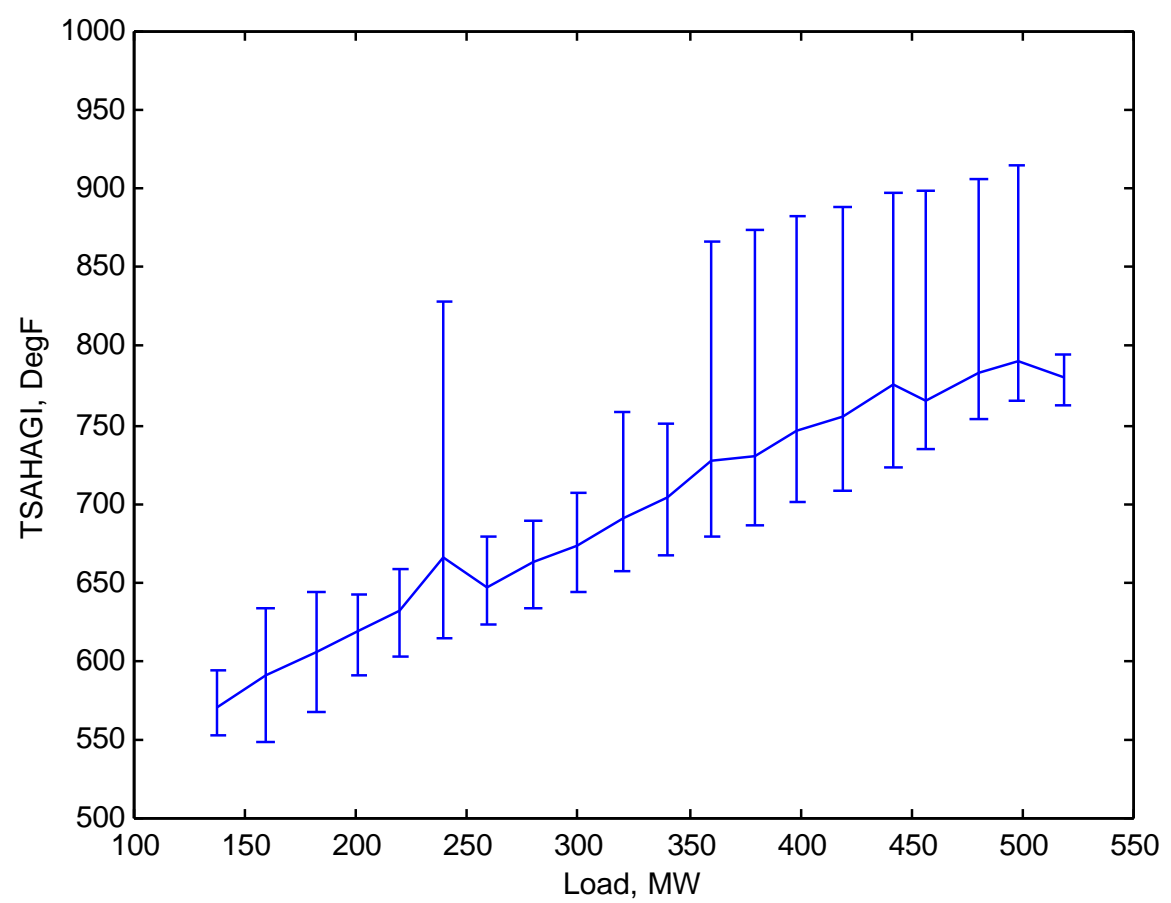

Figure 4-36 P4A - Secondary Air Heater A Gas Inlet Temperature vs. Load (1Q95) 


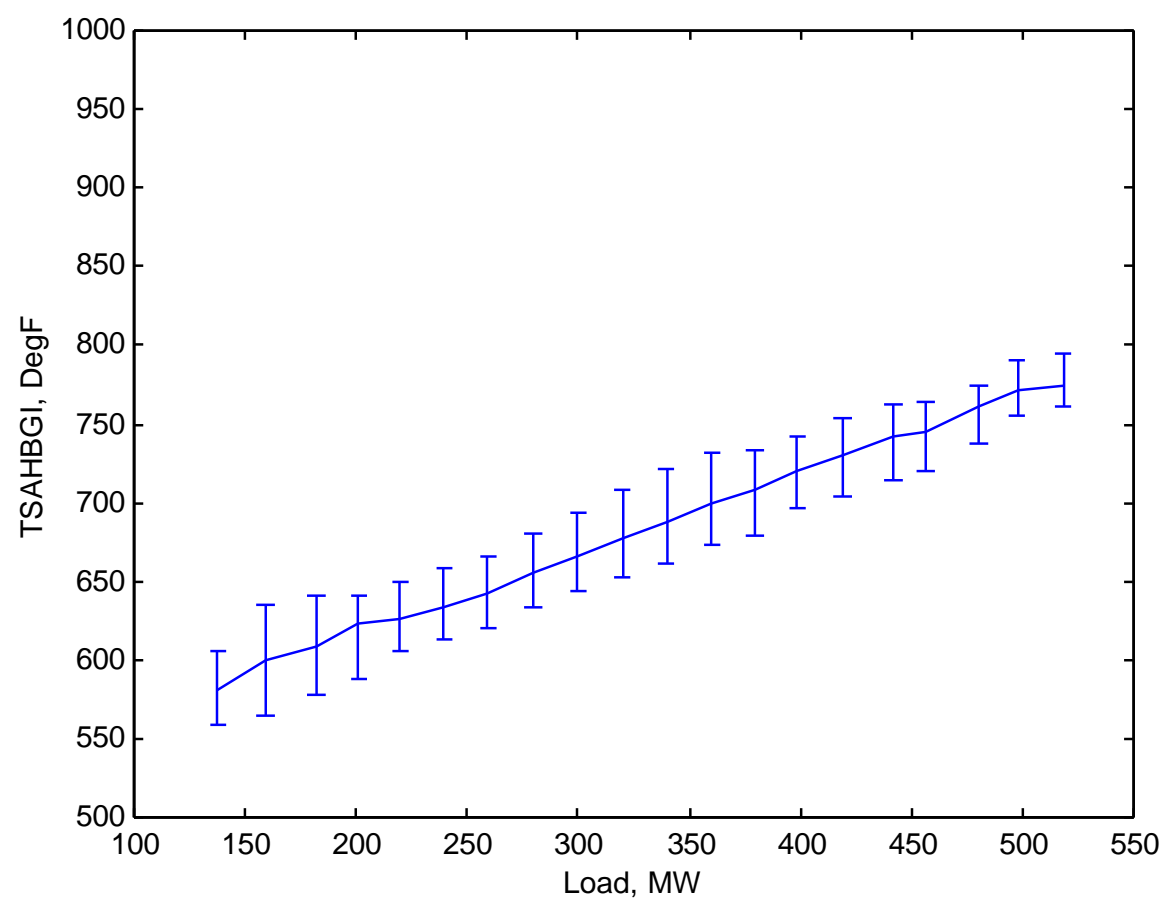

Figure 4-37 P4A - Secondary Air Heater B Gas Inlet Temperature vs. Load (1Q95)

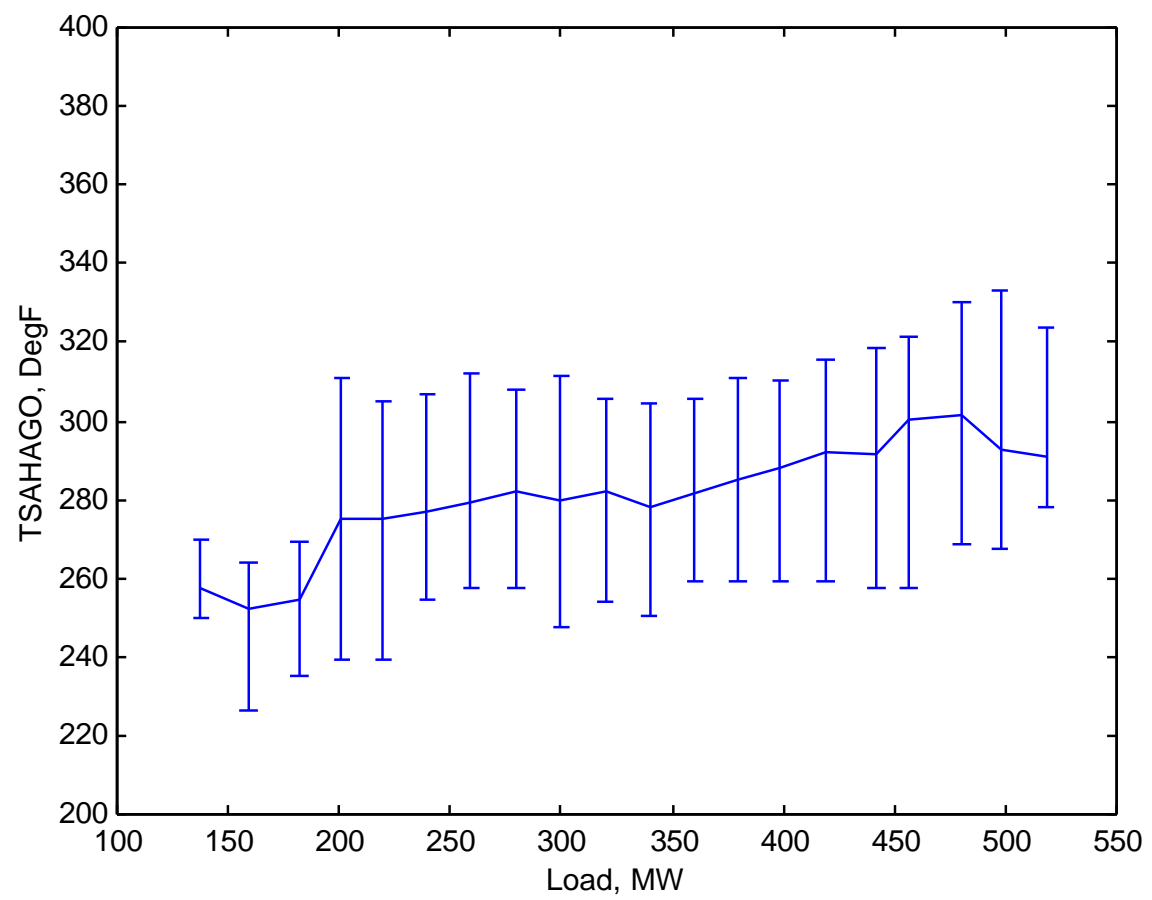

Figure 4-38 P4A - Secondary Air Heater A Gas Outlet Temperature vs. Load (1Q95) 


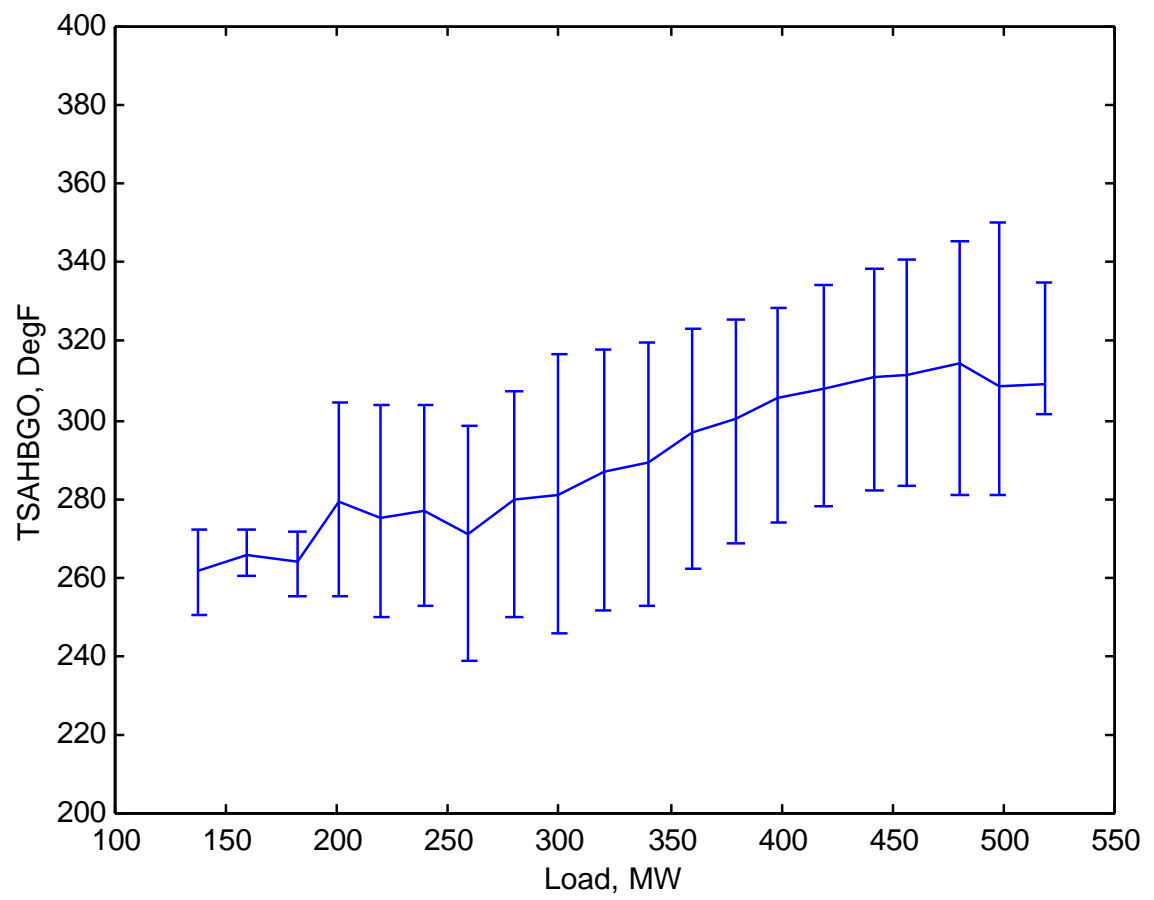

Figure 4-39 P4A - Secondary Air Heater B Gas Outlet Temperature vs. Load (1Q95)

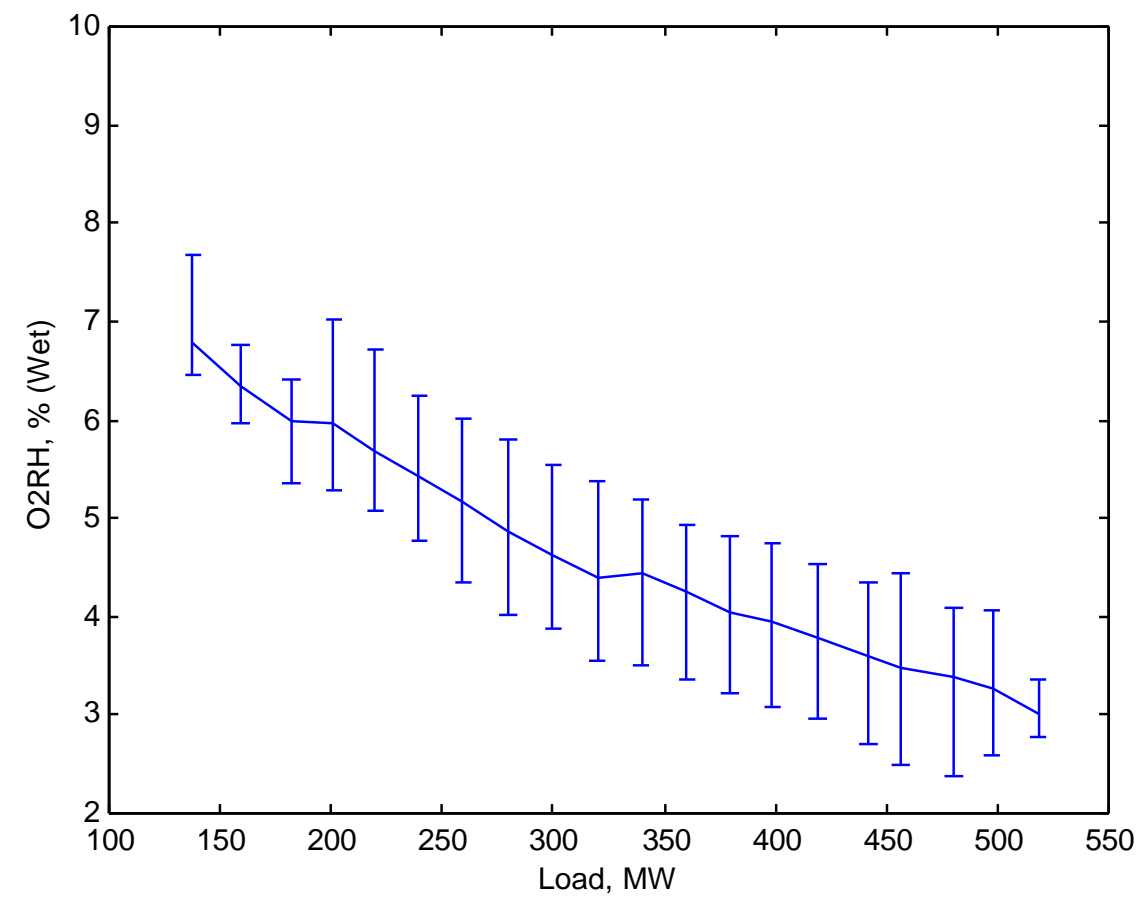

Figure 4-40 P4A - Excess Oxygen East Duct vs. Load (1Q95) 


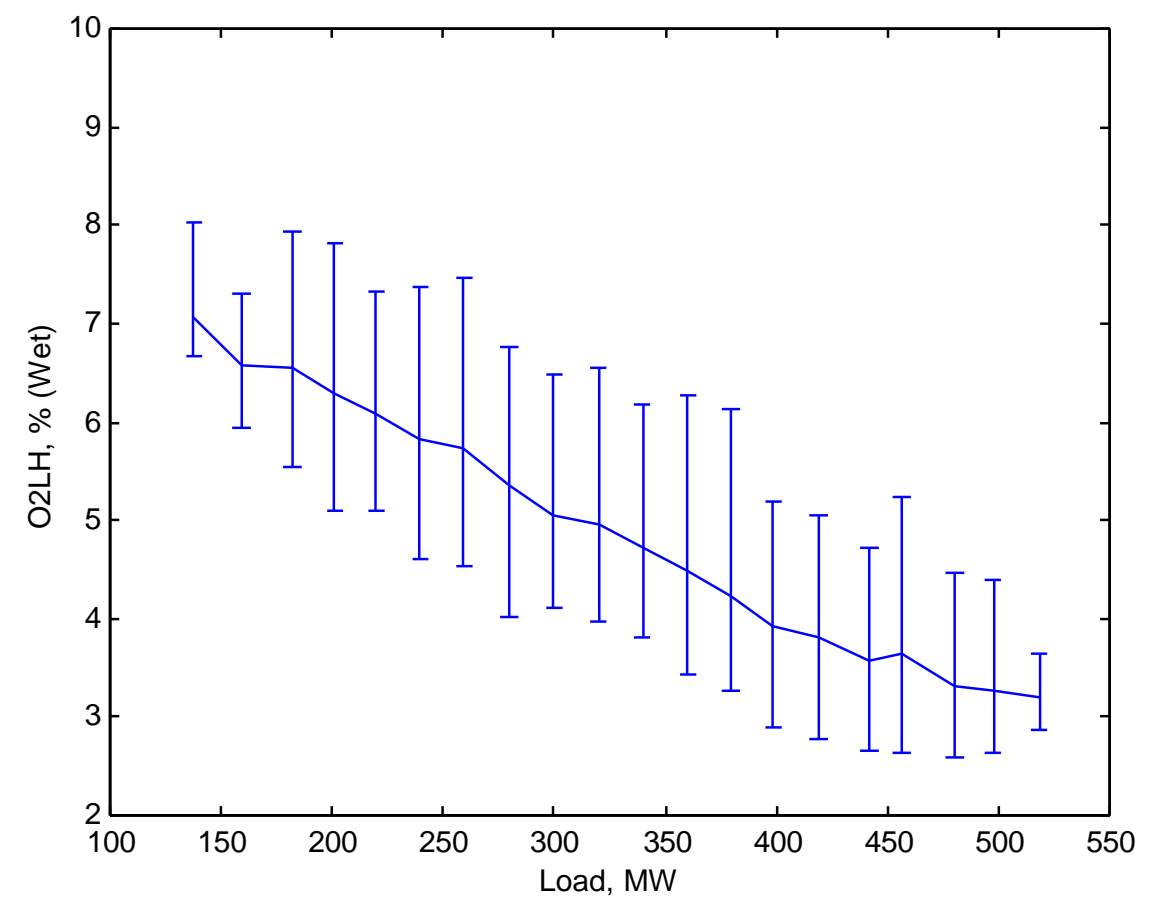

Figure 4-41 P4A - Excess Oxygen West Duct vs. Load (1Q95)

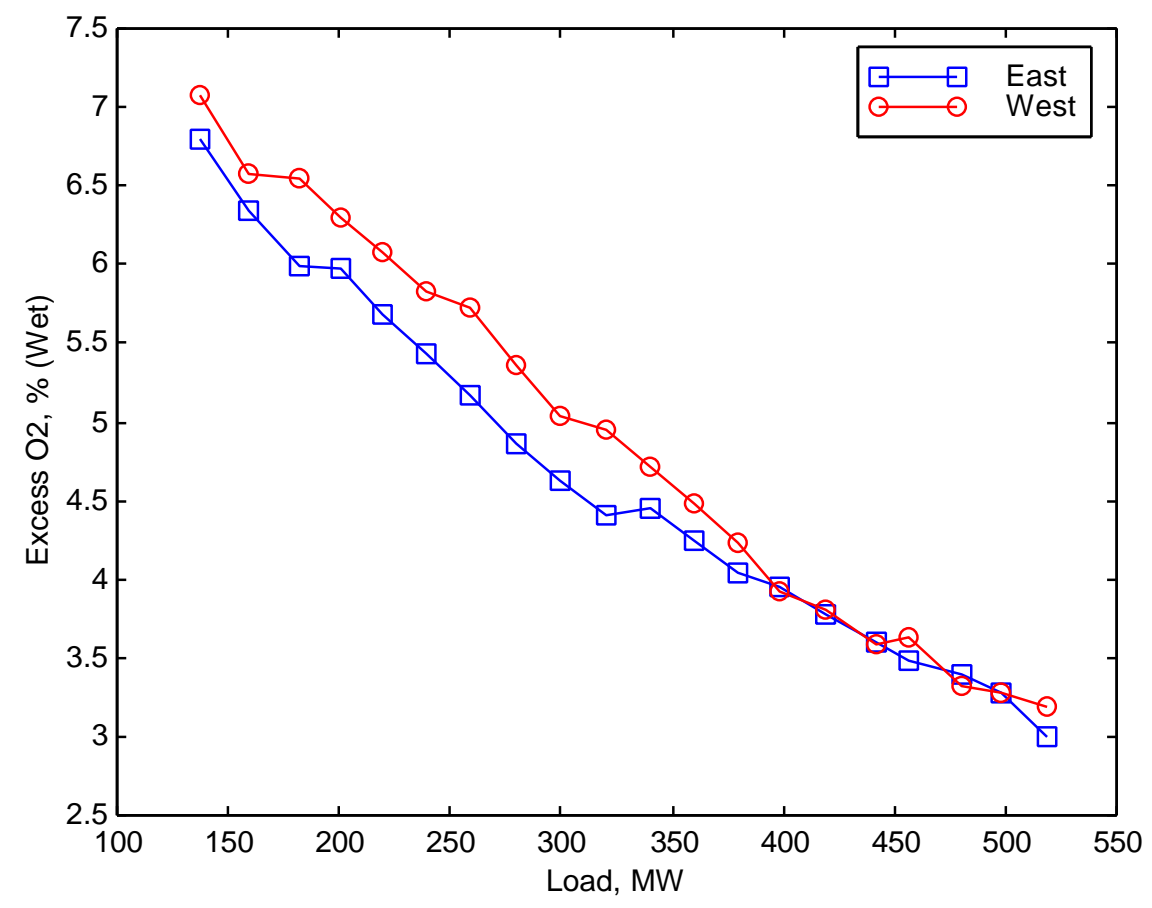

Figure 4-42 P4A - Excess Oxygen vs. Load (1Q95) 


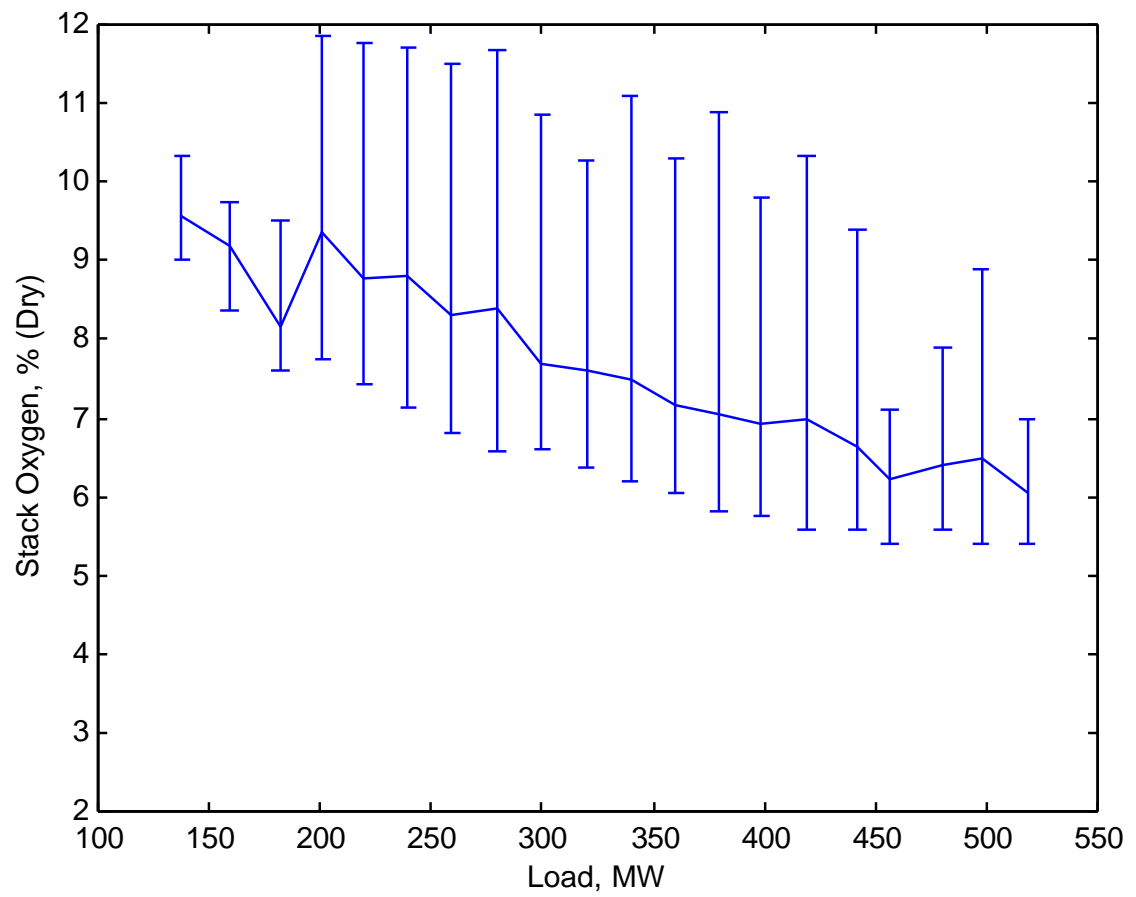

Figure 4-43 P4A - Stack Oxygen vs. Load (1Q95)

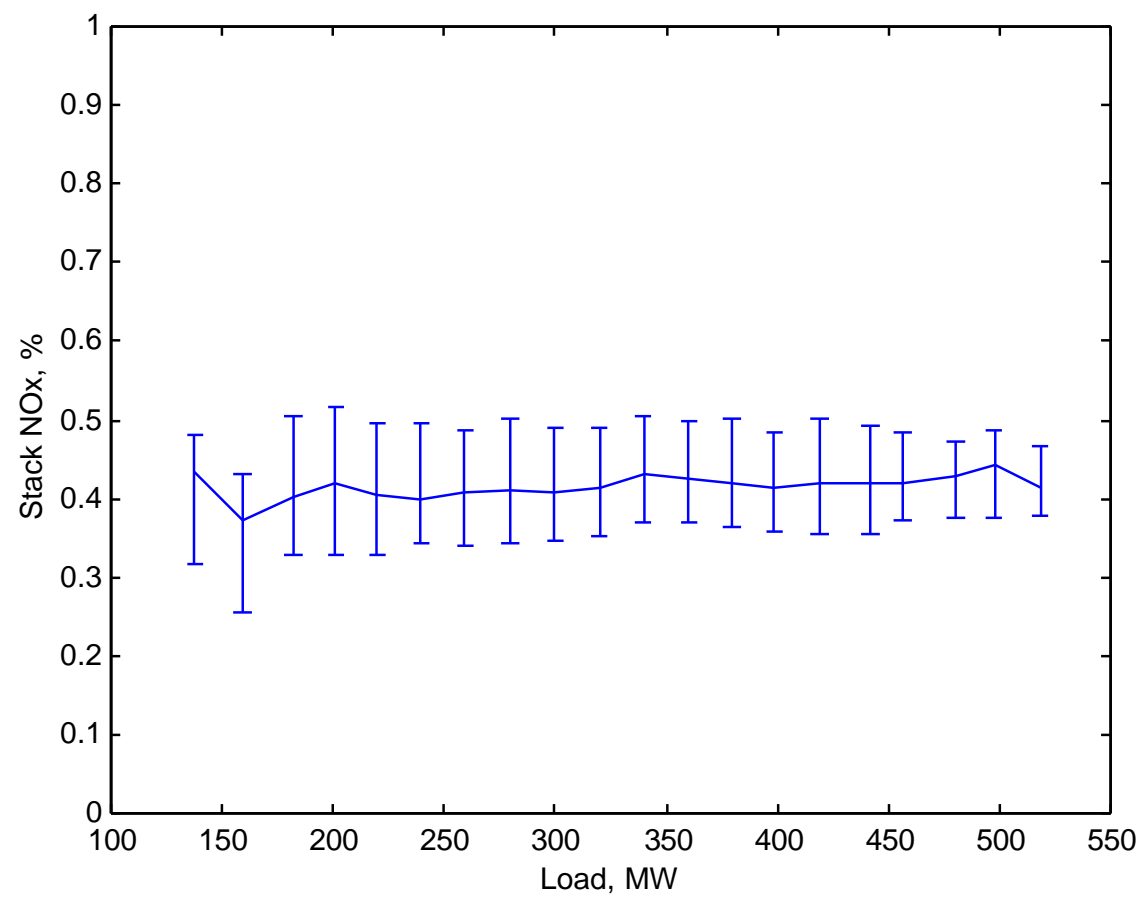

Figure 4-44 P4A - Stack NOx vs. Load (1Q95) 

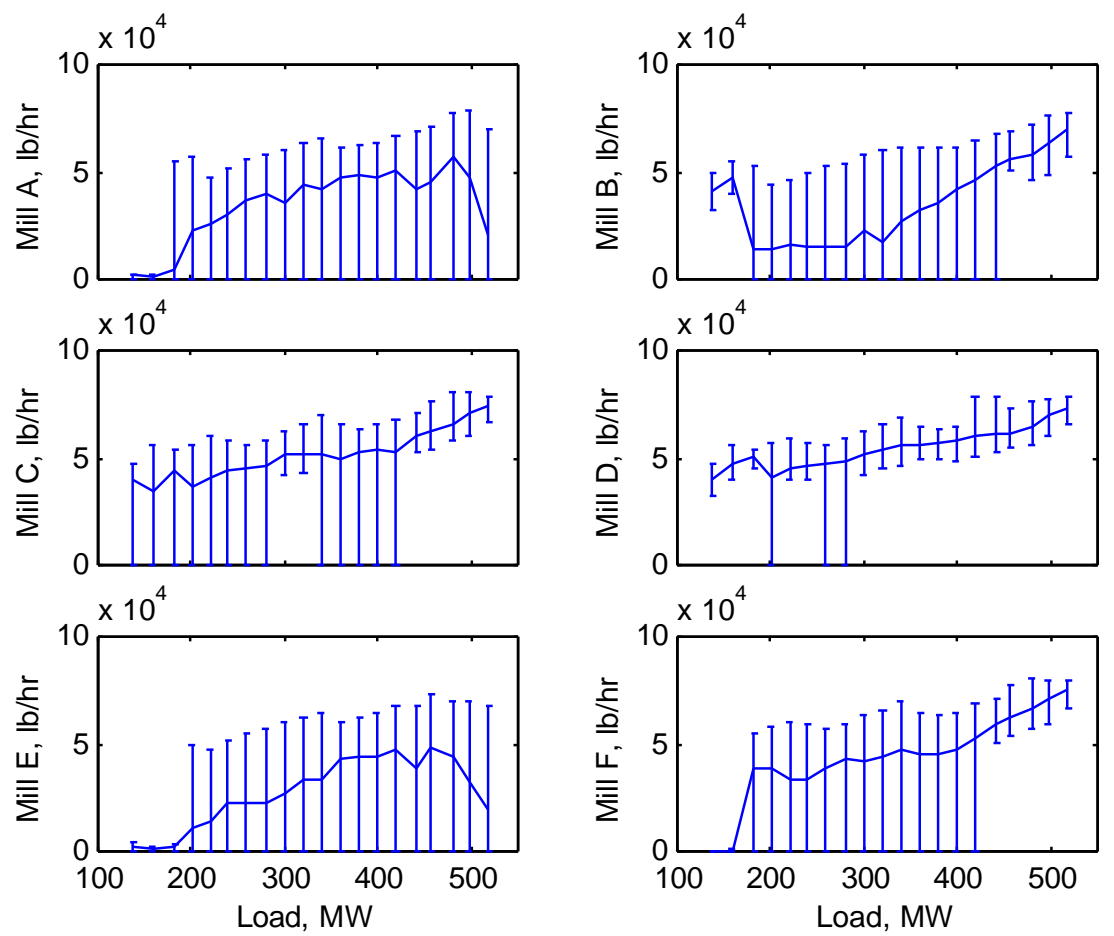

Figure 4-45 P4A - Mill Coal Flows vs. Load (1Q95)

Table 4-8 P4A - NOx Emissions vs. Mill Pattern (1Q95)

\begin{tabular}{ccc}
\hline Load Range & $\begin{array}{c}\text { Mill Pattern } \\
\text { A-B-C-D-E-F }\end{array}$ & $\begin{array}{c}\text { NOx Emissions } \\
\text { lb/MBtu }\end{array}$ \\
\hline $190-210$ & $0-0-1-1-0-1$ & 0.387 \\
& $0-1-1-1-0-1$ & 0.418 \\
& $1-0-1-1-0-1$ & 0.440 \\
$290-310$ & $0-1-1-1-0-1$ & 0.421 \\
& $1-0-1-1-0-1$ & 0.418 \\
$380-400$ & $1-0-1-1-1-1$ & 0.429 \\
& $1-0-1-1-1-1$ & 0.419 \\
$490-510$ & $1-1-1-1-1-0$ & 0.395 \\
& $1-1-1-1-1-1$ & 0.430 \\
& $1-1-1-1-0-1$ & 0.426 \\
& $1-1-1-1-1-1$ & 0.447 \\
\hline
\end{tabular}




\subsubsection{Process Data for 1st Quarter 1996}

For purposes of comparison with earlier data, process data collected during first quarter 1996 is presented.

\section{$\underline{\text { Steam Temperatures }}$}

Main steam and reheat temperatures are shown in Figure 4-46 and Figure 4-47, respectively. Main steam temperature averaged approximately $998^{\circ} \mathrm{F}$ from approximately $200 \mathrm{MW}$ up to full load $(500 \mathrm{MW})$. The design steam temperature for the unit is $1000^{\circ} \mathrm{F}$. In general, a $10^{\circ} \mathrm{F}$ decrease in main steam temperature results in an 0.15 percent increase in turbine cycle heat rate for subcritical, drum units. Hot reheat temperature averaged near $997^{\circ} \mathrm{F}$ at the upper loads but dropped below $990^{\circ} \mathrm{F}$ at approximately $200 \mathrm{MW}$. As with main steam temperatures, the design temperature is $1000^{\circ} \mathrm{F}$ and there is an 0.15 percent increase in turbine cycle heat rate for a $10^{\circ} \mathrm{F}$ decrease in reheat temperature.

\section{$\underline{\text { Main Steam Pressure }}$}

Main steam pressure as a function of load is shown in Figure 4-48. As shown, the pressure remained near the design level of 2400 psig for most of the load range, only dropping significantly below $200 \mathrm{MW}$. There is $0.4 \%$ decrease in turbine cycle heat rate for every $100 \mathrm{psi}$ deviation from design.

\section{$\underline{\text { Secondary Air Heater Inlet and Outlet Gas Temperatures }}$}

The secondary air heater inlet and outlet gas temperatures are shown in Figure 4-49 through Figure 4-52. Full load air heater inlet temperatures (economizer outlet temperatures) averaged near $730^{\circ} \mathrm{F}$ with the east side being nearly $80^{\circ} \mathrm{F}$ hotter than the west. The design temperature for the unit is $710^{\circ} \mathrm{F}$ at full load. However at lower loads, the east side temperatures were less than the corresponding west side temperatures. This large difference in temperatures was not evident in earlier datasets and the cause is unknown. As expected, the temperature dropped with decreasing load, averaging near $650^{\circ} \mathrm{F}$ at $260 \mathrm{MW}$. The design temperature at this load is near $590^{\circ} \mathrm{F}$. The secondary air heater outlet temperature averaged approximately $310^{\circ} \mathrm{F}$ at full load dropping to near $280^{\circ} \mathrm{F}$ at $260 \mathrm{MW}$. The full load design temperature is near $282^{\circ} \mathrm{F}$.

\section{Excess Oxygen}

In addition to the ECEM excess oxygen measurement, excess oxygen was also measured at the economizer outlet using the plant's in situ instrumentation. Excess oxygen for the east and west economizer outlet is shown in Figure 4-54 and Figure 4-53, respectively. As shown in Figure 4-55, based on plant instrumentation, the east and west sides were relatively well balanced over the load range. The stack oxygen level is shown in Figure 4-56. 


\section{$\underline{\text { NOx Emissions }}$}

NOx emissions for first quarter 1996 are shown in Figure 4-57. As shown, NOx emissions averaged approximately $0.40 \mathrm{lb} / \mathrm{Mbtu}$ over the load range. The bars on this figure represent the $5^{\text {th }}$ and $95^{\text {th }}$ percentiles of NOx emissions data collected. As with first quarter 1995 data (Figure 4-44), NOx emissions compared more similar to the Phase 3B data than that collected from July to November 1994 (Figure 4-30).

\section{$\underline{\text { Mill Coal Flows }}$}

Mill coal flows as functions of load are shown in Figure 4-58. As shown, the "A" and "D" mills tended to be utilized earlier than the other mills during this period. The "A" and "D" supply the front and rear middle elevation burners, respectively. The choice of mills will generally affect all boiler performance measures including NOx emissions, LOI, and efficiency. The mill patterns by load are provided in Appendix A. The most common mill patterns along with NOx emissions for several load ranges are shown in Table 4-9. As shown, mill pattern selection appeared to affect NOx emissions by approximately 10 percent. 


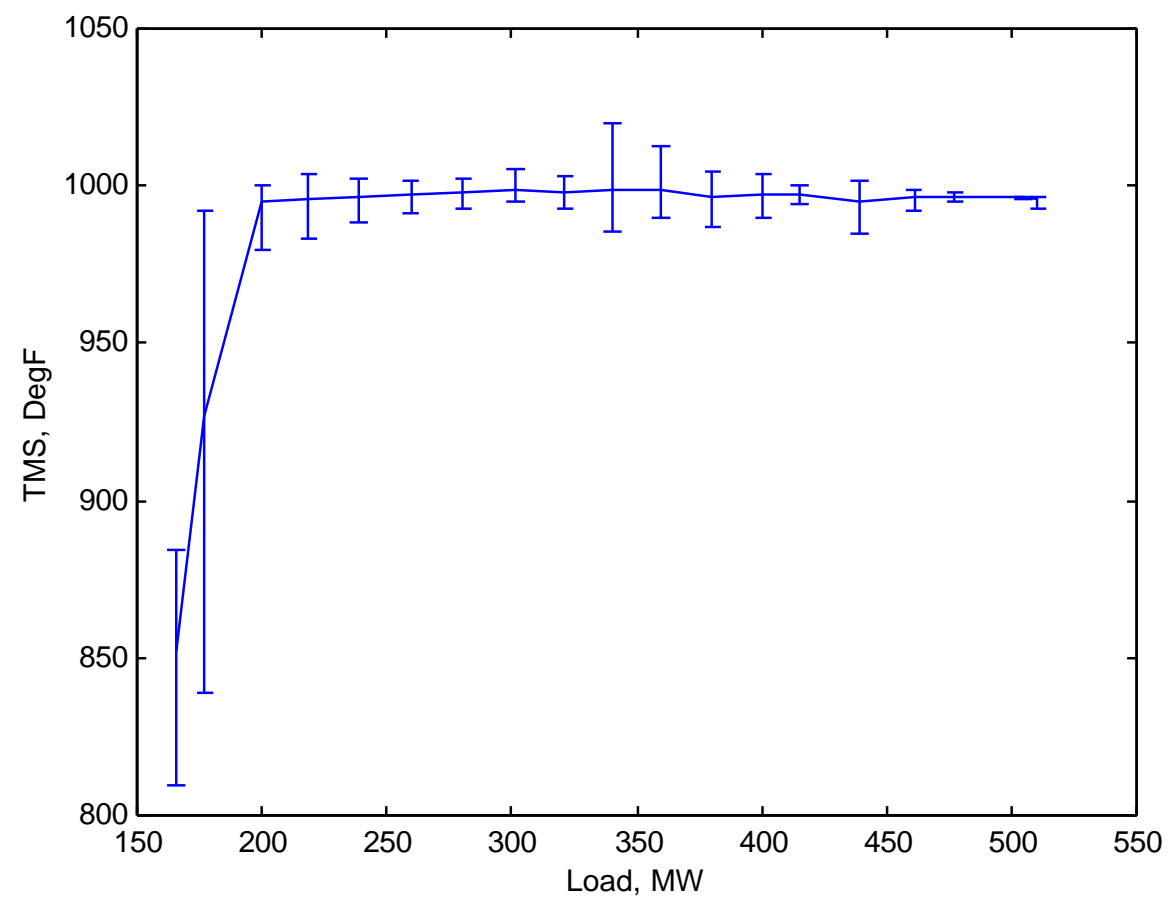

Figure 4-46 P4A - Main Steam Temperature vs. Load (1Q96)

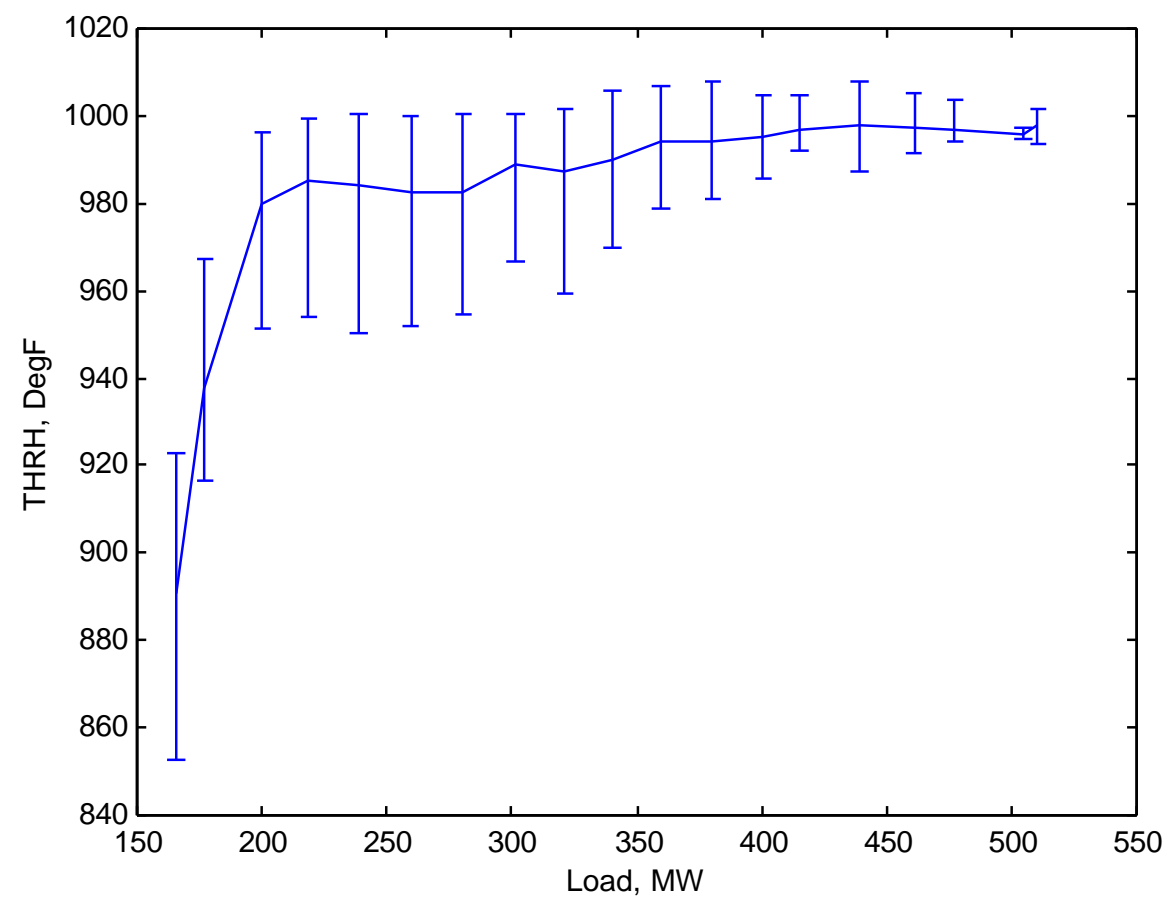

Figure 4-47 P4A - Hot Reheat Temperature vs. Load (1Q96) 


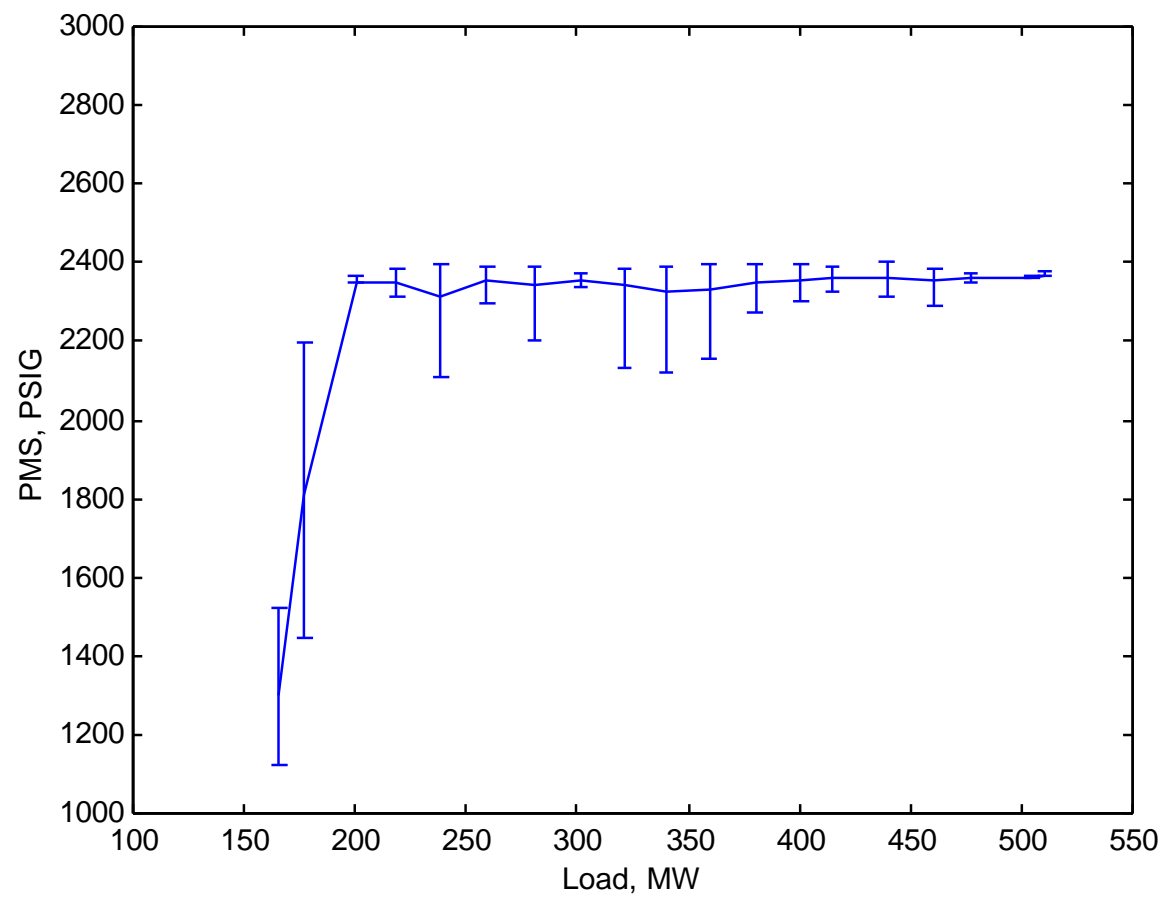

Figure 4-48 P4A - Main Steam Pressure vs. Load (1Q96)

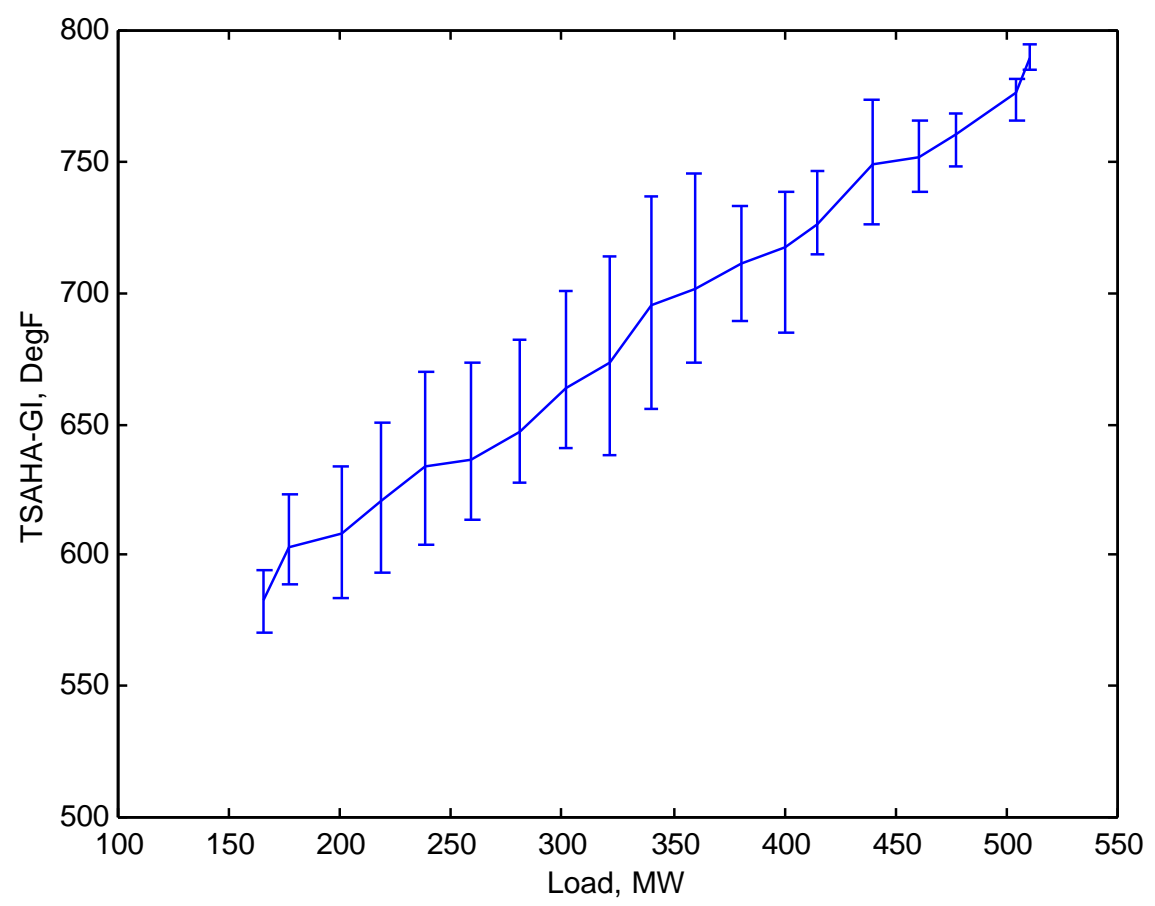

Figure 4-49 P4A - Secondary Air Heater A Gas Inlet Temperature vs. Load (1Q96) 


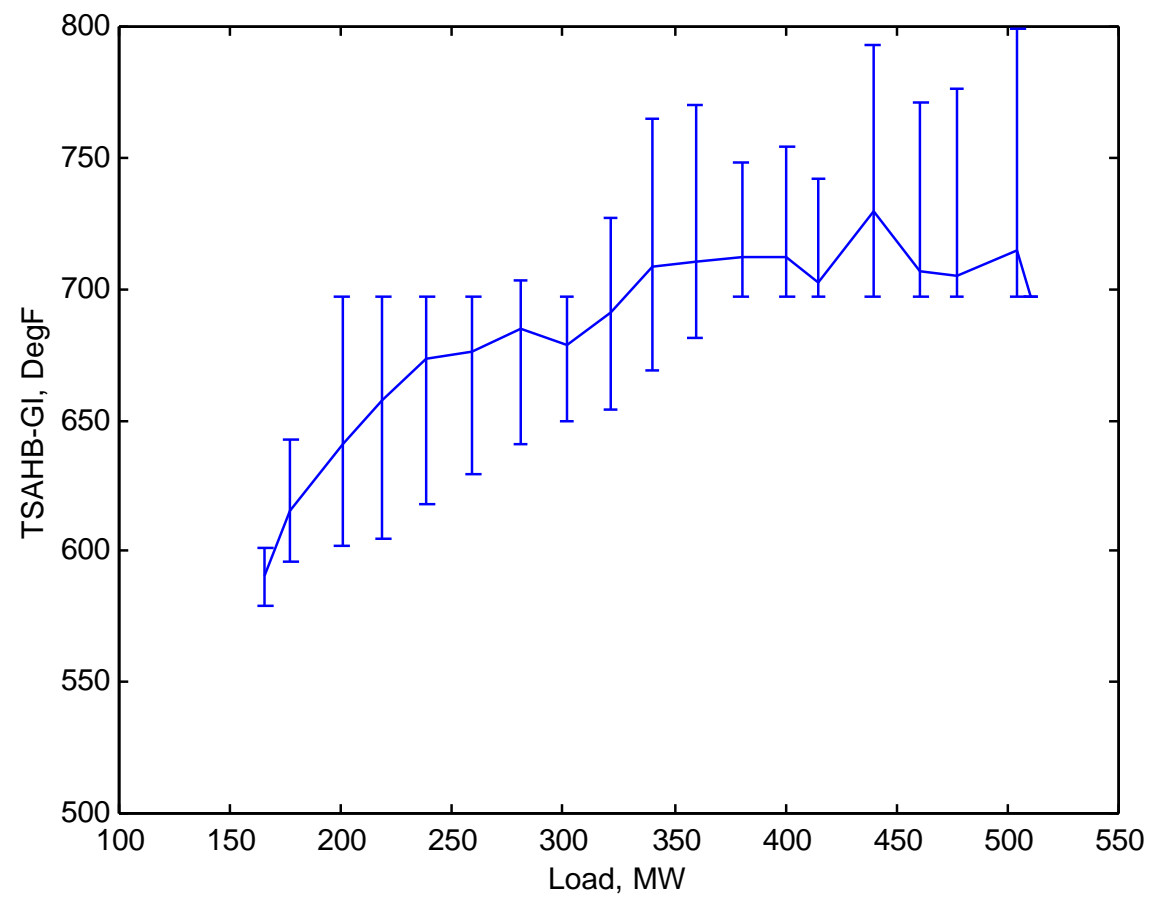

Figure 4-50 P4A - Secondary Air Heater B Gas Inlet Temperature vs. Load (1Q96)

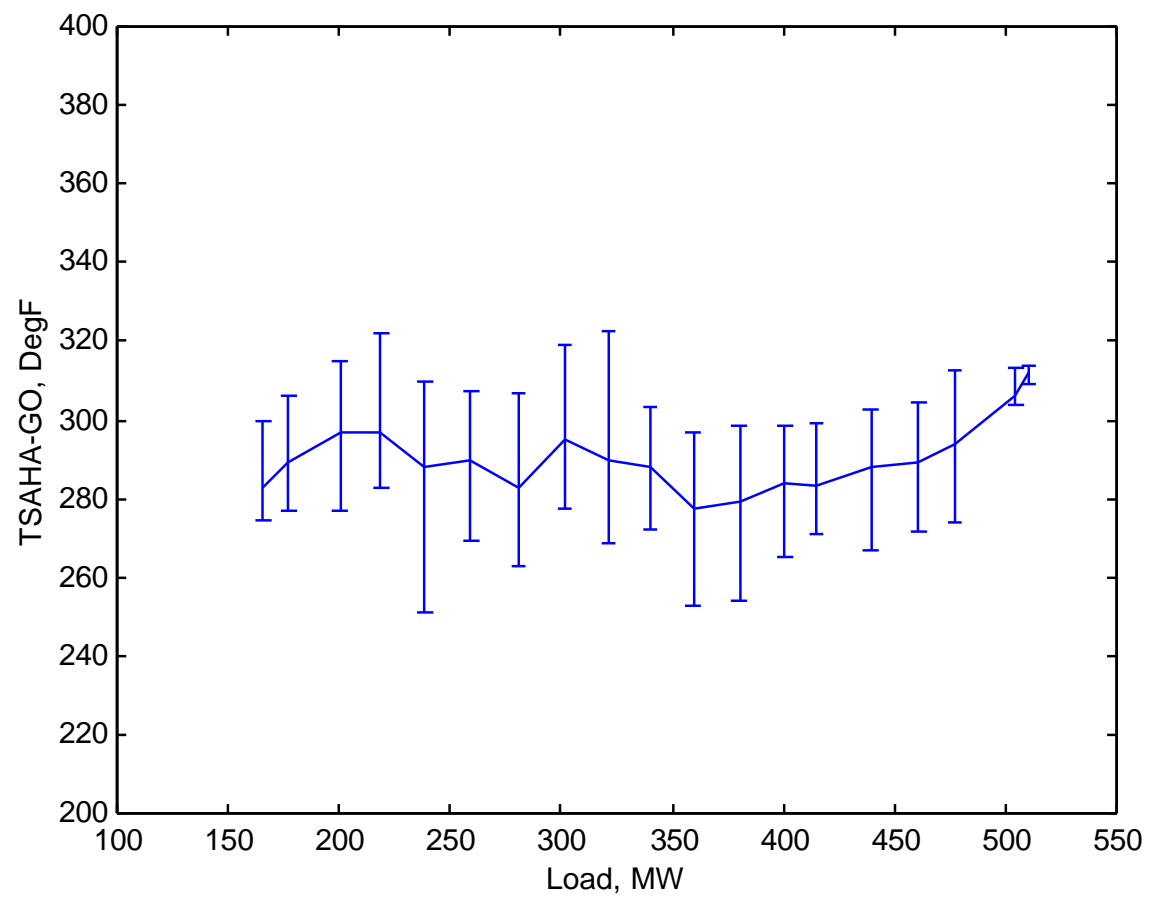

Figure 4-51 P4A - Secondary Air Heater A Gas Outlet Temperature vs. Load (1Q96) 


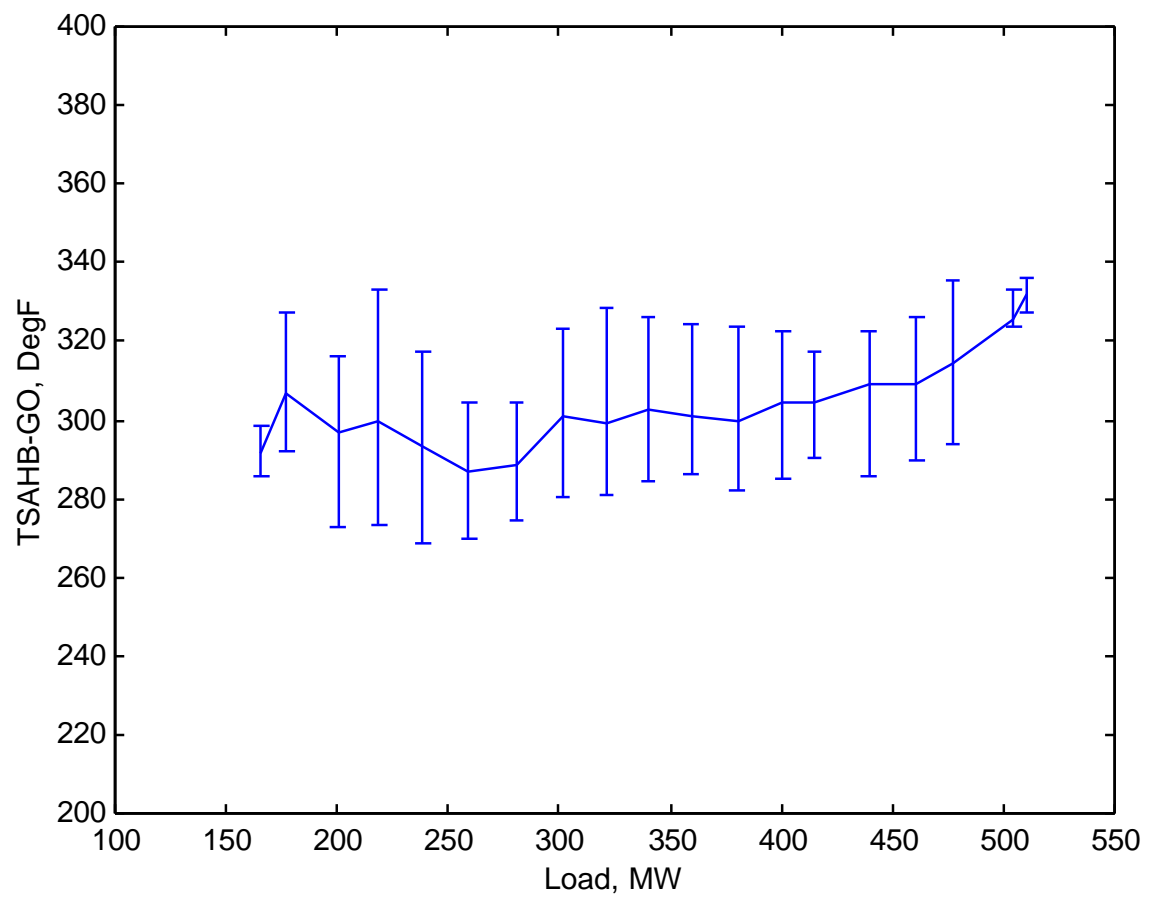

Figure 4-52 P4A - Secondary Air Heater B Gas Outlet Temperature vs. Load (1Q96)

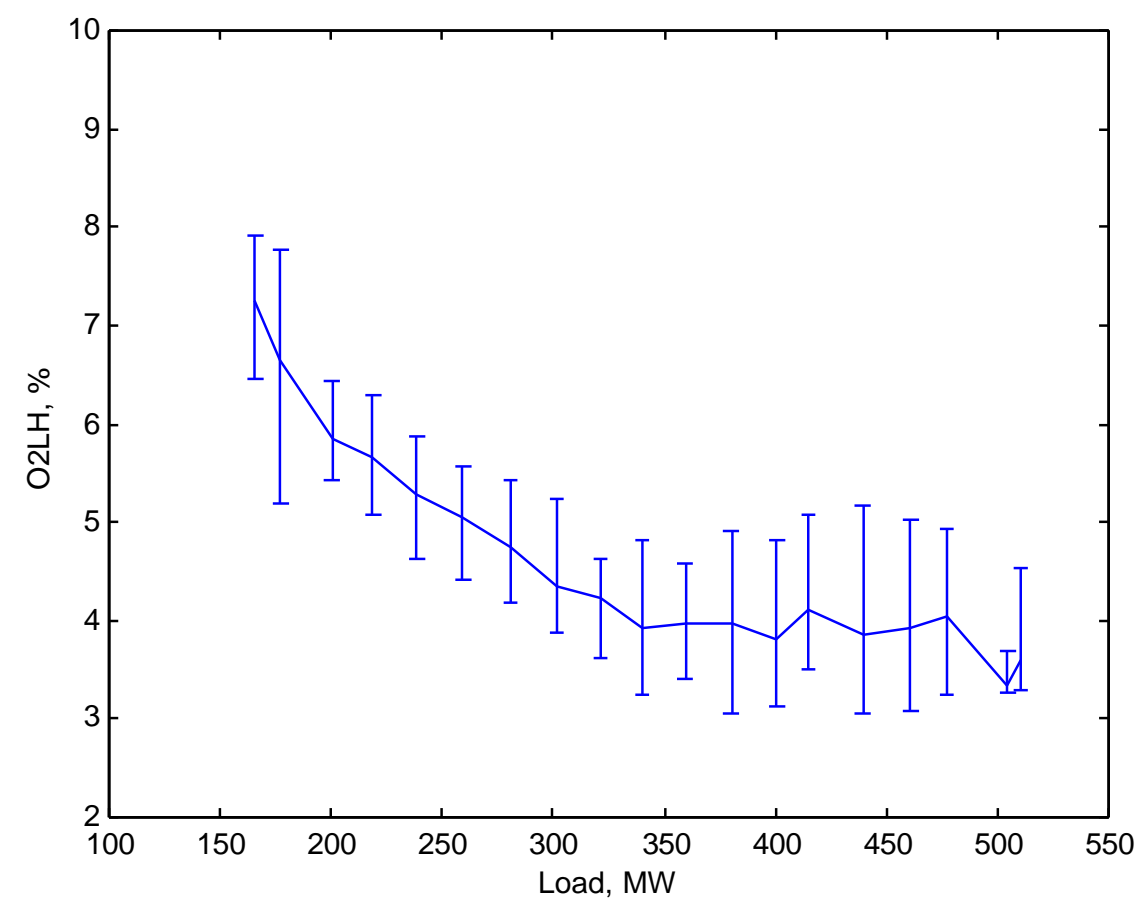

Figure 4-53 P4A - Excess Oxygen Left (West) vs. Load (1Q96) 


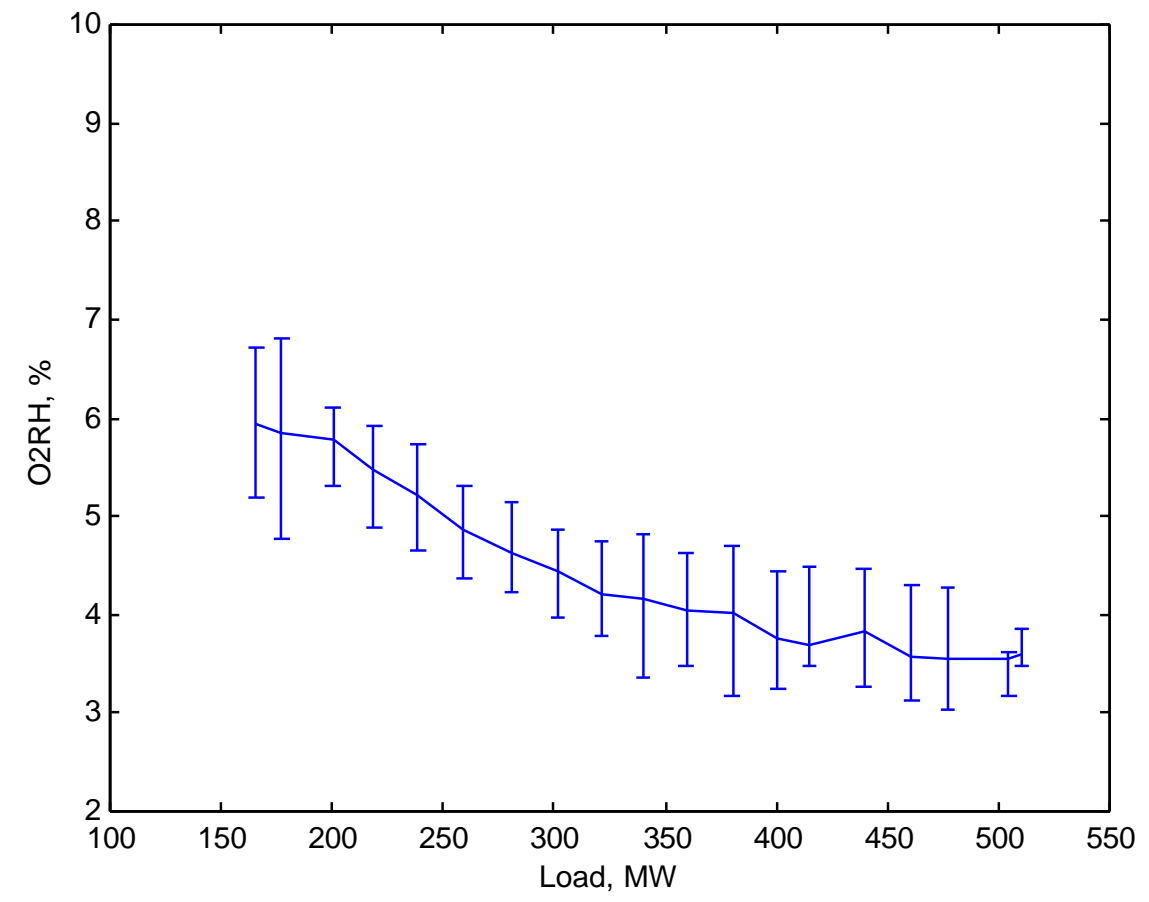

Figure 4-54 P4A - Excess Oxygen Right (East) vs. Load (1Q96)

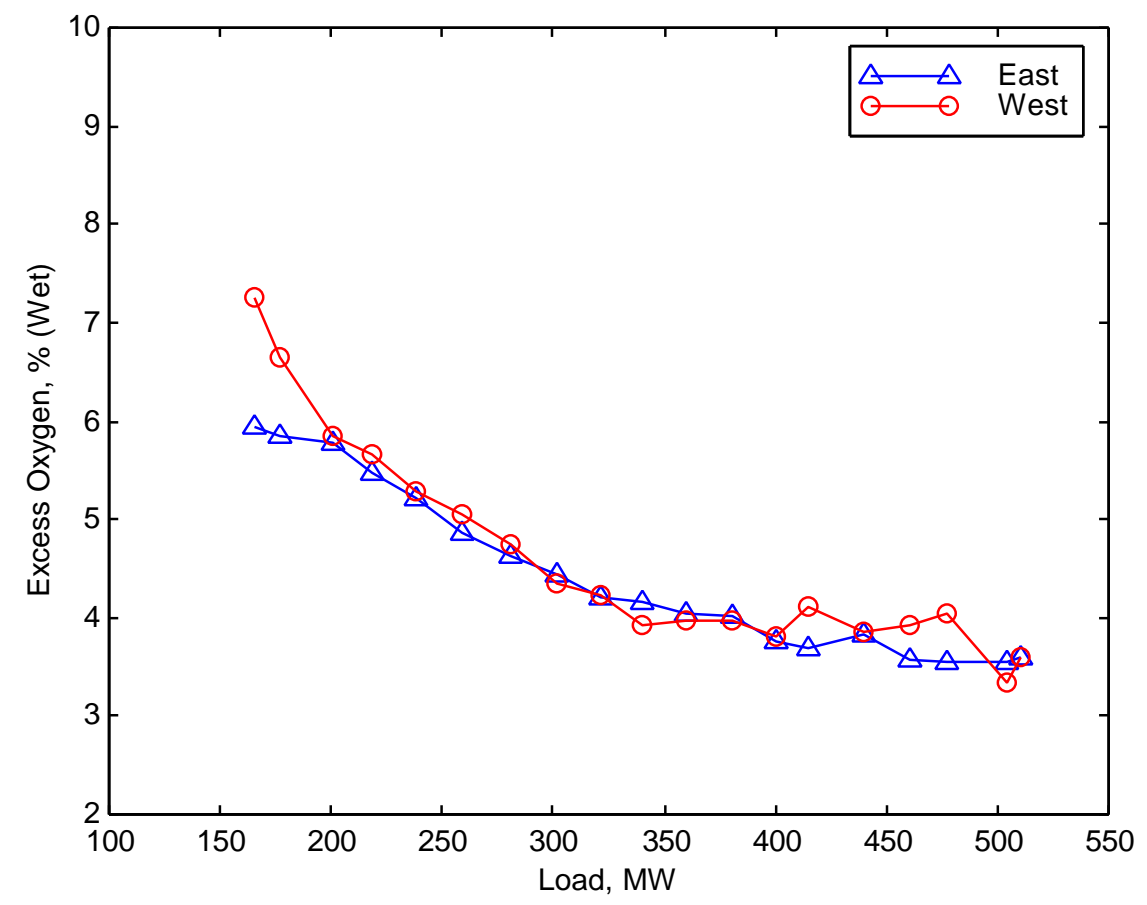

Figure 4-55 P4A - Excess Oxygen vs. Load (1Q96) 


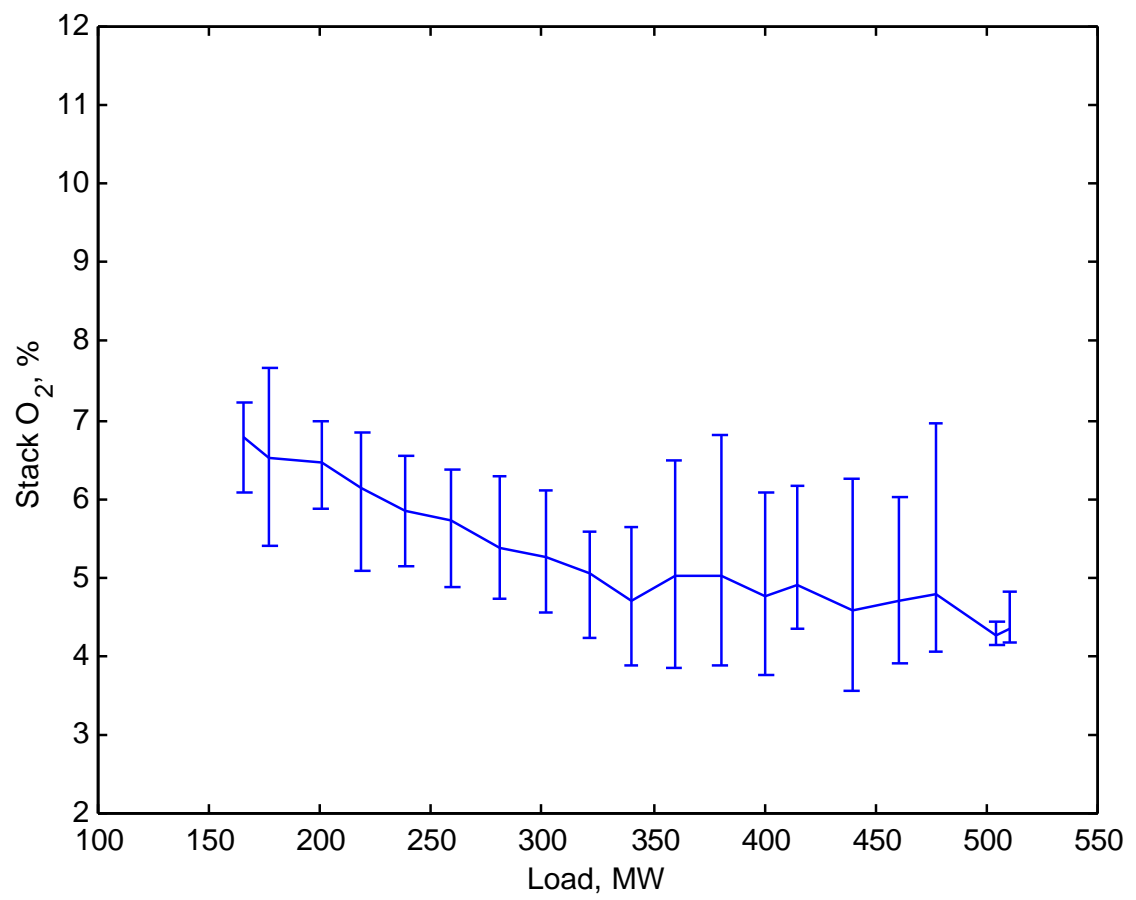

Figure 4-56 P4A - Stack Oxygen (Dry) vs. Load (1Q96)

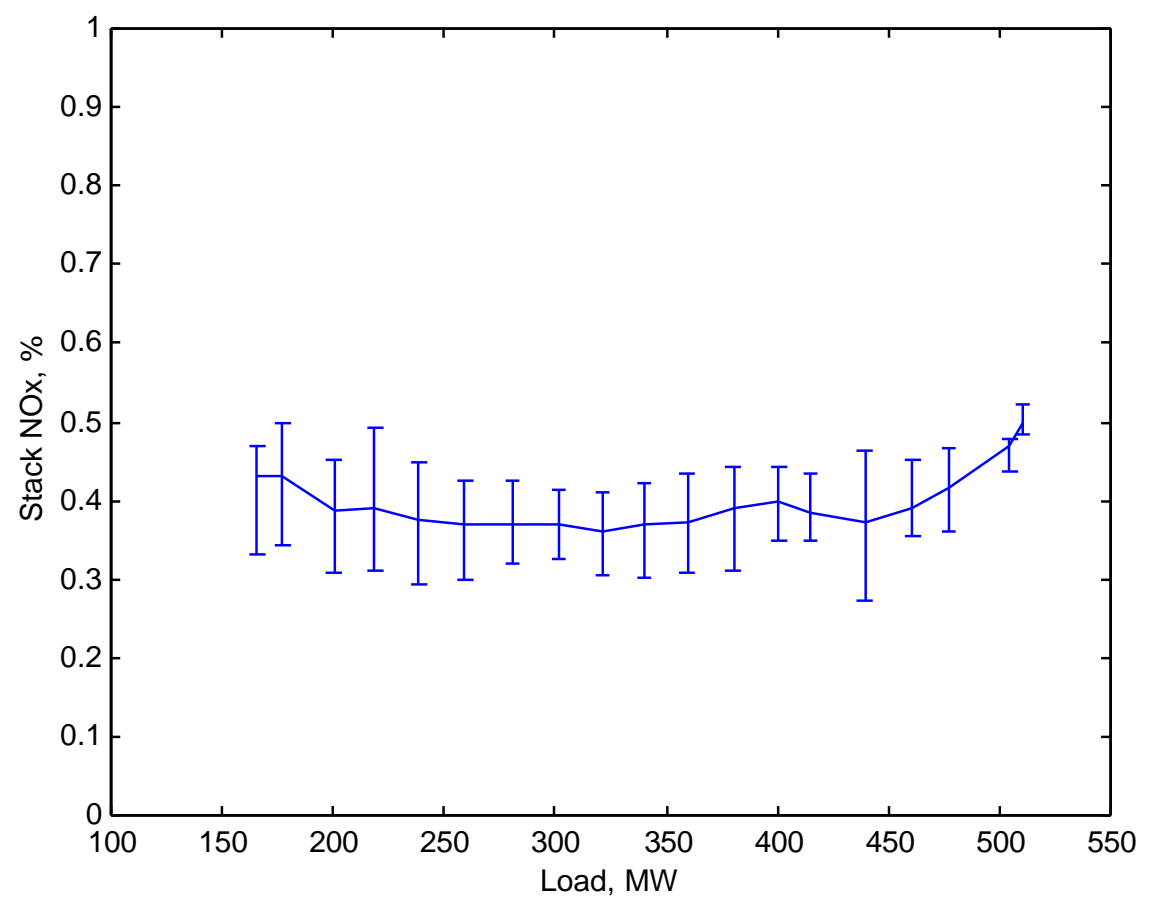

Figure 4-57 P4A - Stack NOx vs. Load (1Q96) 

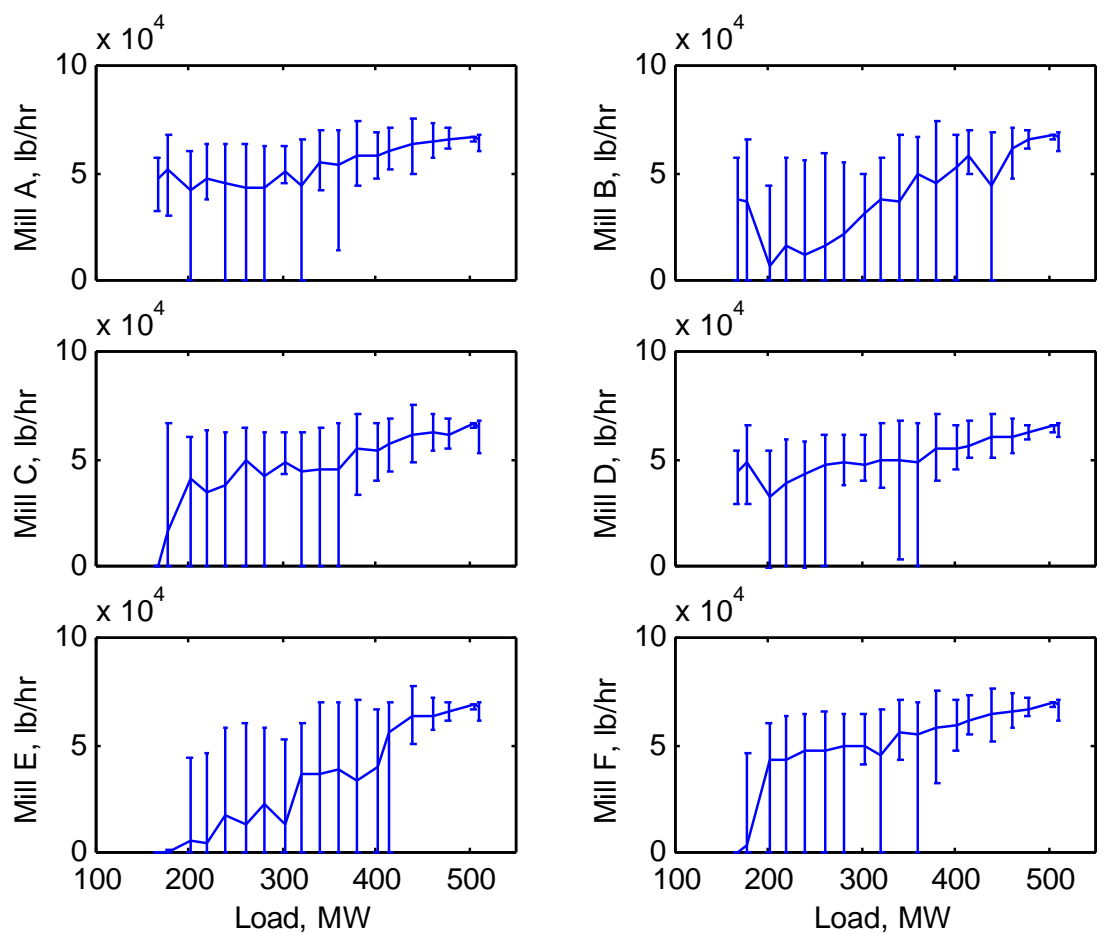

Figure 4-58 P4A - Mill Coal Flow vs. Load (1Q96)

Table 4-9 P4A - NOx Emissions vs. Mill Pattern (1Q96)

\begin{tabular}{ccc}
\hline Load Range & $\begin{array}{c}\text { Mill Pattern } \\
\text { A-B-C-D-E-F }\end{array}$ & $\begin{array}{c}\text { NOx Emissions } \\
\text { lb/MBtu }\end{array}$ \\
\hline $190-210$ & $1-0-1-0-0-1$ & 0.378 \\
& $1-0-1-1-0-1$ & 0.399 \\
& $1-1-1-0-1-0$ & 0.348 \\
$290-310$ & $1-0-1-1-0-1$ & 0.349 \\
& $1-0-1-1-1-1$ & 0.375 \\
$390-410$ & $1-1-1-1-0-1$ & 0.378 \\
& $1-0-1-1-1-1$ & 0.366 \\
$490-510$ & $1-1-1-1-0-1$ & 0.412 \\
& $1-1-1-1-1-1$ & 0.400 \\
& $1-1-1-1-1-1$ & 0.469 \\
\hline
\end{tabular}




\subsection{Performance Comparison}

This section provides a comparison of the performance of the unit after the addition of the DCS to other phases. Factors compared include NOx emissions, fly ash unburned carbon levels, CO emissions, excess oxygen and combustion air, air heater and economizer outlet gas temperatures, steam temperatures, drum and throttle pressure, boiler efficiency, and unit heat rate. When available, both short- and long-term data are used in the comparison. It should be noted that this data reflects how the technologies performed on Hammond Unit 4 and although extrapolation to other units is reasonable, consideration must be given to how close other units are to Hammond 4 in terms of boiler design, coal characteristics, and operating conditions.

\subsubsection{NOx Emissions}

A comparison of the long-term, mean NOx emissions observed during Phase 4A to that observed previously is shown in Figure 4-59. As shown, the Phase 4 NOx emissions were similar to those observed during Phase $3 \mathrm{~B}$ and considerably below the baseline levels (Phase 1). However from this figure it is also evident that NOx emissions did not generally improve from Phase $3 \mathrm{~B}$ to Phase 4A (Figure 4-60).

NOx emissions for the performance tests during each phase are shown in Figure 4-61. As shown, full-load NOx reductions for these tests were greater than those obtained during longterm, normal operation. The principal cause of the increase was the higher NOx emissions during the baseline performance test $(1.44 \mathrm{lb} / \mathrm{Mbtu}$ vs. $1.23 \mathrm{lb} / \mathrm{Mbtu})$. When the performance test $\mathrm{NOx}$ values are corrected to stack $\mathrm{O}_{2}$ levels (Table 4-10) observed during long-term testing, the emission reductions obtained for the performance and long-term tests are very similar. Also, the full-load NOx emissions during Phase 4A were slightly greater than that observed in prior phases. This increase may have been the result of the selection of overall lower operating combustion air levels.

\subsubsection{Fly Ash LOI}

A comparison of the LOI levels for the four phases as determined during the performance tests for Phases 1 through 4A is shown in Figure 4-62. These values are the average of the performance test conducted during the test period. Full-load LOI levels for Phase 3B (LNB+AOFA) and Phase 4A (LNB+AOFA+DCS) were similar, however, at lower load levels, the Phase 4A LOI levels were greater than the Phase 3B tests. This increase occurred despite the replacement of two pulverizes during the intervening outage and the resultant improvement of coal fineness between the phases (Baseline - Pass $200 \mathrm{Mesh}=63 \%$ / Remain 50 Mesh $=2.7 \%$, $\mathrm{AOFA}=67 \% / 2.3 \%, \mathrm{LNB}=66 \% / 1.6 \%, \mathrm{LNB}+\mathrm{AOFA}=74 \% / 0.6 \% ; \mathrm{LNB}+\mathrm{AOFA}+\mathrm{DCS}=$ $76 \% / 0.1)$.

As stated previously, the performance test conditions were selected based on predicted long-term operating factors including excess oxygen and mill patterns. Because the unit was not necessarily operated at these selected conditions, short-term performance tests do not necessarily match that obtained during long-term tests. To partially compensate for differences in the longterm and short-term operating conditions, the LOI can be adjusted to the stack oxygen levels 
observed during the long-term data collection. The full-load estimate for Phase 4A is shown in Table 4-11 with that for all loads in Figure 4-63. A comparison of the Phase 3B and Phase 4A LOI levels are shown in Figure 4-64.

\subsubsection{Excess Oxygen}

As shown in Figure 4-65, measured stack oxygen levels were generally less during Phase 4A than Phase 3B. The differences between the two phases could be the result of several factors including: (1) shift in combustion air, (2) changes in the amount of air in-leakage in the furnace backpass and precipitator (the stack probe is located downstream of the precipitator), and (3) air in-leakage in the sampling system to the stack probe (since the NOx is compensated to $3 \%$ excess $\mathrm{O}_{2}$, this reading would not be affected by the leakage). The first two hypothesis are supported by a reduction in economizer outlet $\mathrm{O}_{2}$ levels (Figure 4-66).

\subsubsection{Economizer Exit and Air Heater Exit Temperatures}

The economizer exit and air heater exit gas temperatures are shown in Figure 4-67 and Figure 4-68, respectively. As shown, economizer outlet temperatures during Phase 3B were in general slightly lower than that observed during Phase 4A. However, air heater gas outlet temperatures during Phase 4A were improved over the Phase 3B temperatures.

\subsubsection{Main Steam and Hot Reheat Temperatures}

There was a general decline in main steam temperatures from Phase 3B to Phase 4A (Figure 4-69). As shown, there was some improvement in temperatures for $1^{\text {st }}$ quarter 1996 when compared to $1^{\text {st }}$ quarter 1995. Hot reheat temperature, shown in Figure 4-70, was similar from about 400 MW upwards but exhibited a degradation below this load level. The cause of the steep decline in steam temperatures below $200 \mathrm{MW}$ is unknown. 


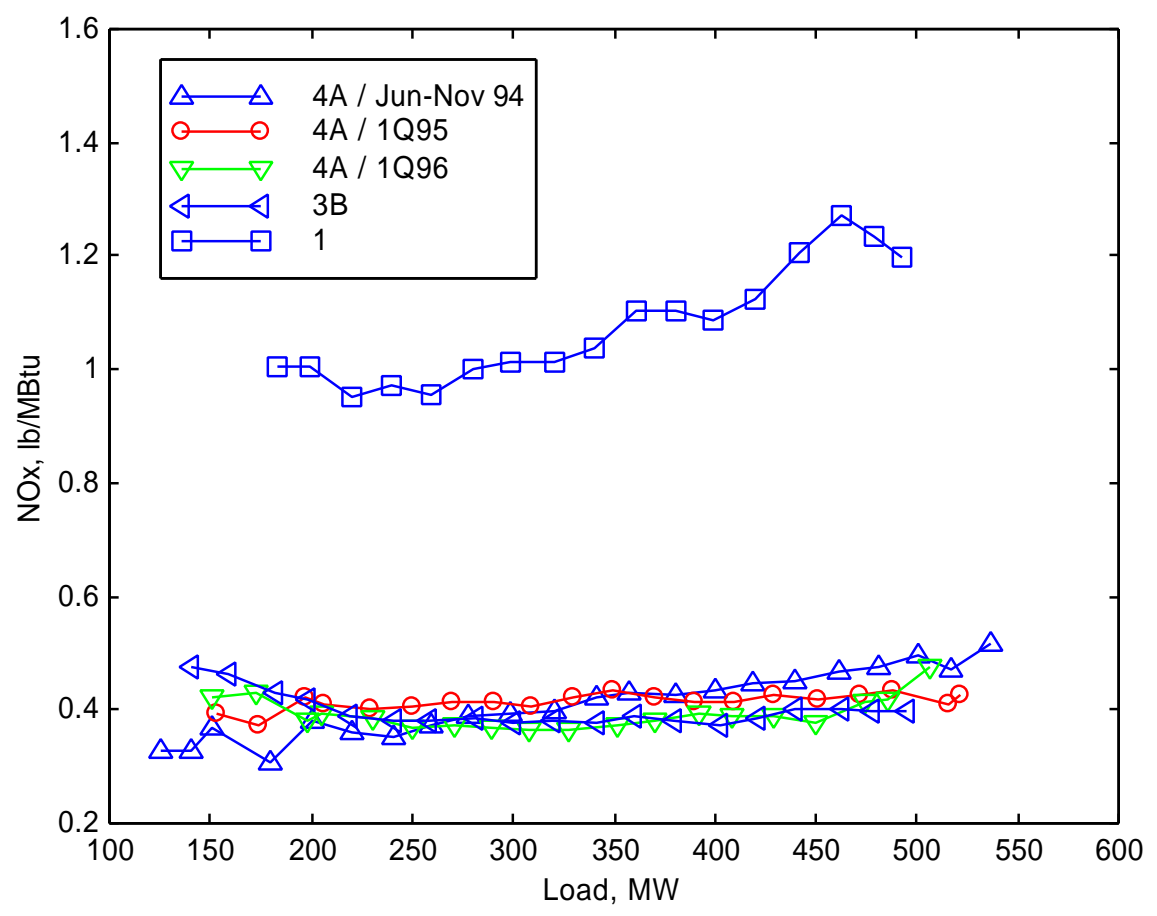

Figure 4-59 Comparison of Long-Term NOx Emissions

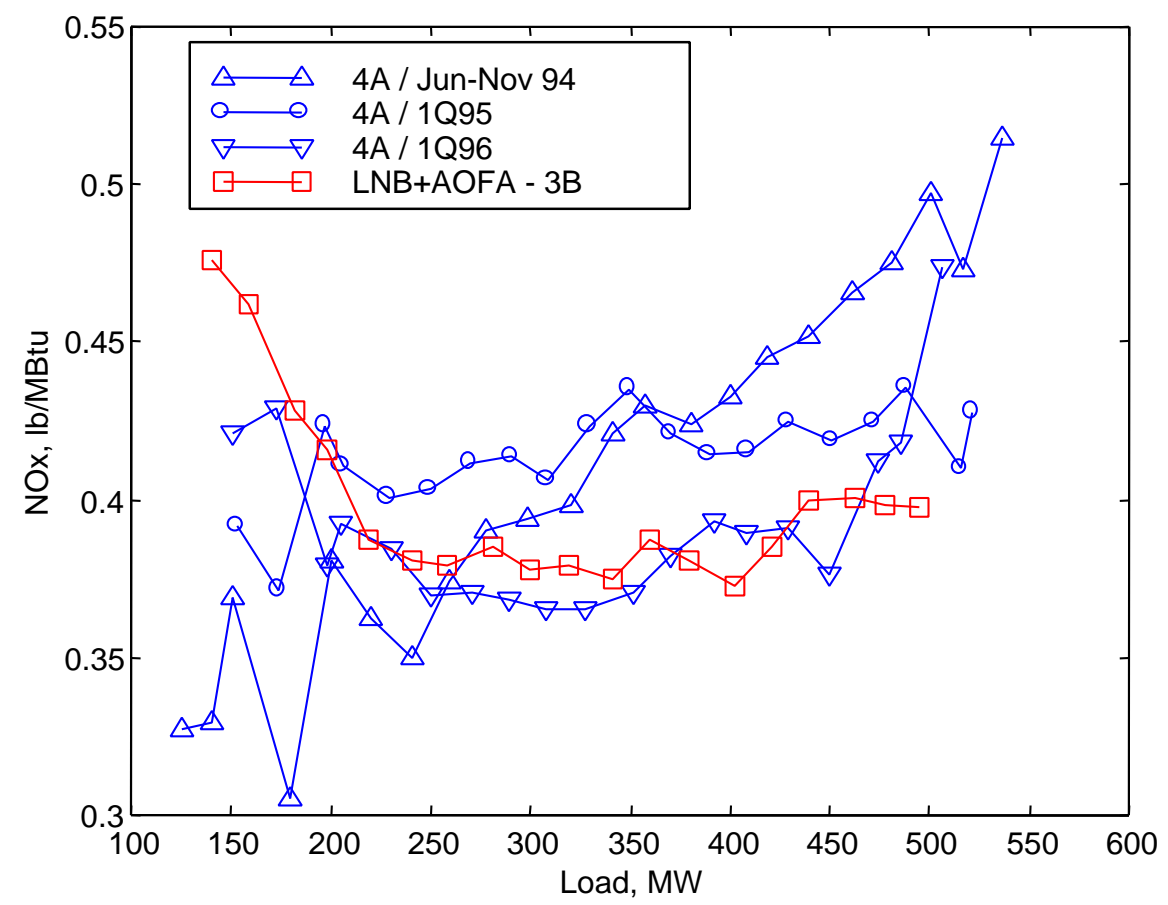

Figure 4-60 Comparison of Long-Term NOx Emissions (Reduced Range) 


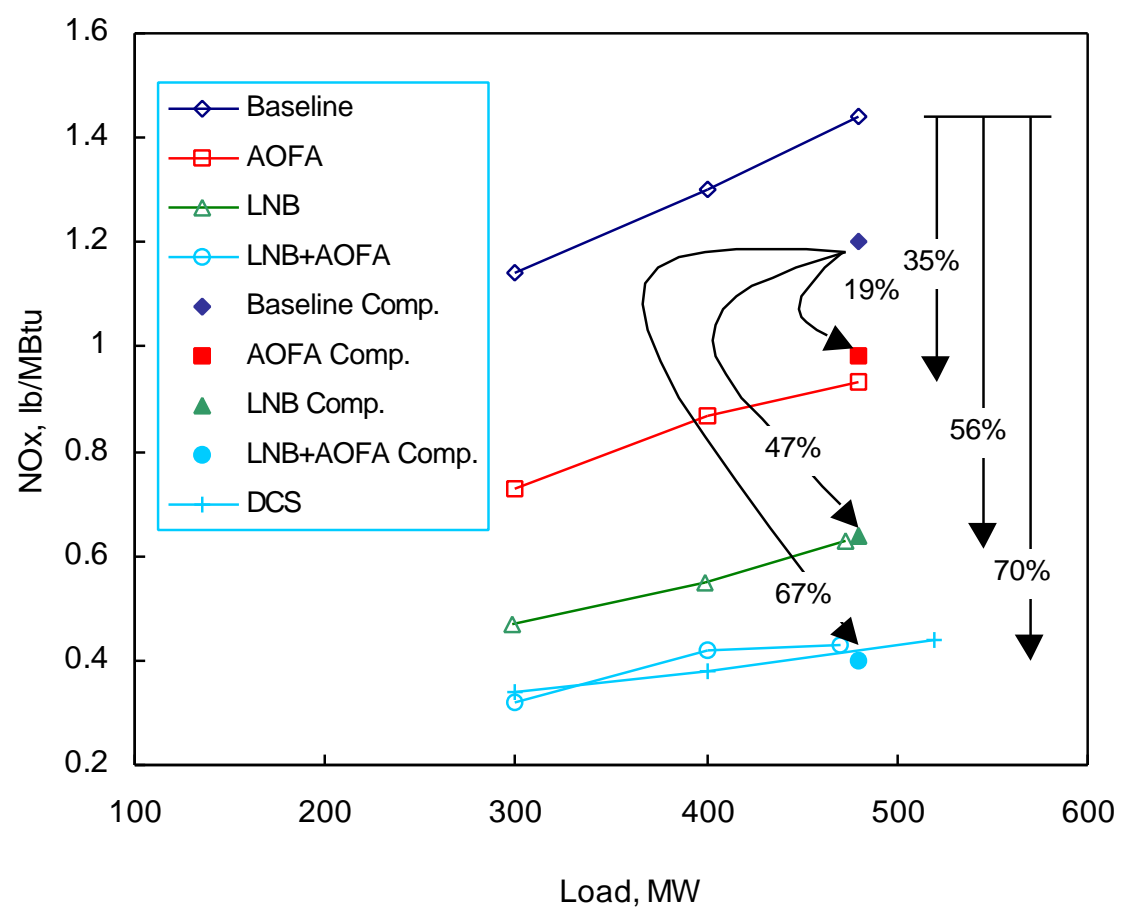

Figure 4-61 P4A - Comparison of Performance Tests NOx Levels

Table 4-10 NOx Emissions Obtained During Long-Term and Performance Tests

\begin{tabular}{lccccc}
\hline & $\begin{array}{c}\text { Long-Term } \\
\text { NOx Emissions } \\
\text { Lb/MBtu }\end{array}$ & $\begin{array}{c}\text { Long-Term } \\
\text { Stack } \mathrm{O}_{2} \\
\text { Percent }\end{array}$ & $\begin{array}{c}\text { Perf. Test } \\
\text { NOx Emissions } \\
\text { Lb/Mbtu }\end{array}$ & $\begin{array}{c}\text { Perf. Test } \\
\text { Stack } \mathrm{O}_{2} \\
\text { Percent }\end{array}$ & $\begin{array}{c}\text { Compensated } \\
\text { Perf. Test } \\
\text { NOx Emissions } \\
\text { Lb/Mbtu }\end{array}$ \\
\hline Baseline & 1.24 & 5.0 & 1.44 & 7.5 & 1.19 \\
AOFA & 0.94 & 6.5 & 0.93 & 6.3 & 0.94 \\
LNB & 0.65 & 6.6 & 0.63 & 6.4 & 0.64 \\
LNB+AOFA & 0.40 & 6.1 & 0.43 & 6.6 & 0.40 \\
+DCS & 0.47 & 5.3 & 0.44 & 5.4 & 0.43 \\
\hline
\end{tabular}

Full-load (480 MW for baseline, AOFA, LNB, LNB+AOFA, 520 MW for DCS)

${ }^{2} \mathrm{NOx}$ emissions compensated to stack $\mathrm{O}_{2}$ levels observed during the corresponding long-term test period. 


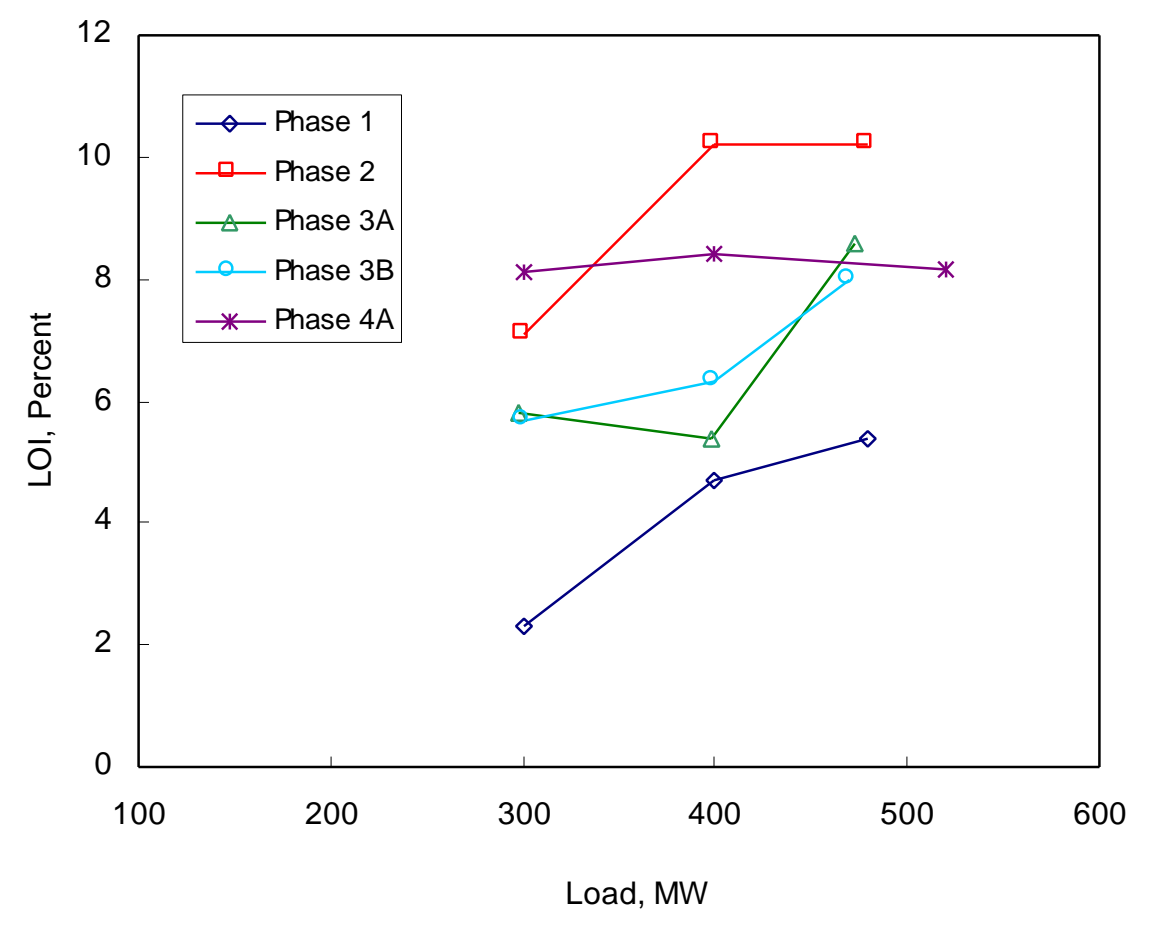

Figure 4-62 P4A - Comparison of Performance Tests LOI Levels

Table 4-11 Full-Load LOI Levels

\begin{tabular}{lcccccc}
\hline & $\begin{array}{c}\text { Perf. Test } \\
\text { Stack } \mathrm{O}_{2} \\
\text { Percent }\end{array}$ & $\begin{array}{c}\text { Perf. Test } \\
\text { LOI } \\
\text { Percent }\end{array}$ & $\begin{array}{c}\text { Perf. Test } \\
\text { Percent } \\
\text { Increase }\end{array}$ & $\begin{array}{c}\text { Long-Term } \\
\text { Stack } \mathrm{O}_{2} \\
\text { Percent }\end{array}$ & $\begin{array}{c}\text { Long-Term } \\
\text { LOI } \\
\text { Percent }\end{array}$ & $\begin{array}{c}\text { Long-Term } \\
\text { Percent } \\
\text { Increase }^{2}\end{array}$ \\
\hline Baseline & 7.5 & 5.2 & na & 5.0 & 7.1 & na \\
AOFA & 6.3 & 10.2 & 96 & 6.5 & 10.1 & 42 \\
LNB & 6.4 & 8.6 & 65 & 6.6 & 8.2 & 16 \\
LNB+AOFA & 6.6 & 8 & 54 & 6.1 & 8.4 & 18 \\
Phase 4A & 5.4 & 8.2 & 58 & 5.3 & 8.3 & 17 \\
\hline
\end{tabular}

${ }^{1}$ LOI compensated to stack $\mathrm{O}_{2}$ levels obtained during long-term test using a sensitivity of 0.75 LOI percent per percent change in excess $\mathrm{O}_{2}$.

${ }^{2}$ Relative to baseline. 


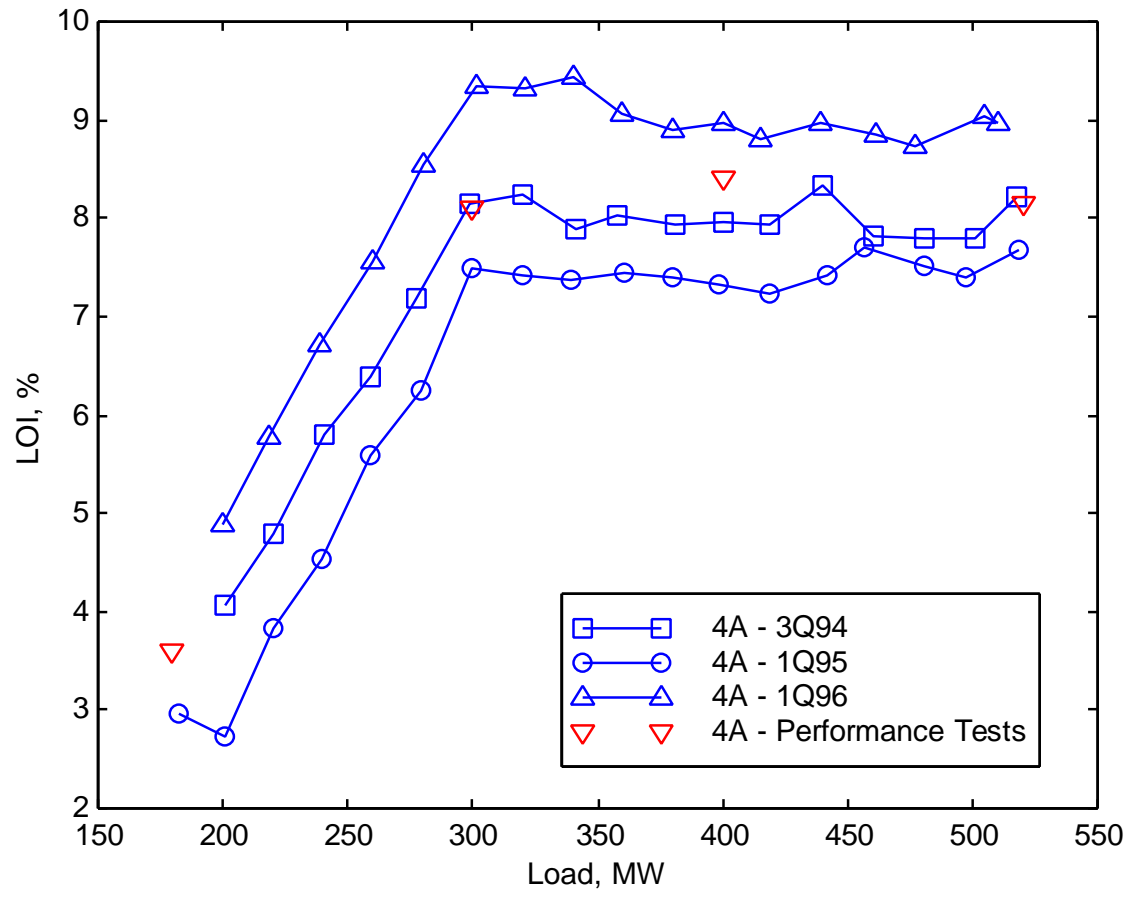

Figure 4-63 P4A - Comparison of Performance Tests to Predicted Long-Term LOI Levels

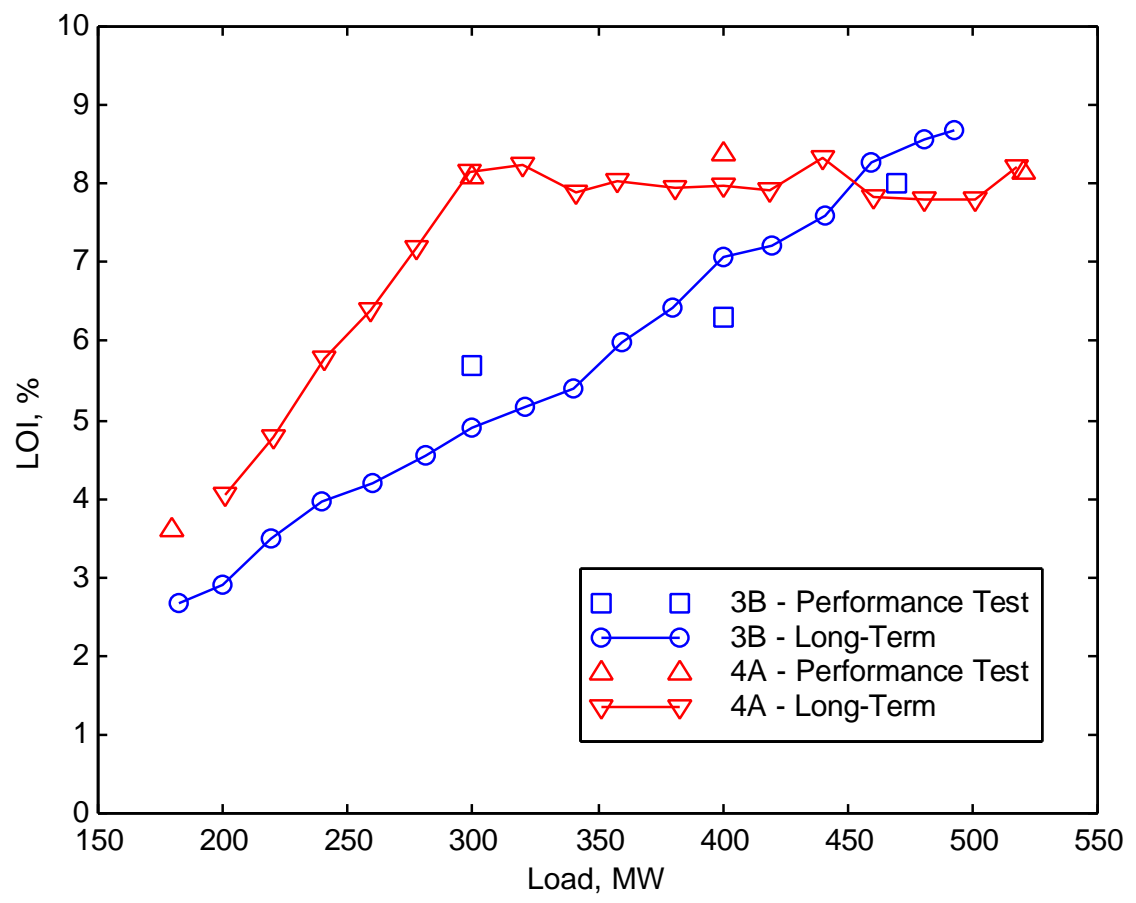

Figure 4-64 P4A - Comparison of LOI Levels 


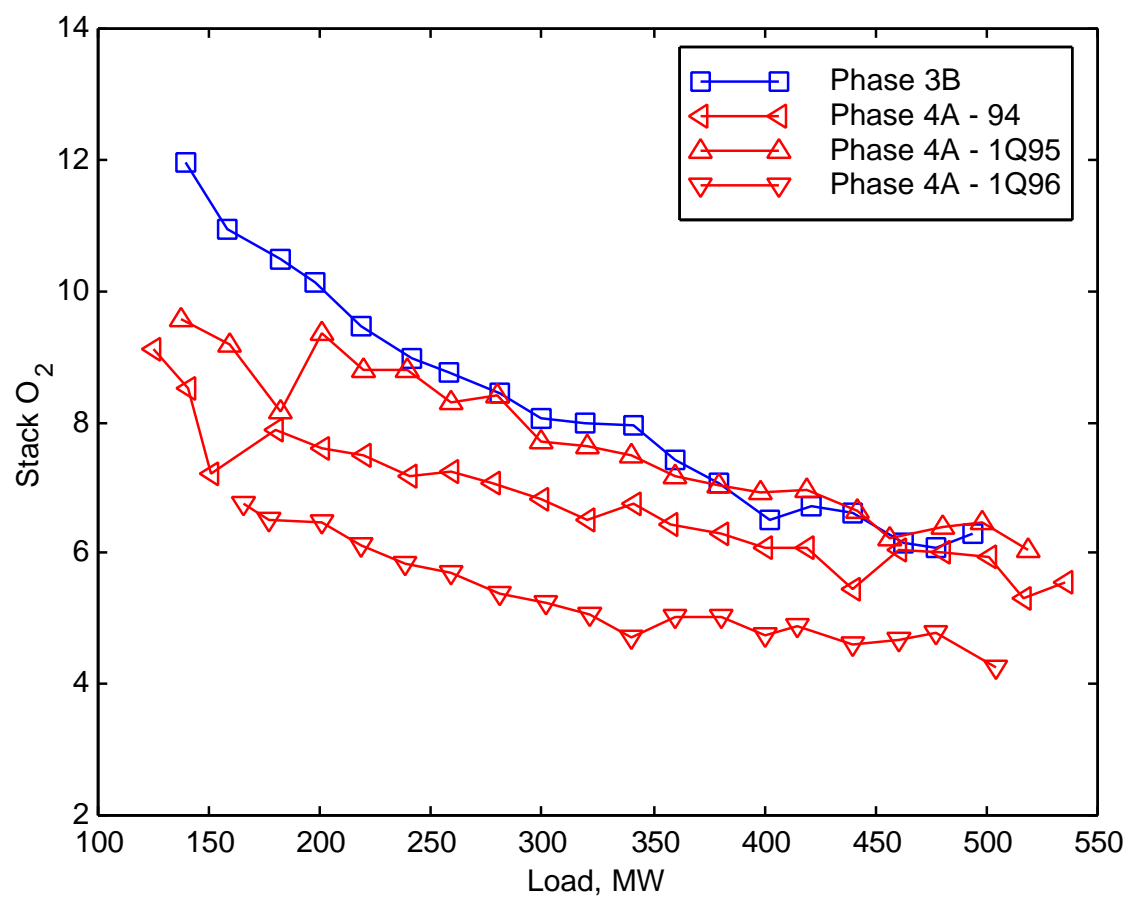

Figure 4-65 P4A - Comparison of Stack $\mathrm{O}_{2}$ Levels

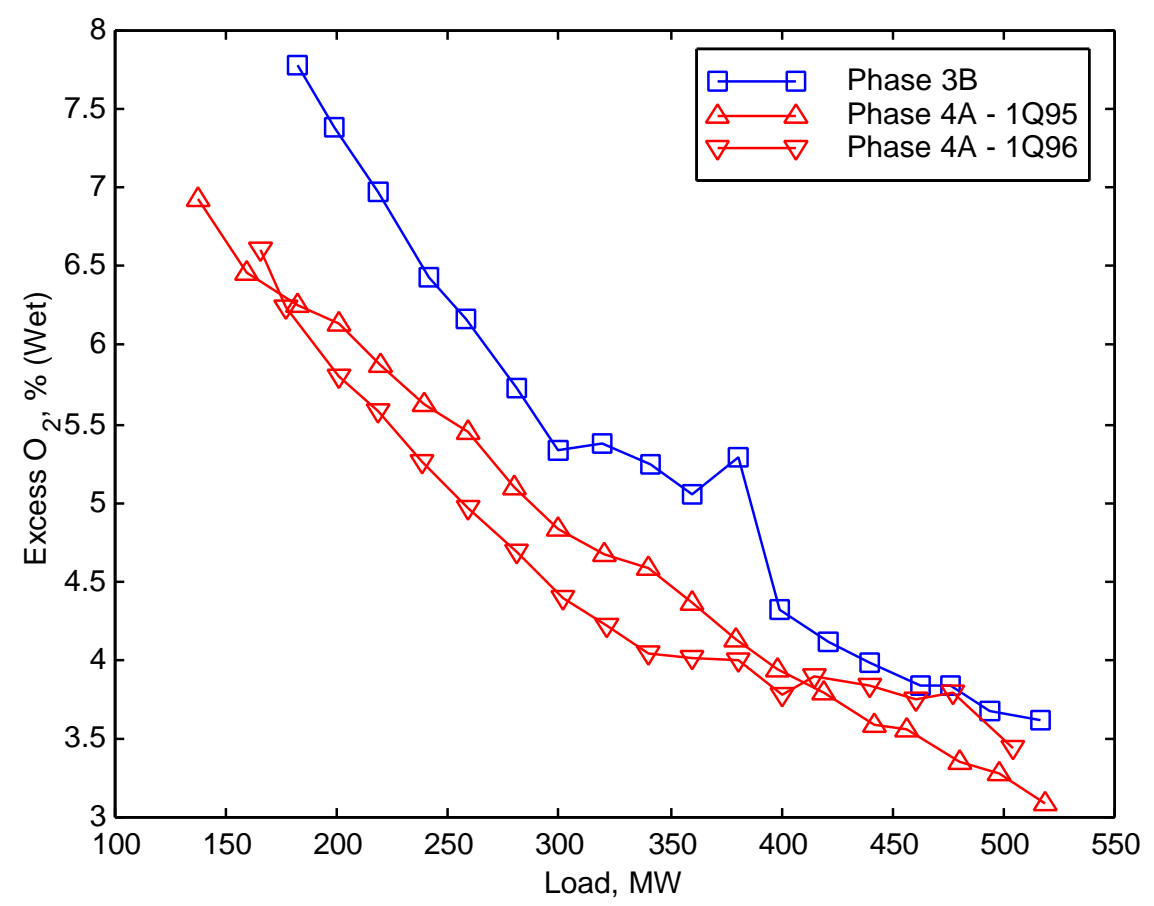

Figure 4-66 P4A - Comparison of Economizer Outlet $\mathrm{O}_{2}$ Levels 


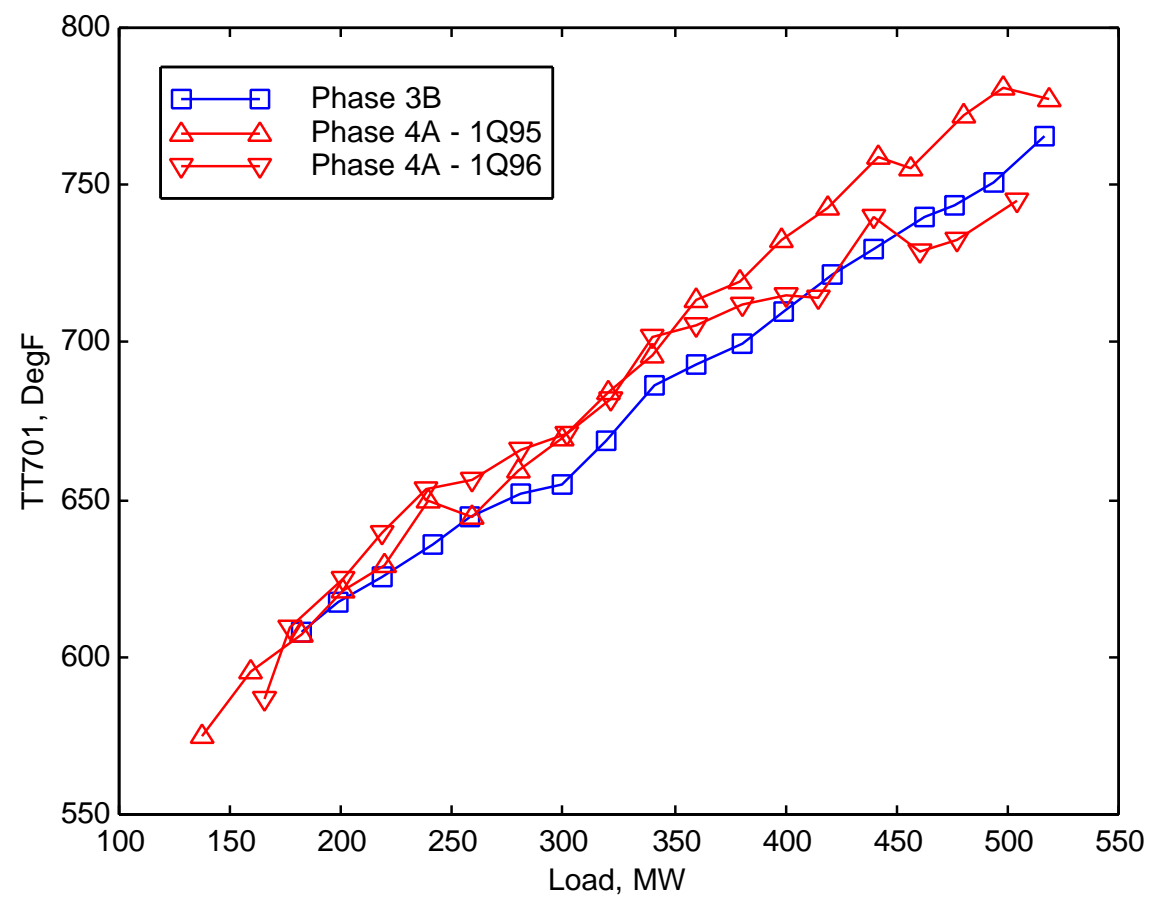

Figure 4-67 P4A - Comparison of Economizer Gas Inlet Temperatures

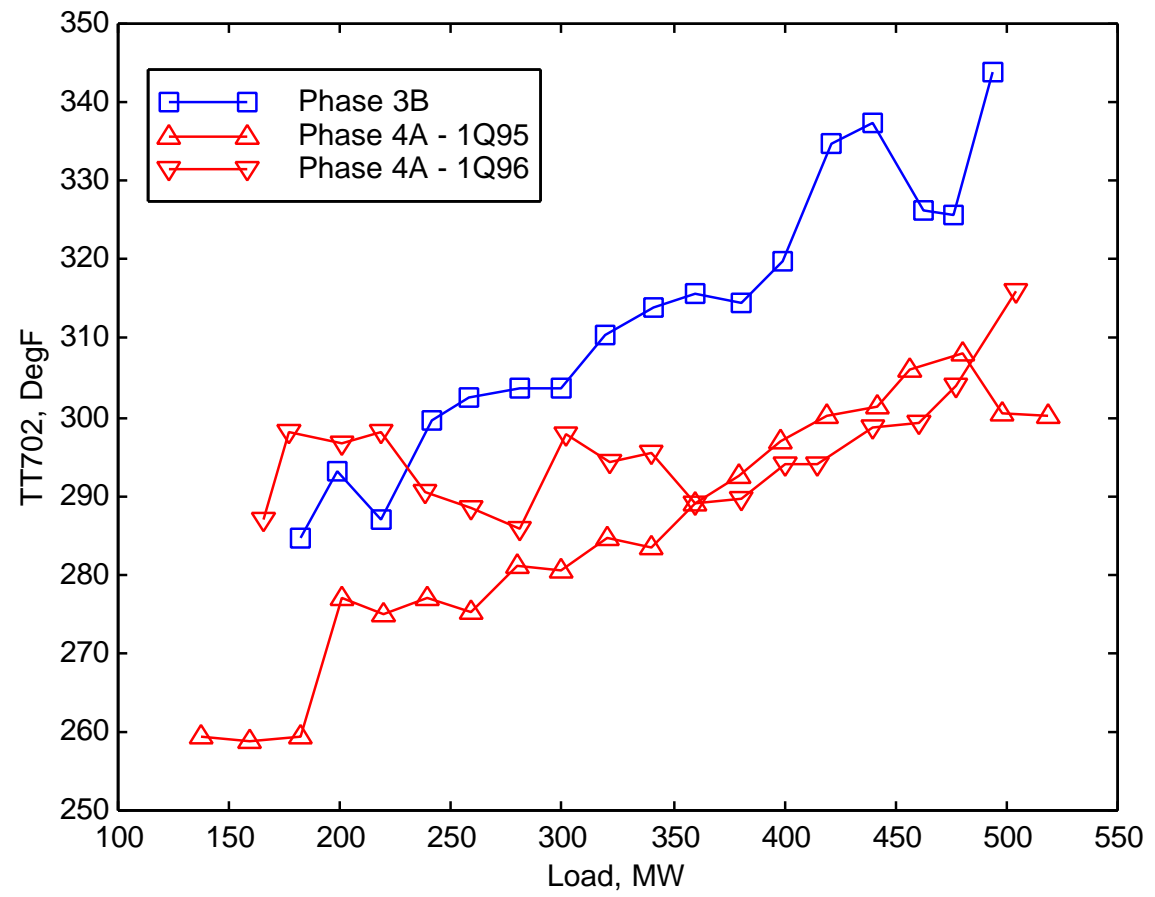

Figure 4-68 P4A - Comparison of Economizer Gas Outlet Temperatures 


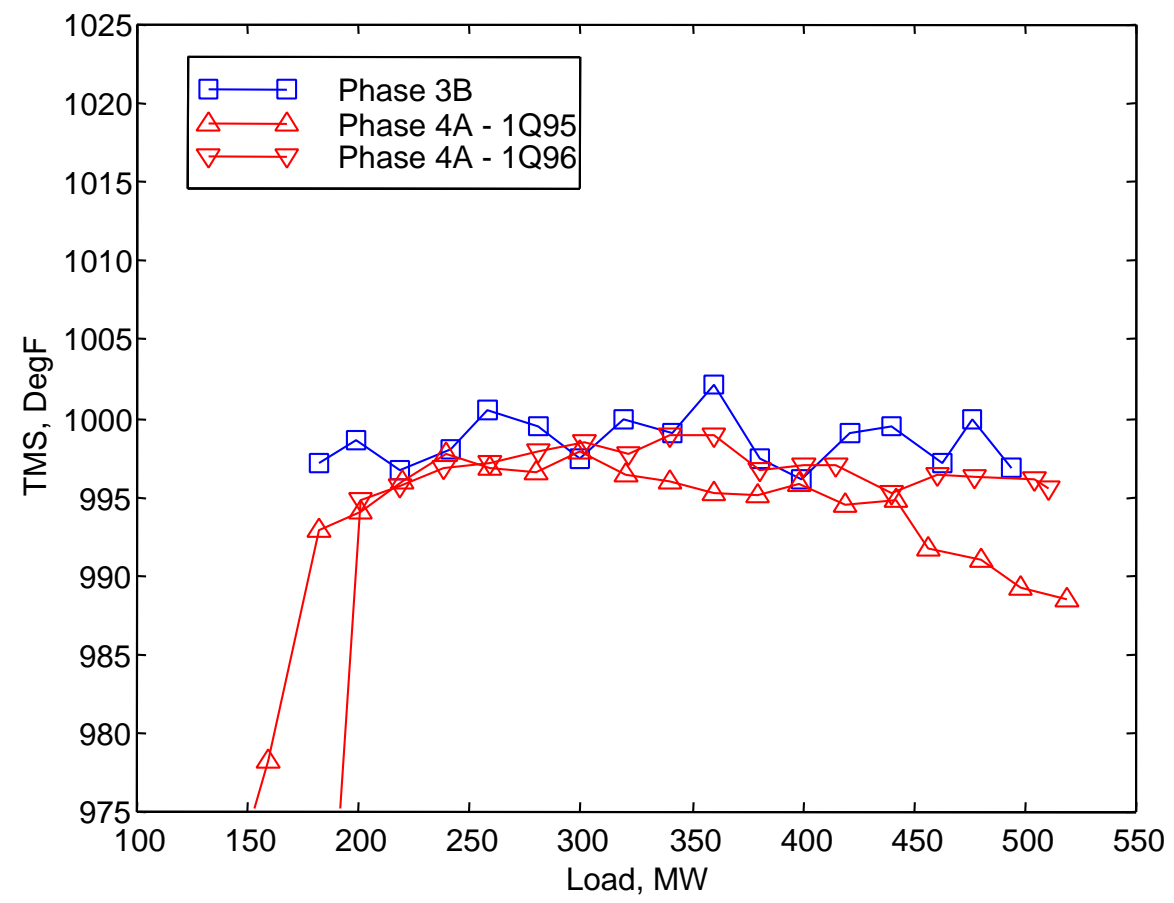

Figure 4-69 P4A - Comparison of Main Steam Temperatures

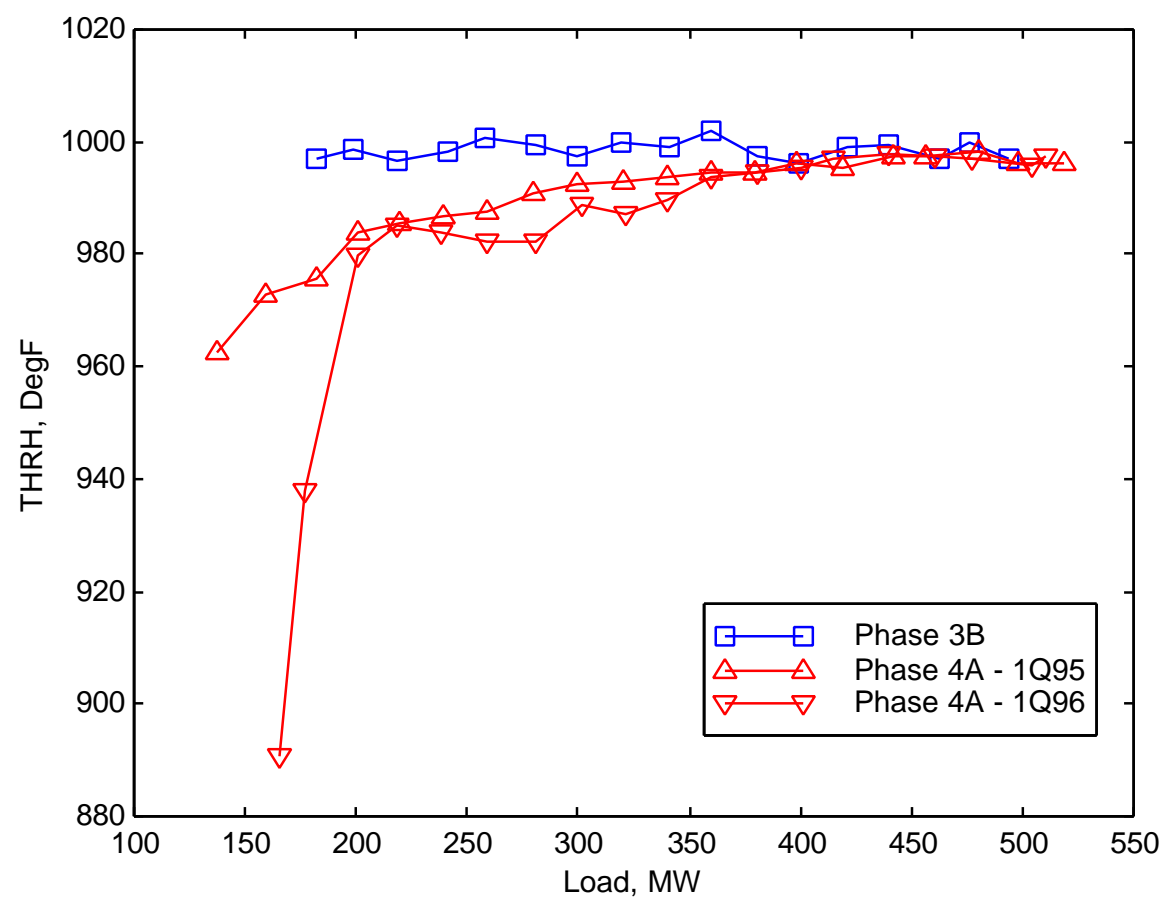

Figure 4-70 P4A - Comparison of Hot Reheat Temperatures 


\section{OPTIMIZATION}

\subsection{Introduction}

As discussed in Section 3, results from Hammond and other sites indicated that there was potential for the use of on-line combustion techniques to improve combustion performance both for NOx emissions and efficiency. During 1991, SCS, along with the other project participants, began initial discussions on extensions to the project that would explore and evaluate these techniques. The following studies grew out of these discussions.

- During 1992, SCS contracted with Tennessee Technological University's Center for Electric Power to perform a feasibility study for advanced controls and optimization which eventually led to a demonstration of ULTRAMAX at Hammond 4.

- As a follow up to this work, the project participants looked at applying neural networks to modeling the combustion process including NOx emissions and boiler performance parameters.

- Following installation of the DCS and testing of this unit, the on-line optimization package GNOCIS (Generic NOx Control Intelligent System) was installed on the unit. GNOCIS became operational on the unit in open-loop mode during first quarter 1996 with closed-loop operation during second quarter 1996.

The major findings of these studies are discussed in the following paragraphs.

\subsection{Feasibility Study}

On January 6, 1992, Southern Company Services proposed to the project participants an initial feasibility study to investigate on-line combustion optimization. This proposal was based on evidence from this and other combustion demonstration projects that control strategies can affect NOx reduction potential. Tennessee Technological University's Center for Electric Power was selected to perform this study.

The broad activities of this study were:

- Literature search to identify existing art and promising technologies.

- Plant testing as necessary to validate promising technologies.

- Computer modeling as necessary to evaluate the effects of the advanced control strategies on NOx emissions.

- Preliminary control development and conceptual design.

Based on these initial investigations, ULTRAMAX ${ }^{\circledR}$, was selected to perform preliminary optimization. ULTRAMAX is a software product from Ultramax Corporation. This selection was based on several factors: 
- It was commercially available

- Does not require a digital control system, data acquisition system, or great computing resources.

- Only a moderate learning curve required to become competent in its use.

\section{Description of ULTRAMAX}

ULTRAMAX is an optimization package by which the improvements to the process are achieved by making adjustments to the process inputs, monitoring the output response, and using the response from prior perturbations to make performance predictions. This commercial package has been available for a number of years and is used extensively in the process industries. This package traverses the multi-dimensional process space in it's search for the optimum operating condition and in doing so develops a regression model of the process. The software uses a goal-oriented, locally accurate model to make predictions and operating recommendations.

Commonly known constrained optimization techniques being used are Simplex and EVOP (Evolutionary Operation). Simplex is used to solve linear programming problems delimited by an objective function where constraint functions may be included [Ragsdell, 1983]. EVOP is a statistical method for process improvement that is best suited for $2^{\mathrm{k}}$ and $3^{\mathrm{k}}$ factorial design of experiments [Box, 1969]. These methods are not very well suited for on-line combustion optimization. Aside from the fact that both of them are not easily applied to ongoing processes and require too much time and attention; Simplex sensitivity to noise and variability makes it an even poorer candidate, and the large number of variables to consider would make the factorial design of experiments a costly technique. "The difficulty of operating an EVOP scheme increases greatly as the number of factors (variables) is increased, because of the number of process conditions involved and the number of changes that must be made" [Box, 1969].

Sequential optimization is based on the principle of EVOP "that a process should be operated so as to produce not only a product but also information on how to improve the product" [Box, 1969]. In addition, a fundamental principle of sequential statistical analysis is that proper and timely use of existing information is more effective than not using it [Wald, 1947]. These principles underline the advantages of sequential optimization over other methods since process data is used cognitively and immediately, instead of being reserved for later analysis. As a result, process models developed using sequential optimization may be able to quickly learn to avoid settings that produce poor performance and tend to move rapidly in the direction of improvement.

A more recent technique is based on a statistical approach to create quadratic models of the measurements in a system and, integrating these models, recommend adjustments to the control settings [Moreno, 1989]. In this technique, the system's variables are categorized in three groups: (1) controlled inputs, (2) external inputs, and (3) results. A problem formulation is then devised where the variables take roles as "controlled" (that can be adjusted by the user), "external" (measurable but not influenced by the user), "ruled" (governed by user-defined rules), "results" (of interest only), "important results" (constrained or used for computational purposes), 
and "measure of performance" (the objective of the optimization). These roles are interchangeable during the process making this technique flexible.

In constrained sequential optimization, linear regression is the tool used to determine the relationship between the independent variable $(\mathrm{X})$ and the dependent variable $(\mathrm{Y})$ so that the expected value of Y, let's call it Y', can be calculated from any given input value X. Based on the principle that continuous functions can be locally approximated with a quadratic expression, this relationship is defined with the formula:

$$
Y^{\prime}=a+b X+c X^{2}
$$

Linear regression uses the technique of least squares to calculate the coefficients $\mathrm{a}, \mathrm{b}$ and $\mathrm{c}$ [Neter, 1990]. The criterion used is, as the name indicates, the minimization of the sum of the squares; that is, the difference between a measured value of $Y$ and the theoretical value $Y^{\prime}$ is the least. For $n$ pairs of values, the relation between $\mathrm{X}$ and $\mathrm{Y}$ becomes:

$$
\mathrm{Y}_{k x 1}=\mathrm{a}_{k x 1}+\mathrm{b}_{k x 1} \mathrm{X}_{1 x k}+\mathrm{c}_{k x 1} \mathrm{X}_{1 x k}^{2}+\varepsilon_{k x 1}
$$

This quadratic model can be extended to multiple input variables $X_{1}, X_{2}, X_{3}, \ldots, X_{n}$ creating a multidimensional surface in which sequential optimization can be applied. Two parameters that determine the goodness of a regression model are (1) the coefficient of determination $\left(\mathrm{R}^{2}\right)$, which measures the proportionate reduction of total variation in the dependent variable (Y) associated with the use of the set of independent variables $\left(\mathrm{X}_{\mathrm{i}}\right)$, and (2) the Standard Distance $(\sigma)$ is a parameter representing a standard (dimensionless) measure of the distance from the current independent variables to the region defined by the run data selected to generate the current local models.

In addition to constructing a multidimensional surface, Moreno's method weights the latest data points collected to create locally accurate or goal-oriented models, avoiding the creation of descriptive (global) models for all the data that may override smaller details. These models are used to predict results and provide sequential advice on how to run the process, that is, how to adjust the input variables for the next cycles. This advice is called sequential since every time it is followed, new data is generated that is used to calculate a new regression function which in turn is used to generate new advice. The advice is not always an optimum prediction because perturbations can be added about the estimated optimum to obtain more information about the process and potentially increase the accuracy of the models. This technique has been integrated into ULTRAMAX [Moreno, 1989].

\section{Testing at Hammond}

Preliminary on-line testing of this software package was conducted at Plant Hammond Unit 4 on July 28-29, 1992 [Catasus-Servia, 1993]. The objective of this experiment was to determine the validity of the data used with the optimization package and the statistical process model (for NOx, CO, opacity, etc.) created by this package. The accuracy of the model represents the software's ability to predict the process outputs given the optimization objective function and constraints (both physical and those defined in the software). Experiment 1 was done using 
instantaneous data as provided by direct readings of the five second scan rate of the DAS with the purpose of investigating the application and performance of the sequential optimization software as a controller. Until now, this methodology has not been applied to an emissions control problem and therefore, this experiment was designed as a limited feasibility study to determine whether this approach had potential for boiler control. The experiment consisted of six independent variables (Total Air, OFA West Front, OFA East Front, OFA West Rear, and OFA East Rear), three constraints (opacity, $\mathrm{O}_{2}$, and $\mathrm{CO}$ ) and $\mathrm{NOx}$ as the measure of performance. The model formulation used is listed in Table 5-1. Opacity, $\mathrm{O}_{2}$, and CO constraints were set to meet the safety and environmental operational requirements of the boiler as prescribed by plant operations personnel. A CO constraint of $30 \mathrm{ppm}$ was required to consistently maintain $\mathrm{CO}$ emissions below $100 \mathrm{ppm}$. The recommendations provided by the software were implemented manually by the operator. The results of these changes on NOx, CO, and opacity were fed back into the optimization package manually.

Table 5-1 Feasibility Study - Problem Formulation Experiment 1

\begin{tabular}{lll}
\hline \multicolumn{1}{c}{ Variable } & Units & \multicolumn{1}{c}{ Variable Type } \\
\hline Total Air & MPPH & 1 - Controlled \\
OFA West Front & KPPH & 1 - Controlled \\
OFA East Front & KPPH & 1 - Controlled \\
OFA West Rear & KPPH & 1 - Controlled \\
OFA East Rear & KPPH & 1 - Controlled \\
Total Coal & KPPH & 2 - External \\
CO & PPM & 5 - Important Result - Constraint $<30 \mathrm{ppm}$ \\
Economizer $\mathrm{O}_{2}$ & PCT & 5 - Important Result - Constraint $>3.0 \%$ \\
Opacity & PCT & 5 - Important Result - Constraint $<30.0 \%$ \\
NOx & Ib/MBtu & 6 - Measure of performance \\
\hline
\end{tabular}

The test was run at approximately $450 \mathrm{MW}$ with five mills in service (mill D out of service). During the test, a "snapshot" reading of the process data was taken from the wall-fired project's data acquisition system following a change in one of the controlled variables and settling of the boiler. A total of 45 data points were collected during the two days of testing of which 42 were considered suitable for the software's use. These snapshot readings were used in real time to generate the advice for the settings of the control variables. In addition to this data, five-minute averages were also collected for later analysis. An evaluation of the data gathered during the test showed that instantaneous data contained too much noise to produce significant improvements on the measure of performance since the models built lacked a satisfactory coefficient of multiple determination, $\mathrm{R}^{2}$. Nevertheless, NOx emissions were reduced from $0.58 \mathrm{lb} / \mathrm{MBtu}$ to about $0.49 \mathrm{lb} / \mathrm{MBtu}$, a reduction of approximately $15 \%$. Later analysis of the data, comparing instantaneous and five-minute averages, showed that five-minute averages should have been used as the input because of the significant reduction of noise. For the variable configuration used in Experiment 1, the adjusted $\mathrm{R}^{2}$ (adjusted for the degrees of freedom) increased from $59.8 \%$ to $76.6 \%$ when using the five-minute averages. Unburned carbon losses included a losson-ignition (LOI) term that was calculated from a linear model developed from prior LOI data since on-line measurements for LOI were not available. Although the model was not as accurate as would be desired, it was still applied to determine the software behavior to a change in the measure of performance. 
With the predefined models created from the data of the first experiment and using the first two runs to duplicate the conditions at the end of the first experiment, 26 more runs were conducted before an apparent optimum had been achieved. The improvement in NOx emissions during the second experiment was on the order of $16 \%$, reducing the NOx emissions level from 0.52 $\mathrm{lb} / \mathrm{MBtu}$ to $0.42 \mathrm{lb} / \mathrm{MBtu}$. At this point, the measure of performance was changed to minimize losses, constraining NOx emissions to $0.45 \mathrm{lb} / \mathrm{MBtu}$. Only five additional points were taken after the measure of performance was changed, but these seemed sufficient to show that changing the objective function did not reduce the ability of the software to maintain the NOx emissions at the level indicated by the constraint. As mentioned earlier, the constraint setpoint for $\mathrm{CO}$ in the software had to be set to $30 \mathrm{ppm}$ to ensure a level below $100 \mathrm{ppm}$ due to the extremely steep, highly non-linear, dependency of CO emissions on local combustion conditions.

\section{Table 5-2 Feasibity Study - Problem Formulation Experiment 2}

\begin{tabular}{lcl}
\hline \multicolumn{1}{c}{ Variable } & Units & Variable Type \\
\hline Air East & MPPH & 1 - Controlled \\
Air West & MPPH & 1 - Controlled \\
OFA West Front & KPPH & 1 - Controlled \\
OFA East Front & KPHH & 1 - Controlled \\
OFA West Rear & KPPH & 1 - Controlled \\
OFA East Rear & KPPH & 1 - Controlled \\
Total Coal Flow & KPPH & 2 - External \\
Fluegas Temperature & oF & 5 - Used in Subroutine \\
CO & PPM & 5 - Important Result - Constraint $<40 \mathrm{ppm}$ \\
Economizer O2 & PCT & 5 - Important Result - Constraint $>2.8 \%$ \\
Opacity & PCT & 5 - Important Result - Constraint $<30.0 \%$ \\
NOx & PPM & 6 - Measure of Performance \\
LOI East & PCT & 5 - Calculated \\
LOI West & PCT & 5 - Calculated \\
Losses & PCT & 5 - Calculated \\
\hline
\end{tabular}

During the course of both optimization sequences (Experiments 1 and 2), NOx was reduced from approximately 0.58 to $0.44 \mathrm{lb} / \mathrm{MBtu}$ (Figure 5-1). It must be noted that the transition from Experiment 1 to Experiment 2 was done with two initial runs to simulate the last point of Experiment 1 which are not represented in the figure. The oscillation of the scatter plot with respect to the moving average can in part be explained by the constrained sequential optimization process. As mentioned before, the advice generated is not always an optimum estimate because exploration runs are made to increase the accuracy of the models being created. During these experiments, the optimum settings were requested every third run. Point " $A$ " corresponds to the change in measure of performance done once it was thought an optimum had been reached. It can be seen that in the five runs conducted, the NOx level remained below the constraint imposed.

To produce an estimate of the performance of the sequential optimization applied to Unit 4, a historical plot corresponding to Experiment 2 was generated (Figure 5-2) using five-minute averages and showing the rated load and the NOx emissions throughout the two days of testing. Figure 5-2 has been divided in 8 sections, "A" through " $\mathrm{H}$ ", that are significant to illustrate the performance of the unit with the actual control system and the performance using constrained sequential optimization for the NOx emissions control. Table 5-3 shows the time period 
corresponding to each section and provides a brief description. Section "A" shows that for constant load, $420 \mathrm{MW}$, it was possible to reduce the NOx emissions from $0.45 \mathrm{lb} / \mathrm{MB}$ tu to about $0.37 \mathrm{lb} / \mathrm{MBtu}$. The spike in the load curve was caused by a mill going out of service. Section B corresponds to a period of time where, maintaining the load, the plant returns to its normal operation. The significance of this section is the increase of NOx levels to approximately 0.5 $\mathrm{lb} / \mathrm{MBtu}$. In section "E" constrained sequential optimization was again used for the air flow distribution, and doing so halted the ascending trend of NOx from the load increase. Sections "F" and "G" show that the NOx level remained below the constraint imposed. Section "H", as it happened the previous day (section "B"), shows that the return to normal operation produced an increase in NOx emissions.

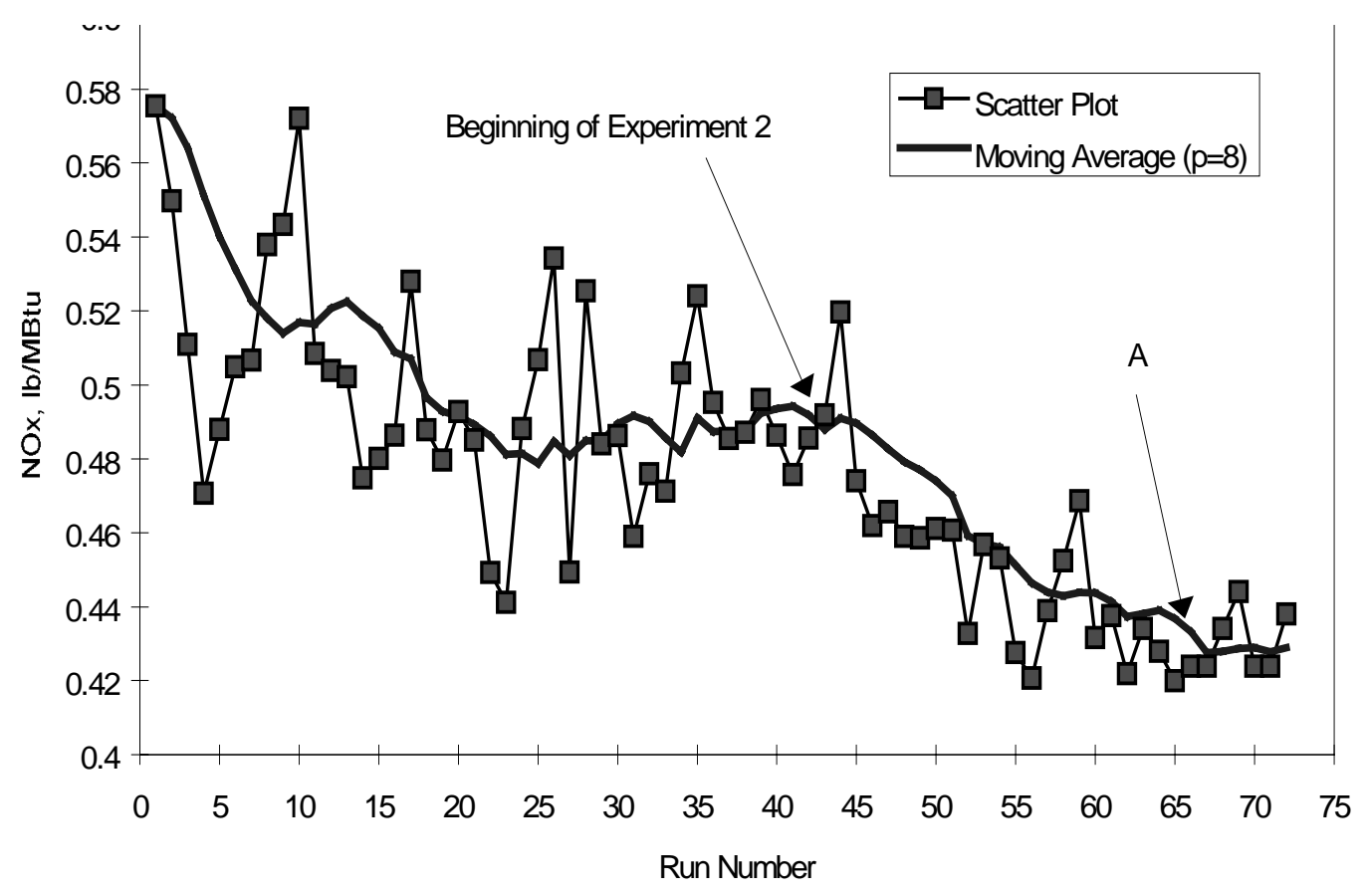

Figure 5-1 Feasibility Study - NOx Reduction for the Two Experiments

Table 5-3 Feasibility Study - Sequence of Experiment 2

\begin{tabular}{ccl}
\hline Section & Time Period & \\
A & September 26 & \\
B & $11: 00-18: 00$ & Following CSO ${ }^{*}$ advice to minimize NOx \\
C & $18: 00-20: 00$ & Return to actual control system \\
& $20: 00-04: 50$ & Reduction of load to night operation \\
D & September 27 & \\
E & $04: 50-08: 00$ & Raising load to resume testing \\
F & $08: 00-13: 05$ & Following CSO ${ }^{*}$ advice to minimize NOx \\
G & $13: 05-14: 25$ & Change the measure of performance \\
H & $14: 25-16: 00$ & Manual operation with settings provided by CSO* \\
\hline
\end{tabular}

* CSO - Constrained Sequential Optimization. 


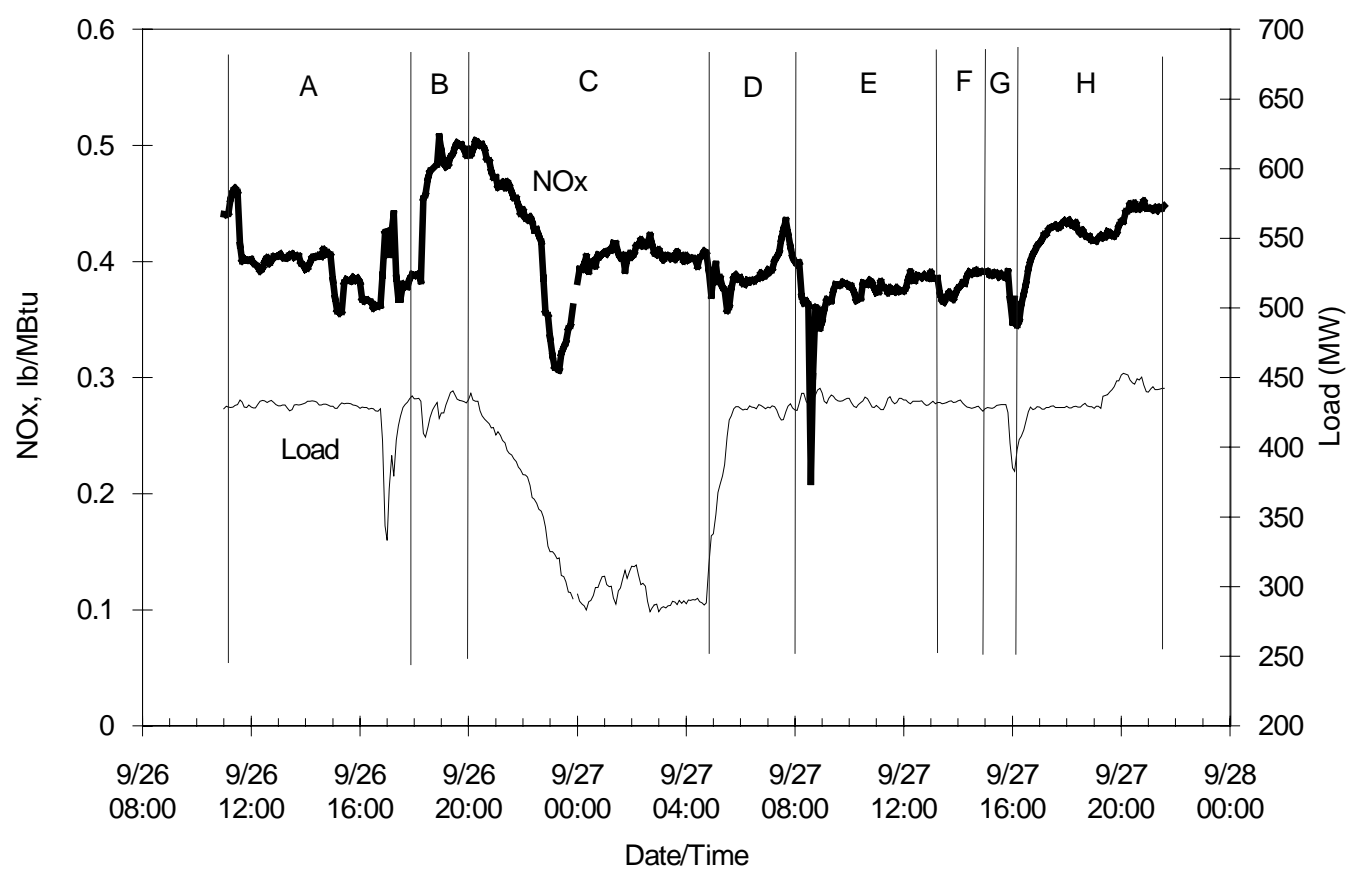

Figure 5-2 Feasibility Study - Plot of the NOx and Load Behavior for Experiment 2

Summary

Overall, this study was successful in that it provided further indication that on-line optimization techniques could be used to improve boiler performance. With this success, the project participants felt it warranted to pursue the additional stages: installation of a digital control system and closed-loop optimization. 


\subsection{Preliminary Modeling}

Modeling of the furnace is a critical element of combustion optimization. Since all optimization techniques make use of models (either local or global) of the process in developing recommendations, the veracity of the process model is highly important for the success of the optimization. There are several broad categories of modeling that are available including those based on (1) statistical / regression methods, (2) neural networks, (3) expert systems, (4) fuzzy logic, and (5) first-principles. No one method is categorically superior to any of the other methods and therefore the selection of a technique is dependent on the problem to be solved. Due to the complexity of the combustion process, techniques which depend on a first principles model are not appropriate for control system design in this case, whereas, an approach which uses a model generated from on-line measurements can be effective.

This type of modeling is known as input-output modeling and there are three types of such modeling:

- Type 1 - Models that are linear in their inputs and their coefficients;

- Type 2 - Models that are non-linear in their inputs but linear in their coefficients; and

- Type 3 - Models that are non-linear in their inputs and in their coefficients.

Type 1 models are the simplest and consist of linear regression using the measured input variables, possibly suitably scaled. Type 2 models are also based on linear regression but they use extra inputs. These extra inputs are non-linear functions of the original variables; for example, powers of the input data. This modeling approach still has the calculational simplicity and uniqueness of linear regression but allows non-linear input-output behaviour. The disadvantages are (i) the modeler has to decide which forms of non-linearity to use and (ii) the effective number of inputs can be quite large. Type 3 modeling used to be a restricted option but the advent of neural network technology has simplified the implementation of this type of modeling, although the time taken for the parameter estimation can be large, and there is no guarantee of unique solutions.

A neural network is a computer code which models the system responses at its' boundaries and as such can be considered a sophisticated curve fitting routine tool. This technique can recognize patterns in a series of inputs and 'learn' to ascribe a particular pattern to a particular plant state. The training phase in which the network learns can be very time consuming. However, once a network has been trained on historical data, it can respond very rapidly to new inputs. Also, in the event any inputs to the model are faulty, neural networks prediction capabilities degrade only gradually as compared to other modeling techniques. To explore the use of the neural network modeling technique to predicting coal fired boiler emission and performance parameters, preliminary modeling studies were performed on data from Phase $3 \mathrm{~B}$ of the project. 
Table 5-4 Preliminary Modeling Data Set

\begin{tabular}{|c|c|c|c|c|c|}
\hline Tag & Description & Type & Tag & Description & Type \\
\hline AT000RH & RELATIVE HUMIDITY & 1 & PT201 & TURBINE $1^{\text {st }}$ STAGE PRESSURE & $\mathrm{D}$ \\
\hline AT7920 & OPACITY & D & PT300 & FEEDWATER PRESSURE & $\mathrm{D}$ \\
\hline $\mathrm{CO}$ & CO EMISSIONS & $\mathrm{D}$ & sox & SOx EMISSIONS (ppm) & D \\
\hline FT103A & SH SPRAY FLOW(DP) LOWER & $\mathrm{D}$ & TT000 & AMBIENT TEMPERATURE & I \\
\hline FT103B & SH SPRAY FLOW(DP) UPPER & D & TT200 & MAIN STEAM TEMP & D \\
\hline FT300 & FEEDWATER FLOW(DP) & D & TT202 & COLD REHEAT TEMP & $\mathrm{D}$ \\
\hline FT510 & "A" MILL COAL FLOW & I & TT300 & FEEDWATER TEMP & $\mathrm{D}$ \\
\hline FT520 & "B" MILL COAL FLOW & i & TT510 & MILL "A" TEMP & $\mathrm{D}$ \\
\hline FT530 & "C" MILL COAL FLOW & i & TT520 & MILL "B" TEMP & $\mathrm{D}$ \\
\hline FT540 & "D" MILL COAL FLOW & l & TT530 & MILL "C" TEMP & $\mathrm{D}$ \\
\hline FT550 & "E" MILL COAL FLOW & i & TT540 & MILL "D" TEMP & $\mathrm{D}$ \\
\hline FT560 & "F" MILL COAL FLOW & 1 & TT550 & MILL "E" TEMP & D \\
\hline FT605A & AOFA-F1 WEST FRONT & I & TT560 & MILL "F" TEMP & $\mathrm{D}$ \\
\hline FT605B & AOFA-F2 EAST FRONT & i & TT611 & SEC AIR "A" INLET TEMP & $\mathrm{D}$ \\
\hline FT605C & AOFA-R1 WEST REAR & l & TT612 & SEC AIR "A" OUT TEMP & $\mathrm{D}$ \\
\hline FT605D & AOFA-R2 EAST REAR & 1 & TT621 & SEC AIR "B" INLET TEMP & D \\
\hline FT611 & SEC AIR "A" FLOW (DP) & D & TT622 & SEC AIR "B" OUT TEMP & $\mathrm{D}$ \\
\hline FT621 & SEC AIR "B" FLOW (DP) & $\mathrm{D}$ & TT631 & PRI AIR "A" INLET TEMP & $\mathrm{D}$ \\
\hline FT631 & PRI AIR "A" FLOW (DP) & $\mathrm{D}$ & TT632 & PRI AIR "A" OUT TEMP & $\mathrm{D}$ \\
\hline FT641 & PRI AIR "B" FLOW (DP) & D & TT641 & PRI AIR "B" INLET TEMP & $\mathrm{D}$ \\
\hline FT750A & TEMP AIR "A" FLOW (DP) & $\mathrm{D}$ & TT642 & PRI AIR "B" OUT TEMP & $\mathrm{D}$ \\
\hline FT750B & TEMP AIR "B" FLOW (DP) & $\mathrm{D}$ & TT711 & SEC "A" GAS IN TEMP & $\mathrm{D}$ \\
\hline JT001 & LOAD & $\mathrm{D}$ & TT712 & SEC "A" GAS OUT TEMP & $\mathrm{D}$ \\
\hline NOX & NOx EMISSIONS & D & TT721 & SEC "B" GAS IN TEMP & $\mathrm{D}$ \\
\hline OT711 & ECON OUT "A" O2 & I & TT722 & SEC "B" GAS OUT TEMP & $\mathrm{D}$ \\
\hline OT712 & SAH OUT "A" O2 & D & TT731 & PRI "A" GAS IN TEMP & $\mathrm{D}$ \\
\hline OT721 & ECON OUT "B" O2 & 1 & TT741 & PRI "B" GAS IN TEMP & $\mathrm{D}$ \\
\hline OT722 & SAH OUT "B" O2 & D & WT103A & SH SPRAY FLOW LOWER & $\mathrm{D}$ \\
\hline PT000 & BAROMETRIC PRESSURE & 1 & WT103B & SH SPRAY FLOW UPPER & D \\
\hline PT100 & DRUM PRESSURE & D & WT300 & FEEDWATER FLOW & $\mathrm{D}$ \\
\hline PT200 & MAIN STEAM PRESSURE & D & & & \\
\hline
\end{tabular}

The data set used for this preliminary modeling covered from May 5, 1993 through June 16, 1993 during which time the unit was in the LNB+AOFA configuration. For most of this period, the unit operated under economic dispatch but there were periods during which the unit was not taken off dispatch so that test could be performed under steady-state conditions. The data set included nearly 12,000 records of 5-minute data collected from the DCS with approximately 65 variables per record (Table 5-4). Details on the data acquisition and archiving methodology can be found in the project final report [SCS, 1998]. No special precautions were taken other than those described in that report to obtain data and the unit was not deliberated "exercised" to obtain operating data out of the normal operating range.

Load, NOx, CO, and SOx for this period are shown in Figure 5-3. As can be seen, the unit operated over the entire load range. Since minimum load during the LNB+AOFA test phase (Phase 3B) was approximately $170 \mathrm{MW}$, periods when loads were below this level were excluded from the data set. NOx and CO emissions also exhibited considerable variability during this period reflecting numerous operating scenarios. SOx emission variation was much less as may be expected since it is largely a function of coal properties and independent of combustion conditions. 

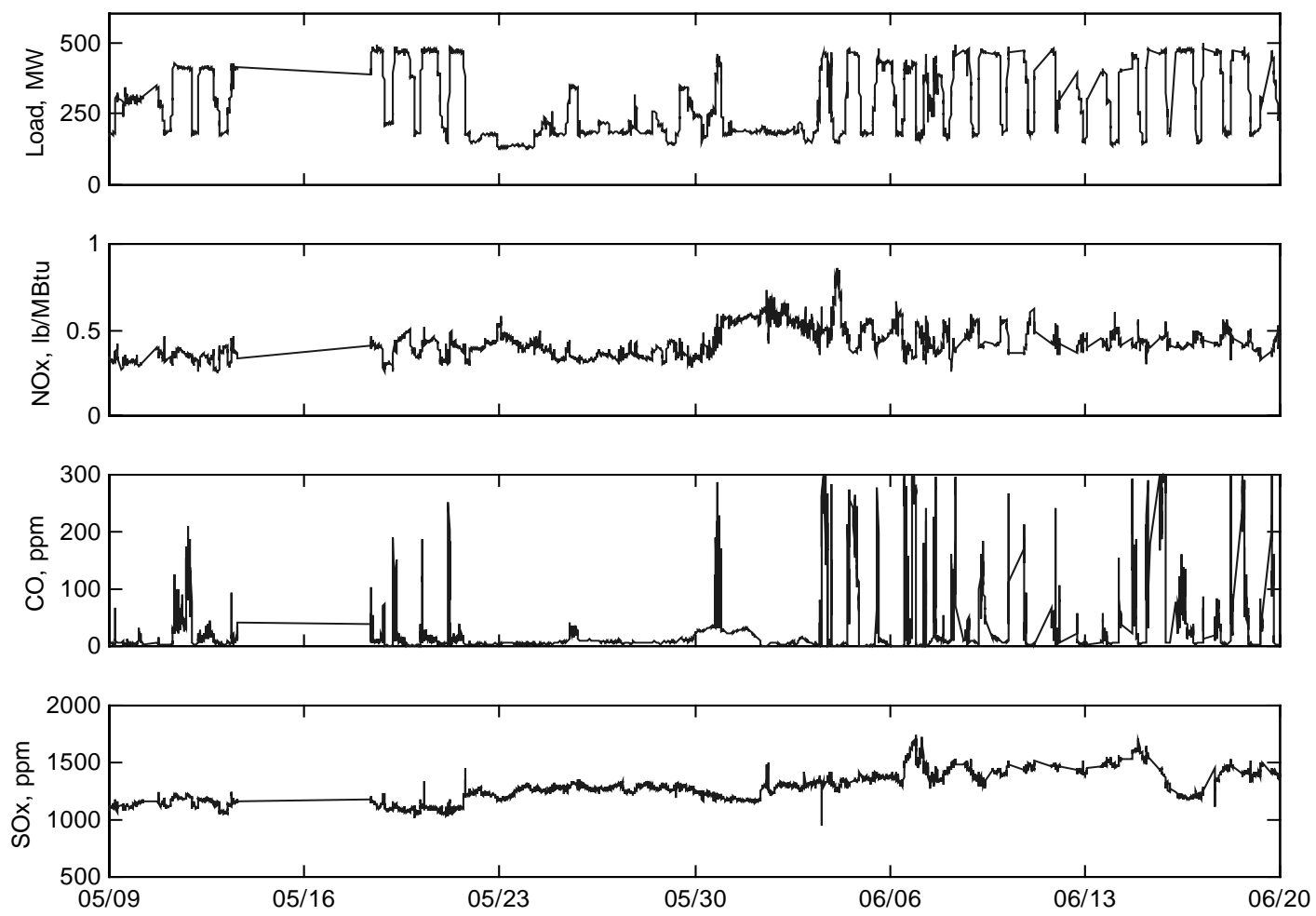

Figure 5-3 Load, NOx, CO, and SOx Profiles During Preliminary Modeling

Many potential strategies could be taken to develop a model suitable for on-line optimization. These include but are not necessarily limited to:

- Input / Output Methods

口 Statistical

Neural network

- Descriptive Methods

․ First principles

Expert systems

ㅁ Fuzzy logic

Due to the complexity of the combustion process and uncertainty about combustion parameters, descriptive models are not particularly well suited for combustion modeling, especially when the models are intended for use in on-line, continuous optimization. 
To exemplify the modeling difficulties, NOx as a function of load and excess oxygen is shown in Figure 5-4. As shown, there was considerable scatter when viewed from this perspective highlighting the little correlation (low $\mathrm{R}^{2}$ ) between load or excess oxygen with NOx and CO (Table 5-1). Air heater gas outlet temperature (TT702) showed moderate correlation with excess oxygen and load. This temperature is important in that it is a major factor in boiler efficiency determination.

Examples of the results obtained with a linear model are shown in Figure 5-5 through Figure 5-8 with the model inputs/outputs shown in Table 5-5. As shown, a linear model was only moderately successful in predicting the outputs. A scatter diagram is shown in the top half of the figure. The prediction mean as a function of the actual mean is shown in the lower half of the figure. Also shown in the lower half are error bars representing the standard deviation of the error (standard deviation ( $\left.\mathrm{y}_{\text {predicted }}-\mathrm{y}_{\text {actual }}\right)$ ). A nonlinear neural network approach created much better models (Figure 5-9 to Figure 5-12). Further indication of the performance of the neural network model in predicting NOx and CO is shown in Figure 5-13 and Figure 5-14. Both the linear and nonlinear models were developed using approximately 67 percent of the May to June 1993 data set. The data shown is a validation set (the remaining 33 percent) which was not used in the development of the models.

As may be imagined, there are almost an infinite variety of input/output models that may be used, with some performing better that others. The variations include both input selection and model structure. Using the same inputs as described in the previous paragraph, a different type of neural network structure was tested, one based on radial basis functions. A histogram comparison of the performance between the radial basis network and the backpropagation network is shown in Figure 5-15 and Figure 5-16. The radial basis network appeared to be a better prediction tool for this data, however this may not hold true for other data presented to the networks. Also, the radial basis network has approximately five times as many neurons as the backpropagation network. This is not untypical since the radial basis functions have only local influence while the activation functions used in backpropagation networks (typically hyperbolic tangent sigmoid or log sigmoid) [NeuralWare, 1993][MathWorks, 1997][Tsoukalis, 1996]. These investigations into model structure were only cursory but they provide sufficient evidence that backpropagation, radial basis, and potentially other network structures would be suitable to use for combustion modeling and provide roughly equivalent results.

Table 5-5 Model Inputs and Outputs

\begin{tabular}{llll}
\hline Inputs & & Outputs & \\
\hline FT510 & "A" MILL COAL FLOW & NOx & NOx EMISSIONS \\
FT520 & "B" MILL COAL FLOW & CO & CO EMISSIONS \\
FT530 & "C" MILL COAL FLOW & SOx & SOx EMISSIONS \\
FT540 & "D" MILL COAL FLOW & TT702 & AIR HEATER GAS OUTLET TEMP \\
FT550 & "E" MILL COAL FLOW & & \\
FT560 & "F" MILL COAL FLOW & & \\
FT605A & AOFA-F1 WEST FRONT & & \\
FT605B & AOFA-F2 EAST FRONT & & \\
FT605C & AOFA-R1 WEST REAR & & \\
FT605D & AOFA-R2 EAST REAR & & \\
OT711 & ECON OUT "A" O2 & & \\
OT721 & ECON OUT "B" O2 & & \\
\hline
\end{tabular}


Since in addition to the parameters shown in Table 5-5 other variables potentially affect NOx and the other performance parameters; models that include these additional parameters may improve the predictions. The results from one model with many more (approximately 50 total) input parameters is shown in Figure 5-17 and Figure 5-18. This model includes as inputs not only parameters which are directly controllable, but also ambient conditions, steam temperatures, and other boiler operating parameters. At least for the data presented, this model performs much better that the twelve input model. As before, the data presented is validation data only. Although increasing the number of input variables may likely improve the prediction performance of a model, these models are not necessarily well suited for on-line optimization. First, increasing the number of variables increases the likelihood of using a bad reading in the model. The overall impact of a faulty reading on the model prediction is model dependent. Also, the input variables may not be independent which leads to problems in determining a set of inputs for a desired set of outputs -- i.e., running the model in reverse.

Using the twelve-input, back propagation network described earlier, the inputs minimizing NOx emissions for the validation data set were determined. Constraints were added to the inputs to limit the recommendations to that which might be implemented on the unit (Table 5-7). Although they could have easily been, $\mathrm{CO}, \mathrm{SOx}$, and furnace exit gas temperature were not included in the objective or constraint functions. As shown, the projected NOx levels when running at the recommended setpoints were considerably below that which the unit actually operated, averaging $0.07 \mathrm{lb} / \mathrm{Mbtu}$ or 16 percent below non-optimized levels (Figure 5-19 and Figure 5-20).

In summary, these studies provided credence that neural network methods could be used to develop combustion models sufficiently robust to perform on-line combustion optimization. 

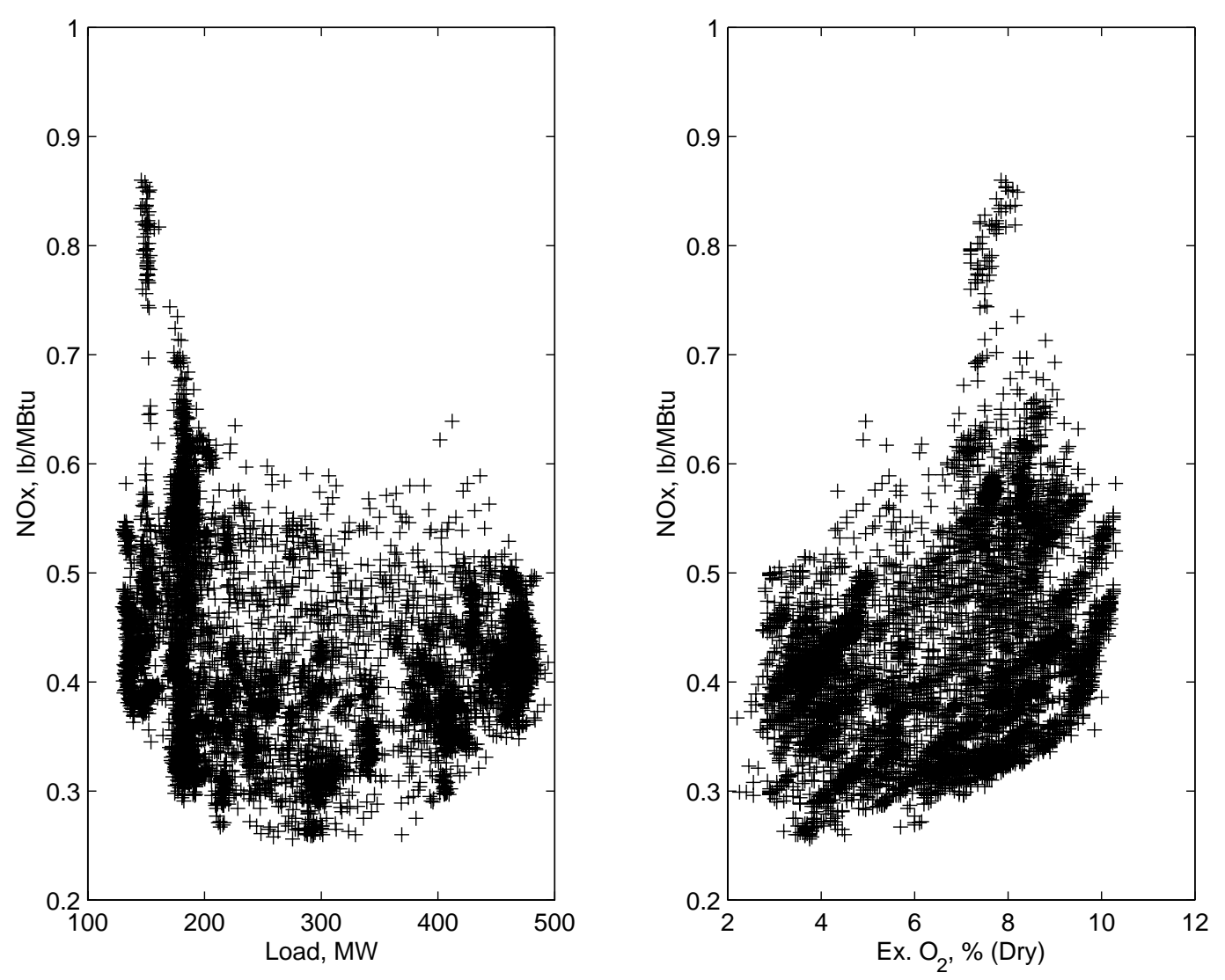

Figure 5-4 NOx vs. Load and Excess Oxygen

Table 5-6 Correlation of Important Process Parameters with Load and $\mathrm{O}_{2}$

\begin{tabular}{lrrrrrr}
\hline & \multicolumn{1}{l}{ Load } & \multicolumn{2}{c}{ O2 } & \multicolumn{2}{c}{ NOx } & \multicolumn{2}{c}{ CO } & \multicolumn{2}{l}{ SOx } & \multicolumn{1}{c}{ TT702 } \\
\hline Load & 1 & -0.9064 & -0.1779 & 0.4526 & 0.0228 & 0.8272 \\
O2 & -0.9064 & 1 & 0.3207 & -0.4688 & 0.0445 & -0.7625 \\
NOx & -0.1779 & 0.3207 & 1 & -0.0795 & 0.1898 & 0.0243 \\
CO & 0.4526 & -0.4688 & -0.0795 & 1 & 0.2172 & 0.4321 \\
SOx & 0.0228 & 0.0445 & 0.1898 & 0.2172 & 1 & 0.1717 \\
TT702 & 0.8272 & -0.7625 & 0.0243 & 0.4321 & 0.1717 & 1 \\
\hline
\end{tabular}

TT702 - Average air heater gas outlet temperature $\mathrm{O}_{2}$ - Excess oxygen (wet) measured at economizer outlet NOx - Measured at the stack.

SOx - Measured at the stack (wet), corrected to $3 \%$ excess $\mathrm{O}_{2}$ $\mathrm{CO}$ - Measured at the stack (wet), 

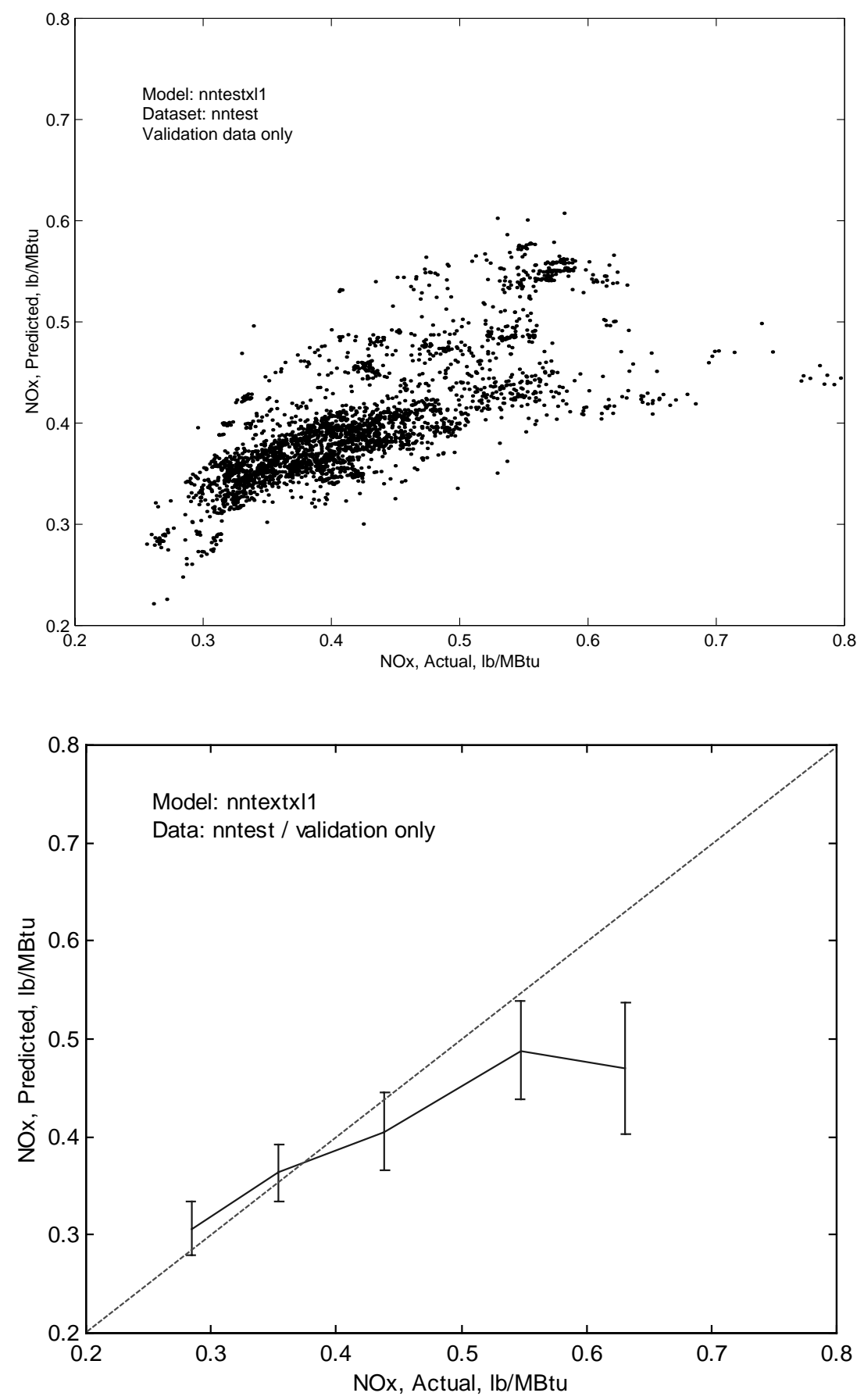

Figure 5-5 Predicted NOx vs. Actual NOx Linear Model $\left(\mathbf{R}^{2}=0.492\right)$ 

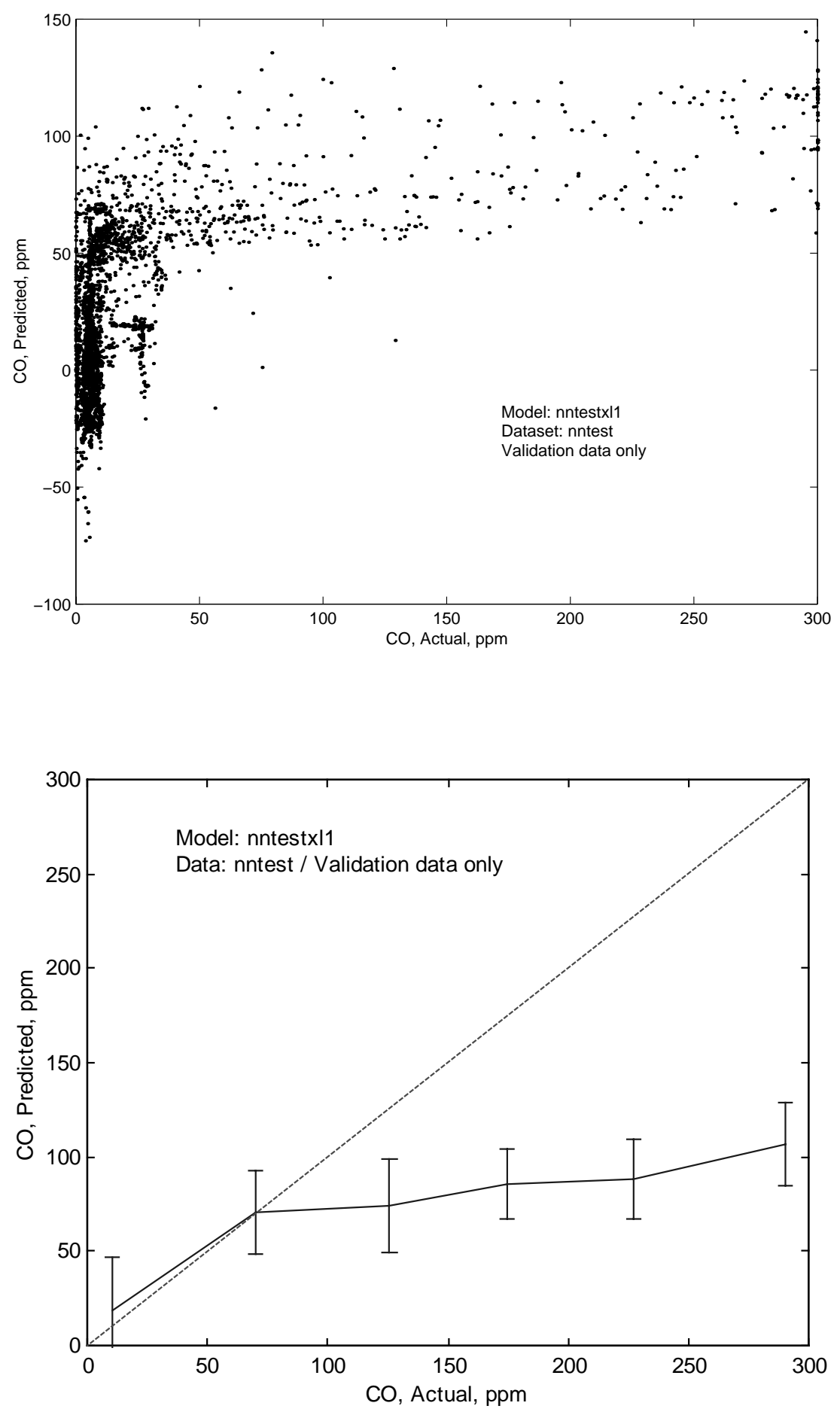

Figure 5-6 Predicted CO vs. Actual CO Linear Model $(\mathrm{R} 2=\mathbf{0 . 3 4 3})$ 

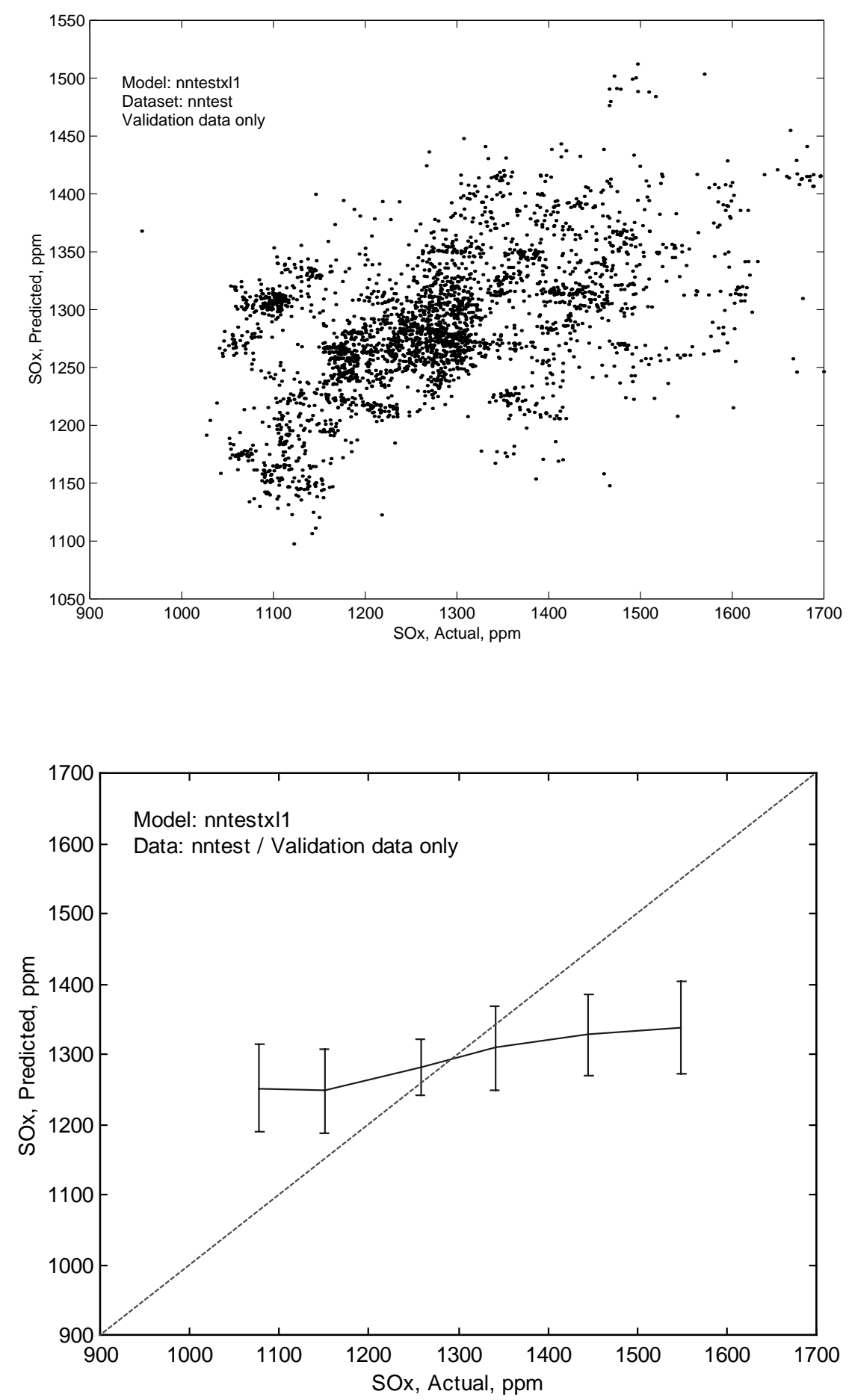

Figure 5-7 Predicted SOx vs. Actual SOx Linear Model $\left(R^{2}=0.26\right)$ 

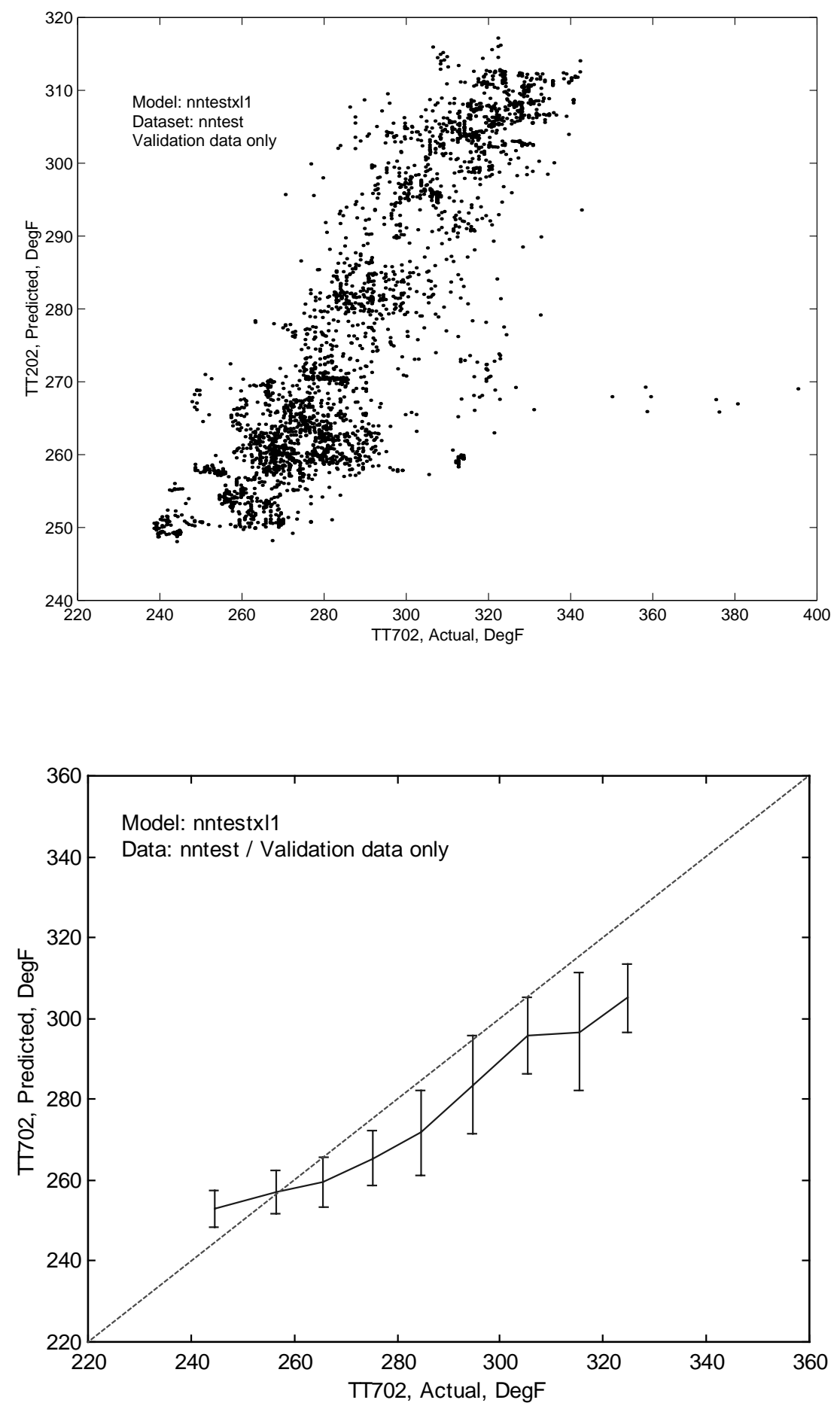

Figure 5-8 Predicted TT702 vs. Actual TT702 Linear Model $\left(\mathbf{R}^{2}=0.51\right)$ 

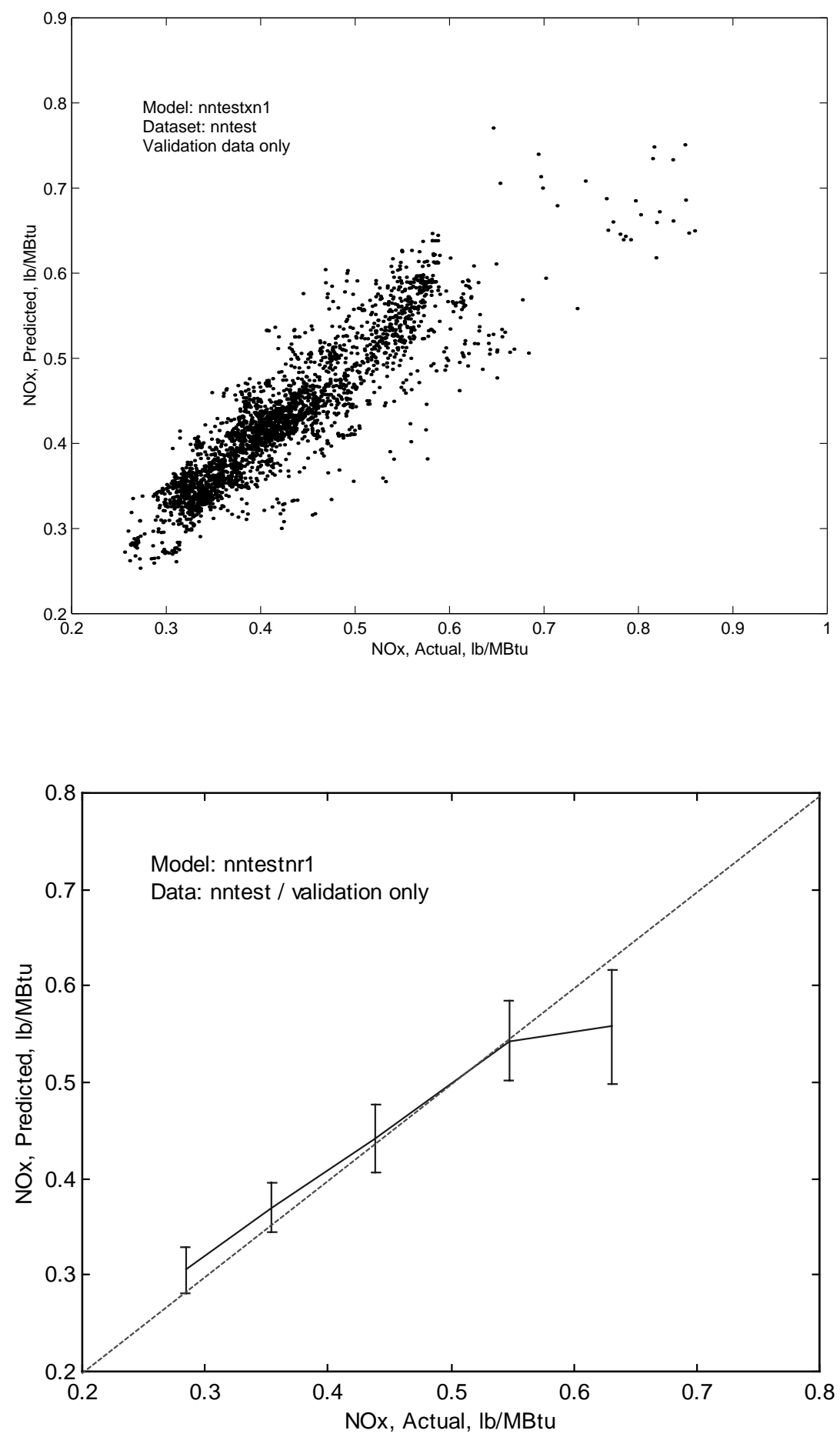

Figure 5-9 Predicted NOx vs. Actual NOx Nonlinear Model $\left(\mathbf{R}^{2}=0.81\right)$ 

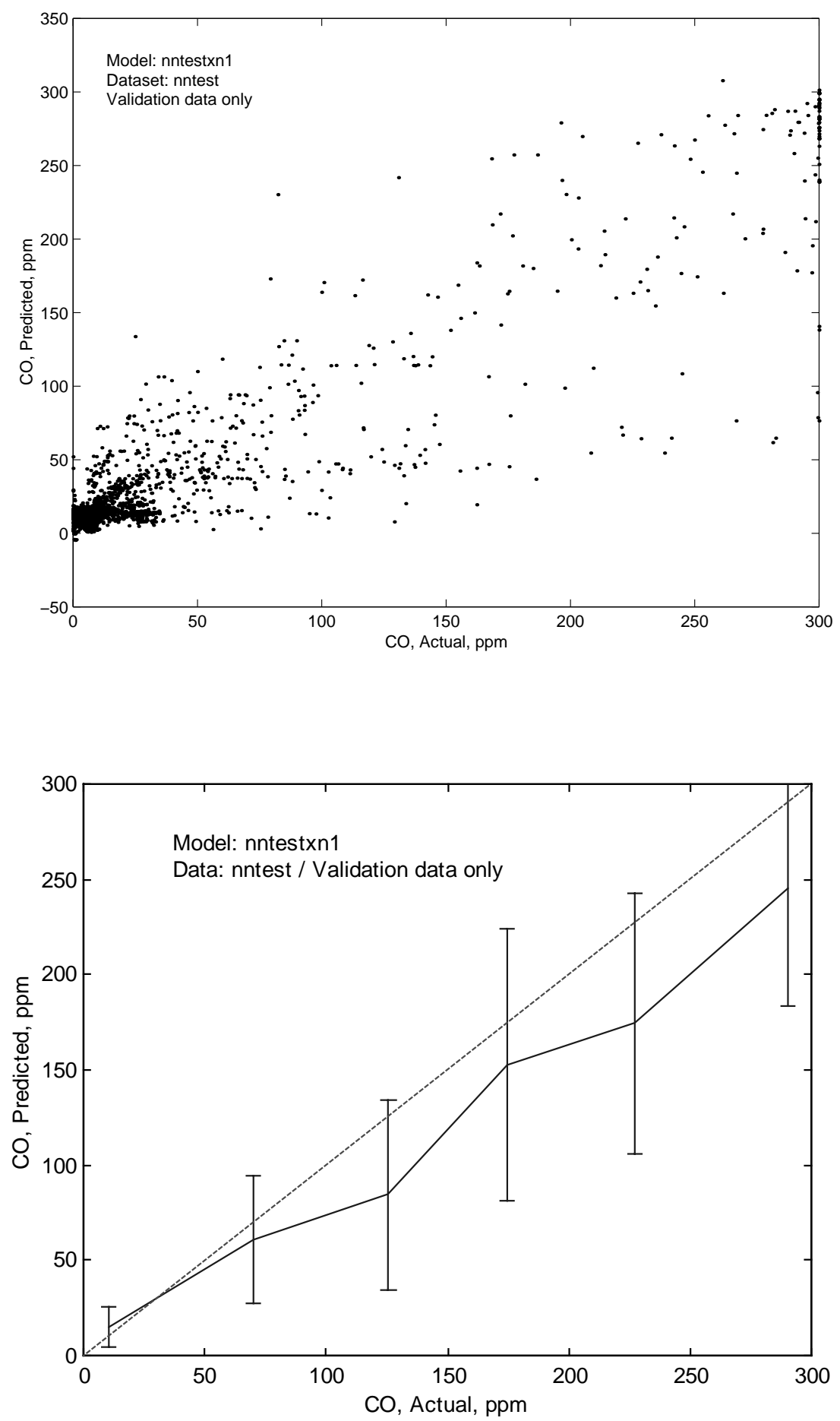

Figure 5-10 Predicted CO vs. Actual CO Nonlinear Model $\left(\mathbf{R}^{2}=\mathbf{0 . 8 1}\right)$ 

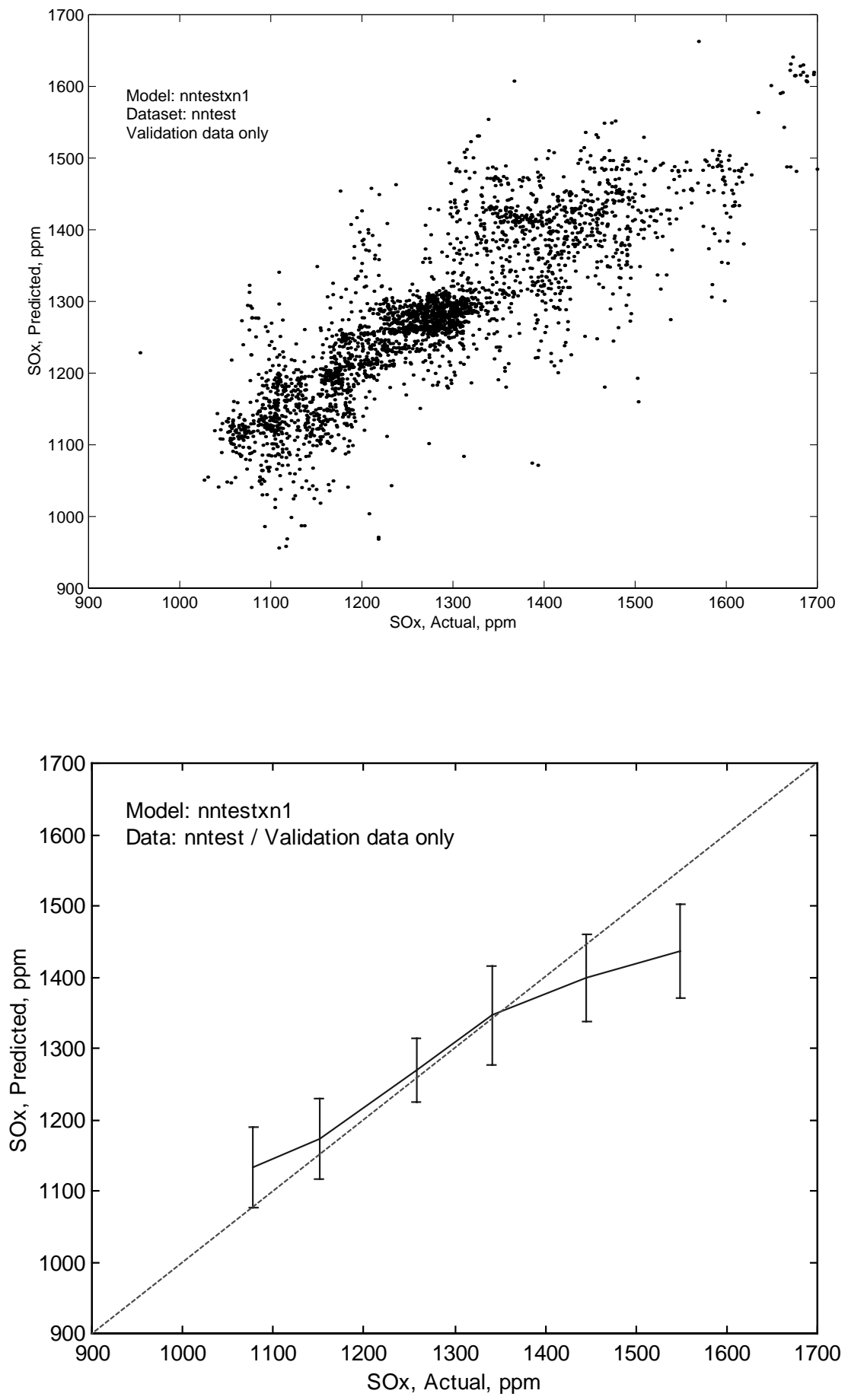

Figure 5-11 Predicted SOx vs. Actual SOx Nonlinear Model $\left(\mathbf{R}^{2}=0.72\right)$ 

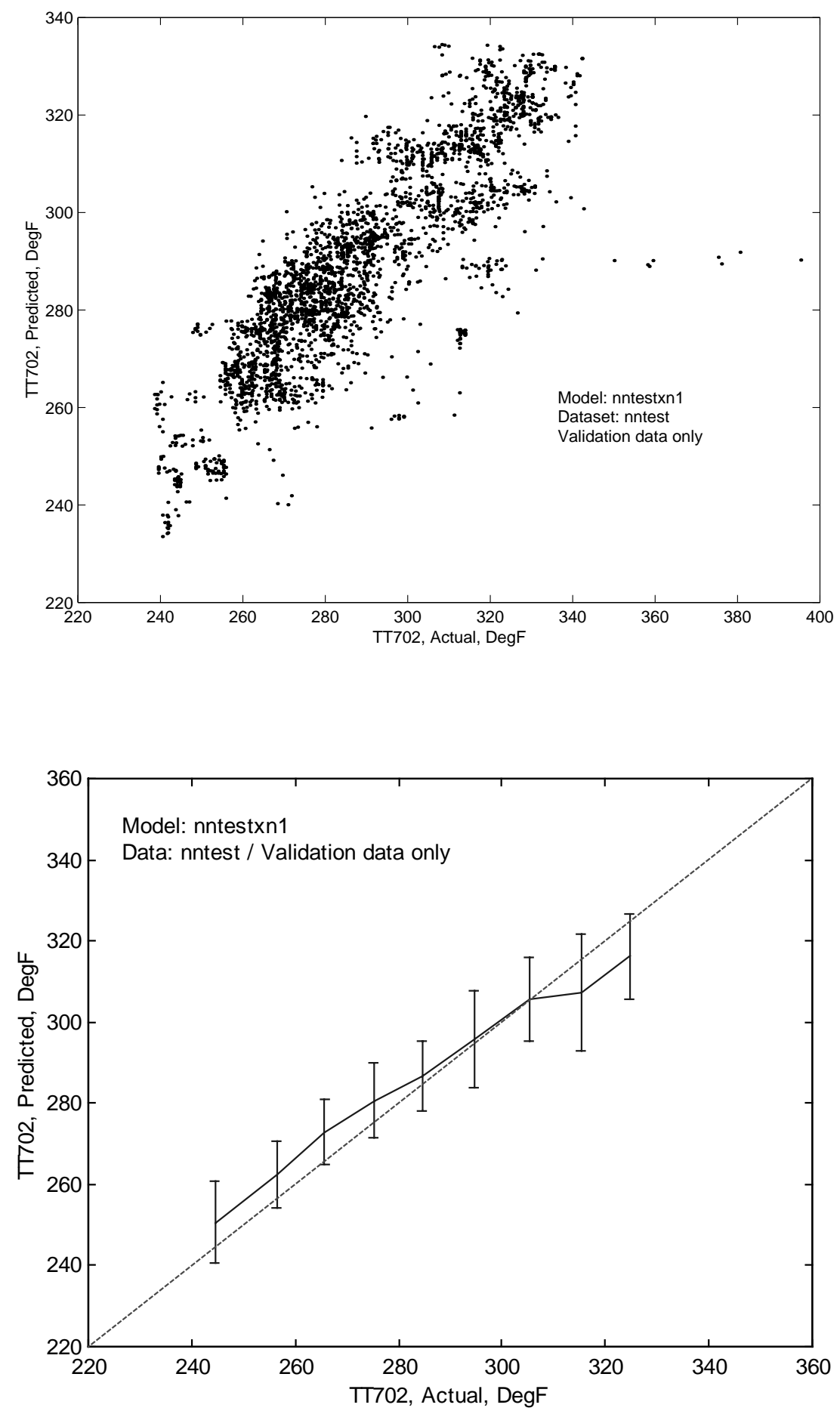

Figure 5-12 Predicted TT702 vs. Actual TT702 Nonlinear Model $\left(R^{2}=0.73\right)$ 


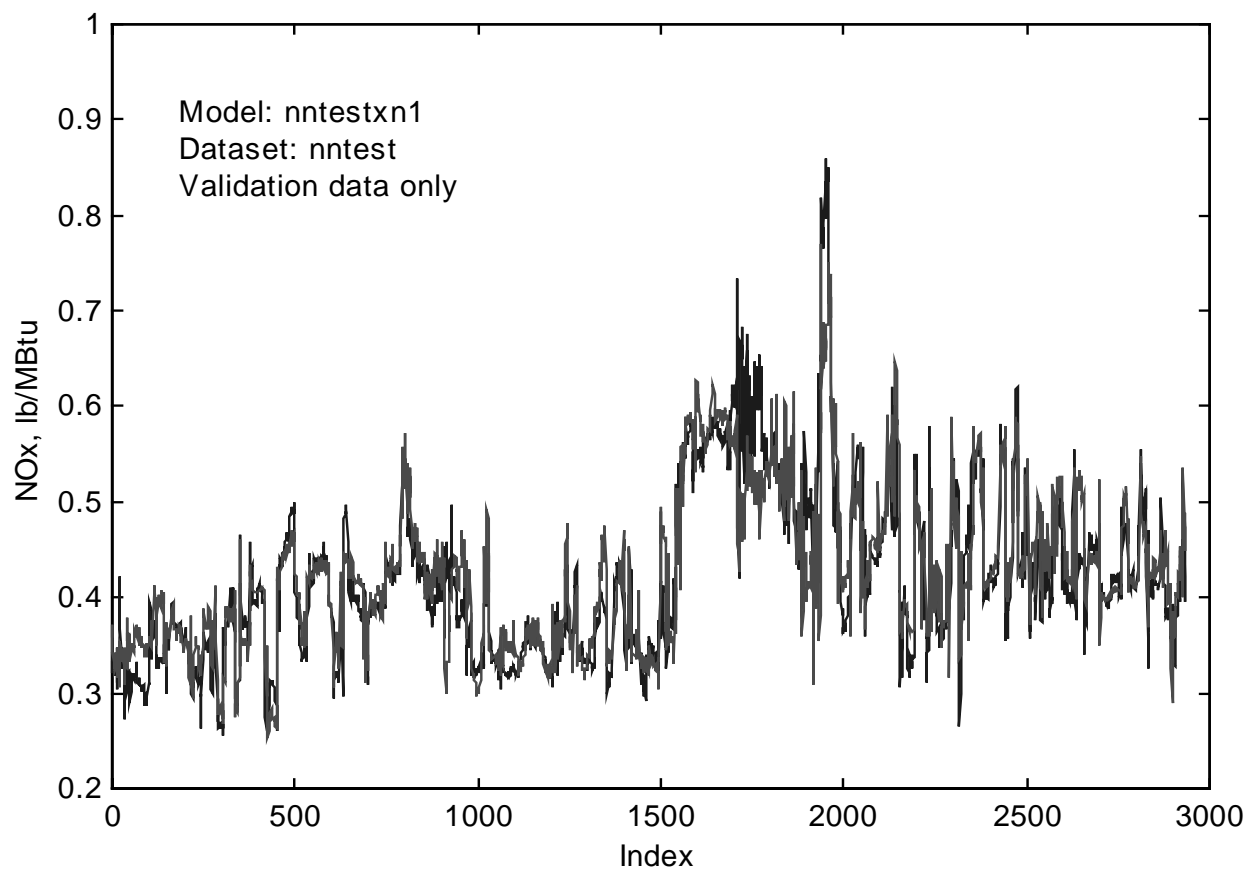

Figure 5-13 Predicted NOx vs. Actual NOx Nonlinear Model

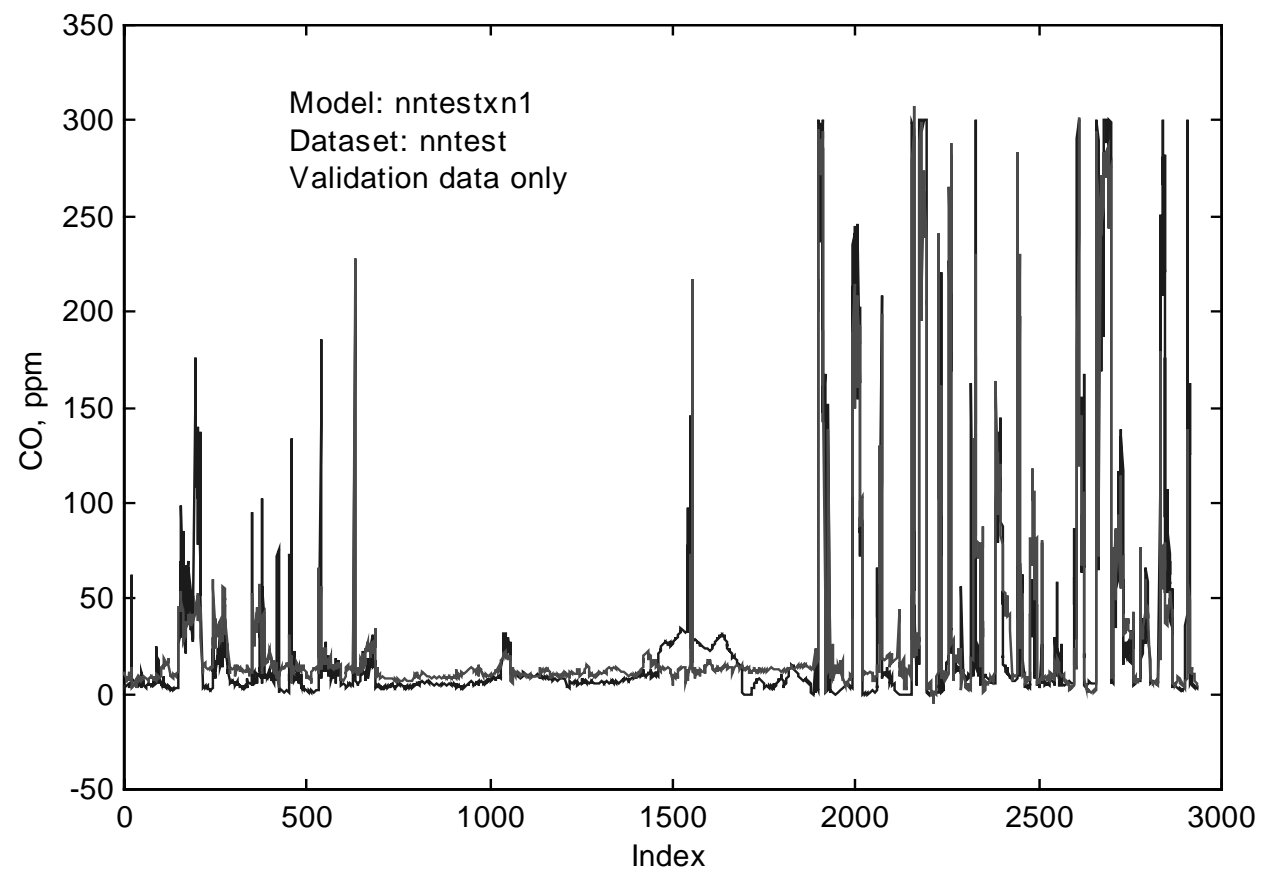

Figure 5-14 Predicted CO vs. Actual CO Nonlinear Model 

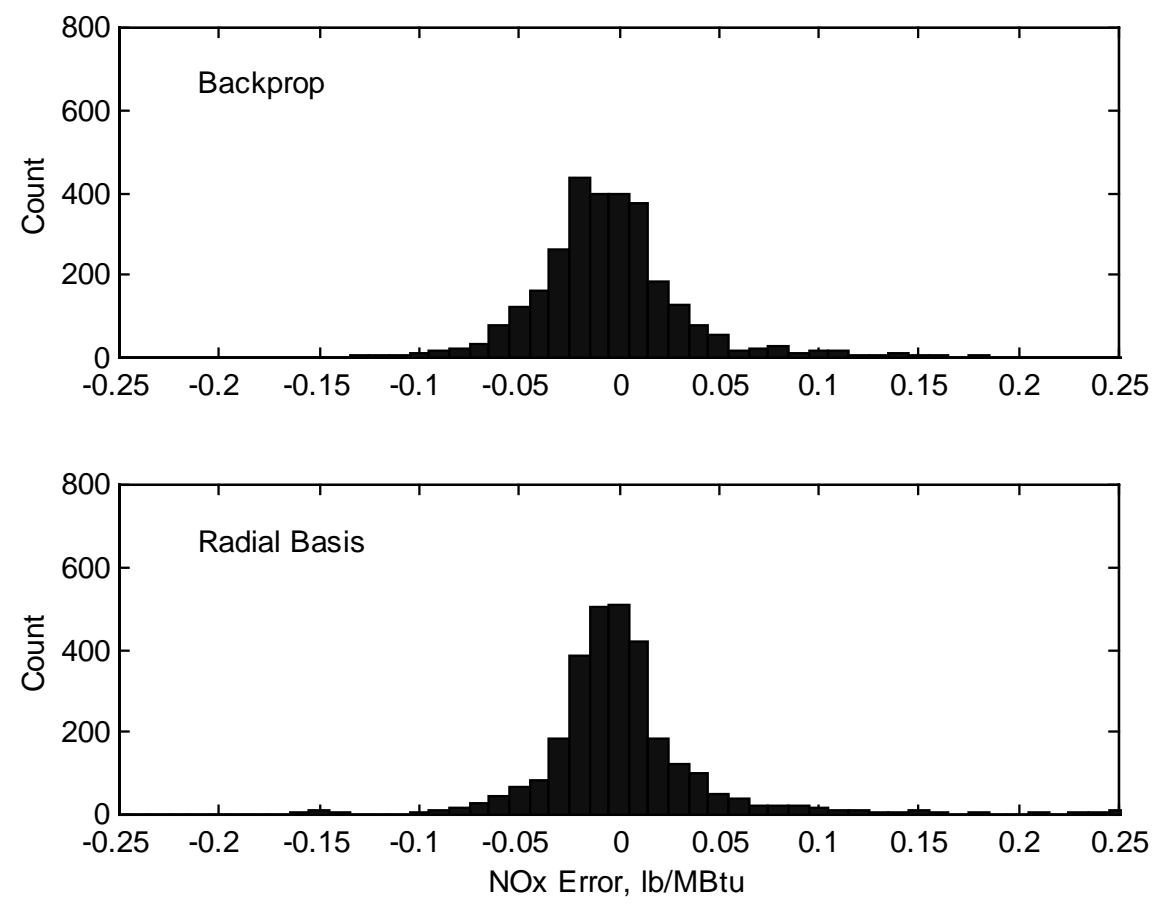

Figure 5-15 Back Propagation Network vs. Radial Basis Network Approximation (NOx)
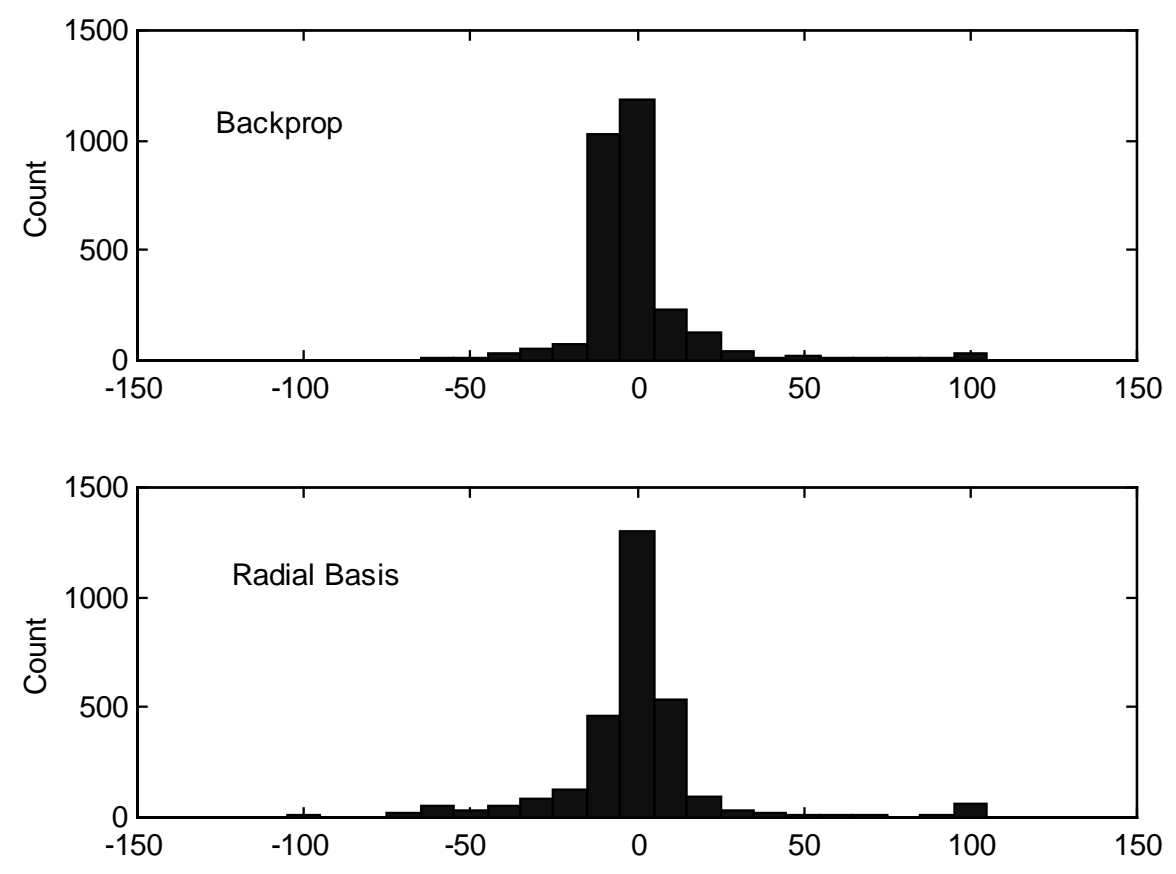

Figure 5-16 Backpropagation Network vs. Radial Basis Network Approximation (CO) 

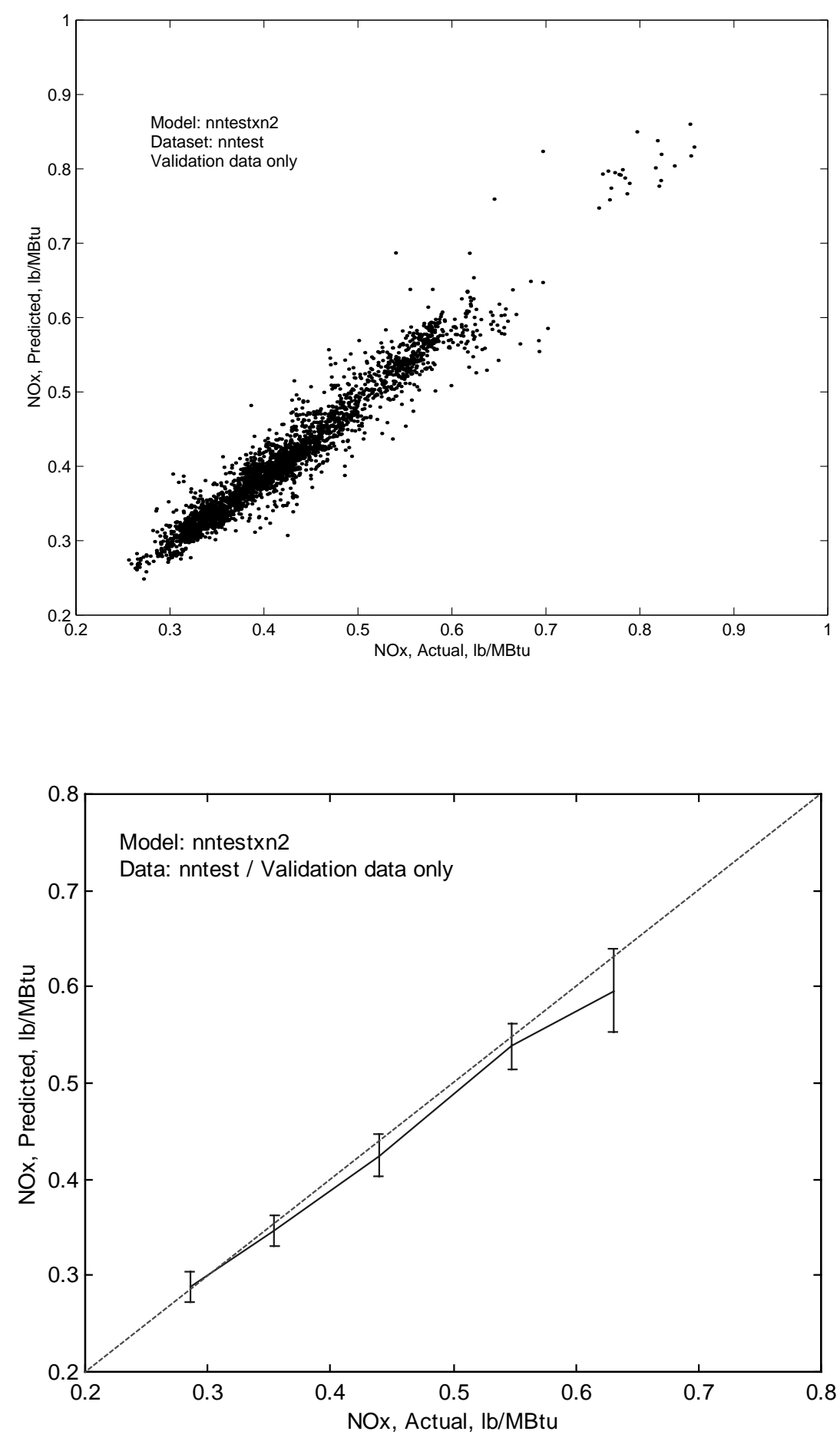

Figure 5-17 Predicted NOx vs. Actual NOx Nonlinear Model $\left(\mathbf{R}^{2}=\mathbf{0 . 9 3}\right)$ 

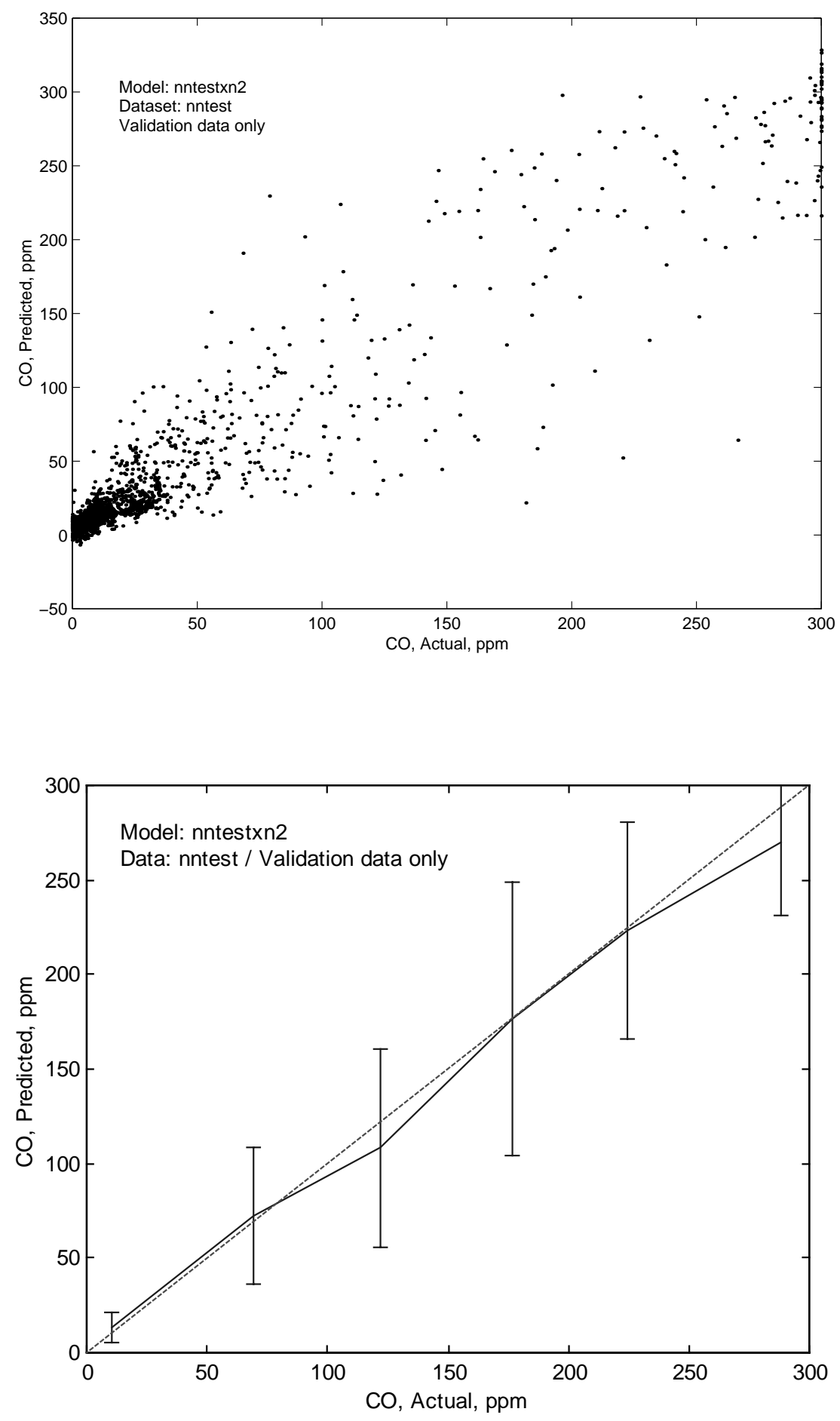

Figure 5-18 Predicted CO vs. Actual CO Nonlinear Model $\left(\mathbf{R}^{2}=0.90\right)$ 
Table 5-7 Constraints Applied to Optimization

\begin{tabular}{|c|c|}
\hline Constraints & Description \\
\hline 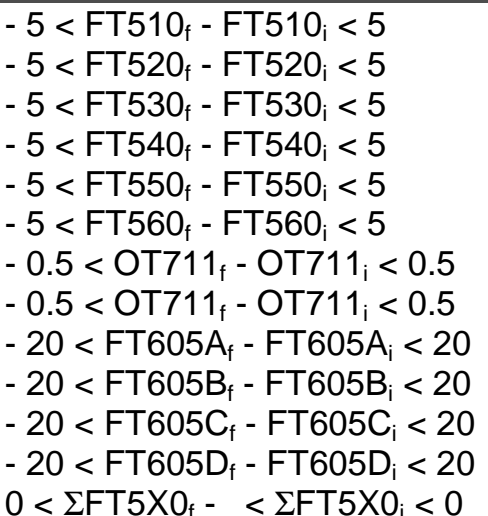 & $\begin{array}{l}\text { Don't change fuel to mill by more than } 5 \mathrm{klb} / \mathrm{h} \text { amount } \\
\text { " } \\
\text { " } \\
\text { " Don't change excess } \mathrm{O}_{2} \text { by more than } 0.5 \text { percent } \\
\text { " Don't change OFA flow by more than } 20 \mathrm{klb} / \mathrm{h} \\
\text { " } \\
\text { " Total coal flow to remain constant }\end{array}$ \\
\hline
\end{tabular}




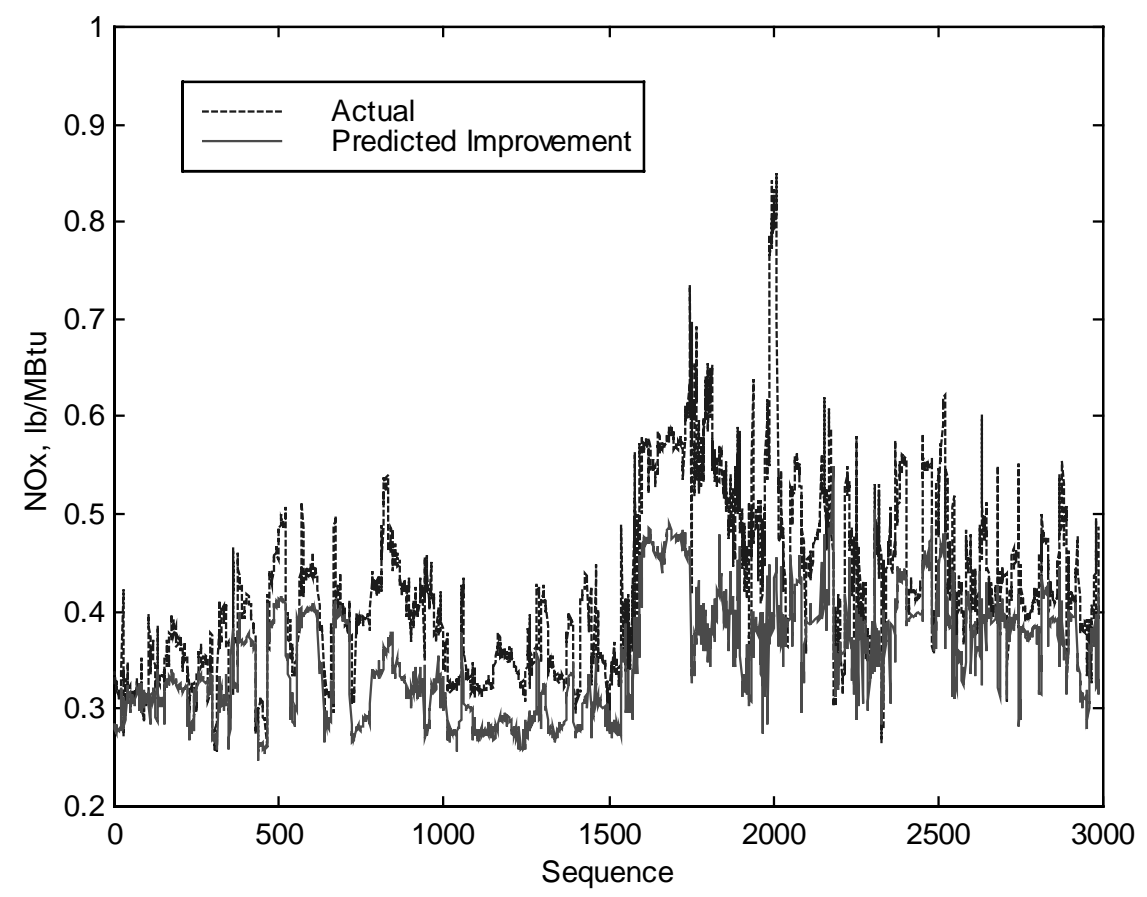

Figure 5-19 Optimizing NOx Emissions
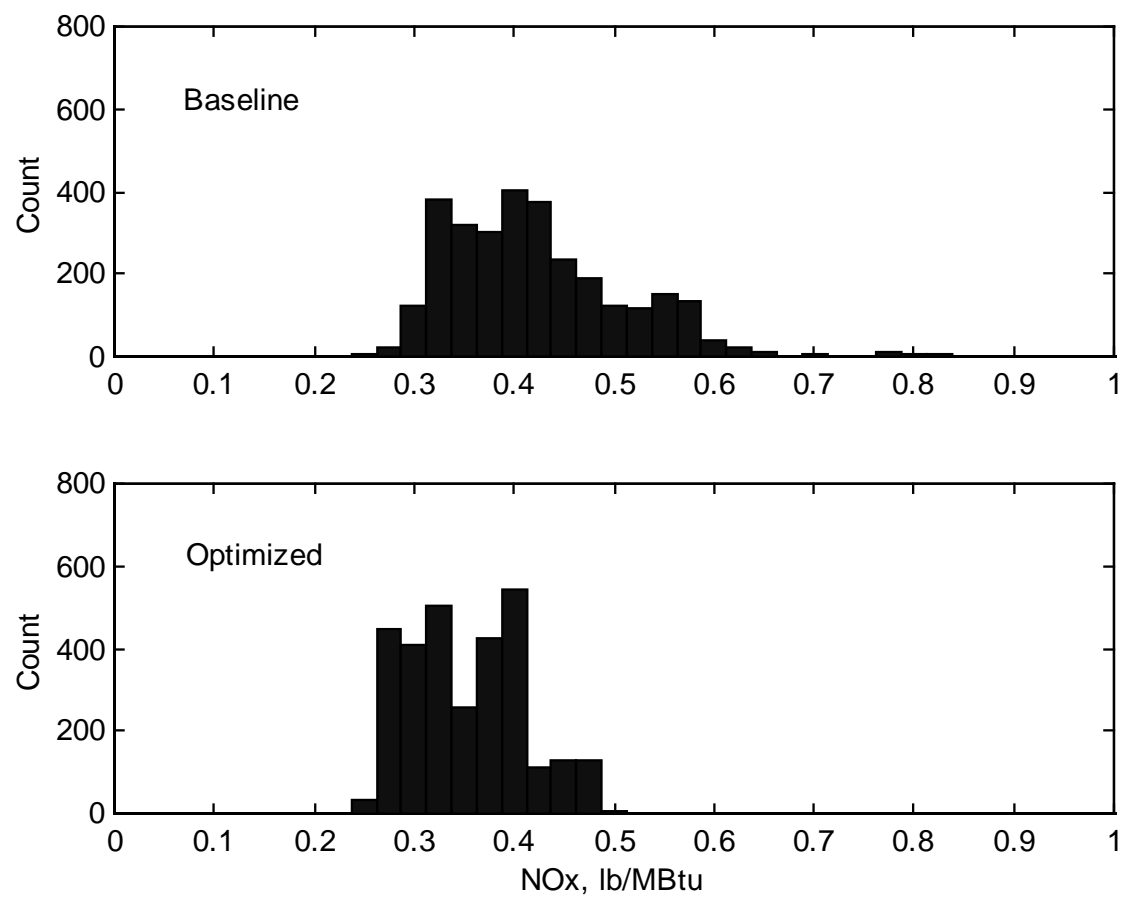

Figure 5-20 Optimizing NOx Emissions 


\subsection{GNOCIS Testing}

\subsubsection{Testing at Developmental Sites}

Prior to testing at Hammond, GNOCIS underwent development and testing at Alabama Power Company's Gaston Unit 4 and PowerGen's Kingsnorth Unit 1. A brief overview of this testing is provided below [PowerGen, 1997].

\subsubsection{Gaston Unit 4}

The objective of the Gaston trial was to develop and demonstrate GNOCIS on a wall-fired unit. Gaston Unit 4 is a 270 MW pulverized coal unit. The Babcock and Wilcox (B\&W) opposedwall-fired boiler is arranged with nine burners $(3 \mathrm{~W} \times 3 \mathrm{H})$ on two opposing walls such that no burner has another burner directly across from it. Combustion air is supplied to the burners via common wind boxes on each side of the boiler. The unit is equipped with $\mathrm{B} \& \mathrm{~W}$ XCL low $\mathrm{NO}_{\mathrm{x}}$ burners and six B\&W EL-76 ball and race mills. Fuel is delivered to the mills by two-speed table feeders. The unit has two forced-draft fans, six primary air fans, and two flue gas recirculation fans. Combustion air is heated with Ljungstrom air heaters. The boiler control system for Gaston Unit 4 is a Leeds and Northrup Max 1000 distributed digital control system. The control system is designed such that the unit is controlled through the CRTs -- there are no bench board mounted controls.

\section{GNOCIS Implementation}

The original objective at Gaston was to implement an open-loop, advisory system with no immediate plans to migrate to closed-loop operation. This objective influenced the original design philosophy in a number of respects, primarily selection and quantity of control variables, increased demand for flexible and informative operator displays, and reduced necessity for stringent recommendation checking and incorporation of safeguards. However, during the course of the project, it was determined that there were significant benefits, both in performance and ease of use of the system, if upgrades were made to GNOCIS to enable closed-loop operation. These enhancements also give the operator an easier way to implement open-loop recommendations.

Figure 5-21 shows the informational flow for the GNOCIS implementation at Gaston. All process data is collected through the DCS and passed on to the GNOCIS host (a PC running Windows NT) for calculation of the recommendations. This system interfaces to the DCS using local area network connection and TCP/IP. These recommendations are then conveyed to the operator via the DCS operator displays. If acceptable, the operator can then implement these changes through the DCS operator displays. Also, the operator has the option of running GNOCIS closed-loop in which the recommendations are automatically implemented. The primary operator display, which resides on the DCS, is shown in Figure 5-22. 


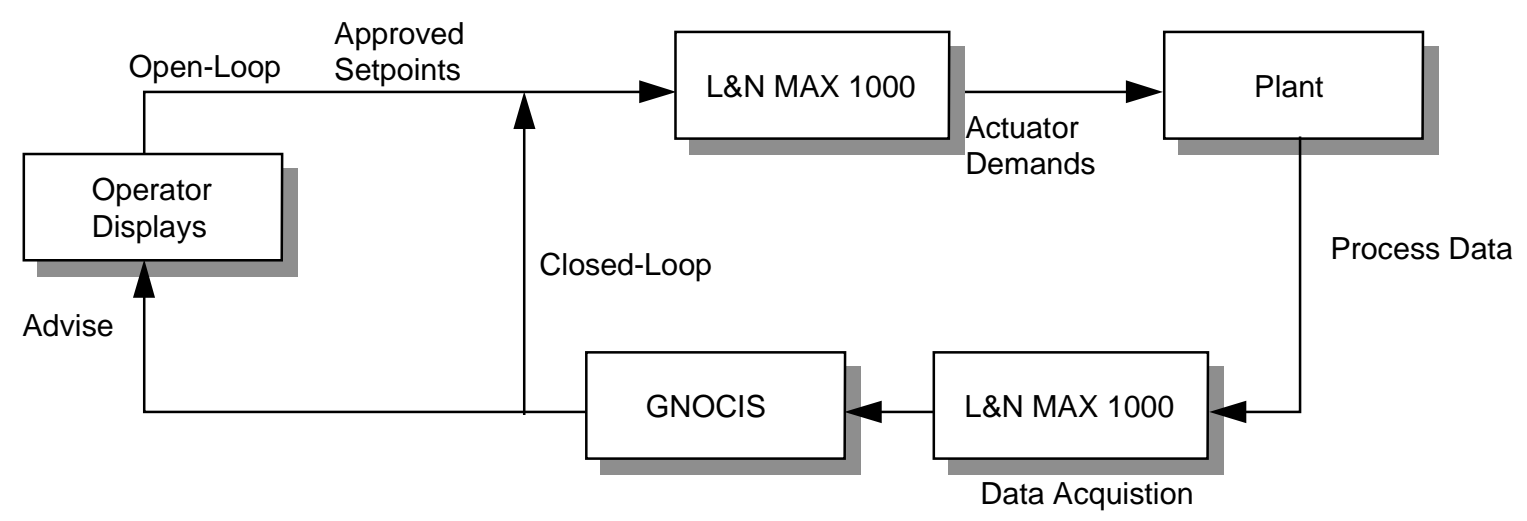

Figure 5-21Gaston GNOCIS Installation

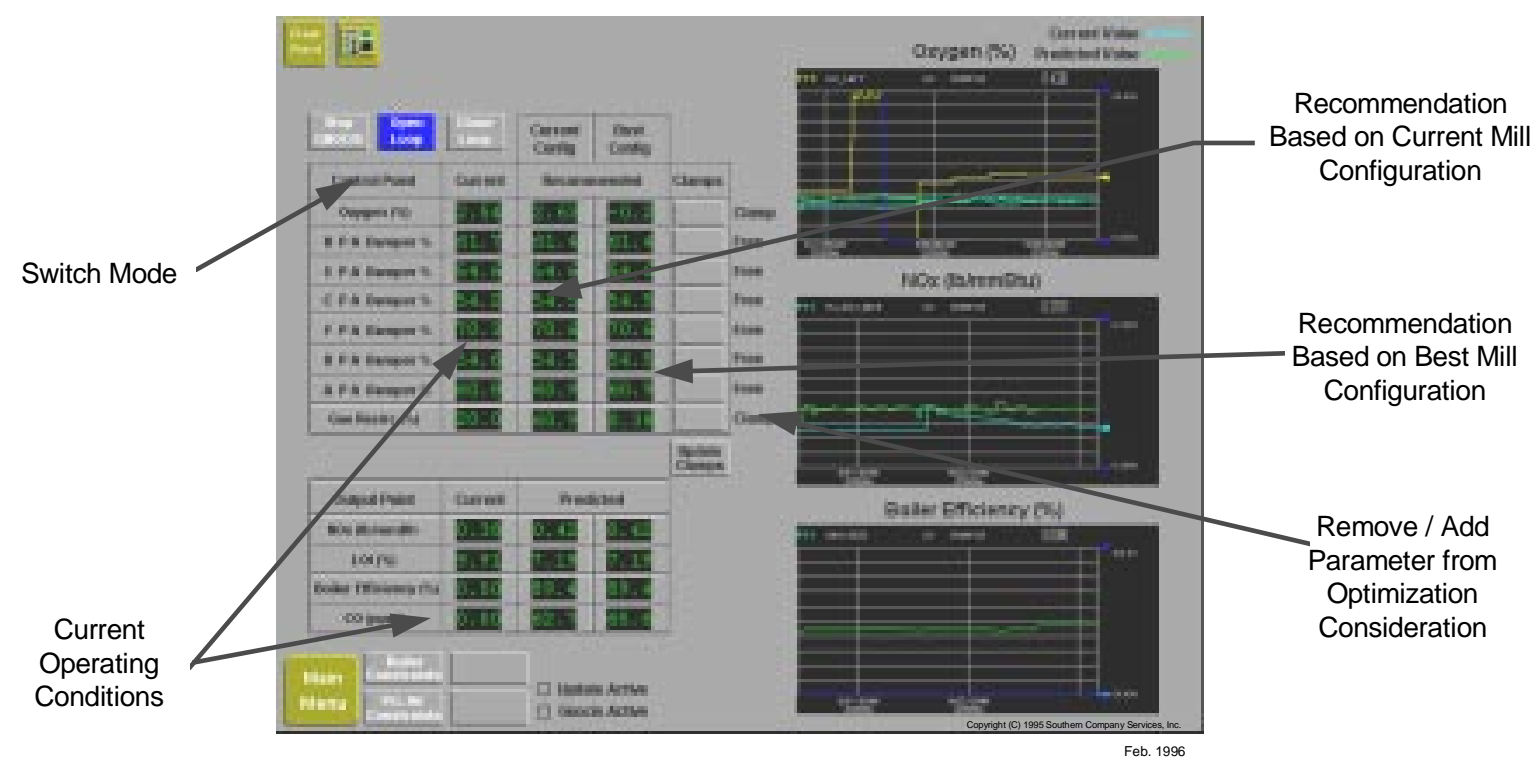

Figure 5-22 Gaston / GNOCIS Operator Interface

\section{$\underline{\text { Model Development }}$}

Data collected through the DCS was used to create the combustion models. Although in excess of 1000 points are being archived in the DCS, early in the project, a subset of approximately 100 parameters were identified as being possibly important for combustion modeling purposes. Modeling efforts have concentrated on the most recent three to four months of long-term data. Short-term tests were periodically run during which the unit was run at off-design conditions to augment data available from normal operation and thereby expand the range over which the combustion model could make estimates. Also, results from testing GNOCIS were generally included in the training data for future models. The collected data was preprocessed to remove invalid data and to some extent, data collected during transients. In general, the existing control system and instrumentation provided an excellent platform for the collection of real-time process data in a format usable by GNOCIS. 


\section{$\underline{\text { Trial Results }}$}

Preliminary open-loop testing of GNOCIS was conducted during second quarter 1995. The combustion model used during these tests was based on training data collected during October and November 1994 and February 1995. Based on these tests, it was evident that the models needed to be retrained using more recent data. Although the actual reason for model inaccuracies still are unknown, possible factors include the result in ongoing mill maintenance or an undetected change in coal characteristics. In September 1995, further open-loop testing was conducted. In general, predictions and recommendations made by GNOCIS were robust and beneficial. The results of two tests are shown in Figure 5-23 and Figure 5-24. In the first, GNOCIS was directed to maximize efficiency with no limitations placed on LOI, NOx, and CO and an approximate 0.5 percent improvement in efficiency was obtained. In the latter, the reduction of NOx emissions was the objective with the improvement being approximately 15 percent. In both these tests, relatively narrow limits were placed on the recommendations GNOCIS was allowed to provide.

Since these initial tests, GNOCIS has been converted to closed-loop operation. Example results are shown in Figure 5-25. Data shown in this figure are from when the unit is under economic dispatch and between 250 and $270 \mathrm{MW}$. Also, excess $\mathrm{O}_{2}$ was excluded from the optimization determinations (i.e. no recommendations were made for $\mathrm{O}_{2}$ ). As shown, LOI was reduced by approximately 2.5 percent and boiler efficiency improved by 0.4 percent.
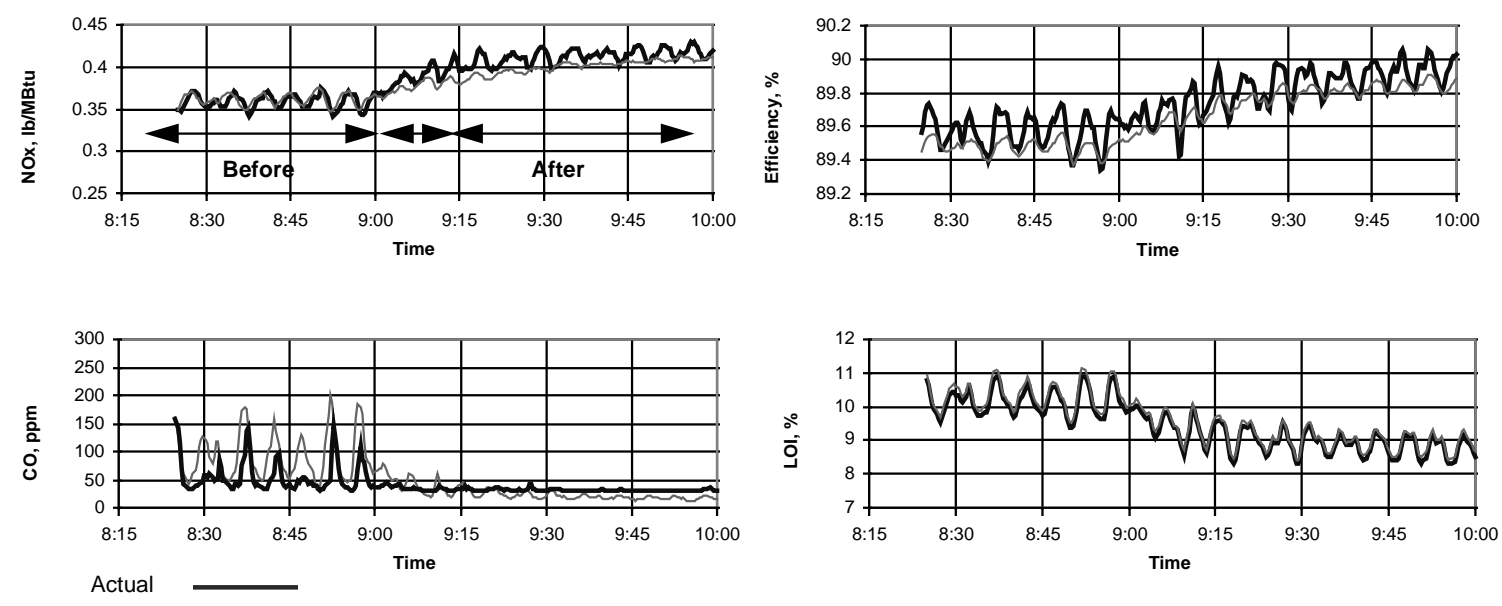

Predicted

Figure 5-23 Gaston / Maximize Efficiency Objective 



\section{$\underline{\text { Model Development }}$}

The data acquisition system was receiving and storing data twenty-four hours a day throughout the Kingsnorth trials. However, not all data was suitable for use in the models; in its raw form the data covered periods when the instrumentation was faulty and when the plant was operating in a regime outside of the GNOCIS specification (zero and low load). Data was therefore preprocessed to remove invalid data and data not corresponding to GNOCIS operating regimes. Predictive models were constructed, as a first step, to give an indication for the overall accuracy of the modeling and to highlight potential difficulties. The performance of the model was evaluated by selecting up to four periods of operation, omitting these from the input data and then running the model on this data. Similar to the predictive model evaluation, four periods of operation were chosen against which the model performance would be assessed. This was done for the control models by taking expert advice on what information should have been given to an operator to prompt any desired control action. The experts were the Kingsnorth efficiency engineer and a PowerGen combustion expert. This advice was then compared with control advice suggested by the model.

\section{$\underline{\text { Trial Results }}$}

Testing of GNOCIS at Kingsnorth began November 1994 and was completed in January 1996. During these tests, the primary interest was to evaluate the performance of GNOCIS especially in regard to its ability to produce recommendations that would result in reduced carbon-in-ash. The final tests of GNOCIS were conducted during four days of testing in December 1995 and February 1996 (Figure 5-26 and Figure 5-27).
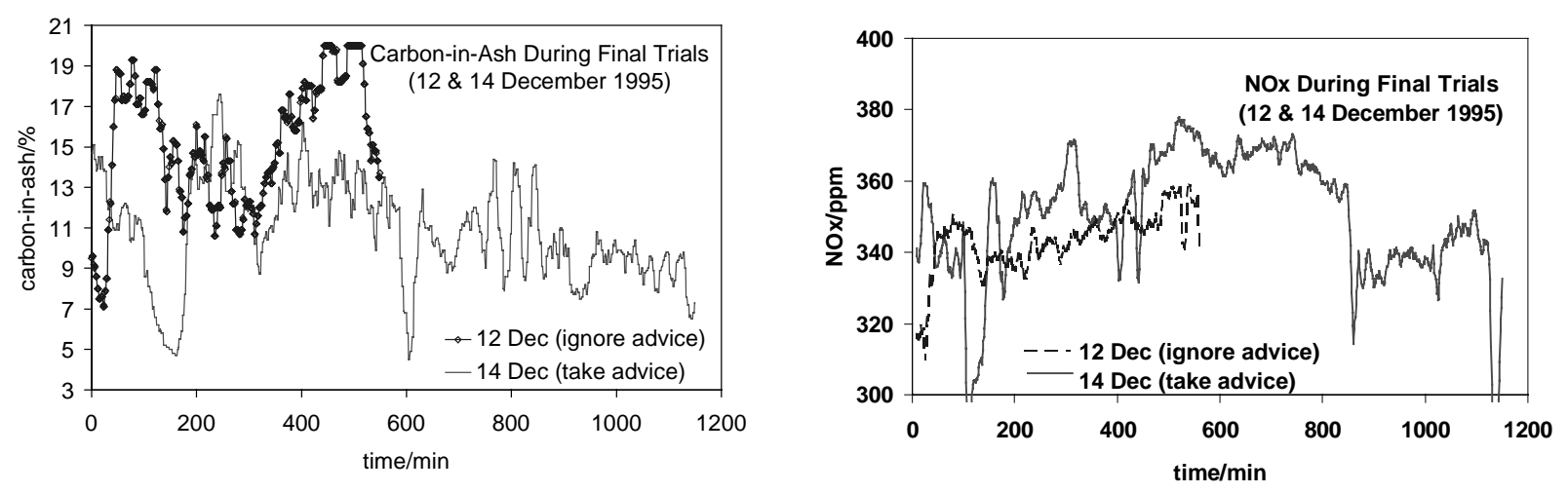

Figure 5-26 Kingsnorth / GNOCIS Minimize Carbon-in-Ash

In the December test, GNOCIS was set to give advice so that carbon-in-ash would be minimized and NOx would remain below 390 ppm (the NOx limit for the unit). During one day of trials, the advice would be taken and during the next it would be ignored and the unit operated at the non-optimized, normal settings. GNOCIS recommended significant changes in "A" and "E" feeder, excess oxygen, and burner tilt. As shown, carbon-in-ash was reduced from 15 percent to near 11 percent with minimal impact on NOx emissions. In the February tests, the objective was modified to minimize NOx emissions. NOx emissions were reduced by near 10 percent with little effect on carbon-in-ash. 


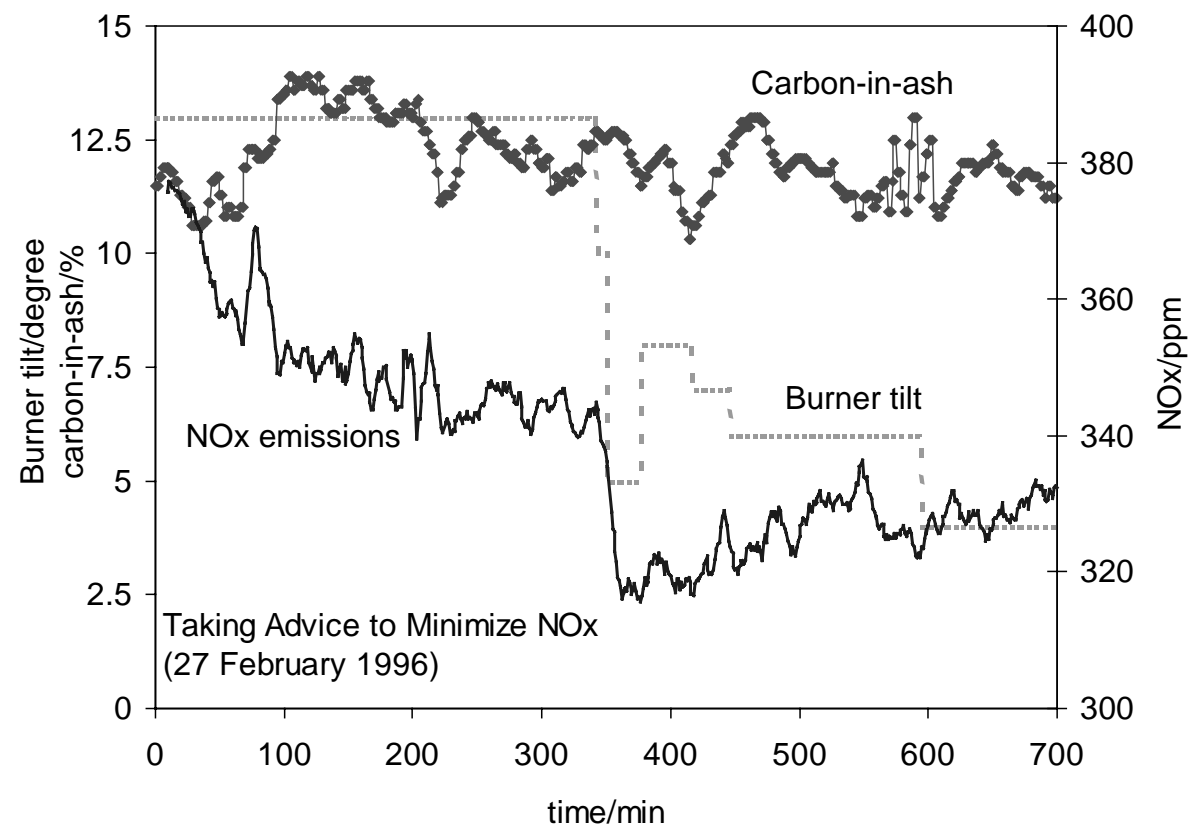

Figure 5-27 Kingsnorth / GNOCIS Minimize NOx 


\subsubsection{GNOCIS Testing at Hammond}

Following the completion of installation, GNOCIS was available for testing at this site first quarter 1996. The results of many of the tests conducted are discussed in the following paragraphs. 


\subsubsection{GNOCIS Testing Conducted First Quarter 1996}

Preliminary testing of GNOCIS at Hammond 4 began during February 1996 with tests being conducted at loads of $500 \mathrm{MW}, 400 \mathrm{MW}$, and $300 \mathrm{MW}$. The control model (hamconfc) used for these tests had the structure shown in Table 5-8. This model was trained on data collected from January 10 to February 7, 1996 and consisted of approximately 40,000 one-minute records. The results of the training are shown in Figure 5-28.

Various combinations of objectives were tested including minimizing NOx emissions, minimizing carbon-in-ash, and maximizing efficiency in both open- and closed-loop modes. Implementation of the GNOCIS recommendations were greatly facilitated as a result of enhancements made to the DCS. The primary purpose of these initial tests was to better help identify implementation and model issues. For these tests, recommendations were provided by GNOCIS for excess oxygen, individual mill coal flows, and overfire airflow to each corner of the windbox. GNOCIS operated in both open- and closed-loop modes. Most of the tests were conducted in open-loop mode, however, some of the latter were in closed-loop.

Table 5-8 Control Model Structure for February 1996 Testing

\begin{tabular}{lc}
\hline Control Model: hamconfc & State Variables \\
Control Variables & Mill Temperatures (A - F) \\
Average Excess Oxygen & Mill Primary Air Flows (A - F) \\
Mill Coal Flow A & Main Steam Temperature \\
Mill Coal Flow B & Main Steam Pressure \\
Mill Coal Flow C & Hot Reheat Temperature \\
Mill Coal Flow D & Cold Reheat Pressure \\
Mill Coal Flow E & Excess Oxygen Side A \\
Mill Coal Flow F & Excess Oxygen Side B \\
AOFA Airflow R1 & Feedwater Flow \\
AOFA Airflow R2 & Drum Pressure \\
AOFA Airflow F1 & First Stage Pressure \\
AOFA Airflow F2 & Superheat Spray Flows \\
& Feedwater Temperature \\
& Total Secondary Air \\
& Air Heater Gas Inlet and Outlet \\
& Temp. \\
Output Variables & Superheat Inlet Temperatures \\
NOx Emissions & External Variables \\
LOI & $<$ None> \\
Boiler Efficiency & \\
\hline
\end{tabular}



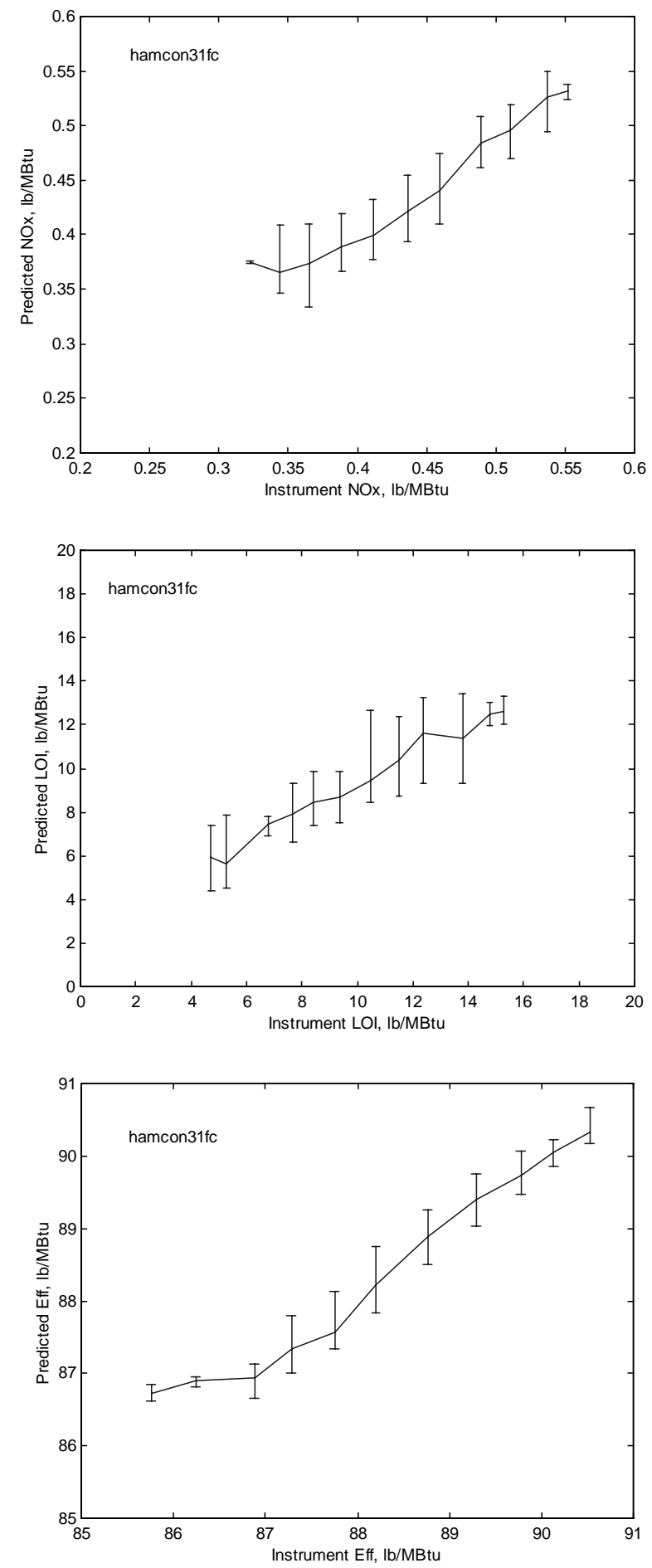

Figure 5-28 GNOCIS / Predicted vs. Actual / Hamcon31fc 
Table 5-9 GNOCIS Testing Conducted First Quarter 1996

\begin{tabular}{|c|c|c|c|c|c|}
\hline Test & $\begin{array}{l}\text { Date } \\
\text { Appr. Start Time } \\
\text { Appr. Stop Time }\end{array}$ & Mode & Goals & Constraints & Notes \\
\hline $154-1$ & $\begin{array}{c}13-F e b-96 \\
12: 30 \\
13: 30\end{array}$ & $\begin{array}{l}\text { Open-Loop } \\
\text { Min NOx }\end{array}$ & $\begin{array}{c}0.2<\mathrm{NOx}<0.2 \\
0<\mathrm{LOI}<20 \\
0<\mathrm{Eff}<100\end{array}$ & $\begin{array}{l}-0.2<\Delta \mathrm{O} 2<0.2 \\
\text { Mills clamped } \\
\text { AOFA clamped }\end{array}$ & \\
\hline $154-2$ & $\begin{array}{l}13-\text { Feb-96 } \\
13: 00 \\
14: 30\end{array}$ & $\begin{array}{l}\text { Open-Loop } \\
\text { Min LOI }\end{array}$ & $\begin{array}{c}0.2<\mathrm{NOx}<1.0 \\
0<\mathrm{LOI}<0 \\
0<\mathrm{Eff}<100\end{array}$ & $\begin{array}{l}-0.2<\Delta \mathrm{O} 2<0.2 \\
\text { Mills clamped } \\
\text { AOFA clamped }\end{array}$ & \\
\hline $154-3$ & $\begin{array}{l}13-\text { Feb-96 } \\
14: 00 \\
15: 30\end{array}$ & $\begin{array}{l}\text { Open-Loop } \\
\text { Min NOx }\end{array}$ & $\begin{array}{c}0.2<\mathrm{NOx}<0.2 \\
0<\mathrm{LOI}<20 \\
0<\mathrm{Eff}<100\end{array}$ & $\begin{array}{l}-0.2<\Delta \mathrm{O} 2<0.2 \\
\text { Mills clamped } \\
-5<\text { AOFA }<5\end{array}$ & \\
\hline $155-1$ & $\begin{array}{l}15-\text { Feb-96 } \\
9: 40 \\
11: 40\end{array}$ & $\begin{array}{l}\text { Open-Loop } \\
\text { Min NOx }\end{array}$ & $\begin{array}{c}0.2<\mathrm{NOx}<0.2 \\
0<\mathrm{LOI}<20 \\
0<\mathrm{Eff}<100\end{array}$ & $\begin{array}{l}-0.2<\Delta \mathrm{O} 2<0.2 \\
\text { Mills clamped } \\
\text { AOFA clamped }\end{array}$ & \\
\hline $155-2$ & $\begin{array}{l}\text { 15-Feb-96 } \\
10: 30 \\
12: 50\end{array}$ & $\begin{array}{l}\text { Open-Loop } \\
\text { Min LOI }\end{array}$ & $\begin{array}{c}0.2<\mathrm{NOx}<1.0 \\
0<\mathrm{LOI}<0 \\
0<\mathrm{Eff}<100\end{array}$ & $\begin{array}{l}-0.2<\Delta \mathrm{O} 2<0.2 \\
\text { Mills clamped } \\
\text { AOFA clamped }\end{array}$ & \\
\hline $155-3$ & $\begin{array}{c}15-\text { Feb-96 } \\
12: 10 \\
14: 30\end{array}$ & $\begin{array}{l}\text { Open-Loop } \\
\text { Min LOI }\end{array}$ & $\begin{array}{c}0.2<\mathrm{NOx}<1.0 \\
0<\mathrm{LOI}<0 \\
0<\mathrm{Eff}<100\end{array}$ & $\begin{array}{l}-0.2<\Delta \mathrm{O} 2<0.2 \\
-5.2<\text { Mills }<5.2 \\
\text { AOFA clamped }\end{array}$ & - $\quad \mathrm{O}_{2}$ recommendation flip flops. \\
\hline $155-4$ & $\begin{array}{l}\text { 15-Feb-96 } \\
14: 00 \\
15: 20\end{array}$ & $\begin{array}{l}\text { Open-Loop } \\
\text { Min NOx }\end{array}$ & $\begin{array}{c}0.2<\mathrm{NOx}<0.2 \\
0<\mathrm{LOI}<20 \\
0<\mathrm{Eff}<100\end{array}$ & $\begin{array}{c}0.2<\Delta \mathrm{O} 2<0.2 \\
-5.2<\text { Mills }<5.2 \\
\text { B Mill clamped } \\
\text { AOFA clamped }\end{array}$ & \\
\hline $156-1$ & $\begin{array}{l}16-\text { Feb-96 } \\
11: 30 \\
13: 30\end{array}$ & $\begin{array}{l}\text { Open-Loop } \\
\text { Min NOx }\end{array}$ & $\begin{array}{c}0.2<\mathrm{NOx}<0.2 \\
0<\mathrm{LOI}<20 \\
0<\mathrm{Eff}<100\end{array}$ & $\begin{array}{l}0.2<\Delta \mathrm{O} 2<0.2 \\
\text { Mills clamped } \\
\text { AOFA clamped }\end{array}$ & \\
\hline $156-2$ & $\begin{array}{l}16-\text { Feb-96 } \\
12: 50 \\
14: 00\end{array}$ & $\begin{array}{l}\text { Open-Loop } \\
\text { Min LOI }\end{array}$ & $\begin{array}{c}0.2<\mathrm{NOx}<0.2 \\
0<\mathrm{LOI}<20 \\
0<\mathrm{Eff}<100\end{array}$ & $\begin{array}{l}0.2<\Delta \mathrm{O} 2<0.2 \\
\text { Mills clamped } \\
\text { AOFA clamped }\end{array}$ & \\
\hline $156-3$ & $\begin{array}{l}16-\text { Feb-96 } \\
\text { 13:45 } \\
15: 00\end{array}$ & $\begin{array}{l}\text { Open-Loop } \\
\text { Max Eff }\end{array}$ & $\begin{array}{c}0.2<\mathrm{NOx}<1.0 \\
0<\mathrm{LOI}<20 \\
100<\mathrm{Eff}<100\end{array}$ & $\begin{array}{c}0.2<\Delta \text { O } 2<0.2 \\
-5.2<\text { Mills }<5.2 \\
-5<\text { AOFA }<5\end{array}$ & \\
\hline $157-1$ & $\begin{array}{l}\text { 22-Feb-96 } \\
14: 30 \\
16: 00\end{array}$ & $\begin{array}{l}\text { Open-Loop } \\
\text { Min NOx }\end{array}$ & $\begin{array}{c}0.2<\mathrm{NOx}<0.2 \\
0<\mathrm{LOI}<20 \\
0<\mathrm{Eff}<100\end{array}$ & $\begin{array}{l}0.2<\Delta \mathrm{O} 2<0.2 \\
\text { Mills clamped } \\
\text { AOFA clamped }\end{array}$ & \\
\hline $157-2$ & $\begin{array}{l}\text { 22-Feb-96 } \\
15: 30 \\
17: 30\end{array}$ & $\begin{array}{l}\text { Closed-Loop } \\
\text { Min LOI }\end{array}$ & $\begin{aligned} 0.2 & <\mathrm{NOx}<1.0 \\
0 & <\mathrm{LOI}<0 \\
0 & <\mathrm{Eff}<100\end{aligned}$ & $\begin{array}{l}0.2<\Delta \mathrm{O} 2<0.2 \\
\text { Mills clamped } \\
\text { AOFA clamped }\end{array}$ & $\begin{array}{l}\text { - } \quad \text { First closed-loop test. } \\
\text { - Test aborted when operator changed mills in } \\
\text { service. }\end{array}$ \\
\hline $157-3$ & $\begin{array}{l}\text { 22-Feb-96 } \\
17: 30 \\
19: 00\end{array}$ & $\begin{array}{l}\text { Closed-Loop } \\
\text { Min LOI }\end{array}$ & $\begin{aligned} 0.2 & <\mathrm{NOx}<1.0 \\
0 & <\mathrm{LOI}<0 \\
0 & <\mathrm{Eff}<100\end{aligned}$ & $\begin{array}{l}0.2<\Delta \mathrm{O} 2<0.2 \\
\text { Mills clamped } \\
\text { AOFA clamped }\end{array}$ & - Move suppression on $\mathrm{O}_{2}$ zero. \\
\hline $157-4$ & $\begin{array}{l}\text { 22-Feb-96 } \\
\text { 19:00 } \\
19: 30\end{array}$ & $\begin{array}{l}\text { Closed-Loop } \\
\text { Min NOx }\end{array}$ & $\begin{aligned} & 0.2<\mathrm{NOx}<0.2 \\
& 0<\mathrm{LOI}<20 \\
& 0<\mathrm{Eff}<100\end{aligned}$ & $\begin{array}{l}0.2<\Delta \mathrm{O} 2<0.2 \\
\text { Mills clamped } \\
\text { AOFA clamped }\end{array}$ & - $\quad$ Move suppression on $\mathrm{O}_{2}$ zero. \\
\hline $157-5$ & $\begin{array}{l}\text { 22-Feb-96 } \\
\text { 19:30 } \\
20: 00\end{array}$ & $\begin{array}{c}\text { Closed-Loop } \\
\text { Min NOx, Max } \\
\text { Eff } \\
\text { LOI <10 }\end{array}$ & $\begin{array}{c}0.2<\mathrm{NOx}<0.2 \\
0<\mathrm{LOI}<10 \\
100<\mathrm{Eff}<100\end{array}$ & & $\begin{array}{l}\text { - Optimizer failure due to starting point being } \\
\text { outside feasible region. }\end{array}$ \\
\hline $157-6$ & $\begin{array}{l}\text { 22-Feb-96 } \\
20: 00 \\
21: 00\end{array}$ & $\begin{array}{l}\text { Closed-Loop } \\
\text { Min LOI }\end{array}$ & $\begin{aligned} 0.2 & <\mathrm{NOx}<1.0 \\
0 & <\mathrm{LOI}<0 \\
0 & <\mathrm{Eff}<100\end{aligned}$ & & $\begin{array}{l}\text { - Optimizer failure due to starting point being } \\
\text { outside feasible region. }\end{array}$ \\
\hline
\end{tabular}




\section{$\underline{\text { Tests } 154}$}

Results of the first day of testing during which three tests were conducted are shown in Figure 5-29 and Figure 5-30. The unit was operating at full load (500 MW) with all mills in service, overfire in operation, and otherwise normal operating conditions.

For the first test (Test 154-1), the goal was to minimize NOx with excess oxygen, with the other control variables (AOFA airflow and mill coal flow) being clamped to the current operating condition. GNOCIS was allowed to make recommendations for excess oxygen of $\pm 0.2 \%$ about the current operating condition. As may be expected, the recommendation was to decrease excess oxygen to the lower bound of the operating limit. This resulted in an approximate $0.02 \mathrm{lb} / \mathrm{MBtu}$ reduction in NOx emissions. This sensitivity $(0.1 \mathrm{lb} / \mathrm{MBtu}$ per $1 \%$ change in excess oxygen) is similar to what had been observed in prior phases. Note that fly ash carbon-inash, as measured by the FOCUS system, increased in response to the decrease in excess oxygen with a sensitivity of $5 \%$ change in CIA per $1 \%$ change in excess oxygen. ${ }^{1}$ This increase was also evident on the SEKAM monitor, but delayed due to the relatively slow response of this instrument.

The objective of the second test (Test 154-2) was to minimize LOI. As before, all control variables other than excess oxygen was clamped with the limits for the latter again being $\pm 0.2 \%$. The recommendation for excess oxygen was to increase it to the upper limit (3.6\%). As shown in Figure 5-29, LOI decreased by about 2 percentage points while NOx increased to around 0.60 $\mathrm{lb} / \mathrm{MBtu}$.

For the final test of the day (Test 154-3), the objective was again to minimize NOx emission, however, in addition to excess oxygen, the AOFA airflow to the four corners of the windbox were included in the optimization mix. As shown, NOx emission levels were not obviously lower than that achieved with excess oxygen alone $(\sim 0.55 \mathrm{lb} / \mathrm{MBtu})$. Potential reasons that the inclusion of AOFA did not improve performance include:

- Relatively small limits placed on AOFA movement $( \pm 5000 \mathrm{lb} / \mathrm{h}$ or approximate $\pm 2 \%$ of full range).

- Relative low sensitivity of NOx to changes in OFA when LNBs are installed (1.25e-7 $\mathrm{lb} / \mathrm{MBtu}$ per lb/h OFA flow). Based on prior testing, for the given constraints placed on the movement of the OFA, this would result in a change in NOx of about $0.003 \mathrm{lb} / \mathrm{MBtu}$.

- There is considerable noise on the OFA flow measurements, in particular the "F2" flow. This makes the process difficult to control to setpoint.

\footnotetext{
${ }^{1}$ The CAM, FOCUS, and SEKAM are on-line LOI monitors; detailed descriptions can be found in the topical report On-Line Carbon-in-Ash Monitors [SCS, 1997].
} 


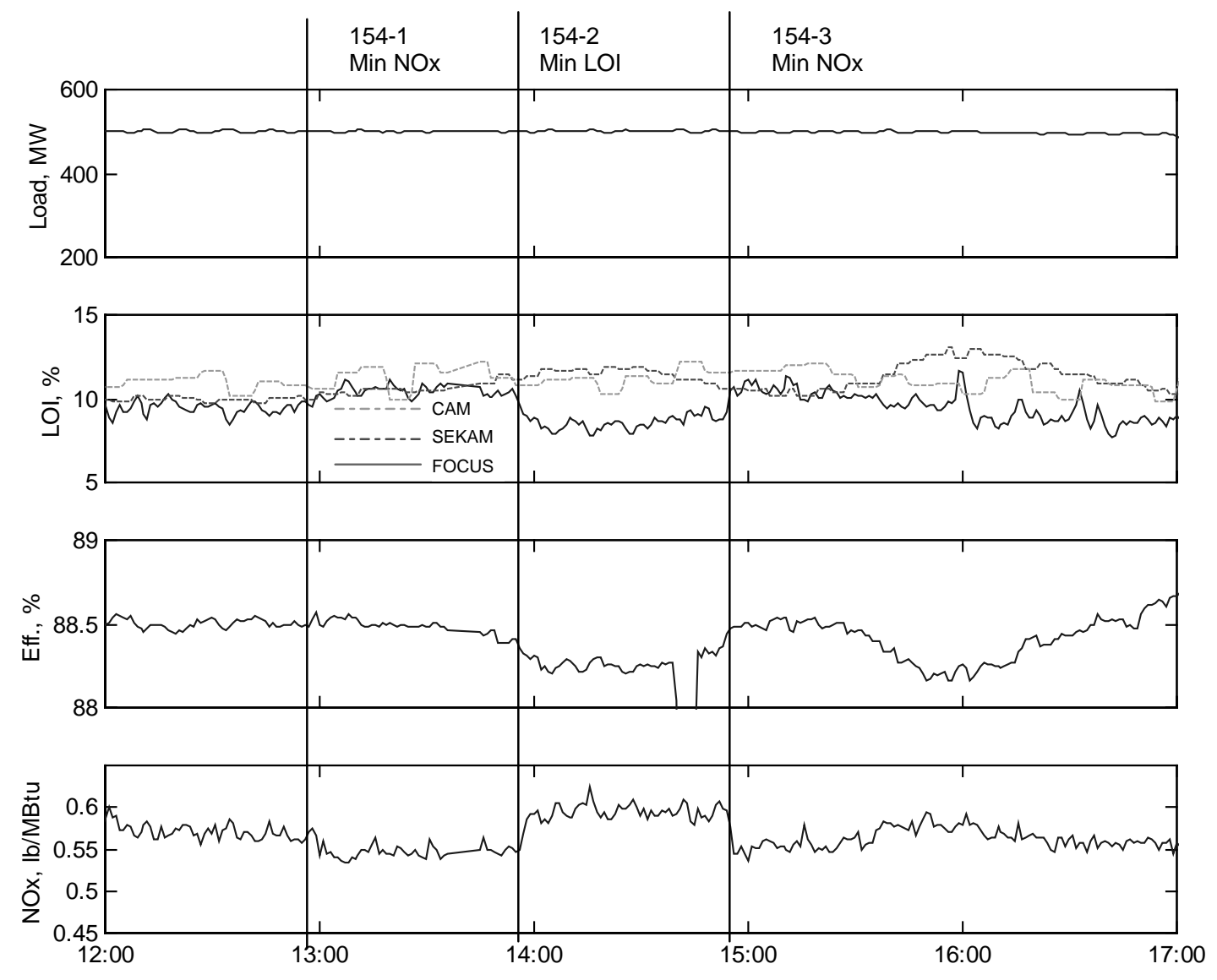

Figure 5-29 GNOCIS / Test 154 / Optimized Variables 


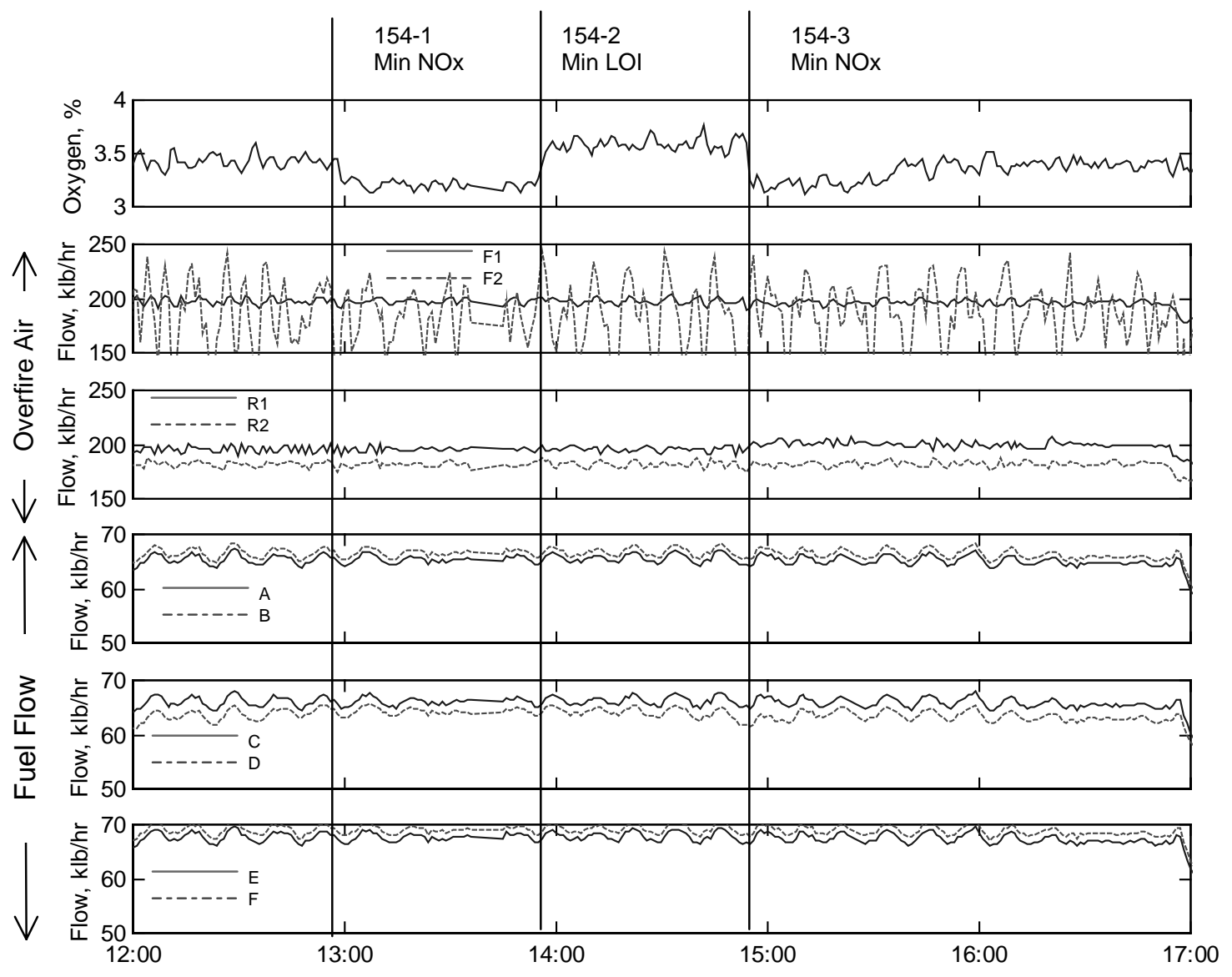

Figure 5-30 GNOCIS / Test 154 / Manipulated Variables 


\section{$\underline{\text { Tests } 155}$}

Test day 155 occurred on February 15, 1996 during which four tests were conducted (Figure 5-31 and Figure 5-32). The tests were conducted at $300 \mathrm{MW}$ with "B" mill out of service and no overfire airflow. As shown, load was relatively constant during the test period. During the entire test period, the combustion side of the process was oscillating at a period of approximately 15 minutes that sometimes made the interpretation of results difficult. Note that this oscillation was independent of whether GNOCIS was operating. Again starting with only excess oxygen in the optimizing mix, recommendations were made to NOx emissions (Test 155-1). Excess oxygen was reduced from the nominal $4.4 \%$ to approximately $4.2 \%$ with the NOx emissions going from 0.52 to $0.49 \mathrm{lb} / \mathrm{MBtu}$. As before, the limits on the excess oxygen bias were set to $\pm 0.2 \%$ around the nominal operating point. As may be expected with the reduction in excess oxygen, LOI increased as a result of the recommendation (Figure 5-31). As shown, the SEKAM, CAM, and FOCUS systems all indicated an increase, however, due to the slow response of the SEKAM, it did not reach its maximum until the beginning of the next test. Also, although the CAM has a relatively response time (about 10 minutes at this load level), it generally increased during the entire time from the beginning of Test 155-1 to the beginning of Test 155-2 (Figure 5-33). Changing coal conditions or otherwise uncontrolled inputs to the furnace may have caused this increase.

In Test 155-2, the objective was to minimize LOI with the result being it reduced by approximately 1 to $2 \%$, using the CAM as reference. However, as shown, LOI began to increase during the test period even though, to our knowledge, no controllable parameters were changed. Again, changing coal conditions or otherwise uncontrolled inputs to the furnace may have caused this increase.

In the Test 155-3, the mills were included in the optimization mix to reduce LOI. The biasing of the mills appeared to, at least temporarily, forestall the increase in LOI. To minimize LOI, the "A" mill (middle elevation, rear wall) was reduced in flow while the "D" mill (middle elevation, front wall) was increased.

The objective of the last test of the day was to minimize NOx emissions using excess oxygen and mill biasing. As shown, the NOx emissions reduced by about $0.03 \mathrm{lb} / \mathrm{MBtu}$, similar to what was achieved with excess oxygen alone. The recommendation was to reduce excess oxygen from the nominal limit to the lower limit allowed. Although included in the optimization mix, the recommendation was to leave the mills in the current operating configuration. Unless disabled, GNOCIS has move suppression that prevents excessive movement in a control variable if only marginal improvement is obtained. This suppression is the likely reason the mills were left in the current configuration. 


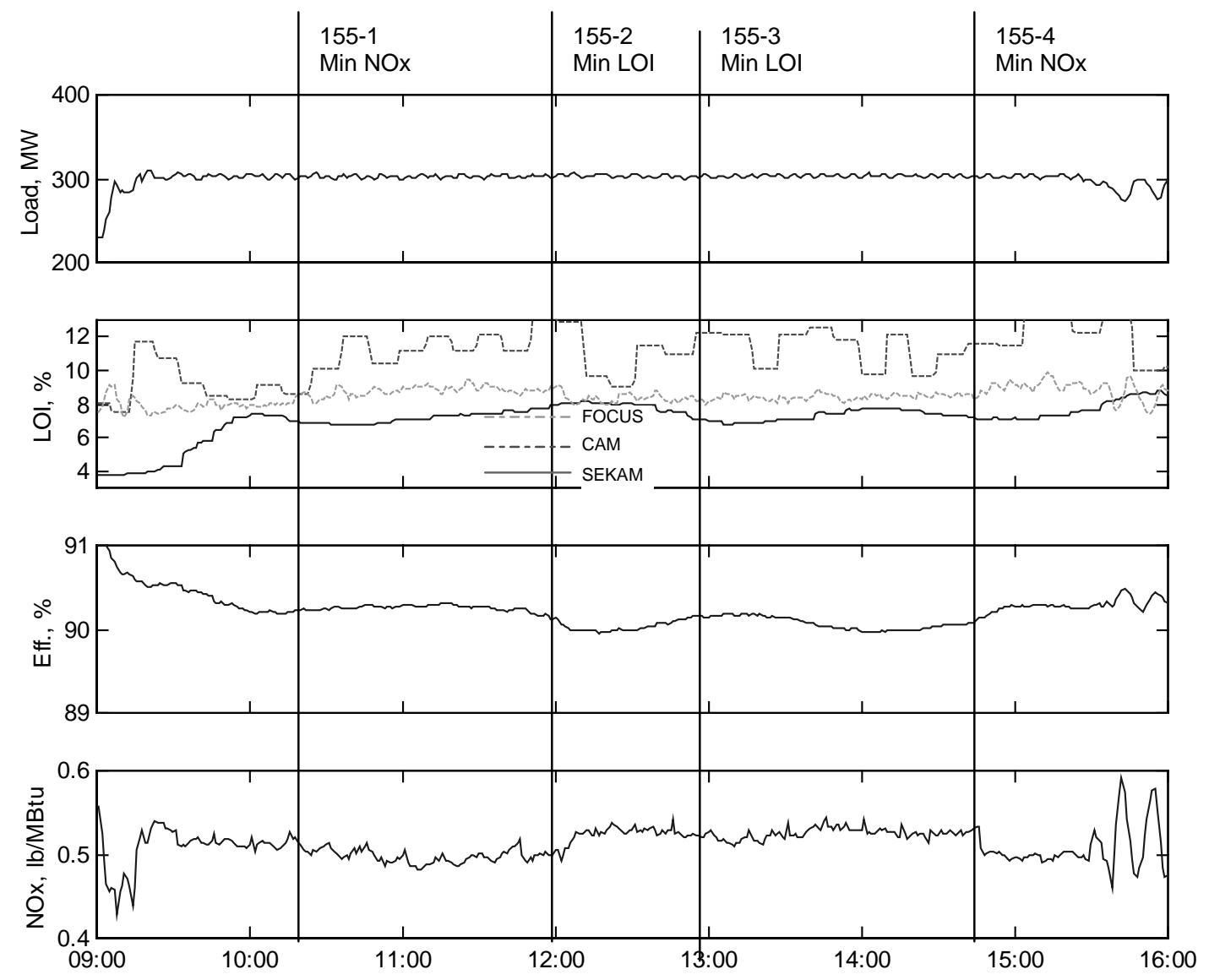

Figure 5-31 GNOCIS / Test 155 / Optimized Variables 


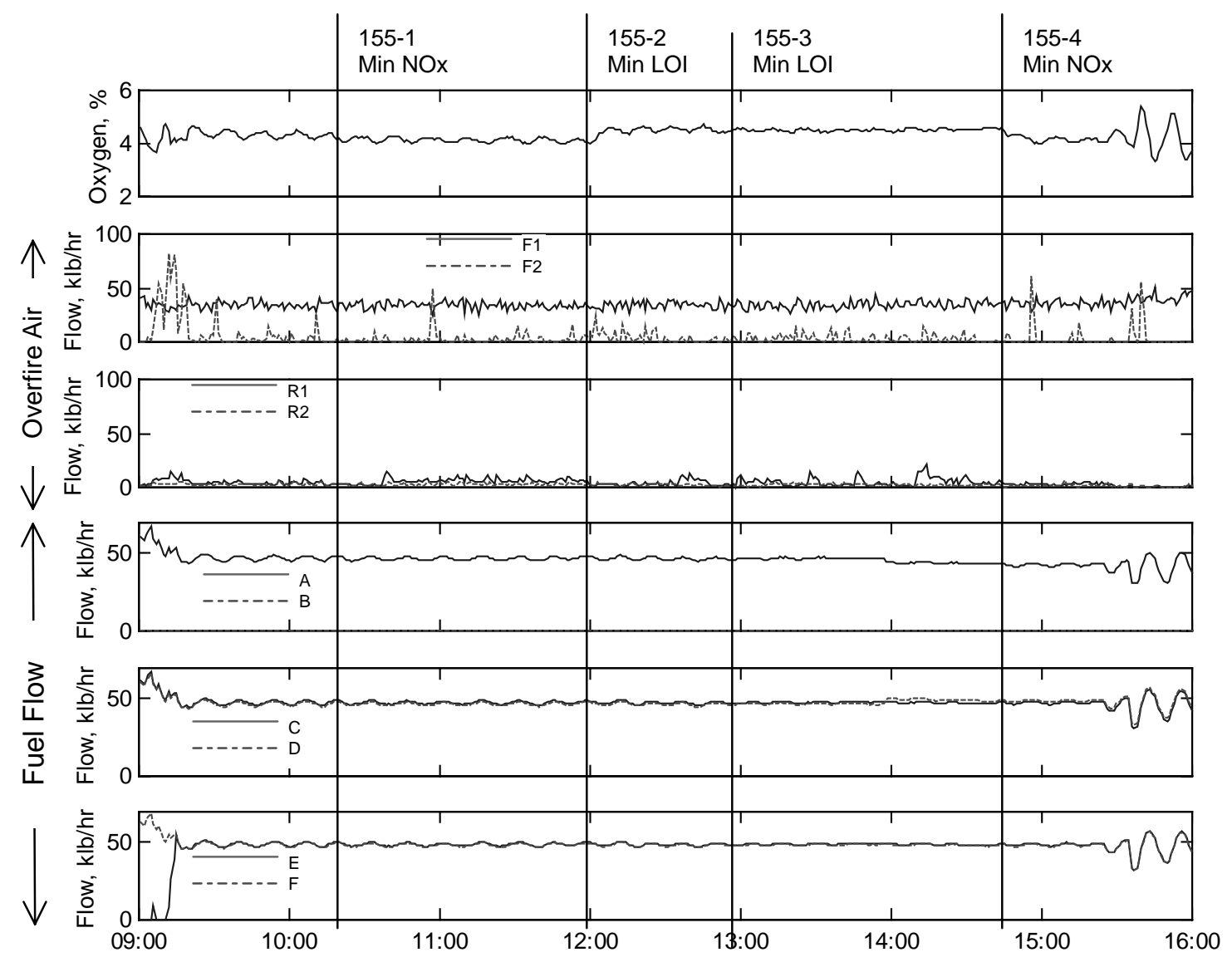

Figure 5-32 GNOCIS / Test 155 / Manipulated Variables 


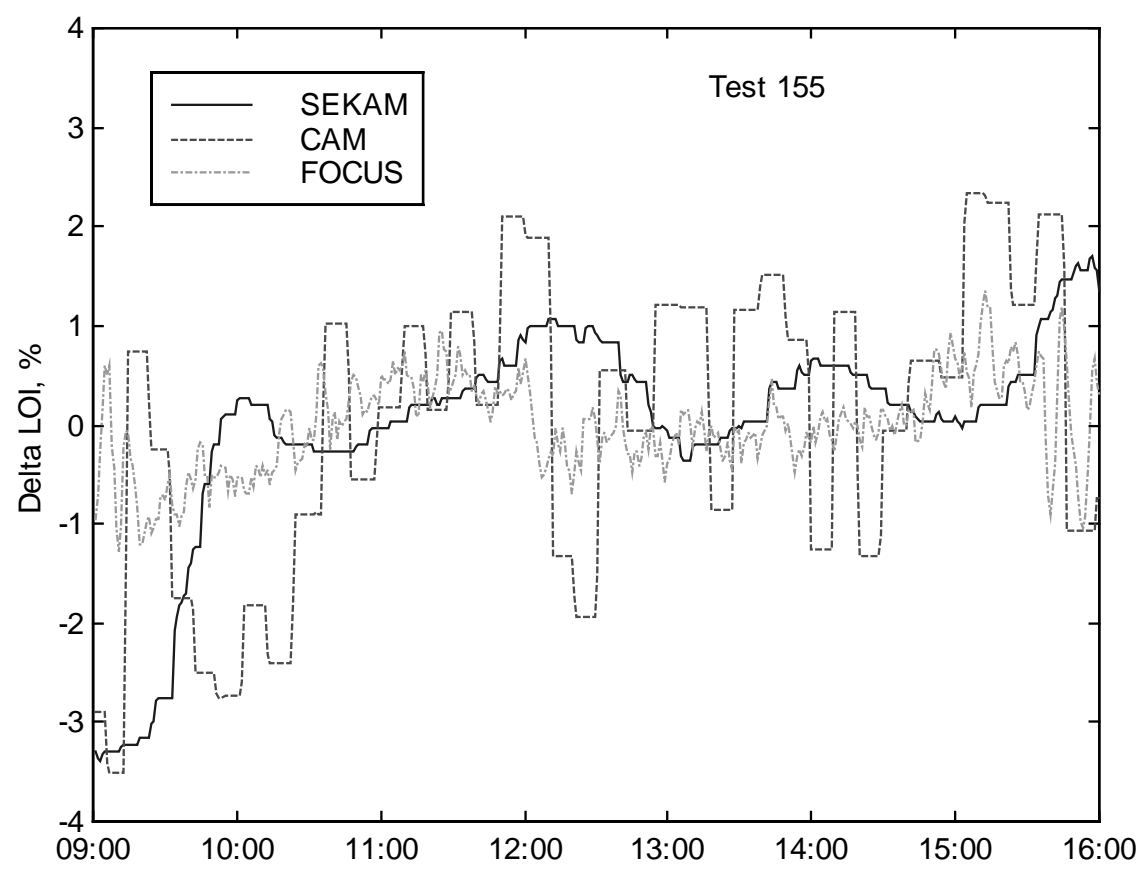

Figure 5-33 GNOCIS / Test 155 / Delta LOI

Tests 156

Three tests were conducted on February 16, 1996. The unit was operating at $400 \mathrm{MW}$ with all mills in service and overfire air at nominal operating conditions. The unit was off economic dispatch and generation remained relatively constant during the test period (Figure 5-34).

The objective of Test 156-1 was to minimize NOx emissions with excess oxygen only, all other control variables being clamped. Excess oxygen, which was allowed to deviate from nominal by $\pm 0.2 \%$, decreased to the lower limit (Figure 5-35). As shown, NOx decreased by approximately $0.02 \mathrm{lb} / \mathrm{MBtu}$. This sensitivity $(0.1 \mathrm{lb} / \mathrm{MBtu}$ per percent change in excess oxygen $)$ is similar to what has been observed in prior tests. Fly ash LOI (as measured by the SEKAM unit) increased by about $1 \%$ from this action (Figure 5-34 and Figure 5-36). This LOI increase would reduce boiler efficiency by approximately $0.13 \%$. A decrease in excess oxygen typically reduces dry flue gas losses (by about 0.4 percentage points per percent change in excess oxygen).

The goal of Test 156-2 was to reduce LOI using excess oxygen alone. As shown, LOI decreased by about $1 \%$ to the original level.

For Test 156-3, with all control variables unclamped, boiler efficiency was optimized. The recommendation was to lower excess oxygen to the lower limit, increase mills " $D$ " and " $F$ ", and decrease mills " $A$ " and "B". Overfire air and mill " $C$ " and "E" coal flows were left unchanged. As shown, there appeared to be some improvement in efficiency (about 0.25\%) (Figure 5-37). 


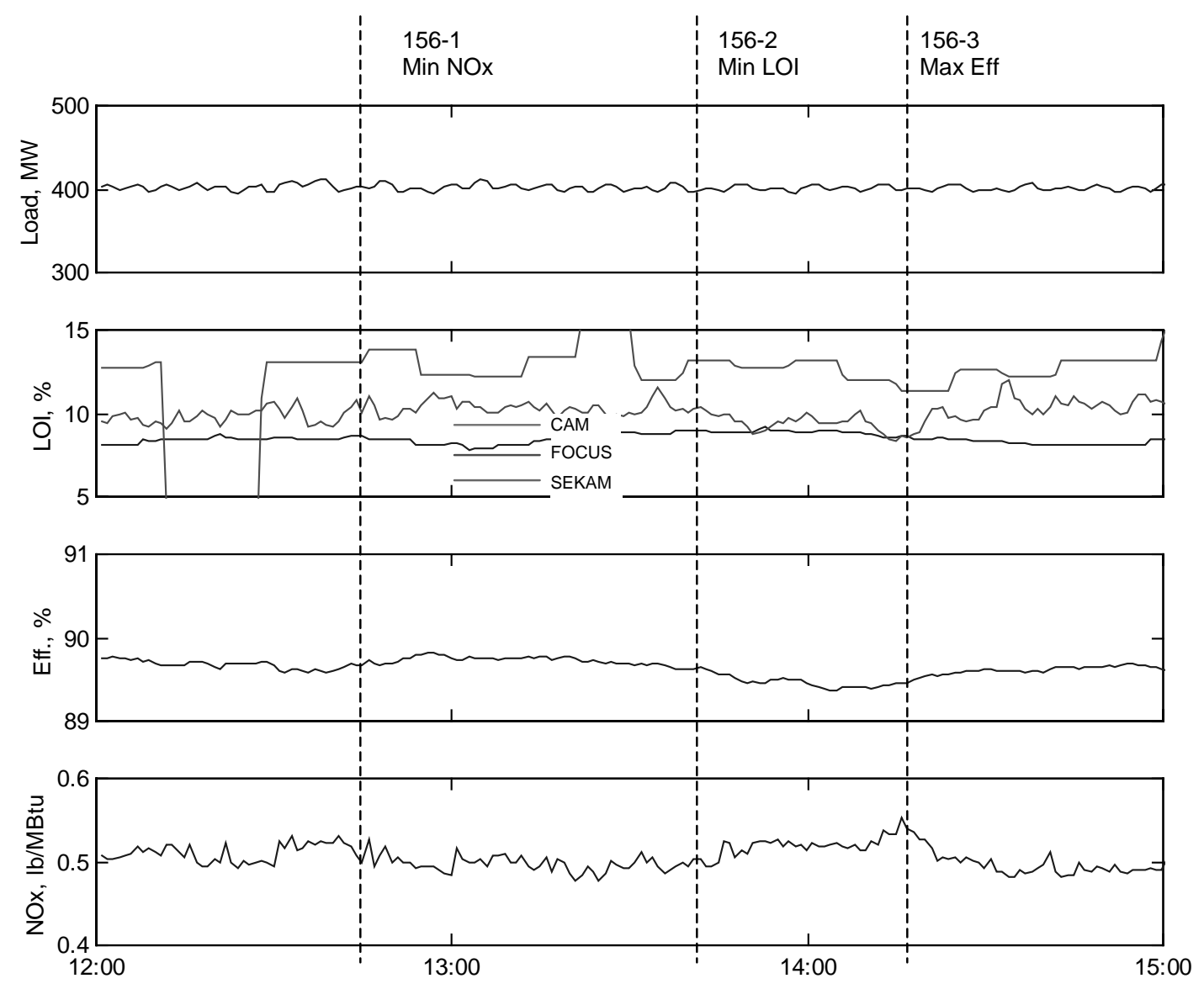

Figure 5-34 GNOCIS / Test 156 / Optimized Variables 

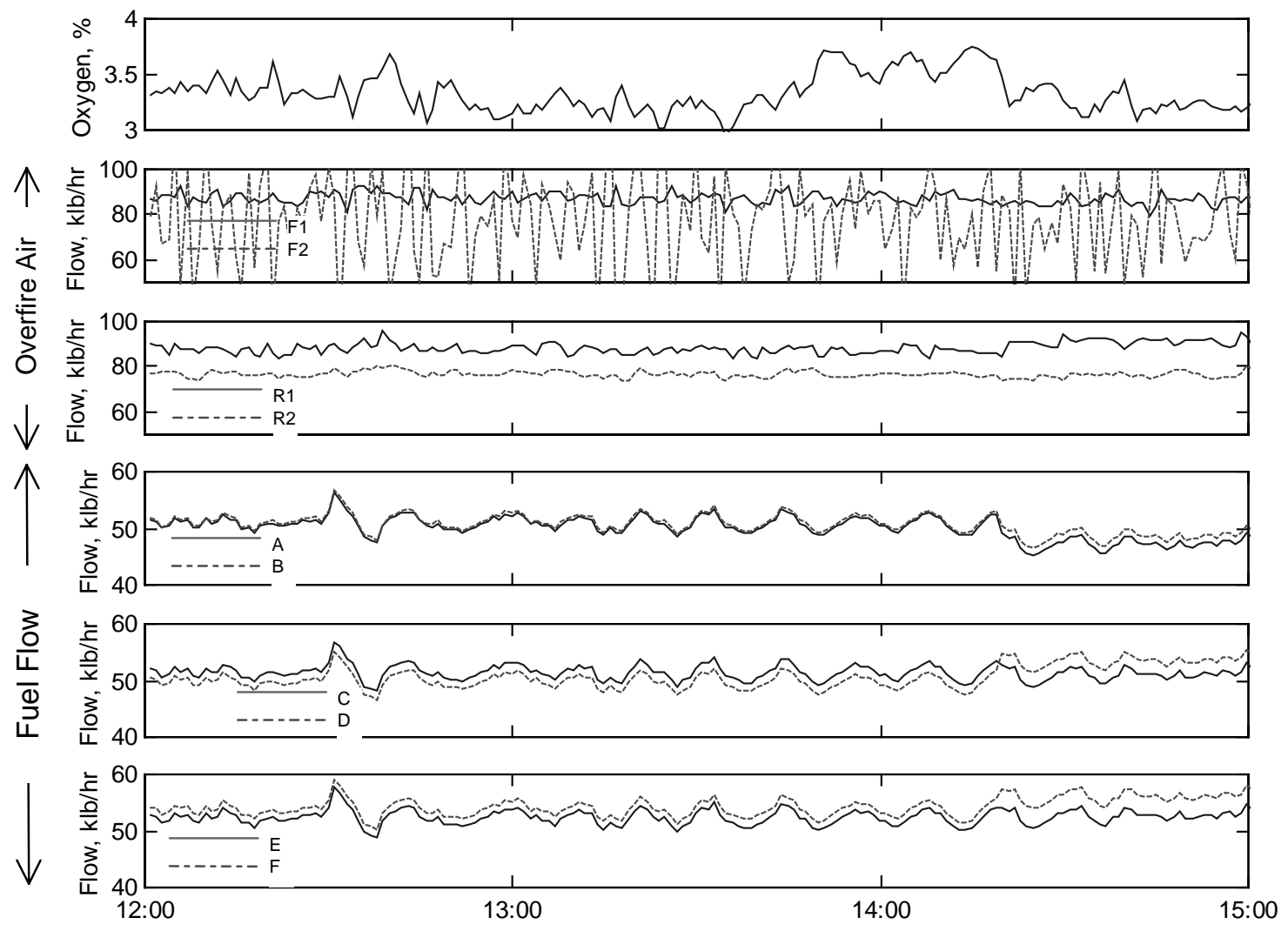

Figure 5-35 GNOCIS / Test 156 / Manipulated Variables 


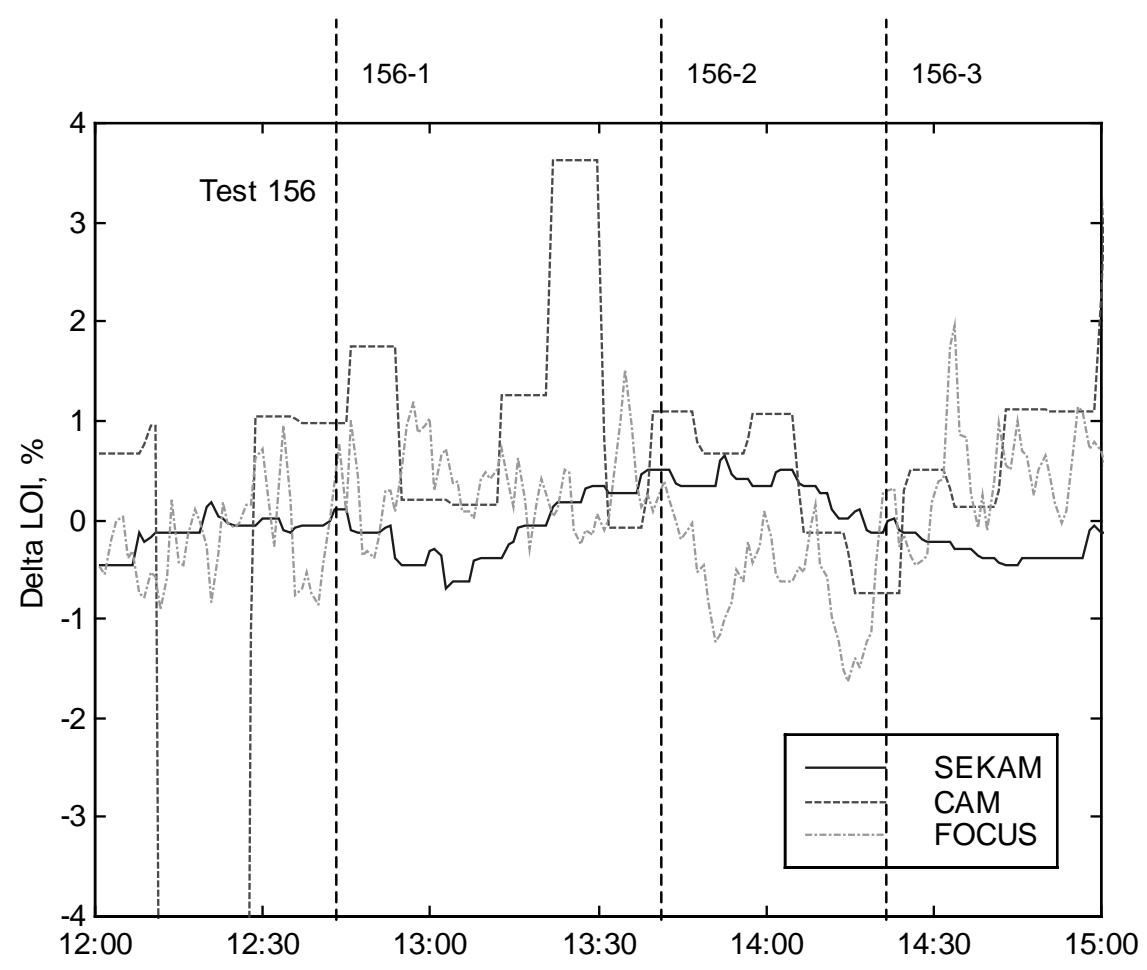

Figure 5-36 GNOCIS / Test 156 / Delta LOI

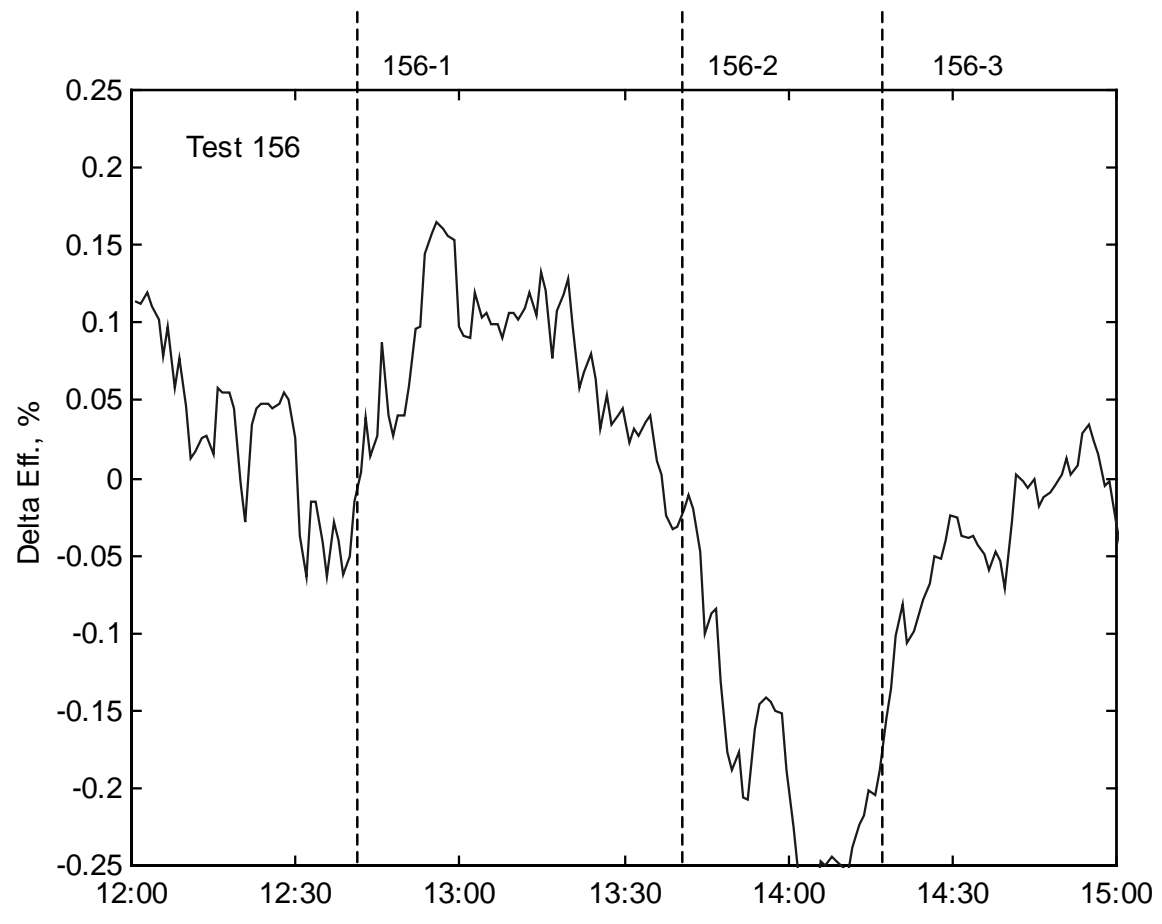

Figure 5-37 GNOCIS / Test 156 / Delta Efficiency 


\section{$\underline{\text { Tests } 157}$}

Five tests were conducted on February 22, 1996. The unit was operating at $250 \mathrm{MW}$ and was under economic dispatch, resulting in load variations of about $50 \mathrm{MW}$ during the test period. This load variation hinders the interpretation of test results. Per design operating procedures, overfire air was at minimum and was not available to be used in the optimization mix. The unit was in a normal operating mode for this load. Midway during the test day, "C" mill was removed from service and "F" mill brought online. Excluding Test 157-1, all tests were conducted in closed-loop mode.

The objective of Test 157-1 was to minimize NOx emissions with excess oxygen only, all other control variables (the mills) being clamped (Figure 5-38). Excess oxygen was allowed to deviate from nominal by $\pm 0.2 \%$ and the resulting recommendation was to decease it to the lower limit (Figure 5-39). A comparison of the actual, design from the control system excess oxygen curve, and recommended levels are shown in Figure 5-40. As shown, NOx decreased by approximately $0.02 \mathrm{lb} / \mathrm{MBtu}$ or about $5 \%$ of baseline. Fly ash LOI (as measured by all the SEKAM, CAM, and FOCUS) showed very little movement and, in fact, moved little during the entire test day (Figure 5-41). This relative lack of movement may be more reflective of the performance of the online LOI monitors than of the process itself.

The goal of Test 157-2 was to minimize LOI, however, this test was aborted when the operator changed the mills in service. As a result, in Test 157-3, GNOCIS was again set to minimize LOI with excess oxygen being increased, the other control variables being clamped. Also, move suppression on excess oxygen was removed. As before, there was very little change in the LOI monitors, with the changes shown being within the accuracy limits of the instruments. The predicted change in LOI (based on the then existing GNOCIS models) was about $0.5 \%$.

The goal for Test 157-4 was to minimize NOx with only excess oxygen. Move suppression for excess oxygen was again turned off. As shown, the recommendation was to increase excess oxygen to the upper limit. Due to load demand variations, the change in excess oxygen as a result of the GNOCIS recommendations is masked.

For Test 157-5, the goal was to minimize NOx emissions while maximizing efficiency and maintaining LOI below $10 \%$. However, due to a failure in the optimizer, the results were not implemented. This failure was the result of the initial starting conditions given to the optimizer being outside the range of model training data. This also occurred on Test 157-6. 


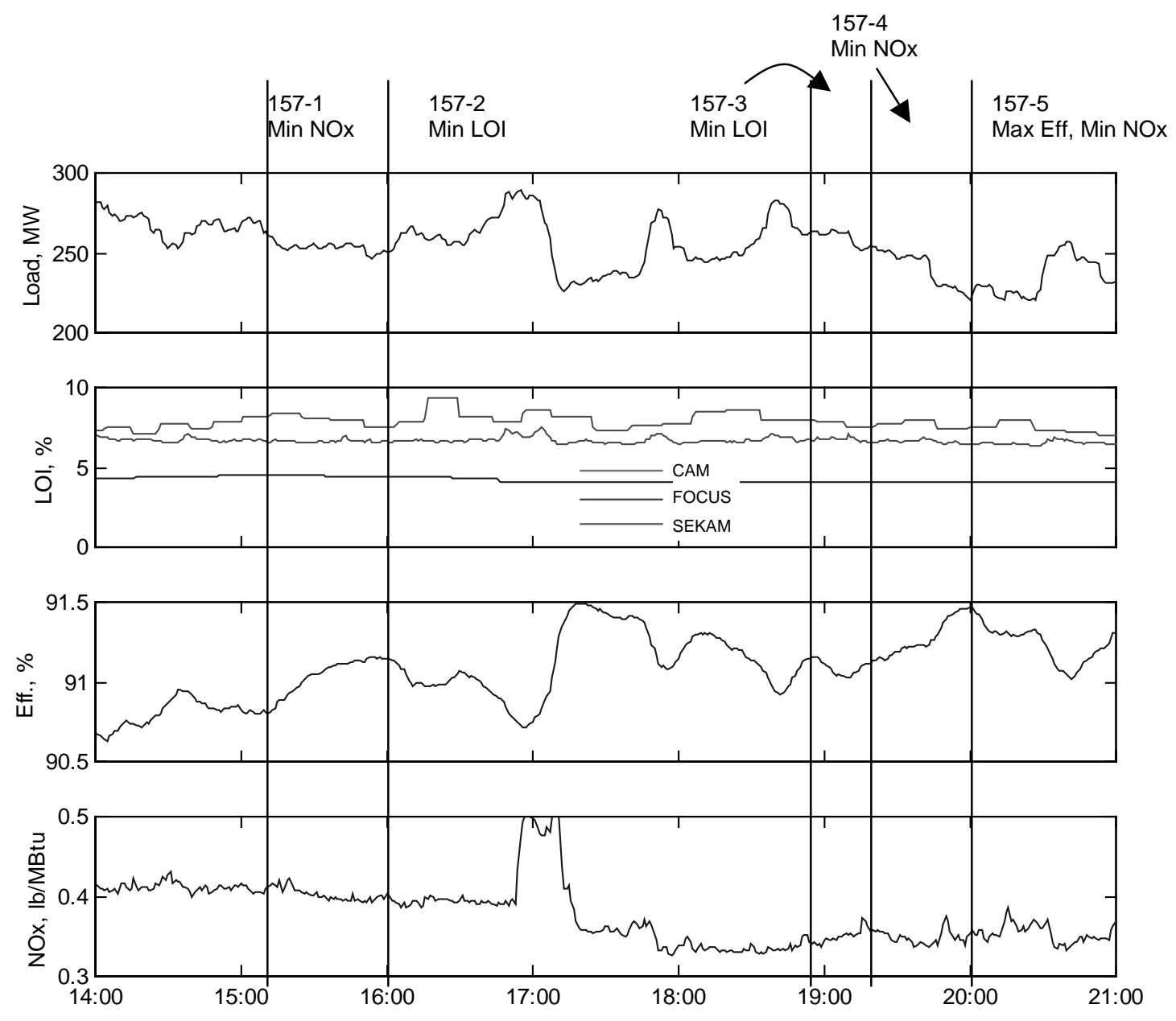

Figure 5-38 GNOCIS / Test 157 / Optimized Variables 


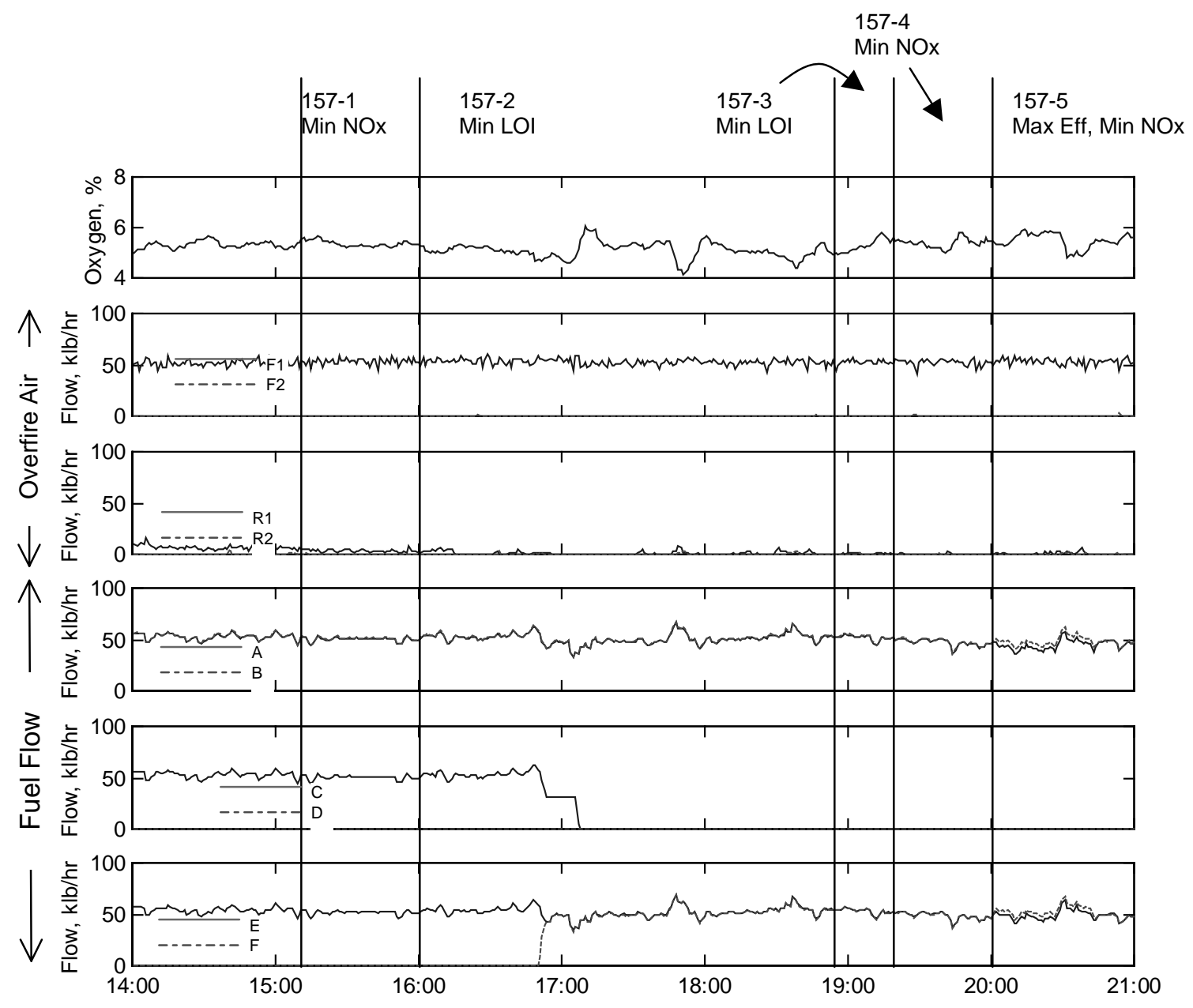

Figure 5-39 GNOCIS / Test 157 / Manipulated Variables 


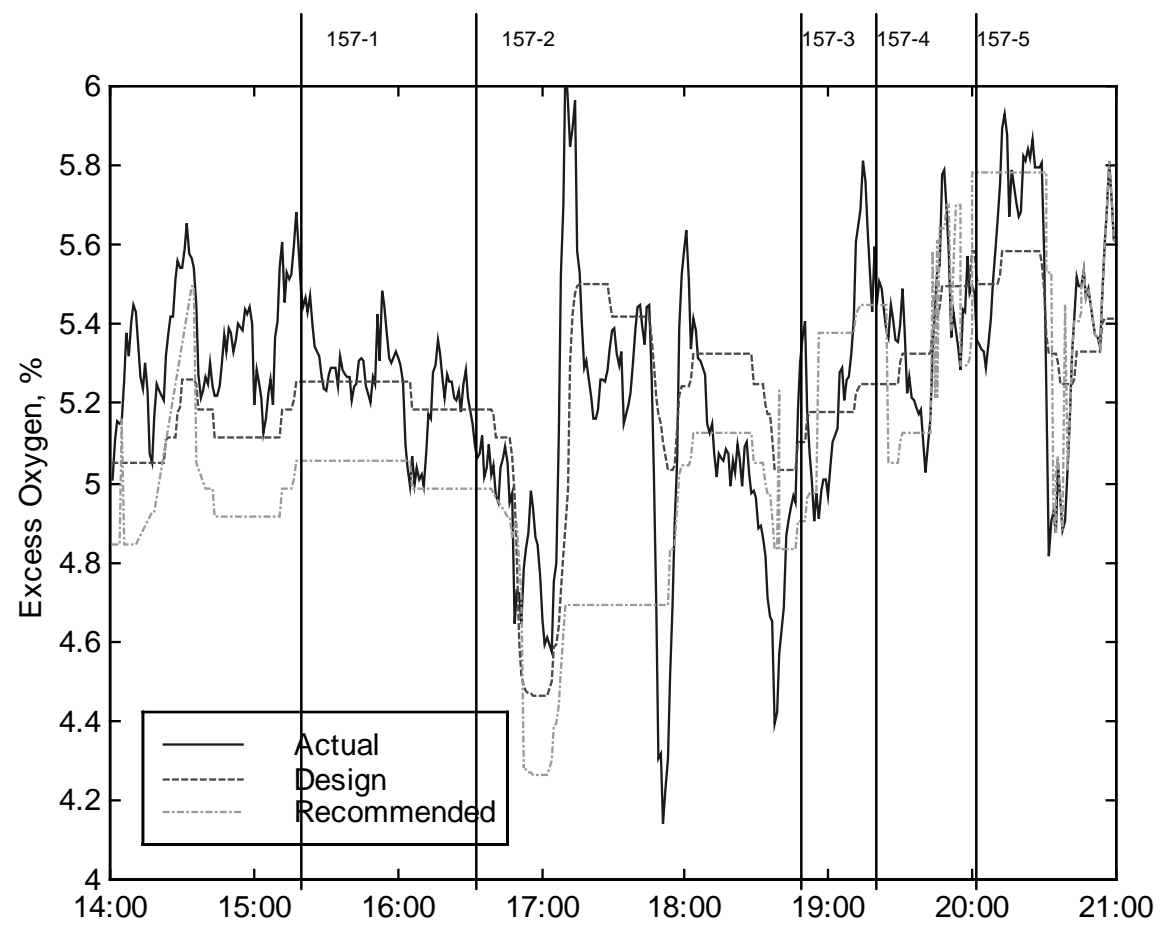

Figure 5-40 GNOCIS / Test 157 / Excess Oxygen Comparison

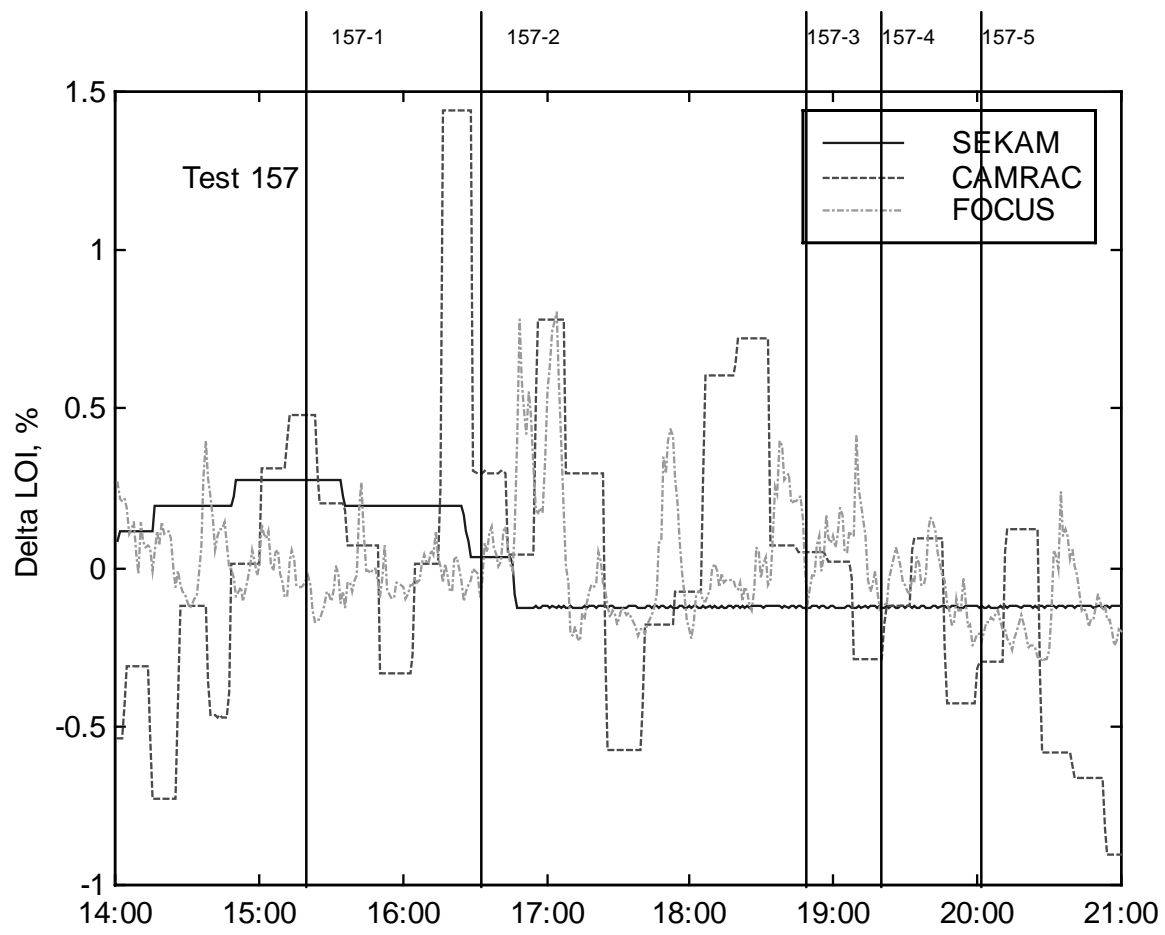

Figure 5-41 GNOCIS / Test 157 / Delta LOI 


\section{Summary of Findings from First Quarter 1996 Testing}

In view of the goals, these tests were successful. The following is a summary of the findings from these tests.

- GNOCIS could be run in a closed-loop mode without adversely influencing unit stability, safety, or reliability.

- Due to instability and unreliability, the AOFA flow monitors were not suitable for inclusion in GNOCIS. As a result, the AOFA flow dampers were substituted for AOFA flows in subsequent models.

- The online LOI monitors, although providing some information, are problematic. Problems include slow response time for the extractive systems, particularly at lower loads. Although not affected by sampling considerations, the non-extractive system suffered from insensitivity to process changes, again during low load conditions (SCS 1997).

- Coding changes must be made to prevent the optimizer from returning an error when the initial starting conditions are not in the feasible region. 


\subsubsection{GNOCIS Testing Conducted Second Quarter 1996}

During second quarter, testing of GNOCIS in both open- and closed-loop modes resumed with 22 tests being conducted. The control model used for these tests (hamcon31h1) was modified from that used previously with the most significant changes being:

- Substitution of AOFA damper position for AOFA flow rates. This change was prompted by the high frequency of problems with the flow monitors and high noise in the signal.

- Reduction in the number of state variables. This modification was made to reduce the complexity.

The structure of the model is shown in Table 5-10. The model was trained on data collected from January 23 to March 21, 1996 and consisted of approximately 39,000 records. Graphs showing predicted versus actual for this data set and model are provided in Figure 5-42. As might be conjectured due to the reduced number of inputs, this model did not have as good predictive qualities as the model used in the first quarter testing (hamcon31fc), particularly for LOI. Additional details on LOI and efficiency for several days of operation are shown in Figure 5-43 and Figure 5-44 and they indicate that the predicted LOI and efficiency trended fairly well with instrument provided values. Although not as accurate as some earlier models, it was judged that the models were sufficiently accurate to use. Also, since the testing was to be conducted following the spring outage, whereas the model was trained on data collected before the outage, there was some curiosity as to how the models would bridge this outage.

Test were conducted at several load levels, both with and without overfire air. All major boiler components, as well as ancillary equipment, were in the normal "as-found" operating conditions. The fuel supply burned was from the normal supply and handled according to common plant practice. As before, various objectives were tested (Table 5-11). The tests conducted during this period are discussed below.

Table 5-10 Control Model Structure for $2^{\text {nd }}$ Quarter 1996 Testing

\begin{tabular}{lc}
\hline Control Model: hamcon31h & State Variables \\
Control Variables & Total Secondary Air Flow \\
Average Excess Oxygen & Excess Oxygen Left Side \\
Mill Coal Flow A & Excess Oxygen Right Side \\
Mill Coal Flow B & \\
Mill Coal Flow C & \\
Mill Coal Flow D & \\
Mill Coal Flow E & \\
Mill Coal Flow F & \\
AOFA Damper R1 & \\
AOFA Damper R2 & \\
AOFA Damper F1 & \\
AOFA Damper F2 & External Variables \\
Output Variables & $<$ None> \\
NOx Emissions & \\
LOI & \\
Boiler Efficiency & \\
\hline
\end{tabular}



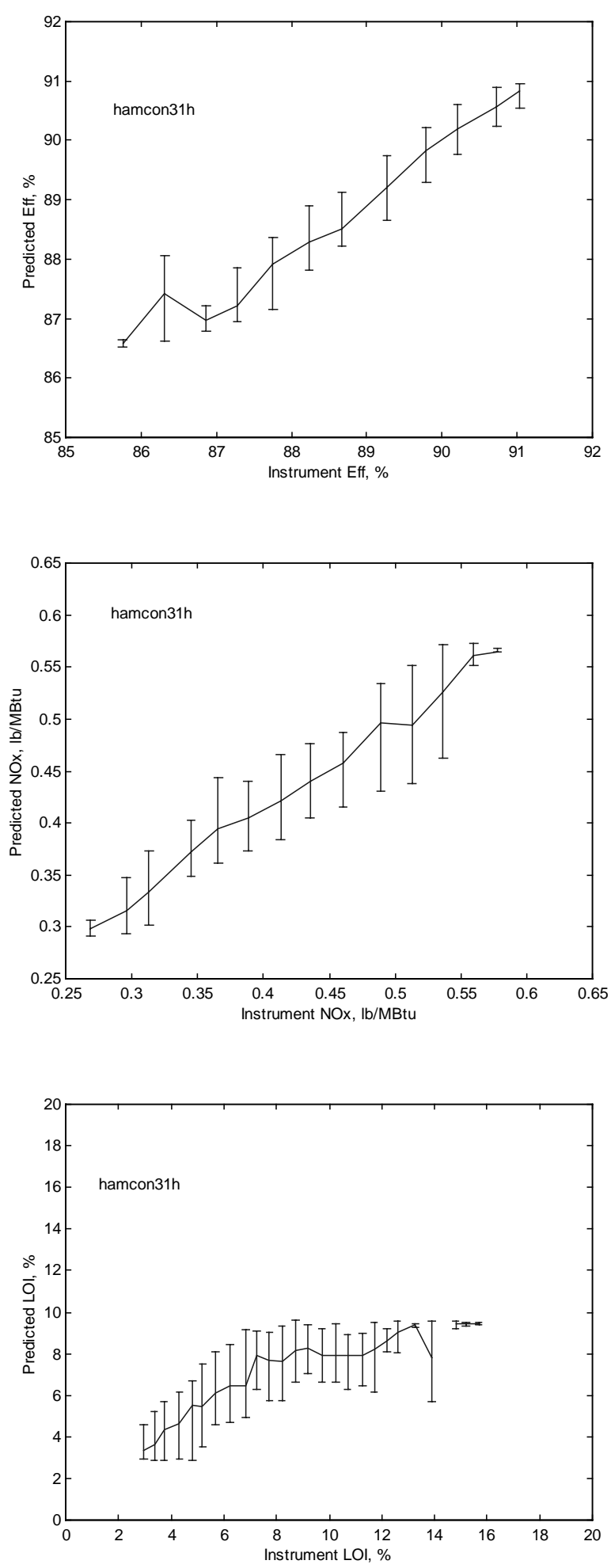

Figure 5-42 GNOCIS / Predicted vs. Actual / Hamcon31h 


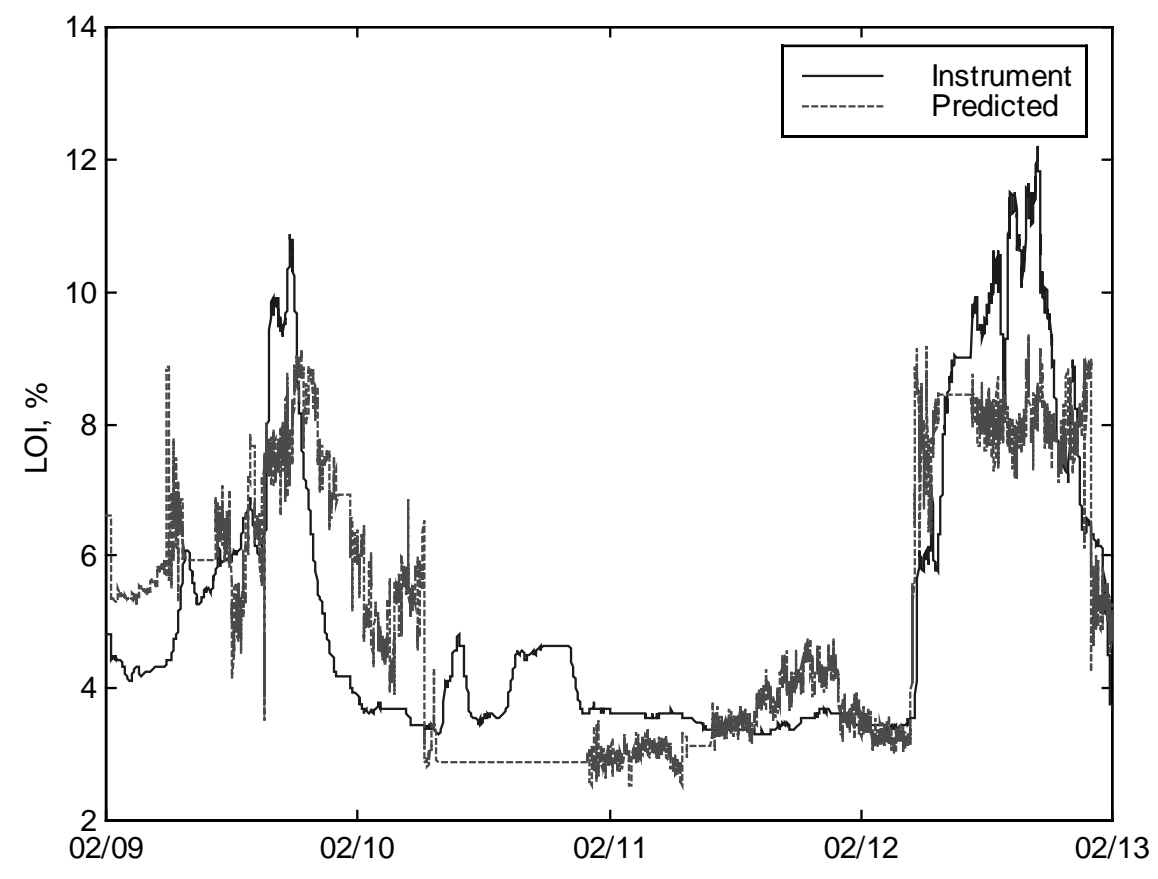

Figure 5-43 GNOCIS / Predicted vs. Actual / Hamcon31h / LOI

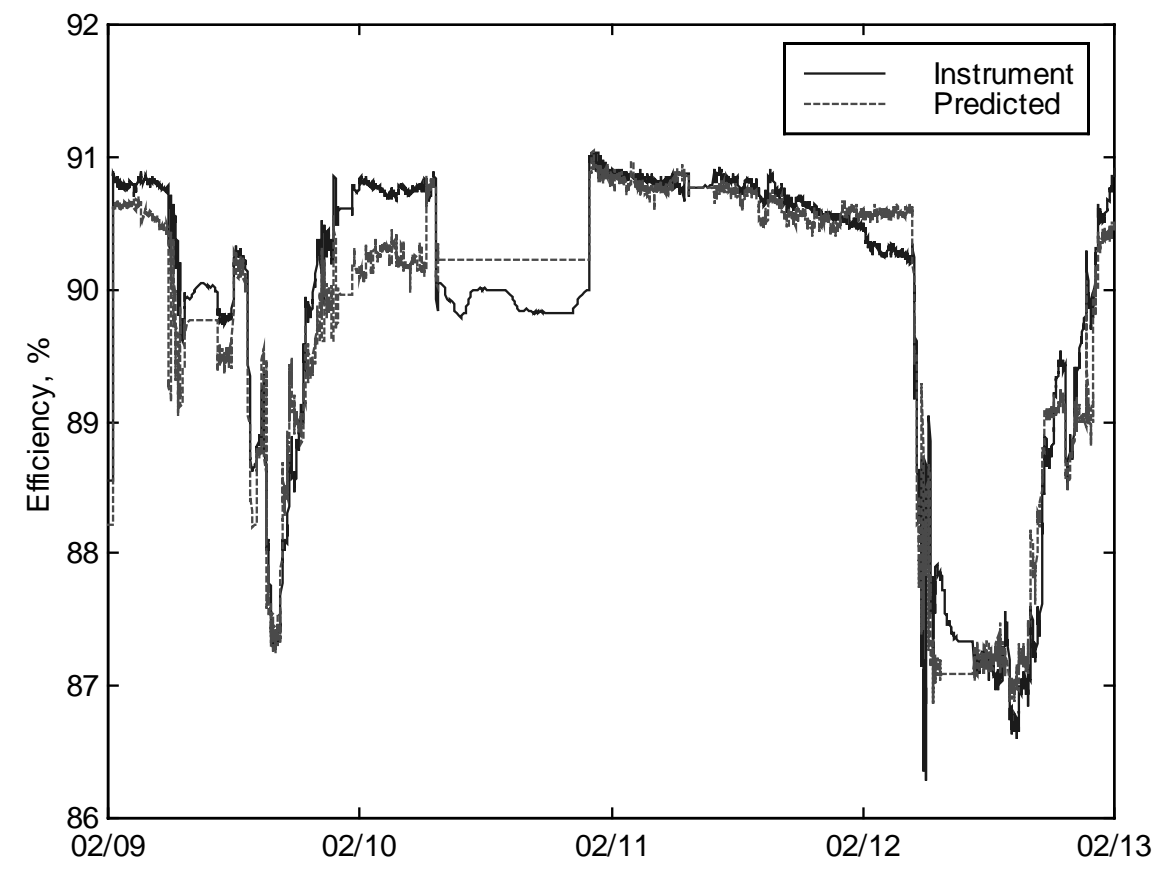

Figure 5-44 GNOCIS / Predicted vs. Actual / Hamcon31h / Efficiency 
Table 5-11 GNOCIS Testing Conducted Second Quarter 1996

\begin{tabular}{|c|c|c|c|c|c|c|c|c|}
\hline \multirow[b]{2}{*}{ Test } & \multirow[b]{2}{*}{ Date } & \multirow[b]{2}{*}{ Mode } & \multicolumn{3}{|c|}{ Goals } & \multicolumn{3}{|c|}{ Limits } \\
\hline & & & $\mathrm{NO}_{\mathrm{x}}$ & LOI & Efficiency & Excess $\mathrm{O}_{2}$ & AOFA Dmpr. & $\begin{array}{c}\text { Mill } \\
\text { Flows }\end{array}$ \\
\hline $158-1$ & $5 / 7 / 96$ & OL & - & - & Max & \pm 0.2 & Clamped & Clamped \\
\hline $158-2$ & $5 / 8 / 96$ & OL & - & - & Max & \pm 0.2 & \pm 5 & Clamped \\
\hline $158-3$ & $5 / 8 / 96$ & $\mathrm{OL}$ & - & - & Max & \pm 0.2 & \pm 5 & $\pm 5 k$ \\
\hline $158-4$ & $5 / 8 / 96$ & OL & - & - & Max & \pm 0.2 & \pm 5 & $\pm 5 \mathrm{k}$ \\
\hline $159-1$ & $5 / 9 / 96$ & OL & - & - & Max & \pm 0.2 & \pm 5 & $\pm 5 k$ \\
\hline $159-2$ & $5 / 9 / 96$ & OL & - & - & Max & \pm 0.2 & \pm 5 & $\pm 5 \mathrm{k}$ \\
\hline $159-3$ & $5 / 9 / 96$ & OL & - & Min & - & \pm 0.2 & \pm 5 & $\pm 5 \mathrm{k}$ \\
\hline $159-4$ & $5 / 9 / 96$ & OL & - & - & Max & \pm 0.2 & \pm 5 & $\pm 5 \mathrm{k}$ \\
\hline $159-5$ & $5 / 9 / 96$ & OL & - & Min & - & \pm 0.2 & \pm 5 & $\pm 5 \mathrm{k}$ \\
\hline $159-6$ & $5 / 9 / 96$ & OL & - & - & Max & \pm 0.2 & \pm 5 & $\pm 5 \mathrm{k}$ \\
\hline $160-1$ & $5 / 14 / 96$ & OL & - & - & Max & \pm 0.2 & \pm 5 & $\pm 5 k$ \\
\hline $160-2$ & $5 / 14 / 96$ & $\mathrm{CL}$ & - & Min & - & \pm 0.2 & \pm 5 & $\pm 5 \mathrm{k}$ \\
\hline $160-3$ & $5 / 14 / 96$ & $C L$ & Min & - & - & \pm 0.2 & \pm 5 & $\pm 5 k$ \\
\hline $161-1$ & $5 / 15 / 96$ & $C L$ & Min & - & - & \pm 0.2 & \pm 5 & $\pm 5 \mathrm{k}$ \\
\hline $161-2$ & $5 / 15 / 96$ & $C L$ & - & - & Max & \pm 0.2 & \pm 5 & $\pm 5 \mathrm{k}$ \\
\hline $161-3$ & $5 / 15 / 96$ & $\mathrm{CL}$ & - & Min & - & \pm 0.2 & \pm 5 & $\pm 5 \mathrm{k}$ \\
\hline $161-4$ & $5 / 15 / 96$ & OL & Min & - & - & \pm 0.2 & \pm 5 & $\pm 5 \mathrm{k}$ \\
\hline $161-5$ & $5 / 15 / 96$ & OL & - & - & Max & \pm 0.2 & \pm 5 & $\pm 5 \mathrm{k}$ \\
\hline $162-1$ & $5 / 16 / 96$ & $\mathrm{CL}$ & - & Min & - & \pm 0.4 & \pm 5 & $\pm 5 \mathrm{k}$ \\
\hline $162-2$ & $5 / 16 / 96$ & $\mathrm{CL}$ & Min & - & - & Clamped & \pm 5 & $\pm 5 \mathrm{k}$ \\
\hline $162-3$ & $5 / 16 / 96$ & $\mathrm{CL}$ & Min & - & - & \pm 0.4 & \pm 5 & $\pm 5 \mathrm{k}$ \\
\hline
\end{tabular}




\section{$\underline{\text { Test158 }}$}

Test 158 was conducted on May 7, 1996 with the unit off economic dispatch and at $480 \mathrm{MW}$. The purpose of the test was to evaluate the performance of GNOCIS in regards to boiler efficiency improvements as GNOCIS was made sequentially less constrained. The tests were conducted in open-loop mode. The testing was compromised since the LOI and NOx monitors were not operational for the test period and the predicted values were used as surrogates. Boiler efficiency and a subset of the independent control variables during the course of the test period are shown in Figure 5-45 and Figure 5-46. As shown, nominal boiler efficiency was near 87.5 percent at the beginning of the testing and with sequential application of the GNOCIS recommendations, an efficiency of approximately 88.3 percent was attained. Recommendations for excess oxygen, AOFA damper, and mill loading were implemented at approximately 11:15, 12:10, and 12:45, respectively. Also note that the recommended damper position is dependent on whether the mills are included in the optimization mix. The final recommendation tended to move fuel from the front of the furnace to the rear and also decreased overfire air flow to the east side while decreasing that to the west.

The dry flue gas losses as measured for the test period are shown in Figure 5-47. These values are determined using the air heater inlet and outlet temperatures and excess oxygen. Using the predicted LOI and these measured losses, boiler efficiency can be estimated and compared to the predicted result (Figure 5-48). As shown, the predicted change was greater than calculated using the measured dry flue gas losses and predicted LOI. The reason for this difference is unknown, however, it may be due to the air/gas temperatures never reaching equilibrium during the test period. 


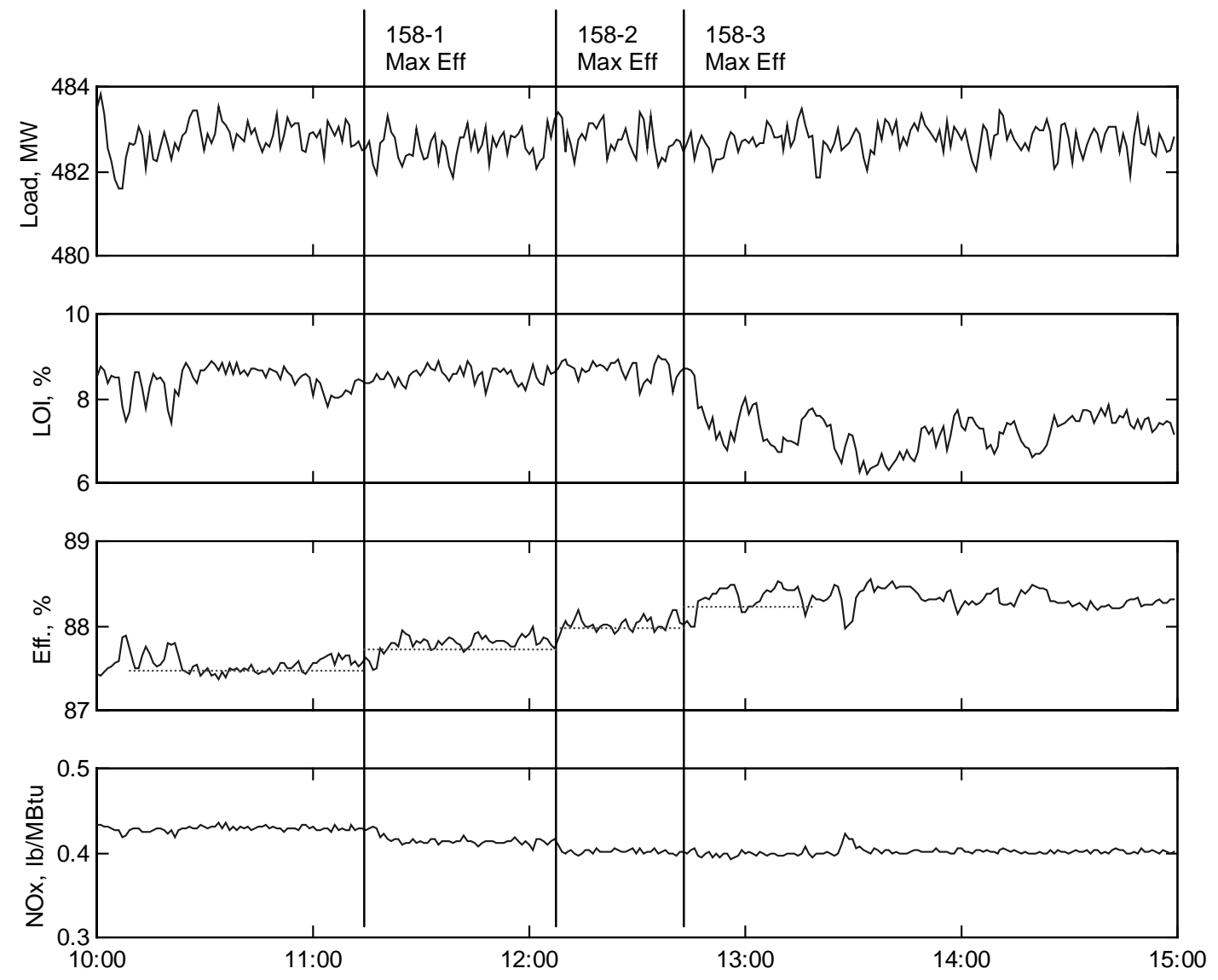

Figure 5-45 GNOCIS / Test 158 / Optimized Variables 
Table 5-12 Recommendations for Test 158

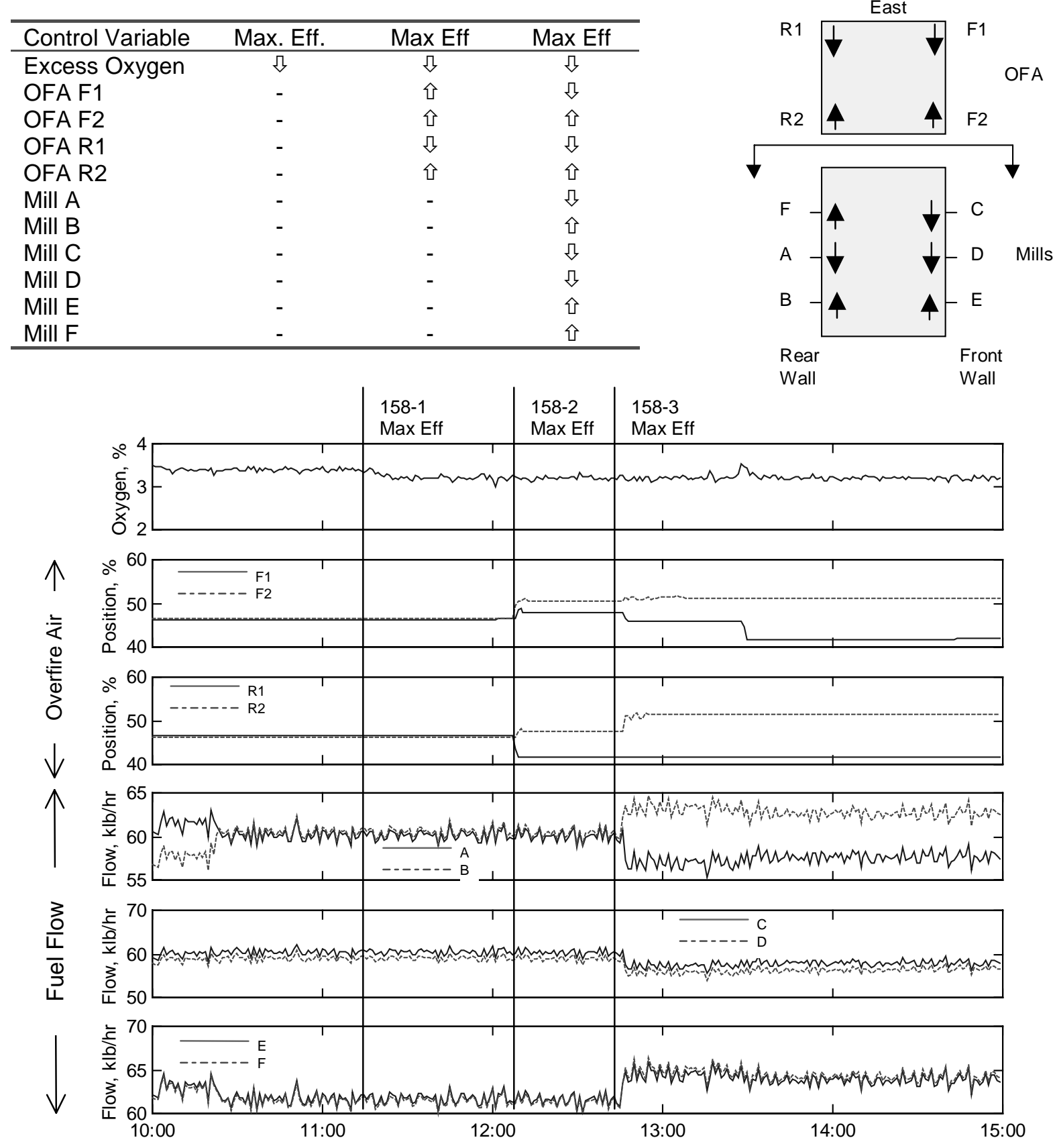

Figure 5-46 GNOCIS / Test 158 / Manipulated Variables 


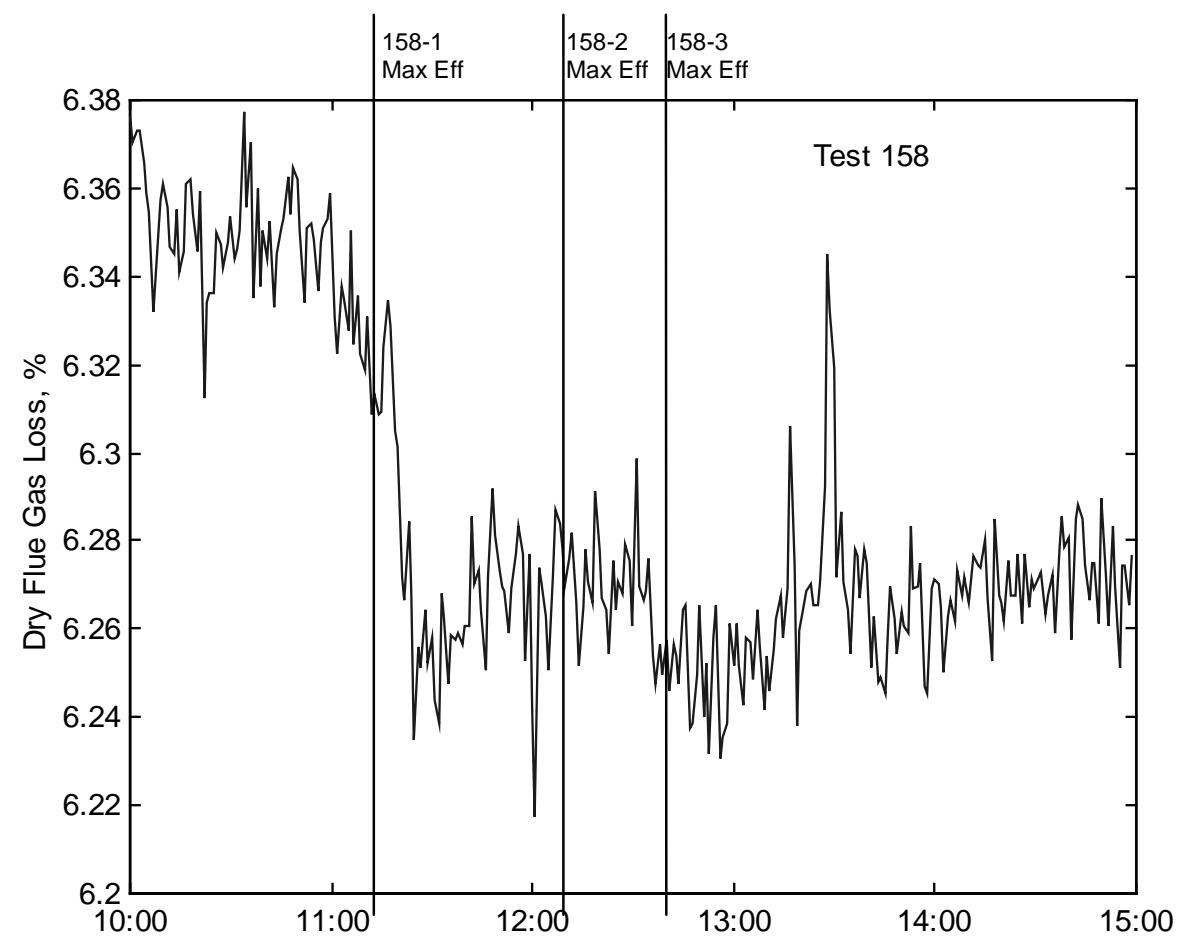

Figure 5-47 GNOCIS / Test 158 / Dry Flue Gas Loss

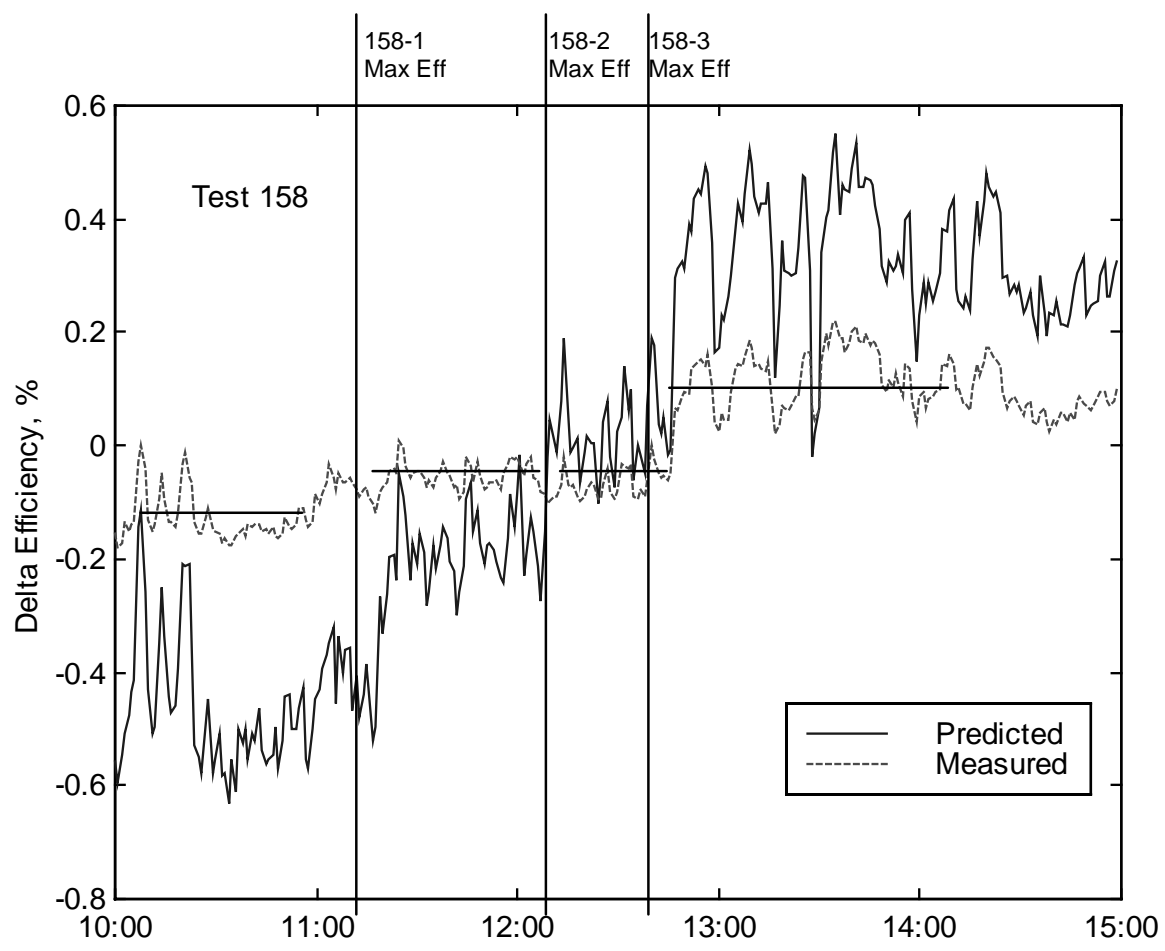

Figure 5-48 GNOCIS / Test 158 / Boiler Efficiency 


\section{$\underline{\text { Test } 159}$}

Test 159 occurred on May 9, 1996 with the unit off economic dispatch and at a load of approximately $480 \mathrm{MW}$. The tests were conducted in open-loop mode. As in Test 158, the LOI and NOx monitors were not operational for the test period and the predicted values were used as surrogates. Six tests were conducted during the test day.

As shown in Figure 5-49, efficiency exhibited a variation of $0.5 \%$ between the maximize efficiency and minimize LOI modes whereas LOI varied approximately $1 \%$ between the two operating modes. The recommendations for the tests are shown in Figure 5-50. As had been previously observed, in all cases, the recommendation was to increase excess oxygen to improve efficiency (Table 5-13). As for the other manipulated variables, for maximizing efficiency, the recommendations tended to move fuel from the rear of the furnace to the front and decreased overfire airflow to the rear of the furnace while increasing that to the front.

The dry flue gas losses as measured for the test period are shown in Figure 5-51. These values are determined using the air heater inlet and outlet temperatures and excess oxygen. Using the predicted LOI and these measured losses, boiler efficiency can be estimated and compared to the predicted result (Figure 5-52). As shown, the predicted change was greater than calculated using the measured dry flue gas losses and predicted LOI. The reason for this difference is unknown, however, it may be due to the air/gas temperatures never reaching equilibrium during the test period.

Note that these recommendations were somewhat different than those for maximize efficiency mode during Test 158. Possible reasons for the different recommendations include:

- Although excess oxygen level was essentially equal for the two days, the excess oxygen split between the left and right side of the furnace was considerably greater for Test 158 (averaging 0.34\%) than Test 159 (averaging 0.68\%). The left and right oxygen levels are brought individually into the combustion model and therefore have the potential to affect the recommendations.

- Move suppression on the manipulated variables could have inadvertently been enabled. Move suppression limits the movements of the manipulated variables when only marginal benefits will be obtained. Since the test had different initial conditions, this could have been a factor.

- The constraints are applied around the current operating point, therefore if starting operating points are different, the recommendations can be different. 


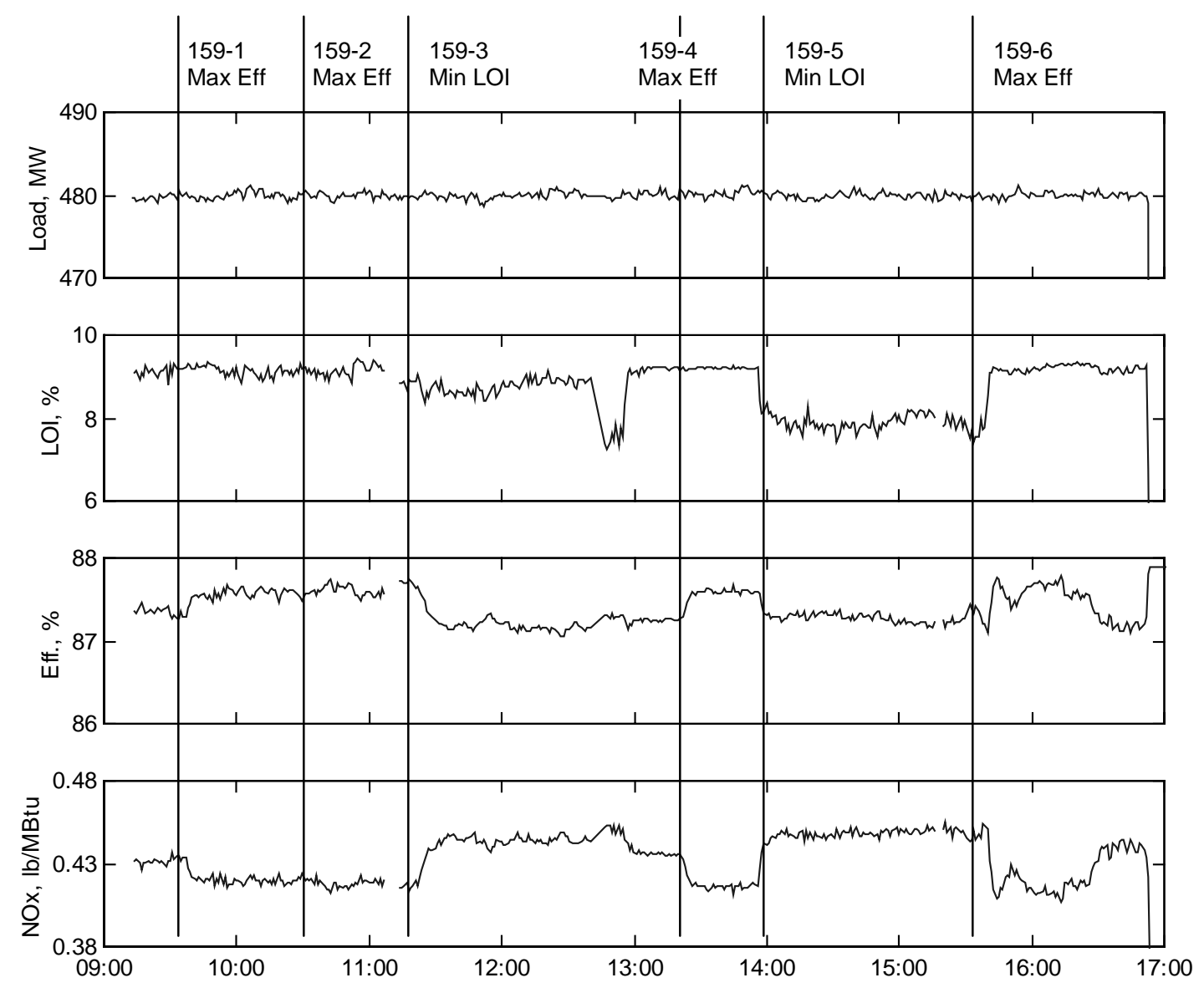

Figure 5-49 GNOCIS / Test 159 / Optimized Variables 
Table 5-13 Recommendations for Test 159

\begin{tabular}{|c|c|c|}
\hline Control Variable & Max. Efficiency & Min LOI \\
\hline Excess Oxygen & ת & $\hat{\mathrm{v}}$ \\
\hline OFA F1 & 仓 & $\sqrt{2}$ \\
\hline OFA F2 & 仓 & $\sqrt{ }$ \\
\hline OFA R1 & ת & 仓 \\
\hline OFA R2 & 凤 & 仓े \\
\hline Mill A & $\sqrt{3}$ & $\sqrt{2}$ \\
\hline Mill B & 仓 & 仓े \\
\hline Mill C & 仓 & $\sqrt{3}$ \\
\hline Mill D & 仓 & $\sqrt{3}$ \\
\hline Mill E & $\sqrt{3}$ & 仓 \\
\hline Mill $F$ & n & $\hat{\imath}$ \\
\hline
\end{tabular}

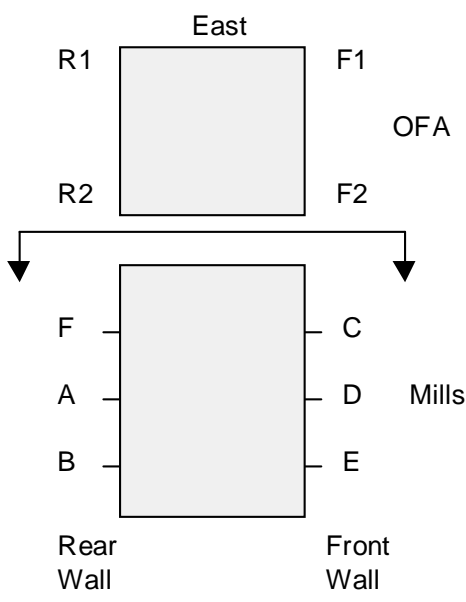

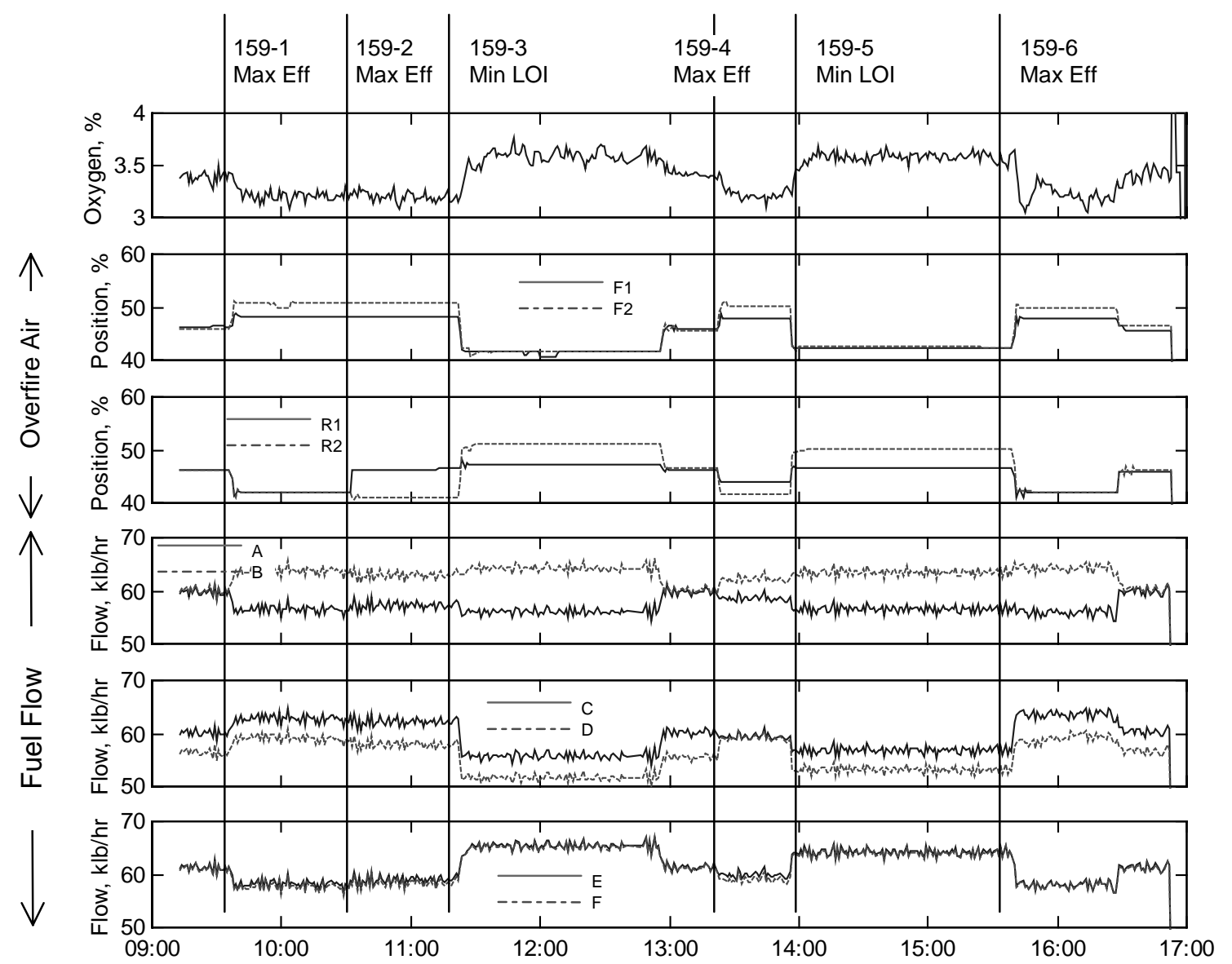

Figure 5-50 GNOCIS / Test 159 / Manipulated Variables 


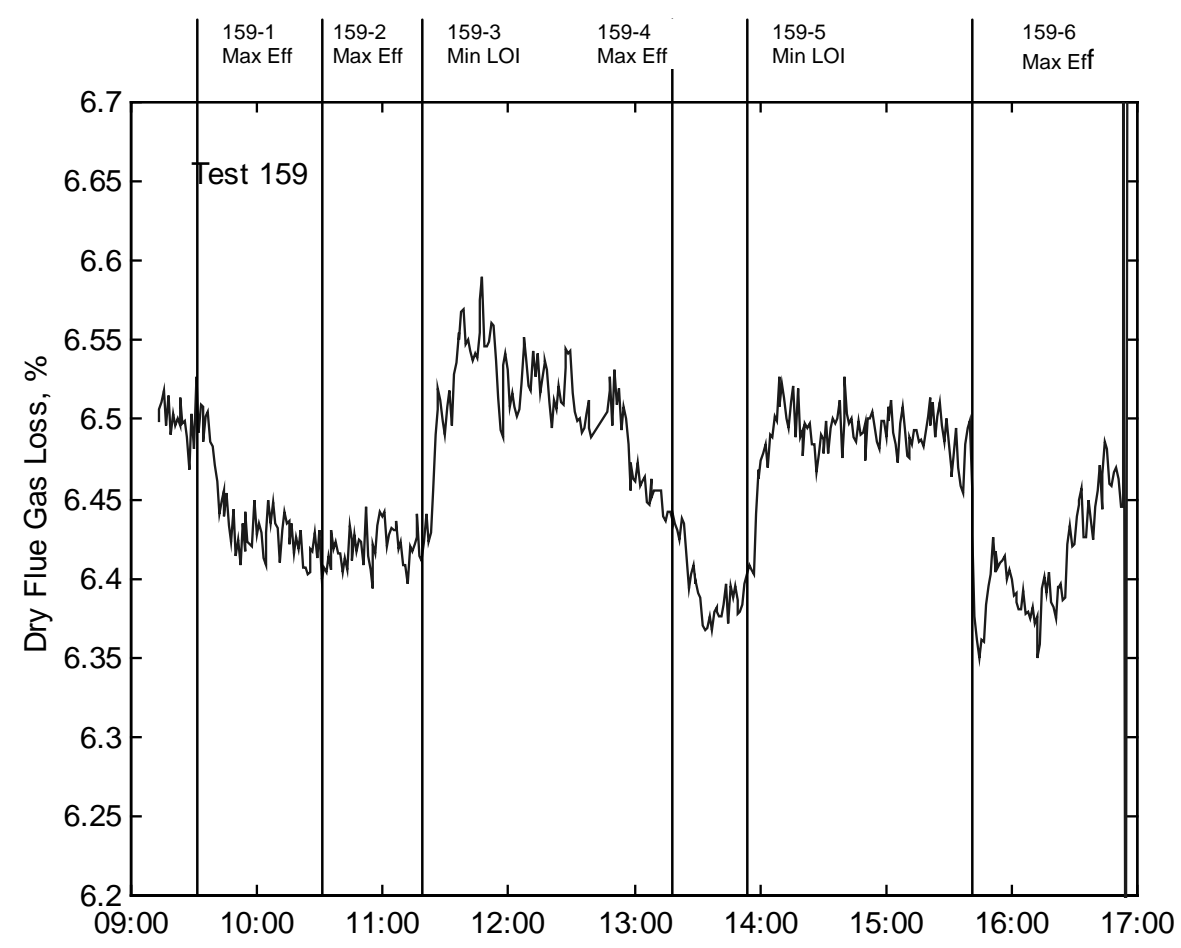

Figure 5-51 GNOCIS / Test 159 / Dry Flue Gas Loss

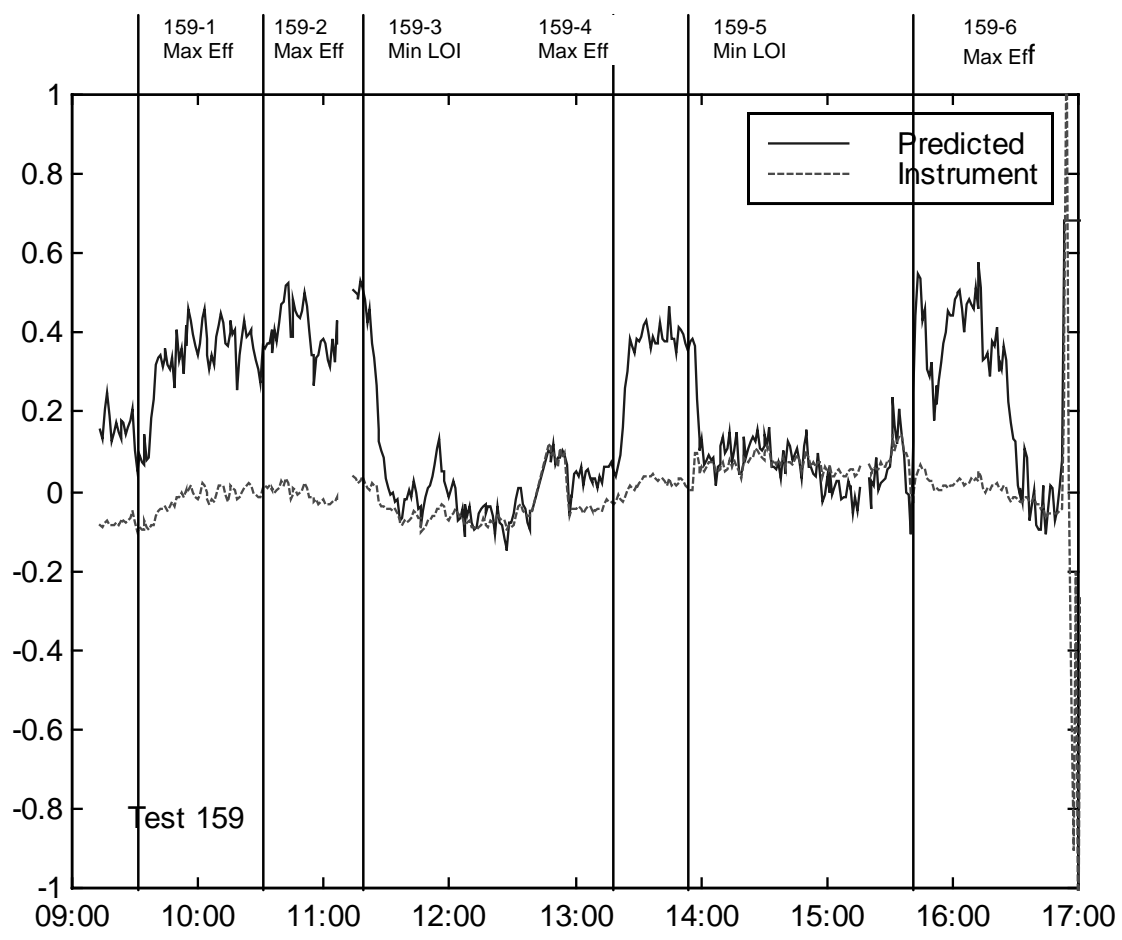

Figure 5-52 GNOCIS / Test 159 / Boiler Efficiency 


\section{$\underline{\text { Test } 160}$}

Test 160 was conducted on May 14 with the unit off economic dispatch and at $480 \mathrm{MW}$. The tests were conducted in open- and closed-loop mode. The variables being optimized and the independent control variables during the course of the test period are shown in Figure 5-53 and Figure 5-54.

The first test of the day (Test 160-1) was to maximize efficiency using all control variables. As shown, the recommendation was to reduce excess oxygen from $3.4 \%$ to $3.2 \%$, the lower constraint. The recommendations for AOFA damper position and coal flow are shown in Table 5-14. As shown, nominal boiler efficiency was near 88 percent at the beginning of the testing. Following implementation of the recommendations, fly ash LOI (as measured by the SEKAM) increased greatly, going from near $12 \%$ to $19 \%$. This large increase was unexpected based on prior testing [SCS, 1998]. For example, during Phase 3B NOx vs. LOI testing, the sensitivity of LOI to excess oxygen variations was found to be approximately $2.5 \%$ change in LOI for every $1 \%$ change in excess oxygen. Since excess oxygen was allowed to move only $0.2 \%$ for this test, one would expect a change in LOI of about $0.5 \%$, far less than what the SEKAM indicated. A comparison of all LOI readings and the predicted value are shown in Figure 5-55. As shown, there was wide discrepancy between the readings (the CAMRAC system was not functional on this day). These tests highlight the importance of obtaining a reliable LOI reading on units with relatively high LOI.

Since the efficiency shown in Figure 5-53 is partly comprised of this LOI reading, the 7\% increase in LOI accounted for an approximate $0.7 \%$ decrease in boiler efficiency. Dry flue gas losses decreased for this test due to the small decrease in excess oxygen $(0.2 \%)$ and air heater gas inlet temperatures $\left(\sim 2^{\circ} \mathrm{F}\right)$ (Figure 5-56). The predicted efficiency improvement was about $0.2 \%$, what might be expected for only moving excess oxygen by $0.2 \%$. The objective of Test $160-2$ was to minimize LOI. As shown, SEKAM indicated a reduction in LOI of about $8 \%$ whereas the FOCUS and predicted reductions were both around 1.5\%. For Test 160-3, the goal was to minimize NOx emissions and they were reduced by about $0.03 \mathrm{lb} / \mathrm{MBtu}$. 


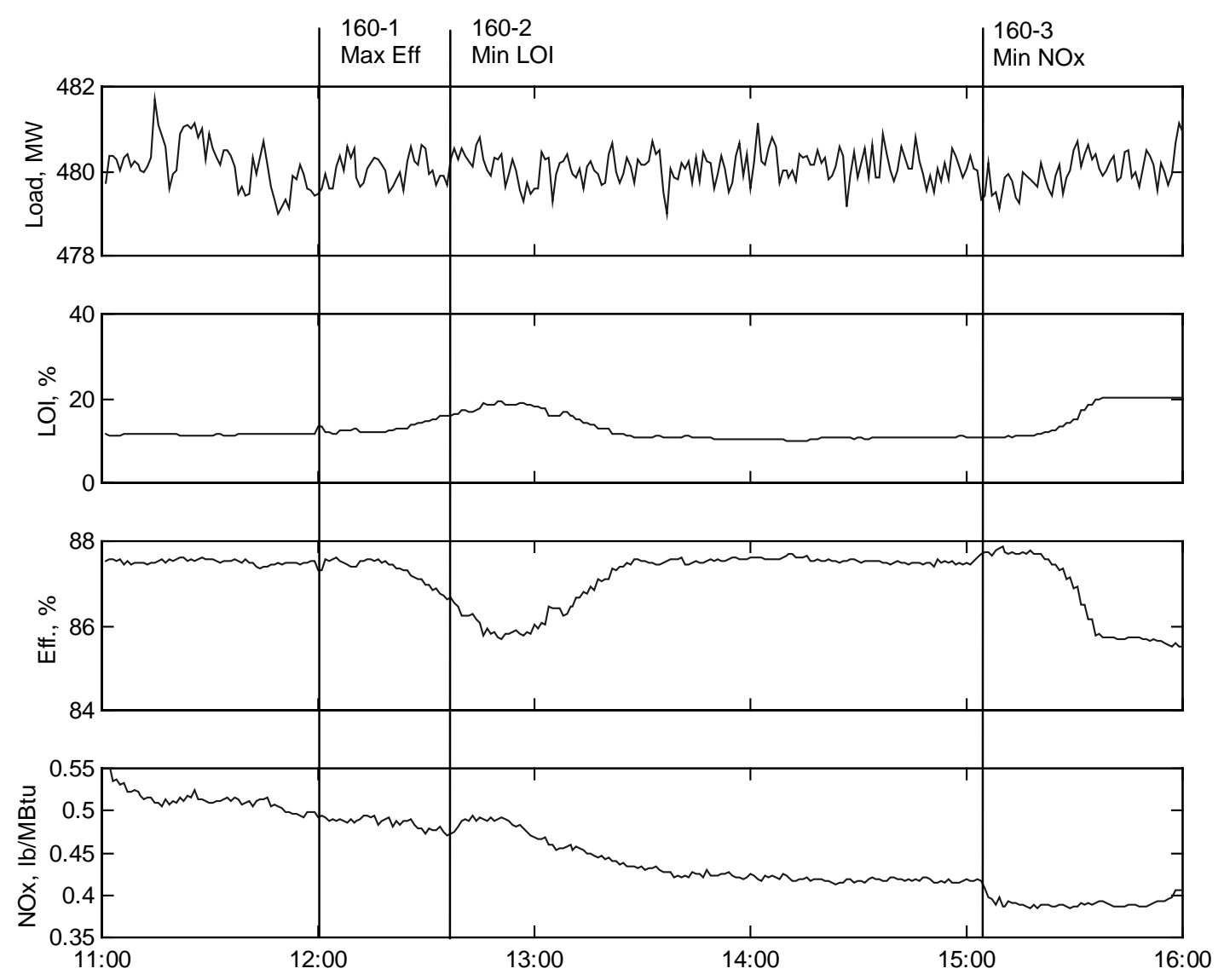

Figure 5-53 GNOCIS / Test 160 / Optimized Variables 
Table 5-14 Recommendations for Test 160

\begin{tabular}{|c|c|c|c|}
\hline Control Variable & Max. Efficiency & Min LOI & Min NOx \\
\hline Excess Oxygen & $\sqrt{n}$ & 仓े & $\sqrt{3}$ \\
\hline OFA F1 & 仓 & $\sqrt{3}$ & ת \\
\hline OFA F2 & 仓 & $\sqrt{3}$ & ת \\
\hline OFA R1 & $\sqrt{3}$ & 仓े & 仓े \\
\hline OFA R2 & $\sqrt{3}$ & 仓 & $\sqrt{3}$ \\
\hline Mill A & \& & \& & ת \\
\hline Mill B & 仓 & 仓 & ת \\
\hline Mill C & 仓 & ת & ת \\
\hline Mill D & 仓 & $\sqrt{3}$ & 仓 \\
\hline Mill E & $\sqrt{3}$ & 仓े & 仓 \\
\hline Mill F & ת & 仓े & 仓े \\
\hline
\end{tabular}

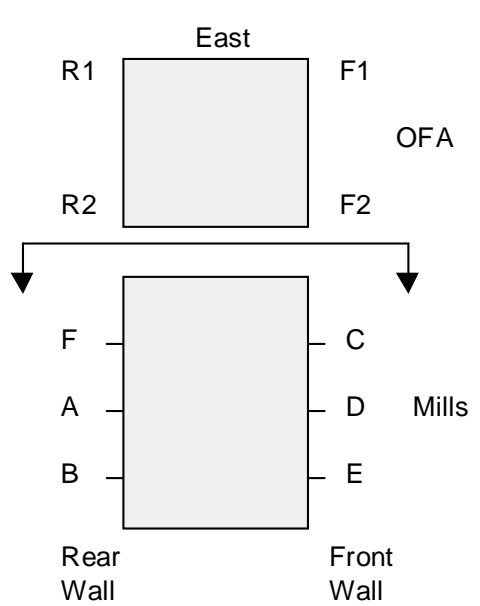

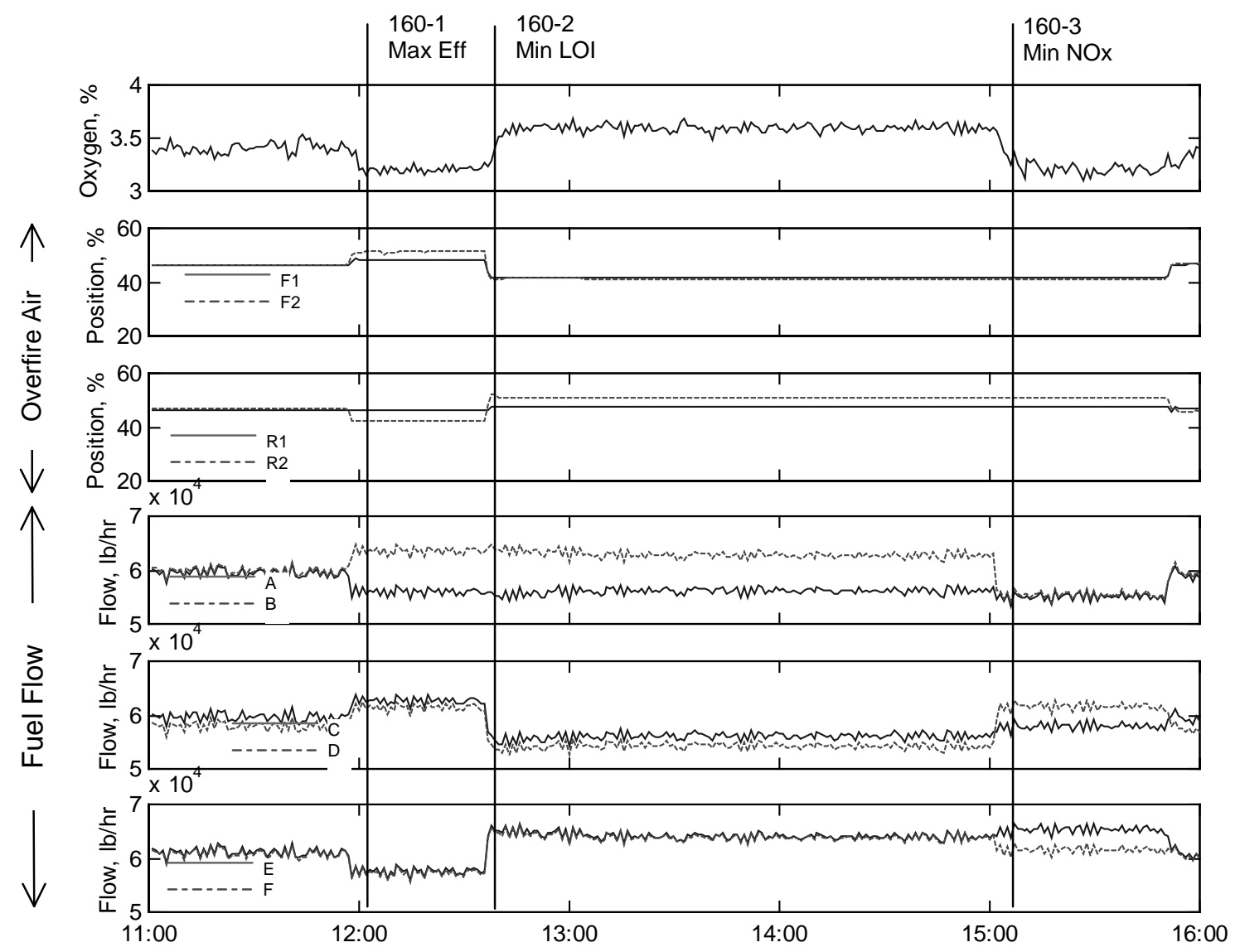

Figure 5-54 GNOCIS / Test 160 / Manipulated Variables 


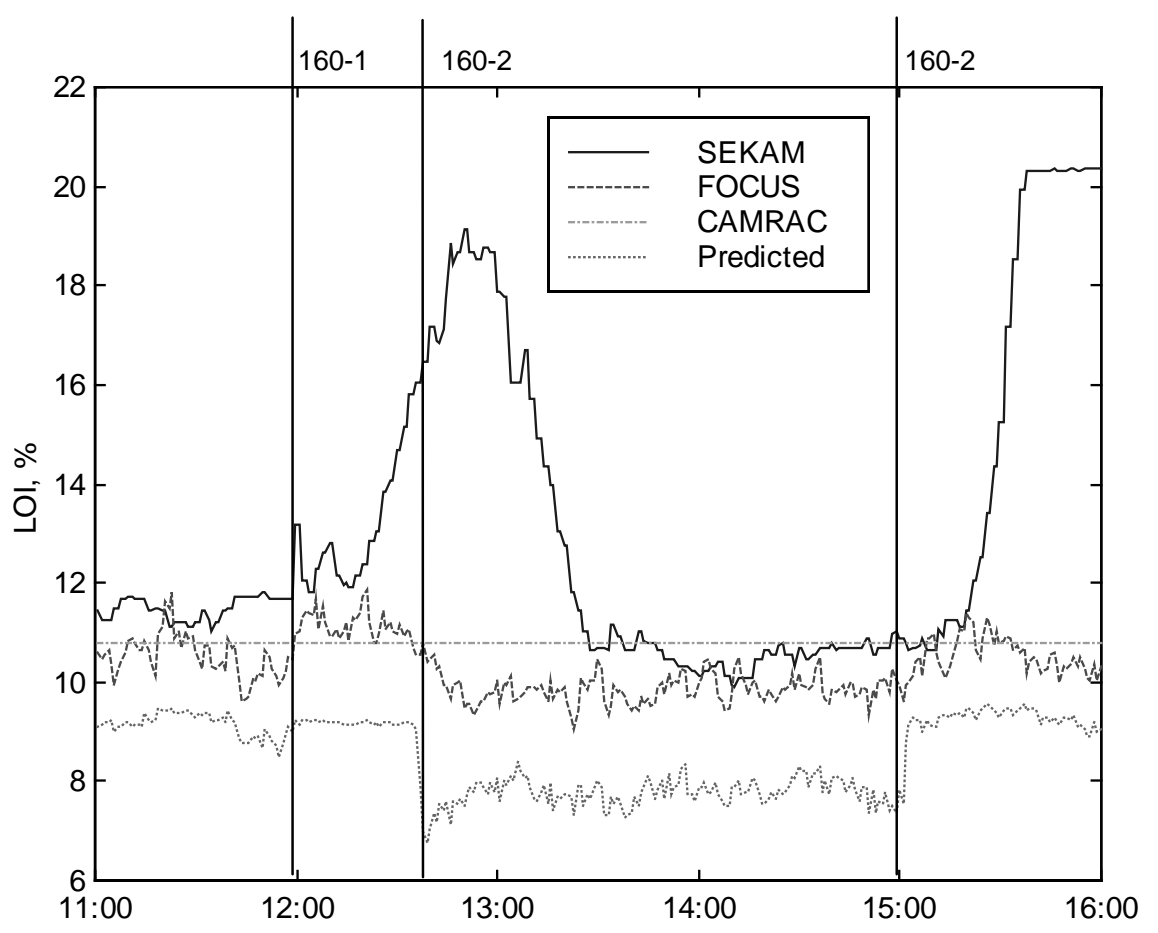

Figure 5-55 GNOCIS / Test 160 / Comparison of LOI Signals 

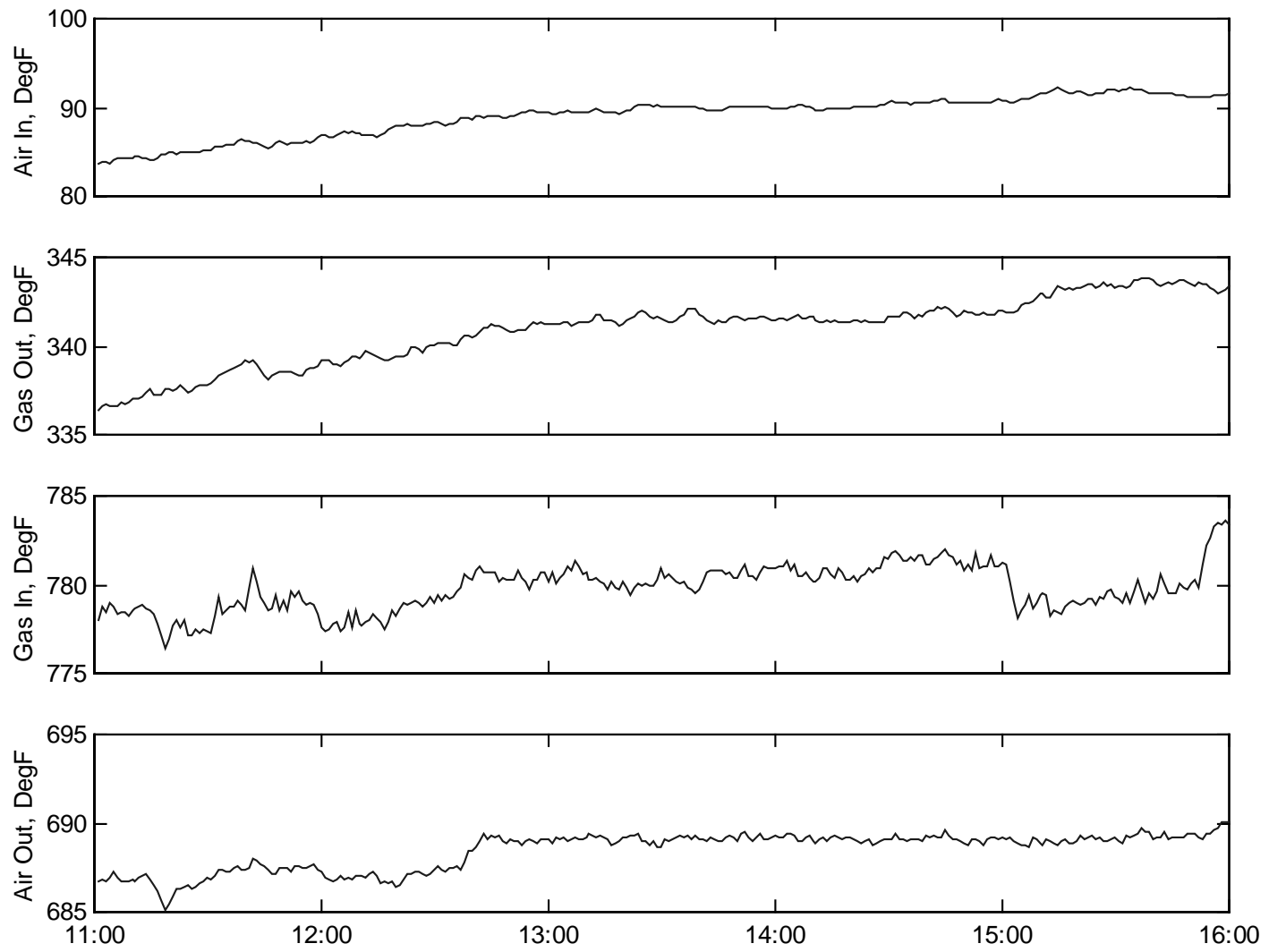

Figure 5-56 GNOCIS / Test 160 / Air Heater Temperatures 


\section{$\underline{\text { Test } 161}$}

Test 161 was conducted on May 15 at full load in both closed- and open-loop modes. During the test period, the unit was off economic dispatch and was at stable conditions. Overfire air was in operation and at nominal conditions. The fuel for the test was the normal coal supply.

Results and control actions taken are shown in Figure 5-57 and Figure 5-58, respectively. During the course of the testing several objectives were tested including minimizing NOx and LOI and maximizing boiler efficiency. As with previous closed-loop tests at this site, recommendations were intentionally made narrow until further confidence was gained in the stability of GNOCIS recommendations (Table 5-11). When NOx minimization was the goal (Test 161-1), NOx emissions were reduced by approximately $10 \%$ from baseline. Similarly, when efficiency and LOI were goals (161-2 and 161-3), improvements of near $0.7 \%$ and $2 \%$, respectively, were obtained. Also, in Test 161-2, simultaneous improvements in NOx, LOI, and efficiency were obtained.

It is interesting to compare the recommendations and outcomes of the min NOx emissions, max efficiency, and min LOI test modes (Table 5-15). For the first two tests, the recommendation was to reduce excess oxygen to the lower constraint. However, the recommendations for the AOFA and mill coal flows were different. It appears that these changes in recommendations produced slightly lower NOx emissions than the min NOx test. However, the boiler efficiency for the maximize efficiency test was approximately $0.25 \%$ above that observed for the min NOx test. For the min LOI test (161-3), the mill configuration was not changed from that recommended for the max efficiency mode, whereas the excess oxygen and OFA damper position recommendations were changed. Note that the change in LOI from the minimize NOx to the minimize LOI mode is approximately 5\%. This change is much higher than the change in LOI that a similar change in excess oxygen alone produced in the past (about $2 \%$ ).

A comparison of the LOI signals for the test day is shown in Figure 5-59. As shown, the SEKAM analyzer was more influenced by operating conditions than the other instruments as well as the predicted value. The LOI swing of the SEKAM for this day was less than the $10 \%$ observed during Test 160 and more inline with earlier experience.

As can be seen, the two minimize NOx tests (161-1 and 161-4) as well as the two maximize efficiency tests (161-2 and 161-5) conducted during the day did not produce the same recommendations. Possible reasons for the different recommendations include:

- Unit changes during the intervening periods creating a different optimum.

- Since the starting points were different for the tests, move suppression could have influenced the recommendation.

A comparison of the calculated (based on current readings of excess oxygen, furnace gas temperatures and LOI via the SEKAM) and predicted efficiency (from the combustion model) changes are shown in Figure 5-60. The predicted changes were greater than that calculated, however time lags and delays in furnace gas temperatures and LOI affect the latter. Both of these measurements are determined using a control volume which excludes the air heaters. 
Alternate calculations that include the air heater are shown also. The trend with the legend Calc/AHO uses the SEKAM reading whereas the one labeled Calc/AHO/pred. LOI uses the predicted LOI.

As can be seen, GNOCIS did not adversely affect the stability of the control actions and the recommendations were very stable. This characteristic is partly due to the inclusion of recommendation move suppression in GNOCIS.

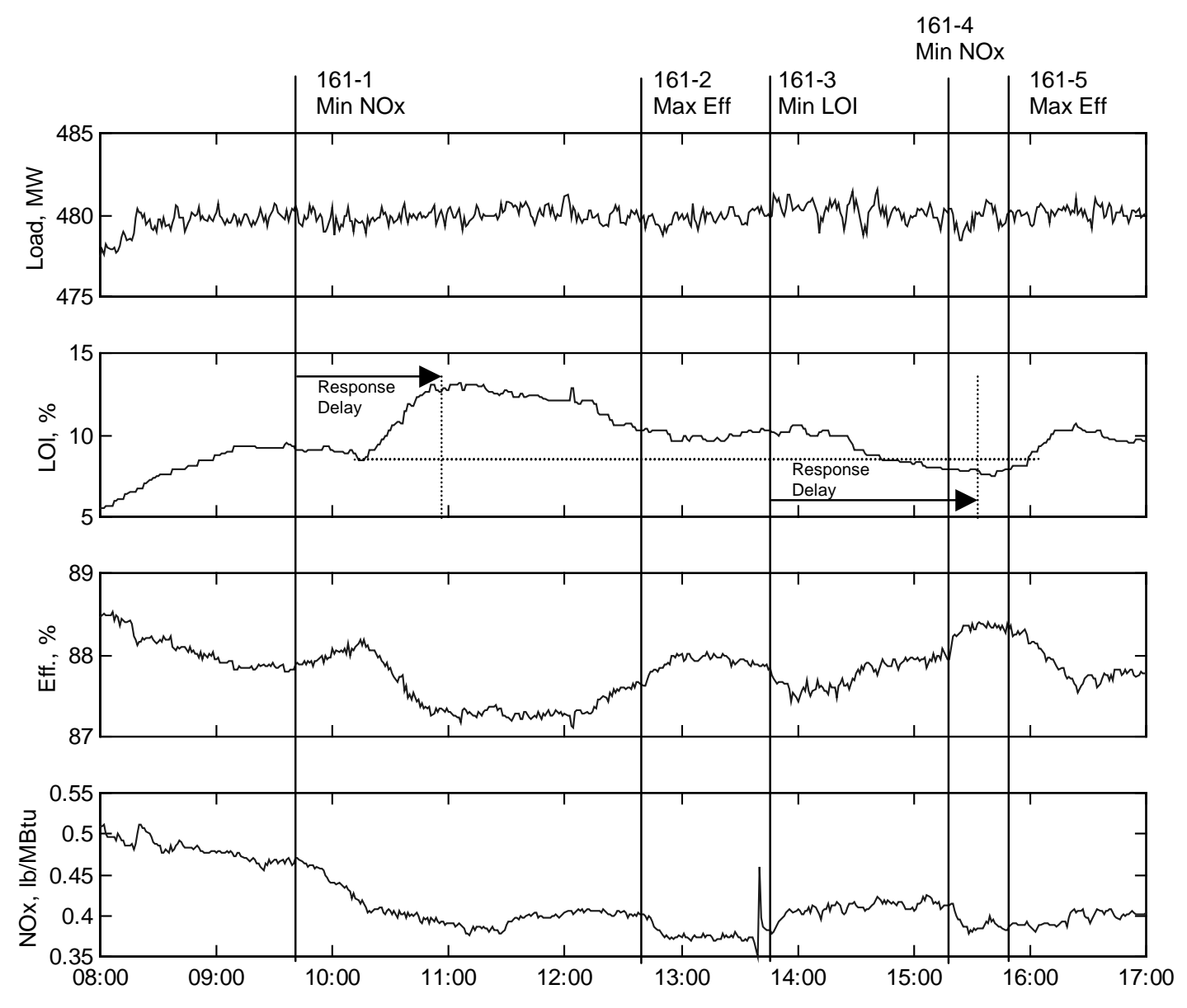

Figure 5-57 GNOCIS / Test 161 / Optimized Variables 
Table 5-15 Recommendations for Test 161

\begin{tabular}{|c|c|c|c|c|c|}
\hline Control Variable & Min NOx & Max Eff. & Min LOI & Min NOx & Max Eff \\
\hline Excess Oxygen & ת & ת & 仓 & ת & $\sqrt{3}$ \\
\hline OFA F1 & 仓 & 仓 & $\sqrt{3}$ & 约 & \& \\
\hline OFA F2 & 仓 & 仓 & ת & 约 & ת \\
\hline OFA R1 & \ & ת & 仓 & 仓े & 仓े \\
\hline OFA R2 & $\sqrt{ }$ & 仓े & 仓े & 仓े & 仓 \\
\hline Mill A & 鸟 & $\sqrt{3}$ & $\sqrt{3}$ & 岛 & $\sqrt{3}$ \\
\hline Mill B & 仓े & 仓 & 仓 & $\sqrt{3}$ & 仓 \\
\hline Mill C & 仓े & $\sqrt{3}$ & \& & - & - \\
\hline Mill D & 仓 & $\sqrt{2}$ & $\sqrt{2}$ & 仓े & ת \\
\hline Mill E & 马 & 仓े & 仓 & 仓 & 仓 \\
\hline Mill $\mathrm{F}$ & ת & 仓 & 仓े & 仓े & 仓 \\
\hline
\end{tabular}
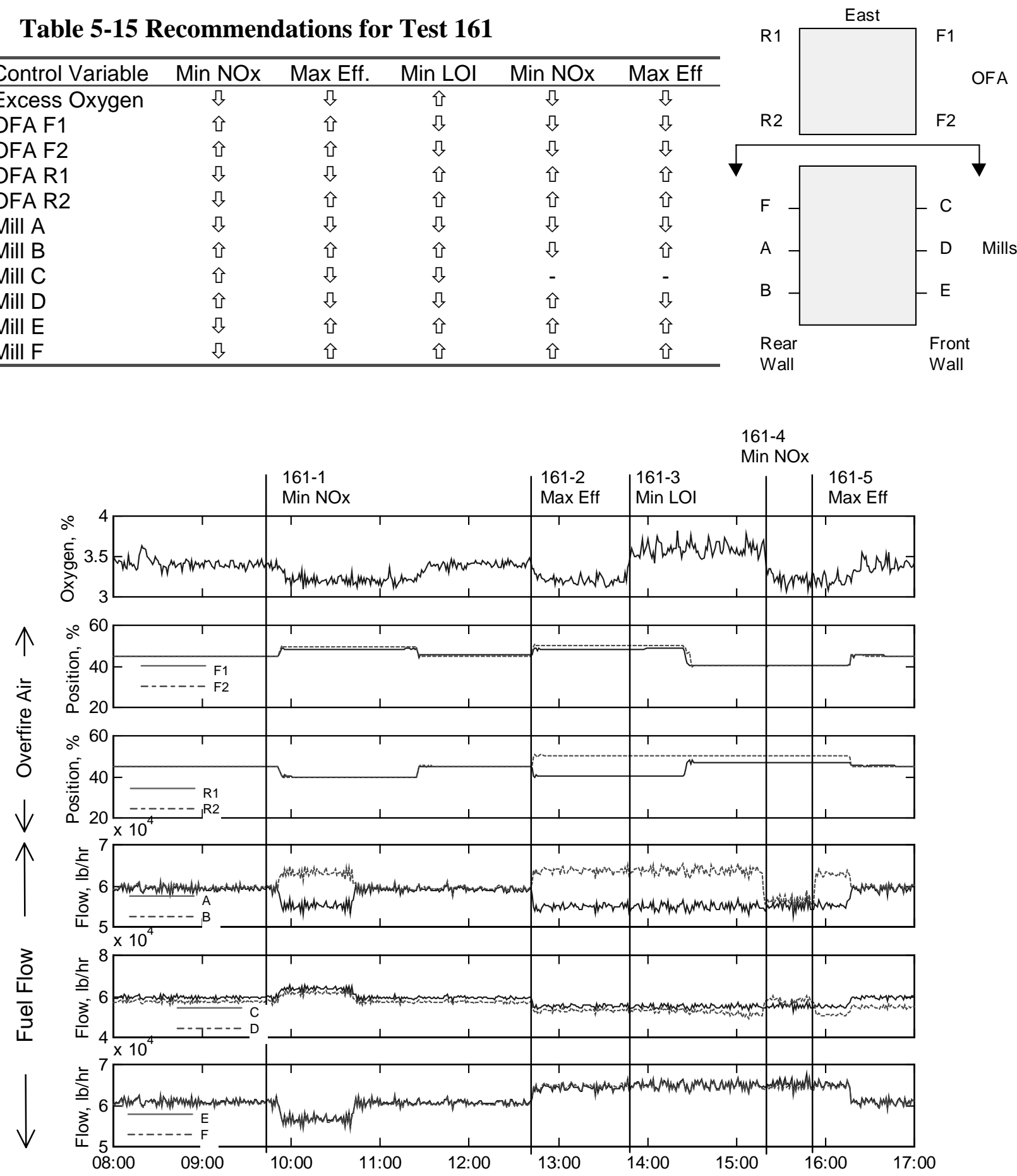

Figure 5-58 GNOCIS / Test 161 / Manipulated Variables 


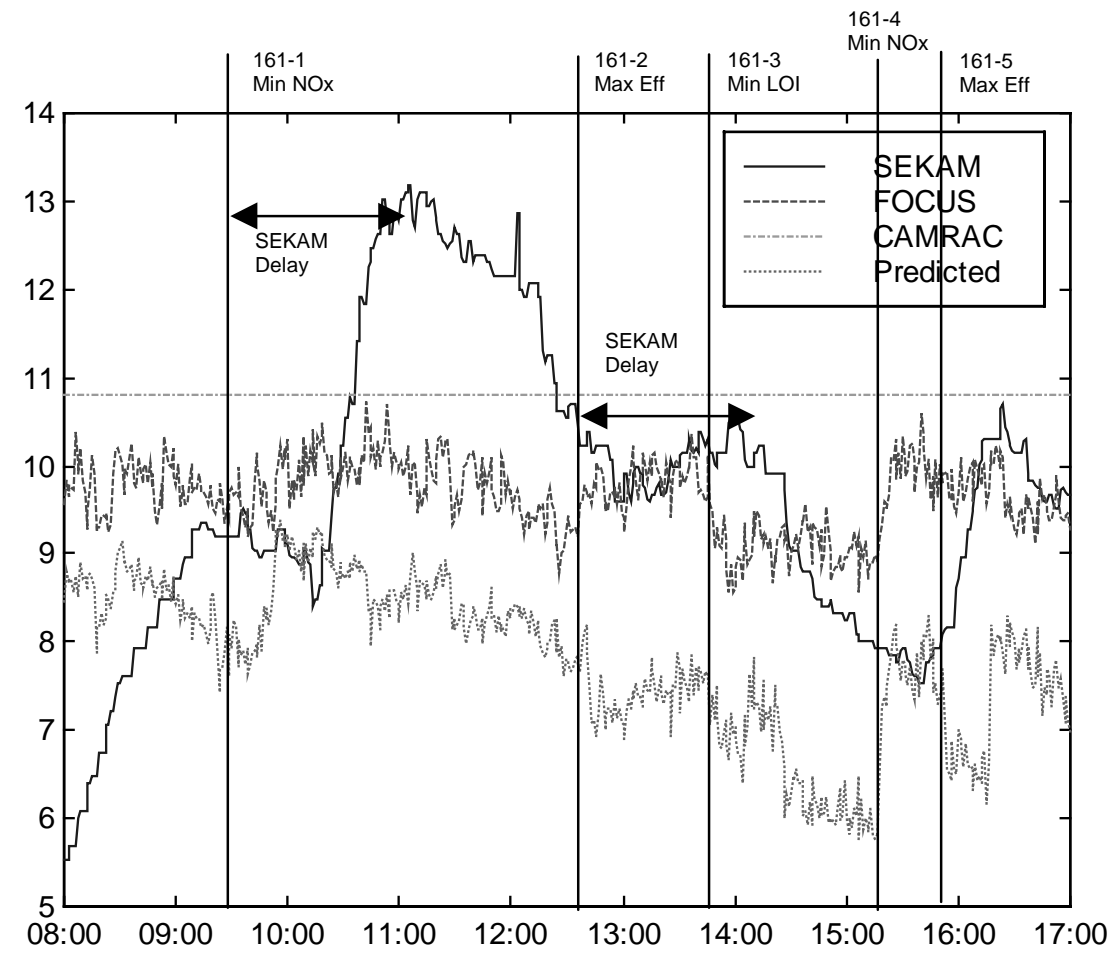

Figure 5-59 GNOCIS / Test 161 / Comparison of LOI Signals

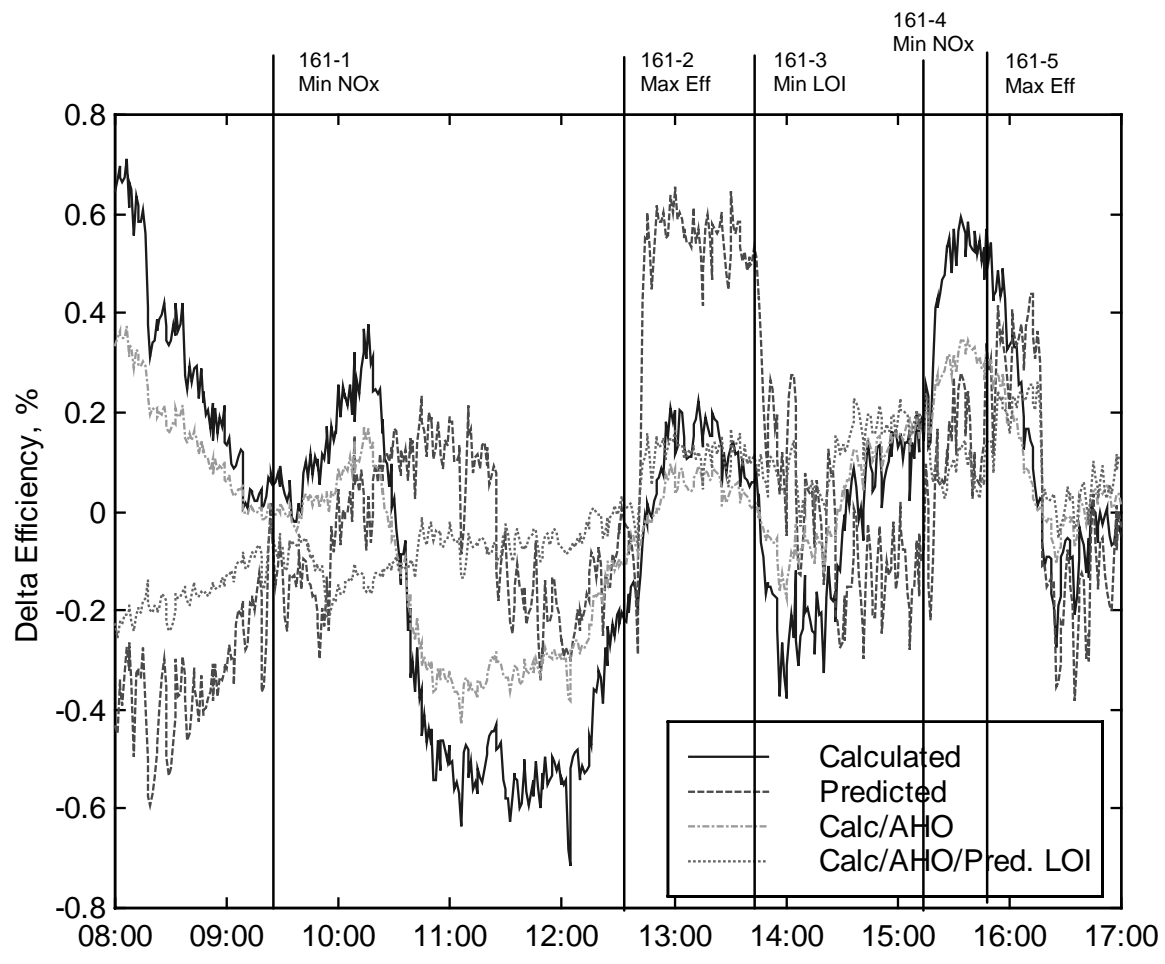

Figure 5-60 GNOCIS / Test 161 / Delta Efficiency 


\section{$\underline{\text { Test } 162}$}

Test 162 (Figure 5-61 and Figure 5-62), conducted on May 16, was also at full load and GNOCIS was operating in closed-loop mode. During the test period, the unit was off economic dispatch and was at stable conditions. Overfire air was in operation and at nominal conditions. The fuel for the test was the normal coal supply. A summary of the control actions for these tests is shown in Table 5-16.

In Test 162-1, minimize LOI was the goal and as shown, a reduction of approximately 2.2 percent was obtained. As expected due to the increased oxygen levels, NOx emissions were increased. The goal was then changed to minimize NOx with oxygen clamped to the current levels. As shown, at least for the conditions present for this test, GNOCIS estimated that the other independent control variables (AOFA dampers and mill loadings) would have minimal impact on NOx emissions and therefore no control action was implemented. The final test (1623 ) freed up excess oxygen and the control action was taken resulting in a NOx reduction of approximately 10 percent. As with the prior days testing, there was no apparent adverse impact on the stability of the unit. 


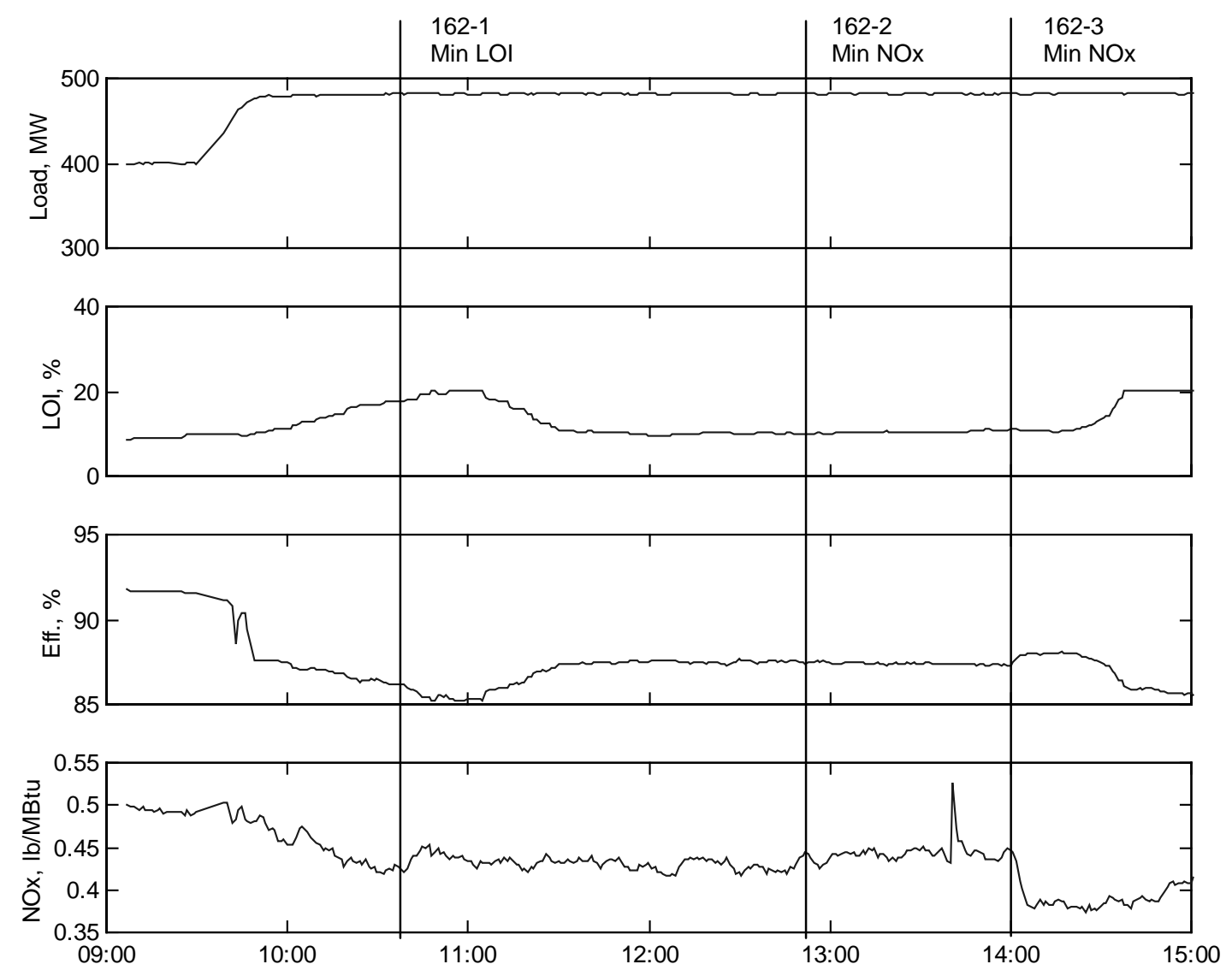

Figure 5-61 GNOCIS / Test 162 / Optimized Variables 
Table 5-16 Recommendations for Test 162

\begin{tabular}{|c|c|c|c|}
\hline Control Variable & Min LOI & Min NOx & Min NOx \\
\hline Excess Oxygen & $\hat{\mathrm{U}}$ & - & ת \\
\hline OFA F1 & 马 & - & - \\
\hline OFA F2 & 』 & - & - \\
\hline OFA R1 & 仓े & - & - \\
\hline OFA R2 & 仓े & - & - \\
\hline Mill A & $\sqrt{3}$ & - & - \\
\hline Mill B & 仓े & $\sqrt{ }$ & $\Omega$ \\
\hline Mill C & $\sqrt{2}$ & - & - \\
\hline Mill D & $\sqrt{ }$ & 仓े & - \\
\hline Mill E & 仓े & $\sqrt{3}$ & 仓े \\
\hline Mill $F$ & 仓े & $\sqrt{3}$ & 仓े \\
\hline
\end{tabular}

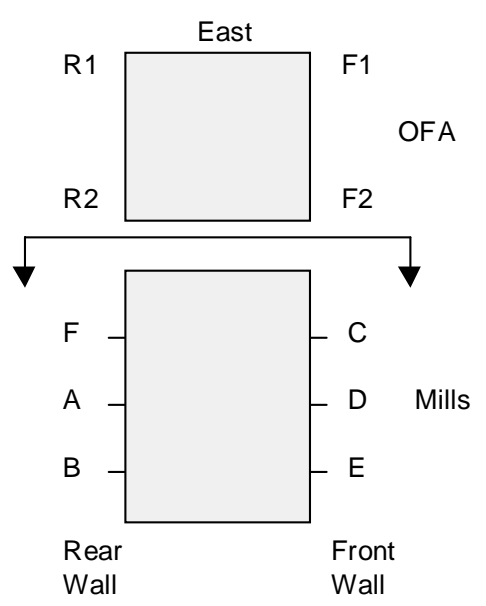

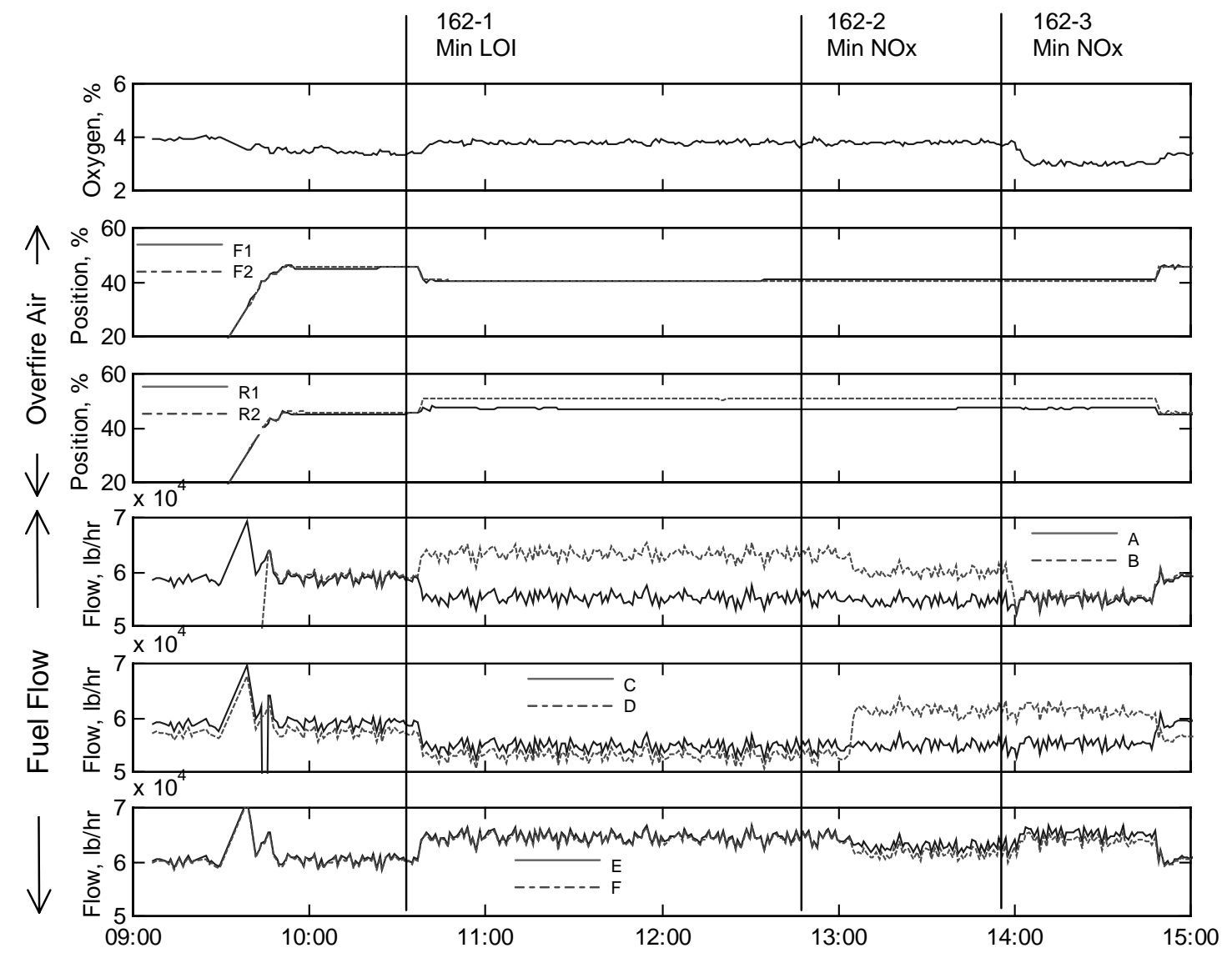

Figure 5-62 GNOCIS / Test 162 / Manipulated Variables 


\section{Summary of Findings from Second Quarter 1996 Testing}

The following is a summary of the findings from these tests.

- GNOCIS could be run in a closed-loop mode without adversely influencing unit stability, safety, or reliability.

- With reasonable constraint limits, GNOCIS could be expected to achieve NOx reductions approximately 10 to $15 \%$ over the load range with a positive impact on boiler efficiency.

- Efficiency improvements of around 0.5 percentage points are achievable within the constraints tested.

- The performance of the online LOI monitors still pose a problem to the implementation of GNOCIS. 


\subsubsection{GNOCIS Performance Estimate}

Based on the actual test data from Hammond and other sites and GNOCIS model studies conducted, estimates can be made as to the impacts of GNOCIS on important unit parameters such as boiler efficiency, NOx emissions, and fly ash LOI. Since GNOCIS can be operated in numerous configurations (minimize NOx, minimize LOI, maximize efficiency, etc.), a decision must be made as to what mode GNOCIS is configured. Also, a decision must be made as to the flexibility GNOCIS is allowed in achieving this goal. With this in mind, the three scenarios considered include: (1) minimize NOx emissions, (2) maximize boiler efficiency, and (3) minimize LOI, all subject to the following constraints on the controllable parameters:

- Fuel change to each mill limited to $\pm 5000 \mathrm{lb} / \mathrm{hr}$ of current operating level.

- Excess oxygen change limited to $\pm 0.5 \%$ from current operating level over the entire load range.

- OFA damper positions restricted to $\pm 5 \%$ from current operating position.

- Total change in fuel to furnace is zero.

- Recommendations given for current mill configuration. Greater benefits may be achieved if the recommendations for mills in service are followed, however, this recommendation is only advisory.

These constraints are in line with those tested at Hammond and other sites.

Using these constraints, the combustion models were run to determine the performance gains that could be expected if the recommendations were followed continuously and over the load range, much as would occur if GNOCIS were operating in closed-loop mode.

Results from these studies are shown in Figure 5-63 through Figure 5-65 in which a comparison of NOx emissions, boiler efficiency, and LOI for the various operating modes are compared. The corresponding recommendations for excess oxygen, mill flows, and overfire air (as biases from baseline) for the various operating modes are shown in Figure 5-66 through Figure 5-72.

As shown, full load NOx emissions were reduced by about $14 \%$ and averaged $11 \%$ below baseline over the entire load range. The maximum efficiency mode reduced NOx emissions by approximately $12 \%$ at full load, however at lower loads (below $340 \mathrm{MW}$ ), the recommendations increased NOx emissions so that the average for the entire load range was near zero. As may be expected, the minimize LOI mode produced the highest emissions averaging $6 \%$ over baseline. The predictions for NOx reduction are consistent with that observed from plant testing.

Boiler efficiency is shown in Figure 5-64. Efficiency improvements of about 1.0 percentage points are predicted with improvements of around 0.7 percentage points indicated over the load range. Even given the broader range allowed of the recommendations, these values are somewhat though not extremely higher than has been observed at Hammond and other sites. 
The LOI characteristic is shown in Figure 5-65. At full load, there was a maximum difference of around 4 percentage points between the LOI in the various operating modes, with the minimize NOx emissions mode having the greatest LOI and the minimize LOI mode having the lowest. At low loads, the differential between the lowest and highest LOI was much less (around 1 percentage point). It is interesting to note that below approximately $370 \mathrm{MW}$, the model predicts that the three optimum modes (Max Efficiency, Min LOI, and Min NOx) all produce lower LOI than the baseline case (though only slightly for the Min NOx case). This result is somewhat curious in that:

- Given all else being equal, a decrease in excess oxygen is expected to increase LOI.

- The excess recommended oxygen level for the minimize NOx scenario for all load levels is, as expected, lower than the baseline case.

Possible explanations for this counter intuitive result are:

- Other manipulated variables (mill biasing and overfire air damper positions) affected the combustion process sufficiently to offset the excess oxygen effect.

- Combustion model inaccuracies with respect to LOI. 


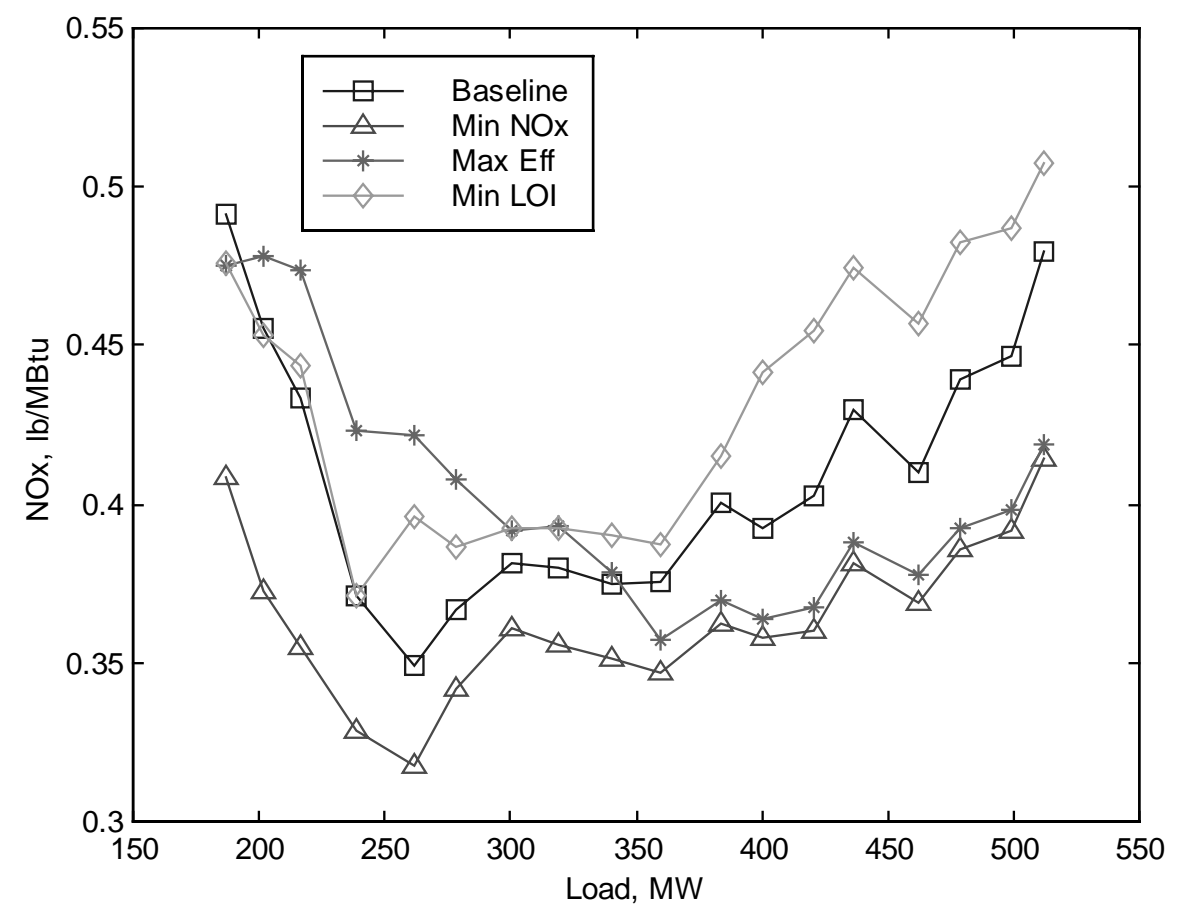

Figure 5-63 GNOCIS / NOx Emissions

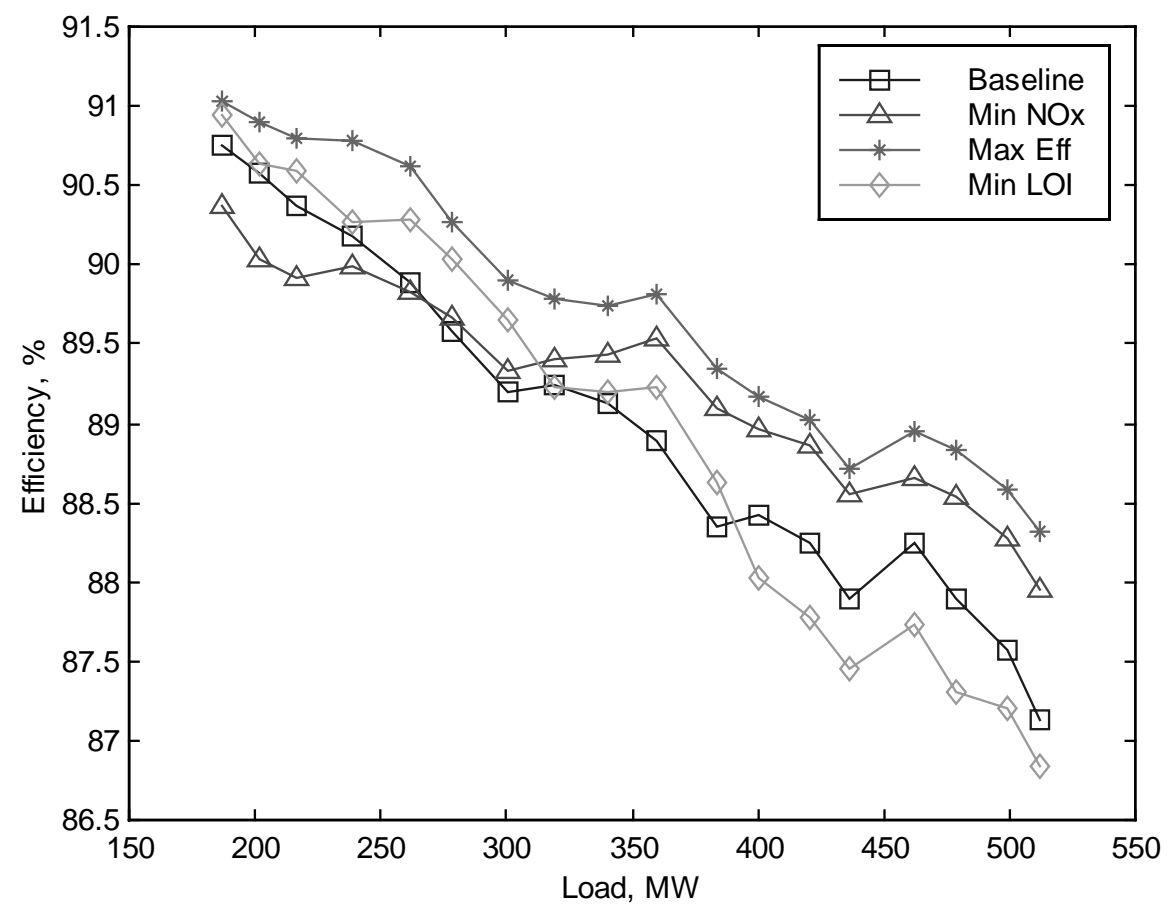

Figure 5-64 GNOCIS / Boiler Efficiency 


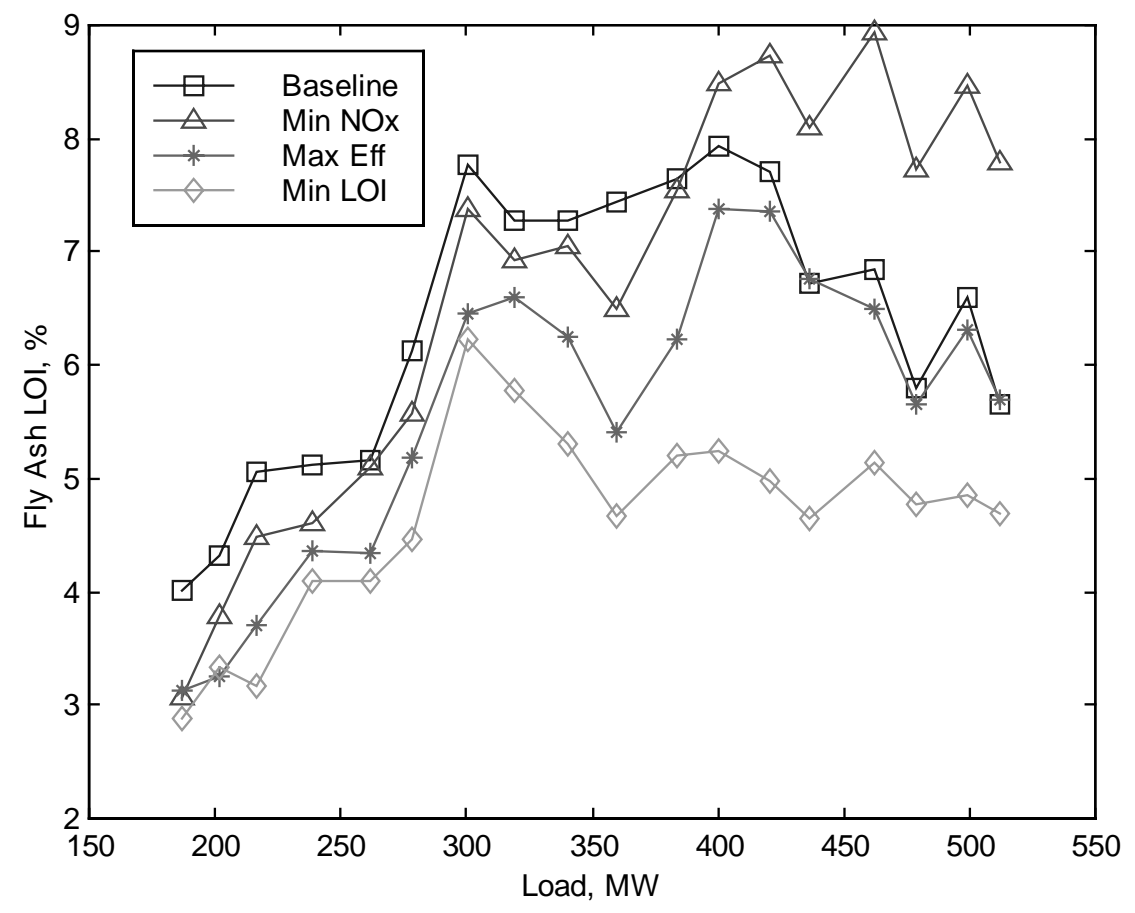

Figure 5-65 GNOCIS / Fly Ash LOI

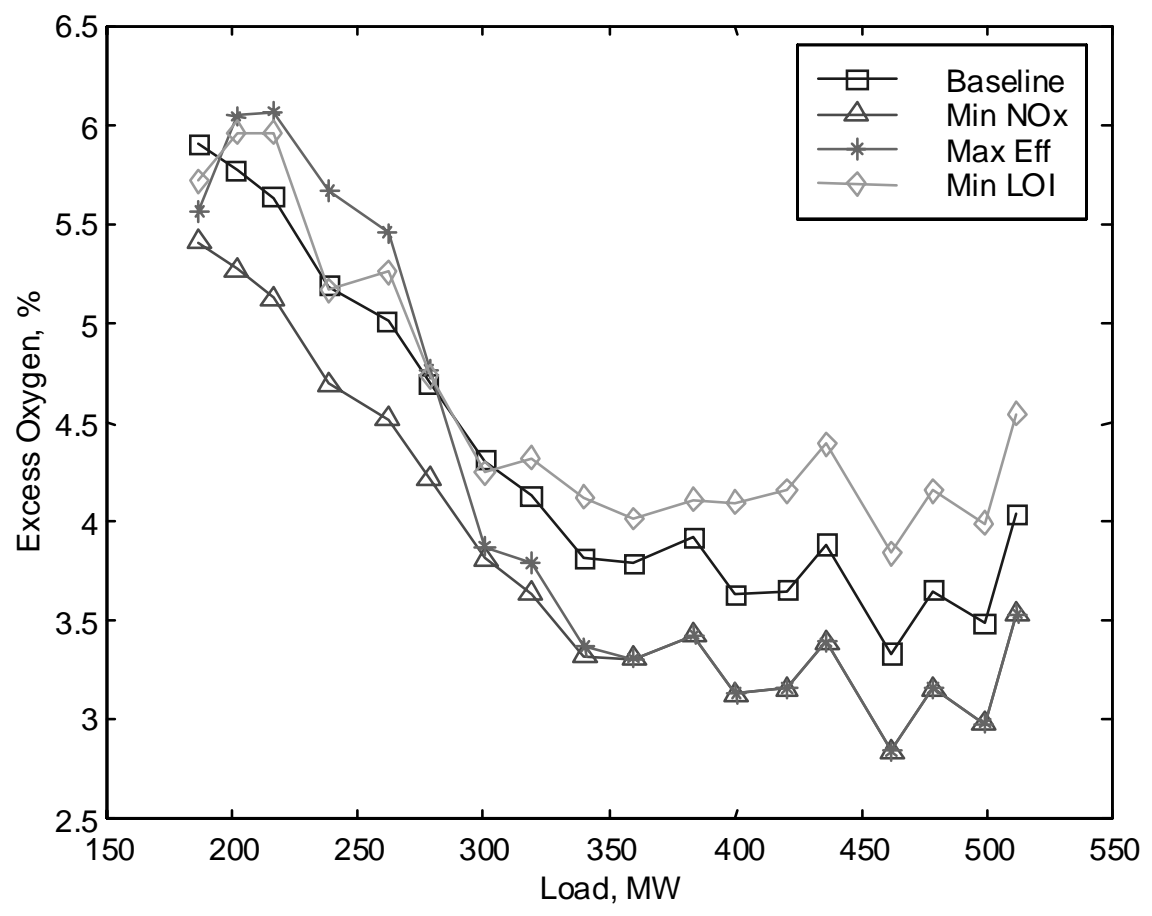

Figure 5-66 GNOCIS / Excess Oxygen 

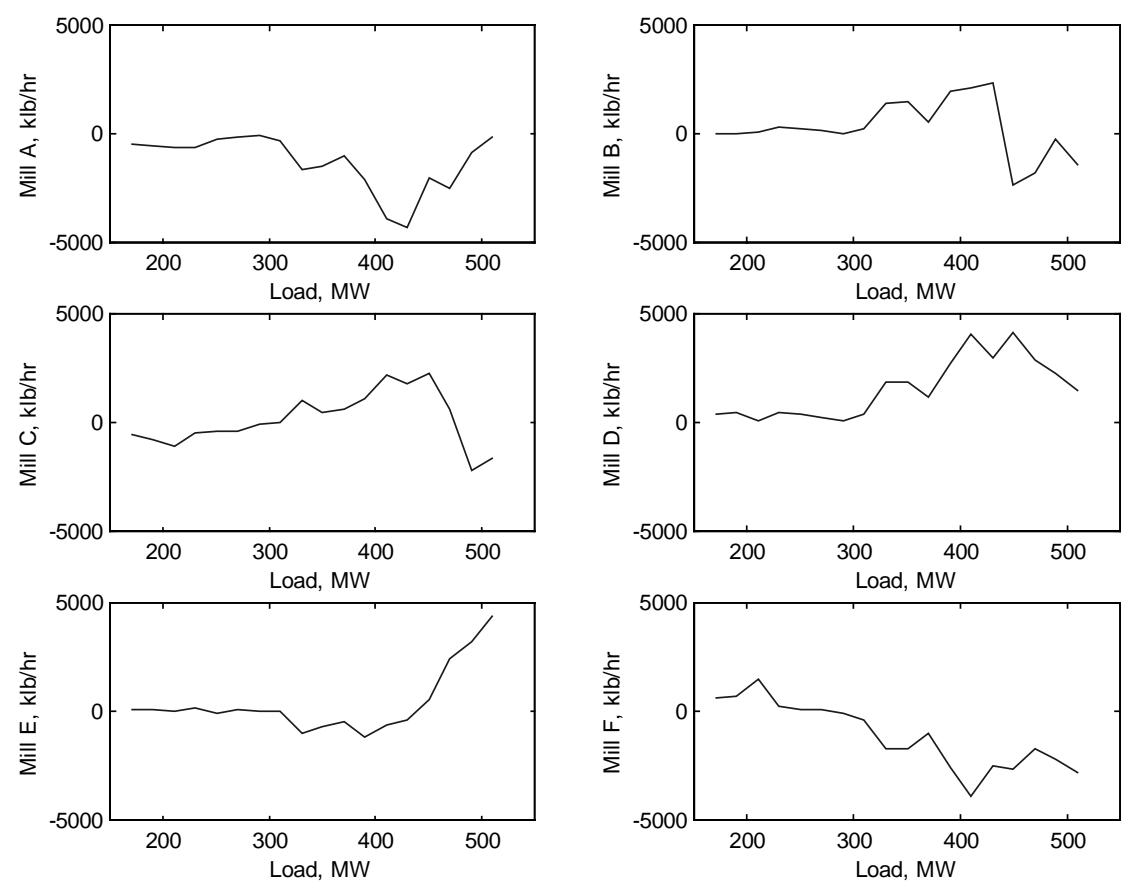

Figure 5-67 GNOCIS / Minimize NOx Emissions / Mill Bias
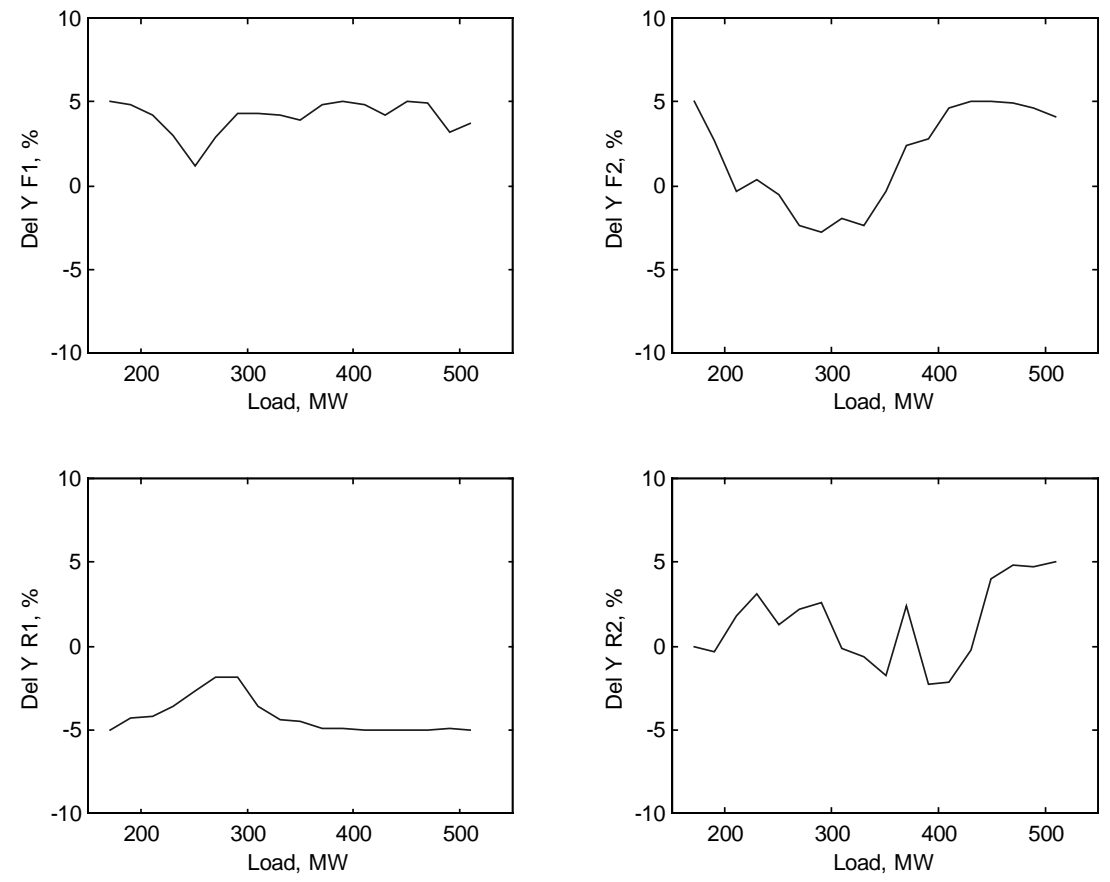

Figure 5-68 GNOCIS / Minimize NOx Emissions / Overfire Air Bias 

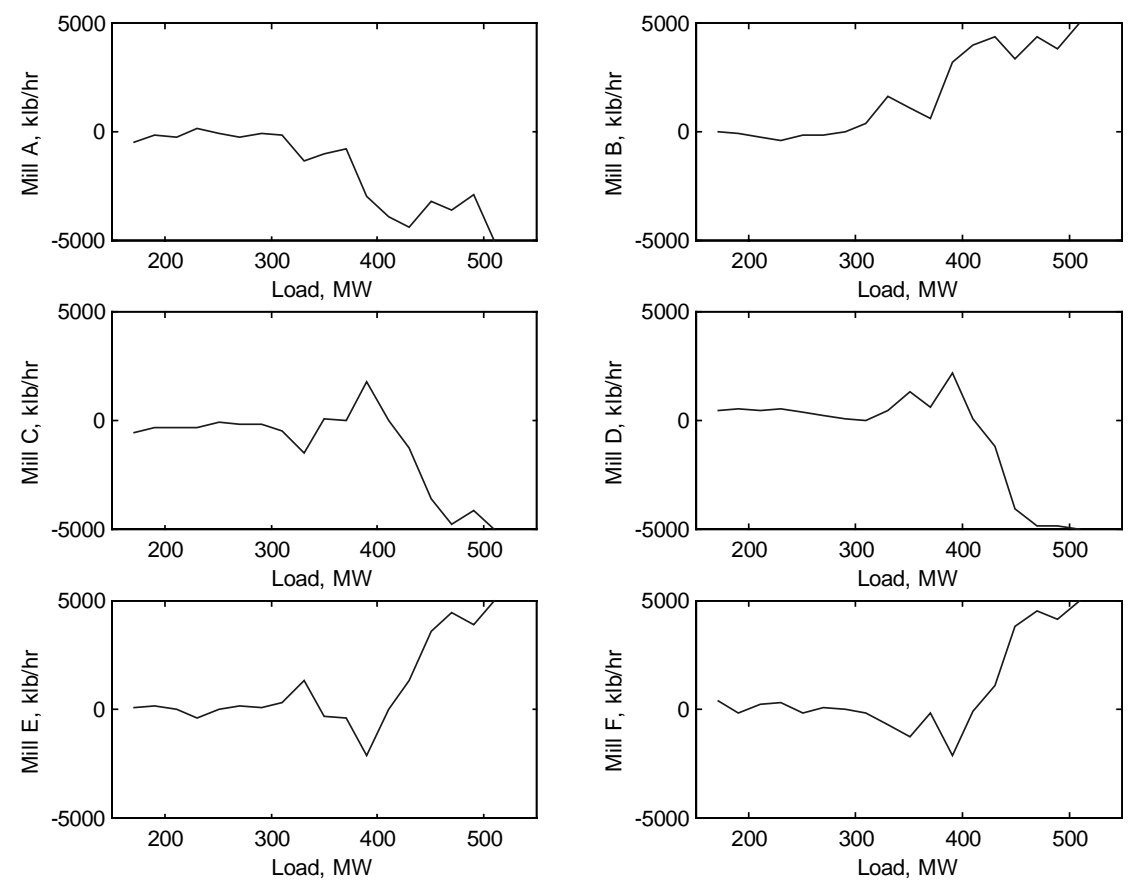

Figure 5-69 GNOCIS / Maximize Efficiency / Mill Bias
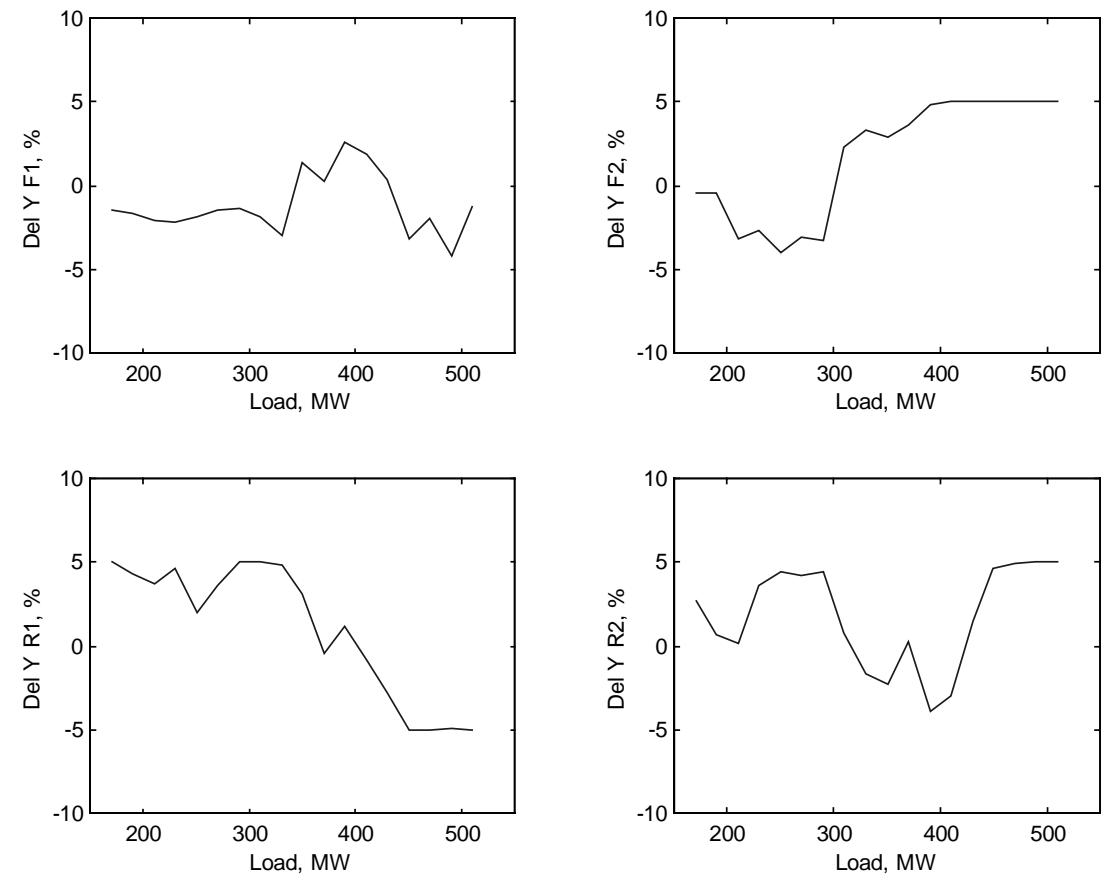

Figure 5-70 GNOCIS / Maximize Efficiency / Overfire Air Bias 

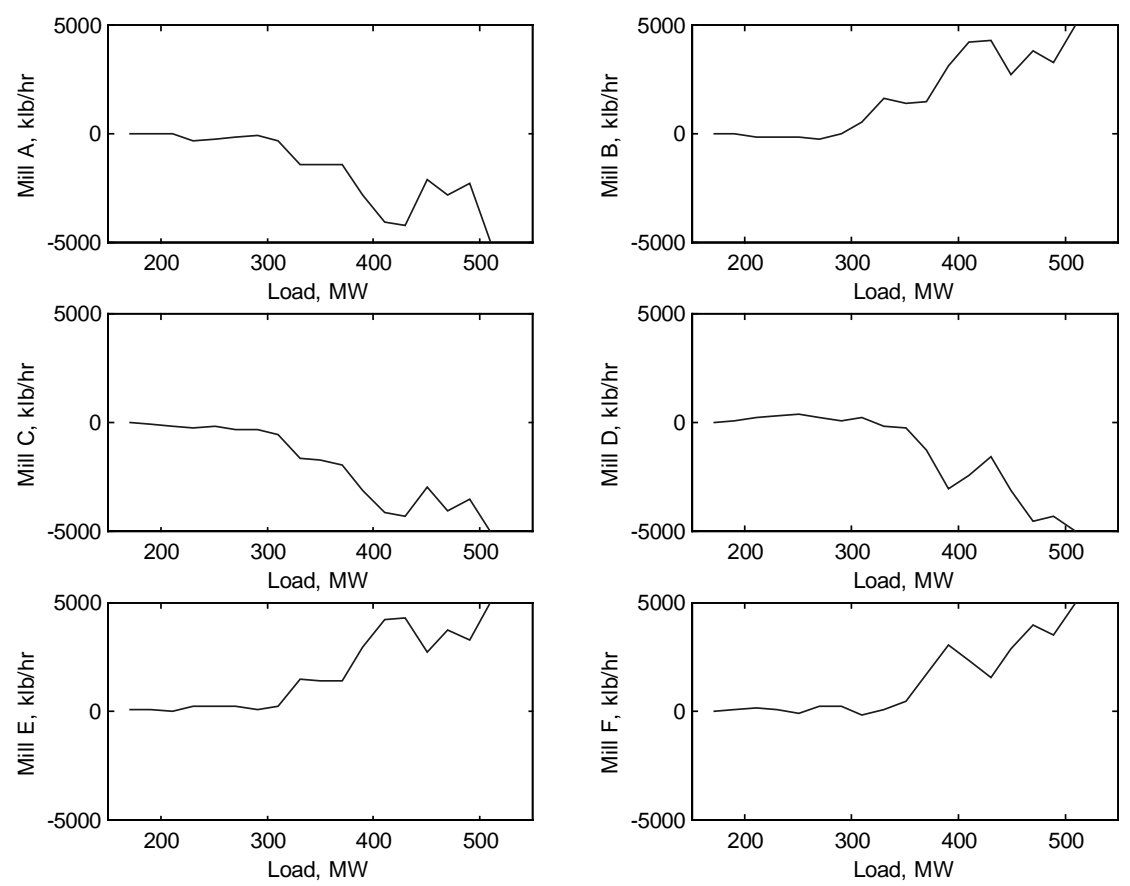

Figure 5-71 GNOCIS / Minimize LOI / Mill Bias
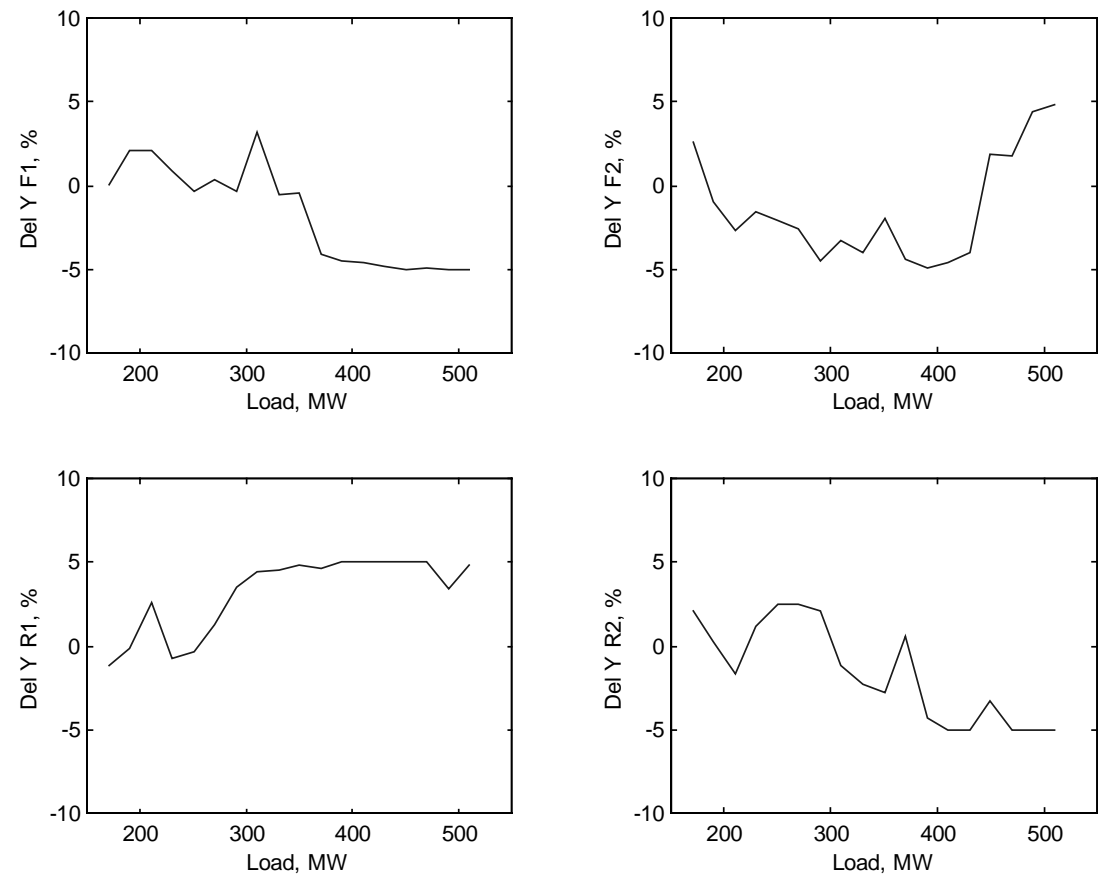

Figure 5-72 GNOCIS / Minimize LOI / Overfire Air Bias 


\section{ECONOMIC EVALUATION}

The economic impacts of the combustion techniques for NOx reduction consist of capital costs for the retrofits, lost revenue as a result of unit outages, and changes in operating and maintenance costs, both fuel and non-fuel related. For the purposes of this report, it is assumed that the non-fuel related costs and the lost revenue due to the outages are similar for the considered NOx reduction technologies. Therefore, the main economic impacts are attributed to the capital costs and fuel related (heat rate related) O\&M costs.

The average cost effectiveness of each NOx reduction technology (expressed in \$/ton of NOx removed) is estimated in this section by taking into account the capital cost, O\&M impacts, and the NOx emission reduction on an annual basis.

\subsection{Estimated Capital Costs}

Although the demonstration nature of the Hammond retrofit had an impact on the total project costs, the capital costs are within the expected range for wall-fired installations $(6-15 \$ / \mathrm{kW}$ for the LNB and $10-20 \$ / \mathrm{kW}$ for the LNB + AOFA). ${ }^{1}$ For the purposes of this report, the following estimates of the actual Hammond capital costs were developed excluding the demonstration related cost adders (e.g., testing, data analysis, and reporting). However, the estimates do include a certain amount of cost sharing by project participants:

$\begin{array}{ll}\text { AOFA } & \$ 3.8 \text { million or } 7.6 \$ / \mathrm{kW} \\ \text { LNB } & \$ 4.5 \text { million or } 9.0 \$ / \mathrm{kW} \\ \text { LNB+AOFA } & \$ 8.3 \text { million or } 16.6 \$ / \mathrm{kW} \\ \text { GNOCIS } & \$ 250 \text { thousand or } 0.5 \$ / \mathrm{kW}\end{array}$

For a $500 \mathrm{MW}$ wall-fired commercial installation, with a scope of supply similar to the Hammond retrofit, it is anticipated that the following estimated costs could be utilized for planning purposes:

$\begin{array}{ll}\text { AOFA } & \$ 4.4 \text { million or } 8.8 \$ / \mathrm{kW} \\ \text { LNB } & \$ 5.0 \text { million or } 10.0 \$ / \mathrm{kW} \\ \text { LNB+AOFA } & \$ 9.4 \text { million or } 18.8 \$ / \mathrm{kW} \\ \text { GNOCIS } & \$ 250 \text { thousand or } 0.5 \$ / \mathrm{kW}\end{array}$

These estimates are based upon the actual Hammond Unit 4 costs and other available cost data from EPRI and additional sources.

Specifics of the costing of AOFA, LNB, and LNB+AOFA technologies can be found in the final report of the project [SCS, 1998]. For GNOCIS, the following assumptions have been made:

\footnotetext{
${ }^{1}$ All costs are in 1995 dollars.
} 
- The DCS was excluded from the cost of a GNOCIS project. The cost of a DCS is very unit specific and is an order of magnitude higher than the cost of the optimization software itself, varying from $\$ 2$ to $\$ 8$ million.

- DCS configuration modifications that are required to incorporate GNOCIS into the DCS are included.

- Additional instrumentation (such as on-line carbon-in-ash monitors) not strictly necessary for GNOCIS operation are excluded. On-line carbon-in-ash monitor pricing ranges from $\$ 50,000$ to $\$ 100,000$.

\subsection{Cost Effectiveness at Full-Load}

The annual O\&M cost and NOx reductions for the installed technologies relative to baseline depend to a large degree on the load profile of the unit. However as a first step, it is informative to perform the analysis for full-load conditions. The annual fuel related O\&M cost changes relative to baseline were estimated based on the changes of the unit net heat rate and the following assumptions:

- Base loaded unit (i.e., full-load operation)

- 65 percent capacity factor; and

- $\$ 1.2$ per MBtu coal cost.

The capital and O\&M cost impacts, along with the annual NOx emission reduction (based on long-term, full-load operation), were used for estimating the average cost-effectiveness of the low NOx technologies tested at Hammond Unit 4.

For GNOCIS, three scenarios were considered. In the first, the objective was to minimize NOx emissions without explicit consideration of boiler efficiency or LOI. In the second, the objective was to maximize boiler efficiency without consideration of NOx emissions and LOI. For the third, the objective was set to minimize LOI without consideration for NOx emissions and boiler efficiency. For these scenarios, the allowable ranges on the manipulated variables were set to that which were shown to be feasible by testing at Hammond.

Given the assumptions above and performance and cost of GNOCIS as described in Section 5 and shown in Table 6-1, the projected annual O \& M costs of GNOCIS operated in the various modes ranged from approximately $\$ 231,000$ (Min LOI) to $-\$ 340,000$ (Max Efficiency). The NOx removal cost effectiveness ranged from -\$299 (Min NOx) to -\$463 (Max Efficiency) per ton of NOx removed. The NOx removal cost effectiveness in the minimize LOI mode is not shown since operating in this mode would produce a NOx emissions increase. When the assumption is made that there would be no efficiency improvements when operating in the maximize efficiency mode, the cost effectiveness of the technology would be approximately \$29 per ton NOx removed (Table 6-2). Also shown in this table is the cost effectiveness of GNOCIS when it is operated in the maximize efficiency mode with the assumption of $1 / 2$ the performance gain shown in Table 6-1 (0.45 vs. 0.9). In the last column of Table 6-2, the effectiveness is 
shown when the cost of the DCS is included in the capital cost. For comparison, corresponding numbers for the other technologies tested at Hammond are shown in Table 6-3.

Table 6-1 NOx Reduction Cost Effectiveness of GNOCIS

\begin{tabular}{lc|c|c|c}
\hline & Baseline & Min NOx & Max Eff & Min LOI \\
\hline O\&M & & & & \\
Boiler Efficiency & 87.9 & 88.5 & 88.8 & 87.3 \\
Efficiency Change & Base & 0.6 & 0.9 & -0.6 \\
Turbine Heat Rate - Btu/kWh & 9,000 & 9,000 & 9,000 & 9,000 \\
Unit Net Heat Rate - Btu/kWh & 10,239 & 10,169 & 10,135 & 10,309 \\
\% NHR Change & Base & -0.68 & -1.01 & 0.69 \\
Annual O \& M & Base & $-\$ 228,058$ & $-\$ 340,931$ & $\$ 231,192$ \\
& & & & \\
Cost Effectiveness & & & & \\
NOx Full Load & 0.44 & 0.39 & 0.39 & 0.48 \\
\% NOx Reduction & Base & 11 & 11 & -9 \\
Annual NOx Reduction - Tons/yr & Base & 696 & 694 & $(564)$ \\
Capital Costs - \$ millions & Base & 0.25 & 0.25 & 0.25 \\
Cost Effectiveness - \$/ton removed & Base & $-\$ 299$ & $-\$ 463$ & $\mathrm{n} / \mathrm{a}$ \\
\hline n & & & \\
\hline
\end{tabular}

$\mathrm{n} / \mathrm{a}$ - There was a net NOx emission increase for this mode.

Table 6-2 NOx Reduction Cost Effectiveness of GNOCIS

\begin{tabular}{lc|c|c|c}
\hline & Baseline & Min NOx (1) & Max Eff (2) & Min NOx (3) \\
\hline O\&M & & & & \\
Boiler Efficiency & 87.9 & 87.9 & 88.45 & 88.5 \\
Efficiency Change & Base & 0 & 0.55 & 0.6 \\
Turbine Heat Rate - Btu/kWh & 9,000 & 9,000 & 9,000 & 9,000 \\
Unit Net Heat Rate - Btu/kWh & 10,239 & 10,239 & 10,175 & 10,169 \\
\% NHR Change & Base & 0.00 & -0.62 & -0.68 \\
Annual O \& M & Base & $\$ 0$ & $-\$ 209,171$ & $-\$ 228,058$ \\
& & & & \\
Cost Effectiveness & & & & \\
NOx Full Load & 0.44 & 0.39 & 0.39 & 0.39 \\
$\%$ NOx Reduction & Base & 11 & 11 & 11 \\
Annual NOx Reduction - Tons/yr & Base & 701 & 696 & 696 \\
Capital Costs - \$ millions & Base & 0.25 & 0.25 & 3.6 \\
Cost Effectiveness - \$/ton removed & Base & $\$ 29$ & $-\$ 272$ & $\$ 86$ \\
\hline (1) Assume no heat ramprove
\end{tabular}

(1) Assume no heat rate improvement.

(2) Assume 1/2 efficiency improvement as base case.

(3) Include DCS cost in cost of technology. 
Table 6-3 NOx Reduction Cost Effectiveness of Low NOx Technologies

\begin{tabular}{|c|c|c|c|c|c|c|}
\hline & Baseline & $\begin{array}{c}\text { Baseline -> } \\
\text { AOFA }\end{array}$ & $\begin{array}{c}\text { Baseline -> } \\
\text { LNB }\end{array}$ & $\begin{array}{l}\text { Baseline -> } \\
\text { LNB+AOFA }\end{array}$ & $\begin{array}{c}\text { LNB -> } \\
\text { LNB+AOFA }\end{array}$ & $\begin{array}{l}\text { LNB (Adj.) -> } \\
\text { LNB+AOFA }\end{array}$ \\
\hline \multicolumn{7}{|l|}{ O\&M } \\
\hline Boiler Efficiency & 90 & 89.2 & 89.3 & 88.7 & 88.7 & 88.7 \\
\hline Efficiency Change & Base & -0.8 & -0.7 & -1.3 & -0.6 & -0.6 \\
\hline Turbine Heat Rate - Btu/kWh & 9,000 & 8,999 & 8,975 & 8,960 & 8,960 & 8,960 \\
\hline Unit Net Heat Rate - Btu/kWh & 10,000 & 10,089 & 10,050 & 10,101 & 10,101 & 10,101 \\
\hline$\%$ NHR Change & Base & 0.89 & 0.50 & 1.01 & 0.51 & -0.51 \\
\hline Annual O \& M & Base & $\$ 290,968$ & $\$ 165,556$ & $\$ 333,351$ & $\$ 167,795$ & $\$ 167,795$ \\
\hline \multicolumn{7}{|l|}{ Cost Effectiveness } \\
\hline NOx Full Load & 1.24 & 0.94 & 0.65 & 0.4 & 0.4 & 0.4 \\
\hline$\%$ NOx Reduction & Base & 24 & 48 & 68 & 38 & 22 \\
\hline Annual NOx Reduction - Tons/yr & Base & 4,143 & 8,117 & 11,615 & 3,457 & 1,521 \\
\hline Capital Costs - \$ millions & Base & 3.8 & 4.5 & 8.3 & 3.8 & 3.8 \\
\hline Cost Effectiveness - \$/ton removed & Base & $\$ 144$ & $\$ 65$ & $\$ 86$ & $\$ 136$ & $\$ 310$ \\
\hline
\end{tabular}

Levelization factor of 0.08 assumed

\subsection{Load Profile Impact on Cost Effectiveness}

The previous analysis was based on NOx and heat rate performance at full load. Because both of these operating parameters are potentially dependent on load, it is important to consider the effect of load profiles on the cost effectiveness of the technologies. Four load scenarios, shown in Figure 6-1 were considered for this analysis. The Phase 1 scenario was the actual load profile for Phase 1 test phase. The base load, peaking, cycling, and flat profiles are hypothetical load profiles. As shown in Table 6-4, for the Phase 1 load profile, NOx emission reductions of 11, 0, and $-9 \%$ were obtained for Min NOx, Max Efficiency, and Min LOI operating modes, respectively. Similarly, for the base load profile, reductions of 12, 7, and $-9 \%$ were obtained. For the peaking load profile, the Max Efficiency mode produced a net increase in NOx emissions. This is in part due to the recommendation for excess oxygen in this mode being greater than the baseline case for higher loads and less than the baseline case for lower loads. Also, it is interesting to note that although there was a $0 \%$ decrease in NOx emissions for the Flat Load / Max Efficiency combination, there was a net emissions reduction because of unit heat rate improvements.

The load average impact on heat rate is shown in Table 6-5. As shown, the Min NOx and Max Efficiency improved heat rate for all load scenarios except one (Peaking / Min NOx). However, the Min LOI mode increased heat rate for all except the Peaking load scenario. The fuel cost implications are shown in Table 6-6. For the Min NOx and Max Efficiency modes, there was actually a net fuel savings (except for the Peaking / Min NOx combination), therefore the cost effectiveness is negative, indicating net savings to the site. Also, for the profile/mode combinations where NOx emissions increased, the cost is not shown since the combination is not at all effective in removing NOx. 


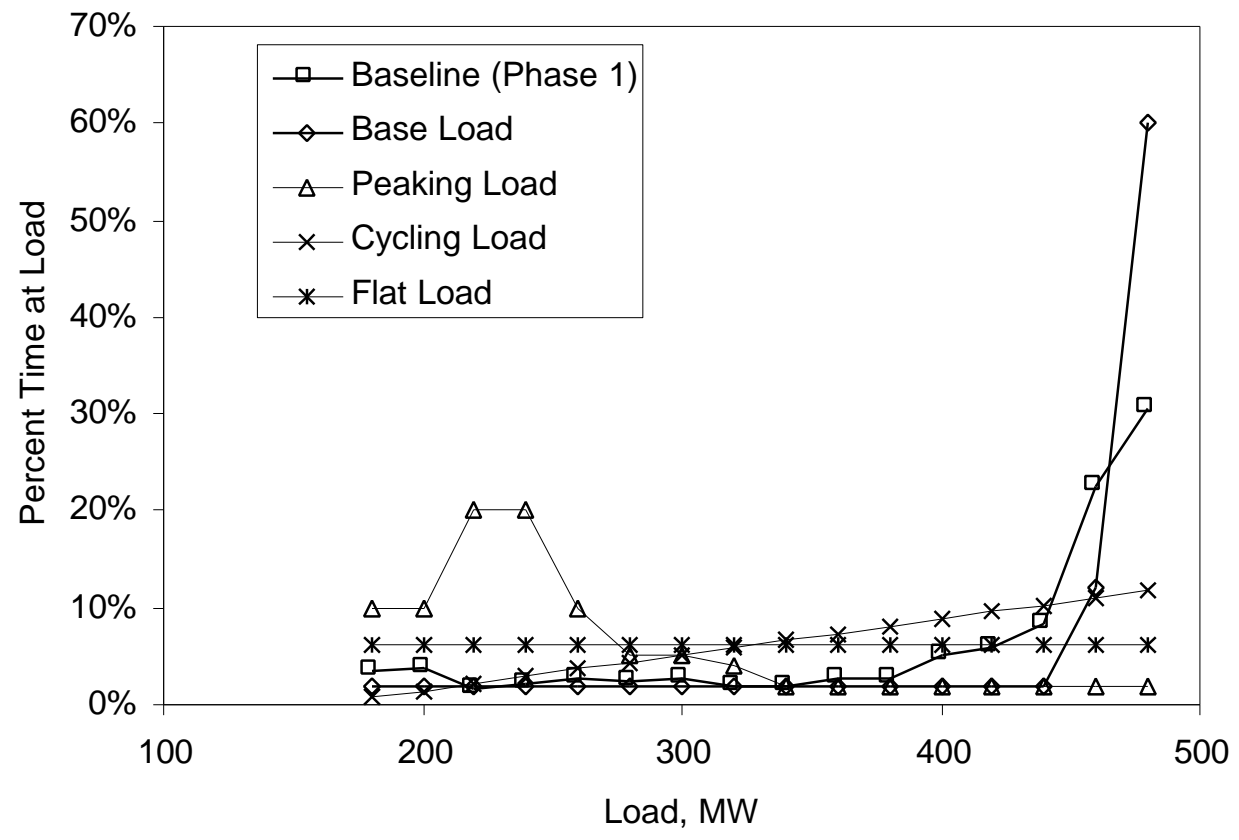

Figure 6-1 Load Profiles

Table 6-4 NOx and NOx Reduction vs. Load Profile and Operating Mode

\begin{tabular}{ccccc}
\hline & & \multicolumn{2}{c}{ Operating Mode } \\
Load Profile & Baseline & Min NOx & Max Eff & Min LOI \\
\hline Phase 1 (Ib/Mbtu) & 0.42 & 0.37 & 0.39 & 0.45 \\
percent reduction & -- & $11 \%$ & $6 \%$ & $-9 \%$ \\
tons reduced/year & -- & 834 & 544 & -717 \\
Base Load (Ib/Mbtu) & 0.43 & 0.38 & 0.39 & 0.46 \\
percent reduction & -- & $12 \%$ & $7 \%$ & $-9 \%$ \\
tons reduced/year & -- & 942 & 680 & -766 \\
percent reduction & -- & 0.35 & 0.43 & 0.42 \\
tons reduced/year & -- & $57 \%$ & $-6 \%$ & $-3 \%$ \\
Peaking Load (Ib/Mbtu) & 0.40 & 0.36 & -226 & -192 \\
percent reduction & -- & $10 \%$ & 0.39 & 0.43 \\
tons reduced/year & -- & 671 & $44 \%$ & $-8 \%$ \\
Cycling Load (Ib/Mbtu) & 0.40 & 0.36 & 0.40 & -576 \\
Flat Load (Ib/Mbtu) & -- & $11 \%$ & 0.43 \\
percent reduction & -- & 604 & 110 & $-6 \%$ \\
tons reduced/year & & & -397 \\
\hline
\end{tabular}


Table 6-5 Average Heat Rate Deviation vs. Load Profile and Operating Mode

\begin{tabular}{rrccc}
\hline & & \multicolumn{3}{c}{ Operating Mode } \\
Load Profile & Baseline & Min NOx & Max Eff & Min LOI \\
\hline Phase 1 & -- & -47 & -78 & 38 \\
Base Load & -- & -56 & -88 & 47 \\
Peaking Load & -- & 1 & -37 & -6 \\
Cycling Load & -- & -43 & -71 & 18 \\
Flat Load & -- & -25 & -56 & 5 \\
\hline
\end{tabular}

Table 6-6 Fuel Cost Deviation vs. Load Profile and Operating Mode

\begin{tabular}{rrrrr}
\hline & \multicolumn{4}{c}{ Operating Mode } \\
Load Profile Baseline & Min NOx & Max Eff & Min LOI \\
\hline Phase 1 & -- & $-\$ 237,610$ & $-\$ 391,804$ & $\$ 190,685$ \\
Base Load & -- & $-\$ 280,727$ & $-\$ 446,273$ & $\$ 237,479$ \\
Peaking Load & -- & $\$ 4,483$ & $-\$ 187,014$ & $-\$ 28,909$ \\
Cycling Load & -- & $-\$ 216,281$ & $-\$ 356,717$ & $\$ 90,939$ \\
Flat Load & -- & $-\$ 127,076$ & $-\$ 283,833$ & $\$ 26,589$ \\
\hline
\end{tabular}

Positive number is an expenditure.

Negative number is a savings.

Table 6-7 NOx Reduction Cost Effectiveness vs. Load Profile and Operating Mode

\begin{tabular}{rrrrc}
\hline & \multicolumn{4}{c}{ Operating Mode } \\
Load Profile Baseline & Min NOx & Max Eff & Min LOI \\
\hline Phase 1 & -- & $-\$ 261$ & $-\$ 684$ & n/a \\
Base Load & -- & $-\$ 277$ & $-\$ 627$ & n/a \\
Peaking Load & -- & $\$ 43$ & n/a & n/a \\
Cycling Load & -- & $-\$ 293$ & $-\$ 975$ & n/a \\
Flat Load & -- & $-\$ 177$ & $-\$ 2,403$ & n/a
\end{tabular}

$\mathrm{n} / \mathrm{a}$ - There was a net NOx emission increase for these load/mode combinations. 


\section{SUMMARY AND CONCLUSIONS}

The primary objective of the demonstration at Hammond Unit 4 was to determine the long-term effects of commercially available wall-fired low NOx combustion technologies on NOx emissions and boiler performance. Short-term tests of each technology were also performed to provide engineering information about emissions and performance trends. A target of achieving fifty percent NOx reduction using combustion modifications was established for the project.

Specifically, the original objectives of the project were:

- Demonstrate in a logical stepwise fashion the short-term NOx reduction capabilities of the following advanced low NOx combustion technologies:

$\diamond \quad$ FWEC's Advanced Overfire Air (AOFA)

$\diamond \quad$ FWEC's Controlled Flow / Split Flame Low NOx burners (LNB)

$\diamond \quad$ LNB with AOFA

- Determine the dynamic, long-term emissions characteristics of each of these combustion NOx reduction methods using statistical techniques.

- Evaluate the progressive cost effectiveness (i.e., dollars per ton NOx removed) of the low NOx combustion techniques tested.

- Determine the effects on other combustion parameters (e.g., CO production, carbon carryover, particulate characteristics) of applying the NOx reduction methods listed above.

Based on observations during the first three phases of the project, Phase 4 of the project was conceived and added to the scope of the project -- the installation and demonstration of a digital control system and advanced on-line optimization system. For the optimization effort, the principal effort was placed on the application of GNOCIS (Generic NOx Control Intelligent System).

GNOCIS is an enhancement to digital control systems (DCS) targeted at improving utility boiler efficiency and reducing emissions. GNOCIS is designed to operate on units burning gas, oil, or coal and is available for all combustion firing geometries. GNOCIS utilizes a neural-network model of the combustion characteristics of the boiler that reflects both short-term and longerterm trends in boiler characteristics. A constrained-nonlinear optimizing procedure is applied to identify the best set points for the plant. These recommended set points can be implemented automatically without operator intervention (closed-loop), or, at the plant's discretion, conveyed to the plant operators for implementation (open-loop). The software is designed for continuous on-line use. GNOCIS development was funded by a consortium consisting of the Electric Power Research Institute, PowerGen, Southern Company, Radian International, U.K. Department of Trade and Industry, and U.S. Department of Energy. 
Based on competitive bidding, a Foxboro I/A DCS was selected for installation at Hammond replacing the pneumatic control system. The DCS was installed at Hammond during a ninemonth outage starting in September 1993 and continuing to June 1994. Since there had been major modifications to the unit during the outage (precipitator replacement, mill replacements, turbine upgrades), testing was conducted on the unit following this outage to reevaluate the performance of the unit in particular to regards to NOx emissions. This test was conducted over an extended period lasting from third quarter 1994 and continuing to first quarter 1996. The major findings were:

- NOx emissions did not change significantly from that observed during Phase 3B.

- LOI levels were similar to that observed during Phase 3B despite the installation of two new mills and a resultant improvement in coal fineness.

- Excess oxygen levels decreased slightly from that observed during Phase 3B.

- Air heater gas outlet temperatures were slightly improved over that observed during Phase 3B.

- There was a degradation in steam temperatures (main and reheat) when compared to Phase 3B.

- Dispatch speed of the unit improved dramatically following the installation of the DCS.

- Boiler/unit stability was much improved over that which had been observed during Phases 1-3B.

- The ability to gather data from the DCS greatly facilitated testing and data analysis.

Although the DCS provided many benefits, overall, it appears that the DCS did not improve the heat rate of the unit.

The second part of Phase 4 of the project was the installation and demonstration of GNOCIS. Prior to this, other work related to the optimization scope of work consisted of the demonstration of Ultramax (at the time, an off-line optimization tool) and modeling studies. Both of these efforts provided additional evidence that optimization was a viable tool for NOx emission abatement and heat rate improvement.

GNOCIS was under development at Alabama Power's Gaston Unit 4 and PowerGen's Kingsnorth Unit 1 from 1994 through 1996 (PowerGen, 1997). Results from these sites further indicated that specifically GNOCIS could provide useful recommendations for unit performance improvement.

Following the work at these two sites, GNOCIS was installed and became fully operational at Hammond during first quarter 1996. At Hammond, GNOCIS was designed to operate in either open-loop (advisory) or closed-loop (supervisory) modes, although more emphasis was placed on the latter. During first quarter and second quarter 1996, short-term testing on the unit was conducted. The results from this testing were similar to that observed at the other GNOCIS sites 
with NOx reductions of around 10 to $15 \%$ and efficiency improvements of about $0.5 \%$. Additional GNOCIS testing at this site was hoped for including additional short-term and longterm testing. However, due in part to the relative unavailability of the unit for testing, this testing never materialized. Although testing was not as extensive as first hoped, numerous GNOCIS tests have been conducted at Hammond and other sites and it is felt that the results obtained at Hammond are representative of the true performance of the technology. With this in consideration and using the available short-term results, model studies further predict that GNOCIS could, at least for this unit, simultaneously reduce NOx emissions and improve unit heat rate.

The major conclusions from this part of the project are:

- GNOCIS has been successfully deployed at Hammond 4.

- GNOCIS provides advice that, if implemented, improves boiler performance, including NOx emissions and efficiency. NOx emissions reductions of around $10 \%$ with improvement in heat rate can be obtained.

- GNOCIS is flexible in that the goals can be modified by plant staff with immediate results. As a result of this flexibility, a utility can dynamically assign goals to a unit in designing a NOx emissions plan (i.e. minimize NOx emissions during the summer months).

- GNOCIS does not adversely impact unit dynamics in either open- or closed-loop mode. The unit can be dispatched at full speed with GNOCIS in closed-loop mode. Also, recommendations do not appear to "wander" at steady-state operation.

- GNOCIS is very cost effective as a NOx reduction strategy.

- The on-line carbon-in-ash monitors used as part of the test program have been both beneficial and detrimental. When working properly, the instruments provide important process information that is not available otherwise. However, the monitors, in general, require maintenance greatly above that of normal instrumentation and reliabilities have been much less than desired. This unreliability impacted the test program at times.

Based on GNOCIS testing at this site and others, at plant management's request, GNOCIS is being incorporated into the unit's standard operating procedures. Also, consideration is being given to applying GNOCIS to other plant processes. 
SUMMARY AND CONCLUSIONS

$7-4$ 


\section{BIBLIOGRAPHY}

Anderson 1989. Anderson, Ken. "Estimation of Losses Due to Oscillating Control Systems in a Fossil Fueled Power Plant.” EPRI 1989 Power Plant Controls and Automation Conference.

ASME 1976. ASME Power Test Codes - Steam Turbines PTC 6. American Society of Mechanical Engineers, NewYork, 1976.

ASME 1985. ASME Power Test Codes - Test Code for Steam Generating Units PTC 4.1, American Society of Mechanical Engineers, NewYork, 1985.

B\&W 1992. STEAM its generation and use. Babcock \& Wilcox, Barberton, Ohio, 1992.

CE 1991. Combustion Fossil Power. Combustion Engineering, Inc., Windsor, Connecticut, 1991.

Beale 1990. Beale, R. and Jackson, T. Neural Computing: an Introduction. John Wiley \& Sons, 1990.

Box 1969. Box, George E. P. and Draper, Norman R. Evolutionary Operation, John Wiley \& Sons, New York, 1969.

EPRI 1982. Transient Efficiencies in Electric Power Plants. Report EL-2439. Electric Power Research Institute, Palo Alto, CA, 1982.

EPRI 1987. Acoustic Emission Monitoring of Cracks in Fossil Fueled Boilers. Report CS-5264, Electric Power Research Institute, Palo Alto, CA, 1987.

EPRI 1992. Control System Retrofit Guidelines. TR-100343. Electric Power Research Institute, Palo Alto, CA, 1992.

EPRI. 1993. Retrofit NOx Controls for Coal-Fired Utility Boilers. Electric Power Research Institute, Palo Alto, CA, 1993.

Hill 1987. Hill, R. W. Boilers and Boiler Controls. Seminar notes. AMTECH Services, Lewiston, New York, 1987.

Mathworks 1995. MATLAB System Identification Toolbox. The Mathworks Inc., Natick, Massachusetts, 1995.

Mathworks 1997. MATLAB Neural Network Toolbox. The Mathworks Inc., Natick Massachusetts, 1997.

Moreno 1989. Moreno, Carlos Wm. "Continuous Process Improvements Through Sequential Optimization", P-Q Systems Annual Meeting, Dayton, OH, June 21-22, 1989.

NeuralWare 1993. Neural Computing A Technology Handbook for Professional II/Plus and NeuralWorks Explorer. NeuralWare, Pittsburgh, PA, 1993. 
Petrill 1993. Petrill, E., Squires, R., Williams, S., Levy, E. "On-Line Performance and Emissions Optimization at Potomax River Unit 4.", Joint ISA POWID/EPRI Controls and Instrumentation Conference, June 7-9, 1993, Phoenix, Arizona.

PowerGen 1997. Generic NOx Control Intelligent System (GNOCIS) - Final Report. PowerGen, plc, Nottingham, UK, and Southern Company Services, Inc., Birmingham, AL, 1997.

Radian 1993. Radian Corporation. 500 MW Demonstration Of Advanced Wall-Fired Combustion Techniques For The Reduction Of Nitrogen Oxide $\left(N O_{x}\right)$ Emissions From Coal-Fired Boilers Field Chemical Emissions Monitoring: Overfire Air and Overfire Air/Low $\mathrm{NO}_{\mathrm{x}}$ Burner Operation Final Report. Southern Company Services, Inc., Birmingham, AL, 1993.

Ragsdell 1983. Ragsdell, K. M. et al. Engineering Optimization, Methods and Applications. John Wiley \& Sons, New York, 1983.

Riccardella 1987. Riccardella, P.C. and Kuo, A. Y. "Application of On-line Monitoring in Nuclear Power Plants.” Fourth Annual International Symposium on Pressure Vessel Technology and Nuclear Codes and Standards, 1989.

Tavoulareas 1993. Tavoulareas, S. 180 MW Demonstration of Advanced Tangentially-Fired Combustion Techniques for the Reduction of Nitrogen Oxide (NOx) Emissions from Coal Fired Boilers - Final Report and Key Project Findings. Southern Company Services, Inc., Birmingham, AL, 1993.

SCS 1993. 250-MW Demonstration of the Babcock \& Wilcox Low-NOx DRB-XCL Burners. Report TR-103346. Electric Power Research Institute, Palo Alto, CA, 1993.

SCS 1997. On-Line Carbon-in-Ash Monitors - Survey and Demonstration. Southern Company Services, Inc., Birmingham, AL, 1997.

SCS 1998. 500 MW Demonstration of Advanced Wall-Fired Combustion Techniques for the Reduction of Nitrogen Oxide $\left(\mathrm{NO}_{x}\right)$ Emissions from Coal-Fired Boilers - Final Report Phases 1-3B. Southern Company Services, Inc., Birmingham, AL, 1998.

Sorge 1993. Sorge, J. N. and Hardman, R. R. "The Effects of Low NOx Combustion on Unburned Carbon Levels in Wall-Fired Boilers, ” EPA/EPRI 1993 Joint Symposium on Stationary Combustion NOx Control, May 24-27, 1993, Miami, Florida.

Tsoukalas 1996. Tsoukalas, L. H. and Uhrig, R. E. Fuzzy and Neural Approches in Engineering. John Wiley \& Sons, 1997.

Wald 1947. Wald, A. Sequential Analysis. John Wiley \& Sons, New York, 1947.

Weinstein 1988. Weinstein, D., Vasatis, I. P. "On-Line Pipe Crack Growth Monitoring." Proceedings of the Third EPRI Incipient-Failure Detection Conference, August 1988. 
APPENDIX A
DCS CHARACTERIZATION 
DCS CHARACTERIZATION 
DCS CHARACTERIZATION

Table A-1 Diagnostic Test Summary

\begin{tabular}{|c|c|c|c|c|c|c|c|c|}
\hline $\begin{array}{c}\text { TEST } \\
\text { NO. }\end{array}$ & DATE & TEST CONDITIONS & $\begin{array}{l}\text { LOAD } \\
\text { MW }\end{array}$ & $\begin{array}{l}\text { MOOS } \\
\text { PATRN }\end{array}$ & $\begin{array}{l}\text { OFA } \\
\text { FLOW } \\
\text { KPPH }\end{array}$ & $\begin{array}{c}\text { Econ. O2 } \\
\text { DRY } \\
(\%)\end{array}$ & $\begin{array}{c}\text { Econ. CO } \\
\text { DRY } \\
(\%)\end{array}$ & $\begin{array}{c}\text { NOx } \\
\text { lb/MBtu }\end{array}$ \\
\hline $129-1$ & 08/05/94 & HI-LOAD NORMAL O2 & 486 & AMIS & NA & 3.0 & 38 & 0.454 \\
\hline $129-2$ & 08/05/94 & HI-LOAD LOW O2 & 483 & AMIS & NA & 2.7 & 177 & 0.399 \\
\hline $129-3$ & 08/05/94 & HI-LOAD HIGH O2 & 483 & AMIS & NA & 3.9 & 7 & 0.533 \\
\hline $130-1$ & 08/06/94 & MID-LOAD LOW O2 & 398 & B & & 2.8 & 128 & 0.368 \\
\hline $130-2$ & 08/06/94 & MID-LOAD NORM O2 & 400 & B & 297 & 3.6 & 7 & 0.442 \\
\hline $130-3$ & 08/06/94 & MID-LOAD HIGH O2 & 398 & B & 318 & 4.7 & 7 & 0.513 \\
\hline $130-4$ & $08 / 06 / 94$ & MID-LOAD NORM O2, DECR OFA & 399 & B & 211 & 4.0 & 6 & 0.457 \\
\hline $130-5$ & $08 / 06 / 94$ & MID-LOAD NORM O2 & 399 & $\mathrm{E}$ & 294 & 3.7 & 6 & 0.451 \\
\hline $131-1$ & 08/07/94 & MD/LO LOAD LOW O2 & 300 & $B, E$ & 119 & 4.4 & 20 & 0.363 \\
\hline $131-2$ & 08/07/94 & MD/LO LOAD NORM O2 & 300 & $B, E$ & 134 & 4.8 & 13 & 0.386 \\
\hline $131-3$ & 08/07/94 & MD/LO LOAD HIGH O2 & 302 & $B, E$ & 143 & 5.5 & 10 & 0.421 \\
\hline $131-4$ & $08 / 07 / 94$ & MD/LO LOAD HIGHER O2 & 301 & $B, E$ & 133 & 6.4 & 8 & 0.462 \\
\hline $132-1$ & 08/08/94 & HI-LOAD LOW O2 & 482 & AMIS & 650 & 2.9 & 118 & 0.440 \\
\hline $132-2$ & 08/08/94 & HI-LOAD NORM O2 & 484 & AMIS & 658 & 3.5 & 16 & 0.498 \\
\hline $132-3$ & 08/08/94 & HI-LOAD HIGH O2 & 479 & AMIS & 666 & 4.1 & 15 & 0.556 \\
\hline $132-4$ & 08/08/94 & HI-LOAD FUEL BIASED TO UPPER MILLS & 476 & AMIS & 613 & 4.1 & 16 & 0.573 \\
\hline $132-5$ & 08/08/94 & HI-LOAD FUEL BIASED TO UPPER MILLS & 479 & AMIS & 596 & 3.4 & 18 & 0.500 \\
\hline $133-1$ & $11 / 02 / 94$ & MID-LOAD NORMAL O2 & 401 & B & 278 & 4.0 & 11 & 0.414 \\
\hline $133-2$ & $11 / 02 / 94$ & MID-LOAD HIGH O2 & 401 & B & 276 & 4.8 & 7 & 0.470 \\
\hline $133-3$ & $11 / 02 / 94$ & MID-LOAD NORMAL O2 & 400 & B & 284 & 3.6 & 21 & 0.390 \\
\hline $133-4$ & $11 / 02 / 94$ & MID-LOAD LOW O2 & 401 & B & 278 & 2.8 & 91 & 0.353 \\
\hline $133-5$ & $11 / 02 / 94$ & MID-LOAD LOW O2 & 400 & $\mathrm{E}$ & 289 & 3.2 & 168 & 0.346 \\
\hline $133-6$ & $11 / 02 / 94$ & MID-LOAD NORMAL O2 & 401 & $\mathrm{E}$ & 306 & 4.2 & 4 & 0.382 \\
\hline $134-1$ & $11 / 03 / 94$ & MID-LOAD NORMAL O2 BAL MILLS & 400 & B & 285 & 3.6 & 18 & 0.404 \\
\hline $134-2$ & $11 / 03 / 94$ & MID-LOAD FUEL BIASED TO LOWER MILLS & 400 & B & 287 & 3.5 & 30 & 0.398 \\
\hline $134-3$ & $11 / 03 / 94$ & MID-LOAD FUEL BIASED TO UPPER MILLS & 400 & B & 276 & 3.7 & 15 & 0.389 \\
\hline $134-4$ & $11 / 03 / 94$ & MID-LOAD NORMAL O2 BAL MILLS & 400 & B & 276 & 3.5 & 24 & 0.382 \\
\hline $135-1$ & $11 / 09 / 94$ & HIGH LOAD, AMIS, NOMINAL O2 & 481 & AMIS & 606 & 3.4 & 28 & 0.390 \\
\hline $135-2$ & $11 / 09 / 94$ & HIGH LOAD, AMIS, LOW O2 & 482 & AMIS & 653 & 2.9 & 315 & 0.352 \\
\hline $135-3$ & $11 / 09 / 94$ & HIGH LOAD, AMIS, HIGH O2 & 479 & AMIS & 675 & 3.9 & 14 & 0.426 \\
\hline $136-1$ & $11 / 10 / 94$ & HIGH LOAD, NOM O2, BALANCED MILLS & 478 & AMIS & 582 & 4.0 & 14 & 0.449 \\
\hline $136-2$ & $11 / 10 / 94$ & HIGH LOAD, NOM O2, COAL BIASED HIGH & 478 & AMIS & 595 & 4.1 & 17 & 0.448 \\
\hline $136-3$ & $11 / 10 / 94$ & HIGH LOAD, NOM O2, COAL BIASED LOW & 479 & AMIS & 597 & 4.0 & 13 & 0.448 \\
\hline $136-4$ & $11 / 10 / 94$ & HIGH LOAD, NOM O2, BALANCED MILLS & 480 & AMIS & 606 & 4.1 & 15 & 0.449 \\
\hline $137-1$ & $11 / 11 / 94$ & HIGH LOAD, NOM O2, BAL MILLS, NOM OFA & 478 & AMIS & 636 & 3.9 & 18 & 0.432 \\
\hline $137-2$ & $11 / 11 / 94$ & HIGH LOAD, NOM O2, BAL MILLS, HIGH OFA & 481 & AMIS & 872 & 4.1 & 56 & 0.413 \\
\hline $137-3$ & $11 / 11 / 94$ & HIGH LOAD, NOM O2, BAL MILLS, MID OFA & 480 & AMIS & 515 & 3.8 & 15 & 0.438 \\
\hline $137-4$ & $11 / 11 / 94$ & HIGH LOAD, NOM O2, BAL MILLS, LOW OFA & 480 & AMIS & 268 & 4.1 & 8 & 0.506 \\
\hline $143-1$ & $11 / 17 / 94$ & MAX LOAD, HIGH O2, BAL MILLS, NOM OFA & 519 & AMIS & 780 & 4.0 & 12 & 0.503 \\
\hline $143-2$ & $11 / 17 / 94$ & MAX LOAD, NOM O2, BAL MILLS, NOM OFA & 520 & AMIS & 774 & 3.3 & 31 & 0.445 \\
\hline $143-3$ & $11 / 17 / 94$ & MAX LOAD, LOW O2, BAL MILLS, NOM OFA & 521 & AMIS & 747 & 3.0 & 169 & 0.408 \\
\hline $143-4$ & $11 / 17 / 94$ & HIGH LOAD, NOM O2, BAL MILLS, HIGH OFA & 480 & AMIS & 823 & 3.8 & 46 & 0.412 \\
\hline $143-5$ & $11 / 17 / 94$ & HIGH LOAD, NOM O2, BAL MILLS, MID OFA & 479 & AMIS & 490 & 3.7 & 12 & 0.453 \\
\hline $143-6$ & $11 / 17 / 94$ & HIGH LOAD, NOM O2, BAL MILLS, MIN OFA & 479 & AMIS & 280 & 3.7 & 13 & 0.489 \\
\hline $144-1$ & $11 / 18 / 94$ & LOW LOAD, HIGH O2, BAL MILLS, NOM OFA & 300 & $\mathrm{~B}, \mathrm{E}$ & 117 & 6.7 & 9 & 0.451 \\
\hline $144-2$ & $11 / 18 / 94$ & LOW LOAD, NOM O2, BAL MILLS, NOM OFA & 301 & $B, E$ & 126 & 6.0 & 27 & 0.407 \\
\hline $144-3$ & $11 / 18 / 94$ & LOW LOAD, LOW 2, BAL MILLS, NOM OFA & 301 & $B, E$ & 100 & 5.0 & 200 & 0.352 \\
\hline $144-4$ & $11 / 18 / 94$ & MID LOAD, HIGH O2, BAL MILLS, NOM OFA & 399 & $\mathrm{E}$ & 306 & 4.7 & 17 & 0.445 \\
\hline $144-5$ & $11 / 18 / 94$ & MID LOAD, LOW O2, BAL MILLS, NOM OFA & 400 & $\mathrm{E}$ & 266 & 3.5 & 110 & 0.372 \\
\hline $144-6$ & $11 / 18 / 94$ & MID LOAD, NOM O2, BAL MILLS, NOM OFA & 399 & $E$ & 307 & 3.9 & 40 & 0.400 \\
\hline $144-7$ & $11 / 18 / 94$ & MID LOAD, NOM O2, BAL MILLS, HIGH OFA & 399 & $\mathrm{E}$ & 492 & 4.0 & 31 & 0.371 \\
\hline
\end{tabular}


Table A-2 Performance Tests Summary

\begin{tabular}{cccccccccc}
\hline Test & Date & $\begin{array}{c}\text { Load } \\
\text { MW }\end{array}$ & $\begin{array}{c}\text { MOOS } \\
\text { Pattern }\end{array}$ & $\begin{array}{c}\text { OFA } \\
\text { Flow } \\
\text { (KPPH) }\end{array}$ & $\begin{array}{c}{\text { DAS })_{2}}_{\text {Dry }}^{\%} \\
\%\end{array}$ & $\begin{array}{c}\text { NOx } \\
\text { lb/MBtu }\end{array}$ & $\begin{array}{c}\text { CO } \\
\text { ppm }\end{array}$ & $\begin{array}{c}\text { Fly Ash } \\
\text { LOI } \\
\%\end{array}$ & $\begin{array}{c}\text { Fly Ash } \\
\text { Carbon } \\
\%\end{array}$ \\
\hline 138 & $11 / 12 / 94$ & 400 & B & 293 & 3.9 & 0.38 & 49 & 8.4 & 7.7 \\
139 & $11 / 13 / 94$ & 300 & B,E & 90 & 4.8 & 0.34 & 51 & 8.1 & 7.1 \\
140 & $11 / 13 / 94$ & 180 & B,D,E & 0 & 5.3 & 0.33 & 9 & 3.6 & 3.3 \\
141 & $11 / 15 / 94$ & 520 & None & 791 & 3.6 & 0.43 & 61 & 8.2 & 7.2 \\
142 & $11 / 16 / 94$ & 520 & None & 786 & 3.5 & 0.45 & 46 & 8.1 & 6.9 \\
\hline
\end{tabular}


Table A-3 Performance Tests / Combustion Air Flow Distribution

\begin{tabular}{|ll|c|c|c|c|c|}
\hline Test Number $\rightarrow$ & & 138 & 139 & 140 & 141 & 142 \\
Unit Load (MW) $\rightarrow$ & & 400 & 300 & 180 & 520 & 520 \\
\hline Pulverizer Primary Air & Total Flow & 734,888 & 556,118 & 383,764 & 902,090 & 899,812 \\
& $\%$ of TUA & $21.60 \%$ & $19.62 \%$ & $19.88 \%$ & $19.61 \%$ & $19.98 \%$ \\
\hline Pulverizer Seal Air & Total Flow & 72,734 & $\mathrm{Na}$ & $\mathrm{Na}$ & 47,990 & 49,208 \\
(Difference between dirty and P.A. airflow) & \% of TUA & $2.14 \%$ & $\mathrm{Na}$ & $\mathrm{Na}$ & $1.04 \%$ & $1.09 \%$ \\
Secondary Air @ Venturi(s) & Total Flow & $2,595,371$ & $2,073,794$ & $1,169,547$ & $3,648,928$ & $3,553,601$ \\
(Combined secondary air to burners \& OFA) $^{*}$ & \% of TUA & $76.27 \%$ & $73.17 \%$ & $60.58 \%$ & $79.34 \%$ & $78.92 \%$ \\
Overfire Air* & Total Flow & 220,179 & 139,312 & $\mathrm{Na}$ & 569,025 & 561,753 \\
& \% of TUA & $6.47 \%$ & $4.92 \%$ & $\mathrm{Na}$ & $12.37 \%$ & $12.48 \%$ \\
Secondary Air to Burners & Total Flow & $2,375,192$ & $1,934,482$ & $\mathrm{Na}$ & $3,079,903$ & $2,991,848$ \\
(by inference) & \% of TUA & $69.80 \%$ & $68.25 \%$ & $\mathrm{Na}$ & $66.97 \%$ & $66.45 \%$ \\
Air to Off-line Mills & Total Flow & $\mathrm{Na}$ & 204,432 & 377,199 & 0 & 0 \\
& \% of TUA & $\mathrm{Na}$ & $7.21 \%$ & $19.54 \%$ & $0.00 \%$ & $0.00 \%$ \\
Total Unit Air (TUA) & Total Flow & $3,402,993$ & $2,834,344$ & $1,930,510$ & $4,599,008$ & $4,502,621$ \\
\hline
\end{tabular}

Note: * Air flow value represents average of individual runs 
Table A-4 Performance Tests / Overfire Air Flow

\begin{tabular}{|c|c|c|c|c|c|c|c|c|c|c|c|c|c|c|c|}
\hline \multirow[b]{2}{*}{ Test } & \multicolumn{3}{|c|}{ Left Front } & \multicolumn{3}{|c|}{ Left Rear } & \multicolumn{3}{|c|}{ Right Front } & \multicolumn{3}{|c|}{ Right Rear } & \multicolumn{3}{|c|}{ Total } \\
\hline & Mea. & Ind. & Err. & Mea. & Ind. & Err. & Mea. & Ind. & Err. & Mea. & Ind. & Err. & Mea. & Ind. & Err. \\
\hline $136-4$ & 143.3 & & & 127.4 & & & 125.5 & & & 119.1 & $\mathrm{Na}$ & & 515.4 & & \\
\hline $137-1$ & 138.6 & 164.6 & $-19 \%$ & 126.9 & 159.3 & $-25 \%$ & 142.3 & 161.6 & $-14 \%$ & 129.3 & 153.4 & $-19 \%$ & 537.1 & 639.0 & $-19 \%$ \\
\hline $137-2$ & 160.5 & 165.6 & $-3 \%$ & 142.4 & 136.0 & $5 \%$ & 156.5 & 165.2 & $-6 \%$ & 157.4 & 150.7 & $4 \%$ & 616.9 & 617.4 & $0 \%$ \\
\hline $137-3$ & 90.6 & 125.6 & $-39 \%$ & 100.7 & 122.2 & $-21 \%$ & 110.1 & 134.0 & $-22 \%$ & 113.6 & 138.2 & $-22 \%$ & 415.1 & 519.9 & $-25 \%$ \\
\hline $137-4$ & 62.9 & 70.2 & $-12 \%$ & 65.5 & 76.6 & $-17 \%$ & 62.2 & 69.4 & $-11 \%$ & 55.2 & 77.6 & $-40 \%$ & 245.9 & 293.8 & $-19 \%$ \\
\hline $138-1$ & 64.7 & 76.8 & $-19 \%$ & 58.7 & 78.6 & $-34 \%$ & 52.4 & 73.7 & $-40 \%$ & 46.5 & 68.2 & $-47 \%$ & 222.3 & 297.2 & $-34 \%$ \\
\hline $138-2$ & 64.9 & 76.8 & $-18 \%$ & 59.5 & 78.6 & $-32 \%$ & 51.1 & 73.7 & $-44 \%$ & 43.5 & 68.2 & $-57 \%$ & 219.0 & 297.2 & $-36 \%$ \\
\hline $138-3$ & 65.2 & 76.8 & $-18 \%$ & 58.0 & 78.6 & $-36 \%$ & 51.4 & 73.7 & $-43 \%$ & 44.7 & 68.2 & $-53 \%$ & 219.2 & 297.2 & $-36 \%$ \\
\hline $139-2$ & 51.0 & 20.3 & $60 \%$ & 55.9 & 9.8 & $83 \%$ & 25.0 & 53.9 & $-116 \%$ & 16.2 & -0.3 & $102 \%$ & 148.1 & 83.7 & $43 \%$ \\
\hline $139-3$ & 28.0 & 20.3 & $27 \%$ & 23.3 & 9.8 & $58 \%$ & 41.3 & 53.9 & $-31 \%$ & 38.0 & -0.3 & $101 \%$ & 130.5 & 83.7 & $36 \%$ \\
\hline $141-1$ & 151.9 & 199.0 & $-31 \%$ & 142.6 & 230.0 & $-61 \%$ & 132.3 & 176.9 & $-34 \%$ & 135.8 & 181.8 & $-34 \%$ & 562.7 & 787.6 & $-40 \%$ \\
\hline $141-2$ & 157.7 & 202.0 & $-28 \%$ & 140.3 & 231.2 & $-65 \%$ & 151.4 & 186.4 & $-23 \%$ & 126.0 & 182.7 & $-45 \%$ & 575.4 & 802.3 & $-39 \%$ \\
\hline $142-1$ & 156.3 & 203.6 & $-30 \%$ & 141.6 & 209.4 & $-48 \%$ & 131.4 & 175.7 & $-34 \%$ & 129.3 & 187.2 & $-45 \%$ & 558.5 & 775.9 & $-39 \%$ \\
\hline $142-2$ & 155.5 & 203.6 & $-31 \%$ & 139.7 & 209.4 & $-50 \%$ & 136.4 & 175.7 & $-29 \%$ & 133.5 & 187.2 & $-40 \%$ & 565.0 & 775.9 & $-37 \%$ \\
\hline
\end{tabular}


Table A-5 Performance Tests / Summary of Mill Performance

\begin{tabular}{|c|c|c|c|c|c|c|c|c|c|}
\hline Test & $\begin{array}{l}\text { Load } \\
\text { MW }\end{array}$ & Parameter & Total & Mill A & Mill B & Mill C & Mill D & Mill E & Mill F \\
\hline \multirow[t]{10}{*}{$141-1$} & 520 & Indicated Fuel Flow, klb/hr & 392.4 & 65.0 & 65.3 & 66.2 & 65.2 & 64.6 & 66.1 \\
\hline & & Pulverizer Air Flow, klb/hr & 902.1 & 145.1 & 150.4 & 145.5 & 149.6 & 168.1 & 143.4 \\
\hline & & Measured Fuel Flow, klb/hr & 446.7 & 76.3 & 69.5 & 79.0 & 72.2 & 79.0 & 70.8 \\
\hline & & Dirty Air Flow, klb/hr & 950.1 & 153.5 & 160.5 & 157.3 & 152.8 & 171.1 & 154.8 \\
\hline & & A/F Ratio & 2.13 & 2.01 & 2.31 & 1.99 & 2.12 & 2.17 & 2.19 \\
\hline & & Passing 200 Mesh & 75.05 & 74.48 & 77.38 & 73.3 & 76.76 & 73.48 & 74.87 \\
\hline & & Remaining 50 Mesh & 0.08 & 0.1 & 0.04 & 0.11 & 0.03 & 0.05 & 0.12 \\
\hline & & Velocity, fpm & 6,321 & 6,109 & 6,370 & 6,312 & 6,117 & 6,843 & 6,173 \\
\hline & & High Pipe Flow, klb/hr & 22.8 & 22.8 & 19.0 & 21.8 & 19.6 & 20.2 & 19.7 \\
\hline & & Low Pipe Flow, klb/hr & 14.9 & 16.4 & 16.1 & 17.2 & 16.5 & 19.3 & 14.9 \\
\hline \multirow[t]{10}{*}{$142-1$} & 520 & Indicated Fuel Flow, klb/hr & 389.5 & 63.2 & 67.6 & 67.3 & 63.5 & 63.6 & 64.2 \\
\hline & & Pulverizer Air Flow, klb/hr & 899.8 & 138.5 & 151.3 & 150.8 & 157.2 & 164.6 & 137.4 \\
\hline & & Measured Fuel Flow, klb/hr & 444.2 & 78.9 & 69.8 & 73.4 & 73.9 & 77.5 & 70.7 \\
\hline & & Dirty Air Flow, klb/hr & 949.0 & 146.9 & 157.4 & 158.2 & 165.6 & 170.8 & 150.0 \\
\hline & & A/F Ratio & 2.14 & 1.86 & 2.25 & 2.16 & 2.24 & 2.2 & 2.12 \\
\hline & & Passing 200 Mesh & 76.49 & 73.69 & 80.03 & 76.49 & 76.73 & 75.41 & 76.58 \\
\hline & & Remaining 50 Mesh & 0.07 & 0.1 & 0.09 & 0.07 & 0.02 & 0.05 & 0.11 \\
\hline & & Velocity, fpm & 6,352 & 5,906 & 6,290 & 6,370 & 6,666 & 6,872 & 6,007 \\
\hline & & High Pipe Flow, klb/hr & 23.2 & 23.2 & 18.9 & 18.9 & 20.4 & 20.5 & 19.5 \\
\hline & & Low Pipe Flow, klb/hr & 15.6 & 15.6 & 16.1 & 17.7 & 17.6 & 18.1 & 16.6 \\
\hline
\end{tabular}


Table A-6 Performance Tests / CP Air Velocities and Fuel Flows

\begin{tabular}{|c|c|c|c|c|c|c|c|c|}
\hline \multirow[b]{2}{*}{ Burner Line } & \multicolumn{4}{|c|}{ Test 141} & \multicolumn{4}{|c|}{ Test 142} \\
\hline & $\begin{array}{l}\text { Dirty Air } \\
\text { Velocity }\end{array}$ & $\begin{array}{l}\text { \%Deviation } \\
\text { from Mean }\end{array}$ & Fuel Flow & $\begin{array}{l}\text { \%Deviation } \\
\text { from Mean }\end{array}$ & $\begin{array}{l}\text { Dirty Air } \\
\text { Velocity }\end{array}$ & $\begin{array}{l}\text { \%Deviation } \\
\text { from Mean }\end{array}$ & Fuel Flow & $\begin{array}{l}\text { \%Deviation } \\
\text { from Mean }\end{array}$ \\
\hline $4 A-A$ & 6,005 & $-1.70 \%$ & 16,415 & $-13.90 \%$ & 5,689 & $-3.68 \%$ & 20,821 & $+5.62 \%$ \\
\hline $4 A-B$ & 6,172 & $+1.03 \%$ & 20,070 & $+5.27 \%$ & 5,883 & $-0.39 \%$ & 23,244 & $+17.91 \%$ \\
\hline $4 A-C$ & 6,016 & $-1.52 \%$ & 22,753 & $+19.34 \%$ & 5,925 & $+0.32 \%$ & 19,165 & $-2.78 \%$ \\
\hline $4 A-D$ & 6,243 & $+2.19 \%$ & 17,026 & $-10.70 \%$ & 6,128 & $+3.75 \%$ & 15,623 & $-20.75 \%$ \\
\hline $4 \mathrm{~B}-\mathrm{A}$ & 6,129 & $-3.78 \%$ & 16,995 & $-2.18 \%$ & 6,108 & $-2.90 \%$ & 18,892 & $+8.25 \%$ \\
\hline $4 \mathrm{~B}-\mathrm{B}$ & 6,313 & $-0.89 \%$ & 16,052 & $-7.61 \%$ & 6,093 & $-3.14 \%$ & 16,824 & $-3.60 \%$ \\
\hline $4 B-C$ & 6,430 & $+0.95 \%$ & 18,991 & $+9.31 \%$ & 6,358 & $+1.07 \%$ & 16,073 & $-7.91 \%$ \\
\hline $4 B-D$ & 6,607 & $+3.72 \%$ & 17,458 & $+0.48 \%$ & 6,603 & $+4.97 \%$ & 18,023 & $+3.27 \%$ \\
\hline $4 C-A$ & 6,239 & $-1.16 \%$ & 21,243 & $+7.59 \%$ & 6,381 & $+0.17 \%$ & 18,000 & $-1.86 \%$ \\
\hline $4 C-B$ & 6,293 & $-0.30 \%$ & 18,690 & $-5.34 \%$ & 6,424 & $+0.85 \%$ & 17,731 & $-3.33 \%$ \\
\hline $4 C-C$ & 6,279 & $-0.52 \%$ & 21,815 & $+10.49 \%$ & 6,249 & $-1.90 \%$ & 18,751 & $+2.23 \%$ \\
\hline $4 C-D$ & 6,437 & $+1.98 \%$ & 17,228 & $-12.74 \%$ & 6,426 & $+0.88 \%$ & 18,884 & $+2.96 \%$ \\
\hline $4 D-A$ & 6,103 & $-0.23 \%$ & 19,431 & $+7.66 \%$ & 6,586 & $-1.20 \%$ & 17,831 & $-3.53 \%$ \\
\hline $4 D-B$ & 6,056 & $-1.00 \%$ & 16,658 & $-7.70 \%$ & 6,471 & $-2.92 \%$ & 17,629 & $-4.63 \%$ \\
\hline $4 D-C$ & 6,114 & $-0.05 \%$ & 16,533 & $-8.40 \%$ & 6,786 & $+1.80 \%$ & 18,028 & $-2.47 \%$ \\
\hline $4 D-D$ & 6,195 & $+1.28 \%$ & 19,571 & $+8.44 \%$ & 6,820 & $+2.31 \%$ & 20,448 & $+10.63 \%$ \\
\hline $4 \mathrm{E}-\mathrm{A}$ & 6,891 & $+0.70 \%$ & 19,875 & $+0.64 \%$ & 6,844 & $-0.41 \%$ & 18,138 & $-6.37 \%$ \\
\hline $4 \mathrm{E}-\mathrm{B}$ & 6,775 & $-1.00 \%$ & 20,215 & $+2.36 \%$ & 7,153 & $+4.09 \%$ & 20,527 & $+5.96 \%$ \\
\hline $4 \mathrm{E}-\mathrm{C}$ & 6,800 & $-0.63 \%$ & 19,331 & $-2.12 \%$ & 6,632 & $-3.49 \%$ & 19,183 & $-0.97 \%$ \\
\hline $4 \mathrm{E}-\mathrm{D}$ & 6,907 & $+0.93 \%$ & 19,576 & $-0.88 \%$ & 6,859 & $-0.19 \%$ & 19,638 & $+1.38 \%$ \\
\hline $4 \mathrm{~F}-\mathrm{A}$ & 6,542 & $+5.98 \%$ & 17,445 & $-1.43 \%$ & 6,394 & $+6.44 \%$ & 17,340 & $-1.92 \%$ \\
\hline $4 \mathrm{~F}-\mathrm{B}$ & 5,663 & $-8.26 \%$ & 18,764 & $+6.02 \%$ & 5,790 & $-3.62 \%$ & 17,343 & $-1.90 \%$ \\
\hline $4 \mathrm{~F}-\mathrm{C}$ & 6,340 & $+2.71 \%$ & 14,925 & $-15.67 \%$ & 6,053 & $+0.76 \%$ & 16,566 & $-6.30 \%$ \\
\hline $4 \mathrm{~F}-\mathrm{D}$ & 6,147 & $-0.42 \%$ & 19,661 & $+11.09 \%$ & 5,792 & $-3.58 \%$ & 19,469 & $+10.12 \%$ \\
\hline
\end{tabular}


Table A-7 Performance Tests / Coal Analysis

\begin{tabular}{rrrrrrrrrrrrr}
\hline & $\mathrm{H} 20$ & $\mathrm{C}$ & $\mathrm{H}$ & $\mathrm{N}$ & $\mathrm{Cl}$ & $\mathrm{S}$ & \multicolumn{1}{c}{ Ash } & $\mathrm{O}$ & & $\mathrm{HHV}$ & $\mathrm{VM}$ & $\mathrm{FC}$ \\
Date & \multicolumn{1}{c}{$\%$} & \multicolumn{1}{c}{$\%$} & \multicolumn{1}{c}{$\%$} & \multicolumn{1}{c}{$\%$} & \multicolumn{1}{c}{$\%$} & \multicolumn{1}{c}{$\%$} & \multicolumn{1}{c}{$\%$} & \multicolumn{1}{c}{$\%$} & TOTAL & BTU/lb & \multicolumn{1}{l}{$\%$} & \multicolumn{1}{c}{$\%$} \\
\hline $11 / 09 / 94$ & 6.07 & 71.33 & 4.6 & 1.32 & 0.03 & 1.32 & 10.59 & 4.78 & 100.04 & 12539 & 31.4 & 51.94 \\
$11 / 11 / 94$ & 6.06 & 70.95 & 4.64 & 1.3 & 0.03 & 1.37 & 10.73 & 4.95 & 100.03 & 12461 & 31.74 & 51.47 \\
$11 / 12 / 94$ & 6.78 & 70.35 & 4.57 & 1.29 & 0.03 & 1.35 & 10.52 & 5.15 & 100.04 & 12416 & 31.57 & 51.13 \\
$11 / 12 / 94$ & 6.74 & 71.07 & 4.63 & 1.31 & 0.03 & 1.34 & 10.12 & 4.79 & 100.03 & 12464 & 31.6 & 51.54 \\
$11 / 13 / 94$ & 5.74 & 72.53 & 4.7 & 1.33 & 0.03 & 1.38 & 9.87 & 4.45 & 100.03 & 12695 & 32.46 & 51.93 \\
$11 / 13 / 94$ & 5.79 & 72.5 & 4.72 & 1.34 & 0.03 & 1.34 & 9.53 & 4.78 & 100.03 & 12748 & 32.47 & 52.2 \\
$11 / 14 / 94$ & 4.7 & 72.27 & 4.73 & 1.35 & 0.03 & 1.26 & 10.72 & 4.97 & 100.03 & 12709 & 32.49 & 52.09 \\
$11 / 14 / 94$ & 4.91 & 73.33 & 4.73 & 1.36 & 0.02 & 1.26 & 9.77 & 4.64 & 100.02 & 12855 & 32.42 & 52.91 \\
$11 / 15 / 94$ & 6.16 & 71.2 & 4.65 & 1.31 & 0.03 & 1.36 & 9.95 & 5.38 & 100.04 & 12545 & 32 & 51.89 \\
$11 / 15 / 94$ & 6.84 & 71.11 & 4.6 & 1.32 & 0.03 & 1.39 & 9.95 & 4.79 & 100.03 & 12438 & 31.39 & 51.82 \\
$11 / 15 / 94$ & 6.62 & 70.94 & 4.61 & 1.31 & 0.04 & 1.37 & 10.03 & 5.12 & 100.04 & 12476 & 31.91 & 51.44 \\
$11 / 16 / 94$ & 6.4 & 71.63 & 4.62 & 1.32 & 0.03 & 1.39 & 10.07 & 4.57 & 100.03 & 12580 & 31.74 & 51.79 \\
$11 / 16 / 94$ & 5.91 & 72.24 & 4.69 & 1.34 & 0.06 & 1.35 & 10.1 & 4.38 & 100.07 & 12646 & 32.32 & 51.67 \\
$11 / 16 / 94$ & 5.86 & 71.86 & 4.68 & 1.32 & 0.03 & 1.36 & 9.97 & 4.96 & 100.04 & 12613 & 32.18 & 51.99 \\
$11 / 17 / 94$ & 4.66 & 73.34 & 4.74 & 1.40 & 0.03 & 1.25 & 10.56 & 4.05 & 100.03 & 12843 & 31.85 & 52.92 \\
Average & 5.95 & 71.78 & 4.66 & 1.33 & 0.03 & 1.34 & 10.17 & 4.78 & 100.04 & 12602 & 32.0 & 51.9 \\
Std. Dev. & 0.72 & 0.90 & 0.06 & 0.03 & 0.01 & 0.05 & 0.37 & 0.34 & 0.01 & 144 & 0.40 & 0.49 \\
Var. & 0.52 & 0.81 & 0.00 & 0.00 & 0.00 & 0.00 & 0.14 & 0.11 & 0.00 & 20683 & 0.16 & 0.24 \\
\hline & & & & & & & & & & & &
\end{tabular}


Table A-8 P4A / Long-Term / Emissions by Load

\begin{tabular}{|c|c|c|c|c|c|c|c|c|c|c|c|c|c|c|c|c|c|c|c|c|}
\hline \multirow[b]{2}{*}{ LoadCat } & \multirow[b]{2}{*}{ Count } & Pct & \multicolumn{3}{|c|}{ <---------Load---------> } & \multicolumn{3}{|c|}{ <----------O $\mathrm{O}_{2}--------->$} & \multicolumn{3}{|c|}{ <--------NOx--------> } & \multicolumn{3}{|c|}{ <---------CO---------->> } & \multicolumn{3}{|c|}{ <----------SOx--------> } & \multicolumn{3}{|c|}{ <---------THC--------> } \\
\hline & & Load & Mean & Per05 & Per95 & Mean & Per05 & Per95 & Mean & Per05 & Per95 & Mean & Per05 & Per95 & Mean & Per05 & Per95 & Mean & Per05 & Per95 \\
\hline $110-130$ & 32 & $0 \%$ & 125 & 121 & 129 & 9.12 & 8.12 & 11.57 & 0.327 & 0.288 & 0.384 & 11 & 0 & 17 & 1.582 & 1.257 & 1.875 & 1.4 & 0.0 & 4.0 \\
\hline $130-150$ & 35 & $0 \%$ & 140 & 131 & 150 & 8.50 & 6.67 & 10.66 & 0.329 & 0.258 & 0.404 & 12 & 0 & 19 & 1.607 & 1.202 & 1.951 & 0.7 & 0.0 & 3.7 \\
\hline $150-170$ & 348 & $2 \%$ & 151 & 150 & 156 & 7.20 & 6.81 & 8.40 & 0.369 & 0.305 & 0.394 & 14 & 6 & 15 & 1.587 & 1.439 & 1.753 & 0.2 & 0.0 & 1.0 \\
\hline $170-190$ & 57 & $0 \%$ & 180 & 172 & 188 & 7.87 & 6.49 & 9.90 & 0.305 & 0.251 & 0.368 & 8 & 0 & 16 & 1.773 & 1.418 & 2.123 & 0.6 & 0.0 & 3.2 \\
\hline $190-210$ & 5741 & $35 \%$ & 201 & 199 & 205 & 7.59 & 6.69 & 9.17 & 0.381 & 0.322 & 0.432 & 5 & 0 & 11 & 1.657 & 1.310 & 2.160 & 0.1 & 0.0 & 0.5 \\
\hline $210-230$ & 680 & $4 \%$ & 220 & 211 & 229 & 7.50 & 6.36 & 8.86 & 0.362 & 0.275 & 0.421 & 6 & 0 & 12 & 1.739 & 1.325 & 2.237 & 0.1 & 0.0 & 0.2 \\
\hline $230-250$ & 804 & $5 \%$ & 241 & 231 & 249 & 7.16 & 6.25 & 8.71 & 0.350 & 0.265 & 0.413 & 7 & 0 & 14 & 1.643 & 1.325 & 2.055 & 0.1 & 0.0 & 0.8 \\
\hline $250-270$ & 674 & $4 \%$ & 259 & 250 & 269 & 7.23 & 6.05 & 8.77 & 0.374 & 0.316 & 0.424 & 7 & 0 & 16 & 1.680 & 1.246 & 2.146 & 0.3 & 0.0 & 1.0 \\
\hline $270-290$ & 691 & $4 \%$ & 278 & 271 & 289 & 7.06 & 5.89 & 8.56 & 0.390 & 0.355 & 0.428 & 7 & 0 & 20 & 1.647 & 1.326 & 2.154 & 0.2 & 0.0 & 1.0 \\
\hline $290-310$ & 477 & $3 \%$ & 299 & 291 & 308 & 6.81 & 5.55 & 8.67 & 0.394 & 0.329 & 0.451 & 8 & 0 & 20 & 1.667 & 1.325 & 2.159 & 0.1 & 0.0 & 0.9 \\
\hline $310-330$ & 287 & $2 \%$ & 320 & 311 & 329 & 6.50 & 5.32 & 8.41 & 0.398 & 0.334 & 0.462 & 8 & 0 & 16 & 1.658 & 1.327 & 2.172 & 0.1 & 0.0 & 0.9 \\
\hline $330-350$ & 687 & $4 \%$ & 341 & 332 & 349 & 6.76 & 5.36 & 7.87 & 0.421 & 0.356 & 0.464 & 7 & 0 & 19 & 1.766 & 1.386 & 2.151 & 0.1 & 0.0 & 0.7 \\
\hline $350-370$ & 484 & $3 \%$ & 358 & 351 & 369 & 6.42 & 5.21 & 7.37 & 0.430 & 0.364 & 0.475 & 6 & 0 & 15 & 1.705 & 1.333 & 2.157 & 0.3 & 0.0 & 1.0 \\
\hline $370-390$ & 363 & $2 \%$ & 381 & 371 & 389 & 6.31 & 5.00 & 7.43 & 0.424 & 0.373 & 0.484 & 7 & 0 & 19 & 1.668 & 1.328 & 2.144 & 0.1 & 0.0 & 1.0 \\
\hline $390-410$ & 379 & $2 \%$ & 400 & 391 & 409 & 6.08 & 4.87 & 7.23 & 0.433 & 0.367 & 0.515 & 8 & 0 & 17 & 1.724 & 1.405 & 2.145 & 0.3 & 0.0 & 1.0 \\
\hline $410-430$ & 335 & $2 \%$ & 419 & 412 & 428 & 6.06 & 5.01 & 7.17 & 0.445 & 0.393 & 0.529 & 10 & 0 & 24 & 1.739 & 1.352 & 2.180 & 0.2 & 0.0 & 1.0 \\
\hline $430-450$ & 423 & $3 \%$ & 440 & 431 & 448 & 5.46 & 4.48 & 6.98 & 0.452 & 0.404 & 0.548 & 11 & 0 & 36 & 1.741 & 1.381 & 2.179 & 0.2 & 0.0 & 1.0 \\
\hline $450-470$ & 426 & $3 \%$ & 461 & 450 & 470 & 6.05 & 4.75 & 7.08 & 0.466 & 0.401 & 0.549 & 10 & 0 & 23 & 1.760 & 1.382 & 2.195 & 0.5 & 0.0 & 1.0 \\
\hline $470-490$ & 541 & $3 \%$ & 481 & 470 & 489 & 6.02 & 4.71 & 8.04 & 0.475 & 0.391 & 0.574 & 11 & 0 & 29 & 1.702 & 1.371 & 2.154 & 0.4 & 0.0 & 1.9 \\
\hline $490-510$ & 1582 & $10 \%$ & 501 & 491 & 509 & 5.93 & 4.89 & 7.13 & 0.497 & 0.407 & 0.606 & 10 & 0 & 25 & 1.738 & 1.303 & 2.168 & 0.4 & 0.0 & 1.3 \\
\hline $510-530$ & 965 & $6 \%$ & 517 & 511 & 522 & 5.31 & 4.14 & 6.45 & 0.473 & 0.414 & 0.563 & 15 & 0 & 39 & 1.651 & 1.294 & 2.125 & 0.2 & 0.0 & 1.0 \\
\hline $530-550$ & 161 & $1 \%$ & 536 & 531 & 541 & 5.54 & 4.59 & 6.78 & 0.515 & 0.431 & 0.591 & 9 & 3 & 12 & 1.874 & . 1.617 & 2.175 & 1.6 & 0.0 & 1.2 \\
\hline All Loads & 16172 & $100 \%$ & 311 & 200 & 515 & 6.85 & 4.97 & 8.69 & 0.411 & 0.321 & 0.537 & 8 & 0 & 18 & 1.685 & 1.322 & 2.161 & 0.2 & 0.0 & 1.0 \\
\hline
\end{tabular}




\section{Table A-9 P4A / Long-Term / Within-Day Averages}

\begin{tabular}{|c|c|c|c|c|c|c|}
\hline HOUR & LOAD & NOX & $\mathrm{CO}$ & THC & $\mathrm{O} 2$ & \\
\hline & 0 & 214 & 0.383 & 4.6 & 0.1 & 7.54 \\
\hline & 1 & 206 & 0.379 & 4.4 & 0.1 & 7.63 \\
\hline & 2 & 203 & 0.380 & 4.4 & 0.1 & 7.64 \\
\hline & 3 & 202 & 0.380 & 4.3 & 0.1 & 7.67 \\
\hline & 4 & 206 & 0.382 & 4.3 & 0.1 & 7.62 \\
\hline & 5 & 227 & 0.393 & 4.9 & 0.0 & 7.49 \\
\hline & 6 & 249 & 0.396 & 5.9 & 0.0 & 7.37 \\
\hline & 7 & 266 & 0.405 & 5.9 & 0.0 & 7.29 \\
\hline & 8 & 281 & 0.418 & 8.6 & 0.2 & 7.06 \\
\hline & 9 & 306 & 0.401 & 12.6 & 0.5 & 6.79 \\
\hline & 10 & 328 & 0.396 & 10.0 & 0.1 & 6.80 \\
\hline & 11 & 349 & 0.414 & 9.0 & 0.2 & 6.57 \\
\hline & 12 & 381 & 0.440 & 9.2 & 0.3 & 6.32 \\
\hline & 13 & 401 & 0.437 & 13.8 & 0.3 & 6.19 \\
\hline & 14 & 402 & 0.434 & 13.1 & 0.3 & 6.34 \\
\hline & 15 & 415 & 0.444 & 11.8 & 0.4 & 6.27 \\
\hline & 16 & 420 & 0.440 & 9.7 & 0.4 & 6.30 \\
\hline & 17 & 406 & 0.437 & 8.5 & 0.3 & 6.25 \\
\hline & 18 & 388 & 0.429 & 7.9 & 0.3 & 6.29 \\
\hline & 19 & 379 & 0.425 & 7.3 & 0.2 & 6.33 \\
\hline & 20 & 362 & 0.420 & 6.8 & 0.2 & 6.47 \\
\hline & 21 & 323 & 0.409 & 6.1 & 0.2 & 6.63 \\
\hline & 22 & 268 & 0.391 & 6.3 & 0.2 & 7.05 \\
\hline & 23 & 230 & 0.381 & 5.9 & 0.2 & 7.45 \\
\hline
\end{tabular}


Table A-10 P4A / Long-Term / Within-Day Averages

\begin{tabular}{|c|c|c|c|c|c|c|c|}
\hline DID & ICOUNT & LOAD & $\mathrm{O} 2$ & $\mathrm{CO}$ & THC & NOX & SOX \\
\hline 940712 & & $3 \quad 230.592$ & 7.475 & 5 & 0 & 0.342 & 1.992 \\
\hline 940713 & 24 & 285.924 & 7.417 & 0.433 & 0 & 0.421 & 1.97 \\
\hline 940714 & 24 & 306.792 & 7.55 & 1.778 & 0 & 0.429 & 2.057 \\
\hline 940715 & 24 & 410.959 & 6.751 & 5.642 & 0 & 0.49 & 2.126 \\
\hline 940716 & 24 & 356.735 & 7.216 & 0.713 & 0 & 0.474 & 2.147 \\
\hline 940717 & 21 & 323.698 & 8.209 & 0 & 0 & 0.452 & 2.08 \\
\hline 940718 & 24 & 259.57 & 9.144 & 0.018 & 0 & 0.444 & 2.071 \\
\hline 940719 & 18 & 367.068 & 8.952 & 13.234 & 0.019 & 0.441 & 1.906 \\
\hline 940720 & 11 & 424.955 & 7.848 & 15.531 & 1.654 & 0.515 & 1.392 \\
\hline 940721 & 22 & 337.017 & 7.594 & 6.405 & 0.843 & 0.448 & 1.636 \\
\hline 940722 & 24 & 401.308 & 7.116 & 1.561 & 0.851 & 0.485 & 1.724 \\
\hline 940723 & & 443.765 & 6.699 & 8.186 & 1.664 & 0.488 & 1.572 \\
\hline 940724 & & & & & & & \\
\hline 940725 & & 123.246 & 9.343 & 14.168 & 4.041 & 0.298 & 1.453 \\
\hline 940726 & 24 & 232.46 & 8.019 & 4.238 & 1.102 & 0.385 & 1.734 \\
\hline 940727 & 24 & 358.479 & 7.503 & 4.188 & 0.035 & 0.436 & 1.997 \\
\hline 940728 & 24 & 358.259 & 7.84 & 3.36 & 0.002 & 0.457 & 2.14 \\
\hline 940729 & 21 & 328.968 & 7.722 & 4.72 & 0.156 & 0.444 & 2.217 \\
\hline 940730 & & & & & & & \\
\hline 940801 & & & & & & & \\
\hline 940802 & & & & & & & \\
\hline 940803 & 24 & 357.177 & 7.016 & 6.141 & 0.002 & 0.467 & 2.103 \\
\hline 940804 & 24 & 350.085 & 6.89 & 5.85 & 0.558 & 0.453 & 2.015 \\
\hline 940805 & 12 & 468.844 & 5.72 & 10.368 & 2.884 & 0.479 & 1.872 \\
\hline 940806 & & & & & & & \\
\hline 940807 & & & & & & & \\
\hline 940808 & & & & & & & \\
\hline 940809 & 12 & 235.781 & 6.807 & 11.398 & 0.062 & 0.387 & 1.581 \\
\hline 940810 & 24 & 323.329 & 6.076 & 15.788 & 0.824 & 0.408 & 1.509 \\
\hline 940811 & 24 & 350.609 & 5.911 & 12.093 & 0.825 & 0.431 & 1.735 \\
\hline 940812 & 24 & 363.11 & 6.042 & 13.676 & 0.746 & 0.446 & 1.724 \\
\hline 940813 & 24 & 288.462 & 6.166 & 14.342 & 0.559 & 0.406 & 1.665 \\
\hline 940814 & 24 & 184.42 & 6.885 & 14.863 & 0.014 & 0.385 & 1.483 \\
\hline 940815 & 18 & 295.31 & 5.967 & 12.916 & 0.446 & 0.392 & 1.427 \\
\hline 940816 & 14 & 266.071 & 6.578 & 4.818 & 0.124 & 0.39 & 1.364 \\
\hline 940817 & & 394.334 & 5.703 & 10.025 & 0.111 & 0.401 & 1.666 \\
\hline 940818 & & & & & & & \\
\hline 940819 & & & & & & & \\
\hline 940820 & & & & & & & \\
\hline 940821 & & & & & & & \\
\hline 940822 & & & & & & & \\
\hline 940823 & & & & & & & \\
\hline 940824 & & 138.442 & 7.981 & 13.974 & 0 & 0.301 & 1.559 \\
\hline 940825 & 23 & 225.368 & 6.627 & 8.098 & 0 & 0.281 & 1.51 \\
\hline 940826 & 24 & 295.482 & 6.769 & 0 & 0 & 0.407 & 1.505 \\
\hline 940827 & 14 & 353.469 & 6.036 & 0 & 0 & 0.428 & 1.765 \\
\hline 940828 & & & & & & & \\
\hline 940829 & & & & & & & \\
\hline 940830 & & & & & & & \\
\hline 940831 & & 336.581 & 9.635 & 0 & 0 & 0.095 & 2.227 \\
\hline
\end{tabular}


Table A-9 P4A / Long-Term / Within-Day Averages

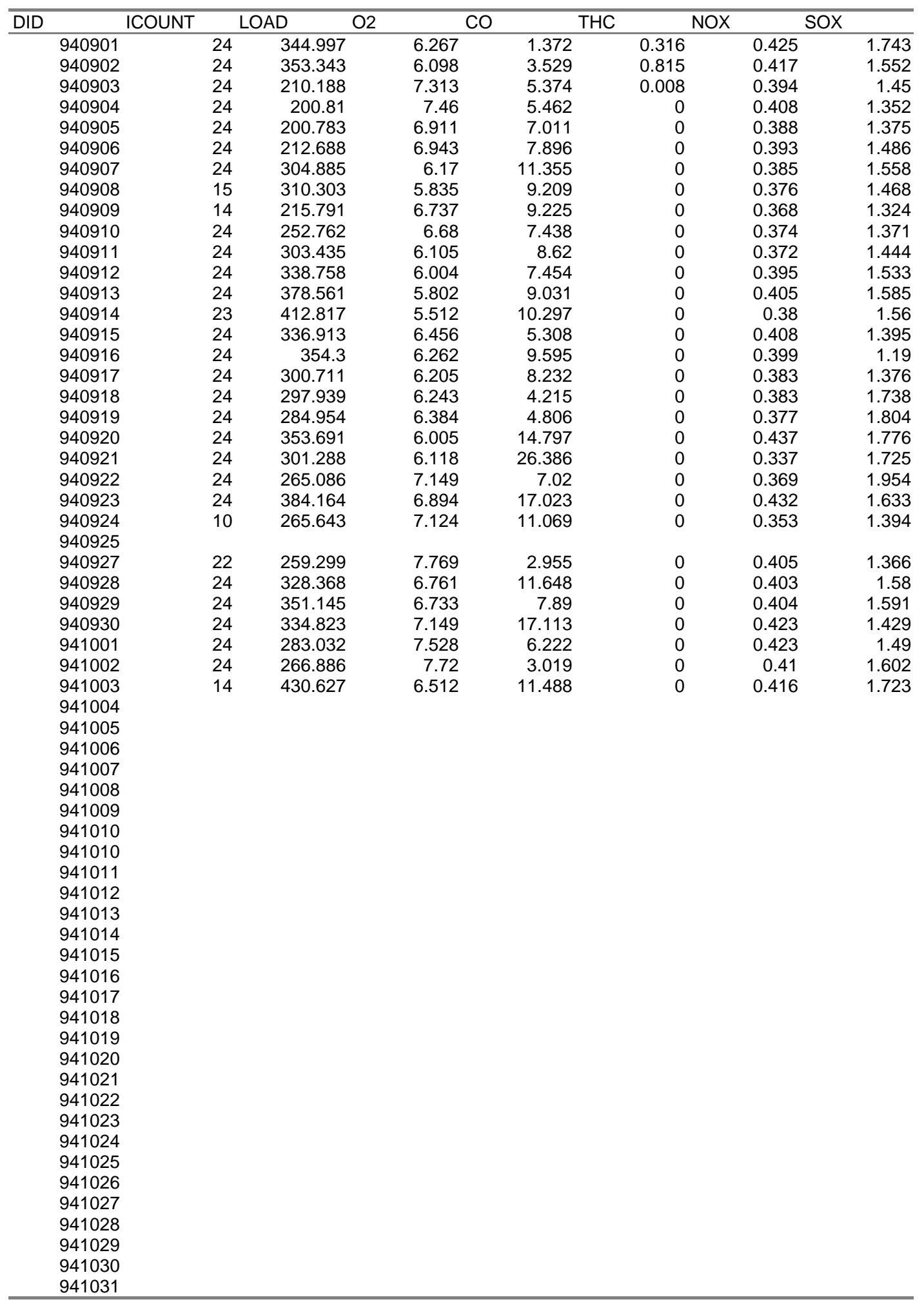


Table A-9 P4A / Long-Term / Within-Day Averages

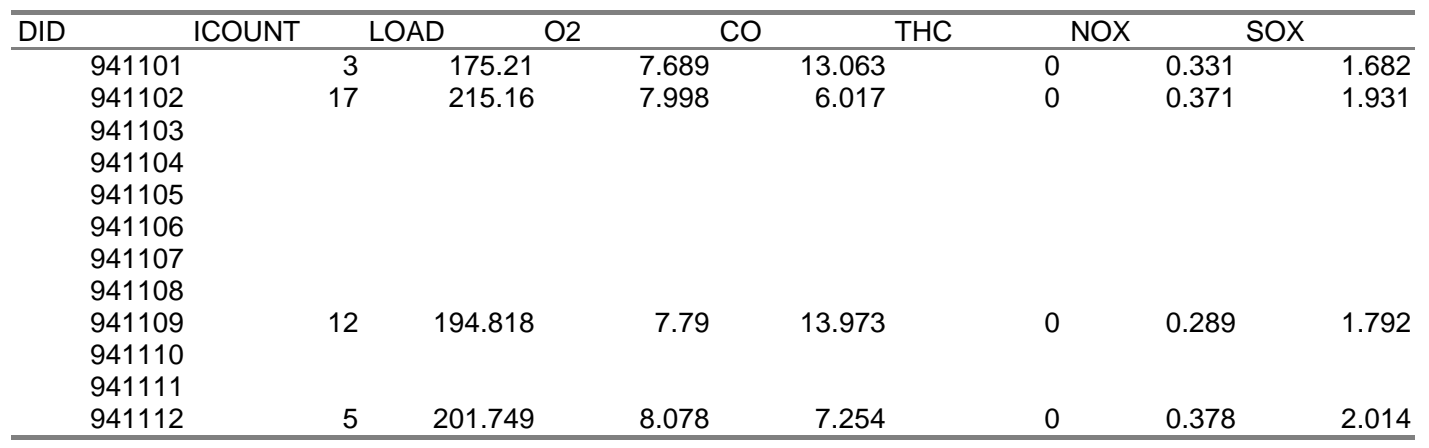


Table A-11 LOI Test Summary

\begin{tabular}{lrllcccc}
\hline Test & Date & Load Description & MOOS & Ex. O2. & AOFA & NOx & LOI \\
\hline $150-1$ & 20-Jul-95 & 519 Full-Load / Low O2 & AMIS & 50 & 0.39 & 9.47 \\
$150-2$ & 20-Jul-95 & 520 Full-Load / Med. O2 & AMIS & 50 & 0.45 & 6.37 \\
$150-3$ & 20-Jul-95 & 500 Full-Load / Hi O2 & AMIS & 50 & 0.54 & 5.16 \\
$151-1$ & 21-Jul-95 & 305 Low-Load / Low O2 & E & 0 & 0.36 & 8.64 \\
$151-2$ & 21-Jul-95 & 305 Low-Load / Med. O2 & E & 0 & 0.43 & 4.23 \\
$151-3$ & 21-Jul-95 & 305 Low-Load / Hi O2 & E & 0 & 0.49 & 2.59 \\
$151-4$ & 21-Jul-95 & 400 Med-Load / Low O2 & E & 20 & 0.35 & 8.98 \\
$151-5$ & 21-Jul-95 & 400 Med-Load / Med. O2 & E & 20 & 0.43 & 5.62 \\
$151-6$ & 21-Jul-95 & 400 Med-Load / Hi O2 & E & 20 & 0.51 & 4.35 \\
$152-1$ & 8-Feb-96 & 480 Full-Load / Low O2 & AMIS & 40 & 0.40 & 9.3 \\
$152-2$ & 8-Feb-96 & 480 Full-Load / Mid O2 & AMIS & 40 & 0.44 & 8.2 \\
$152-3$ & 8-Feb-96 & 480 Full-Load / High O2 & AMIS & 40 & 0.49 & 6.3 \\
$152-4$ & 8-Feb-96 & 400 Mid-Load / Mid O2 & E & 20 & 0.44 & 9.5 \\
$152-5$ & 8-Feb-96 & 400 Mid-Load / Low O2 & E & 20 & 0.38 & 11.1 \\
$153-1$ & 9-Feb-96 & 300 Mid-Load / Mid O2 & B & 0 & 0.37 & 7.5 \\
$153-2$ & 9-Feb-96 & 300 Mid-Load / Low O2 & B & 0 & 0.34 & 9.4 \\
$153-3$ & 9-Feb-96 & 300 Mid-Load / High O2 & B & 0 & 0.42 & 5.7 \\
$153-4$ & 9-Feb-96 & 390 Mid-Load / High O2 & B & 20 & 0.38 & 7.6 \\
\hline
\end{tabular}


Table A-12 Process Data for 1st Quarter 1995

\begin{tabular}{rrrrrrrrrr}
\multicolumn{1}{c}{$\begin{array}{c}\text { Bin } \\
\text { Low }\end{array}$} & $\begin{array}{c}\text { Bin } \\
\text { High }\end{array}$ & Samples & \multicolumn{1}{c}{ Load } & \multicolumn{1}{c}{ PV } & PV & PV & PV & \multicolumn{1}{c}{ PV } & PV \\
Mean & \multicolumn{1}{c}{ Mean } & Min & Max & \multicolumn{1}{c}{ Std } & \multicolumn{1}{c}{ 5thP } & \multicolumn{1}{c}{95 thP } \\
\hline 130 & 150 & 120 & 137.669 & 137.669 & 130.425 & 149.856 & 3.72083 & 131.694 & 147.23 \\
150 & 170 & 86 & 159.078 & 159.078 & 150.041 & 169.969 & 5.31443 & 151.606 & 168.081 \\
170 & 190 & 238 & 182.11 & 182.11 & 170.353 & 189.931 & 4.99533 & 174.476 & 189.554 \\
190 & 210 & 2824 & 201.171 & 201.171 & 190.141 & 209.947 & 3.18294 & 197.556 & 207.998 \\
210 & 230 & 1110 & 220.026 & 220.026 & 210.047 & 229.978 & 5.50638 & 211.353 & 229.034 \\
230 & 250 & 1072 & 239.646 & 239.646 & 230.006 & 249.981 & 5.99319 & 230.974 & 249.068 \\
250 & 270 & 1281 & 259.368 & 259.368 & 250.009 & 270 & 5.80464 & 250.563 & 268.683 \\
270 & 290 & 1084 & 279.773 & 279.773 & 270.069 & 289.984 & 5.82234 & 270.972 & 289.087 \\
290 & 310 & 1194 & 299.899 & 299.899 & 290.025 & 309.969 & 5.72843 & 290.903 & 308.641 \\
310 & 330 & 1007 & 320.148 & 320.148 & 310.003 & 330 & 5.91449 & 310.719 & 328.945 \\
330 & 350 & 857 & 339.69 & 339.69 & 330.009 & 349.997 & 5.75978 & 330.721 & 349.074 \\
350 & 370 & 817 & 360.282 & 360.282 & 350.069 & 370 & 5.95176 & 350.682 & 369.129 \\
370 & 390 & 798 & 379.563 & 379.563 & 370.016 & 390 & 5.83973 & 370.55 & 388.891 \\
390 & 410 & 729 & 398.761 & 398.761 & 390.009 & 409.984 & 5.80076 & 390.578 & 408.287 \\
410 & 430 & 605 & 418.97 & 418.97 & 410.006 & 429.991 & 5.67919 & 410.686 & 428.074 \\
430 & 450 & 572 & 441.973 & 441.973 & 430.006 & 449.959 & 6.49924 & 430.934 & 449.632 \\
450 & 470 & 668 & 456.323 & 456.323 & 450.025 & 469.963 & 5.73437 & 450.188 & 468.256 \\
470 & 490 & 430 & 480.33 & 480.33 & 470.031 & 489.984 & 5.38917 & 471.144 & 489.641 \\
490 & 510 & 242 & 497.522 & 497.522 & 490.025 & 509.966 & 6.55732 & 490.138 & 509.214 \\
510 & 530 & 571 & 518.616 & 518.616 & 510.003 & 525.35 & 2.88668 & 511.874 & 522.262 \\
\hline
\end{tabular}

Main Steam Temperature, ${ }^{\circ} \mathrm{F}$

\begin{tabular}{|c|c|c|c|c|c|c|c|c|c|}
\hline $\begin{array}{l}\text { Bin } \\
\text { Low }\end{array}$ & $\begin{array}{l}\text { Bin } \\
\text { High }\end{array}$ & Samples & $\begin{array}{l}\text { Load } \\
\text { Mean }\end{array}$ & $\begin{array}{c}\text { PV } \\
\text { Mean }\end{array}$ & $\begin{array}{l}\text { PV } \\
\text { Min }\end{array}$ & $\begin{array}{l}\text { PV } \\
\text { Max }\end{array}$ & $\begin{array}{l}\text { PV } \\
\text { Std }\end{array}$ & $\begin{array}{l}\text { PV } \\
5 \text { thP }\end{array}$ & $\begin{array}{c}\text { PV } \\
\text { 95thP }\end{array}$ \\
\hline 130 & 150 & 120 & 137.669 & 964.48 & 884.333 & 1009.69 & 23.9794 & 924.242 & 1004.2 \\
\hline 150 & 170 & 86 & 159.078 & 978.261 & 913.183 & 1009.33 & 31.5398 & 915.186 & 1005.38 \\
\hline 170 & 190 & 238 & 182.11 & 992.855 & 935.268 & 1007.62 & 14.8249 & 957.035 & 1002.14 \\
\hline 190 & 210 & 2824 & 201.171 & 994.12 & 943.309 & 1004.27 & 7.272 & 988.419 & 1001.82 \\
\hline 210 & 230 & 1110 & 220.026 & 995.927 & 943.309 & 1008.39 & 8.74645 & 988.218 & 1002 \\
\hline 230 & 250 & 1072 & 239.646 & 997.755 & 974.19 & 1039.65 & 5.15352 & 989.526 & 1002.49 \\
\hline 250 & 270 & 1281 & 259.368 & 996.787 & 963.017 & 1019.4 & 6.09937 & 988.498 & 1002.22 \\
\hline 270 & 290 & 1084 & 279.773 & 996.582 & 955.921 & 1050.76 & 6.29332 & 988.739 & 1002.06 \\
\hline 290 & 310 & 1194 & 299.899 & 997.883 & 955.821 & 1024.29 & 5.27878 & 989.332 & 1001.71 \\
\hline 310 & 330 & 1007 & 320.148 & 996.35 & 964.257 & 1009.8 & 5.78822 & 988.889 & 1001.51 \\
\hline 330 & 350 & 857 & 339.69 & 995.957 & 942.231 & 1008.38 & 6.22316 & 987.922 & 1002.35 \\
\hline 350 & 370 & 817 & 360.282 & 995.209 & 951.304 & 1005.45 & 6.11202 & 987.915 & 1002.52 \\
\hline 370 & 390 & 798 & 379.563 & 995.151 & 952.383 & 1013.58 & 6.38383 & 985.998 & 1003.7 \\
\hline 390 & 410 & 729 & 398.761 & 995.825 & 965.166 & 1005.28 & 6.62601 & 985.327 & 1003.7 \\
\hline 410 & 430 & 605 & 418.97 & 994.536 & 963.049 & 1004.49 & 6.28455 & 984.594 & 1003.7 \\
\hline 430 & 450 & 572 & 441.973 & 994.848 & 967.356 & 1004.89 & 7.1247 & 981.001 & 1003.7 \\
\hline 450 & 470 & 668 & 456.323 & 991.673 & 966.846 & 1007.91 & 7.20751 & 978.279 & 1000.38 \\
\hline 470 & 490 & 430 & 480.33 & 990.91 & 953.19 & 1003.02 & 8.31134 & 975.953 & 1000.58 \\
\hline 490 & 510 & 242 & 497.522 & 989.265 & 962.986 & 1001.11 & 9.53225 & 971.117 & 1001.11 \\
\hline 510 & 530 & 571 & 518.616 & 988.478 & 965.349 & 1001.11 & 8.88287 & 972.89 & 1001.1 \\
\hline
\end{tabular}

Hot Reheat Temperature, ${ }^{\circ} \mathrm{F}$

\begin{tabular}{|c|c|c|c|c|c|c|c|c|c|}
\hline $\begin{array}{l}\text { Bin } \\
\text { Low }\end{array}$ & $\begin{array}{c}\text { Bin } \\
\text { High }\end{array}$ & Samples & $\begin{array}{l}\text { Load } \\
\text { Mean }\end{array}$ & $\begin{array}{c}\text { PV } \\
\text { Mean }\end{array}$ & $\begin{array}{l}\text { PV } \\
\text { Min }\end{array}$ & $\begin{array}{l}\text { PV } \\
\text { Max }\end{array}$ & $\begin{array}{l}\text { PV } \\
\text { Std }\end{array}$ & $\begin{array}{c}\text { PV } \\
5 \text { thP }\end{array}$ & $\begin{array}{c}\text { PV } \\
95 \text { thP }\end{array}$ \\
\hline 130 & 150 & 120 & 137.669 & 962.659 & 888.989 & 1003.66 & 26.539 & 907.922 & 1001.74 \\
\hline 150 & 170 & 86 & 159.078 & 972.978 & 915.274 & 1006.92 & 33.27 & 915.274 & 1003.07 \\
\hline 170 & 190 & 238 & 182.11 & 975.811 & 917.887 & 1012.29 & 25.0288 & 933.485 & 1002.81 \\
\hline 190 & 210 & 2824 & 201.171 & 984.053 & 906.311 & 1006.02 & 14.6157 & 956.106 & 1001.58 \\
\hline 210 & 230 & 1110 & 220.026 & 985.436 & 942.012 & 1008.68 & 12.9598 & 960.354 & 1001.05 \\
\hline 230 & 250 & 1072 & 239.646 & 986.572 & 949.061 & 1006.42 & 12.6732 & 961.344 & 1002.17 \\
\hline 250 & 270 & 1281 & 259.368 & 987.738 & 951.241 & 1010.15 & 10.7238 & 966.522 & 1001.34 \\
\hline 270 & 290 & 1084 & 279.773 & 990.858 & 954.664 & 1008.19 & 10.2194 & 970.93 & 1002.62 \\
\hline 290 & 310 & 1194 & 299.899 & 992.33 & 947.474 & 1010.37 & 10.2321 & 972.311 & 1002.75 \\
\hline 310 & 330 & 1007 & 320.148 & 992.703 & 950.331 & 1010.24 & 9.19696 & 976.563 & 1003.32 \\
\hline 330 & 350 & 857 & 339.69 & 993.747 & 951.184 & 1011.1 & 8.90022 & 978.762 & 1003.95 \\
\hline 350 & 370 & 817 & 360.282 & 994.363 & 956.866 & 1012.54 & 8.29917 & 980.353 & 1005.58 \\
\hline 370 & 390 & 798 & 379.563 & 994.521 & 959.821 & 1011.97 & 8.5231 & 980.302 & 1005.19 \\
\hline 390 & 410 & 729 & 398.761 & 995.996 & 962.662 & 1013.84 & 7.39954 & 982.6 & 1004.77 \\
\hline 410 & 430 & 605 & 418.97 & 995.226 & 964.768 & 1012.17 & 7.79817 & 981.143 & 1005.92 \\
\hline 430 & 450 & 572 & 441.973 & 997.439 & 966.091 & 1014.61 & 6.73199 & 984.862 & 1006.96 \\
\hline 450 & 470 & 668 & 456.323 & 997.561 & 966.358 & 1011.73 & 6.42844 & 985.187 & 1006.93 \\
\hline 470 & 490 & 430 & 480.33 & 998.183 & 976.348 & 1015.08 & 5.79424 & 987.602 & 1006.41 \\
\hline 490 & 510 & 242 & 497.522 & 996.024 & 980.918 & 1014.79 & 5.82914 & 987.609 & 1005.72 \\
\hline 510 & 530 & 571 & 518.616 & 995.991 & 985.262 & 1011.58 & 3.73174 & 989.995 & 1002.27 \\
\hline
\end{tabular}


Excess O2 Left Hand, \%

\begin{tabular}{|c|c|c|c|c|c|c|c|c|c|}
\hline $\begin{array}{l}\text { Bin } \\
\text { Low }\end{array}$ & $\begin{array}{c}\text { Bin } \\
\text { High }\end{array}$ & Samples & $\begin{array}{l}\text { Load } \\
\text { Mean }\end{array}$ & $\begin{array}{c}\text { PV } \\
\text { Mean }\end{array}$ & $\begin{array}{l}\text { PV } \\
\text { Min }\end{array}$ & $\begin{array}{l}\text { PV } \\
\text { Max }\end{array}$ & $\begin{array}{l}\text { PV } \\
\text { Std }\end{array}$ & $\begin{array}{c}P V \\
5 \text { thP }\end{array}$ & $\begin{array}{l}\text { PV } \\
\text { 95thP }\end{array}$ \\
\hline 130 & 150 & 120 & 137.669 & 7.06996 & 6.15835 & 9.22035 & 0.47618 & 6.67023 & 8.02803 \\
\hline 150 & 170 & 86 & 159.078 & 6.58039 & 4.06675 & 9.30478 & 0.58105 & 5.95158 & 7.30202 \\
\hline 170 & 190 & 238 & 182.11 & 6.54002 & 5.26639 & 8.52375 & 0.81 & 5.54036 & 7.94409 \\
\hline 190 & 210 & 2824 & 201.171 & 6.29503 & 4.11886 & 8.12534 & 0.79343 & 5.08946 & 7.81373 \\
\hline 210 & 230 & 1110 & 220.026 & 6.0722 & 4.35246 & 7.97128 & 0.63776 & 5.10378 & 7.32796 \\
\hline 230 & 250 & 1072 & 239.646 & 5.82814 & 3.85311 & 7.82574 & 0.7248 & 4.61369 & 7.37915 \\
\hline 250 & 270 & 1281 & 259.368 & 5.72995 & 3.52137 & 8.30507 & 0.90004 & 4.52997 & 7.47532 \\
\hline 270 & 290 & 1084 & 279.773 & 5.35278 & 3.3405 & 7.67151 & 0.76936 & 4.02318 & 6.75169 \\
\hline 290 & 310 & 1194 & 299.899 & 5.0421 & 3.08207 & 7.46712 & 0.66957 & 4.11922 & 6.48174 \\
\hline 310 & 330 & 1007 & 320.148 & 4.94753 & 2.90298 & 7.29754 & 0.7115 & 3.97111 & 6.55723 \\
\hline 330 & 350 & 857 & 339.69 & 4.71355 & 2.5182 & 7.2225 & 0.68828 & 3.80613 & 6.17249 \\
\hline 350 & 370 & 817 & 360.282 & 4.4787 & 2.36996 & 7.03945 & 0.81326 & 3.43452 & 6.26489 \\
\hline 370 & 390 & 798 & 379.563 & 4.23047 & 2.30139 & 6.68774 & 0.81482 & 3.26276 & 6.13554 \\
\hline 390 & 410 & 729 & 398.761 & 3.91697 & 2.27198 & 6.16085 & 0.66257 & 2.8847 & 5.18161 \\
\hline 410 & 430 & 605 & 418.97 & 3.79792 & 1.90751 & 5.92257 & 0.65377 & 2.77445 & 5.04102 \\
\hline 430 & 450 & 572 & 441.973 & 3.5784 & 1.30876 & 6.01612 & 0.65538 & 2.66738 & 4.72894 \\
\hline 450 & 470 & 668 & 456.323 & 3.63598 & 1.44957 & 5.59206 & 0.72536 & 2.63019 & 5.24723 \\
\hline 470 & 490 & 430 & 480.33 & 3.31669 & 1.97125 & 5.59302 & 0.59967 & 2.59421 & 4.46315 \\
\hline 490 & 510 & 242 & 497.522 & 3.2702 & 1.72922 & 4.92533 & 0.54137 & 2.64404 & 4.39595 \\
\hline 510 & 530 & 571 & 518.616 & 3.18607 & 2.7081 & 4.26435 & 0.25716 & 2.878 & 3.63487 \\
\hline \multicolumn{10}{|c|}{ Excess O2, Right Hand, \% } \\
\hline Bin & Bin & Samples & Load & PV & PV & PV & PV & PV & PV \\
\hline Low & High & & Mean & Mean & Min & $\operatorname{Max}$ & Std & 5thP & 95thP \\
\hline 130 & 150 & 120 & 137.669 & 6.79295 & 6.26245 & 9.03593 & 0.41623 & 6.46107 & 7.67042 \\
\hline 150 & 170 & 86 & 159.078 & 6.3484 & 3.70395 & 7.85667 & 0.42888 & 5.9555 & 6.76204 \\
\hline 170 & 190 & 238 & 182.11 & 5.98261 & 5.23919 & 6.59914 & 0.3583 & 5.34656 & 6.4034 \\
\hline 190 & 210 & 2824 & 201.171 & 5.96794 & 4.64792 & 7.95109 & 0.49803 & 5.28066 & 7.01764 \\
\hline 210 & 230 & 1110 & 220.026 & 5.68512 & 4.4425 & 7.55495 & 0.47778 & 5.07251 & 6.71314 \\
\hline 230 & 250 & 1072 & 239.646 & 5.43225 & 4.04461 & 6.95904 & 0.45711 & 4.76702 & 6.23921 \\
\hline 250 & 270 & 1281 & 259.368 & 5.16239 & 3.80702 & 6.58551 & 0.49676 & 4.34869 & 6.00994 \\
\hline 270 & 290 & 1084 & 279.773 & 4.85374 & 3.11426 & 6.406 & 0.54545 & 4.01965 & 5.80832 \\
\hline 290 & 310 & 1194 & 299.899 & 4.62471 & 3.56303 & 5.99237 & 0.50035 & 3.87129 & 5.5322 \\
\hline 310 & 330 & 1007 & 320.148 & 4.39944 & 3.29984 & 5.87956 & 0.52816 & 3.55015 & 5.36727 \\
\hline 330 & 350 & 857 & 339.69 & 4.45005 & 2.91832 & 5.71426 & 0.50159 & 3.50134 & 5.19157 \\
\hline 350 & 370 & 817 & 360.282 & 4.24396 & 2.52837 & 5.7901 & 0.49545 & 3.35245 & 4.92137 \\
\hline 370 & 390 & 798 & 379.563 & 4.04215 & 2.76714 & 5.49658 & 0.51159 & 3.21956 & 4.80556 \\
\hline 390 & 410 & 729 & 398.761 & 3.9492 & 2.59811 & 5.49145 & 0.51557 & 3.08925 & 4.73424 \\
\hline 410 & 430 & 605 & 418.97 & 3.7713 & 2.53711 & 4.86411 & 0.50619 & 2.96681 & 4.5359 \\
\hline 430 & 450 & 572 & 441.973 & 3.59927 & 1.4562 & 4.71649 & 0.47991 & 2.70245 & 4.3359 \\
\hline 450 & 470 & 668 & 456.323 & 3.48839 & 1.26072 & 4.69703 & 0.56038 & 2.48512 & 4.44238 \\
\hline 470 & 490 & 430 & 480.33 & 3.39439 & 1.83543 & 4.56292 & 0.50575 & 2.37861 & 4.08233 \\
\hline 490 & 510 & 242 & 497.522 & 3.27408 & 1.82659 & 4.43596 & 0.42144 & 2.58561 & 4.06914 \\
\hline 510 & 530 & 571 & 518.616 & 2.99719 & 2.49305 & 4.25366 & 0.24261 & 2.77487 & 3.36263 \\
\hline \multicolumn{10}{|c|}{ Main Steam Pressure, PSIG } \\
\hline Bin & Bin & Samples & Load & PV & PV & PV & PV & PV & PV \\
\hline Low & High & & Mean & Mean & Min & $\operatorname{Max}$ & Std & 5thP & 95thP \\
\hline 130 & 150 & 120 & 137.669 & 1709.85 & 1054.99 & 2426.46 & 223.514 & 1554.67 & 2100.02 \\
\hline 150 & 170 & 86 & 159.078 & 1832.37 & 1034.94 & 2531.26 & 515.178 & 1034.94 & 2398.54 \\
\hline 170 & 190 & 238 & 182.11 & 2288.7 & 1095 & 2422.35 & 311.615 & 1247.98 & 2410.25 \\
\hline 190 & 210 & 2824 & 201.171 & 2363.44 & 1179.34 & 2454.7 & 125.299 & 2347.92 & 2415.53 \\
\hline 210 & 230 & 1110 & 220.026 & 2369.39 & 1602.02 & 2550.16 & 114.137 & 2287.64 & 2415.53 \\
\hline 230 & 250 & 1072 & & 2397.53 & 2248.55 & 2480.4 & 24.539 & 2357.44 & 2415.53 \\
\hline 250 & 270 & 1281 & 259.368 & 2393.42 & 2327.54 & 2446.71 & 25.3622 & 2356.69 & 2415.53 \\
\hline 270 & 290 & 1084 & 279.773 & 2393.12 & 2314.65 & 2482.07 & 25.7526 & 2356.55 & 2415.53 \\
\hline 290 & 310 & 1194 & 299.899 & 2400.03 & 2333.12 & 2430.22 & 21.4315 & 2359.34 & 2415.52 \\
\hline 310 & 330 & 1007 & 320.148 & 2393.23 & 2343.87 & 2472.65 & 24.796 & 2358.36 & 2415.53 \\
\hline 330 & 350 & 857 & 339.69 & 2393.02 & 2334.89 & 2429.47 & 24.7267 & 2357.28 & 2421.56 \\
\hline 350 & 370 & 817 & 360.282 & 2392.88 & 2336.36 & 2456.82 & 25.066 & 2358.84 & 2421.74 \\
\hline 370 & 390 & 798 & 379.563 & 2395.61 & 2243.64 & 2458.32 & 26.0045 & 2358.38 & 2421.74 \\
\hline 390 & 410 & 729 & 398.761 & 2400.14 & 2310.14 & 2442.13 & 24.6346 & 2359.49 & 2421.74 \\
\hline 410 & 430 & 605 & 418.97 & 2394.71 & 2233.59 & 2438.02 & 27.0047 & 2354.96 & 2421.74 \\
\hline 430 & 450 & 572 & 441.973 & 2403.59 & 2257.77 & 2457.57 & 24.0609 & 2357.86 & 2421.74 \\
\hline 450 & 470 & 668 & 456.323 & 2399.44 & 2234.12 & 2434.9 & 27.1558 & 2351.83 & 2415.53 \\
\hline 470 & 490 & 430 & 480.33 & 2402.18 & 2263.1 & 2431.41 & 24.2279 & 2354.31 & 2416.89 \\
\hline 490 & 510 & 242 & 497.522 & 2392.5 & 2216.98 & 2435.6 & 37.3012 & 2322.72 & 2415.53 \\
\hline 510 & 530 & 571 & 518.616 & 2398.36 & 2287.92 & 2424.36 & 26.5153 & 2354.59 & 2415.53 \\
\hline
\end{tabular}


Secondary Air Heater A Gas Outlet Temperature, ${ }^{\circ} \mathrm{F}$

\begin{tabular}{|c|c|c|c|c|c|c|c|c|c|}
\hline $\begin{array}{l}\text { Bin } \\
\text { Low }\end{array}$ & $\begin{array}{l}\text { Bin } \\
\text { High }\end{array}$ & Samples & $\begin{array}{l}\text { Load } \\
\text { Mean }\end{array}$ & $\begin{array}{l}\text { PV } \\
\text { Mean }\end{array}$ & $\begin{array}{l}\text { PV } \\
\text { Min }\end{array}$ & $\begin{array}{l}\text { PV } \\
\text { Max }\end{array}$ & $\begin{array}{l}\text { PV } \\
\text { Std }\end{array}$ & $\begin{array}{c}\mathrm{PV} \\
5 \text { thP } \\
\end{array}$ & $\begin{array}{c}\mathrm{PV} \\
95 \text { thP }\end{array}$ \\
\hline 130 & 150 & 120 & 137.669 & 257.73 & 228.286 & 284.541 & 7.5709 & 249.861 & 270.011 \\
\hline 150 & 170 & 86 & 159.078 & 252.085 & 218.961 & 276.344 & 12.4483 & 226.544 & 263.658 \\
\hline 170 & 190 & 238 & 182.11 & 254.636 & 233.094 & 281.233 & 8.80402 & 235.002 & 269.094 \\
\hline 190 & 210 & 2824 & 201.171 & 275.028 & 155.062 & 314.73 & 25.7784 & 239.05 & 310.678 \\
\hline 210 & 230 & 1110 & 220.026 & 274.952 & 232.875 & 325.979 & 21.6311 & 239.05 & 304.888 \\
\hline 230 & 250 & 1072 & 239.646 & 277.075 & 234.141 & 325.93 & 19.1568 & 254.442 & 306.845 \\
\hline 250 & 270 & 1281 & 259.368 & 279.397 & 239.05 & 324.604 & 18.2344 & 257.235 & 312.082 \\
\hline 270 & 290 & 1084 & 279.773 & 282.298 & 239.05 & 321.184 & 18.2668 & 257.403 & 308.176 \\
\hline 290 & 310 & 1194 & 299.899 & 279.881 & 237.393 & 320.529 & 21.5695 & 247.752 & 311.511 \\
\hline 310 & 330 & 1007 & 320.148 & 282.251 & 235.861 & 316.873 & 17.4981 & 254.15 & 305.79 \\
\hline 330 & 350 & 857 & 339.69 & 277.878 & 239.05 & 312.823 & 17.2173 & 250.613 & 304.178 \\
\hline 350 & 370 & 817 & 360.282 & 281.576 & 239.05 & 313.906 & 15.9081 & 259.107 & 305.38 \\
\hline 370 & 390 & 798 & 379.563 & 284.842 & 243.062 & 316.627 & 16.5372 & 259.114 & 310.752 \\
\hline 390 & 410 & 729 & 398.761 & 288.148 & 245.049 & 322.471 & 17.7341 & 259.114 & 310.542 \\
\hline 410 & 430 & 605 & 418.97 & 292.094 & 253.795 & 323.744 & 17.7938 & 259.114 & 315.473 \\
\hline 430 & 450 & 572 & 441.973 & 291.649 & 255.054 & 326.572 & 22.7083 & 257.702 & 318.554 \\
\hline 450 & 470 & 668 & 456.323 & 300.32 & 257.702 & 329.241 & 20.2029 & 257.702 & 321.126 \\
\hline 470 & 490 & 430 & 480.33 & 301.709 & 257.702 & 336.152 & 22.2142 & 268.873 & 329.924 \\
\hline 490 & 510 & 242 & 497.522 & 292.528 & 257.785 & 341.045 & 22.7252 & 267.636 & 333.045 \\
\hline 510 & 530 & 571 & 518.616 & 291.143 & 257.785 & 342.826 & 14.3064 & 277.804 & 323.718 \\
\hline \multicolumn{10}{|c|}{ Secondary Air Heater B Gas Outlet Temperature, ${ }^{\circ} \mathrm{F}$} \\
\hline Bin & Bin & Samples & Load & PV & PV & PV & PV & PV & PV \\
\hline Low & High & & Mean & Mean & Min & $\operatorname{Max}$ & Std & 5thP & 95thP \\
\hline 130 & 150 & 120 & 137.669 & 261.299 & 241.211 & 287.136 & 7.83188 & 250.539 & 272.377 \\
\hline 150 & 170 & 86 & 159.078 & 265.488 & 243.383 & 286.478 & 4.98619 & 260.184 & 272.098 \\
\hline 170 & 190 & 238 & 182.11 & 263.99 & 246.581 & 293.07 & 5.38636 & 255.247 & 271.696 \\
\hline 190 & 210 & 2824 & 201.171 & 279.052 & 233.51 & 478.768 & 32.0532 & 255.136 & 304.664 \\
\hline 210 & 230 & 1110 & 220.026 & 275.118 & 232.441 & 316.094 & 16.9282 & 249.911 & 303.64 \\
\hline 230 & 250 & 1072 & 239.646 & 276.607 & 234.415 & 308.962 & 16.2241 & 252.63 & 303.635 \\
\hline 250 & 270 & 1281 & 259.368 & 270.901 & 218.605 & 309.067 & 18.2945 & 238.759 & 298.63 \\
\hline 270 & 290 & 1084 & 279.773 & 279.805 & 225.71 & 315.593 & 17.0882 & 250.112 & 307.069 \\
\hline 290 & 310 & 1194 & 299.899 & 280.863 & 232.645 & 329.903 & 21.9569 & 245.826 & 316.46 \\
\hline 310 & 330 & 1007 & 320.148 & 287.08 & 237.788 & 333.265 & 20.2937 & 251.623 & 317.832 \\
\hline 330 & 350 & 857 & 339.69 & 288.989 & 242.905 & 333.391 & 20.4736 & 252.922 & 319.529 \\
\hline 350 & 370 & 817 & 360.282 & 296.52 & 245.015 & 334.944 & 18.6181 & 262.1 & 323.029 \\
\hline 370 & 390 & 798 & 379.563 & 300.264 & 253.348 & 337.869 & 18.0748 & 268.486 & 325.668 \\
\hline 390 & 410 & 729 & 398.761 & 305.7 & 259.057 & 340.47 & 17.3454 & 274.148 & 328.234 \\
\hline 410 & 430 & 605 & 418.97 & 308.115 & 261.448 & 340.704 & 17.5865 & 277.915 & 334.461 \\
\hline 430 & 450 & 572 & 441.973 & 311.006 & 261.448 & 345.021 & 17.4079 & 282.32 & 338.564 \\
\hline 450 & 470 & 668 & 456.323 & 311.66 & 270.957 & 348.358 & 17.449 & 283.452 & 340.782 \\
\hline 470 & 490 & 430 & 480.33 & 314.437 & 276.354 & 353.438 & 22.3807 & 280.71 & 345.37 \\
\hline 490 & 510 & 242 & 497.522 & 308.314 & 280.183 & 354.299 & 21.4497 & 281.079 & 350.378 \\
\hline 510 & 530 & 571 & 518.616 & 308.9 & 281.48 & 356.908 & 11.4397 & 301.527 & 334.718 \\
\hline
\end{tabular}

Secondary Air Heater A Gas Inlet Temperature, ${ }^{\circ} \mathrm{F}$

\begin{tabular}{|c|c|c|c|c|c|c|c|c|c|}
\hline $\begin{array}{l}\text { Bin } \\
\text { Low }\end{array}$ & $\begin{array}{l}\text { Bin } \\
\text { High }\end{array}$ & Samples & $\begin{array}{l}\text { Load } \\
\text { Mean }\end{array}$ & $\begin{array}{c}\text { PV } \\
\text { Mean }\end{array}$ & $\begin{array}{l}\text { PV } \\
\text { Min }\end{array}$ & $\begin{array}{l}\text { PV } \\
\text { Max }\end{array}$ & $\begin{array}{l}\text { PV } \\
\text { Std }\end{array}$ & $\begin{array}{l}\text { PV } \\
\text { 5thP }\end{array}$ & $\begin{array}{c}\text { PV } \\
\text { 95thP }\end{array}$ \\
\hline 130 & 150 & 120 & 137.669 & 569.945 & 529.187 & 597.836 & 14.2611 & 552.485 & 594.186 \\
\hline 150 & 170 & 86 & 159.078 & 590.601 & 544.338 & 635.579 & 24.3437 & 548.36 & 632.952 \\
\hline 170 & 190 & 238 & 182.11 & 606.016 & 557.391 & 648.698 & 27.0821 & 567.403 & 643.935 \\
\hline 190 & 210 & 2824 & 201.171 & 619.233 & 562.762 & 818.081 & 30.4923 & 590.381 & 641.569 \\
\hline 210 & 230 & 1110 & 220.026 & 631.532 & 586.646 & 827.599 & 38.3451 & 602.366 & 657.653 \\
\hline 230 & 250 & 1072 & 239.646 & 665.549 & 599.718 & 837.788 & 71.031 & 613.981 & 828.85 \\
\hline 250 & 270 & 1281 & 259.368 & 647.27 & 604.525 & 845.445 & 37.3032 & 623.25 & 679.588 \\
\hline 270 & 290 & 1084 & 279.773 & 662.463 & 616.533 & 842.595 & 30.0391 & 632.998 & 689.84 \\
\hline 290 & 310 & 1194 & 299.899 & 673.656 & 618.447 & 856.953 & 33.7326 & 644.105 & 707.034 \\
\hline 310 & 330 & 1007 & 320.148 & 690.348 & 630.902 & 865.397 & 39.9367 & 657.235 & 758.259 \\
\hline 330 & 350 & 857 & 339.69 & 704.21 & 645.781 & 870.393 & 38.59 & 667.484 & 750.733 \\
\hline 350 & 370 & 817 & 360.282 & 727.207 & 654.773 & 876.277 & 57.1912 & 678.553 & 866.598 \\
\hline 370 & 390 & 798 & 379.563 & 729.696 & 657.936 & 883.419 & 50.4866 & 686.633 & 874.157 \\
\hline 390 & 410 & 729 & 398.761 & 745.933 & 670.871 & 887.109 & 56.4707 & 700.618 & 882.542 \\
\hline 410 & 430 & 605 & 418.97 & 755.291 & 676.747 & 897.381 & 52.882 & 707.712 & 887.975 \\
\hline 430 & 450 & 572 & 441.973 & 775.77 & 686.312 & 903.635 & 57.8336 & 722.322 & 897.817 \\
\hline 450 & 470 & 668 & 456.323 & 765.352 & 709.107 & 909.698 & 41.4852 & 734.532 & 898.802 \\
\hline 470 & 490 & 430 & 480.33 & 782.557 & 708.687 & 913.261 & 42.3767 & 753.101 & 906.772 \\
\hline 490 & 510 & 242 & 497.522 & 790.468 & 759.958 & 923.757 & 44.4161 & 765.786 & 914.521 \\
\hline 510 & 530 & 571 & 518.616 & 779.381 & 761.768 & 925.44 & 21.1743 & 761.768 & 793.992 \\
\hline
\end{tabular}


Secondary Air Heater A Gas Inlet Temperature, ${ }^{\circ} \mathrm{F}$

\begin{tabular}{|c|c|c|c|c|c|c|c|c|c|}
\hline $\begin{array}{l}\text { Bin } \\
\text { Low }\end{array}$ & $\begin{array}{l}\text { Bin } \\
\text { High }\end{array}$ & Samples & $\begin{array}{l}\text { Load } \\
\text { Mean }\end{array}$ & $\begin{array}{l}\text { PV } \\
\text { Mean }\end{array}$ & $\begin{array}{l}\text { PV } \\
\text { Min }\end{array}$ & $\begin{array}{l}\text { PV } \\
\text { Max }\end{array}$ & $\begin{array}{l}\text { PV } \\
\text { Std }\end{array}$ & $\begin{array}{c}\mathrm{PV} \\
5 \text { thP }\end{array}$ & $\begin{array}{c}\mathrm{PV} \\
95 \mathrm{thP}\end{array}$ \\
\hline 130 & 150 & 120 & 137.669 & 579.968 & 537.59 & 610.856 & 15.6271 & 558.616 & 605.158 \\
\hline 150 & 170 & 86 & 159.078 & 599.863 & 565.217 & 639.45 & 24.2671 & 565.217 & 635.043 \\
\hline 170 & 190 & 238 & 182.11 & 608.264 & 565.065 & 647.473 & 23.1888 & 577.364 & 641.458 \\
\hline 190 & 210 & 2824 & 201.171 & 622.938 & 569.594 & 813.993 & 37.4805 & 587.704 & 640.098 \\
\hline 210 & 230 & 1110 & 220.026 & 626.468 & 591.084 & 815.921 & 18.4724 & 605.409 & 649.134 \\
\hline 230 & 250 & 1072 & 239.646 & 634.084 & 602.002 & 820.014 & 17.9587 & 612.914 & 657.732 \\
\hline 250 & 270 & 1281 & 259.368 & 641.658 & 605.493 & 838.683 & 24.3404 & 619.841 & 665.748 \\
\hline 270 & 290 & 1084 & 279.773 & 655.942 & 617.218 & 843.856 & 19.9579 & 632.853 & 679.858 \\
\hline 290 & 310 & 1194 & 299.899 & 666.049 & 620.372 & 849.048 & 20.7201 & 643.289 & 693.817 \\
\hline 310 & 330 & 1007 & 320.148 & 677.648 & 613.837 & 855.142 & 21.6763 & 652.62 & 708.036 \\
\hline 330 & 350 & 857 & 339.69 & 687.47 & 375.035 & 858.337 & 41.384 & 661.026 & 721.081 \\
\hline 350 & 370 & 817 & 360.282 & 699.894 & 655.336 & 844.216 & 18.4771 & 672.44 & 731.365 \\
\hline 370 & 390 & 798 & 379.563 & 708.584 & 659.891 & 851.048 & 18.1142 & 679.589 & 732.407 \\
\hline 390 & 410 & 729 & 398.761 & 719.855 & 669.737 & 849.894 & 17.8946 & 696.555 & 742.621 \\
\hline 410 & 430 & 605 & 418.97 & 730.246 & 676.321 & 834.701 & 16.5503 & 703.398 & 753.425 \\
\hline 430 & 450 & 572 & 441.973 & 742.319 & 686.826 & 784.853 & 13.3456 & 714.139 & 761.78 \\
\hline 450 & 470 & 668 & 456.323 & 744.732 & 698.741 & 800.551 & 12.9756 & 719.977 & 763.281 \\
\hline 470 & 490 & 430 & 480.33 & 761.082 & 277.623 & 805.419 & 26.1163 & 737.927 & 774.774 \\
\hline 490 & 510 & 242 & 497.522 & 771.706 & 747.126 & 800.688 & 10.4555 & 754.417 & 790.333 \\
\hline 510 & 530 & 571 & 518.616 & 774.521 & 754.573 & 805.795 & 11.2627 & 760.972 & 794.911 \\
\hline \multicolumn{10}{|c|}{ Stack O2, \% (Dry) } \\
\hline Bin & Bin & Samples & Load & PV & PV & PV & PV & PV & PV \\
\hline Low & High & & Mean & Mean & Min & $\operatorname{Max}$ & Std & 5thP & 95thP \\
\hline 130 & 150 & 120 & 137.669 & 9.55185 & 8.8165 & 11.1613 & 0.44792 & 9.00269 & 10.3263 \\
\hline 150 & 170 & 86 & 159.078 & 9.17885 & 7.31201 & 9.92559 & 0.40912 & 8.35268 & 9.73531 \\
\hline 170 & 190 & 238 & 182.11 & 8.1505 & 7.38574 & 9.70254 & 0.5631 & 7.60908 & 9.49414 \\
\hline 190 & 210 & 2824 & 201.171 & 9.37226 & 3.84209 & 11.9997 & 1.39371 & 7.7417 & 11.8628 \\
\hline 210 & 230 & 1110 & 220.026 & 8.78639 & 2.00176 & 11.9982 & 1.32931 & 7.43359 & 11.7656 \\
\hline 230 & 250 & 1072 & 239.646 & 8.80363 & 3.50205 & 11.9981 & 1.42654 & 7.14209 & 11.693 \\
\hline 250 & 270 & 1281 & 259.368 & 8.3104 & 2.04287 & 11.9976 & 1.34172 & 6.81628 & 11.4959 \\
\hline 270 & 290 & 1084 & 279.773 & 8.4003 & 3.5832 & 11.9887 & 1.64032 & 6.57022 & 11.6912 \\
\hline 290 & 310 & 1194 & 299.899 & 7.69515 & 4.36406 & 11.9607 & 1.19753 & 6.60498 & 10.8605 \\
\hline 310 & 330 & 1007 & 320.148 & 7.61385 & 4.45918 & 11.9923 & 1.2015 & 6.36182 & 10.2592 \\
\hline 330 & 350 & 857 & 339.69 & 7.47573 & 3.64766 & 11.9995 & 1.34753 & 6.19358 & 11.0851 \\
\hline 350 & 370 & 817 & 360.282 & 7.17325 & 4.64766 & 11.9987 & 1.24873 & 6.0604 & 10.2957 \\
\hline 370 & 390 & 798 & 379.563 & 7.02968 & 2.06543 & 11.9703 & 1.36766 & 5.81049 & 10.8857 \\
\hline 390 & 410 & 729 & 398.761 & 6.9389 & 5.14248 & 11.9458 & 1.18138 & 5.76532 & 9.80063 \\
\hline 410 & 430 & 605 & 418.97 & 6.97807 & 3.68115 & 11.9634 & 1.44174 & 5.59033 & 10.3201 \\
\hline 430 & 450 & 572 & 441.973 & 6.64241 & 3.94727 & 11.8345 & 1.08069 & 5.57627 & 9.37878 \\
\hline 450 & 470 & 668 & 456.323 & 6.215 & 2.77002 & 11.6539 & 0.73461 & 5.38916 & 7.09561 \\
\hline 470 & 490 & 430 & 480.33 & 6.40135 & 4.69063 & 11.6869 & 0.8902 & 5.57959 & 7.89746 \\
\hline 490 & 510 & 242 & 497.522 & 6.48363 & 2.65859 & 11.7107 & 1.11214 & 5.39088 & 8.88666 \\
\hline 510 & 530 & 571 & 518.616 & 6.03488 & 4.7959 & 10.0775 & 0.49224 & 5.40772 & 6.99463 \\
\hline \multicolumn{10}{|c|}{ Stack NOx, Ib/MBtu } \\
\hline $\begin{array}{l}\text { Bin } \\
\text { Low }\end{array}$ & $\begin{array}{l}\text { Bin } \\
\text { High }\end{array}$ & Samples & $\begin{array}{l}\text { Load } \\
\text { Mean }\end{array}$ & $\begin{array}{l}\text { PV } \\
\text { Mean }\end{array}$ & $\begin{array}{l}\text { PV } \\
\text { Min }\end{array}$ & $\begin{array}{l}\text { PV } \\
\text { Max }\end{array}$ & $\begin{array}{l}\text { PV } \\
\text { Std }\end{array}$ & $\begin{array}{l}P V \\
\text { 5thP }\end{array}$ & $\begin{array}{l}\text { PV } \\
\text { 95thP }\end{array}$ \\
\hline 130 & 150 & 120 & 137.669 & 0.43389 & 0.28282 & 0.52066 & 0.04377 & 0.31746 & 0.48061 \\
\hline 150 & 170 & 86 & 159.078 & 0.37187 & 0.25294 & 0.50001 & 0.0656 & 0.25566 & 0.43072 \\
\hline 170 & 190 & 238 & 182.11 & 0.40316 & 0.26589 & 0.53447 & 0.05897 & 0.32701 & 0.50577 \\
\hline 190 & 210 & 2824 & 201.171 & 0.41802 & 0.2631 & 0.70432 & 0.05747 & 0.32961 & 0.51721 \\
\hline 210 & 230 & 1110 & 220.026 & 0.40452 & 0.26829 & 0.66673 & 0.05288 & 0.32762 & 0.49605 \\
\hline 230 & 250 & 1072 & 239.646 & 0.40018 & 0.26851 & 0.62132 & 0.04889 & 0.34191 & 0.4962 \\
\hline 250 & 270 & 1281 & 259.368 & 0.40688 & 0.27271 & 0.62114 & 0.04758 & 0.34048 & 0.48615 \\
\hline 270 & 290 & 1084 & 279.773 & 0.41155 & 0.29181 & 0.6252 & 0.04847 & 0.34362 & 0.50169 \\
\hline 290 & 310 & 1194 & 299.899 & 0.40881 & 0.3012 & 0.56768 & 0.04646 & 0.3469 & 0.48868 \\
\hline 310 & 330 & 1007 & 320.148 & 0.41431 & 0.29688 & 0.54403 & 0.04218 & 0.35196 & 0.48851 \\
\hline 330 & 350 & 857 & 339.69 & 0.43238 & 0.17927 & 0.58883 & 0.0432 & 0.36988 & 0.50522 \\
\hline 350 & 370 & 817 & 360.282 & 0.42642 & 0.29329 & 0.57418 & 0.04058 & 0.37016 & 0.49729 \\
\hline 370 & 390 & 798 & 379.563 & 0.41851 & 0.17325 & 0.55466 & 0.04381 & 0.36374 & 0.50077 \\
\hline 390 & 410 & 724 & 398.78 & 0.41315 & 0.23929 & 0.76575 & 0.04209 & 0.35805 & 0.48477 \\
\hline 410 & 430 & 599 & 419.005 & 0.41901 & 0.2422 & 0.57154 & 0.04375 & 0.35345 & 0.50069 \\
\hline 430 & 450 & 571 & 441.989 & 0.42002 & 0.29404 & 0.56059 & 0.04582 & 0.35522 & 0.4928 \\
\hline 450 & 470 & 666 & 456.311 & 0.42029 & 0.28058 & 0.54058 & 0.03413 & 0.37388 & 0.48278 \\
\hline 470 & 490 & 425 & 480.253 & 0.42693 & 0.34267 & 0.54619 & 0.02942 & 0.37574 & 0.47085 \\
\hline 490 & 510 & 233 & 497.675 & 0.4417 & 0.23366 & 0.95977 & 0.0962 & 0.37596 & 0.48826 \\
\hline 510 & 530 & 570 & 518.627 & 0.41314 & 0.30337 & 0.4938 & 0.02897 & 0.37691 & 0.46648 \\
\hline
\end{tabular}


Stack CO, ppm (not corrected to 3\% O2) (Dry)

\begin{tabular}{|c|c|c|c|c|c|c|c|c|c|}
\hline $\begin{array}{l}\text { Bin } \\
\text { Low }\end{array}$ & $\begin{array}{l}\text { Bin } \\
\text { High }\end{array}$ & Samples & $\begin{array}{l}\text { Load } \\
\text { Mean }\end{array}$ & $\begin{array}{l}\text { PV } \\
\text { Mean }\end{array}$ & $\begin{array}{l}\text { PV } \\
\text { Min }\end{array}$ & $\begin{array}{l}\text { PV } \\
\text { Max }\end{array}$ & $\begin{array}{l}\text { PV } \\
\text { Std }\end{array}$ & $\begin{array}{l}\text { PV } \\
\text { 5thP }\end{array}$ & $\begin{array}{l}\text { PV } \\
\text { 95thP }\end{array}$ \\
\hline 130 & 150 & 119 & 137.667 & 17.7724 & 0 & 35.0859 & 11.5827 & 0.12129 & 31.6172 \\
\hline 150 & 170 & 86 & 159.078 & 4.99536 & -0.9375 & 12.0586 & 3.62313 & -0.9375 & 12.0586 \\
\hline 170 & 190 & 219 & 182.378 & 1.97793 & -4.97227 & 45.8414 & 5.8301 & -4.68305 & 9.90486 \\
\hline 190 & 210 & 2824 & 201.171 & 38.816 & -4.63008 & 90.8438 & 33.0688 & -2.29688 & 86.2597 \\
\hline 210 & 230 & 1098 & 220.03 & 26.4077 & -4.98926 & 88.4895 & 29.6276 & -1.1543 & 85.6474 \\
\hline 230 & 250 & 1071 & 239.652 & 25.8261 & -4.58496 & 108.205 & 28.9923 & -2.54268 & 83.0162 \\
\hline 250 & 270 & 1280 & 259.361 & 25.6585 & -4.7915 & 159.851 & 29.9398 & 0 & 86.4955 \\
\hline 270 & 290 & 1081 & 279.785 & 36.0752 & -4.93945 & 198.052 & 35.5961 & -2.95529 & 90.0227 \\
\hline 290 & 310 & 1186 & 299.908 & 26.8744 & -4.98047 & 269.027 & 38.8228 & -3.59004 & 113.111 \\
\hline 310 & 330 & 1004 & 320.139 & 35.1771 & -4.93242 & 175.289 & 40.8179 & 0 & 113.61 \\
\hline 330 & 350 & 843 & 339.663 & 26.0184 & -4.99414 & 215.351 & 36.0591 & -1.35023 & 90.7717 \\
\hline 350 & 370 & 816 & 360.281 & 22.7526 & -4.83398 & 253.606 & 33.762 & -1.2668 & 87.3471 \\
\hline 370 & 390 & 797 & 379.551 & 26.9018 & -4.95996 & 216.056 & 36.5263 & -1.76115 & 104.815 \\
\hline 390 & 410 & 727 & 398.733 & 29.1881 & -4.9248 & 265.119 & 47.4892 & -2.90443 & 130.981 \\
\hline 410 & 430 & 604 & 418.968 & 33.0523 & -4.84375 & 304.066 & 56.376 & -2.58351 & 149.943 \\
\hline 430 & 450 & 567 & 441.908 & 20.6288 & -4.97266 & 273.526 & 38.507 & -3.78862 & 94.3912 \\
\hline 450 & 470 & 664 & 456.36 & 55.3165 & -4.88438 & 276.158 & 58.5749 & -0.0457 & 179.153 \\
\hline 470 & 490 & 430 & 480.33 & 68.1448 & -1.89258 & 304.02 & 76.8394 & 0 & 236.555 \\
\hline 490 & 510 & 242 & 497.522 & 99.2433 & -2.42285 & 294.404 & 88.825 & 0 & 251.632 \\
\hline 510 & 530 & 571 & 518.616 & 79.9254 & -3.04834 & 300.047 & 54.619 & 9.7957 & 211.35 \\
\hline \multicolumn{10}{|c|}{ Mill A Coal Flow, lb/hr } \\
\hline $\begin{array}{l}\text { Bin } \\
\text { Low }\end{array}$ & $\begin{array}{l}\text { Bin } \\
\text { High }\end{array}$ & Samples & $\begin{array}{l}\text { Load } \\
\text { Mean }\end{array}$ & $\begin{array}{l}\mathrm{PV} \\
\text { Mean }\end{array}$ & $\begin{array}{l}\text { PV } \\
\text { Min }\end{array}$ & $\begin{array}{l}\text { PV } \\
\text { Max }\end{array}$ & $\begin{array}{l}\text { PV } \\
\text { Std }\end{array}$ & $\begin{array}{c}\text { PV } \\
5 \text { thP }\end{array}$ & $\begin{array}{c}\text { PV } \\
\text { 95thP }\end{array}$ \\
\hline 130 & 150 & 120 & 137.669 & 1978.46 & 1.71875 & 58930.1 & 9530.83 & 1.71875 & 1808.13 \\
\hline 150 & 170 & 86 & 159.078 & 1205.22 & 0 & 52071.9 & 7847.49 & 0 & 1.71875 \\
\hline 170 & 190 & 238 & 182.11 & 4417.66 & 0 & 67802.6 & 15056.1 & 0 & 54412 \\
\hline 190 & 210 & 2824 & 201.171 & 23067.7 & -39.5313 & 77431.4 & 22006.7 & 0 & 56576.5 \\
\hline 210 & 230 & 1110 & 220.026 & 25378.7 & -39.5313 & 69069.7 & 21846.4 & 0 & 47400 \\
\hline 230 & 250 & 1072 & 239.646 & 29656.1 & -39.5313 & 78053.6 & 23349.3 & 0 & 51214.6 \\
\hline 250 & 270 & 1281 & 259.368 & 36480.3 & 0 & 73273.4 & 22809.1 & 0 & 55428.3 \\
\hline 270 & 290 & 1084 & 279.773 & 39444.3 & -39.5313 & 73469 & 21315.8 & 0 & 57831.7 \\
\hline 290 & 310 & 1194 & 299.899 & 35620.7 & -39.5313 & 74878.4 & 24580.2 & 0 & 60505.3 \\
\hline 310 & 330 & 1007 & 320.148 & 44442.9 & -39.5313 & 74792.1 & 20737.1 & 0 & 63729 \\
\hline 330 & 350 & 857 & 339.69 & 42381.8 & -39.5313 & 79921.2 & 23291.9 & 0 & 65787.4 \\
\hline 350 & 370 & 817 & 360.282 & 47073.7 & 0 & 73615.4 & 20058.4 & 0 & 60863.1 \\
\hline 370 & 390 & 798 & 379.563 & 47869.2 & 0 & 75862.9 & 21552 & 0 & 62164.8 \\
\hline 390 & 410 & 729 & 398.761 & 46870.5 & 0 & 72178.9 & 23457.9 & 0 & 63720 \\
\hline 410 & 430 & 605 & 418.97 & 50446.6 & 0 & 82417.8 & 22003.1 & 0 & 67063.8 \\
\hline 430 & 450 & 572 & 441.973 & 42021.7 & 0 & 83420.6 & 26605 & 0 & 68943.2 \\
\hline 450 & 470 & 668 & 456.323 & 45432 & 0 & 82322.3 & 24837.7 & 0 & 71270.3 \\
\hline 470 & 490 & 430 & 480.33 & 57208.5 & 0 & 83899.8 & 21417.2 & 0 & 77928.1 \\
\hline 490 & 510 & 242 & 497.522 & 47272.9 & 0 & 82913.9 & 32260.9 & 0 & 78238.4 \\
\hline 510 & 530 & 571 & 518.616 & 20071.9 & 0 & 82313 & 31049.6 & 0 & 69953.9 \\
\hline \multicolumn{10}{|c|}{ Mill B Coal Flow, lb/hr } \\
\hline Bin & Bin & Samples & Load & PV & PV & PV & PV & PV & PV \\
\hline Low & High & & Mean & Mean & Min & Max & Std & 5thP & 95thP \\
\hline 130 & 150 & 120 & 137.669 & 41048.7 & 30.9375 & 66107.6 & 8079.17 & 32521.2 & 49133.1 \\
\hline 150 & 170 & 86 & 159.078 & 46954.8 & 30.9375 & 64053.7 & 7253.19 & 39622.3 & 55141.6 \\
\hline 170 & 190 & 238 & 182.11 & 13949.5 & 30.9375 & & 22354.8 & 37.8125 & 52249 \\
\hline 190 & 210 & 2824 & 201.171 & 14448 & 27.5 & 66321.8 & 19773.7 & 32.6563 & 43738.1 \\
\hline 210 & 230 & 1110 & 220.026 & 15970.8 & 27.5 & 65402.2 & 20959.4 & 30.9375 & 46207.9 \\
\hline 230 & 250 & 1072 & 239.646 & 14851.6 & 30.9375 & 59886.4 & 21664.5 & 32.6563 & 49705.9 \\
\hline 250 & 270 & 1281 & 259.368 & 15305.7 & 30.9375 & 70047 & 22743.5 & 34.5469 & 52996 \\
\hline 270 & 290 & 1084 & 279.773 & 15329.7 & 30.9375 & 67709.5 & 22610.7 & 32.6563 & 53995.1 \\
\hline 290 & 310 & 1194 & 299.899 & 22338.7 & 30.9375 & 71784.6 & 24794.5 & 32.6563 & 58417.6 \\
\hline 310 & 330 & 1007 & 320.148 & 17282.8 & 30.9375 & 71576.3 & 24040.4 & 32.6563 & 60660.1 \\
\hline 330 & 350 & 857 & 339.69 & 26348 & 30.9375 & 72464.2 & 25836.7 & 32.6563 & 60874.7 \\
\hline 350 & 370 & 817 & 360.282 & 32093.1 & 30.9375 & 75955.7 & 25887.9 & 32.6563 & 60871.6 \\
\hline 370 & 390 & 798 & 379.563 & 35461.1 & 32.6563 & 78639 & 25711 & 32.6563 & 61007.4 \\
\hline 390 & 410 & 729 & 398.761 & 41568.3 & 32.6563 & 71354.9 & 23856.8 & 32.6563 & 61612.5 \\
\hline 410 & 430 & 605 & 418.97 & 46041.7 & 32.6563 & 82656.4 & 22049.5 & 36.0938 & 64375.3 \\
\hline 430 & 450 & 572 & 441.973 & 52181.2 & 36.0938 & 79863.8 & 18561.1 & 37.8125 & 67982.7 \\
\hline 450 & 470 & 668 & 456.323 & 55826.8 & 36.0938 & 79669.9 & 10658.5 & 50892.4 & 68796.1 \\
\hline 470 & 490 & 430 & 480.33 & 57707.6 & 36.0938 & 75674.5 & 11789.1 & 46218.2 & 71920.4 \\
\hline 490 & 510 & 242 & 497.522 & 63633.2 & 36.0938 & 83113.9 & 10124.2 & 48687.8 & 76564.3 \\
\hline 510 & 530 & 571 & 518.616 & 70340.1 & 36.0938 & 80600.4 & 11254.4 & 56814.4 & 77721.9 \\
\hline
\end{tabular}


Mill C Coal Flow, lb/hr

\begin{tabular}{|c|c|c|c|c|c|c|c|c|c|}
\hline $\begin{array}{l}\text { Bin } \\
\text { Low }\end{array}$ & $\begin{array}{l}\text { Bin } \\
\text { High }\end{array}$ & Samples & $\begin{array}{l}\text { Load } \\
\text { Mean }\end{array}$ & $\begin{array}{l}\text { PV } \\
\text { Mean }\end{array}$ & $\begin{array}{l}\text { PV } \\
\text { Min }\end{array}$ & $\begin{array}{l}\text { PV } \\
\text { Max }\end{array}$ & $\begin{array}{l}\text { PV } \\
\text { Std }\end{array}$ & $\begin{array}{c}P V \\
5 \text { thP }\end{array}$ & $\begin{array}{l}\mathrm{PV} \\
95 \text { thP }\end{array}$ \\
\hline 130 & 150 & 120 & 137.669 & 39615.4 & -8.59375 & 61815.2 & 12472.6 & -6.875 & 47549.4 \\
\hline 150 & 170 & 86 & 159.078 & 34939.9 & -8.59375 & 65164.7 & 22405.6 & -5.15625 & 56208.9 \\
\hline 170 & 190 & 238 & 182.11 & 44620.4 & -8.59375 & 61181.3 & 18646.7 & -5.15625 & 54215.2 \\
\hline 190 & 210 & 2824 & 201.171 & 36653.8 & -8.59375 & 77306.3 & 17559.1 & -5.15625 & 55687.1 \\
\hline 210 & 230 & 1110 & 220.026 & 40885.2 & -8.59375 & 75311.2 & 16408.9 & -5.15625 & 59709 \\
\hline 230 & 250 & 1072 & 239.646 & 44347.7 & -8.59375 & 78372.3 & 14284.7 & 6.875 & 57736.8 \\
\hline 250 & 270 & 1281 & 259.368 & 45388.9 & -8.59375 & 74823 & 16224.4 & 0 & 56395.5 \\
\hline 270 & 290 & 1084 & 279.773 & 46691.2 & -8.59375 & 73819.6 & 14512.9 & 0 & 58589.2 \\
\hline 290 & 310 & 1194 & 299.899 & 51165.7 & -8.59375 & 78358.8 & 11959.4 & 42286.5 & 62886.5 \\
\hline 310 & 330 & 1007 & 320.148 & 51949.8 & -8.59375 & 75686.9 & 12937.9 & 42895.4 & 65713.6 \\
\hline 330 & 350 & 857 & 339.69 & 51961 & -6.875 & 86210.4 & 16922 & 0 & 69729.1 \\
\hline 350 & 370 & 817 & 360.282 & 49134.4 & -6.875 & 76542.5 & 18870.7 & 0 & 65187.6 \\
\hline 370 & 390 & 798 & 379.563 & 52820.9 & -6.875 & 76046.1 & 16123 & 0 & 63126.2 \\
\hline 390 & 410 & 729 & 398.761 & 54042.2 & -6.875 & 73752.3 & 16443.8 & -6.875 & 65631.9 \\
\hline 410 & 430 & 605 & 418.97 & 52473.3 & -6.875 & 80562.6 & 20326.1 & -6.875 & 68263.9 \\
\hline 430 & 450 & 572 & 441.973 & 60717.4 & 10792.4 & 83631.3 & 6796.35 & 52883.6 & 71388.1 \\
\hline 450 & 470 & 668 & 456.323 & 62064 & -6.875 & 84586.9 & 7761.35 & 53771.6 & 75843.6 \\
\hline 470 & 490 & 430 & 480.33 & 65768.5 & -6.875 & 85363.1 & 8936.59 & 57801.2 & 80393.5 \\
\hline 490 & 510 & 242 & 497.522 & 70988.7 & 53135.2 & 83081.3 & 6966.22 & 60502.8 & 80730 \\
\hline 510 & 530 & 571 & 518.616 & 74677.7 & 55329 & 83569.8 & 4568.47 & 66188.2 & 78667.3 \\
\hline \multicolumn{10}{|c|}{ Mill D Coal Flow, lb/hr } \\
\hline Bin & Bin & Samples & Load & PV & PV & PV & $\begin{array}{l}\text { PV } \\
\text { Sta }\end{array}$ & $\begin{array}{l}\mathrm{PV} \\
5 \text { thP }\end{array}$ & $\begin{array}{c}P V \\
\text { PVthP }\end{array}$ \\
\hline $\begin{array}{l}\text { Low } \\
130\end{array}$ & $\begin{aligned} \text { High } \\
150\end{aligned}$ & 120 & $\begin{array}{l}\text { Mean } \\
137.669\end{array}$ & $\begin{array}{l}\text { Mean } \\
402515\end{array}$ & $\frac{\text { Min }}{-134.063}$ & $\frac{\operatorname{Max}}{604962}$ & $\begin{array}{l}\text { Std } \\
795352\end{array}$ & $\begin{array}{l}5 \text { thP } \\
317666\end{array}$ & $\frac{95 \text { thP }}{470711}$ \\
\hline 150 & 170 & 86 & 159.078 & 47196.9 & 30709.8 & 64556.9 & 5408.6 & 39905.6 & 55588.4 \\
\hline 170 & 190 & 238 & 182.11 & 51021.1 & 33004.1 & 66248.2 & 3221.01 & 45259.7 & 53563.1 \\
\hline 190 & 210 & 2824 & 201.171 & 40608.9 & -986.563 & 71262.8 & 13750 & -440 & 56803.1 \\
\hline 210 & 230 & 1110 & 220.026 & 45274.4 & -823.281 & 73502 & 8516.28 & 39518.5 & 59153.9 \\
\hline 230 & 250 & 1072 & 239.646 & 46353.8 & -962.5 & 76322.5 & 10338.1 & 40024.2 & 57447.1 \\
\hline 250 & 270 & 1281 & 259.368 & 47045.2 & -965.938 & 77734.6 & 13195.5 & -80.7813 & 55890.2 \\
\hline 270 & 290 & 1084 & 279.773 & 47898.1 & -965.938 & 79698.8 & 12825.9 & 0 & 58811.2 \\
\hline 290 & 310 & 1194 & 299.899 & 51405.3 & -720.156 & 75859.8 & 11431.9 & 41865.7 & 62725.4 \\
\hline 310 & 330 & 1007 & 320.148 & 53407.3 & -699.531 & 79616.6 & 9785.92 & 44763.7 & 65299.3 \\
\hline 330 & 350 & 857 & 339.69 & 55452.1 & -699.531 & 83478 & 9969.53 & 46588.4 & 69230.3 \\
\hline 350 & 370 & 817 & 360.282 & 55586.2 & -699.531 & 79572.3 & 6204.66 & 49508.4 & 64447 \\
\hline 370 & 390 & 798 & 379.563 & 56801.1 & -699.531 & 79321.3 & 7042.1 & 49092.7 & 63225.7 \\
\hline 390 & 410 & 729 & 398.761 & 57899 & -699.531 & 79584.7 & 7589.88 & 48721.9 & 64518.5 \\
\hline 410 & 430 & 605 & 418.97 & 60577 & -80.7813 & 80768.9 & 7682.01 & 50188.9 & 78368.8 \\
\hline 430 & 450 & 572 & 441.973 & 61083.7 & -658.281 & 82783.6 & 8966.82 & 52644.7 & 78108.1 \\
\hline 450 & 470 & 668 & 456.323 & 61287.1 & -658.281 & 81163.8 & 7017.13 & 55042.9 & 73418.4 \\
\hline 470 & 490 & 430 & 480.33 & 64227.3 & 5667.41 & 84589.3 & 8927.07 & 56268.4 & 76550 \\
\hline 490 & 510 & 242 & 497.522 & 70056.7 & 52922.4 & 84142.8 & 6083.36 & 60063.3 & 77385.3 \\
\hline 510 & 530 & 571 & 518.616 & 73655.3 & 56209.7 & 82624.1 & 4268.22 & 65591.5 & 78465.8 \\
\hline \multicolumn{10}{|c|}{ Mill E Coal Flow, lb/hr } \\
\hline Bin & Bin & Samples & Load & PV & PV & PV & PV & PV & PV \\
\hline Low & High & & Mean & Mean & Min & $\operatorname{Max}$ & Std & 5thP & 95thP \\
\hline 130 & 150 & 120 & 137.669 & 2234.46 & -110 & 69266 & 11034.1 & 0 & 0 \\
\hline 150 & 170 & 86 & 159.078 & 1158.64 & 0 & 53079.5 & 7569.41 & 0 & 0 \\
\hline 170 & 190 & 238 & 182.11 & 1760.7 & -110 & 62180.3 & 9630.97 & -110 & 0 \\
\hline 190 & 210 & 2824 & 201.171 & 10226 & -110 & 78948.7 & 19318.4 & -103.125 & 49049.4 \\
\hline 210 & 230 & 1110 & 220.026 & 13814.6 & -110 & 76321.8 & 21092.6 & -103.125 & 47101 \\
\hline 230 & 250 & 1072 & 239.646 & 22431 & -110 & 68783.3 & 24334.3 & -99.6875 & 51511.8 \\
\hline 250 & 270 & 1281 & 259.368 & 22556.8 & -110 & 75887.6 & 25229.4 & -103.125 & 54627.5 \\
\hline 270 & 290 & 1084 & 279.773 & 22728.5 & -110 & 71064.8 & 24930.9 & -99.6875 & 56743.5 \\
\hline 290 & 310 & 1194 & & 26405.1 & -110 & 76193.6 & 25939.5 & -99.6875 & 60292.8 \\
\hline 310 & 330 & 1007 & 320.148 & 33044.1 & -110 & 71654.7 & 25511.7 & -99.6875 & 62629.1 \\
\hline 330 & 350 & 857 & 339.69 & 33637.8 & -115.156 & 72178.6 & 26159.5 & -94.5313 & 64103.2 \\
\hline 350 & 370 & 817 & 360.282 & 43047.8 & -110 & 80855.8 & 23431.2 & -89.375 & 60049.2 \\
\hline 370 & 390 & 798 & 379.563 & 44156.2 & -110 & 77280.2 & 24771 & 0 & 62651.9 \\
\hline 390 & 410 & 729 & 398.761 & 44396.2 & -104.844 & 73491.3 & 25572 & 0 & 64337.4 \\
\hline 410 & 430 & 605 & 418.97 & 46880 & -104.844 & 83712.8 & 25055.6 & 0 & 67479 \\
\hline 430 & 450 & 572 & 441.973 & 39020.5 & -104.844 & 77968.3 & 27803.4 & 0 & 67284.8 \\
\hline 450 & 470 & 668 & 456.323 & 47950.3 & -104.844 & 81483.2 & 23783.5 & 0 & 73217.5 \\
\hline 470 & 490 & 430 & 480.33 & 44598 & -104.844 & 82820.4 & 28392.3 & 0 & 70352.9 \\
\hline 490 & 510 & 242 & 497.522 & 31856.4 & 0 & 83811.8 & 32866.6 & 0 & 69834.3 \\
\hline 510 & 530 & 571 & 518.616 & 19733.5 & 0 & 81864.1 & 30514.1 & 0 & 67954.2 \\
\hline
\end{tabular}


DCS CHARACTERIZATION

Mill F Coal Flow, lb/hr

\begin{tabular}{|c|c|c|c|c|c|c|c|c|c|}
\hline $\begin{array}{l}\text { Bin } \\
\text { Low }\end{array}$ & $\begin{array}{l}\text { Bin } \\
\text { High }\end{array}$ & Samples & $\begin{array}{l}\text { Load } \\
\text { Mean }\end{array}$ & $\begin{array}{c}\text { PV } \\
\text { Mean }\end{array}$ & $\begin{array}{l}\text { PV } \\
\text { Min }\end{array}$ & $\begin{array}{l}\text { PV } \\
\text { Max }\end{array}$ & $\begin{array}{l}\text { PV } \\
\text { Std }\end{array}$ & $\begin{array}{c}\mathrm{PV} \\
5 \text { thP }\end{array}$ & $\begin{array}{c}\text { PV } \\
95 \text { thP }\end{array}$ \\
\hline 130 & 150 & 120 & 137.669 & -21.8282 & -22.3438 & -10.3125 & 2.08549 & -22.3438 & -17.1875 \\
\hline 150 & 170 & 86 & 159.078 & 345.958 & -24.0625 & 31668.8 & 3417.37 & -24.0625 & -22 \\
\hline 170 & 190 & 238 & 182.11 & 38894.2 & -22.3438 & 60773.6 & 22616.5 & -22.3438 & 54394.9 \\
\hline 190 & 210 & 2824 & 201.171 & 38654 & -20.625 & 71902.2 & 17161.1 & -18.9063 & 58244.3 \\
\hline 210 & 230 & 1110 & 220.026 & 33790.9 & -20.625 & 76084.9 & 22475 & -18.9063 & 60145.6 \\
\hline 230 & 250 & 1072 & 239.646 & 33234.4 & -20.625 & 79111 & 23765.6 & -18.9063 & 59429.6 \\
\hline 250 & 270 & 1281 & 259.368 & 38488.5 & -20.625 & 75620.9 & 22813.4 & -18.9063 & 57208.1 \\
\hline 270 & 290 & 1084 & 279.773 & 43513.9 & -20.625 & 74285.4 & 18849.1 & -18.9063 & 59261.5 \\
\hline 290 & 310 & 1194 & 299.899 & 41475.4 & -20.625 & 79496.3 & 23341 & -18.9063 & 63429.3 \\
\hline 310 & 330 & 1007 & 320.148 & 43937.6 & -20.625 & 75113.8 & 22731 & -18.9063 & 66097.1 \\
\hline 330 & 350 & 857 & 339.69 & 47651.9 & -18.9063 & 86412.6 & 21906.5 & -18.9063 & 69910.9 \\
\hline 350 & 370 & 817 & 360.282 & 45242.8 & -18.9063 & 80817.7 & 22647 & -18.9063 & 64097.7 \\
\hline 370 & 390 & 798 & 379.563 & 45256.6 & -18.9063 & 79918.4 & 23775.9 & -18.9063 & 63661.7 \\
\hline 390 & 410 & 729 & 398.761 & 47042.2 & -18.9063 & 74397.8 & 23465 & -18.9063 & 65028.1 \\
\hline 410 & 430 & 605 & 418.97 & 52516.9 & -18.9063 & 83548.4 & 20498.6 & -10.3125 & 69005.2 \\
\hline 430 & 450 & 572 & 441.973 & 58712.9 & -18.9063 & 84704.8 & 11749.7 & 50052.5 & 70578.1 \\
\hline 450 & 470 & 668 & 456.323 & 62271.8 & 5227.41 & 85432.9 & 8580.59 & 53414 & 76919.5 \\
\hline 470 & 490 & 430 & 480.33 & 66355.1 & 45731.5 & 86295.3 & 8517.25 & 56672.7 & 80342.3 \\
\hline 490 & 510 & 242 & 497.522 & 71479.3 & 51881.5 & 84033.5 & 7189.85 & 58938.2 & 80048.2 \\
\hline 510 & 530 & 571 & 518.616 & 75204.5 & 56130.6 & 85095 & 4336.81 & 67092.2 & 79130.9 \\
\hline
\end{tabular}


Table A-13 P4A - Mill Pattern Frequency by Load (1Q95)

\begin{tabular}{|c|c|c|c|c|c|c|c|c|c|c|c|c|c|c|c|c|c|c|c|c|}
\hline \multirow[b]{2}{*}{$\begin{array}{c}\text { Mill } \\
\text { A-B-C-D-E-F }\end{array}$} & \multicolumn{20}{|c|}{ Load, MW } \\
\hline & 130 & 150 & 170 & 190 & 210 & 230 & 250 & 270 & 290 & 310 & 330 & 350 & 370 & 390 & 410 & 430 & 450 & 470 & 490 & 510 \\
\hline $0-0-0-0-0-1$ & 0 & 0 & 0 & 0 & 0 & 0 & 0 & 0 & 0 & 0 & 0 & 0 & 0 & 0 & 0 & 0 & 0 & 0 & 0 & 0 \\
\hline $0-0-0-0-1-0$ & 0 & 0 & 0 & 0 & 0 & 0 & 0 & 0 & 0 & 0 & 0 & 0 & 0 & 0 & 0 & 0 & 0 & 0 & 0 & 0 \\
\hline $0-0-0-0-1-1$ & 0 & 0 & 0 & 0 & 0 & 0 & 0 & 0 & 0 & 0 & 0 & 0 & 0 & 0 & 0 & 0 & 0 & 0 & 0 & 0 \\
\hline $0-0-0-1-0-0$ & 0 & 0 & 0 & 0 & 0 & 0 & 0 & 0 & 0 & 0 & 0 & 0 & 0 & 0 & 0 & 0 & 0 & 0 & 0 & 0 \\
\hline $0-0-0-1-0-1$ & 0 & 0 & 0 & 0 & 0 & 0 & 0 & 0 & 0 & 0 & 0 & 0 & 0 & 0 & 0 & 0 & 0 & 0 & 0 & 0 \\
\hline $0-0-0-1-1-0$ & 0 & 0 & 0 & 0 & 0 & 0 & 0 & 0 & 0 & 0 & 0 & 0 & 0 & 0 & 0 & 0 & 0 & 0 & 0 & 0 \\
\hline $0-0-0-1-1-1$ & 0 & 0 & 0 & 21 & 9 & 5 & 0 & 0 & 0 & 0 & 0 & 0 & 0 & 0 & 0 & 0 & 0 & 0 & 0 & 0 \\
\hline $0-0-1-0-0-0$ & 0 & 0 & 0 & 0 & 0 & 0 & 0 & 0 & 0 & 0 & 0 & 0 & 0 & 0 & 0 & 0 & 0 & 0 & 0 & 0 \\
\hline $0-0-1-0-0-1$ & 0 & 0 & 0 & 0 & 0 & 0 & 0 & 0 & 0 & 0 & 0 & 0 & 0 & 0 & 0 & 0 & 0 & 0 & 0 & 0 \\
\hline $0-0-1-0-1-0$ & 0 & 0 & 0 & 0 & 0 & 0 & 0 & 0 & 0 & 0 & 0 & 0 & 0 & 0 & 0 & 0 & 0 & 0 & 0 & 0 \\
\hline $0-0-1-0-1-1$ & 0 & 0 & 0 & 13 & 1 & 1 & 0 & 0 & 0 & 0 & 0 & 0 & 0 & 0 & 0 & 0 & 0 & 0 & 0 & 0 \\
\hline $0-0-1-1-0-0$ & 0 & 0 & 0 & 1 & 0 & 0 & 0 & 0 & 0 & 0 & 0 & 0 & 0 & 0 & 0 & 0 & 0 & 0 & 0 & 0 \\
\hline $0-0-1-1-0-1$ & 0 & 0 & 170 & 454 & 120 & 48 & 10 & 0 & 0 & 0 & 0 & 0 & 0 & 0 & 0 & 0 & 0 & 0 & 0 & 0 \\
\hline $0-0-1-1-1-0$ & 0 & 0 & 0 & 0 & 0 & 0 & 0 & 0 & 0 & 0 & 0 & 0 & 0 & 0 & 0 & 0 & 0 & 0 & 0 & 0 \\
\hline $0-0-1-1-1-1$ & 0 & 0 & 0 & 3 & 31 & 54 & 50 & 19 & 1 & 0 & 0 & 0 & 0 & 0 & 0 & 0 & 0 & 0 & 0 & 0 \\
\hline $0-1-0-0-0-0$ & 0 & 0 & 0 & 0 & 0 & 0 & 0 & 0 & 0 & 0 & 0 & 0 & 0 & 0 & 0 & 0 & 0 & 0 & 0 & 0 \\
\hline $0-1-0-0-0-1$ & 0 & 0 & 0 & 0 & 0 & 0 & 0 & 0 & 0 & 0 & 0 & 0 & 0 & 0 & 0 & 0 & 0 & 0 & 0 & 0 \\
\hline $0-1-0-0-1-0$ & 3 & 0 & 0 & 0 & 0 & 0 & 0 & 0 & 0 & 0 & 0 & 0 & 0 & 0 & 0 & 0 & 0 & 0 & 0 & 0 \\
\hline $0-1-0-0-1-1$ & 0 & 0 & 0 & 1 & 0 & 0 & 0 & 0 & 0 & 0 & 0 & 0 & 0 & 0 & 0 & 0 & 0 & 0 & 0 & 0 \\
\hline $0-1-0-1-0-0$ & 1 & 21 & 0 & 0 & 0 & 0 & 0 & 0 & 0 & 0 & 0 & 0 & 0 & 0 & 0 & 0 & 0 & 0 & 0 & 0 \\
\hline $0-1-0-1-0-1$ & 0 & 0 & 9 & 121 & 78 & 3 & 0 & 0 & 0 & 0 & 0 & 0 & 1 & 1 & 0 & 0 & 0 & 0 & 0 & 0 \\
\hline $0-1-0-1-1-0$ & 1 & 1 & 7 & 19 & 1 & 0 & 0 & 0 & 0 & 0 & 0 & 0 & 0 & 0 & 0 & 0 & 0 & 0 & 0 & 0 \\
\hline $0-1-0-1-1-1$ & 0 & 0 & 0 & 7 & 13 & 36 & 4 & 6 & 5 & 2 & 2 & 0 & 0 & 0 & 0 & 0 & 0 & 0 & 0 & 0 \\
\hline $0-1-1-0-0-0$ & 0 & 0 & 0 & 0 & 0 & 0 & 0 & 0 & 0 & 0 & 0 & 0 & 0 & 0 & 0 & 0 & 0 & 0 & 0 & 0 \\
\hline $0-1-1-0-0-1$ & 0 & 0 & 0 & 0 & 0 & 0 & 0 & 0 & 0 & 0 & 0 & 0 & 1 & 0 & 0 & 0 & 0 & 0 & 0 & 0 \\
\hline $0-1-1-0-1-0$ & 0 & 0 & 0 & 0 & 0 & 0 & 0 & 0 & 0 & 0 & 0 & 0 & 0 & 0 & 0 & 0 & 0 & 0 & 0 & 0 \\
\hline $0-1-1-0-1-1$ & 0 & 0 & 0 & 87 & 16 & 9 & 6 & 2 & 0 & 0 & 0 & 0 & 0 & 0 & 0 & 0 & 0 & 0 & 0 & 0 \\
\hline $0-1-1-1-0-0$ & 110 & 61 & 33 & 0 & 0 & 0 & 0 & 0 & 0 & 0 & 0 & 0 & 0 & 0 & 0 & 0 & 0 & 0 & 0 & 0 \\
\hline $0-1-1-1-0-1$ & 0 & 1 & 0 & 573 & 198 & 251 & 277 & 200 & 357 & 150 & 145 & 65 & 86 & 111 & 63 & 155 & 80 & 37 & 75 & 402 \\
\hline $0-1-1-1-1-0$ & 0 & 0 & 0 & 15 & 1 & 0 & 0 & 2 & 3 & 2 & 0 & 0 & 0 & 0 & 0 & 0 & 0 & 0 & 0 & 0 \\
\hline $0-1-1-1-1-1$ & 0 & 0 & 0 & 0 & 0 & 0 & 6 & 4 & 6 & 14 & 43 & 56 & 43 & 29 & 28 & 4 & 69 & 11 & 0 & 0 \\
\hline $1-0-0-0-0-0$ & 0 & 0 & 0 & 0 & 0 & 0 & 0 & 0 & 0 & 0 & 0 & 0 & 0 & 0 & 0 & 0 & 0 & 0 & 0 & 0 \\
\hline $1-0-0-0-0-1$ & 0 & 0 & 0 & 0 & 0 & 0 & 0 & 0 & 0 & 0 & 0 & 0 & 0 & 0 & 0 & 0 & 0 & 0 & 0 & 0 \\
\hline $1-0-0-0-1-0$ & 0 & 0 & 0 & 0 & 0 & 0 & 0 & 0 & 0 & 0 & 0 & 0 & 0 & 0 & 0 & 0 & 0 & 0 & 0 & 0 \\
\hline $1-0-0-0-1-1$ & 0 & 0 & 0 & 0 & 0 & 0 & 0 & 0 & 0 & 0 & 0 & 0 & 0 & 0 & 0 & 0 & 0 & 0 & 0 & 0 \\
\hline $1-0-0-1-0-0$ & 2 & 0 & 0 & 0 & 1 & 0 & 0 & 0 & 0 & 0 & 0 & 0 & 0 & 0 & 0 & 0 & 0 & 0 & 0 & 0 \\
\hline $1-0-0-1-0-1$ & 0 & 0 & 0 & 74 & 2 & 2 & 0 & 0 & 0 & 0 & 0 & 0 & 0 & 0 & 0 & 0 & 0 & 0 & 0 & 0 \\
\hline $1-0-0-1-1-0$ & 1 & 1 & 1 & 35 & 1 & 2 & 0 & 0 & 0 & 0 & 0 & 0 & 0 & 0 & 0 & 0 & 0 & 0 & 0 & 0 \\
\hline $1-0-0-1-1-1$ & 0 & 0 & 0 & 141 & 23 & 25 & 98 & 50 & 27 & 26 & 5 & 0 & 0 & 0 & 0 & 0 & 0 & 0 & 0 & 0 \\
\hline $1-0-1-0-0-0$ & 0 & 0 & 0 & 0 & 0 & 0 & 0 & 0 & 0 & 0 & 0 & 0 & 0 & 0 & 0 & 0 & 0 & 0 & 0 & 0 \\
\hline $1-0-1-0-0-1$ & 0 & 0 & 0 & 27 & 0 & 2 & 0 & 0 & 0 & 0 & 0 & 0 & 0 & 0 & 0 & 0 & 0 & 0 & 0 & 0 \\
\hline $1-0-1-0-1-0$ & 0 & 0 & 0 & 5 & 0 & 0 & 0 & 0 & 0 & 0 & 0 & 0 & 0 & 0 & 0 & 0 & 0 & 0 & 0 & 0 \\
\hline $1-0-1-0-1-1$ & 0 & 0 & 0 & 7 & 0 & 12 & 34 & 36 & 28 & 5 & 0 & 0 & 0 & 0 & 0 & 0 & 0 & 0 & 0 & 0 \\
\hline $1-0-1-1-0-0$ & 0 & 0 & 0 & 17 & 1 & 4 & 0 & 2 & 0 & 0 & 0 & 0 & 0 & 0 & 0 & 0 & 0 & 0 & 0 & 0 \\
\hline $1-0-1-1-0-1$ & 0 & 0 & 0 & 872 & 278 & 238 & 376 & 314 & 177 & 163 & 88 & 16 & 3 & 0 & 0 & 0 & 0 & 0 & 0 & 0 \\
\hline $1-0-1-1-1-0$ & 0 & 0 & 0 & 168 & 235 & 324 & 252 & 100 & 144 & 89 & 44 & 8 & 2 & 0 & 0 & 1 & 0 & 0 & 0 & 0 \\
\hline $1-0-1-1-1-1$ & 0 & 0 & 0 & 0 & 0 & 11 & 58 & 217 & 273 & 373 & 277 & 294 & 267 & 176 & 106 & 56 & 18 & 14 & 3 & 8 \\
\hline $1-1-0-0-0-0$ & 0 & 0 & 0 & 0 & 0 & 0 & 0 & 0 & 0 & 0 & 0 & 0 & 0 & 0 & 0 & 0 & 0 & 0 & 0 & 0 \\
\hline $1-1-0-0-0-1$ & 0 & 0 & 0 & 0 & 0 & 0 & 0 & 0 & 0 & 0 & 0 & 0 & 0 & 0 & 0 & 0 & 0 & 0 & 0 & 0 \\
\hline $1-1-0-0-1-0$ & 0 & 0 & 0 & 37 & 1 & 0 & 0 & 0 & 0 & 0 & 0 & 0 & 0 & 0 & 0 & 0 & 0 & 0 & 0 & 0 \\
\hline $1-1-0-0-1-1$ & 0 & 0 & 0 & 0 & 0 & 16 & 6 & 6 & 4 & 3 & 0 & 0 & 0 & 0 & 0 & 0 & 0 & 0 & 0 & 0 \\
\hline $1-1-0-1-0-0$ & 2 & 1 & 18 & 5 & 0 & 0 & 0 & 0 & 0 & 0 & 0 & 0 & 0 & 0 & 0 & 0 & 0 & 0 & 0 & 0 \\
\hline $1-1-0-1-0-1$ & 0 & 0 & 0 & 4 & 12 & 5 & 27 & 8 & 0 & 0 & 0 & 0 & 0 & 0 & 0 & 0 & 0 & 0 & 0 & 0 \\
\hline $1-1-0-1-1-0$ & 0 & 0 & 0 & 22 & 0 & 0 & 0 & 0 & 0 & 0 & 0 & 0 & 0 & 0 & 0 & 0 & 0 & 0 & 0 & 0 \\
\hline $1-1-0-1-1-1$ & 0 & 0 & 0 & 0 & 0 & 0 & 4 & 11 & 5 & 11 & 60 & 100 & 63 & 55 & 73 & 1 & 1 & 1 & 0 & 0 \\
\hline $1-1-1-0-0-0$ & 0 & 0 & 0 & 0 & 0 & 0 & 0 & 0 & 0 & 0 & 0 & 0 & 0 & 0 & 0 & 0 & 0 & 0 & 0 & 0 \\
\hline $1-1-1-0-0-1$ & 0 & 0 & 0 & 0 & 0 & 0 & 0 & 0 & 0 & 0 & 0 & 0 & 0 & 0 & 0 & 0 & 0 & 0 & 0 & 0 \\
\hline $1-1-1-0-1-0$ & 0 & 0 & 0 & 55 & 5 & 2 & 38 & 10 & 0 & 0 & 0 & 0 & 0 & 0 & 0 & 0 & 0 & 0 & 0 & 0 \\
\hline $1-1-1-0-1-1$ & 0 & 0 & 0 & 0 & 0 & 0 & 0 & 2 & 4 & 9 & 13 & 5 & 7 & 7 & 1 & 4 & 1 & 1 & 0 & 0 \\
\hline $1-1-1-1-0-0$ & 0 & 0 & 0 & 40 & 83 & 22 & 16 & 10 & 3 & 2 & 0 & 1 & 0 & 0 & 0 & 0 & 0 & 0 & 0 & 0 \\
\hline $1-1-1-1-0-1$ & 0 & 0 & 0 & 0 & 0 & 0 & 1 & 50 & 39 & 53 & 86 & 101 & 97 & 65 & 66 & 34 & 44 & 85 & 49 & 0 \\
\hline $1-1-1-1-1-0$ & 0 & 0 & 0 & 0 & 0 & 0 & 18 & 35 & 118 & 105 & 92 & 149 & 166 & 139 & 72 & 14 & 3 & 0 & 0 & 0 \\
\hline $1-1-1-1-1-1$ & 0 & 0 & 0 & 0 & 0 & 0 & 0 & 0 & 0 & 0 & 2 & 22 & 62 & 146 & 196 & 303 & 452 & 281 & 115 & 161 \\
\hline
\end{tabular}

${ }^{1}$ Number of occurrances of mill combination

${ }^{2}$ Mill on $=1$, Mill off $=0$ (assumed off if flow $<20000 \mathrm{lb} / \mathrm{hr}$ ) 
Table A-14 P4A - NOx Emissions by Load and Mill Pattern (1Q95)

\begin{tabular}{|c|c|c|c|c|c|c|c|c|c|c|c|c|c|c|c|c|c|c|c|c|}
\hline \multirow[b]{2}{*}{$\begin{array}{c}\text { Mill } \\
\text { A-B-C-D-E-F }\end{array}$} & \multicolumn{20}{|c|}{ Load, MW } \\
\hline & 130 & 150 & 170 & 190 & 210 & 230 & 250 & 270 & 290 & 310 & 330 & 350 & 370 & 390 & 410 & 430 & 450 & 470 & 490 & 510 \\
\hline $0-0-0-0-0-1$ & na & na & na & na & na & na & na & na & na & na & na & na & na & na & na & na & na & na & na & na \\
\hline $0-0-0-0-1-0$ & na & na & na & na & na & na & na & na & na & na & na & na & na & na & na & na & na & na & na & na \\
\hline $0-0-0-0-1-1$ & na & na & na & na & na & na & na & na & na & na & na & na & na & na & na & na & na & na & na & na \\
\hline $0-0-0-1-0-0$ & na & na & na & na & na & na & na & na & na & na & na & na & na & na & na & na & na & na & na & na \\
\hline $0-0-0-1-0-1$ & na & na & na & na & na & na & na & na & na & na & na & na & na & na & na & na & na & na & na & na \\
\hline $0-0-0-1-1-0$ & na & na & na & na & na & na & na & na & na & na & na & na & na & na & na & na & na & na & na & na \\
\hline $0-0-0-1-1-1$ & na & na & na & 0.427 & 0.361 & 0.329 & na & na & na & na & na & na & na & na & na & na & na & na & na & na \\
\hline $0-0-1-0-0-0$ & na & na & na & na & na & na & na & na & na & na & na & na & na & na & na & na & na & na & na & na \\
\hline $0-0-1-0-0-1$ & na & na & na & na & na & na & na & na & na & na & na & na & na & na & na & na & na & na & na & na \\
\hline $0-0-1-0-1-0$ & na & na & na & na & na & na & na & na & na & na & na & na & na & na & na & na & na & na & na & na \\
\hline $0-0-1-0-1-1$ & na & na & na & 0.563 & 0.596 & 0.462 & na & na & na & na & na & na & na & na & na & na & na & na & na & na \\
\hline $0-0-1-1-0-0$ & na & na & na & 0.367 & na & na & na & na & na & na & na & na & na & na & na & na & na & na & na & na \\
\hline $0-0-1-1-0-1$ & na & na & 0.421 & 0.387 & 0.378 & 0.378 & 0.383 & na & na & na & na & na & na & na & na & na & na & na & na & na \\
\hline $0-0-1-1-1-0$ & na & na & na & na & na & na & na & na & na & na & na & na & na & na & na & na & na & na & na & na \\
\hline $0-0-1-1-1-1$ & na & na & na & 0.544 & 0.435 & 0.421 & 0.473 & 0.460 & 0.392 & na & na & na & na & na & na & na & na & na & na & na \\
\hline $0-1-0-0-0-0$ & na & na & na & na & na & na & na & na & na & na & na & na & na & na & na & na & na & na & na & na \\
\hline $0-1-0-0-0-1$ & na & na & na & na & na & na & na & na & na & na & na & na & na & na & na & na & na & na & na & na \\
\hline $0-1-0-0-1-0$ & 0.294 & na & na & na & na & na & na & na & na & na & na & na & na & na & na & na & na & na & na & na \\
\hline $0-1-0-0-1-1$ & na & na & na & 0.505 & na & na & na & na & na & na & na & na & na & na & na & na & na & na & na & na \\
\hline $0-1-0-1-0-0$ & 0.331 & 0.267 & na & na & na & na & na & na & na & na & na & na & na & na & na & na & na & na & na & na \\
\hline $0-1-0-1-0-1$ & na & na & 0.309 & 0.334 & 0.327 & 0.328 & na & na & na & na & na & na & 0.324 & 0.338 & na & na & na & na & na & na \\
\hline $0-1-0-1-1-0$ & 0.283 & 0.332 & 0.318 & 0.326 & 0.397 & na & na & na & na & na & na & na & na & na & na & na & na & na & na & na \\
\hline $0-1-0-1-1-1$ & na & na & na & 0.490 & 0.409 & 0.369 & 0.363 & 0.401 & 0.363 & 0.393 & 0.397 & na & na & na & na & na & na & na & na & na \\
\hline $0-1-1-0-0-0$ & na & na & na & na & na & na & na & na & na & na & na & na & na & na & na & na & na & na & na & na \\
\hline $0-1-1-0-0-1$ & na & na & na & na & na & na & na & na & na & na & na & na & 0.382 & na & na & na & na & na & na & na \\
\hline $0-1-1-0-1-0$ & na & na & na & na & na & na & na & na & na & na & na & na & na & na & na & na & na & na & na & na \\
\hline $0-1-1-0-1-1$ & na & na & na & 0.513 & 0.516 & 0.488 & 0.470 & 0.454 & na & na & na & na & na & na & na & na & na & na & na & na \\
\hline $0-1-1-1-0-0$ & 0.445 & 0.409 & 0.389 & na & na & na & na & na & na & na & na & na & na & na & na & na & na & na & na & na \\
\hline $0-1-1-1-0-1$ & na & 0.415 & na & 0.418 & 0.412 & 0.421 & 0.423 & 0.403 & 0.421 & 0.425 & 0.442 & 0.401 & 0.376 & 0.368 & 0.373 & 0.379 & 0.386 & 0.392 & 0.449 & 0.399 \\
\hline $0-1-1-1-1-0$ & na & na & na & 0.513 & 0.522 & na & na & 0.393 & 0.438 & 0.413 & na & na & na & na & na & na & na & na & na & na \\
\hline $0-1-1-1-1-1$ & na & na & na & na & na & na & 0.542 & 0.494 & 0.472 & 0.465 & 0.462 & 0.460 & 0.431 & 0.436 & 0.437 & 0.463 & 0.408 & 0.428 & na & na \\
\hline $1-0-0-0-0-0$ & na & na & na & na & na & na & na & na & na & na & na & na & na & na & na & na & na & na & na & na \\
\hline $1-0-0-0-0-1$ & na & na & na & na & na & na & na & na & na & na & na & na & na & na & na & na & na & na & na & na \\
\hline $1-0-0-0-1-0$ & na & na & na & na & na & na & na & na & na & na & na & na & na & na & na & na & na & na & na & na \\
\hline $1-0-0-0-1-1$ & na & na & na & na & na & na & na & na & na & na & na & na & na & na & na & na & na & na & na & na \\
\hline $1-0-0-1-0-0$ & 0.323 & na & na & na & 0.384 & na & na & na & na & na & na & na & na & na & na & na & na & na & na & na \\
\hline $1-0-0-1-0-1$ & na & na & na & 0.400 & 0.411 & 0.434 & na & na & na & na & na & na & na & na & na & na & na & na & na & na \\
\hline $1-0-0-1-1-0$ & 0.320 & 0.387 & 0.346 & 0.283 & 0.268 & 0.307 & na & na & na & na & na & na & na & na & na & na & na & na & na & na \\
\hline $1-0-0-1-1-1$ & na & na & na & 0.429 & 0.380 & 0.362 & 0.349 & 0.371 & 0.353 & 0.352 & 0.355 & na & na & na & na & na & na & na & na & na \\
\hline $1-0-1-0-0-0$ & na & na & na & na & na & na & na & na & na & na & na & na & na & na & na & na & na & na & na & na \\
\hline $1-0-1-0-0-1$ & na & na & na & 0.482 & na & 0.501 & na & na & na & na & na & na & na & na & na & na & na & na & na & na \\
\hline $1-0-1-0-1-0$ & na & na & na & 0.522 & na & na & na & na & na & na & na & na & na & na & na & na & na & na & na & na \\
\hline $1-0-1-0-1-1$ & na & na & na & 0.558 & na & 0.511 & 0.449 & 0.432 & 0.410 & 0.394 & na & na & na & na & na & na & na & na & na & na \\
\hline $1-0-1-1-0-0$ & na & na & na & 0.438 & 0.424 & 0.431 & na & 0.374 & na & na & na & na & na & na & na & na & na & na & na & na \\
\hline $1-0-1-1-0-1$ & na & na & na & 0.440 & 0.435 & 0.425 & 0.425 & 0.418 & 0.418 & 0.417 & 0.441 & 0.447 & 0.465 & na & na & na & na & na & na & na \\
\hline $1-0-1-1-1-0$ & na & na & na & 0.379 & 0.365 & 0.359 & 0.357 & 0.353 & 0.355 & 0.367 & 0.383 & 0.400 & 0.383 & na & na & 0.451 & na & na & na & na \\
\hline $1-0-1-1-1-1$ & na & na & na & na & na & 0.467 & 0.412 & 0.415 & 0.429 & 0.425 & 0.434 & 0.431 & 0.428 & 0.419 & 0.414 & 0.417 & 0.421 & 0.397 & 0.411 & 0.426 \\
\hline $1-1-0-0-0-0$ & na & na & na & na & na & na & na & na & na & na & na & na & na & na & na & na & na & na & na & na \\
\hline $1-1-0-0-0-1$ & na & na & na & na & na & na & na & na & na & na & na & na & na & na & na & na & na & na & na & na \\
\hline $1-1-0-0-1-0$ & na & na & na & 0.300 & 0.328 & na & na & na & na & na & na & na & na & na & na & na & na & na & na & na \\
\hline $1-1-0-0-1-1$ & na & na & na & na & na & 0.428 & 0.451 & 0.392 & 0.365 & 0.371 & na & na & na & na & na & na & na & na & na & na \\
\hline $1-1-0-1-0-0$ & 0.314 & 0.272 & 0.343 & 0.363 & na & na & na & na & na & na & na & na & na & na & na & na & na & na & na & na \\
\hline $1-1-0-1-0-1$ & na & na & na & 0.512 & 0.527 & 0.470 & 0.441 & 0.499 & na & na & na & na & na & na & na & na & na & na & na & na \\
\hline $1-1-0-1-1-0$ & na & na & na & 0.439 & na & na & na & na & na & na & na & na & na & na & na & na & na & na & na & na \\
\hline $1-1-0-1-1-1$ & na & na & na & na & na & na & 0.414 & 0.431 & 0.400 & 0.415 & 0.393 & 0.397 & 0.394 & 0.390 & 0.387 & 0.496 & 0.388 & 0.391 & na & na \\
\hline $1-1-1-0-0-0$ & na & na & na & na & na & na & na & na & na & na & na & na & na & na & na & na & na & na & na & na \\
\hline $1-1-1-0-0-1$ & na & na & na & na & na & na & na & na & na & na & na & na & na & na & na & na & na & na & na & na \\
\hline $1-1-1-0-1-0$ & na & na & na & 0.493 & 0.436 & 0.403 & 0.406 & 0.401 & na & na & na & na & na & na & na & na & na & na & na & na \\
\hline $1-1-1-0-1-1$ & na & na & na & na & na & na & na & 0.449 & 0.453 & 0.446 & 0.437 & 0.450 & 0.418 & 0.419 & 0.455 & 0.420 & 0.385 & 0.380 & na & na \\
\hline $1-1-1-1-0-0$ & na & na & na & 0.436 & 0.462 & 0.447 & 0.430 & 0.433 & 0.452 & 0.433 & na & 0.456 & na & na & na & na & na & na & na & na \\
\hline $1-1-1-1-0-1$ & na & na & na & na & na & na & 0.503 & 0.511 & 0.495 & 0.488 & 0.499 & 0.488 & 0.484 & 0.481 & 0.481 & 0.463 & 0.453 & 0.445 & 0.445 & na \\
\hline $1-1-1-1-1-0$ & na & na & na & na & na & na & 0.374 & 0.386 & 0.360 & 0.369 & 0.385 & 0.391 & 0.391 & 0.395 & 0.412 & 0.404 & 0.407 & na & na & na \\
\hline $1-1-1-1-1-1$ & na & na & na & na & na & na & na & na & na & na & 0.465 & 0.442 & 0.428 & 0.430 & 0.428 & 0.437 & 0.425 & 0.427 & 0.437 & 0.447 \\
\hline
\end{tabular}


Table A-15 P4A - Stack O2 by Load and Mill Pattern (1Q95)

\begin{tabular}{|c|c|c|c|c|c|c|c|c|c|c|c|c|c|c|c|c|c|c|c|c|}
\hline \multirow[b]{2}{*}{$\begin{array}{c}\text { Mill } \\
\text { A-B-C-D-E-F }\end{array}$} & \multicolumn{20}{|c|}{ Load, MW } \\
\hline & 130 & 150 & 170 & 190 & 210 & 230 & 250 & 270 & 290 & 310 & 330 & 350 & 370 & 390 & 410 & 430 & 450 & 470 & 490 & 510 \\
\hline $0-0-0-0-0-1$ & na & na & na & na & na & na & na & na & na & na & na & na & na & na & na & na & na & na & na & na \\
\hline $0-0-0-0-1-0$ & na & na & na & na & na & na & na & na & na & na & na & na & na & na & na & na & na & na & na & na \\
\hline $0-0-0-0-1-1$ & na & na & na & na & na & na & na & na & na & na & na & na & na & na & na & na & na & na & na & na \\
\hline $0-0-0-1-0-0$ & na & na & na & na & na & na & na & na & na & na & na & na & na & na & na & na & na & na & na & na \\
\hline $0-0-0-1-0-1$ & na & na & na & na & na & na & na & na & na & na & na & na & na & na & na & na & na & na & na & na \\
\hline $0-0-0-1-1-0$ & na & na & na & na & na & na & na & na & na & na & na & na & na & na & na & na & na & na & na & na \\
\hline $0-0-0-1-1-1$ & na & na & na & 9.940 & 8.898 & 8.296 & na & na & na & na & na & na & na & na & na & na & na & na & na & na \\
\hline $0-0-1-0-0-0$ & na & na & na & na & na & na & na & na & na & na & na & na & na & na & na & na & na & na & na & na \\
\hline $0-0-1-0-0-1$ & na & na & na & na & na & na & na & na & na & na & na & na & na & na & na & na & na & na & na & na \\
\hline $0-0-1-0-1-0$ & na & na & na & na & na & na & na & na & na & na & na & na & na & na & na & na & na & na & na & na \\
\hline $0-0-1-0-1-1$ & na & na & na & 11.454 & 11.827 & 11.087 & na & na & na & na & na & na & na & na & na & na & na & na & na & na \\
\hline $0-0-1-1-0-0$ & na & na & na & 9.372 & na & na & na & na & na & na & na & na & na & na & na & na & na & na & na & na \\
\hline $0-0-1-1-0-1$ & na & na & 7.859 & 10.486 & 9.069 & 11.534 & 11.479 & na & na & na & na & na & na & na & na & na & na & na & na & na \\
\hline $0-0-1-1-1-0$ & na & na & na & na & na & na & na & na & na & na & na & na & na & na & na & na & na & na & na & na \\
\hline $0-0-1-1-1-1$ & na & na & na & 11.200 & 9.222 & 9.147 & 10.289 & 10.326 & 8.416 & na & na & na & na & na & na & na & na & na & na & na \\
\hline $0-1-0-0-0-0$ & na & na & na & na & na & na & na & na & na & na & na & na & na & na & na & na & na & na & na & na \\
\hline $0-1-0-0-0-1$ & na & na & na & na & na & na & na & na & na & na & na & na & na & na & na & na & na & na & na & na \\
\hline $0-1-0-0-1-0$ & 9.281 & na & na & na & na & na & na & na & na & na & na & na & na & na & na & na & na & na & na & na \\
\hline $0-1-0-0-1-1$ & na & na & na & 11.156 & na & na & na & na & na & na & na & na & na & na & na & na & na & na & na & na \\
\hline $0-1-0-1-0-0$ & 10.332 & 9.282 & na & na & na & na & na & na & na & na & na & na & na & na & na & na & na & na & na & na \\
\hline $0-1-0-1-0-1$ & na & na & 8.815 & 8.839 & 8.691 & 8.707 & na & na & na & na & na & na & 6.140 & 6.147 & na & na & na & na & na & na \\
\hline $0-1-0-1-1-0$ & 9.180 & 8.842 & 8.608 & 8.576 & 7.869 & na & na & na & na & na & na & na & na & na & na & na & na & na & na & na \\
\hline $0-1-0-1-1-1$ & na & na & na & 10.885 & 7.223 & 8.780 & 7.929 & 7.888 & 8.541 & 7.628 & 7.206 & na & na & na & na & na & na & na & na & na \\
\hline $0-1-1-0-0-0$ & na & na & na & na & na & na & na & na & na & na & na & na & na & na & na & na & na & na & na & na \\
\hline $0-1-1-0-0-1$ & na & na & na & na & na & na & na & na & na & na & na & na & 6.063 & na & na & na & na & na & na & na \\
\hline $0-1-1-0-1-0$ & na & na & na & na & na & na & na & na & na & na & na & na & na & na & na & na & na & na & na & na \\
\hline $0-1-1-0-1-1$ & na & na & na & 11.113 & 11.267 & 11.182 & 10.929 & 10.630 & na & na & na & na & na & na & na & na & na & na & na & na \\
\hline $0-1-1-1-0-0$ & 9.527 & 9.188 & 9.267 & na & na & na & na & na & na & na & na & na & na & na & na & na & na & na & na & na \\
\hline $0-1-1-1-0-1$ & na & 7.312 & na & 8.750 & 8.463 & 8.743 & 8.280 & 7.887 & 7.549 & 7.355 & 7.120 & 7.014 & 6.426 & 6.836 & 6.543 & 6.701 & 6.475 & 6.563 & 6.373 & 6.083 \\
\hline $0-1-1-1-1-0$ & na & na & na & 11.000 & 11.415 & na & na & 9.941 & 10.479 & 10.927 & na & na & na & na & na & na & na & na & na & na \\
\hline $0-1-1-1-1-1$ & na & na & na & na & na & na & 10.546 & 10.321 & 9.837 & 8.048 & 8.275 & 7.805 & 8.348 & 8.430 & 7.849 & 8.077 & 6.231 & 6.648 & na & na \\
\hline $1-0-0-0-0-0$ & na & na & na & na & na & na & na & na & na & na & na & na & na & na & na & na & na & na & na & na \\
\hline $1-0-0-0-0-1$ & na & na & na & na & na & na & na & na & na & na & na & na & na & na & na & na & na & na & na & na \\
\hline $1-0-0-0-1-0$ & na & na & na & na & na & na & na & na & na & na & na & na & na & na & na & na & na & na & na & na \\
\hline $1-0-0-0-1-1$ & na & na & na & na & na & na & na & na & na & na & na & na & na & na & na & na & na & na & na & na \\
\hline $1-0-0-1-0-0$ & 10.231 & na & na & na & 7.658 & na & na & na & na & na & na & na & na & na & na & na & na & na & na & na \\
\hline $1-0-0-1-0-1$ & na & na & na & 11.266 & 11.198 & 10.286 & na & na & na & na & na & na & na & na & na & na & na & na & na & na \\
\hline $1-0-0-1-1-0$ & 9.929 & 9.926 & 9.087 & 7.765 & 7.549 & 7.042 & na & na & na & na & na & na & na & na & na & na & na & na & na & na \\
\hline $1-0-0-1-1-1$ & na & na & na & 8.906 & 8.396 & 7.773 & 7.274 & 8.524 & 7.261 & 6.434 & 6.213 & na & na & na & na & na & na & na & na & na \\
\hline $1-0-1-0-0-0$ & na & na & na & na & na & na & na & na & na & na & na & na & na & na & na & na & na & na & na & na \\
\hline $1-0-1-0-0-1$ & na & na & na & 11.630 & na & 11.431 & na & na & na & na & na & na & na & na & na & na & na & na & na & na \\
\hline $1-0-1-0-1-0$ & na & na & na & 11.495 & na & na & na & na & na & na & na & na & na & na & na & na & na & na & na & na \\
\hline $1-0-1-0-1-1$ & na & na & na & 11.011 & na & 11.321 & 10.040 & 9.821 & 8.651 & 8.142 & na & na & na & na & na & na & na & na & na & na \\
\hline $1-0-1-1-0-0$ & na & na & na & 10.142 & 7.132 & 9.489 & na & 8.750 & na & na & na & na & na & na & na & na & na & na & na & na \\
\hline $1-0-1-1-0-1$ & na & na & na & 9.002 & 9.088 & 9.314 & 8.783 & 9.528 & 9.130 & 8.992 & 9.327 & 7.628 & 9.043 & na & na & na & na & na & na & na \\
\hline $1-0-1-1-1-0$ & na & na & na & 8.041 & 7.767 & 7.679 & 7.331 & 7.139 & 7.273 & 7.224 & 7.176 & 7.754 & 6.451 & na & na & 6.851 & na & na & na & na \\
\hline $1-0-1-1-1-1$ & na & na & na & na & na & 8.301 & 7.026 & 7.070 & 7.176 & 7.262 & 7.091 & 6.756 & 6.683 & 6.472 & 7.524 & 7.711 & 6.885 & 7.827 & 7.055 & 7.289 \\
\hline $1-1-0-0-0-0$ & na & na & na & na & na & na & na & na & na & na & na & na & na & na & na & na & na & na & na & na \\
\hline $1-1-0-0-0-1$ & na & na & na & na & na & na & na & na & na & na & na & na & na & na & na & na & na & na & na & na \\
\hline $1-1-0-0-1-0$ & na & na & na & 9.098 & 8.116 & na & na & na & na & na & na & na & na & na & na & na & na & na & na & na \\
\hline $1-1-0-0-1-1$ & na & na & na & na & na & 11.309 & 10.124 & $\begin{array}{l}4.881 \\
+\end{array}$ & 8.055 & 8.001 & na & na & na & na & na & na & na & na & na & na \\
\hline $1-1-0-1-0-0$ & 10.249 & 7.927 & 8.291 & 10.374 & na & na & na & na & na & na & na & na & na & na & na & na & na & na & na & na \\
\hline $1-1-0-1-0-1$ & na & na & na & 11.602 & 11.221 & 10.857 & 8.803 & 10.060 & na & na & na & na & na & na & na & na & na & na & na & na \\
\hline $1-1-0-1-1-0$ & na & na & na & 11.225 & na & na & na & na & na & na & na & na & na & na & na & na & na & na & na & na \\
\hline $1-1-0-1-1-1$ & na & na & na & na & na & na & 9.408 & 8.604 & 7.782 & 8.243 & 6.634 & 7.131 & 6.629 & 6.515 & 6.673 & 9.955 & 6.120 & 5.553 & na & na \\
\hline $1-1-1-0-0-0$ & na & na & na & na & na & na & na & na & na & na & na & na & na & na & na & na & na & na & na & na \\
\hline $1-1-1-0-0-1$ & na & na & na & na & na & na & na & na & na & na & na & na & na & na & na & na & na & na & na & na \\
\hline $1-1-1-0-1-0$ & na & na & na & 10.838 & 8.895 & 8.407 & 8.546 & 7.984 & na & na & na & na & na & na & na & na & na & na & na & na \\
\hline $1-1-1-0-1-1$ & na & na & na & na & na & na & na & 8.061 & 7.166 & 7.496 & 7.537 & 8.550 & 6.936 & 6.728 & 6.406 & 7.475 & 7.639 & 6.937 & na & na \\
\hline $1-1-1-1-0-0$ & na & na & na & 9.497 & 10.396 & 10.273 & 9.227 & 8.878 & 9.087 & 8.582 & na & 8.227 & na & na & na & na & na & na & na & na \\
\hline $1-1-1-1-0-1$ & na & na & na & na & na & na & 8.366 & 9.060 & 8.550 & 8.282 & 8.118 & 7.863 & 7.850 & 7.778 & 7.543 & 6.837 & 6.296 & 6.292 & 6.317 & na \\
\hline $1-1-1-1-1-0$ & na & na & na & na & na & na & 7.458 & 8.374 & 7.037 & 7.146 & 7.234 & 7.246 & 7.244 & 7.191 & 7.286 & 6.957 & 6.266 & na & na & na \\
\hline $1-1-1-1-1-1$ & na & na & na & na & na & na & na & na & na & na & 6.253 & 7.242 & 6.959 & 6.844 & 6.512 & 6.337 & 6.129 & 6.334 & 6.612 & 5.853 \\
\hline
\end{tabular}


Table A-16 Process Data for 1st Quarter 1996

\begin{tabular}{rrrrrrrrrr}
\multicolumn{1}{c}{$\begin{array}{c}\text { Bin } \\
\text { Low }\end{array}$} & $\begin{array}{c}\text { Bin } \\
\text { High }\end{array}$ & Samples & \multicolumn{1}{c}{ Load } & PV & PV & PV & PV & PV & PV \\
Mean & Mean & \multicolumn{1}{c}{ Min } & Max & Std & \multicolumn{1}{c}{5 thP } & 95 thP \\
\hline 130 & 150 & 0 & 147.50 & 65535.00 & 65535.00 & 65535.00 & 65535.00 & 65535.00 & 65535.00 \\
150 & 170 & 8 & 165.87 & 165.87 & 154.87 & 169.19 & 4.72 & 154.87 & 169.19 \\
170 & 190 & 28 & 177.21 & 177.21 & 171.24 & 189.78 & 5.95 & 171.35 & 189.66 \\
190 & 210 & 2710 & 200.35 & 200.35 & 190.43 & 209.85 & 3.16 & 195.52 & 206.56 \\
210 & 230 & 522 & 218.82 & 218.82 & 210.03 & 229.98 & 6.32 & 210.88 & 228.89 \\
230 & 250 & 363 & 238.61 & 238.61 & 230.02 & 249.96 & 5.52 & 230.69 & 248.91 \\
250 & 270 & 268 & 259.51 & 259.51 & 250.09 & 269.98 & 6.04 & 250.85 & 269.21 \\
270 & 290 & 413 & 280.65 & 280.65 & 270.00 & 290.00 & 5.33 & 271.95 & 288.44 \\
290 & 310 & 557 & 301.52 & 301.52 & 290.05 & 309.96 & 5.45 & 291.32 & 308.18 \\
310 & 330 & 288 & 321.22 & 321.22 & 310.12 & 330.00 & 5.55 & 311.30 & 328.80 \\
330 & 350 & 112 & 340.14 & 340.14 & 330.19 & 349.80 & 5.97 & 331.65 & 349.23 \\
350 & 370 & 165 & 359.59 & 359.59 & 350.15 & 369.94 & 5.69 & 351.30 & 368.83 \\
370 & 390 & 152 & 380.28 & 380.28 & 370.19 & 389.97 & 5.98 & 371.35 & 389.30 \\
390 & 410 & 292 & 400.56 & 400.56 & 390.04 & 409.98 & 4.95 & 390.85 & 408.82 \\
410 & 430 & 276 & 414.98 & 414.98 & 410.04 & 429.95 & 6.33 & 410.32 & 427.26 \\
430 & 450 & 106 & 439.34 & 439.34 & 430.09 & 449.67 & 5.67 & 430.69 & 448.80 \\
450 & 470 & 141 & 460.92 & 460.92 & 450.29 & 469.95 & 5.81 & 451.55 & 469.34 \\
470 & 490 & 352 & 477.40 & 477.40 & 470.04 & 489.12 & 3.40 & 471.26 & 482.11 \\
490 & 510 & 231 & 504.77 & 504.77 & 490.72 & 509.90 & 3.53 & 497.06 & 509.33 \\
510 & 530 & 6 & 510.64 & 510.64 & 510.13 & 512.59 & 0.97 & 510.13 & 512.59 \\
\hline
\end{tabular}

\begin{tabular}{|c|c|c|c|c|c|c|c|c|c|}
\hline $\begin{array}{l}\text { Bin } \\
\text { Low }\end{array}$ & $\begin{array}{l}\text { Bin } \\
\text { High }\end{array}$ & Samples & $\begin{array}{l}\text { Load } \\
\text { Mean }\end{array}$ & $\begin{array}{c}\text { PV } \\
\text { Mean }\end{array}$ & $\begin{array}{l}\text { PV } \\
\text { Min }\end{array}$ & $\begin{array}{l}\text { PV } \\
\text { Max }\end{array}$ & $\begin{array}{l}\text { PV } \\
\text { Std }\end{array}$ & $\begin{array}{l}\text { PV } \\
\text { 5thP }\end{array}$ & $\begin{array}{c}\text { PV } \\
\text { 95thP }\end{array}$ \\
\hline 130 & 150 & 0 & 147.50 & 65535.00 & 65535.00 & 65535.00 & 65535.00 & 65535.00 & 65535.00 \\
\hline 150 & 170 & 8 & 165.87 & 852.31 & 809.21 & 884.07 & 24.04 & 809.21 & 884.07 \\
\hline 170 & 190 & 28 & 177.21 & 926.74 & 824.66 & 993.93 & 44.79 & 839.18 & 992.34 \\
\hline 190 & 210 & 2710 & 200.35 & 994.81 & 849.68 & 1015.70 & 12.65 & 979.56 & 999.99 \\
\hline 210 & 230 & 522 & 218.82 & 995.74 & 876.47 & 1010.75 & 10.32 & 983.04 & 1003.52 \\
\hline 230 & 250 & 363 & 238.61 & 996.81 & 945.25 & 1008.14 & 7.18 & 988.60 & 1002.70 \\
\hline 250 & 270 & 268 & 259.51 & 997.19 & 947.24 & 1052.81 & 7.14 & 991.46 & 1001.62 \\
\hline 270 & 290 & 413 & 280.65 & 997.82 & 960.72 & 1054.26 & 5.47 & 993.04 & 1002.25 \\
\hline 290 & 310 & 557 & 301.52 & 998.44 & 960.29 & 1026.10 & 4.35 & 995.09 & 1005.28 \\
\hline 310 & 330 & 288 & 321.22 & 997.67 & 973.29 & 1024.77 & 4.39 & 992.83 & 1002.76 \\
\hline 330 & 350 & 112 & 340.14 & 998.88 & 963.55 & 1040.51 & 10.34 & 985.61 & 1019.66 \\
\hline 350 & 370 & 165 & 359.59 & 998.97 & 958.32 & 1051.99 & 8.74 & 990.14 & 1012.85 \\
\hline 370 & 390 & 152 & 380.28 & 996.68 & 975.20 & 1036.41 & 6.47 & 987.03 & 1004.64 \\
\hline 390 & 410 & 292 & 400.56 & 997.05 & 970.22 & 1036.85 & 5.43 & 989.54 & 1003.84 \\
\hline 410 & 430 & 276 & 414.98 & 996.97 & 980.85 & 1028.64 & 3.36 & 994.19 & 1000.22 \\
\hline 430 & 450 & 106 & 439.34 & 995.21 & 976.62 & 1009.28 & 4.99 & 985.06 & 1001.25 \\
\hline 450 & 470 & 141 & 460.92 & 996.34 & 987.60 & 1006.60 & 2.19 & 992.14 & 998.99 \\
\hline 470 & 490 & 352 & 477.40 & 996.29 & 990.01 & 1001.92 & 1.08 & 995.05 & 998.10 \\
\hline 490 & 510 & 231 & 504.77 & 996.16 & 992.10 & 999.40 & 0.55 & 995.52 & 996.43 \\
\hline 510 & 530 & 6 & 510.64 & 995.50 & 993.17 & 996.23 & 1.18 & 993.17 & 996.23 \\
\hline
\end{tabular}

Hot Reheat Temperature, of

\begin{tabular}{|c|c|c|c|c|c|c|c|c|c|}
\hline $\begin{array}{l}\text { Bin } \\
\text { Low }\end{array}$ & $\begin{array}{l}\text { Bin } \\
\text { High }\end{array}$ & Samples & $\begin{array}{l}\text { Load } \\
\text { Mean }\end{array}$ & $\begin{array}{c}\text { PV } \\
\text { Mean }\end{array}$ & $\begin{array}{l}\text { PV } \\
\text { Min }\end{array}$ & $\begin{array}{l}\text { PV } \\
\text { Max }\end{array}$ & $\begin{array}{l}\text { PV } \\
\text { Std }\end{array}$ & $\begin{array}{c}\text { PV } \\
\text { 5thP }\end{array}$ & $\begin{array}{c}\text { PV } \\
\text { 95thP }\end{array}$ \\
\hline 130 & 150 & 0 & 147.50 & 65535.00 & 65535.00 & 65535.00 & 65535.00 & 65535.00 & 65535.00 \\
\hline 150 & 170 & 8 & 165.87 & 890.67 & 852.65 & 922.85 & 25.18 & 852.65 & 922.85 \\
\hline 170 & 190 & 28 & 177.21 & 937.83 & 913.12 & 979.16 & 19.49 & 916.44 & 966.97 \\
\hline 190 & 210 & 2710 & 200.35 & 979.81 & 850.58 & 1005.48 & 17.63 & 951.31 & 996.49 \\
\hline 210 & 230 & 522 & 218.82 & 984.92 & 936.38 & 1009.50 & 14.25 & 953.79 & 999.21 \\
\hline 230 & 250 & 363 & 238.61 & 983.91 & 937.57 & 1007.25 & 15.15 & 950.34 & 1000.64 \\
\hline 250 & 270 & 268 & 259.51 & 982.28 & 934.20 & 1006.82 & 15.54 & 952.05 & 999.70 \\
\hline 270 & 290 & 413 & 280.65 & 982.37 & 938.43 & 1009.57 & 15.37 & 954.30 & 1000.30 \\
\hline 290 & 310 & 557 & 301.52 & 988.69 & 948.85 & 1013.40 & 9.33 & 966.91 & 1000.37 \\
\hline 310 & 330 & 288 & 321.22 & 987.13 & 950.11 & 1008.93 & 13.02 & 959.25 & 1001.67 \\
\hline 330 & 350 & 112 & 340.14 & 989.80 & 961.04 & 1009.52 & 10.93 & 970.08 & 1005.63 \\
\hline 350 & 370 & 165 & 359.59 & 993.87 & 965.00 & 1011.78 & 8.98 & 978.70 & 1006.86 \\
\hline 370 & 390 & 152 & 380.28 & 994.39 & 973.24 & 1015.36 & 7.33 & 980.86 & 1007.65 \\
\hline 390 & 410 & 292 & 400.56 & 995.34 & 974.44 & 1015.78 & 5.49 & 985.47 & 1004.48 \\
\hline 410 & 430 & 276 & 414.98 & 996.85 & 979.77 & 1013.81 & 3.88 & 991.82 & 1004.66 \\
\hline 430 & 450 & 106 & 439.34 & 997.92 & 981.56 & 1012.69 & 6.02 & 987.25 & 1007.72 \\
\hline 450 & 470 & 141 & 460.92 & 997.49 & 981.07 & 1009.61 & 4.48 & 991.70 & 1005.46 \\
\hline 470 & 490 & 352 & 477.40 & 996.81 & 988.21 & 1008.49 & 2.78 & 994.31 & 1003.42 \\
\hline 490 & 510 & 231 & 504.77 & 995.76 & 989.11 & 1007.32 & 1.58 & 994.86 & 997.29 \\
\hline 510 & 530 & 6 & 510.64 & 997.60 & 993.61 & 1001.51 & 3.11 & 993.61 & 1001.51 \\
\hline
\end{tabular}


Excess Oxygen, Left Hand, \%

\begin{tabular}{|c|c|c|c|c|c|c|c|c|c|}
\hline $\begin{array}{l}\text { Bin } \\
\text { Low }\end{array}$ & $\begin{array}{l}\text { Bin } \\
\text { High }\end{array}$ & Samples & $\begin{array}{l}\text { Load } \\
\text { Mean }\end{array}$ & $\begin{array}{c}\text { PV } \\
\text { Mean }\end{array}$ & $\begin{array}{l}\text { PV } \\
\text { Min }\end{array}$ & $\begin{array}{c}\text { PV } \\
\text { Max }\end{array}$ & $\begin{array}{l}\text { PV } \\
\text { Std }\end{array}$ & $\begin{array}{c}\mathrm{PV} \\
\text { 5thP }\end{array}$ & $\begin{array}{c}\mathrm{PV} \\
\text { 95thP }\end{array}$ \\
\hline 130 & 150 & 0 & 147.50 & 65535.00 & 65535.00 & 65535.00 & 65535.00 & 65535.00 & 65535.00 \\
\hline 150 & 170 & 8 & 165.87 & 7.26 & 6.47 & 7.91 & 0.54 & 6.47 & 7.91 \\
\hline 170 & 190 & 28 & 177.21 & 6.64 & 4.70 & 7.94 & 0.87 & 5.19 & 7.77 \\
\hline 190 & 210 & 2710 & 200.35 & 5.84 & 4.94 & 7.16 & 0.31 & 5.42 & 6.44 \\
\hline 210 & 230 & 522 & 218.82 & 5.67 & 4.44 & 6.82 & 0.36 & 5.08 & 6.30 \\
\hline 230 & 250 & 363 & 238.61 & 5.29 & 3.71 & 6.49 & 0.39 & 4.62 & 5.88 \\
\hline 250 & 270 & 268 & 259.51 & 5.06 & 3.36 & 5.96 & 0.38 & 4.42 & 5.56 \\
\hline 270 & 290 & 413 & 280.65 & 4.74 & 3.64 & 6.39 & 0.39 & 4.18 & 5.41 \\
\hline 290 & 310 & 557 & 301.52 & 4.35 & 3.41 & 5.76 & 0.37 & 3.87 & 5.24 \\
\hline 310 & 330 & 288 & 321.22 & 4.22 & 2.93 & 5.47 & 0.33 & 3.62 & 4.62 \\
\hline 330 & 350 & 112 & 340.14 & 3.93 & 2.55 & 5.48 & 0.50 & 3.23 & 4.82 \\
\hline 350 & 370 & 165 & 359.59 & 3.97 & 2.76 & 4.81 & 0.39 & 3.40 & 4.58 \\
\hline 370 & 390 & 152 & 380.28 & 3.98 & 2.41 & 5.68 & 0.57 & 3.06 & 4.92 \\
\hline 390 & 410 & 292 & 400.56 & 3.81 & 2.97 & 5.54 & 0.54 & 3.12 & 4.81 \\
\hline 410 & 430 & 276 & 414.98 & 4.10 & 2.99 & 5.28 & 0.40 & 3.50 & 5.06 \\
\hline 430 & 450 & 106 & 439.34 & 3.85 & 2.73 & 5.63 & 0.66 & 3.06 & 5.16 \\
\hline 450 & 470 & 141 & 460.92 & 3.93 & 2.78 & 5.19 & 0.59 & 3.09 & 5.03 \\
\hline 470 & 490 & 352 & 477.40 & 4.05 & 2.79 & 5.14 & 0.57 & 3.24 & 4.94 \\
\hline 490 & 510 & 231 & 504.77 & 3.34 & 3.16 & 4.39 & 0.19 & 3.26 & 3.70 \\
\hline 510 & 530 & 6 & 510.64 & 3.59 & 3.30 & 4.54 & 0.48 & 3.30 & 4.54 \\
\hline \multicolumn{10}{|c|}{ Excess Oxygen Right Hand, \% } \\
\hline Bin & $\begin{array}{c}\text { Bin } \\
\text { Hiah }\end{array}$ & Samples & Load & PV & $\begin{array}{l}\text { PV } \\
\text { Min }\end{array}$ & $\begin{array}{l}\text { PV } \\
\text { Max }\end{array}$ & $\begin{array}{l}\text { PV } \\
\text { Std }\end{array}$ & $\begin{array}{l}P V \\
5 \text { thP }\end{array}$ & $\begin{array}{l}\mathrm{PV} \\
95 \text { thP }\end{array}$ \\
\hline 130 & 150 & 0 & 147.50 & 65535.00 & 65535.00 & 65535.00 & 65535.00 & 65535.00 & 65535.00 \\
\hline 150 & 170 & 8 & 165.87 & 5.95 & 5.20 & 6.72 & 0.51 & 5.20 & 6.72 \\
\hline 170 & 190 & 28 & 177.21 & 5.85 & 4.66 & 7.10 & 0.56 & 4.78 & 6.82 \\
\hline 190 & 210 & 2710 & 200.35 & 5.77 & 4.40 & 6.53 & 0.24 & 5.31 & 6.10 \\
\hline 210 & 230 & 522 & 218.82 & 5.48 & 4.55 & 6.79 & 0.32 & 4.89 & 5.91 \\
\hline 230 & 250 & 363 & 238.61 & 5.21 & 4.16 & 6.21 & 0.32 & 4.65 & 5.73 \\
\hline 250 & 270 & 268 & 259.51 & 4.86 & 4.12 & 5.84 & 0.31 & 4.37 & 5.31 \\
\hline 270 & 290 & 413 & 280.65 & 4.62 & 3.37 & 5.82 & 0.32 & 4.23 & 5.15 \\
\hline 290 & 310 & 557 & 301.52 & 4.44 & 3.18 & 5.36 & 0.32 & 3.97 & 4.85 \\
\hline 310 & 330 & 288 & 321.22 & 4.20 & 3.28 & 5.62 & 0.32 & 3.78 & 4.75 \\
\hline 330 & 350 & 112 & 340.14 & 4.16 & 3.12 & 5.07 & 0.46 & 3.35 & 4.81 \\
\hline 350 & 370 & 165 & 359.59 & 4.04 & 2.77 & 4.76 & 0.37 & 3.48 & 4.62 \\
\hline 370 & 390 & 152 & 380.28 & 4.02 & 2.72 & 5.26 & 0.46 & 3.17 & 4.70 \\
\hline 390 & 410 & 292 & 400.56 & 3.76 & 2.99 & 4.79 & 0.41 & 3.25 & 4.44 \\
\hline 410 & 430 & 276 & 414.98 & 3.69 & 3.07 & 4.82 & 0.34 & 3.47 & 4.48 \\
\hline 430 & 450 & 106 & 439.34 & 3.82 & 2.91 & 5.49 & 0.40 & 3.28 & 4.46 \\
\hline 450 & 470 & 141 & 460.92 & 3.58 & 2.91 & 4.58 & 0.39 & 3.12 & 4.29 \\
\hline 470 & 490 & 352 & 477.40 & 3.55 & 2.78 & 4.42 & 0.42 & 3.04 & 4.27 \\
\hline 490 & 510 & 231 & 504.77 & 3.54 & 2.77 & 3.76 & 0.15 & 3.16 & 3.61 \\
\hline 510 & 530 & 6 & 510.64 & 3.59 & 3.47 & 3.86 & 0.15 & 3.47 & 3.86 \\
\hline \multicolumn{10}{|c|}{ Main Steam Pressure, PSIG } \\
\hline Bin & Bin & Samples & Load & PV & PV & PV & PV & PV & PV \\
\hline Low & High & & Mean & Mean & Min & Max & Std & 5thP & 95thP \\
\hline 130 & 150 & 0 & 147.50 & 65535.00 & 65535.00 & 65535.00 & 65535.00 & 65535.00 & 65535.00 \\
\hline 150 & 170 & 8 & 165.87 & 1300.08 & 1124.30 & 1523.50 & 134.53 & 1124.30 & 1523.50 \\
\hline 170 & 190 & 28 & 177.21 & 1807.98 & 1310.75 & 2332.23 & 239.89 & 1445.88 & 2197.77 \\
\hline 190 & 210 & 2710 & 200.35 & 2350.64 & 1502.34 & 2452.66 & 71.45 & 2347.24 & 2367.93 \\
\hline 210 & 230 & 522 & 218.82 & 2349.87 & 2016.90 & 2449.21 & 53.48 & 2313.57 & 2383.80 \\
\hline 230 & 250 & 363 & 238.61 & 2316.41 & 2081.30 & 2455.60 & 96.27 & 2108.92 & 2393.16 \\
\hline 250 & 270 & 268 & 259.51 & 2352.98 & 2095.42 & 2444.13 & 44.66 & 2293.79 & 2391.55 \\
\hline 270 & 290 & 413 & 280.65 & 2345.83 & 2097.40 & 2450.10 & 58.88 & 2204.55 & 2390.38 \\
\hline 290 & 310 & 557 & 301.52 & 2355.92 & 2075.79 & 2427.11 & 38.34 & 2337.58 & 2373.35 \\
\hline 310 & 330 & 288 & 321.22 & 2345.70 & 2082.03 & 2452.15 & 60.67 & 2131.13 & 2382.44 \\
\hline 330 & 350 & 112 & 340.14 & 2324.76 & 2046.08 & 2458.69 & 85.51 & 2121.56 & 2390.48 \\
\hline 350 & 370 & 165 & 359.59 & 2333.77 & 2066.21 & 2439.43 & 74.04 & 2152.58 & 2398.25 \\
\hline 370 & 390 & 152 & 380.28 & 2349.73 & 2081.42 & 2474.94 & 53.25 & 2274.42 & 2396.84 \\
\hline 390 & 410 & 292 & 400.56 & 2354.33 & 2070.23 & 2428.98 & 50.31 & 2304.38 & 2394.01 \\
\hline 410 & 430 & 276 & 414.98 & 2359.68 & 2107.55 & 2437.07 & 26.23 & 2325.56 & 2392.41 \\
\hline 430 & 450 & 106 & 439.34 & 2361.08 & 2167.05 & 2450.91 & 32.34 & 2312.40 & 2400.21 \\
\hline 450 & 470 & 141 & 460.92 & 2355.11 & 2169.19 & 2411.36 & 33.26 & 2292.74 & 2385.87 \\
\hline 470 & 490 & 352 & 477.40 & 2359.80 & 2122.43 & 2412.32 & 27.04 & 2347.80 & 2371.43 \\
\hline 490 & 510 & 231 & 504.77 & 2362.99 & 2318.76 & 2387.83 & 6.29 & 2360.39 & 2366.93 \\
\hline 510 & 530 & 6 & 510.64 & 2367.06 & 2363.86 & 2378.24 & 5.58 & 2363.86 & 2378.24 \\
\hline
\end{tabular}


Secondary Air Heater A Gas Outlet Temperature, ${ }^{\circ} \mathrm{F}$

\begin{tabular}{|c|c|c|c|c|c|c|c|c|c|}
\hline $\begin{array}{l}\text { Bin } \\
\text { Low }\end{array}$ & $\begin{array}{l}\text { Bin } \\
\text { High }\end{array}$ & Samples & $\begin{array}{l}\text { Load } \\
\text { Mean }\end{array}$ & $\begin{array}{c}\text { PV } \\
\text { Mean }\end{array}$ & $\begin{array}{l}\text { PV } \\
\text { Min }\end{array}$ & $\begin{array}{l}\mathrm{PV} \\
\mathrm{Max}\end{array}$ & $\begin{array}{l}\text { PV } \\
\text { Std }\end{array}$ & $\begin{array}{c}\text { PV } \\
\text { 5thP }\end{array}$ & $\begin{array}{c}\text { PV } \\
95 \text { thP }\end{array}$ \\
\hline 130 & 150 & 0 & 147.50 & 65535.00 & 65535.00 & 65535.00 & 65535.00 & 65535.00 & 65535.00 \\
\hline 150 & 170 & 8 & 165.87 & 282.44 & 274.69 & 299.91 & 7.78 & 274.69 & 299.91 \\
\hline 170 & 190 & 28 & 177.21 & 289.34 & 275.78 & 319.26 & 11.31 & 276.90 & 305.99 \\
\hline 190 & 210 & 2710 & 200.35 & 296.49 & 257.17 & 327.55 & 13.04 & 277.07 & 315.10 \\
\hline 210 & 230 & 522 & 218.82 & 296.52 & 257.93 & 338.12 & 14.17 & 282.69 & 321.80 \\
\hline 230 & 250 & 363 & 238.61 & 287.90 & 247.18 & 336.24 & 18.16 & 250.87 & 309.61 \\
\hline 250 & 270 & 268 & 259.51 & 289.89 & 257.50 & 327.96 & 11.70 & 269.26 & 307.13 \\
\hline 270 & 290 & 413 & 280.65 & 282.80 & 258.24 & 333.15 & 13.76 & 262.93 & 306.82 \\
\hline 290 & 310 & 557 & 301.52 & 295.19 & 260.55 & 336.74 & 11.54 & 277.35 & 319.25 \\
\hline 310 & 330 & 288 & 321.22 & 289.65 & 261.45 & 333.92 & 18.26 & 268.36 & 322.77 \\
\hline 330 & 350 & 112 & 340.14 & 288.01 & 256.71 & 328.86 & 11.69 & 272.37 & 303.13 \\
\hline 350 & 370 & 165 & 359.59 & 277.61 & 248.76 & 302.88 & 13.77 & 253.02 & 297.00 \\
\hline 370 & 390 & 152 & 380.28 & 279.29 & 251.65 & 303.47 & 12.28 & 253.76 & 298.58 \\
\hline 390 & 410 & 292 & 400.56 & 283.79 & 252.21 & 304.22 & 9.56 & 265.01 & 298.44 \\
\hline 410 & 430 & 276 & 414.98 & 283.54 & 259.33 & 307.77 & 7.25 & 270.94 & 299.00 \\
\hline 430 & 450 & 106 & 439.34 & 288.23 & 263.42 & 307.21 & 10.53 & 266.76 & 302.84 \\
\hline 450 & 470 & 141 & 460.92 & 289.44 & 266.02 & 311.56 & 9.68 & 271.27 & 304.50 \\
\hline 470 & 490 & 352 & 477.40 & 293.64 & 270.20 & 314.09 & 12.31 & 274.19 & 312.36 \\
\hline 490 & 510 & 231 & 504.77 & 306.05 & 304.05 & 314.24 & 3.39 & 304.05 & 313.28 \\
\hline 510 & 530 & 6 & 510.64 & 311.95 & 308.83 & 313.67 & 1.69 & 308.83 & 313.67 \\
\hline \multicolumn{10}{|c|}{ Secondary Air Heater B Gas Outlet Temperature, ${ }^{\circ} \mathrm{F}$} \\
\hline Bin & Bin & Samples & Load & PV & PV & PV & PV & PV & PV \\
\hline Low & High & & Mean & Mean & Min & $\operatorname{Max}$ & Std & 5 thP & 95thP \\
\hline 130 & 150 & 0 & 147.50 & 65535.00 & 65535.00 & 65535.00 & 65535.00 & 65535.00 & 65535.00 \\
\hline 150 & 170 & 8 & 165.87 & 291.66 & 285.88 & 298.50 & 4.28 & 285.88 & 298.50 \\
\hline 170 & 190 & 28 & 177.21 & 306.80 & 291.63 & 329.32 & 13.12 & 292.34 & 327.26 \\
\hline 190 & 210 & 2710 & 200.35 & 296.58 & 255.23 & 347.70 & 13.45 & 272.47 & 316.02 \\
\hline 210 & 230 & 522 & 218.82 & 299.45 & 261.10 & 338.48 & 17.50 & 273.05 & 333.19 \\
\hline 230 & 250 & 363 & 238.61 & 293.04 & 247.54 & 329.85 & 14.42 & 268.82 & 317.17 \\
\hline 250 & 270 & 268 & 259.51 & 287.01 & 247.72 & 320.35 & 12.64 & 269.73 & 304.16 \\
\hline 270 & 290 & 413 & 280.65 & 288.74 & 264.31 & 333.26 & 9.48 & 274.73 & 304.47 \\
\hline 290 & 310 & 557 & 301.52 & 300.59 & 269.32 & 336.10 & 11.63 & 280.35 & 323.38 \\
\hline 310 & 330 & 288 & 321.22 & 299.02 & 276.64 & 337.08 & 16.52 & 281.10 & 328.48 \\
\hline 330 & 350 & 112 & 340.14 & 302.82 & 275.80 & 335.71 & 14.50 & 284.36 & 326.38 \\
\hline 350 & 370 & 165 & 359.59 & 300.61 & 280.62 & 330.95 & 11.42 & 286.33 & 324.30 \\
\hline 370 & 390 & 152 & 380.28 & 299.62 & 273.71 & 328.81 & 13.65 & 282.22 & 323.49 \\
\hline 390 & 410 & 292 & 400.56 & 304.16 & 273.24 & 329.12 & 10.82 & 285.23 & 322.36 \\
\hline 410 & 430 & 276 & 414.98 & 304.37 & 281.34 & 328.75 & 7.03 & 290.16 & 317.23 \\
\hline 430 & 450 & 106 & 439.34 & 309.15 & 283.86 & 329.47 & 11.44 & 285.51 & 322.56 \\
\hline 450 & 470 & 141 & 460.92 & 308.90 & 285.60 & 334.42 & 10.28 & 289.53 & 326.10 \\
\hline 470 & 490 & 352 & 477.40 & 314.21 & 287.27 & 337.11 & 13.21 & 293.60 & 335.37 \\
\hline 490 & 510 & 231 & 504.77 & 325.62 & 323.60 & 337.87 & 3.60 & 323.60 & 333.21 \\
\hline 510 & 530 & 6 & 510.64 & 332.00 & 327.19 & 335.79 & 2.92 & 327.19 & 335.79 \\
\hline
\end{tabular}

Secondary Air Heater A Gas Inlet Temperature, ${ }^{\circ} \mathrm{F}$

\begin{tabular}{|c|c|c|c|c|c|c|c|c|c|}
\hline $\begin{array}{l}\text { Bin } \\
\text { Low }\end{array}$ & $\begin{array}{l}\text { Bin } \\
\text { High }\end{array}$ & Samples & $\begin{array}{l}\text { Load } \\
\text { Mean }\end{array}$ & $\begin{array}{l}\text { PV } \\
\text { Mean }\end{array}$ & $\begin{array}{l}\text { PV } \\
\text { Min }\end{array}$ & $\begin{array}{l}\text { PV } \\
\text { Max }\end{array}$ & $\begin{array}{l}\text { PV } \\
\text { Std }\end{array}$ & $\begin{array}{c}\text { PV } \\
5 \text { thP }\end{array}$ & $\begin{array}{c}\text { PV } \\
95 \text { thP }\end{array}$ \\
\hline 130 & 150 & 0 & 147.50 & 65535.00 & 65535.00 & 65535.00 & 65535.00 & 65535.00 & 65535.00 \\
\hline 150 & 170 & 8 & 165.87 & 582.98 & 570.09 & 594.43 & 7.91 & 570.09 & 594.43 \\
\hline 170 & 190 & 28 & 177.21 & 603.07 & 588.60 & 627.94 & 10.87 & 589.09 & 623.06 \\
\hline 190 & 210 & 2710 & 200.35 & 607.93 & 574.32 & 652.53 & 15.96 & 583.65 & 633.29 \\
\hline 210 & 230 & 522 & 218.82 & 620.74 & 585.21 & 663.73 & 20.22 & 593.60 & 650.62 \\
\hline 230 & 250 & 363 & 238.61 & 633.76 & 591.07 & 678.57 & 22.13 & 603.98 & 669.53 \\
\hline 250 & 270 & 268 & 259.51 & 636.37 & 605.66 & 690.95 & 16.66 & 613.17 & 673.42 \\
\hline 270 & 290 & 413 & 280.65 & 647.06 & 617.60 & 703.60 & 18.99 & 627.25 & 682.22 \\
\hline 290 & 310 & 557 & 301.52 & 663.99 & 626.61 & 719.55 & 16.16 & 640.47 & 700.82 \\
\hline 310 & 330 & 288 & 321.22 & 673.19 & 635.59 & 733.94 & 25.43 & 638.49 & 714.20 \\
\hline 330 & 350 & 112 & 340.14 & 695.11 & 653.87 & 743.92 & 26.76 & 655.49 & 736.43 \\
\hline 350 & 370 & 165 & 359.59 & 701.32 & 662.13 & 755.17 & 21.50 & 673.58 & 745.33 \\
\hline 370 & 390 & 152 & 380.28 & 711.51 & 682.24 & 760.35 & 14.86 & 688.74 & 733.10 \\
\hline 390 & 410 & 292 & 400.56 & 717.58 & 680.80 & 771.86 & 15.55 & 684.35 & 738.20 \\
\hline 410 & 430 & 276 & 414.98 & 726.44 & 710.27 & 767.23 & 9.11 & 714.85 & 746.73 \\
\hline 430 & 450 & 106 & 439.34 & 749.38 & 721.93 & 777.08 & 15.84 & 726.36 & 773.37 \\
\hline 450 & 470 & 141 & 460.92 & 751.25 & 726.36 & 779.10 & 9.12 & 738.19 & 765.77 \\
\hline 470 & 490 & 352 & 477.40 & 760.56 & 743.19 & 780.44 & 6.29 & 748.18 & 768.48 \\
\hline 490 & 510 & 231 & 504.77 & 776.15 & 759.31 & 794.89 & 4.92 & 765.49 & 781.30 \\
\hline 510 & 530 & 6 & 510.64 & 789.36 & 784.63 & 795.01 & 4.27 & 784.63 & 795.01 \\
\hline
\end{tabular}


Secondary Air Heater B Gas Inlet Temperature, ${ }^{\circ} \mathrm{F}$

\begin{tabular}{|c|c|c|c|c|c|c|c|c|c|}
\hline $\begin{array}{l}\text { Bin } \\
\text { Low }\end{array}$ & $\begin{array}{l}\text { Bin } \\
\text { High }\end{array}$ & Samples & $\begin{array}{l}\text { Load } \\
\text { Mean }\end{array}$ & $\begin{array}{c}\text { PV } \\
\text { Mean }\end{array}$ & $\begin{array}{l}\text { PV } \\
\text { Min }\end{array}$ & $\begin{array}{l}\text { PV } \\
\text { Max }\end{array}$ & $\begin{array}{l}\text { PV } \\
\text { Std }\end{array}$ & $\begin{array}{c}P V \\
5 \text { thP }\end{array}$ & $\begin{array}{c}\mathrm{PV} \\
\text { 95thP }\end{array}$ \\
\hline 130 & 150 & 0 & 147.50 & 65535.00 & 65535.00 & 65535.00 & 65535.00 & 65535.00 & 65535.00 \\
\hline 150 & 170 & 8 & 165.87 & 590.99 & 579.30 & 600.98 & 6.95 & 579.30 & 600.98 \\
\hline 170 & 190 & 28 & 177.21 & 615.14 & 593.93 & 697.51 & 19.64 & 595.87 & 642.94 \\
\hline 190 & 210 & 2710 & 200.35 & 641.02 & 587.02 & 697.51 & 34.77 & 601.65 & 697.51 \\
\hline 210 & 230 & 522 & 218.82 & 657.62 & 588.15 & 697.51 & 33.35 & 604.98 & 697.51 \\
\hline 230 & 250 & 363 & 238.61 & 673.26 & 606.81 & 697.51 & 27.19 & 617.51 & 697.51 \\
\hline 250 & 270 & 268 & 259.51 & 676.13 & 615.43 & 706.39 & 26.84 & 629.58 & 697.51 \\
\hline 270 & 290 & 413 & 280.65 & 684.60 & 630.01 & 728.62 & 20.64 & 641.08 & 703.47 \\
\hline 290 & 310 & 557 & 301.52 & 678.41 & 640.86 & 733.51 & 17.40 & 649.55 & 697.51 \\
\hline 310 & 330 & 288 & 321.22 & 690.90 & 647.52 & 764.67 & 19.61 & 653.68 & 727.39 \\
\hline 330 & 350 & 112 & 340.14 & 708.51 & 661.51 & 771.94 & 31.95 & 668.80 & 764.85 \\
\hline 350 & 370 & 165 & 359.59 & 709.91 & 672.19 & 785.28 & 27.74 & 681.36 & 770.09 \\
\hline 370 & 390 & 152 & 380.28 & 711.90 & 688.07 & 788.20 & 19.50 & 697.51 & 747.74 \\
\hline 390 & 410 & 292 & 400.56 & 712.29 & 694.49 & 806.21 & 21.25 & 697.51 & 754.60 \\
\hline 410 & 430 & 276 & 414.98 & 702.29 & 697.51 & 787.51 & 15.79 & 697.51 & 742.15 \\
\hline 430 & 450 & 106 & 439.34 & 729.98 & 697.51 & 796.59 & 40.60 & 697.51 & 793.32 \\
\hline 450 & 470 & 141 & 460.92 & 706.84 & 697.51 & 799.10 & 25.16 & 697.51 & 770.98 \\
\hline 470 & 490 & 352 & 477.40 & 705.17 & 697.51 & 793.24 & 24.41 & 697.51 & 776.35 \\
\hline 490 & 510 & 231 & 504.77 & 714.24 & 697.51 & 801.50 & 37.25 & 697.51 & 799.28 \\
\hline 510 & 530 & 6 & 510.64 & 697.51 & 697.51 & 697.51 & 0.00 & 697.51 & 697.51 \\
\hline \multicolumn{10}{|c|}{ Stack O2, \% } \\
\hline Bin & Bin & Samples & Load & PV & PV & PV & PV & PV & PV \\
\hline Low & High & & Mean & Mean & $\operatorname{Min}$ & $\operatorname{Max}$ & Std & 5 thP & 95thP \\
\hline 130 & 150 & 0 & 147.50 & 65535.00 & 65535.00 & 65535.00 & 65535.00 & 65535.00 & 65535.00 \\
\hline 150 & 170 & 8 & 165.87 & 6.77 & 6.08 & 7.23 & 0.41 & 6.08 & 7.23 \\
\hline 170 & 190 & 28 & 177.21 & 6.51 & 4.68 & 8.05 & 0.72 & 5.41 & 7.65 \\
\hline 190 & 210 & 2710 & 200.35 & 6.46 & 4.31 & 7.75 & 0.33 & 5.86 & 6.99 \\
\hline 210 & 230 & 522 & 218.82 & 6.13 & 4.66 & 7.51 & 0.51 & 5.09 & 6.85 \\
\hline 230 & 250 & 363 & 238.61 & 5.83 & 4.78 & 7.35 & 0.45 & 5.15 & 6.56 \\
\hline 250 & 270 & 268 & 259.51 & 5.71 & 4.52 & 6.80 & 0.41 & 4.88 & 6.37 \\
\hline 270 & 290 & 413 & 280.65 & 5.38 & 4.35 & 7.06 & 0.49 & 4.74 & 6.28 \\
\hline 290 & 310 & 557 & 301.52 & 5.24 & 4.07 & 6.79 & 0.41 & 4.55 & 6.10 \\
\hline 310 & 330 & 288 & 321.22 & 5.05 & 3.58 & 8.97 & 0.53 & 4.22 & 5.58 \\
\hline 330 & 350 & 112 & 340.14 & 4.71 & 3.76 & 6.90 & 0.58 & 3.89 & 5.63 \\
\hline 350 & 370 & 165 & 359.59 & 5.03 & 3.63 & 8.37 & 0.83 & 3.84 & 6.49 \\
\hline 370 & 390 & 152 & 380.28 & 5.02 & 3.61 & 10.62 & 0.85 & 3.89 & 6.81 \\
\hline 390 & 410 & 292 & 400.56 & 4.75 & 3.59 & 10.24 & 0.86 & 3.77 & 6.09 \\
\hline 410 & 430 & 276 & 414.98 & 4.90 & 3.62 & 10.39 & 0.83 & 4.33 & 6.16 \\
\hline 430 & 450 & 106 & 439.34 & 4.59 & 3.24 & 7.75 & 0.86 & 3.57 & 6.24 \\
\hline 450 & 470 & 141 & 460.92 & 4.69 & 3.54 & 9.50 & 0.82 & 3.89 & 6.03 \\
\hline 470 & 490 & 352 & 477.40 & 4.79 & 3.73 & 10.14 & 0.91 & 4.04 & 6.95 \\
\hline 490 & 510 & 231 & 504.77 & 4.26 & 3.65 & 4.73 & 0.09 & 4.14 & 4.42 \\
\hline 510 & 530 & 6 & 510.64 & 4.35 & 4.16 & 4.81 & 0.24 & 4.16 & 4.81 \\
\hline \multicolumn{10}{|c|}{ Stack NOx, lb/MBtu } \\
\hline Bin & Bin & Samples & Load & PV & PV & PV & PV & PV & PV \\
\hline Low & High & & Mean & Mean & Min & $\operatorname{Max}$ & Std & 5thP & 95thP \\
\hline 130 & 150 & 0 & 147.50 & 65535.000 & 65535.000 & 65535.000 & 65535.000 & 65535.000 & 65535.000 \\
\hline 150 & 170 & 8 & 165.87 & 0.431 & 0.331 & 0.469 & 0.047 & 0.331 & 0.469 \\
\hline 170 & 190 & 28 & 177.21 & 0.430 & 0.336 & 0.540 & 0.049 & 0.344 & 0.500 \\
\hline 190 & 210 & 2710 & 200.35 & 0.386 & 0.282 & 0.834 & 0.042 & 0.307 & 0.451 \\
\hline 210 & 230 & 522 & 218.82 & 0.390 & 0.278 & 0.582 & 0.052 & 0.311 & 0.492 \\
\hline 230 & 250 & 363 & 238.61 & 0.374 & 0.245 & 0.523 & 0.047 & 0.293 & 0.447 \\
\hline 250 & 270 & 268 & 259.51 & 0.369 & 0.278 & 0.519 & 0.040 & 0.299 & 0.425 \\
\hline 270 & 290 & 413 & 280.65 & 0.371 & 0.261 & 0.510 & 0.037 & 0.321 & 0.424 \\
\hline 290 & 310 & 557 & 301.52 & 0.368 & 0.292 & 0.508 & 0.028 & 0.326 & 0.414 \\
\hline 310 & 330 & 288 & 321.22 & 0.361 & 0.287 & 0.481 & 0.035 & 0.305 & 0.410 \\
\hline 330 & 350 & 112 & 340.14 & 0.368 & 0.243 & 0.463 & 0.040 & 0.302 & 0.423 \\
\hline 350 & 370 & 165 & 359.59 & 0.373 & 0.285 & 0.507 & 0.037 & 0.307 & 0.433 \\
\hline 370 & 390 & 152 & 380.28 & 0.390 & 0.263 & 0.485 & 0.037 & 0.310 & 0.443 \\
\hline 390 & 410 & 292 & 400.56 & 0.399 & 0.275 & 0.492 & 0.033 & 0.350 & 0.443 \\
\hline 410 & 430 & 276 & 414.98 & 0.385 & 0.270 & 0.465 & 0.027 & 0.350 & 0.435 \\
\hline 430 & 450 & 106 & 439.34 & 0.374 & 0.254 & 0.529 & 0.066 & 0.273 & 0.463 \\
\hline 450 & 470 & 141 & 460.92 & 0.390 & 0.227 & 0.469 & 0.041 & 0.354 & 0.452 \\
\hline 470 & 490 & 352 & 477.40 & 0.415 & 0.227 & 0.498 & 0.035 & 0.362 & 0.468 \\
\hline 490 & 510 & 231 & 504.77 & 0.469 & 0.401 & 0.516 & 0.014 & 0.436 & 0.478 \\
\hline 510 & 530 & 6 & 510.64 & 0.500 & 0.485 & 0.522 & 0.014 & 0.485 & 0.522 \\
\hline
\end{tabular}


Stack CO, ppm (Uncorrected)

\begin{tabular}{|c|c|c|c|c|c|c|c|c|c|}
\hline $\begin{array}{l}\text { Bin } \\
\text { Low }\end{array}$ & $\begin{array}{l}\text { Bin } \\
\text { High }\end{array}$ & Samples & $\begin{array}{l}\text { Load } \\
\text { Mean }\end{array}$ & $\begin{array}{c}\text { PV } \\
\text { Mean }\end{array}$ & $\begin{array}{l}\mathrm{PV} \\
\mathrm{Min}\end{array}$ & $\begin{array}{c}\text { PV } \\
\text { Max }\end{array}$ & $\begin{array}{l}\text { PV } \\
\text { Std }\end{array}$ & $\begin{array}{c}\mathrm{PV} \\
\text { 5thP }\end{array}$ & $\begin{array}{c}\mathrm{PV} \\
95 \text { thP }\end{array}$ \\
\hline 130 & 150 & 0 & 147.50 & 65535.00 & 65535.00 & 65535.00 & 65535.00 & 65535.00 & 65535.00 \\
\hline 150 & 170 & 2 & 165.77 & 10.53 & -4.91 & 25.96 & 21.83 & -4.91 & 25.96 \\
\hline 170 & 190 & 11 & 177.86 & 6.41 & -4.96 & 56.18 & 19.39 & -4.96 & 54.94 \\
\hline 190 & 210 & 2154 & 200.38 & 28.09 & -5.00 & 88.50 & 23.64 & -3.97 & 62.32 \\
\hline 210 & 230 & 433 & 218.26 & 24.55 & -4.99 & 78.44 & 22.40 & -3.42 & 68.30 \\
\hline 230 & 250 & 318 & 238.92 & 22.57 & -4.92 & 78.52 & 19.53 & -3.13 & 61.40 \\
\hline 250 & 270 & 245 & 259.27 & 28.42 & -4.91 & 195.61 & 23.40 & -3.80 & 65.61 \\
\hline 270 & 290 & 389 & 280.76 & 42.29 & -4.98 & 280.99 & 46.25 & -3.06 & 126.04 \\
\hline 290 & 310 & 546 & 301.51 & 63.01 & -4.78 & 298.71 & 47.19 & 7.64 & 129.31 \\
\hline 310 & 330 & 286 & 321.23 & 61.77 & -4.96 & 298.32 & 58.47 & 0.00 & 157.88 \\
\hline 330 & 350 & 112 & 340.14 & 89.51 & -3.41 & 289.49 & 76.48 & 1.87 & 252.42 \\
\hline 350 & 370 & 165 & 359.59 & 94.12 & -1.95 & 294.39 & 79.22 & 12.34 & 266.22 \\
\hline 370 & 390 & 150 & 380.22 & 69.91 & -4.96 & 296.99 & 65.95 & 3.31 & 221.39 \\
\hline 390 & 410 & 290 & 400.52 & 74.57 & -5.00 & 295.68 & 67.15 & 0.26 & 245.02 \\
\hline 410 & 430 & 273 & 414.91 & 75.60 & -4.80 & 300.37 & 51.78 & -2.62 & 165.38 \\
\hline 430 & 450 & 105 & 439.38 & 97.75 & -4.85 & 296.34 & 86.05 & -3.04 & 279.37 \\
\hline 450 & 470 & 141 & 460.92 & 101.16 & -4.69 & 305.07 & 78.67 & -1.22 & 270.43 \\
\hline 470 & 490 & 352 & 477.40 & 105.20 & -3.86 & 300.77 & 87.92 & -0.38 & 276.51 \\
\hline 490 & 510 & 231 & 504.77 & 43.87 & 12.96 & 294.22 & 28.36 & 22.64 & 66.90 \\
\hline 510 & 530 & 6 & 510.64 & 41.41 & 23.28 & 55.23 & 11.23 & 23.28 & 55.23 \\
\hline \multicolumn{10}{|c|}{ NOx, Compliance CEM, Ib/Mbtu } \\
\hline Bin & Bin & Samples & Load & PV & PV & PV & PV & PV & PV \\
\hline Low & High & & Mean & Mean & Min & $\operatorname{Max}$ & Std & 5thP & 95thP \\
\hline 130 & 150 & 0 & 147.50 & 65535.000 & 65535.000 & 65535.000 & 65535.000 & 65535.000 & 65535.000 \\
\hline 150 & 170 & 8 & 165.87 & 0.4394 & 0.3730 & 0.4650 & 0.0290 & 0.3730 & 0.4650 \\
\hline 170 & 190 & 28 & 177.21 & 0.5557 & 0.3840 & 1.3130 & 0.2565 & 0.4056 & 1.1915 \\
\hline 190 & 210 & 2710 & 200.35 & 0.5183 & 0.2620 & 1.3290 & 0.2152 & 0.3630 & 1.2720 \\
\hline 210 & 230 & 522 & 218.82 & 0.4386 & 0.2510 & 0.7260 & 0.0586 & 0.3402 & 0.5150 \\
\hline 230 & 250 & 363 & 238.61 & 0.4249 & 0.2700 & 1.0100 & 0.0812 & 0.3267 & 0.5254 \\
\hline 250 & 270 & 268 & 259.51 & 0.4146 & 0.2850 & 0.9730 & 0.0823 & 0.3270 & 0.5099 \\
\hline 270 & 290 & 413 & 280.65 & 0.4070 & 0.2360 & 0.7020 & 0.0578 & 0.3380 & 0.5379 \\
\hline 290 & 310 & 557 & 301.52 & 0.3918 & 0.2410 & 0.7230 & 0.0626 & 0.3214 & 0.5243 \\
\hline 310 & 330 & 288 & 321.22 & 0.3696 & 0.2030 & 0.6160 & 0.0476 & 0.3069 & 0.4371 \\
\hline 330 & 350 & 112 & 340.14 & 0.3834 & 0.2500 & 0.6580 & 0.0653 & 0.3100 & 0.5062 \\
\hline 350 & 370 & 165 & 359.59 & 0.4047 & 0.2370 & 1.4490 & 0.1465 & 0.2785 & 0.6480 \\
\hline 370 & 390 & 152 & 380.28 & 0.4239 & 0.2380 & 0.8230 & 0.0888 & 0.3545 & 0.5934 \\
\hline 390 & 410 & 292 & 400.56 & 0.3991 & 0.2420 & 0.7980 & 0.0606 & 0.3440 & 0.5039 \\
\hline 410 & 430 & 276 & 414.98 & 0.4070 & 0.3390 & 0.8320 & 0.0548 & 0.3708 & 0.5100 \\
\hline 430 & 450 & 106 & 439.34 & 0.4190 & 0.2470 & 0.5670 & 0.0681 & 0.3426 & 0.5514 \\
\hline 450 & 470 & 141 & 460.92 & 0.4257 & 0.2780 & 0.6450 & 0.0692 & 0.3580 & 0.5282 \\
\hline 470 & 490 & 352 & 477.40 & 0.4422 & 0.2700 & 0.7340 & 0.0675 & 0.3630 & 0.5479 \\
\hline 490 & 510 & 231 & 504.77 & 0.4777 & 0.3170 & 0.6880 & 0.0562 & 0.4160 & 0.6230 \\
\hline 510 & 530 & 6 & 510.64 & 0.4822 & 0.4300 & 0.6650 & 0.0913 & 0.4300 & 0.6650 \\
\hline \multicolumn{10}{|c|}{ Mill A Coal Flow, lb/hr } \\
\hline Bin & Bin & Samples & Load & PV & PV & PV & PV & PV & PV \\
\hline Low & High & & Mean & Mean & Min & $\operatorname{Max}$ & Std & 5thP & 95thP \\
\hline 130 & 150 & 0 & 147.50 & 65535.00 & 65535.00 & 65535.00 & 65535.00 & 65535.00 & 65535.00 \\
\hline 150 & 170 & 8 & 165.87 & 47324.00 & 32360.97 & 56774.84 & 8831.89 & 32360.97 & 56774.84 \\
\hline 170 & 190 & 28 & 177.21 & 51307.44 & 13.64 & 69303.56 & 14364.56 & 30034.30 & 67549.81 \\
\hline 190 & 210 & 2710 & 200.35 & 42317.10 & 11.69 & 73375.67 & 13975.05 & 14.78 & 59783.80 \\
\hline 210 & 230 & 522 & 218.82 & 47846.17 & 11.52 & 76869.55 & 11154.45 & 37319.28 & 63853.02 \\
\hline 230 & 250 & 363 & 238.61 & 45679.48 & 11.52 & 71537.81 & 17924.37 & 12.38 & 62946.08 \\
\hline 250 & 270 & 268 & 259.51 & 42995.39 & 12.03 & 76811.91 & 21049.09 & 12.38 & 63831.39 \\
\hline 270 & 290 & 413 & 280.65 & 43158.20 & 11.34 & 77781.28 & 21086.94 & 13.18 & 62780.78 \\
\hline 290 & 310 & 557 & 301.52 & 50265.05 & 15.13 & 79195.48 & 6843.75 & 44707.22 & 62817.31 \\
\hline 310 & 330 & 288 & 321.22 & 44123.96 & 12.83 & 79000.06 & 20415.79 & 13.98 & 65108.82 \\
\hline 330 & 350 & 112 & 340.14 & 54766.64 & 13.64 & 76511.48 & 9695.72 & 42061.78 & 69577.61 \\
\hline 350 & 370 & 165 & 359.59 & 53910.29 & 11.52 & 78342.23 & 14930.48 & 13526.51 & 69362.43 \\
\hline 370 & 390 & 152 & 380.28 & 58570.35 & 20008.77 & 80782.06 & 8520.22 & 43742.92 & 73901.97 \\
\hline 390 & 410 & 292 & 400.56 & 57567.79 & 13.29 & 80498.23 & 9024.26 & 47012.68 & 68590.93 \\
\hline 410 & 430 & 276 & 414.98 & 60579.54 & 12.55 & 80648.39 & 8948.79 & 51749.29 & 70891.87 \\
\hline 430 & 450 & 106 & 439.34 & 63130.83 & 13.23 & 81920.90 & 10671.40 & 49479.61 & 75167.92 \\
\hline 450 & 470 & 141 & 460.92 & 64955.80 & 11427.00 & 77245.09 & 6489.94 & 56773.30 & 73011.69 \\
\hline 470 & 490 & 352 & 477.40 & 65992.57 & 50762.94 & 73406.56 & 3343.61 & 60962.85 & 71334.62 \\
\hline 490 & 510 & 231 & 504.77 & 66219.61 & 57295.11 & 71513.29 & 1181.51 & 64589.43 & 66474.09 \\
\hline 510 & 530 & 6 & 510.64 & 65696.81 & 60134.65 & 67228.05 & 2747.15 & 60134.65 & 67228.05 \\
\hline
\end{tabular}


Mill B Coal Flow, lb/hr

\begin{tabular}{|c|c|c|c|c|c|c|c|c|c|}
\hline $\begin{array}{l}\text { Bin } \\
\text { Low }\end{array}$ & $\begin{array}{l}\text { Bin } \\
\text { High }\end{array}$ & Samples & $\begin{array}{l}\text { Load } \\
\text { Mean }\end{array}$ & $\begin{array}{l}\text { PV } \\
\text { Mean }\end{array}$ & $\begin{array}{l}\text { PV } \\
\text { Min }\end{array}$ & $\begin{array}{l}\text { PV } \\
\text { Max }\end{array}$ & $\begin{array}{l}\text { PV } \\
\text { Std }\end{array}$ & $\begin{array}{c}P V \\
5 \text { thP }\end{array}$ & $\begin{array}{l}\text { PV } \\
95 \text { thP }\end{array}$ \\
\hline 130 & 150 & 0 & 147.50 & 65535.00 & 65535.00 & 65535.00 & 65535.00 & 65535.00 & 65535.00 \\
\hline 150 & 170 & 8 & 165.87 & 37175.04 & 7.73 & 57127.70 & 23550.46 & 7.73 & 57127.70 \\
\hline 170 & 190 & 28 & 177.21 & 36587.57 & 12.03 & 66145.92 & 25063.52 & 12.19 & 66063.01 \\
\hline 190 & 210 & 2710 & 200.35 & 6473.24 & 3.27 & 73799.29 & 16028.74 & 12.20 & 43613.17 \\
\hline 210 & 230 & 522 & 218.82 & 15594.42 & 3.44 & 64415.83 & 23090.41 & 11.86 & 57294.40 \\
\hline 230 & 250 & 363 & 238.61 & 12050.94 & 3.32 & 70303.92 & 21673.97 & 12.94 & 55378.49 \\
\hline 250 & 270 & 268 & 259.51 & 16086.02 & 3.32 & 69792.25 & 24311.09 & 12.36 & 58994.23 \\
\hline 270 & 290 & 413 & 280.65 & 21808.20 & 3.09 & 66152.22 & 22744.45 & 11.88 & 54504.76 \\
\hline 290 & 310 & 557 & 301.52 & 31229.44 & 3.09 & 72141.04 & 21923.30 & 12.72 & 49995.10 \\
\hline 310 & 330 & 288 & 321.22 & 37848.57 & 12.72 & 76848.35 & 22010.23 & 17.53 & 57159.18 \\
\hline 330 & 350 & 112 & 340.14 & 36797.58 & 11.00 & 76943.11 & 24899.65 & 13.45 & 67365.21 \\
\hline 350 & 370 & 165 & 359.59 & 49049.76 & 10.48 & 78786.24 & 19766.52 & 16.37 & 66765.20 \\
\hline 370 & 390 & 152 & 380.28 & 45376.03 & 13.75 & 80727.28 & 23832.96 & 16.84 & 73721.79 \\
\hline 390 & 410 & 292 & 400.56 & 53077.30 & 13.06 & 79420.34 & 17304.64 & 17.88 & 68242.02 \\
\hline 410 & 430 & 276 & 414.98 & 58427.53 & 14.95 & 79780.82 & 10411.53 & 49076.26 & 69486.64 \\
\hline 430 & 450 & 106 & 439.34 & 44017.74 & 15.30 & 82189.08 & 27641.24 & 15.64 & 69056.26 \\
\hline 450 & 470 & 141 & 460.92 & 61507.26 & 15.70 & 78385.60 & 12004.02 & 47213.66 & 70649.05 \\
\hline 470 & 490 & 352 & 477.40 & 65368.77 & 51088.01 & 73018.52 & 2652.15 & 61426.23 & 69378.41 \\
\hline 490 & 510 & 231 & 504.77 & 67308.87 & 57746.79 & 72043.81 & 1197.02 & 65739.69 & 67580.37 \\
\hline 510 & 530 & 6 & 510.64 & 66708.26 & 60571.61 & 68341.06 & 3025.38 & 60571.61 & 68341.06 \\
\hline \multicolumn{10}{|c|}{ Mill C Coal Flow, lb/hr } \\
\hline Bin & Bin & Samples & Load & PV & PV & PV & PV & PV & PV \\
\hline Low & High & & Mean & Mean & Min & $\operatorname{Max}$ & Std & 5thP & 95thP \\
\hline 130 & 150 & 0 & 147.50 & 65535.00 & 65535.00 & 65535.00 & 65535.00 & 65535.00 & 65535.00 \\
\hline 150 & 170 & 8 & 165.87 & 0.24 & -6.02 & 1.55 & 2.54 & -6.02 & 1.55 \\
\hline 170 & 190 & 28 & 177.21 & 16578.28 & 1.20 & 68685.03 & 27058.78 & 1.20 & 66922.78 \\
\hline 190 & 210 & 2710 & 200.35 & 40635.33 & -7.22 & 72409.56 & 15622.81 & 3.61 & 59713.44 \\
\hline 210 & 230 & 522 & 218.82 & 34932.70 & -5.50 & 76851.38 & 21721.70 & -2.27 & 63140.64 \\
\hline 230 & 250 & 363 & 238.61 & 37363.32 & -6.70 & 73137.80 & 23172.21 & -2.64 & 62882.57 \\
\hline 250 & 270 & 268 & 259.51 & 49071.35 & -5.61 & 74008.00 & 13942.22 & 1.82 & 63992.72 \\
\hline 270 & 290 & 413 & 280.65 & 41989.48 & -3.78 & 75445.10 & 20095.78 & 2.39 & 62311.20 \\
\hline 290 & 310 & 557 & 301.52 & 48008.33 & -3.44 & 79155.66 & 9042.90 & 42754.35 & 62401.46 \\
\hline 310 & 330 & 288 & 321.22 & 44225.98 & 0.17 & 78508.89 & 17528.62 & 1.72 & 62423.90 \\
\hline 330 & 350 & 112 & 340.14 & 44954.42 & 0.52 & 73342.45 & 20254.34 & 1.22 & 65019.14 \\
\hline 350 & 370 & 165 & 359.59 & 45202.71 & 0.52 & 76049.99 & 22879.12 & 1.20 & 67138.80 \\
\hline 370 & 390 & 152 & 380.28 & 55022.66 & -0.34 & 77103.47 & 12736.78 & 33568.54 & 70481.12 \\
\hline 390 & 410 & 292 & & 53747.76 & -0.17 & & 10715.44 & 40152.81 & 66395.41 \\
\hline 410 & 430 & 276 & 414.98 & 57422.35 & -41.82 & 77138.99 & 9694.87 & 44471.62 & 68966.72 \\
\hline 430 & 450 & 106 & 439.34 & 61695.01 & 9.63 & & 10954.17 & 48182.23 & 75405.75 \\
\hline 450 & 470 & 141 & 460.92 & 62238.82 & 7.33 & 77795.78 & 7238.18 & 53827.81 & 71037.99 \\
\hline 470 & 490 & 352 & 477.40 & 61569.26 & 22780.89 & 71766.18 & 5741.77 & 54379.16 & 68667.20 \\
\hline 490 & 510 & 231 & 504.77 & 66393.78 & 49778.04 & 68001.54 & 2207.38 & 64030.20 & 67122.88 \\
\hline 510 & 530 & 6 & 510.64 & 65017.34 & 52641.25 & 67950.04 & 6074.66 & 52641.25 & 67950.04 \\
\hline \multicolumn{10}{|c|}{ Mill D Coal Flow, lb/hr } \\
\hline Bin & Bin & Samples & Load & PV & PV & PV & PV & PV & PV \\
\hline Low & High & & Mean & Mean & Min & Max & Std & 5 thP & 95thP \\
\hline 130 & 150 & 0 & 147.50 & 65535.00 & 65535.00 & 65535.00 & 65535.00 & 65535.00 & 65535.00 \\
\hline 150 & 170 & 8 & 165.87 & 44539.72 & 28594.62 & 53898.68 & 8958.84 & 28594.62 & 53898.68 \\
\hline 170 & 190 & 28 & 7.21 & 48798.49 & -924.12 & 67238.70 & 14003.79 & 28501.52 & 65517.75 \\
\hline 190 & 210 & 2710 & 200.35 & 31850.78 & -996.65 & 69423.92 & 20102.97 & -591.59 & 53827.47 \\
\hline 210 & 230 & 522 & 218.82 & 38906.79 & -938.09 & 69654.23 & 17672.21 & -487.51 & 59241.46 \\
\hline 230 & 250 & 363 & 238.61 & 42607.92 & -993.21 & 68611.87 & 16380.53 & -546.65 & 58099.71 \\
\hline 250 & 270 & 268 & 259.51 & 46786.86 & -799.79 & 69182.27 & 13477.75 & $\begin{array}{l}-377.90 \\
\end{array}$ & 60957.89 \\
\hline 270 & 290 & 413 & 280.65 & 48844.13 & -790.57 & 77670.59 & 9622.64 & 37409.60 & 61242.59 \\
\hline 290 & 310 & 557 & 301.52 & 47044.03 & -738.72 & 75720.91 & 11472.15 & 39302.27 & 61789.73 \\
\hline 310 & 330 & 288 & 321.22 & 49939.66 & -778.65 & 75311.96 & 11078.63 & 36351.26 & 66949.07 \\
\hline 330 & 350 & 112 & 340.14 & 49983.69 & -758.54 & 74429.84 & 14380.62 & 2992.76 & 67807.46 \\
\hline 350 & 370 & 165 & 359.59 & 48253.09 & -376.64 & 76420.84 & 18391.02 & -374.86 & 66370.51 \\
\hline 370 & 390 & 152 & 380.28 & 55255.49 & -518.38 & 75337.63 & 12236.81 & 40002.14 & 70936.38 \\
\hline 390 & 410 & 292 & 400.56 & 54943.17 & -521.47 & 74343.04 & 9106.60 & 45428.43 & 65201.05 \\
\hline 410 & 430 & 276 & 414.98 & 55629.13 & -488.30 & 74630.88 & 5872.41 & 50916.05 & 67266.74 \\
\hline 430 & 450 & 106 & 439.34 & 60319.34 & 41616.50 & 76765.10 & 6687.83 & 50170.60 & 70827.82 \\
\hline 450 & 470 & 141 & 460.92 & 60060.67 & 50461.07 & 73219.73 & 4565.23 & 52982.56 & 68852.23 \\
\hline 470 & 490 & 352 & 477.40 & 61967.55 & 50451.44 & 72117.77 & 2409.72 & 58687.69 & 65673.56 \\
\hline 490 & 510 & 231 & 504.77 & 65381.86 & 56995.81 & 71129.15 & 1367.45 & 62888.69 & 65835.97 \\
\hline 510 & 530 & 6 & 510.64 & 65178.66 & 59831.75 & 66703.95 & 2647.73 & 59831.75 & 66703.95 \\
\hline
\end{tabular}


Mill E Coal Flow, lb/hr

\begin{tabular}{|c|c|c|c|c|c|c|c|c|c|}
\hline $\begin{array}{l}\text { Bin } \\
\text { Low }\end{array}$ & $\begin{array}{l}\text { Bin } \\
\text { High }\end{array}$ & Samples & $\begin{array}{l}\text { Load } \\
\text { Mean }\end{array}$ & $\begin{array}{l}\text { PV } \\
\text { Mean }\end{array}$ & $\begin{array}{l}\text { PV } \\
\text { Min }\end{array}$ & $\begin{array}{l}\text { PV } \\
\text { Max }\end{array}$ & $\begin{array}{l}\text { PV } \\
\text { Std }\end{array}$ & $\begin{array}{c}\text { PV } \\
\text { 5thP }\end{array}$ & $\begin{array}{c}\text { PV } \\
95 \text { thP }\end{array}$ \\
\hline 130 & 150 & 0 & 147.50 & 65535.00 & 65535.00 & 65535.00 & 65535.00 & 65535.00 & 65535.00 \\
\hline 150 & 170 & 8 & 165.87 & -97.88 & -99.00 & -92.98 & 2.00 & -99.00 & -92.98 \\
\hline 170 & 190 & 28 & 177.21 & 4.78 & -105.53 & 2227.67 & 449.60 & -103.98 & 663.01 \\
\hline 190 & 210 & 2710 & 200.35 & 5737.45 & -105.53 & 60756.38 & 15066.50 & -103.81 & 44053.00 \\
\hline 210 & 230 & 522 & 218.82 & 4123.76 & -105.36 & 69969.97 & 14489.69 & -103.64 & 46752.27 \\
\hline 230 & 250 & 363 & 238.61 & 17526.91 & -106.05 & 74973.13 & 25007.87 & -102.78 & 57619.78 \\
\hline 250 & 270 & 268 & 259.51 & 12942.95 & -104.50 & 75872.27 & 23289.26 & -103.64 & 60611.66 \\
\hline 270 & 290 & 413 & 280.65 & 22389.24 & -104.50 & 73393.43 & 25477.28 & -102.83 & 58446.07 \\
\hline 290 & 310 & 557 & 301.52 & 12536.42 & -104.39 & 65506.61 & 22165.21 & -103.98 & 52573.07 \\
\hline 310 & 330 & 288 & 321.22 & 36135.71 & -103.93 & 71703.45 & 25582.85 & -101.41 & 60207.96 \\
\hline 330 & 350 & 112 & 340.14 & 36891.08 & -104.04 & 78331.12 & 27527.37 & -101.57 & 69824.78 \\
\hline 350 & 370 & 165 & 359.59 & 38520.76 & -103.81 & 80236.23 & 28066.96 & -100.98 & 69674.89 \\
\hline 370 & 390 & 152 & 380.28 & 32971.15 & -103.01 & 78466.27 & 30063.25 & -102.08 & 71309.83 \\
\hline 390 & 410 & 292 & 400.56 & 39415.50 & -104.50 & 80193.61 & 25986.24 & -103.93 & 67160.83 \\
\hline 410 & 430 & 276 & 414.98 & 55564.65 & -104.16 & 81101.97 & 16741.21 & -95.39 & 69588.71 \\
\hline 430 & 450 & 106 & 439.34 & 63027.31 & -95.39 & 82664.31 & 10809.64 & 50823.71 & 77006.04 \\
\hline 450 & 470 & 141 & 460.92 & 63942.83 & 16731.98 & 79080.03 & 6182.04 & 56913.28 & 72413.12 \\
\hline 470 & 490 & 352 & 477.40 & 65236.50 & 48579.90 & 74182.91 & 2966.05 & 61151.79 & 70219.48 \\
\hline 490 & 510 & 231 & 504.77 & 68489.90 & 58697.95 & 73167.93 & 1237.97 & 66816.98 & 68786.09 \\
\hline 510 & 530 & 6 & 510.64 & 67902.81 & 61553.65 & 69667.24 & 3137.30 & 61553.65 & 69667.24 \\
\hline \multicolumn{10}{|c|}{ Mill F Coal Flow, lb/hr } \\
\hline Bin & Bin & Samples & Load & PV & PV & PV & PV & PV & PV \\
\hline Low & High & & Mean & Mean & Min & $\operatorname{Max}$ & Std & 5thP & 95thP \\
\hline 130 & 150 & 0 & 147.50 & 65535.00 & 65535.00 & 65535.00 & 65535.00 & 65535.00 & 65535.00 \\
\hline 150 & 170 & 8 & 165.87 & 0.54 & -0.80 & 7.22 & 2.71 & -0.80 & 7.22 \\
\hline 170 & 190 & 28 & 177.21 & 3471.94 & -6.36 & 51428.61 & 12774.75 & -5.59 & 46374.87 \\
\hline 190 & 210 & 2710 & 200.35 & 42862.81 & -425.96 & 73756.72 & 15910.75 & 1.72 & 59724.16 \\
\hline 210 & 230 & 522 & 218.82 & 42755.71 & -1.89 & 78128.07 & 17914.95 & 2.89 & 62935.96 \\
\hline 230 & 250 & 363 & 238.61 & 47648.19 & -3.09 & 74504.38 & 16769.75 & 1.18 & 64091.31 \\
\hline 250 & 270 & 268 & 259.51 & 47785.46 & -0.69 & 75382.66 & 17948.02 & 0.17 & 65260.73 \\
\hline 270 & 290 & 413 & 280.65 & 49804.53 & -0.69 & 79236.49 & 15299.93 & 0.59 & 64584.28 \\
\hline 290 & 310 & 557 & 301.52 & 49492.51 & 0.23 & 80557.30 & 12437.42 & 40466.96 & 64748.59 \\
\hline 310 & 330 & 288 & 321.22 & 45025.61 & -0.17 & 80444.32 & 21761.08 & 4.30 & 66572.65 \\
\hline 330 & 350 & 112 & 340.14 & 55418.54 & -0.69 & 77909.79 & 12122.98 & 42605.52 & 70865.65 \\
\hline 350 & 370 & 165 & 359.59 & 54311.84 & -3.44 & 79807.41 & 16433.80 & -0.99 & 69748.99 \\
\hline 370 & 390 & 152 & 380.28 & 57727.84 & -4.81 & 83173.46 & 15002.81 & 32151.85 & 75673.05 \\
\hline 390 & 410 & 292 & 400.56 & 59022.64 & 3150.81 & 80403.30 & 9652.12 & 47137.57 & 70860.03 \\
\hline 410 & 430 & 276 & 414.98 & 61343.70 & 36768.30 & 83086.78 & 5404.38 & 54340.98 & 72608.77 \\
\hline 430 & 450 & 106 & 439.34 & 64452.35 & -3.27 & 82183.29 & 9933.99 & 52011.99 & 76591.68 \\
\hline 450 & 470 & 141 & 460.92 & 65624.65 & 26548.10 & 79206.31 & 5709.95 & 58217.59 & 74670.58 \\
\hline 470 & 490 & 352 & 477.40 & 67055.26 & 51679.55 & 76525.97 & 3259.45 & 63332.21 & 72293.68 \\
\hline 490 & 510 & 231 & 504.77 & 69727.38 & 58386.74 & 72769.07 & 1362.03 & 68169.16 & 70112.54 \\
\hline 510 & 530 & 6 & 510.64 & 68948.81 & 61233.85 & 70945.76 & 3797.71 & 61233.85 & 70945.76 \\
\hline
\end{tabular}


Table A-17 P4A - Mill Pattern Frequency by Load (1Q96)

\begin{tabular}{|c|c|c|c|c|c|c|c|c|c|c|c|c|c|c|c|c|c|c|c|c|}
\hline \multirow[b]{2}{*}{$\begin{array}{c}\text { Mill } \\
\text { A-B-C-D-E-F }\end{array}$} & \multicolumn{20}{|c|}{ Load, MW } \\
\hline & 130 & 150 & 170 & 190 & 210 & 230 & 250 & 270 & 290 & 310 & 330 & 350 & 370 & 390 & 410 & 430 & 450 & 470 & 490 & 510 \\
\hline $0-0-0-0-0-1$ & 0 & 0 & 0 & 0 & 0 & 0 & 0 & 0 & 0 & 0 & 0 & 0 & 0 & 0 & 0 & 0 & 0 & 0 & 0 & 0 \\
\hline $0-0-0-0-1-0$ & 0 & 0 & 0 & 0 & 0 & 0 & 0 & 0 & 0 & 0 & 0 & 0 & 0 & 0 & 0 & 0 & 0 & 0 & 0 & 0 \\
\hline $0-0-0-0-1-1$ & 0 & 0 & 0 & 0 & 0 & 0 & 0 & 0 & 0 & 0 & 0 & 0 & 0 & 0 & 0 & 0 & 0 & 0 & 0 & 0 \\
\hline $0-0-0-1-0-0$ & 0 & 0 & 0 & 0 & 0 & 0 & 0 & 0 & 0 & 0 & 0 & 0 & 0 & 0 & 0 & 0 & 0 & 0 & 0 & 0 \\
\hline $0-0-0-1-0-1$ & 0 & 0 & 0 & 0 & 0 & 0 & 0 & 0 & 0 & 0 & 0 & 0 & 0 & 0 & 0 & 0 & 0 & 0 & 0 & 0 \\
\hline $0-0-0-1-1-0$ & 0 & 0 & 0 & 0 & 0 & 0 & 0 & 0 & 0 & 0 & 0 & 0 & 0 & 0 & 0 & 0 & 0 & 0 & 0 & 0 \\
\hline $0-0-0-1-1-1$ & 0 & 0 & 0 & 0 & 0 & 0 & 0 & 1 & 0 & 0 & 0 & 0 & 0 & 0 & 0 & 0 & 0 & 0 & 0 & 0 \\
\hline $0-0-1-0-0-0$ & 0 & 0 & 0 & 0 & 0 & 0 & 0 & 0 & 0 & 0 & 0 & 0 & 0 & 0 & 0 & 0 & 0 & 0 & 0 & 0 \\
\hline $0-0-1-0-0-1$ & 1 & 0 & 1 & 2 & 0 & 0 & 0 & 0 & 0 & 0 & 0 & 0 & 0 & 0 & 0 & 0 & 0 & 0 & 0 & 0 \\
\hline $0-0-1-0-1-0$ & 0 & 0 & 0 & 0 & 0 & 0 & 0 & 0 & 0 & 0 & 0 & 0 & 0 & 0 & 0 & 0 & 0 & 0 & 0 & 0 \\
\hline $0-0-1-0-1-1$ & 0 & 0 & 0 & 0 & 0 & 1 & 0 & 0 & 0 & 0 & 0 & 0 & 0 & 0 & 0 & 0 & 0 & 0 & 0 & 0 \\
\hline $0-0-1-1-0-0$ & 0 & 0 & 0 & 0 & 0 & 0 & 0 & 0 & 0 & 0 & 0 & 0 & 0 & 0 & 0 & 0 & 0 & 0 & 0 & 0 \\
\hline $0-0-1-1-0-1$ & 0 & 0 & 0 & 107 & 1 & 0 & 0 & 0 & 0 & 0 & 0 & 0 & 0 & 0 & 0 & 0 & 0 & 0 & 0 & 0 \\
\hline $0-0-1-1-1-0$ & 0 & 0 & 0 & 0 & 0 & 0 & 0 & 0 & 0 & 0 & 0 & 0 & 0 & 0 & 0 & 0 & 0 & 0 & 0 & 0 \\
\hline $0-0-1-1-1-1$ & 0 & 0 & 0 & 0 & 0 & 1 & 2 & 17 & 0 & 0 & 0 & 0 & 0 & 0 & 0 & 0 & 0 & 0 & 0 & 0 \\
\hline $0-1-0-0-0-0$ & 0 & 0 & 0 & 0 & 0 & 0 & 0 & 0 & 0 & 0 & 0 & 0 & 0 & 0 & 0 & 0 & 0 & 0 & 0 & 0 \\
\hline $0-1-0-0-0-1$ & 0 & 0 & 0 & 0 & 0 & 0 & 0 & 0 & 0 & 0 & 0 & 0 & 0 & 0 & 0 & 0 & 0 & 0 & 0 & 0 \\
\hline $0-1-0-0-1-0$ & 0 & 0 & 0 & 0 & 0 & 0 & 0 & 0 & 0 & 0 & 0 & 0 & 0 & 0 & 0 & 0 & 0 & 0 & 0 & 0 \\
\hline $0-1-0-0-1-1$ & 0 & 0 & 0 & 0 & 0 & 0 & 0 & 0 & 0 & 0 & 0 & 0 & 0 & 0 & 0 & 0 & 0 & 0 & 0 & 0 \\
\hline $0-1-0-1-0-0$ & 0 & 0 & 0 & 0 & 0 & 0 & 0 & 0 & 0 & 0 & 0 & 0 & 0 & 0 & 0 & 0 & 0 & 0 & 0 & 0 \\
\hline $0-1-0-1-0-1$ & 0 & 0 & 0 & 62 & 0 & 0 & 0 & 0 & 0 & 0 & 0 & 0 & 0 & 0 & 0 & 0 & 0 & 0 & 0 & 0 \\
\hline $0-1-0-1-1-0$ & 0 & 0 & 0 & 0 & 0 & 0 & 0 & 0 & 0 & 0 & 0 & 0 & 0 & 0 & 0 & 0 & 0 & 0 & 0 & 0 \\
\hline $0-1-0-1-1-1$ & 0 & 0 & 0 & 0 & 0 & 0 & 0 & 0 & 0 & 2 & 0 & 0 & 0 & 0 & 0 & 0 & 0 & 0 & 0 & 0 \\
\hline $0-1-1-0-0-0$ & 0 & 0 & 0 & 0 & 0 & 0 & 0 & 0 & 0 & 0 & 0 & 0 & 0 & 0 & 0 & 0 & 0 & 0 & 0 & 0 \\
\hline $0-1-1-0-0-1$ & 0 & 0 & 0 & 0 & 0 & 1 & 0 & 0 & 0 & 0 & 0 & 0 & 0 & 0 & 0 & 0 & 0 & 0 & 0 & 0 \\
\hline $0-1-1-0-1-0$ & 0 & 0 & 0 & 0 & 0 & 0 & 0 & 0 & 0 & 0 & 0 & 0 & 0 & 0 & 0 & 0 & 0 & 0 & 0 & 0 \\
\hline $0-1-1-0-1-1$ & 0 & 0 & 0 & 15 & 3 & 4 & 3 & 0 & 0 & 0 & 0 & 0 & 0 & 0 & 0 & 0 & 0 & 0 & 0 & 0 \\
\hline $0-1-1-1-0-0$ & 0 & 0 & 0 & 0 & 0 & 0 & 0 & 0 & 0 & 0 & 0 & 0 & 0 & 0 & 0 & 0 & 0 & 0 & 0 & 0 \\
\hline $0-1-1-1-0-1$ & 0 & 0 & 0 & 5 & 8 & 33 & 29 & 12 & 2 & 1 & 0 & 0 & 0 & 0 & 0 & 0 & 0 & 0 & 0 & 0 \\
\hline $0-1-1-1-1-0$ & 0 & 0 & 0 & 27 & 3 & 3 & 14 & 0 & 0 & 0 & 0 & 1 & 0 & 0 & 0 & 0 & 0 & 0 & 0 & 0 \\
\hline $0-1-1-1-1-1$ & 0 & 0 & 0 & 0 & 0 & 1 & 0 & 44 & 0 & 44 & 1 & 8 & 0 & 2 & 4 & 1 & 1 & 0 & 0 & 0 \\
\hline $1-0-0-0-0-0$ & 0 & 0 & 0 & 0 & 0 & 0 & 0 & 0 & 0 & 0 & 0 & 0 & 0 & 0 & 0 & 0 & 0 & 0 & 0 & 0 \\
\hline $1-0-0-0-0-1$ & 0 & 0 & 0 & 0 & 0 & 0 & 0 & 0 & 0 & 0 & 0 & 0 & 0 & 0 & 0 & 0 & 0 & 0 & 0 & 0 \\
\hline $1-0-0-0-1-0$ & 0 & 0 & 0 & 0 & 0 & 0 & 0 & 0 & 0 & 0 & 0 & 0 & 0 & 0 & 0 & 0 & 0 & 0 & 0 & 0 \\
\hline $1-0-0-0-1-1$ & 0 & 0 & 0 & 0 & 0 & 0 & 0 & 0 & 0 & 0 & 0 & 0 & 0 & 0 & 0 & 0 & 0 & 0 & 0 & 0 \\
\hline $1-0-0-1-0-0$ & 0 & 2 & 0 & 1 & 0 & 0 & 0 & 0 & 0 & 0 & 0 & 0 & 0 & 0 & 0 & 0 & 0 & 0 & 0 & 0 \\
\hline $1-0-0-1-0-1$ & 0 & 0 & 0 & 143 & 2 & 1 & 0 & 0 & 0 & 0 & 0 & 0 & 0 & 0 & 0 & 0 & 0 & 0 & 0 & 0 \\
\hline $1-0-0-1-1-0$ & 0 & 0 & 0 & 11 & 15 & 4 & 0 & 1 & 0 & 0 & 0 & 0 & 0 & 0 & 0 & 0 & 0 & 0 & 0 & 0 \\
\hline $1-0-0-1-1-1$ & 0 & 0 & 0 & 0 & 3 & 59 & 1 & 9 & 2 & 0 & 0 & 0 & 0 & 0 & 0 & 0 & 0 & 0 & 0 & 0 \\
\hline $1-0-1-0-0-0$ & 0 & 0 & 0 & 0 & 0 & 0 & 0 & 0 & 0 & 0 & 0 & 0 & 0 & 0 & 0 & 0 & 0 & 0 & 0 & 0 \\
\hline $1-0-1-0-0-1$ & 0 & 0 & 0 & 397 & 43 & 8 & 1 & 0 & 0 & 0 & 0 & 0 & 0 & 0 & 0 & 0 & 0 & 0 & 0 & 0 \\
\hline $1-0-1-0-1-0$ & 0 & 0 & 0 & 0 & 0 & 0 & 0 & 0 & 0 & 0 & 0 & 0 & 0 & 0 & 0 & 0 & 0 & 0 & 0 & 0 \\
\hline $1-0-1-0-1-1$ & 0 & 0 & 0 & 113 & 6 & 16 & 5 & 2 & 1 & 2 & 0 & 0 & 0 & 0 & 0 & 0 & 0 & 0 & 0 & 0 \\
\hline $1-0-1-1-0-0$ & 0 & 0 & 6 & 43 & 13 & 0 & 0 & 0 & 0 & 0 & 0 & 0 & 0 & 0 & 0 & 0 & 0 & 0 & 0 & 0 \\
\hline $1-0-1-1-0-1$ & 0 & 0 & 1 & 1510 & 270 & 176 & 153 & 152 & 94 & 5 & 0 & 0 & 0 & 0 & 0 & 0 & 0 & 0 & 0 & 0 \\
\hline $1-0-1-1-1-0$ & 0 & 0 & 0 & 0 & 2 & 4 & 3 & 3 & 0 & 1 & 0 & 0 & 0 & 0 & 0 & 0 & 0 & 0 & 0 & 0 \\
\hline $1-0-1-1-1-1$ & 0 & 0 & 0 & 0 & 0 & 6 & 20 & 30 & 82 & 59 & 32 & 21 & 30 & 23 & 7 & 29 & 4 & 0 & 0 & 0 \\
\hline $1-1-0-0-0-0$ & 0 & 0 & 0 & 0 & 0 & 0 & 0 & 0 & 0 & 0 & 0 & 0 & 0 & 0 & 0 & 0 & 0 & 0 & 0 & 0 \\
\hline $1-1-0-0-0-1$ & 0 & 0 & 0 & 0 & 0 & 0 & 0 & 0 & 0 & 0 & 0 & 0 & 0 & 0 & 0 & 0 & 0 & 0 & 0 & 0 \\
\hline $1-1-0-0-1-0$ & 0 & 0 & 0 & 0 & 0 & 0 & 0 & 0 & 0 & 0 & 0 & 0 & 0 & 0 & 0 & 0 & 0 & 0 & 0 & 0 \\
\hline $1-1-0-0-1-1$ & 0 & 0 & 0 & 0 & 0 & 7 & 3 & 0 & 0 & 0 & 0 & 0 & 0 & 0 & 0 & 0 & 0 & 0 & 0 & 0 \\
\hline $1-1-0-1-0-0$ & 0 & 6 & 20 & 13 & 16 & 2 & 0 & 0 & 0 & 0 & 0 & 0 & 0 & 0 & 0 & 0 & 0 & 0 & 0 & 0 \\
\hline $1-1-0-1-0-1$ & 0 & 0 & 0 & 65 & 94 & 10 & 2 & 11 & 3 & 3 & 0 & 0 & 0 & 0 & 0 & 0 & 0 & 0 & 0 & 0 \\
\hline $1-1-0-1-1-0$ & 0 & 0 & 0 & 0 & 0 & 13 & 8 & 1 & 0 & 0 & 0 & 0 & 0 & 0 & 0 & 0 & 0 & 0 & 0 & 0 \\
\hline $1-1-0-1-1-1$ & 0 & 0 & 0 & 0 & 0 & 0 & 1 & 49 & 6 & 30 & 17 & 30 & 5 & 7 & 5 & 1 & 1 & 0 & 0 & 0 \\
\hline $1-1-1-0-0-0$ & 0 & 0 & 0 & 0 & 0 & 1 & 0 & 0 & 0 & 0 & 0 & 0 & 0 & 0 & 0 & 0 & 0 & 0 & 0 & 0 \\
\hline $1-1-1-0-0-1$ & 0 & 0 & 0 & 7 & 21 & 2 & 0 & 0 & 0 & 0 & 0 & 0 & 0 & 0 & 0 & 0 & 0 & 0 & 0 & 0 \\
\hline $1-1-1-0-1-0$ & 0 & 0 & 0 & 189 & 10 & 1 & 3 & 2 & 1 & 1 & 0 & 0 & 0 & 0 & 0 & 0 & 0 & 0 & 0 & 0 \\
\hline $1-1-1-0-1-1$ & 0 & 0 & 0 & 0 & 0 & 0 & 1 & 2 & 21 & 5 & 6 & 19 & 5 & 3 & 1 & 0 & 0 & 0 & 0 & 0 \\
\hline $1-1-1-1-0-0$ & 0 & 0 & 0 & 0 & 10 & 6 & 0 & 0 & 0 & 0 & 0 & 0 & 0 & 0 & 0 & 0 & 0 & 0 & 0 & 0 \\
\hline $1-1-1-1-0-1$ & 0 & 0 & 0 & 0 & 2 & 3 & 18 & 54 & 321 & 85 & 38 & 54 & 66 & 85 & 21 & 1 & 1 & 0 & 0 & 0 \\
\hline $1-1-1-1-1-0$ & 0 & 0 & 0 & 0 & 0 & 0 & 1 & 22 & 24 & 49 & 3 & 11 & 7 & 3 & 0 & 1 & 0 & 0 & 0 & 0 \\
\hline $1-1-1-1-1-1$ & 0 & 0 & 0 & 0 & 0 & 0 & 0 & 1 & 0 & 1 & 15 & 21 & 39 & 169 & 238 & 73 & 134 & 352 & 231 & 6 \\
\hline
\end{tabular}

${ }^{1}$ Number of occurrances of mill combination

${ }^{2}$ Mill on $=1$, Mill off $=0$ (assumed off if flow $<20000 \mathrm{lb} / \mathrm{hr}$ ) 
Table A-18 P4A - NOx Emissions by Load and Mill Pattern (1Q96)

\begin{tabular}{|c|c|c|c|c|c|c|c|c|c|c|c|c|c|c|c|c|c|c|c|c|}
\hline \multirow[b]{2}{*}{$\begin{array}{c}\text { Mill } \\
\text { A-B-C-D-E-F }\end{array}$} & \multicolumn{20}{|c|}{ Load, MW } \\
\hline & 130 & 150 & 170 & 190 & 210 & 230 & 250 & 270 & 290 & 310 & 330 & 350 & 370 & 390 & 410 & 430 & 450 & 470 & 490 & 510 \\
\hline $0-0-0-0-0-1$ & $\mathrm{n} / \mathrm{a}$ & $\mathrm{n} / \mathrm{a}$ & $\mathrm{n} / \mathrm{a}$ & $\mathrm{n} / \mathrm{a}$ & $n / a$ & $\mathrm{n} / \mathrm{a}$ & $\mathrm{n} / \mathrm{a}$ & $\mathrm{n} / \mathrm{a}$ & $\mathrm{n} / \mathrm{a}$ & $n / a$ & $n / a$ & $\mathrm{n} / \mathrm{a}$ & $n / a$ & $\mathrm{n} / \mathrm{a}$ & $n / a$ & $n / a$ & $n / a$ & $\mathrm{n} / \mathrm{a}$ & $\mathrm{n} / \mathrm{a}$ & $\mathrm{n} / \mathrm{a}$ \\
\hline $0-0-0-0-1-0$ & $\mathrm{n} / \mathrm{a}$ & $\mathrm{n} / \mathrm{a}$ & $\mathrm{n} / \mathrm{a}$ & $\mathrm{n} / \mathrm{a}$ & $n / a$ & $\mathrm{n} / \mathrm{a}$ & $\mathrm{n} / \mathrm{a}$ & $\mathrm{n} / \mathrm{a}$ & $\mathrm{n} / \mathrm{a}$ & $n / a$ & $n / a$ & $\mathrm{n} / \mathrm{a}$ & $n / a$ & $n / a$ & $n / a$ & $n / a$ & $n / a$ & $\mathrm{n} / \mathrm{a}$ & $n / a$ & $n / a$ \\
\hline $0-0-0-0-1-1$ & $\mathrm{n} / \mathrm{a}$ & $\mathrm{n} / \mathrm{a}$ & $\mathrm{n} / \mathrm{a}$ & $\mathrm{n} / \mathrm{a}$ & $\mathrm{n} / \mathrm{a}$ & $\mathrm{n} / \mathrm{a}$ & $\mathrm{n} / \mathrm{a}$ & $\mathrm{n} / \mathrm{a}$ & $\mathrm{n} / \mathrm{a}$ & $n / a$ & $n / a$ & $n / a$ & $n / a$ & $n / a$ & $n / a$ & $n / a$ & $n / a$ & $\mathrm{n} / \mathrm{a}$ & $n / a$ & $\mathrm{n} / \mathrm{a}$ \\
\hline $0-0-0-1-0-0$ & $\mathrm{n} / \mathrm{a}$ & $\mathrm{n} / \mathrm{a}$ & $\mathrm{n} / \mathrm{a}$ & $\mathrm{n} / \mathrm{a}$ & $\mathrm{n} / \mathrm{a}$ & $\mathrm{n} / \mathrm{a}$ & $\mathrm{n} / \mathrm{a}$ & $\mathrm{n} / \mathrm{a}$ & $\mathrm{n} / \mathrm{a}$ & $n / a$ & $n / a$ & $n / a$ & $n / a$ & $n / a$ & $\mathrm{n} / \mathrm{a}$ & $n / a$ & $n / a$ & $\mathrm{n} / \mathrm{a}$ & $\mathrm{n} / \mathrm{a}$ & $\mathrm{n} / \mathrm{a}$ \\
\hline $0-0-0-1-0-1$ & $\mathrm{n} / \mathrm{a}$ & $\mathrm{n} / \mathrm{a}$ & $\mathrm{n} / \mathrm{a}$ & $n / a$ & $n / a$ & $n / a$ & $\mathrm{n} / \mathrm{a}$ & $n / a$ & $n / a$ & $n / a$ & $n / a$ & $\mathrm{n} / \mathrm{a}$ & $n / a$ & $n / a$ & $n / a$ & $n / a$ & $n / a$ & $\mathrm{n} / \mathrm{a}$ & $n / a$ & $\mathrm{n} / \mathrm{a}$ \\
\hline $0-0-0-1-1-0$ & $\mathrm{n} / \mathrm{a}$ & $\mathrm{n} / \mathrm{a}$ & $\mathrm{n} / \mathrm{a}$ & $\mathrm{n} / \mathrm{a}$ & $\mathrm{n} / \mathrm{a}$ & $\mathrm{n} / \mathrm{a}$ & $\mathrm{n} / \mathrm{a}$ & $\mathrm{n} / \mathrm{a}$ & $\mathrm{n} / \mathrm{a}$ & $n / a$ & $n / a$ & $n / a$ & $n / a$ & $\mathrm{n} / \mathrm{a}$ & $n / a$ & $n / a$ & $\mathrm{n} / \mathrm{a}$ & $\mathrm{n} / \mathrm{a}$ & $\mathrm{n} / \mathrm{a}$ & $\mathrm{n} / \mathrm{a}$ \\
\hline $0-0-0-1-1-1$ & $\mathrm{n} / \mathrm{a}$ & $\mathrm{n} / \mathrm{a}$ & $\mathrm{n} / \mathrm{a}$ & $\mathrm{n} / \mathrm{a}$ & $\mathrm{n} / \mathrm{a}$ & $\mathrm{n} / \mathrm{a}$ & $\mathrm{n} / \mathrm{a}$ & 0.313 & $\mathrm{n} / \mathrm{a}$ & $\mathrm{n} / \mathrm{a}$ & $\mathrm{n} / \mathrm{a}$ & $\mathrm{n} / \mathrm{a}$ & $\mathrm{n} / \mathrm{a}$ & $\mathrm{n} / \mathrm{a}$ & $\mathrm{n} / \mathrm{a}$ & $\mathrm{n} / \mathrm{a}$ & $\mathrm{n} / \mathrm{a}$ & $\mathrm{n} / \mathrm{a}$ & $\mathrm{n} / \mathrm{a}$ & $\mathrm{n} / \mathrm{a}$ \\
\hline $0-0-1-0-0-0$ & $\mathrm{n} / \mathrm{a}$ & $\mathrm{n} / \mathrm{a}$ & $\mathrm{n} / \mathrm{a}$ & $\mathrm{n} / \mathrm{a}$ & $\mathrm{n} / \mathrm{a}$ & $\mathrm{n} / \mathrm{a}$ & $\mathrm{n} / \mathrm{a}$ & $\mathrm{n} / \mathrm{a}$ & $\mathrm{n} / \mathrm{a}$ & $\mathrm{n} / \mathrm{a}$ & $\mathrm{n} / \mathrm{a}$ & $\mathrm{n} / \mathrm{a}$ & $\mathrm{n} / \mathrm{a}$ & $\mathrm{n} / \mathrm{a}$ & $\mathrm{n} / \mathrm{a}$ & $\mathrm{n} / \mathrm{a}$ & $\mathrm{n} / \mathrm{a}$ & $\mathrm{n} / \mathrm{a}$ & $\mathrm{n} / \mathrm{a}$ & $\mathrm{n} / \mathrm{a}$ \\
\hline $0-0-1-0-0-1$ & 0.386 & $\mathrm{n} / \mathrm{a}$ & 0.336 & 0.348 & $\mathrm{n} / \mathrm{a}$ & $\mathrm{n} / \mathrm{a}$ & $\mathrm{n} / \mathrm{a}$ & $\mathrm{n} / \mathrm{a}$ & $\mathrm{n} / \mathrm{a}$ & $n / a$ & $n / a$ & $n / a$ & $\mathrm{n} / \mathrm{a}$ & $\mathrm{n} / \mathrm{a}$ & $n / a$ & $n / a$ & $\mathrm{n} / \mathrm{a}$ & $\mathrm{n} / \mathrm{a}$ & $n / a$ & $\mathrm{n} / \mathrm{a}$ \\
\hline $0-0-1-0-1-0$ & $\mathrm{n} / \mathrm{a}$ & $\mathrm{n} / \mathrm{a}$ & $\mathrm{n} / \mathrm{a}$ & $\mathrm{n} / \mathrm{a}$ & $n / a$ & $\mathrm{n} / \mathrm{a}$ & $\mathrm{n} / \mathrm{a}$ & $n / a$ & $n / a$ & $n / a$ & $n / a$ & $n / a$ & $\mathrm{n} / \mathrm{a}$ & $n / a$ & $n / a$ & $n / a$ & $n / a$ & $\mathrm{n} / \mathrm{a}$ & $\mathrm{n} / \mathrm{a}$ & $\mathrm{n} / \mathrm{a}$ \\
\hline $0-0-1-0-1-1$ & $\mathrm{n} / \mathrm{a}$ & $n / a$ & $\mathrm{n} / \mathrm{a}$ & $\mathrm{n} / \mathrm{a}$ & $n / a$ & 0.392 & $\mathrm{n} / \mathrm{a}$ & $n / a$ & $\mathrm{n} / \mathrm{a}$ & $n / a$ & $n / a$ & $\mathrm{n} / \mathrm{a}$ & $n / a$ & $\mathrm{n} / \mathrm{a}$ & $\mathrm{n} / \mathrm{a}$ & $n / a$ & $\mathrm{n} / \mathrm{a}$ & $\mathrm{n} / \mathrm{a}$ & $n / a$ & $n / a$ \\
\hline $0-0-1-1-0-0$ & $\mathrm{n} / \mathrm{a}$ & $n / a$ & $\mathrm{n} / \mathrm{a}$ & $\mathrm{n} / \mathrm{a}$ & $\mathrm{n} / \mathrm{a}$ & $\mathrm{n} / \mathrm{a}$ & $\mathrm{n} / \mathrm{a}$ & $\mathrm{n} / \mathrm{a}$ & $\mathrm{n} / \mathrm{a}$ & $n / a$ & $n / a$ & $n / a$ & $n / a$ & $n / a$ & $n / a$ & $n / a$ & $\mathrm{n} / \mathrm{a}$ & $\mathrm{n} / \mathrm{a}$ & $n / a$ & $n / a$ \\
\hline $0-0-1-1-0-1$ & $\mathrm{n} / \mathrm{a}$ & $\mathrm{n} / \mathrm{a}$ & $\mathrm{n} / \mathrm{a}$ & 0.342 & 0.351 & $\mathrm{n} / \mathrm{a}$ & $\mathrm{n} / \mathrm{a}$ & $n / a$ & $\mathrm{n} / \mathrm{a}$ & $n / a$ & $n / a$ & $n / a$ & $n / a$ & $n / a$ & $n / a$ & $n / a$ & $\mathrm{n} / \mathrm{a}$ & $n / a$ & $\mathrm{n} / \mathrm{a}$ & $\mathrm{n} / \mathrm{a}$ \\
\hline $0-0-1-1-1-0$ & $\mathrm{n} / \mathrm{a}$ & $\mathrm{n} / \mathrm{a}$ & $\mathrm{n} / \mathrm{a}$ & $\mathrm{n} / \mathrm{a}$ & $\mathrm{n} / \mathrm{a}$ & $\mathrm{n} / \mathrm{a}$ & $\mathrm{n} / \mathrm{a}$ & $\mathrm{n} / \mathrm{a}$ & $\mathrm{n} / \mathrm{a}$ & $\mathrm{n} / \mathrm{a}$ & $\mathrm{n} / \mathrm{a}$ & $\mathrm{n} / \mathrm{a}$ & $\mathrm{n} / \mathrm{a}$ & $\mathrm{n} / \mathrm{a}$ & $\mathrm{n} / \mathrm{a}$ & $\mathrm{n} / \mathrm{a}$ & $\mathrm{n} / \mathrm{a}$ & $\mathrm{n} / \mathrm{a}$ & $\mathrm{n} / \mathrm{a}$ & $\mathrm{n} / \mathrm{a}$ \\
\hline $0-0-1-1-1-1$ & $\mathrm{n} / \mathrm{a}$ & $\mathrm{n} / \mathrm{a}$ & $\mathrm{n} / \mathrm{a}$ & $\mathrm{n} / \mathrm{a}$ & $\mathrm{n} / \mathrm{a}$ & 0.329 & 0.356 & 0.348 & $\mathrm{n} / \mathrm{a}$ & $\mathrm{n} / \mathrm{a}$ & $\mathrm{n} / \mathrm{a}$ & $\mathrm{n} / \mathrm{a}$ & $\mathrm{n} / \mathrm{a}$ & $\mathrm{n} / \mathrm{a}$ & $\mathrm{n} / \mathrm{a}$ & $\mathrm{n} / \mathrm{a}$ & $\mathrm{n} / \mathrm{a}$ & $\mathrm{n} / \mathrm{a}$ & $\mathrm{n} / \mathrm{a}$ & $\mathrm{n} / \mathrm{a}$ \\
\hline $0-1-0-0-0-0$ & $\mathrm{n} / \mathrm{a}$ & $\mathrm{n} / \mathrm{a}$ & $\mathrm{n} / \mathrm{a}$ & $\mathrm{n} / \mathrm{a}$ & $\mathrm{n} / \mathrm{a}$ & $\mathrm{n} / \mathrm{a}$ & $\mathrm{n} / \mathrm{a}$ & $\mathrm{n} / \mathrm{a}$ & $\mathrm{n} / \mathrm{a}$ & $\mathrm{n} / \mathrm{a}$ & $\mathrm{n} / \mathrm{a}$ & $\mathrm{n} / \mathrm{a}$ & $\mathrm{n} / \mathrm{a}$ & $\mathrm{n} / \mathrm{a}$ & $\mathrm{n} / \mathrm{a}$ & $\mathrm{n} / \mathrm{a}$ & $\mathrm{n} / \mathrm{a}$ & $\mathrm{n} / \mathrm{a}$ & $\mathrm{n} / \mathrm{a}$ & $\mathrm{n} / \mathrm{a}$ \\
\hline $0-1-0-0-0-1$ & $\mathrm{n} / \mathrm{a}$ & $\mathrm{n} / \mathrm{a}$ & $\mathrm{n} / \mathrm{a}$ & $\mathrm{n} / \mathrm{a}$ & $\mathrm{n} / \mathrm{a}$ & $\mathrm{n} / \mathrm{a}$ & $\mathrm{n} / \mathrm{a}$ & $\mathrm{n} / \mathrm{a}$ & $\mathrm{n} / \mathrm{a}$ & $n / a$ & $n / a$ & $n / a$ & $n / a$ & $n / a$ & $n / a$ & $n / a$ & $n / a$ & $n / a$ & $\mathrm{n} / \mathrm{a}$ & $\mathrm{n} / \mathrm{a}$ \\
\hline $0-1-0-0-1-0$ & $\mathrm{n} / \mathrm{a}$ & $\mathrm{n} / \mathrm{a}$ & $\mathrm{n} / \mathrm{a}$ & $\mathrm{n} / \mathrm{a}$ & $\mathrm{n} / \mathrm{a}$ & $\mathrm{n} / \mathrm{a}$ & $\mathrm{n} / \mathrm{a}$ & $\mathrm{n} / \mathrm{a}$ & $\mathrm{n} / \mathrm{a}$ & $n / a$ & $\mathrm{n} / \mathrm{a}$ & $\mathrm{n} / \mathrm{a}$ & $n / a$ & $n / a$ & $\mathrm{n} / \mathrm{a}$ & $\mathrm{n} / \mathrm{a}$ & $\mathrm{n} / \mathrm{a}$ & $\mathrm{n} / \mathrm{a}$ & $\mathrm{n} / \mathrm{a}$ & $\mathrm{n} / \mathrm{a}$ \\
\hline $0-1-0-0-1-1$ & $\mathrm{n} / \mathrm{a}$ & $\mathrm{n} / \mathrm{a}$ & $\mathrm{n} / \mathrm{a}$ & $\mathrm{n} / \mathrm{a}$ & $\mathrm{n} / \mathrm{a}$ & $\mathrm{n} / \mathrm{a}$ & $\mathrm{n} / \mathrm{a}$ & $\mathrm{n} / \mathrm{a}$ & $\mathrm{n} / \mathrm{a}$ & $\mathrm{n} / \mathrm{a}$ & $\mathrm{n} / \mathrm{a}$ & $\mathrm{n} / \mathrm{a}$ & $\mathrm{n} / \mathrm{a}$ & $\mathrm{n} / \mathrm{a}$ & $\mathrm{n} / \mathrm{a}$ & $\mathrm{n} / \mathrm{a}$ & $\mathrm{n} / \mathrm{a}$ & $\mathrm{n} / \mathrm{a}$ & $\mathrm{n} / \mathrm{a}$ & $\mathrm{n} / \mathrm{a}$ \\
\hline $0-1-0-1-0-0$ & $\mathrm{n} / \mathrm{a}$ & $\mathrm{n} / \mathrm{a}$ & $\mathrm{n} / \mathrm{a}$ & $\mathrm{n} / \mathrm{a}$ & $\mathrm{n} / \mathrm{a}$ & $\mathrm{n} / \mathrm{a}$ & $\mathrm{n} / \mathrm{a}$ & $\mathrm{n} / \mathrm{a}$ & $\mathrm{n} / \mathrm{a}$ & $n / a$ & $n / a$ & $n / a$ & $n / a$ & $\mathrm{n} / \mathrm{a}$ & $n / a$ & $n / a$ & $\mathrm{n} / \mathrm{a}$ & $\mathrm{n} / \mathrm{a}$ & $\mathrm{n} / \mathrm{a}$ & $\mathrm{n} / \mathrm{a}$ \\
\hline $0-1-0-1-0-1$ & $\mathrm{n} / \mathrm{a}$ & $\mathrm{n} / \mathrm{a}$ & $\mathrm{n} / \mathrm{a}$ & 0.364 & $\mathrm{n} / \mathrm{a}$ & $\mathrm{n} / \mathrm{a}$ & $\mathrm{n} / \mathrm{a}$ & $\mathrm{n} / \mathrm{a}$ & $\mathrm{n} / \mathrm{a}$ & $\mathrm{n} / \mathrm{a}$ & $\mathrm{n} / \mathrm{a}$ & $\mathrm{n} / \mathrm{a}$ & $\mathrm{n} / \mathrm{a}$ & $\mathrm{n} / \mathrm{a}$ & $\mathrm{n} / \mathrm{a}$ & $\mathrm{n} / \mathrm{a}$ & $\mathrm{n} / \mathrm{a}$ & $\mathrm{n} / \mathrm{a}$ & $\mathrm{n} / \mathrm{a}$ & $\mathrm{n} / \mathrm{a}$ \\
\hline $0-1-0-1-1-0$ & $\mathrm{n} / \mathrm{a}$ & $\mathrm{n} / \mathrm{a}$ & $\mathrm{n} / \mathrm{a}$ & $\mathrm{n} / \mathrm{a}$ & $\mathrm{n} / \mathrm{a}$ & $\mathrm{n} / \mathrm{a}$ & $n / a$ & $\mathrm{n} / \mathrm{a}$ & $\mathrm{n} / \mathrm{a}$ & $\mathrm{n} / \mathrm{a}$ & $n / a$ & $n / a$ & $n / a$ & $\mathrm{n} / \mathrm{a}$ & $n / a$ & $n / a$ & $\mathrm{n} / \mathrm{a}$ & $\mathrm{n} / \mathrm{a}$ & $n / a$ & $\mathrm{n} / \mathrm{a}$ \\
\hline $0-1-0-1-1-1$ & $\mathrm{n} / \mathrm{a}$ & $\mathrm{n} / \mathrm{a}$ & $\mathrm{n} / \mathrm{a}$ & $\mathrm{n} / \mathrm{a}$ & $\mathrm{n} / \mathrm{a}$ & $\mathrm{n} / \mathrm{a}$ & $\mathrm{n} / \mathrm{a}$ & $\mathrm{n} / \mathrm{a}$ & $\mathrm{n} / \mathrm{a}$ & 0.370 & $\mathrm{n} / \mathrm{a}$ & $\mathrm{n} / \mathrm{a}$ & $\mathrm{n} / \mathrm{a}$ & $\mathrm{n} / \mathrm{a}$ & $\mathrm{n} / \mathrm{a}$ & $\mathrm{n} / \mathrm{a}$ & $\mathrm{n} / \mathrm{a}$ & $\mathrm{n} / \mathrm{a}$ & $\mathrm{n} / \mathrm{a}$ & $\mathrm{n} / \mathrm{a}$ \\
\hline $0-1-1-0-0-0$ & $\mathrm{n} / \mathrm{a}$ & $\mathrm{n} / \mathrm{a}$ & $\mathrm{n} / \mathrm{a}$ & $\mathrm{n} / \mathrm{a}$ & $\mathrm{n} / \mathrm{a}$ & $\mathrm{n} / \mathrm{a}$ & $\mathrm{n} / \mathrm{a}$ & $\mathrm{n} / \mathrm{a}$ & $\mathrm{n} / \mathrm{a}$ & $\mathrm{n} / \mathrm{a}$ & $n / a$ & $n / a$ & $n / a$ & $n / a$ & $n / a$ & $n / a$ & $n / a$ & $n / a$ & $\mathrm{n} / \mathrm{a}$ & $\mathrm{n} / \mathrm{a}$ \\
\hline $0-1-1-0-0-1$ & $\mathrm{n} / \mathrm{a}$ & $\mathrm{n} / \mathrm{a}$ & $\mathrm{n} / \mathrm{a}$ & $\mathrm{n} / \mathrm{a}$ & $\mathrm{n} / \mathrm{a}$ & 0.413 & $\mathrm{n} / \mathrm{a}$ & $\mathrm{n} / \mathrm{a}$ & $\mathrm{n} / \mathrm{a}$ & $n / a$ & $\mathrm{n} / \mathrm{a}$ & $\mathrm{n} / \mathrm{a}$ & $\mathrm{n} / \mathrm{a}$ & $\mathrm{n} / \mathrm{a}$ & $\mathrm{n} / \mathrm{a}$ & $\mathrm{n} / \mathrm{a}$ & $\mathrm{n} / \mathrm{a}$ & $\mathrm{n} / \mathrm{a}$ & $n / a$ & $\mathrm{n} / \mathrm{a}$ \\
\hline $0-1-1-0-1-0$ & $\mathrm{n} / \mathrm{a}$ & $\mathrm{n} / \mathrm{a}$ & $\mathrm{n} / \mathrm{a}$ & $\mathrm{n} / \mathrm{a}$ & $\mathrm{n} / \mathrm{a}$ & $\mathrm{n} / \mathrm{a}$ & $\mathrm{n} / \mathrm{a}$ & $\mathrm{n} / \mathrm{a}$ & $\mathrm{n} / \mathrm{a}$ & $\mathrm{n} / \mathrm{a}$ & $\mathrm{n} / \mathrm{a}$ & $\mathrm{n} / \mathrm{a}$ & $\mathrm{n} / \mathrm{a}$ & $\mathrm{n} / \mathrm{a}$ & $\mathrm{n} / \mathrm{a}$ & $\mathrm{n} / \mathrm{a}$ & $\mathrm{n} / \mathrm{a}$ & $\mathrm{n} / \mathrm{a}$ & $n / a$ & $\mathrm{n} / \mathrm{a}$ \\
\hline $0-1-1-0-1-1$ & $\mathrm{n} / \mathrm{a}$ & $\mathrm{n} / \mathrm{a}$ & $\mathrm{n} / \mathrm{a}$ & 0.431 & 0.410 & 0.415 & 0.400 & $\mathrm{n} / \mathrm{a}$ & $\mathrm{n} / \mathrm{a}$ & $\mathrm{n} / \mathrm{a}$ & $\mathrm{n} / \mathrm{a}$ & $\mathrm{n} / \mathrm{a}$ & $\mathrm{n} / \mathrm{a}$ & $n / a$ & $\mathrm{n} / \mathrm{a}$ & $\mathrm{n} / \mathrm{a}$ & $\mathrm{n} / \mathrm{a}$ & $\mathrm{n} / \mathrm{a}$ & $\mathrm{n} / \mathrm{a}$ & $\mathrm{n} / \mathrm{a}$ \\
\hline $0-1-1-1-0-0$ & $\mathrm{n} / \mathrm{a}$ & $\mathrm{n} / \mathrm{a}$ & $\mathrm{n} / \mathrm{a}$ & $\mathrm{n} / \mathrm{a}$ & $\mathrm{n} / \mathrm{a}$ & $\mathrm{n} / \mathrm{a}$ & $\mathrm{n} / \mathrm{a}$ & $\mathrm{n} / \mathrm{a}$ & $\mathrm{n} / \mathrm{a}$ & $\mathrm{n} / \mathrm{a}$ & $\mathrm{n} / \mathrm{a}$ & $\mathrm{n} / \mathrm{a}$ & $\mathrm{n} / \mathrm{a}$ & $\mathrm{n} / \mathrm{a}$ & $\mathrm{n} / \mathrm{a}$ & $\mathrm{n} / \mathrm{a}$ & $\mathrm{n} / \mathrm{a}$ & $\mathrm{n} / \mathrm{a}$ & $\mathrm{n} / \mathrm{a}$ & $\mathrm{n} / \mathrm{a}$ \\
\hline $0-1-1-1-0-1$ & $\mathrm{n} / \mathrm{a}$ & $\mathrm{n} / \mathrm{a}$ & $\mathrm{n} / \mathrm{a}$ & 0.473 & 0.426 & 0.424 & 0.395 & 0.374 & 0.394 & 0.365 & $n / a$ & $\mathrm{n} / \mathrm{a}$ & $n / a$ & $n / a$ & $n / a$ & $n / a$ & $n / a$ & $\mathrm{n} / \mathrm{a}$ & $n / a$ & $n / a$ \\
\hline $0-1-1-1-1-0$ & $\mathrm{n} / \mathrm{a}$ & $\mathrm{n} / \mathrm{a}$ & $\mathrm{n} / \mathrm{a}$ & 0.398 & 0.342 & 0.339 & 0.302 & $\mathrm{n} / \mathrm{a}$ & $\mathrm{n} / \mathrm{a}$ & $\mathrm{n} / \mathrm{a}$ & $\mathrm{n} / \mathrm{a}$ & 0.332 & $\mathrm{n} / \mathrm{a}$ & $\mathrm{n} / \mathrm{a}$ & $\mathrm{n} / \mathrm{a}$ & $\mathrm{n} / \mathrm{a}$ & $\mathrm{n} / \mathrm{a}$ & $\mathrm{n} / \mathrm{a}$ & $\mathrm{n} / \mathrm{a}$ & $\mathrm{n} / \mathrm{a}$ \\
\hline $0-1-1-1-1-1$ & $\mathrm{n} / \mathrm{a}$ & $\mathrm{n} / \mathrm{a}$ & $\mathrm{n} / \mathrm{a}$ & $\mathrm{n} / \mathrm{a}$ & $\mathrm{n} / \mathrm{a}$ & 0.501 & $\mathrm{n} / \mathrm{a}$ & 0.406 & $\mathrm{n} / \mathrm{a}$ & 0.372 & 0.372 & 0.370 & $n / a$ & 0.397 & 0.341 & 0.373 & 0.399 & $\mathrm{n} / \mathrm{a}$ & $\mathrm{n} / \mathrm{a}$ & $\mathrm{n} / \mathrm{a}$ \\
\hline $1-0-0-0-0-0$ & $\mathrm{n} / \mathrm{a}$ & $\mathrm{n} / \mathrm{a}$ & $\mathrm{n} / \mathrm{a}$ & $\mathrm{n} / \mathrm{a}$ & $\mathrm{n} / \mathrm{a}$ & $\mathrm{n} / \mathrm{a}$ & $\mathrm{n} / \mathrm{a}$ & $\mathrm{n} / \mathrm{a}$ & $\mathrm{n} / \mathrm{a}$ & $\mathrm{n} / \mathrm{a}$ & $\mathrm{n} / \mathrm{a}$ & $\mathrm{n} / \mathrm{a}$ & $\mathrm{n} / \mathrm{a}$ & $\mathrm{n} / \mathrm{a}$ & $\mathrm{n} / \mathrm{a}$ & $\mathrm{n} / \mathrm{a}$ & $\mathrm{n} / \mathrm{a}$ & $\mathrm{n} / \mathrm{a}$ & $\mathrm{n} / \mathrm{a}$ & $\mathrm{n} / \mathrm{a}$ \\
\hline $1-0-0-0-0-1$ & $\mathrm{n} / \mathrm{a}$ & $\mathrm{n} / \mathrm{a}$ & $\mathrm{n} / \mathrm{a}$ & $\mathrm{n} / \mathrm{a}$ & $\mathrm{n} / \mathrm{a}$ & $\mathrm{n} / \mathrm{a}$ & $\mathrm{n} / \mathrm{a}$ & $\mathrm{n} / \mathrm{a}$ & $\mathrm{n} / \mathrm{a}$ & $n / a$ & $n / a$ & $n / a$ & $n / a$ & $\mathrm{n} / \mathrm{a}$ & $n / a$ & $\mathrm{n} / \mathrm{a}$ & $\mathrm{n} / \mathrm{a}$ & $\mathrm{n} / \mathrm{a}$ & $\mathrm{n} / \mathrm{a}$ & $\mathrm{n} / \mathrm{a}$ \\
\hline $1-0-0-0-1-0$ & $\mathrm{n} / \mathrm{a}$ & $n / a$ & $\mathrm{n} / \mathrm{a}$ & $\mathrm{n} / \mathrm{a}$ & $n / a$ & $\mathrm{n} / \mathrm{a}$ & $\mathrm{n} / \mathrm{a}$ & $\mathrm{n} / \mathrm{a}$ & $\mathrm{n} / \mathrm{a}$ & $n / a$ & $n / a$ & $n / a$ & $\mathrm{n} / \mathrm{a}$ & $n / a$ & $\mathrm{n} / \mathrm{a}$ & $\mathrm{n} / \mathrm{a}$ & $\mathrm{n} / \mathrm{a}$ & $\mathrm{n} / \mathrm{a}$ & $\mathrm{n} / \mathrm{a}$ & $\mathrm{n} / \mathrm{a}$ \\
\hline $1-0-0-0-1-1$ & $n / a$ & $\mathrm{n} / \mathrm{a}$ & $\mathrm{n} / \mathrm{a}$ & $\mathrm{n} / \mathrm{a}$ & $n / a$ & $\mathrm{n} / \mathrm{a}$ & $\mathrm{n} / \mathrm{a}$ & $\mathrm{n} / \mathrm{a}$ & $\mathrm{n} / \mathrm{a}$ & $\mathrm{n} / \mathrm{a}$ & $\mathrm{n} / \mathrm{a}$ & $\mathrm{n} / \mathrm{a}$ & $\mathrm{n} / \mathrm{a}$ & $\mathrm{n} / \mathrm{a}$ & $\mathrm{n} / \mathrm{a}$ & $\mathrm{n} / \mathrm{a}$ & $\mathrm{n} / \mathrm{a}$ & $\mathrm{n} / \mathrm{a}$ & $\mathrm{n} / \mathrm{a}$ & $n / a$ \\
\hline $1-0-0-1-0-0$ & $\mathrm{n} / \mathrm{a}$ & 0.394 & $\mathrm{n} / \mathrm{a}$ & 0.321 & $\mathrm{n} / \mathrm{a}$ & $\mathrm{n} / \mathrm{a}$ & $\mathrm{n} / \mathrm{a}$ & $\mathrm{n} / \mathrm{a}$ & $\mathrm{n} / \mathrm{a}$ & $n / a$ & $n / a$ & $n / a$ & $\mathrm{n} / \mathrm{a}$ & $\mathrm{n} / \mathrm{a}$ & $n / a$ & $\mathrm{n} / \mathrm{a}$ & $\mathrm{n} / \mathrm{a}$ & $\mathrm{n} / \mathrm{a}$ & $n / a$ & $\mathrm{n} / \mathrm{a}$ \\
\hline $1-0-0-1-0-1$ & $\mathrm{n} / \mathrm{a}$ & $\mathrm{n} / \mathrm{a}$ & $\mathrm{n} / \mathrm{a}$ & 0.298 & 0.341 & 0.346 & $\mathrm{n} / \mathrm{a}$ & $\mathrm{n} / \mathrm{a}$ & $\mathrm{n} / \mathrm{a}$ & $\mathrm{n} / \mathrm{a}$ & $\mathrm{n} / \mathrm{a}$ & $\mathrm{n} / \mathrm{a}$ & $\mathrm{n} / \mathrm{a}$ & $\mathrm{n} / \mathrm{a}$ & $\mathrm{n} / \mathrm{a}$ & $\mathrm{n} / \mathrm{a}$ & $\mathrm{n} / \mathrm{a}$ & $\mathrm{n} / \mathrm{a}$ & $\mathrm{n} / \mathrm{a}$ & $\mathrm{n} / \mathrm{a}$ \\
\hline $1-0-0-1-1-0$ & $\mathrm{n} / \mathrm{a}$ & $n / a$ & $\mathrm{n} / \mathrm{a}$ & 0.298 & 0.303 & 0.300 & $\mathrm{n} / \mathrm{a}$ & 0.333 & $\mathrm{n} / \mathrm{a}$ & $n / a$ & $n / a$ & $\mathrm{n} / \mathrm{a}$ & $n / a$ & $\mathrm{n} / \mathrm{a}$ & $\mathrm{n} / \mathrm{a}$ & $\mathrm{n} / \mathrm{a}$ & $\mathrm{n} / \mathrm{a}$ & $\mathrm{n} / \mathrm{a}$ & $\mathrm{n} / \mathrm{a}$ & $n / a$ \\
\hline $1-0-0-1-1-1$ & $\mathrm{n} / \mathrm{a}$ & $\mathrm{n} / \mathrm{a}$ & $\mathrm{n} / \mathrm{a}$ & $\mathrm{n} / \mathrm{a}$ & 0.455 & 0.395 & 0.364 & 0.351 & 0.338 & $\mathrm{n} / \mathrm{a}$ & $\mathrm{n} / \mathrm{a}$ & $\mathrm{n} / \mathrm{a}$ & $\mathrm{n} / \mathrm{a}$ & $\mathrm{n} / \mathrm{a}$ & $\mathrm{n} / \mathrm{a}$ & $\mathrm{n} / \mathrm{a}$ & $\mathrm{n} / \mathrm{a}$ & $\mathrm{n} / \mathrm{a}$ & $\mathrm{n} / \mathrm{a}$ & $\mathrm{n} / \mathrm{a}$ \\
\hline $1-0-1-0-0-0$ & $\mathrm{n} / \mathrm{a}$ & $\mathrm{n} / \mathrm{a}$ & $\mathrm{n} / \mathrm{a}$ & $\mathrm{n} / \mathrm{a}$ & $\mathrm{n} / \mathrm{a}$ & $\mathrm{n} / \mathrm{a}$ & $\mathrm{n} / \mathrm{a}$ & $\mathrm{n} / \mathrm{a}$ & $\mathrm{n} / \mathrm{a}$ & $n / a$ & $n / a$ & $n / a$ & $n / a$ & $n / a$ & $n / a$ & $\mathrm{n} / \mathrm{a}$ & $n / a$ & $\mathrm{n} / \mathrm{a}$ & $\mathrm{n} / \mathrm{a}$ & $\mathrm{n} / \mathrm{a}$ \\
\hline $1-0-1-0-0-1$ & $\mathrm{n} / \mathrm{a}$ & $\mathrm{n} / \mathrm{a}$ & $\mathrm{n} / \mathrm{a}$ & 0.378 & 0.375 & 0.359 & 0.387 & $\mathrm{n} / \mathrm{a}$ & $\mathrm{n} / \mathrm{a}$ & $\mathrm{n} / \mathrm{a}$ & $\mathrm{n} / \mathrm{a}$ & $\mathrm{n} / \mathrm{a}$ & $\mathrm{n} / \mathrm{a}$ & $\mathrm{n} / \mathrm{a}$ & $\mathrm{n} / \mathrm{a}$ & $\mathrm{n} / \mathrm{a}$ & $\mathrm{n} / \mathrm{a}$ & $\mathrm{n} / \mathrm{a}$ & $\mathrm{n} / \mathrm{a}$ & $\mathrm{n} / \mathrm{a}$ \\
\hline $1-0-1-0-1-0$ & $\mathrm{n} / \mathrm{a}$ & $\mathrm{n} / \mathrm{a}$ & $\mathrm{n} / \mathrm{a}$ & $\mathrm{n} / \mathrm{a}$ & $\mathrm{n} / \mathrm{a}$ & $\mathrm{n} / \mathrm{a}$ & $\mathrm{n} / \mathrm{a}$ & $\mathrm{n} / \mathrm{a}$ & $\mathrm{n} / \mathrm{a}$ & $\mathrm{n} / \mathrm{a}$ & $\mathrm{n} / \mathrm{a}$ & $\mathrm{n} / \mathrm{a}$ & $\mathrm{n} / \mathrm{a}$ & $\mathrm{n} / \mathrm{a}$ & $\mathrm{n} / \mathrm{a}$ & $\mathrm{n} / \mathrm{a}$ & $\mathrm{n} / \mathrm{a}$ & $\mathrm{n} / \mathrm{a}$ & $\mathrm{n} / \mathrm{a}$ & $\mathrm{n} / \mathrm{a}$ \\
\hline $1-0-1-0-1-1$ & $\mathrm{n} / \mathrm{a}$ & $\mathrm{n} / \mathrm{a}$ & $\mathrm{n} / \mathrm{a}$ & 0.451 & 0.407 & 0.398 & 0.428 & 0.371 & 0.417 & 0.372 & $\mathrm{n} / \mathrm{a}$ & $\mathrm{n} / \mathrm{a}$ & $\mathrm{n} / \mathrm{a}$ & $\mathrm{n} / \mathrm{a}$ & $\mathrm{n} / \mathrm{a}$ & $\mathrm{n} / \mathrm{a}$ & $\mathrm{n} / \mathrm{a}$ & $\mathrm{n} / \mathrm{a}$ & $\mathrm{n} / \mathrm{a}$ & $\mathrm{n} / \mathrm{a}$ \\
\hline $1-0-1-1-0-0$ & $\mathrm{n} / \mathrm{a}$ & $\mathrm{n} / \mathrm{a}$ & 0.478 & 0.411 & 0.417 & $\mathrm{n} / \mathrm{a}$ & $\mathrm{n} / \mathrm{a}$ & $\mathrm{n} / \mathrm{a}$ & $\mathrm{n} / \mathrm{a}$ & $\mathrm{n} / \mathrm{a}$ & $n / a$ & $\mathrm{n} / \mathrm{a}$ & $n / a$ & $\mathrm{n} / \mathrm{a}$ & $n / a$ & $\mathrm{n} / \mathrm{a}$ & $n / a$ & $\mathrm{n} / \mathrm{a}$ & $\mathrm{n} / \mathrm{a}$ & $\mathrm{n} / \mathrm{a}$ \\
\hline $1-0-1-1-0-1$ & $\mathrm{n} / \mathrm{a}$ & $\mathrm{n} / \mathrm{a}$ & 0.540 & 0.399 & 0.381 & 0.362 & 0.367 & 0.370 & 0.349 & 0.353 & $n / a$ & $\mathrm{n} / \mathrm{a}$ & $n / a$ & $n / a$ & $n / a$ & $n / a$ & $\mathrm{n} / \mathrm{a}$ & $\mathrm{n} / \mathrm{a}$ & $n / a$ & $\mathrm{n} / \mathrm{a}$ \\
\hline $1-0-1-1-1-0$ & $\mathrm{n} / \mathrm{a}$ & $\mathrm{n} / \mathrm{a}$ & $\mathrm{n} / \mathrm{a}$ & $\mathrm{n} / \mathrm{a}$ & 0.382 & 0.387 & 0.387 & 0.352 & $\mathrm{n} / \mathrm{a}$ & 0.338 & $\mathrm{n} / \mathrm{a}$ & $\mathrm{n} / \mathrm{a}$ & $\mathrm{n} / \mathrm{a}$ & $\mathrm{n} / \mathrm{a}$ & $\mathrm{n} / \mathrm{a}$ & $\mathrm{n} / \mathrm{a}$ & $\mathrm{n} / \mathrm{a}$ & $\mathrm{n} / \mathrm{a}$ & $\mathrm{n} / \mathrm{a}$ & $\mathrm{n} / \mathrm{a}$ \\
\hline $1-0-1-1-1-1$ & $\mathrm{n} / \mathrm{a}$ & $\mathrm{n} / \mathrm{a}$ & $\mathrm{n} / \mathrm{a}$ & $\mathrm{n} / \mathrm{a}$ & $\mathrm{n} / \mathrm{a}$ & 0.447 & 0.383 & 0.364 & 0.375 & 0.367 & 0.349 & 0.360 & 0.368 & 0.366 & 0.302 & 0.282 & 0.276 & $\mathrm{n} / \mathrm{a}$ & $\mathrm{n} / \mathrm{a}$ & $\mathrm{n} / \mathrm{a}$ \\
\hline $1-1-0-0-0-0$ & $\mathrm{n} / \mathrm{a}$ & $\mathrm{n} / \mathrm{a}$ & $\mathrm{n} / \mathrm{a}$ & $\mathrm{n} / \mathrm{a}$ & $\mathrm{n} / \mathrm{a}$ & $\mathrm{n} / \mathrm{a}$ & $\mathrm{n} / \mathrm{a}$ & $\mathrm{n} / \mathrm{a}$ & $\mathrm{n} / \mathrm{a}$ & $\mathrm{n} / \mathrm{a}$ & $\mathrm{n} / \mathrm{a}$ & $\mathrm{n} / \mathrm{a}$ & $\mathrm{n} / \mathrm{a}$ & $\mathrm{n} / \mathrm{a}$ & $\mathrm{n} / \mathrm{a}$ & $\mathrm{n} / \mathrm{a}$ & $\mathrm{n} / \mathrm{a}$ & $\mathrm{n} / \mathrm{a}$ & $\mathrm{n} / \mathrm{a}$ & $\mathrm{n} / \mathrm{a}$ \\
\hline $1-1-0-0-0-1$ & $\mathrm{n} / \mathrm{a}$ & $\mathrm{n} / \mathrm{a}$ & $\mathrm{n} / \mathrm{a}$ & $\mathrm{n} / \mathrm{a}$ & $\mathrm{n} / \mathrm{a}$ & $\mathrm{n} / \mathrm{a}$ & $\mathrm{n} / \mathrm{a}$ & $\mathrm{n} / \mathrm{a}$ & $\mathrm{n} / \mathrm{a}$ & $n / a$ & $n / a$ & $\mathrm{n} / \mathrm{a}$ & $n / a$ & $\mathrm{n} / \mathrm{a}$ & $\mathrm{n} / \mathrm{a}$ & $\mathrm{n} / \mathrm{a}$ & $n / a$ & $n / a$ & $\mathrm{n} / \mathrm{a}$ & $\mathrm{n} / \mathrm{a}$ \\
\hline $1-1-0-0-1-0$ & $\mathrm{n} / \mathrm{a}$ & $\mathrm{n} / \mathrm{a}$ & $\mathrm{n} / \mathrm{a}$ & $\mathrm{n} / \mathrm{a}$ & $\mathrm{n} / \mathrm{a}$ & $\mathrm{n} / \mathrm{a}$ & $\mathrm{n} / \mathrm{a}$ & $\mathrm{n} / \mathrm{a}$ & $\mathrm{n} / \mathrm{a}$ & $\mathrm{n} / \mathrm{a}$ & $\mathrm{n} / \mathrm{a}$ & $\mathrm{n} / \mathrm{a}$ & $\mathrm{n} / \mathrm{a}$ & $\mathrm{n} / \mathrm{a}$ & $\mathrm{n} / \mathrm{a}$ & $\mathrm{n} / \mathrm{a}$ & $\mathrm{n} / \mathrm{a}$ & $\mathrm{n} / \mathrm{a}$ & $\mathrm{n} / \mathrm{a}$ & $\mathrm{n} / \mathrm{a}$ \\
\hline $1-1-0-0-1-1$ & $\mathrm{n} / \mathrm{a}$ & $\mathrm{n} / \mathrm{a}$ & $\mathrm{n} / \mathrm{a}$ & $\mathrm{n} / \mathrm{a}$ & $\mathrm{n} / \mathrm{a}$ & 0.366 & 0.340 & $\mathrm{n} / \mathrm{a}$ & $\mathrm{n} / \mathrm{a}$ & $\mathrm{n} / \mathrm{a}$ & $\mathrm{n} / \mathrm{a}$ & $\mathrm{n} / \mathrm{a}$ & $\mathrm{n} / \mathrm{a}$ & $\mathrm{n} / \mathrm{a}$ & $\mathrm{n} / \mathrm{a}$ & $\mathrm{n} / \mathrm{a}$ & $\mathrm{n} / \mathrm{a}$ & $\mathrm{n} / \mathrm{a}$ & $\mathrm{n} / \mathrm{a}$ & $\mathrm{n} / \mathrm{a}$ \\
\hline $1-1-0-1-0-0$ & $\mathrm{n} / \mathrm{a}$ & 0.444 & 0.415 & 0.348 & 0.322 & 0.283 & $\mathrm{n} / \mathrm{a}$ & $\mathrm{n} / \mathrm{a}$ & $\mathrm{n} / \mathrm{a}$ & $\mathrm{n} / \mathrm{a}$ & $n / a$ & $\mathrm{n} / \mathrm{a}$ & $n / a$ & $\mathrm{n} / \mathrm{a}$ & $\mathrm{n} / \mathrm{a}$ & $n / a$ & $\mathrm{n} / \mathrm{a}$ & $\mathrm{n} / \mathrm{a}$ & $n / a$ & $n / a$ \\
\hline $1-1-0-1-0-1$ & $\mathrm{n} / \mathrm{a}$ & $\mathrm{n} / \mathrm{a}$ & $\mathrm{n} / \mathrm{a}$ & 0.393 & 0.435 & 0.350 & 0.346 & 0.356 & 0.363 & 0.395 & $\mathrm{n} / \mathrm{a}$ & $\mathrm{n} / \mathrm{a}$ & $\mathrm{n} / \mathrm{a}$ & $\mathrm{n} / \mathrm{a}$ & $\mathrm{n} / \mathrm{a}$ & $\mathrm{n} / \mathrm{a}$ & $\mathrm{n} / \mathrm{a}$ & $\mathrm{n} / \mathrm{a}$ & $\mathrm{n} / \mathrm{a}$ & $\mathrm{n} / \mathrm{a}$ \\
\hline $1-1-0-1-1-0$ & $\mathrm{n} / \mathrm{a}$ & $\mathrm{n} / \mathrm{a}$ & $\mathrm{n} / \mathrm{a}$ & $\mathrm{n} / \mathrm{a}$ & $\mathrm{n} / \mathrm{a}$ & 0.285 & 0.280 & 0.324 & $\mathrm{n} / \mathrm{a}$ & $\mathrm{n} / \mathrm{a}$ & $\mathrm{n} / \mathrm{a}$ & $\mathrm{n} / \mathrm{a}$ & $\mathrm{n} / \mathrm{a}$ & $\mathrm{n} / \mathrm{a}$ & $\mathrm{n} / \mathrm{a}$ & $\mathrm{n} / \mathrm{a}$ & $\mathrm{n} / \mathrm{a}$ & $\mathrm{n} / \mathrm{a}$ & $n / a$ & $\mathrm{n} / \mathrm{a}$ \\
\hline $1-1-0-1-1-1$ & $\mathrm{n} / \mathrm{a}$ & $\mathrm{n} / \mathrm{a}$ & $\mathrm{n} / \mathrm{a}$ & $\mathrm{n} / \mathrm{a}$ & $\mathrm{n} / \mathrm{a}$ & $\mathrm{n} / \mathrm{a}$ & 0.369 & 0.339 & 0.345 & 0.322 & 0.355 & 0.352 & 0.417 & 0.358 & 0.355 & 0.348 & 0.447 & $\mathrm{n} / \mathrm{a}$ & $\mathrm{n} / \mathrm{a}$ & $\mathrm{n} / \mathrm{a}$ \\
\hline $1-1-1-0-0-0$ & $\mathrm{n} / \mathrm{a}$ & $n / a$ & $\mathrm{n} / \mathrm{a}$ & $\mathrm{n} / \mathrm{a}$ & $\mathrm{n} / \mathrm{a}$ & 0.386 & $\mathrm{n} / \mathrm{a}$ & $\mathrm{n} / \mathrm{a}$ & $\mathrm{n} / \mathrm{a}$ & $\mathrm{n} / \mathrm{a}$ & $\mathrm{n} / \mathrm{a}$ & $\mathrm{n} / \mathrm{a}$ & $\mathrm{n} / \mathrm{a}$ & $\mathrm{n} / \mathrm{a}$ & $\mathrm{n} / \mathrm{a}$ & $\mathrm{n} / \mathrm{a}$ & $\mathrm{n} / \mathrm{a}$ & $n / a$ & $n / a$ & $\mathrm{n} / \mathrm{a}$ \\
\hline $1-1-1-0-0-1$ & $\mathrm{n} / \mathrm{a}$ & $\mathrm{n} / \mathrm{a}$ & $\mathrm{n} / \mathrm{a}$ & 0.444 & 0.427 & 0.414 & $\mathrm{n} / \mathrm{a}$ & $\mathrm{n} / \mathrm{a}$ & $\mathrm{n} / \mathrm{a}$ & $\mathrm{n} / \mathrm{a}$ & $\mathrm{n} / \mathrm{a}$ & $\mathrm{n} / \mathrm{a}$ & $\mathrm{n} / \mathrm{a}$ & $\mathrm{n} / \mathrm{a}$ & $\mathrm{n} / \mathrm{a}$ & $\mathrm{n} / \mathrm{a}$ & $\mathrm{n} / \mathrm{a}$ & $\mathrm{n} / \mathrm{a}$ & $\mathrm{n} / \mathrm{a}$ & $\mathrm{n} / \mathrm{a}$ \\
\hline $1-1-1-0-1-0$ & $\mathrm{n} / \mathrm{a}$ & $\mathrm{n} / \mathrm{a}$ & $\mathrm{n} / \mathrm{a}$ & 0.348 & 0.340 & 0.370 & 0.304 & 0.308 & 0.325 & 0.301 & $\mathrm{n} / \mathrm{a}$ & $\mathrm{n} / \mathrm{a}$ & $\mathrm{n} / \mathrm{a}$ & $\mathrm{n} / \mathrm{a}$ & $\mathrm{n} / \mathrm{a}$ & $\mathrm{n} / \mathrm{a}$ & $\mathrm{n} / \mathrm{a}$ & $\mathrm{n} / \mathrm{a}$ & $n / a$ & $\mathrm{n} / \mathrm{a}$ \\
\hline $1-1-1-0-1-1$ & $\mathrm{n} / \mathrm{a}$ & $\mathrm{n} / \mathrm{a}$ & $\mathrm{n} / \mathrm{a}$ & $\mathrm{n} / \mathrm{a}$ & $\mathrm{n} / \mathrm{a}$ & $\mathrm{n} / \mathrm{a}$ & 0.387 & 0.361 & 0.335 & 0.330 & 0.336 & 0.353 & 0.363 & 0.361 & 0.361 & $\mathrm{n} / \mathrm{a}$ & $\mathrm{n} / \mathrm{a}$ & $\mathrm{n} / \mathrm{a}$ & $\mathrm{n} / \mathrm{a}$ & $\mathrm{n} / \mathrm{a}$ \\
\hline $1-1-1-1-0-0$ & $\mathrm{n} / \mathrm{a}$ & $\mathrm{n} / \mathrm{a}$ & $\mathrm{n} / \mathrm{a}$ & $\mathrm{n} / \mathrm{a}$ & 0.388 & 0.390 & $\mathrm{n} / \mathrm{a}$ & $\mathrm{n} / \mathrm{a}$ & $\mathrm{n} / \mathrm{a}$ & $\mathrm{n} / \mathrm{a}$ & $\mathrm{n} / \mathrm{a}$ & $\mathrm{n} / \mathrm{a}$ & $\mathrm{n} / \mathrm{a}$ & $\mathrm{n} / \mathrm{a}$ & $\mathrm{n} / \mathrm{a}$ & $\mathrm{n} / \mathrm{a}$ & $\mathrm{n} / \mathrm{a}$ & $\mathrm{n} / \mathrm{a}$ & $\mathrm{n} / \mathrm{a}$ & $\mathrm{n} / \mathrm{a}$ \\
\hline $1-1-1-1-0-1$ & $\mathrm{n} / \mathrm{a}$ & $n / a$ & $\mathrm{n} / \mathrm{a}$ & $\mathrm{n} / \mathrm{a}$ & 0.487 & 0.439 & 0.408 & 0.404 & 0.378 & 0.389 & 0.392 & 0.397 & 0.401 & 0.412 & 0.399 & 0.381 & 0.448 & $\mathrm{n} / \mathrm{a}$ & $\mathrm{n} / \mathrm{a}$ & $\mathrm{n} / \mathrm{a}$ \\
\hline $1-1-1-1-1-0$ & $\mathrm{n} / \mathrm{a}$ & $\mathrm{n} / \mathrm{a}$ & $\mathrm{n} / \mathrm{a}$ & $\mathrm{n} / \mathrm{a}$ & $\mathrm{n} / \mathrm{a}$ & $\mathrm{n} / \mathrm{a}$ & 0.387 & 0.344 & 0.323 & 0.321 & 0.321 & 0.337 & 0.354 & 0.368 & $\mathrm{n} / \mathrm{a}$ & 0.423 & $\mathrm{n} / \mathrm{a}$ & $\mathrm{n} / \mathrm{a}$ & $\mathrm{n} / \mathrm{a}$ & $\mathrm{n} / \mathrm{a}$ \\
\hline $1-1-1-1-1-1$ & $\mathrm{n} / \mathrm{a}$ & $\mathrm{n} / \mathrm{a}$ & $\mathrm{n} / \mathrm{a}$ & $n / a$ & $\mathrm{n} / \mathrm{a}$ & $\mathrm{n} / \mathrm{a}$ & $\mathrm{n} / \mathrm{a}$ & 0.368 & $\mathrm{n} / \mathrm{a}$ & 0.381 & 0.385 & 0.397 & 0.395 & 0.400 & 0.387 & 0.410 & 0.393 & 0.415 & 0.469 & 0.500 \\
\hline
\end{tabular}


Table A-19 P4A - Stack O2 by Load and Mill Pattern (1Q96)

\begin{tabular}{|c|c|c|c|c|c|c|c|c|c|c|c|c|c|c|c|c|c|c|c|c|}
\hline & & & & & & & & & & Load, & MW & & & & & & & & & \\
\hline $\begin{array}{c}\text { Mill } \\
\text { A-B-C-D-E-F }\end{array}$ & 130 & 150 & 170 & 190 & 210 & 230 & 250 & 270 & 290 & 310 & 330 & 350 & 370 & 390 & 410 & 430 & 450 & 470 & 490 & 510 \\
\hline $0-0-0-0-0-1$ & $n / a$ & $n / a$ & $n / a$ & $n / a$ & $n / a$ & $n / a$ & $n / a$ & $n / a$ & $n / a$ & $n / a$ & $n / a$ & $n / a$ & $n / a$ & $n / a$ & $n / a$ & $n / a$ & $n / a$ & $n / a$ & $n / a$ & $n / a$ \\
\hline $0-0-0-0-1-0$ & $\mathrm{n} / \mathrm{a}$ & $\mathrm{n} / \mathrm{a}$ & $\mathrm{n} / \mathrm{a}$ & $\mathrm{n} / \mathrm{a}$ & $\mathrm{n} / \mathrm{a}$ & $\mathrm{n} / \mathrm{a}$ & $\mathrm{n} / \mathrm{a}$ & $\mathrm{n} / \mathrm{a}$ & $\mathrm{n} / \mathrm{a}$ & $\mathrm{n} / \mathrm{a}$ & $\mathrm{n} / \mathrm{a}$ & $\mathrm{n} / \mathrm{a}$ & $\mathrm{n} / \mathrm{a}$ & $\mathrm{n} / \mathrm{a}$ & $\mathrm{n} / \mathrm{a}$ & $\mathrm{n} / \mathrm{a}$ & $\mathrm{n} / \mathrm{a}$ & $\mathrm{n} / \mathrm{a}$ & $\mathrm{n} / \mathrm{a}$ & $\mathrm{n} / \mathrm{a}$ \\
\hline $0-0-0-0-1-1$ & $n / a$ & $n / a$ & $\mathrm{n} / \mathrm{a}$ & $n / a$ & $\mathrm{n} / \mathrm{a}$ & $\mathrm{n} / \mathrm{a}$ & $n / a$ & $n / a$ & $n / a$ & $n / a$ & $n / a$ & $n / a$ & $\mathrm{n} / \mathrm{a}$ & $\mathrm{n} / \mathrm{a}$ & $n / a$ & $\mathrm{n} / \mathrm{a}$ & $\mathrm{n} / \mathrm{a}$ & $\mathrm{n} / \mathrm{a}$ & $n / a$ & $\mathrm{n} / \mathrm{a}$ \\
\hline $0-0-0-1-0-0$ & $\mathrm{n} / \mathrm{a}$ & $\mathrm{n} / \mathrm{a}$ & $\mathrm{n} / \mathrm{a}$ & $\mathrm{n} / \mathrm{a}$ & $\mathrm{n} / \mathrm{a}$ & $\mathrm{n} / \mathrm{a}$ & $\mathrm{n} / \mathrm{a}$ & $\mathrm{n} / \mathrm{a}$ & $\mathrm{n} / \mathrm{a}$ & $\mathrm{n} / \mathrm{a}$ & $\mathrm{n} / \mathrm{a}$ & $\mathrm{n} / \mathrm{a}$ & $\mathrm{n} / \mathrm{a}$ & $\mathrm{n} / \mathrm{a}$ & $\mathrm{n} / \mathrm{a}$ & $\mathrm{n} / \mathrm{a}$ & $\mathrm{n} / \mathrm{a}$ & $\mathrm{n} / \mathrm{a}$ & $\mathrm{n} / \mathrm{a}$ & $\mathrm{n} / \mathrm{a}$ \\
\hline $0-0-0-1-0-1$ & $\mathrm{n} / \mathrm{a}$ & $n / a$ & $n / a$ & $n / a$ & $n / a$ & $\mathrm{n} / \mathrm{a}$ & $\mathrm{n} / \mathrm{a}$ & $n / a$ & $n / a$ & $n / a$ & $\mathrm{n} / \mathrm{a}$ & $n / a$ & $\mathrm{n} / \mathrm{a}$ & $n / a$ & $\mathrm{n} / \mathrm{a}$ & $\mathrm{n} / \mathrm{a}$ & $\mathrm{n} / \mathrm{a}$ & $n / a$ & $n / a$ & $n / a$ \\
\hline $0-0-0-1-1-0$ & $\mathrm{n} / \mathrm{a}$ & $\mathrm{n} / \mathrm{a}$ & $\mathrm{n} / \mathrm{a}$ & $\mathrm{n} / \mathrm{a}$ & $\mathrm{n} / \mathrm{a}$ & $\mathrm{n} / \mathrm{a}$ & $\mathrm{n} / \mathrm{a}$ & $\mathrm{n} / \mathrm{a}$ & $\mathrm{n} / \mathrm{a}$ & $\mathrm{n} / \mathrm{a}$ & $\mathrm{n} / \mathrm{a}$ & $\mathrm{n} / \mathrm{a}$ & $\mathrm{n} / \mathrm{a}$ & $\mathrm{n} / \mathrm{a}$ & $\mathrm{n} / \mathrm{a}$ & $\mathrm{n} / \mathrm{a}$ & $\mathrm{n} / \mathrm{a}$ & $\mathrm{n} / \mathrm{a}$ & $\mathrm{n} / \mathrm{a}$ & $\mathrm{n} / \mathrm{a}$ \\
\hline $0-0-0-1-1-1$ & $n / a$ & $n / a$ & $\mathrm{n} / \mathrm{a}$ & $n / a$ & $n / a$ & $\mathrm{n} / \mathrm{a}$ & $n / a$ & 5.226 & $n / a$ & $n / a$ & $n / a$ & $n / a$ & $n / a$ & $\mathrm{n} / \mathrm{a}$ & $n / a$ & $\mathrm{n} / \mathrm{a}$ & $\mathrm{n} / \mathrm{a}$ & $n / a$ & $n / a$ & $\mathrm{n} / \mathrm{a}$ \\
\hline $0-0-1-0-0-0$ & $\mathrm{n} / \mathrm{a}$ & $\mathrm{n} / \mathrm{a}$ & $\mathrm{n} / \mathrm{a}$ & $\mathrm{n} / \mathrm{a}$ & $n / a$ & $\mathrm{n} / \mathrm{a}$ & $\mathrm{n} / \mathrm{a}$ & $\mathrm{n} / \mathrm{a}$ & $\mathrm{n} / \mathrm{a}$ & $\mathrm{n} / \mathrm{a}$ & $\mathrm{n} / \mathrm{a}$ & $\mathrm{n} / \mathrm{a}$ & $\mathrm{n} / \mathrm{a}$ & $\mathrm{n} / \mathrm{a}$ & $\mathrm{n} / \mathrm{a}$ & $\mathrm{n} / \mathrm{a}$ & $\mathrm{n} / \mathrm{a}$ & $\mathrm{n} / \mathrm{a}$ & $\mathrm{n} / \mathrm{a}$ & $\mathrm{n} / \mathrm{a}$ \\
\hline $0-0-1-0-0-1$ & 9.423 & $\mathrm{n} / \mathrm{a}$ & 8.051 & 7.041 & $\mathrm{n} / \mathrm{a}$ & $\mathrm{n} / \mathrm{a}$ & $\mathrm{n} / \mathrm{a}$ & $\mathrm{n} / \mathrm{a}$ & $\mathrm{n} / \mathrm{a}$ & $\mathrm{n} / \mathrm{a}$ & $\mathrm{n} / \mathrm{a}$ & $\mathrm{n} / \mathrm{a}$ & $\mathrm{n} / \mathrm{a}$ & $\mathrm{n} / \mathrm{a}$ & $\mathrm{n} / \mathrm{a}$ & $\mathrm{n} / \mathrm{a}$ & $\mathrm{n} / \mathrm{a}$ & $\mathrm{n} / \mathrm{a}$ & $\mathrm{n} / \mathrm{a}$ & $\mathrm{n} / \mathrm{a}$ \\
\hline $0-0-1-0-1-0$ & $\mathrm{n} / \mathrm{a}$ & $\mathrm{n} / \mathrm{a}$ & $\mathrm{n} / \mathrm{a}$ & $\mathrm{n} / \mathrm{a}$ & $\mathrm{n} / \mathrm{a}$ & $\mathrm{n} / \mathrm{a}$ & $\mathrm{n} / \mathrm{a}$ & $\mathrm{n} / \mathrm{a}$ & $n / a$ & $\mathrm{n} / \mathrm{a}$ & $\mathrm{n} / \mathrm{a}$ & $\mathrm{n} / \mathrm{a}$ & $\mathrm{n} / \mathrm{a}$ & $\mathrm{n} / \mathrm{a}$ & $\mathrm{n} / \mathrm{a}$ & $\mathrm{n} / \mathrm{a}$ & $\mathrm{n} / \mathrm{a}$ & $n / a$ & $\mathrm{n} / \mathrm{a}$ & $\mathrm{n} / \mathrm{a}$ \\
\hline $0-0-1-0-1-1$ & $\mathrm{n} / \mathrm{a}$ & $\mathrm{n} / \mathrm{a}$ & $\mathrm{n} / \mathrm{a}$ & $\mathrm{n} / \mathrm{a}$ & $\mathrm{n} / \mathrm{a}$ & 5.574 & $\mathrm{n} / \mathrm{a}$ & $\mathrm{n} / \mathrm{a}$ & $\mathrm{n} / \mathrm{a}$ & $\mathrm{n} / \mathrm{a}$ & $\mathrm{n} / \mathrm{a}$ & $\mathrm{n} / \mathrm{a}$ & $\mathrm{n} / \mathrm{a}$ & $\mathrm{n} / \mathrm{a}$ & $\mathrm{n} / \mathrm{a}$ & $\mathrm{n} / \mathrm{a}$ & $\mathrm{n} / \mathrm{a}$ & $\mathrm{n} / \mathrm{a}$ & $\mathrm{n} / \mathrm{a}$ & $\mathrm{n} / \mathrm{a}$ \\
\hline $0-0-1-1-0-0$ & $n / a$ & $n / a$ & $n / a$ & $\mathrm{n} / \mathrm{a}$ & $\mathrm{n} / \mathrm{a}$ & $\mathrm{n} / \mathrm{a}$ & $n / a$ & $\mathrm{n} / \mathrm{a}$ & $n / a$ & $n / a$ & $n / a$ & $n / a$ & $n / a$ & $n / a$ & $n / a$ & $\mathrm{n} / \mathrm{a}$ & $\mathrm{n} / \mathrm{a}$ & $n / a$ & $n / a$ & $\mathrm{n} / \mathrm{a}$ \\
\hline $0-0-1-1-0-1$ & $\mathrm{n} / \mathrm{a}$ & $\mathrm{n} / \mathrm{a}$ & $\mathrm{n} / \mathrm{a}$ & 6.221 & 6.548 & $\mathrm{n} / \mathrm{a}$ & $\mathrm{n} / \mathrm{a}$ & $\mathrm{n} / \mathrm{a}$ & $\mathrm{n} / \mathrm{a}$ & $\mathrm{n} / \mathrm{a}$ & $\mathrm{n} / \mathrm{a}$ & $\mathrm{n} / \mathrm{a}$ & $\mathrm{n} / \mathrm{a}$ & $\mathrm{n} / \mathrm{a}$ & $\mathrm{n} / \mathrm{a}$ & $\mathrm{n} / \mathrm{a}$ & $\mathrm{n} / \mathrm{a}$ & $\mathrm{n} / \mathrm{a}$ & $\mathrm{n} / \mathrm{a}$ & $\mathrm{n} / \mathrm{a}$ \\
\hline $0-0-1-1-1-0$ & $\mathrm{n} / \mathrm{a}$ & $n / a$ & $\mathrm{n} / \mathrm{a}$ & $\mathrm{n} / \mathrm{a}$ & $\mathrm{n} / \mathrm{a}$ & $\mathrm{n} / \mathrm{a}$ & $\mathrm{n} / \mathrm{a}$ & $\mathrm{n} / \mathrm{a}$ & $n / a$ & $n / a$ & $n / a$ & $n / a$ & $\mathrm{n} / \mathrm{a}$ & $\mathrm{n} / \mathrm{a}$ & $n / a$ & $n / a$ & $\mathrm{n} / \mathrm{a}$ & $n / a$ & $n / a$ & $\mathrm{n} / \mathrm{a}$ \\
\hline $0-0-1-1-1-1$ & $\mathrm{n} / \mathrm{a}$ & $\mathrm{n} / \mathrm{a}$ & $\mathrm{n} / \mathrm{a}$ & $\mathrm{n} / \mathrm{a}$ & $\mathrm{n} / \mathrm{a}$ & 5.751 & 5.662 & 5.175 & $\mathrm{n} / \mathrm{a}$ & $\mathrm{n} / \mathrm{a}$ & $\mathrm{n} / \mathrm{a}$ & $\mathrm{n} / \mathrm{a}$ & $\mathrm{n} / \mathrm{a}$ & $\mathrm{n} / \mathrm{a}$ & $\mathrm{n} / \mathrm{a}$ & $\mathrm{n} / \mathrm{a}$ & $\mathrm{n} / \mathrm{a}$ & $\mathrm{n} / \mathrm{a}$ & $\mathrm{n} / \mathrm{a}$ & $\mathrm{n} / \mathrm{a}$ \\
\hline $0-1-0-0-0-0$ & $n / a$ & $n / a$ & $n / a$ & $n / a$ & $n / a$ & $\mathrm{n} / \mathrm{a}$ & $\mathrm{n} / \mathrm{a}$ & $\mathrm{n} / \mathrm{a}$ & $n / a$ & $n / a$ & $n / a$ & $n / a$ & $\mathrm{n} / \mathrm{a}$ & $\mathrm{n} / \mathrm{a}$ & $n / a$ & $\mathrm{n} / \mathrm{a}$ & $\mathrm{n} / \mathrm{a}$ & $n / a$ & $n / a$ & $\mathrm{n} / \mathrm{a}$ \\
\hline $0-1-0-0-0-1$ & $n / a$ & $\mathrm{n} / \mathrm{a}$ & $\mathrm{n} / \mathrm{a}$ & $\mathrm{n} / \mathrm{a}$ & $\mathrm{n} / \mathrm{a}$ & $\mathrm{n} / \mathrm{a}$ & $\mathrm{n} / \mathrm{a}$ & $\mathrm{n} / \mathrm{a}$ & $\mathrm{n} / \mathrm{a}$ & $\mathrm{n} / \mathrm{a}$ & $\mathrm{n} / \mathrm{a}$ & $\mathrm{n} / \mathrm{a}$ & $\mathrm{n} / \mathrm{a}$ & $\mathrm{n} / \mathrm{a}$ & $\mathrm{n} / \mathrm{a}$ & $\mathrm{n} / \mathrm{a}$ & $\mathrm{n} / \mathrm{a}$ & $\mathrm{n} / \mathrm{a}$ & $\mathrm{n} / \mathrm{a}$ & $\mathrm{n} / \mathrm{a}$ \\
\hline $0-1-0-0-1-0$ & $n / a$ & $n / a$ & $\mathrm{n} / \mathrm{a}$ & $n / a$ & $\mathrm{n} / \mathrm{a}$ & $\mathrm{n} / \mathrm{a}$ & $\mathrm{n} / \mathrm{a}$ & $\mathrm{n} / \mathrm{a}$ & $\mathrm{n} / \mathrm{a}$ & $\mathrm{n} / \mathrm{a}$ & $\mathrm{n} / \mathrm{a}$ & $\mathrm{n} / \mathrm{a}$ & $\mathrm{n} / \mathrm{a}$ & $\mathrm{n} / \mathrm{a}$ & $\mathrm{n} / \mathrm{a}$ & $\mathrm{n} / \mathrm{a}$ & $\mathrm{n} / \mathrm{a}$ & $\mathrm{n} / \mathrm{a}$ & $n / a$ & $\mathrm{n} / \mathrm{a}$ \\
\hline $0-1-0-0-1-1$ & $\mathrm{n} / \mathrm{a}$ & $n / a$ & $n / a$ & $n / a$ & $n / a$ & $\mathrm{n} / \mathrm{a}$ & $\mathrm{n} / \mathrm{a}$ & $n / a$ & $n / a$ & $n / a$ & $\mathrm{n} / \mathrm{a}$ & $n / a$ & $\mathrm{n} / \mathrm{a}$ & $n / a$ & $\mathrm{n} / \mathrm{a}$ & $\mathrm{n} / \mathrm{a}$ & $\mathrm{n} / \mathrm{a}$ & $n / a$ & $n / a$ & $n / a$ \\
\hline $0-1-0-1-0-0$ & $\mathrm{n} / \mathrm{a}$ & $\mathrm{n} / \mathrm{a}$ & $\mathrm{n} / \mathrm{a}$ & $\mathrm{n} / \mathrm{a}$ & $\mathrm{n} / \mathrm{a}$ & $\mathrm{n} / \mathrm{a}$ & $\mathrm{n} / \mathrm{a}$ & $\mathrm{n} / \mathrm{a}$ & $\mathrm{n} / \mathrm{a}$ & $\mathrm{n} / \mathrm{a}$ & $\mathrm{n} / \mathrm{a}$ & $\mathrm{n} / \mathrm{a}$ & $\mathrm{n} / \mathrm{a}$ & $\mathrm{n} / \mathrm{a}$ & $\mathrm{n} / \mathrm{a}$ & $\mathrm{n} / \mathrm{a}$ & $\mathrm{n} / \mathrm{a}$ & $\mathrm{n} / \mathrm{a}$ & $\mathrm{n} / \mathrm{a}$ & $\mathrm{n} / \mathrm{a}$ \\
\hline $0-1-0-1-0-1$ & $n / a$ & $n / a$ & $\mathrm{n} / \mathrm{a}$ & 6.382 & $n / a$ & $\mathrm{n} / \mathrm{a}$ & $n / a$ & $\mathrm{n} / \mathrm{a}$ & $\mathrm{n} / \mathrm{a}$ & $n / a$ & $\mathrm{n} / \mathrm{a}$ & $n / a$ & $n / a$ & $n / a$ & $n / a$ & $n / a$ & $\mathrm{n} / \mathrm{a}$ & $n / a$ & $n / a$ & $n / a$ \\
\hline $0-1-0-1-1-0$ & $\mathrm{n} / \mathrm{a}$ & $\mathrm{n} / \mathrm{a}$ & $\mathrm{n} / \mathrm{a}$ & $\mathrm{n} / \mathrm{a}$ & $\mathrm{n} / \mathrm{a}$ & $\mathrm{n} / \mathrm{a}$ & $\mathrm{n} / \mathrm{a}$ & $\mathrm{n} / \mathrm{a}$ & $\mathrm{n} / \mathrm{a}$ & $\mathrm{n} / \mathrm{a}$ & $\mathrm{n} / \mathrm{a}$ & $\mathrm{n} / \mathrm{a}$ & $\mathrm{n} / \mathrm{a}$ & $\mathrm{n} / \mathrm{a}$ & $\mathrm{n} / \mathrm{a}$ & $\mathrm{n} / \mathrm{a}$ & $\mathrm{n} / \mathrm{a}$ & $\mathrm{n} / \mathrm{a}$ & $\mathrm{n} / \mathrm{a}$ & $\mathrm{n} / \mathrm{a}$ \\
\hline $0-1-0-1-1-1$ & $n / a$ & $\mathrm{n} / \mathrm{a}$ & $n / a$ & $n / a$ & $n / a$ & $\mathrm{n} / \mathrm{a}$ & $n / a$ & $\mathrm{n} / \mathrm{a}$ & $n / a$ & 4.838 & $n / a$ & $n / a$ & $\mathrm{n} / \mathrm{a}$ & $\mathrm{n} / \mathrm{a}$ & $n / a$ & $\mathrm{n} / \mathrm{a}$ & $\mathrm{n} / \mathrm{a}$ & $n / a$ & $n / a$ & $\mathrm{n} / \mathrm{a}$ \\
\hline $0-1-1-0-0-0$ & $\mathrm{n} / \mathrm{a}$ & $\mathrm{n} / \mathrm{a}$ & $\mathrm{n} / \mathrm{a}$ & $\mathrm{n} / \mathrm{a}$ & $\mathrm{n} / \mathrm{a}$ & $\mathrm{n} / \mathrm{a}$ & $\mathrm{n} / \mathrm{a}$ & $\mathrm{n} / \mathrm{a}$ & $\mathrm{n} / \mathrm{a}$ & $\mathrm{n} / \mathrm{a}$ & $\mathrm{n} / \mathrm{a}$ & $\mathrm{n} / \mathrm{a}$ & $\mathrm{n} / \mathrm{a}$ & $\mathrm{n} / \mathrm{a}$ & $\mathrm{n} / \mathrm{a}$ & $\mathrm{n} / \mathrm{a}$ & $\mathrm{n} / \mathrm{a}$ & $\mathrm{n} / \mathrm{a}$ & $\mathrm{n} / \mathrm{a}$ & $\mathrm{n} / \mathrm{a}$ \\
\hline $0-1-1-0-0-1$ & $\mathrm{n} / \mathrm{a}$ & $n / a$ & $\mathrm{n} / \mathrm{a}$ & $\mathrm{n} / \mathrm{a}$ & $\mathrm{n} / \mathrm{a}$ & 5.962 & $\mathrm{n} / \mathrm{a}$ & $\mathrm{n} / \mathrm{a}$ & $\mathrm{n} / \mathrm{a}$ & $\mathrm{n} / \mathrm{a}$ & $\mathrm{n} / \mathrm{a}$ & $\mathrm{n} / \mathrm{a}$ & $\mathrm{n} / \mathrm{a}$ & $\mathrm{n} / \mathrm{a}$ & $\mathrm{n} / \mathrm{a}$ & $\mathrm{n} / \mathrm{a}$ & $\mathrm{n} / \mathrm{a}$ & $\mathrm{n} / \mathrm{a}$ & $n / a$ & $\mathrm{n} / \mathrm{a}$ \\
\hline $0-1-1-0-1-0$ & $\mathrm{n} / \mathrm{a}$ & $\mathrm{n} / \mathrm{a}$ & $\mathrm{n} / \mathrm{a}$ & $\mathrm{n} / \mathrm{a}$ & $\mathrm{n} / \mathrm{a}$ & $\mathrm{n} / \mathrm{a}$ & $\mathrm{n} / \mathrm{a}$ & $\mathrm{n} / \mathrm{a}$ & $\mathrm{n} / \mathrm{a}$ & $\mathrm{n} / \mathrm{a}$ & $\mathrm{n} / \mathrm{a}$ & $\mathrm{n} / \mathrm{a}$ & $\mathrm{n} / \mathrm{a}$ & $\mathrm{n} / \mathrm{a}$ & $\mathrm{n} / \mathrm{a}$ & $\mathrm{n} / \mathrm{a}$ & $\mathrm{n} / \mathrm{a}$ & $\mathrm{n} / \mathrm{a}$ & $\mathrm{n} / \mathrm{a}$ & $\mathrm{n} / \mathrm{a}$ \\
\hline $0-1-1-0-1-1$ & $\mathrm{n} / \mathrm{a}$ & $\mathrm{n} / \mathrm{a}$ & $\mathrm{n} / \mathrm{a}$ & 6.377 & 6.253 & 5.868 & 5.415 & $\mathrm{n} / \mathrm{a}$ & $\mathrm{n} / \mathrm{a}$ & $\mathrm{n} / \mathrm{a}$ & $\mathrm{n} / \mathrm{a}$ & $\mathrm{n} / \mathrm{a}$ & $\mathrm{n} / \mathrm{a}$ & $\mathrm{n} / \mathrm{a}$ & $\mathrm{n} / \mathrm{a}$ & $\mathrm{n} / \mathrm{a}$ & $\mathrm{n} / \mathrm{a}$ & $\mathrm{n} / \mathrm{a}$ & $\mathrm{n} / \mathrm{a}$ & $\mathrm{n} / \mathrm{a}$ \\
\hline $0-1-1-1-0-0$ & $\mathrm{n} / \mathrm{a}$ & $n / a$ & $\mathrm{n} / \mathrm{a}$ & $\mathrm{n} / \mathrm{a}$ & $\mathrm{n} / \mathrm{a}$ & $\mathrm{n} / \mathrm{a}$ & $\mathrm{n} / \mathrm{a}$ & $\mathrm{n} / \mathrm{a}$ & $\mathrm{n} / \mathrm{a}$ & $\mathrm{n} / \mathrm{a}$ & $\mathrm{n} / \mathrm{a}$ & $n / a$ & $\mathrm{n} / \mathrm{a}$ & $n / a$ & $n / a$ & $n / a$ & $\mathrm{n} / \mathrm{a}$ & $n / a$ & $n / a$ & $\mathrm{n} / \mathrm{a}$ \\
\hline $0-1-1-1-0-1$ & $\mathrm{n} / \mathrm{a}$ & $\mathrm{n} / \mathrm{a}$ & $\mathrm{n} / \mathrm{a}$ & 6.810 & 6.504 & 5.879 & 5.596 & 5.360 & 5.284 & 5.331 & $\mathrm{n} / \mathrm{a}$ & $\mathrm{n} / \mathrm{a}$ & $\mathrm{n} / \mathrm{a}$ & $\mathrm{n} / \mathrm{a}$ & $\mathrm{n} / \mathrm{a}$ & $\mathrm{n} / \mathrm{a}$ & $\mathrm{n} / \mathrm{a}$ & $\mathrm{n} / \mathrm{a}$ & $\mathrm{n} / \mathrm{a}$ & $\mathrm{n} / \mathrm{a}$ \\
\hline $0-1-1-1-1-0$ & $n / a$ & $n / a$ & $\mathrm{n} / \mathrm{a}$ & 6.218 & 5.952 & 5.723 & 5.531 & $\mathrm{n} / \mathrm{a}$ & $\mathrm{n} / \mathrm{a}$ & $\mathrm{n} / \mathrm{a}$ & $\mathrm{n} / \mathrm{a}$ & 6.615 & $\mathrm{n} / \mathrm{a}$ & $\mathrm{n} / \mathrm{a}$ & $\mathrm{n} / \mathrm{a}$ & $\mathrm{n} / \mathrm{a}$ & $\mathrm{n} / \mathrm{a}$ & $n / a$ & $n / a$ & $\mathrm{n} / \mathrm{a}$ \\
\hline $0-1-1-1-1-1$ & $\mathrm{n} / \mathrm{a}$ & $\mathrm{n} / \mathrm{a}$ & $\mathrm{n} / \mathrm{a}$ & $\mathrm{n} / \mathrm{a}$ & $\mathrm{n} / \mathrm{a}$ & 6.012 & $\mathrm{n} / \mathrm{a}$ & 4.916 & $\mathrm{n} / \mathrm{a}$ & 4.849 & 4.870 & 5.872 & $\mathrm{n} / \mathrm{a}$ & 6.342 & 4.690 & 5.874 & 5.054 & $\mathrm{n} / \mathrm{a}$ & $\mathrm{n} / \mathrm{a}$ & $\mathrm{n} / \mathrm{a}$ \\
\hline $1-0-0-0-0-0$ & $n / a$ & $n / a$ & $n / a$ & $n / a$ & $n / a$ & $\mathrm{n} / \mathrm{a}$ & $n / a$ & $\mathrm{n} / \mathrm{a}$ & $n / a$ & $\mathrm{n} / \mathrm{a}$ & $\mathrm{n} / \mathrm{a}$ & $\mathrm{n} / \mathrm{a}$ & $n / a$ & $\mathrm{n} / \mathrm{a}$ & $\mathrm{n} / \mathrm{a}$ & $\mathrm{n} / \mathrm{a}$ & $\mathrm{n} / \mathrm{a}$ & $\mathrm{n} / \mathrm{a}$ & $n / a$ & $n / a$ \\
\hline $1-0-0-0-0-1$ & $\mathrm{n} / \mathrm{a}$ & $\mathrm{n} / \mathrm{a}$ & $\mathrm{n} / \mathrm{a}$ & $\mathrm{n} / \mathrm{a}$ & $\mathrm{n} / \mathrm{a}$ & $\mathrm{n} / \mathrm{a}$ & $\mathrm{n} / \mathrm{a}$ & $\mathrm{n} / \mathrm{a}$ & $\mathrm{n} / \mathrm{a}$ & $\mathrm{n} / \mathrm{a}$ & $\mathrm{n} / \mathrm{a}$ & $\mathrm{n} / \mathrm{a}$ & $\mathrm{n} / \mathrm{a}$ & $\mathrm{n} / \mathrm{a}$ & $\mathrm{n} / \mathrm{a}$ & $\mathrm{n} / \mathrm{a}$ & $\mathrm{n} / \mathrm{a}$ & $\mathrm{n} / \mathrm{a}$ & $\mathrm{n} / \mathrm{a}$ & $\mathrm{n} / \mathrm{a}$ \\
\hline $1-0-0-0-1-0$ & $\mathrm{n} / \mathrm{a}$ & $\mathrm{n} / \mathrm{a}$ & $\mathrm{n} / \mathrm{a}$ & $\mathrm{n} / \mathrm{a}$ & $\mathrm{n} / \mathrm{a}$ & $\mathrm{n} / \mathrm{a}$ & $\mathrm{n} / \mathrm{a}$ & $\mathrm{n} / \mathrm{a}$ & $\mathrm{n} / \mathrm{a}$ & $\mathrm{n} / \mathrm{a}$ & $\mathrm{n} / \mathrm{a}$ & $\mathrm{n} / \mathrm{a}$ & $\mathrm{n} / \mathrm{a}$ & $\mathrm{n} / \mathrm{a}$ & $\mathrm{n} / \mathrm{a}$ & $\mathrm{n} / \mathrm{a}$ & $\mathrm{n} / \mathrm{a}$ & $\mathrm{n} / \mathrm{a}$ & $\mathrm{n} / \mathrm{a}$ & $\mathrm{n} / \mathrm{a}$ \\
\hline $1-0-0-0-1-1$ & $\mathrm{n} / \mathrm{a}$ & $\mathrm{n} / \mathrm{a}$ & $\mathrm{n} / \mathrm{a}$ & $\mathrm{n} / \mathrm{a}$ & $n / a$ & $\mathrm{n} / \mathrm{a}$ & $n / a$ & $\mathrm{n} / \mathrm{a}$ & $\mathrm{n} / \mathrm{a}$ & $n / a$ & $\mathrm{n} / \mathrm{a}$ & $n / a$ & $n / a$ & $n / a$ & $n / a$ & $n / a$ & $\mathrm{n} / \mathrm{a}$ & $n / a$ & $n / a$ & $n / a$ \\
\hline $1-0-0-1-0-0$ & $\mathrm{n} / \mathrm{a}$ & 7.140 & $\mathrm{n} / \mathrm{a}$ & 6.431 & $\mathrm{n} / \mathrm{a}$ & $\mathrm{n} / \mathrm{a}$ & $\mathrm{n} / \mathrm{a}$ & $\mathrm{n} / \mathrm{a}$ & $\mathrm{n} / \mathrm{a}$ & $\mathrm{n} / \mathrm{a}$ & $\mathrm{n} / \mathrm{a}$ & $\mathrm{n} / \mathrm{a}$ & $\mathrm{n} / \mathrm{a}$ & $\mathrm{n} / \mathrm{a}$ & $\mathrm{n} / \mathrm{a}$ & $\mathrm{n} / \mathrm{a}$ & $\mathrm{n} / \mathrm{a}$ & $\mathrm{n} / \mathrm{a}$ & $\mathrm{n} / \mathrm{a}$ & $\mathrm{n} / \mathrm{a}$ \\
\hline $1-0-0-1-0-1$ & $\mathrm{n} / \mathrm{a}$ & $\mathrm{n} / \mathrm{a}$ & $n / a$ & 6.099 & 6.071 & 6.034 & $\mathrm{n} / \mathrm{a}$ & $\mathrm{n} / \mathrm{a}$ & $n / a$ & $\mathrm{n} / \mathrm{a}$ & $\mathrm{n} / \mathrm{a}$ & $\mathrm{n} / \mathrm{a}$ & $\mathrm{n} / \mathrm{a}$ & $\mathrm{n} / \mathrm{a}$ & $\mathrm{n} / \mathrm{a}$ & $n / a$ & $\mathrm{n} / \mathrm{a}$ & $\mathrm{n} / \mathrm{a}$ & $\mathrm{n} / \mathrm{a}$ & $\mathrm{n} / \mathrm{a}$ \\
\hline $1-0-0-1-1-0$ & $\mathrm{n} / \mathrm{a}$ & $\mathrm{n} / \mathrm{a}$ & $\mathrm{n} / \mathrm{a}$ & 6.068 & 5.836 & 5.375 & $\mathrm{n} / \mathrm{a}$ & 5.058 & $\mathrm{n} / \mathrm{a}$ & $\mathrm{n} / \mathrm{a}$ & $\mathrm{n} / \mathrm{a}$ & $\mathrm{n} / \mathrm{a}$ & $\mathrm{n} / \mathrm{a}$ & $\mathrm{n} / \mathrm{a}$ & $\mathrm{n} / \mathrm{a}$ & $\mathrm{n} / \mathrm{a}$ & $\mathrm{n} / \mathrm{a}$ & $\mathrm{n} / \mathrm{a}$ & $\mathrm{n} / \mathrm{a}$ & $\mathrm{n} / \mathrm{a}$ \\
\hline $1-0-0-1-1-1$ & $\mathrm{n} / \mathrm{a}$ & $n / a$ & $n / a$ & $\mathrm{n} / \mathrm{a}$ & 6.091 & 5.384 & 4.682 & 4.948 & 4.626 & $n / a$ & $n / a$ & $n / a$ & $\mathrm{n} / \mathrm{a}$ & $\mathrm{n} / \mathrm{a}$ & $n / a$ & $n / a$ & $\mathrm{n} / \mathrm{a}$ & $n / a$ & $n / a$ & $\mathrm{n} / \mathrm{a}$ \\
\hline $1-0-1-0-0-0$ & $\mathrm{n} / \mathrm{a}$ & $\mathrm{n} / \mathrm{a}$ & $\mathrm{n} / \mathrm{a}$ & $\mathrm{n} / \mathrm{a}$ & $\mathrm{n} / \mathrm{a}$ & $\mathrm{n} / \mathrm{a}$ & $\mathrm{n} / \mathrm{a}$ & $\mathrm{n} / \mathrm{a}$ & $\mathrm{n} / \mathrm{a}$ & $\mathrm{n} / \mathrm{a}$ & $\mathrm{n} / \mathrm{a}$ & $\mathrm{n} / \mathrm{a}$ & $\mathrm{n} / \mathrm{a}$ & $\mathrm{n} / \mathrm{a}$ & $\mathrm{n} / \mathrm{a}$ & $\mathrm{n} / \mathrm{a}$ & $\mathrm{n} / \mathrm{a}$ & $\mathrm{n} / \mathrm{a}$ & $\mathrm{n} / \mathrm{a}$ & $\mathrm{n} / \mathrm{a}$ \\
\hline $1-0-1-0-0-1$ & $\mathrm{n} / \mathrm{a}$ & $n / a$ & $\mathrm{n} / \mathrm{a}$ & 6.771 & 6.727 & 6.452 & 6.155 & $n / a$ & $n / a$ & $n / a$ & $n / a$ & $n / a$ & $\mathrm{n} / \mathrm{a}$ & $\mathrm{n} / \mathrm{a}$ & $n / a$ & $n / a$ & $\mathrm{n} / \mathrm{a}$ & $n / a$ & $n / a$ & $\mathrm{n} / \mathrm{a}$ \\
\hline $1-0-1-0-1-0$ & $\mathrm{n} / \mathrm{a}$ & $\mathrm{n} / \mathrm{a}$ & $\mathrm{n} / \mathrm{a}$ & $\mathrm{n} / \mathrm{a}$ & $\mathrm{n} / \mathrm{a}$ & $\mathrm{n} / \mathrm{a}$ & $\mathrm{n} / \mathrm{a}$ & $\mathrm{n} / \mathrm{a}$ & $\mathrm{n} / \mathrm{a}$ & $\mathrm{n} / \mathrm{a}$ & $\mathrm{n} / \mathrm{a}$ & $\mathrm{n} / \mathrm{a}$ & $\mathrm{n} / \mathrm{a}$ & $\mathrm{n} / \mathrm{a}$ & $\mathrm{n} / \mathrm{a}$ & $\mathrm{n} / \mathrm{a}$ & $\mathrm{n} / \mathrm{a}$ & $\mathrm{n} / \mathrm{a}$ & $\mathrm{n} / \mathrm{a}$ & $\mathrm{n} / \mathrm{a}$ \\
\hline $1-0-1-0-1-1$ & $\mathrm{n} / \mathrm{a}$ & $n / a$ & $\mathrm{n} / \mathrm{a}$ & 6.546 & 6.300 & 5.999 & 5.533 & 5.296 & 5.572 & 8.965 & $n / a$ & $n / a$ & $n / a$ & $\mathrm{n} / \mathrm{a}$ & $n / a$ & $n / a$ & $\mathrm{n} / \mathrm{a}$ & $n / a$ & $n / a$ & $\mathrm{n} / \mathrm{a}$ \\
\hline $1-0-1-1-0-0$ & $\mathrm{n} / \mathrm{a}$ & $n / a$ & 5.778 & 6.272 & 5.826 & $\mathrm{n} / \mathrm{a}$ & $\mathrm{n} / \mathrm{a}$ & $\mathrm{n} / \mathrm{a}$ & $\mathrm{n} / \mathrm{a}$ & $\mathrm{n} / \mathrm{a}$ & $\mathrm{n} / \mathrm{a}$ & $\mathrm{n} / \mathrm{a}$ & $\mathrm{n} / \mathrm{a}$ & $\mathrm{n} / \mathrm{a}$ & $\mathrm{n} / \mathrm{a}$ & $n / a$ & $\mathrm{n} / \mathrm{a}$ & $\mathrm{n} / \mathrm{a}$ & $n / a$ & $\mathrm{n} / \mathrm{a}$ \\
\hline $1-0-1-1-0-1$ & $\mathrm{n} / \mathrm{a}$ & $\mathrm{n} / \mathrm{a}$ & 7.106 & 6.410 & 6.199 & 5.906 & 5.857 & 5.812 & 5.713 & 5.370 & $\mathrm{n} / \mathrm{a}$ & $\mathrm{n} / \mathrm{a}$ & $\mathrm{n} / \mathrm{a}$ & $\mathrm{n} / \mathrm{a}$ & $\mathrm{n} / \mathrm{a}$ & $\mathrm{n} / \mathrm{a}$ & $\mathrm{n} / \mathrm{a}$ & $\mathrm{n} / \mathrm{a}$ & $\mathrm{n} / \mathrm{a}$ & $\mathrm{n} / \mathrm{a}$ \\
\hline $1-0-1-1-1-0$ & $\mathrm{n} / \mathrm{a}$ & $n / a$ & $\mathrm{n} / \mathrm{a}$ & $\mathrm{n} / \mathrm{a}$ & 5.778 & 5.936 & 5.502 & 5.130 & $\mathrm{n} / \mathrm{a}$ & 4.707 & $\mathrm{n} / \mathrm{a}$ & $\mathrm{n} / \mathrm{a}$ & $\mathrm{n} / \mathrm{a}$ & $\mathrm{n} / \mathrm{a}$ & $\mathrm{n} / \mathrm{a}$ & $\mathrm{n} / \mathrm{a}$ & $\mathrm{n} / \mathrm{a}$ & $\mathrm{n} / \mathrm{a}$ & $n / a$ & $n / a$ \\
\hline $1-0-1-1-1-1$ & $\mathrm{n} / \mathrm{a}$ & $\mathrm{n} / \mathrm{a}$ & $\mathrm{n} / \mathrm{a}$ & $\mathrm{n} / \mathrm{a}$ & $\mathrm{n} / \mathrm{a}$ & 5.541 & 5.262 & 5.132 & 5.149 & 5.011 & 4.576 & 4.806 & 4.934 & 4.706 & 3.919 & 3.696 & 3.634 & $\mathrm{n} / \mathrm{a}$ & $\mathrm{n} / \mathrm{a}$ & $\mathrm{n} / \mathrm{a}$ \\
\hline $1-1-0-0-0-0$ & $n / a$ & $n / a$ & $\mathrm{n} / \mathrm{a}$ & $\mathrm{n} / \mathrm{a}$ & $n / a$ & $\mathrm{n} / \mathrm{a}$ & $\mathrm{n} / \mathrm{a}$ & $\mathrm{n} / \mathrm{a}$ & $\mathrm{n} / \mathrm{a}$ & $\mathrm{n} / \mathrm{a}$ & $\mathrm{n} / \mathrm{a}$ & $\mathrm{n} / \mathrm{a}$ & $\mathrm{n} / \mathrm{a}$ & $\mathrm{n} / \mathrm{a}$ & $\mathrm{n} / \mathrm{a}$ & $\mathrm{n} / \mathrm{a}$ & $\mathrm{n} / \mathrm{a}$ & $n / a$ & $n / a$ & $n / a$ \\
\hline $1-1-0-0-0-1$ & $\mathrm{n} / \mathrm{a}$ & $\mathrm{n} / \mathrm{a}$ & $\mathrm{n} / \mathrm{a}$ & $\mathrm{n} / \mathrm{a}$ & $\mathrm{n} / \mathrm{a}$ & $\mathrm{n} / \mathrm{a}$ & $\mathrm{n} / \mathrm{a}$ & $\mathrm{n} / \mathrm{a}$ & $\mathrm{n} / \mathrm{a}$ & $\mathrm{n} / \mathrm{a}$ & $\mathrm{n} / \mathrm{a}$ & $\mathrm{n} / \mathrm{a}$ & $\mathrm{n} / \mathrm{a}$ & $\mathrm{n} / \mathrm{a}$ & $\mathrm{n} / \mathrm{a}$ & $\mathrm{n} / \mathrm{a}$ & $\mathrm{n} / \mathrm{a}$ & $\mathrm{n} / \mathrm{a}$ & $\mathrm{n} / \mathrm{a}$ & $\mathrm{n} / \mathrm{a}$ \\
\hline $1-1-0-0-1-0$ & $\mathrm{n} / \mathrm{a}$ & $n / a$ & $n / a$ & $n / a$ & $n / a$ & $\mathrm{n} / \mathrm{a}$ & $\mathrm{n} / \mathrm{a}$ & $\mathrm{n} / \mathrm{a}$ & $n / a$ & $n / a$ & $n / a$ & $n / a$ & $\mathrm{n} / \mathrm{a}$ & $\mathrm{n} / \mathrm{a}$ & $n / a$ & $n / a$ & $\mathrm{n} / \mathrm{a}$ & $n / a$ & $n / a$ & $\mathrm{n} / \mathrm{a}$ \\
\hline $1-1-0-0-1-1$ & $\mathrm{n} / \mathrm{a}$ & $\mathrm{n} / \mathrm{a}$ & $\mathrm{n} / \mathrm{a}$ & $\mathrm{n} / \mathrm{a}$ & $\mathrm{n} / \mathrm{a}$ & 5.377 & 4.869 & $\mathrm{n} / \mathrm{a}$ & $n / a$ & $\mathrm{n} / \mathrm{a}$ & $\mathrm{n} / \mathrm{a}$ & $\mathrm{n} / \mathrm{a}$ & $\mathrm{n} / \mathrm{a}$ & $\mathrm{n} / \mathrm{a}$ & $\mathrm{n} / \mathrm{a}$ & $\mathrm{n} / \mathrm{a}$ & $\mathrm{n} / \mathrm{a}$ & $\mathrm{n} / \mathrm{a}$ & $\mathrm{n} / \mathrm{a}$ & $\mathrm{n} / \mathrm{a}$ \\
\hline $1-1-0-1-0-0$ & $\mathrm{n} / \mathrm{a}$ & 6.644 & 6.616 & 6.069 & 6.399 & 6.386 & $\mathrm{n} / \mathrm{a}$ & $\mathrm{n} / \mathrm{a}$ & $\mathrm{n} / \mathrm{a}$ & $\mathrm{n} / \mathrm{a}$ & $\mathrm{n} / \mathrm{a}$ & $\mathrm{n} / \mathrm{a}$ & $\mathrm{n} / \mathrm{a}$ & $\mathrm{n} / \mathrm{a}$ & $\mathrm{n} / \mathrm{a}$ & $\mathrm{n} / \mathrm{a}$ & $\mathrm{n} / \mathrm{a}$ & $\mathrm{n} / \mathrm{a}$ & $\mathrm{n} / \mathrm{a}$ & $\mathrm{n} / \mathrm{a}$ \\
\hline $1-1-0-1-0-1$ & $\mathrm{n} / \mathrm{a}$ & $\mathrm{n} / \mathrm{a}$ & $\mathrm{n} / \mathrm{a}$ & 6.433 & 5.502 & 5.792 & 5.531 & 5.308 & 5.036 & 4.012 & $\mathrm{n} / \mathrm{a}$ & $\mathrm{n} / \mathrm{a}$ & $\mathrm{n} / \mathrm{a}$ & $\mathrm{n} / \mathrm{a}$ & $\mathrm{n} / \mathrm{a}$ & $\mathrm{n} / \mathrm{a}$ & $\mathrm{n} / \mathrm{a}$ & $\mathrm{n} / \mathrm{a}$ & $\mathrm{n} / \mathrm{a}$ & $\mathrm{n} / \mathrm{a}$ \\
\hline $1-1-0-1-1-0$ & $\mathrm{n} / \mathrm{a}$ & $\mathrm{n} / \mathrm{a}$ & $\mathrm{n} / \mathrm{a}$ & $\mathrm{n} / \mathrm{a}$ & $\mathrm{n} / \mathrm{a}$ & 6.147 & 6.061 & 5.689 & $\mathrm{n} / \mathrm{a}$ & $\mathrm{n} / \mathrm{a}$ & $\mathrm{n} / \mathrm{a}$ & $\mathrm{n} / \mathrm{a}$ & $\mathrm{n} / \mathrm{a}$ & $\mathrm{n} / \mathrm{a}$ & $\mathrm{n} / \mathrm{a}$ & $\mathrm{n} / \mathrm{a}$ & $\mathrm{n} / \mathrm{a}$ & $\mathrm{n} / \mathrm{a}$ & $\mathrm{n} / \mathrm{a}$ & $\mathrm{n} / \mathrm{a}$ \\
\hline $1-1-0-1-1-1$ & $\mathrm{n} / \mathrm{a}$ & $n / a$ & $\mathrm{n} / \mathrm{a}$ & $n / a$ & $n / a$ & $\mathrm{n} / \mathrm{a}$ & 4.607 & 4.853 & 4.331 & 4.507 & 4.253 & 4.301 & 5.865 & 5.926 & 5.984 & 4.493 & 5.487 & $n / a$ & $n / a$ & $\mathrm{n} / \mathrm{a}$ \\
\hline $1-1-1-0-0-0$ & $\mathrm{n} / \mathrm{a}$ & $\mathrm{n} / \mathrm{a}$ & $\mathrm{n} / \mathrm{a}$ & $\mathrm{n} / \mathrm{a}$ & $\mathrm{n} / \mathrm{a}$ & 6.484 & $\mathrm{n} / \mathrm{a}$ & $\mathrm{n} / \mathrm{a}$ & $\mathrm{n} / \mathrm{a}$ & $\mathrm{n} / \mathrm{a}$ & $\mathrm{n} / \mathrm{a}$ & $\mathrm{n} / \mathrm{a}$ & $\mathrm{n} / \mathrm{a}$ & $\mathrm{n} / \mathrm{a}$ & $\mathrm{n} / \mathrm{a}$ & $\mathrm{n} / \mathrm{a}$ & $\mathrm{n} / \mathrm{a}$ & $\mathrm{n} / \mathrm{a}$ & $\mathrm{n} / \mathrm{a}$ & $\mathrm{n} / \mathrm{a}$ \\
\hline $1-1-1-0-0-1$ & $\mathrm{n} / \mathrm{a}$ & $n / a$ & $\mathrm{n} / \mathrm{a}$ & 6.951 & 6.616 & 6.331 & $\mathrm{n} / \mathrm{a}$ & $\mathrm{n} / \mathrm{a}$ & $\mathrm{n} / \mathrm{a}$ & $\mathrm{n} / \mathrm{a}$ & $n / a$ & $n / a$ & $\mathrm{n} / \mathrm{a}$ & $\mathrm{n} / \mathrm{a}$ & $n / a$ & $n / a$ & $\mathrm{n} / \mathrm{a}$ & $n / a$ & $n / a$ & $\mathrm{n} / \mathrm{a}$ \\
\hline $1-1-1-0-1-0$ & $\mathrm{n} / \mathrm{a}$ & $\mathrm{n} / \mathrm{a}$ & $\mathrm{n} / \mathrm{a}$ & 6.642 & 6.191 & 5.505 & 5.726 & 5.856 & 5.556 & 4.990 & $\mathrm{n} / \mathrm{a}$ & $\mathrm{n} / \mathrm{a}$ & $\mathrm{n} / \mathrm{a}$ & $\mathrm{n} / \mathrm{a}$ & $\mathrm{n} / \mathrm{a}$ & $\mathrm{n} / \mathrm{a}$ & $\mathrm{n} / \mathrm{a}$ & $\mathrm{n} / \mathrm{a}$ & $\mathrm{n} / \mathrm{a}$ & $\mathrm{n} / \mathrm{a}$ \\
\hline $1-1-1-0-1-1$ & $\mathrm{n} / \mathrm{a}$ & $\mathrm{n} / \mathrm{a}$ & $\mathrm{n} / \mathrm{a}$ & $\mathrm{n} / \mathrm{a}$ & $\mathrm{n} / \mathrm{a}$ & $\mathrm{n} / \mathrm{a}$ & 5.460 & 5.442 & 5.153 & 4.999 & 5.083 & 5.479 & 6.601 & 4.834 & 4.446 & $\mathrm{n} / \mathrm{a}$ & $\mathrm{n} / \mathrm{a}$ & $\mathrm{n} / \mathrm{a}$ & $\mathrm{n} / \mathrm{a}$ & $\mathrm{n} / \mathrm{a}$ \\
\hline $1-1-1-1-0-0$ & $\mathrm{n} / \mathrm{a}$ & $\mathrm{n} / \mathrm{a}$ & $\mathrm{n} / \mathrm{a}$ & $\mathrm{n} / \mathrm{a}$ & 6.608 & 6.407 & $\mathrm{n} / \mathrm{a}$ & $\mathrm{n} / \mathrm{a}$ & $\mathrm{n} / \mathrm{a}$ & $\mathrm{n} / \mathrm{a}$ & $\mathrm{n} / \mathrm{a}$ & $\mathrm{n} / \mathrm{a}$ & $\mathrm{n} / \mathrm{a}$ & $\mathrm{n} / \mathrm{a}$ & $\mathrm{n} / \mathrm{a}$ & $\mathrm{n} / \mathrm{a}$ & $\mathrm{n} / \mathrm{a}$ & $\mathrm{n} / \mathrm{a}$ & $\mathrm{n} / \mathrm{a}$ & $\mathrm{n} / \mathrm{a}$ \\
\hline $1-1-1-1-0-1$ & $\mathrm{n} / \mathrm{a}$ & $\mathrm{n} / \mathrm{a}$ & $\mathrm{n} / \mathrm{a}$ & $\mathrm{n} / \mathrm{a}$ & 5.429 & 5.726 & 5.570 & 5.350 & 5.155 & 5.150 & 5.085 & 5.221 & 5.026 & 5.156 & 4.688 & 4.522 & 7.742 & $\mathrm{n} / \mathrm{a}$ & $\mathrm{n} / \mathrm{a}$ & $\mathrm{n} / \mathrm{a}$ \\
\hline $1-1-1-1-1-0$ & $n / a$ & $n / a$ & $\mathrm{n} / \mathrm{a}$ & $\mathrm{n} / \mathrm{a}$ & $\mathrm{n} / \mathrm{a}$ & $\mathrm{n} / \mathrm{a}$ & 5.021 & 5.363 & 5.245 & 5.326 & 5.317 & 5.910 & 5.956 & 5.846 & $\mathrm{n} / \mathrm{a}$ & 5.897 & $\mathrm{n} / \mathrm{a}$ & $\mathrm{n} / \mathrm{a}$ & $\mathrm{n} / \mathrm{a}$ & $\mathrm{n} / \mathrm{a}$ \\
\hline $1-1-1-1-1-1$ & $\mathrm{n} / \mathrm{a}$ & $\mathrm{n} / \mathrm{a}$ & $\mathrm{n} / \mathrm{a}$ & $\mathrm{n} / \mathrm{a}$ & $\mathrm{n} / \mathrm{a}$ & $\mathrm{n} / \mathrm{a}$ & $\mathrm{n} / \mathrm{a}$ & 5.220 & $\mathrm{n} / \mathrm{a}$ & 4.357 & 4.291 & 4.577 & 4.594 & 4.465 & 4.931 & 4.913 & 4.686 & 4.790 & 4.259 & 4.354 \\
\hline
\end{tabular}


DCS CHARACTERIZATION

A-34 